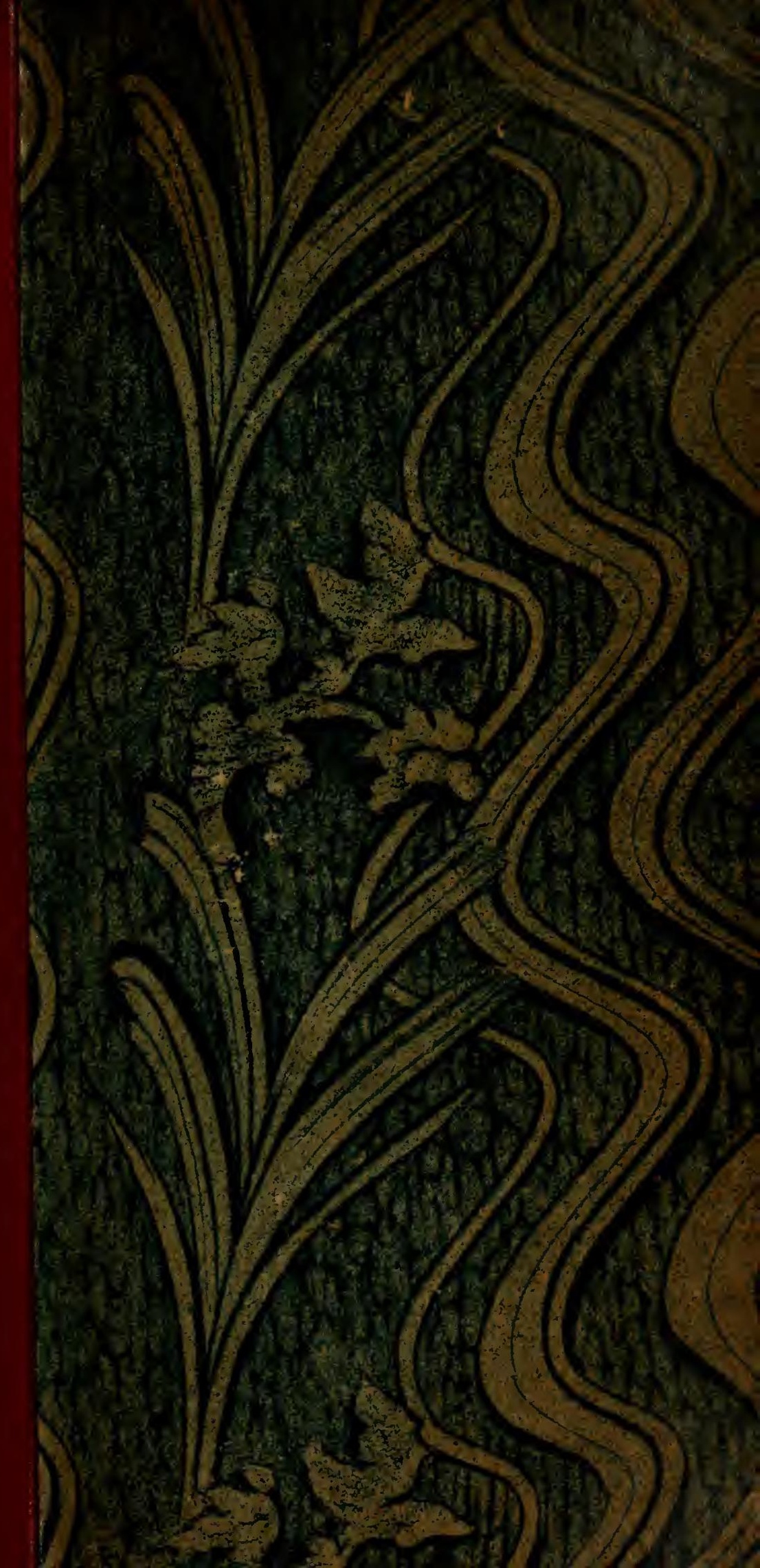




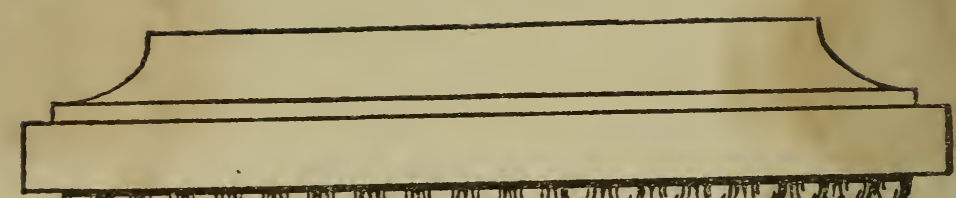

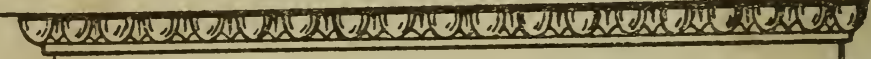

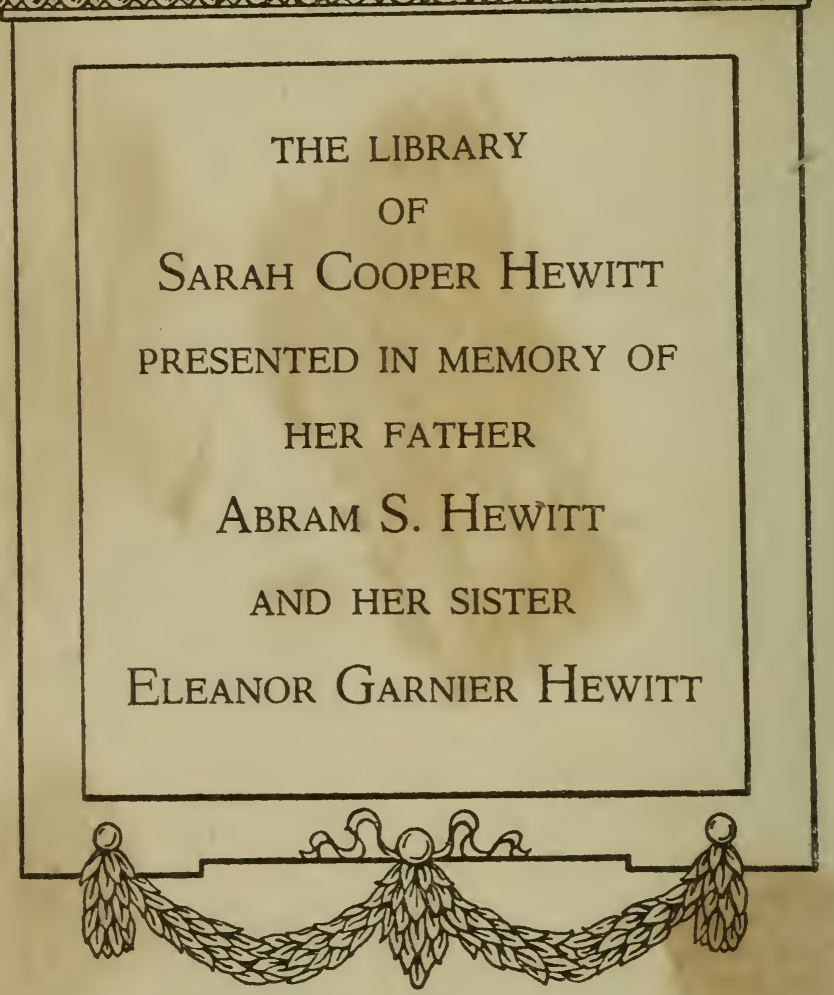





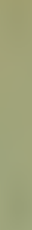
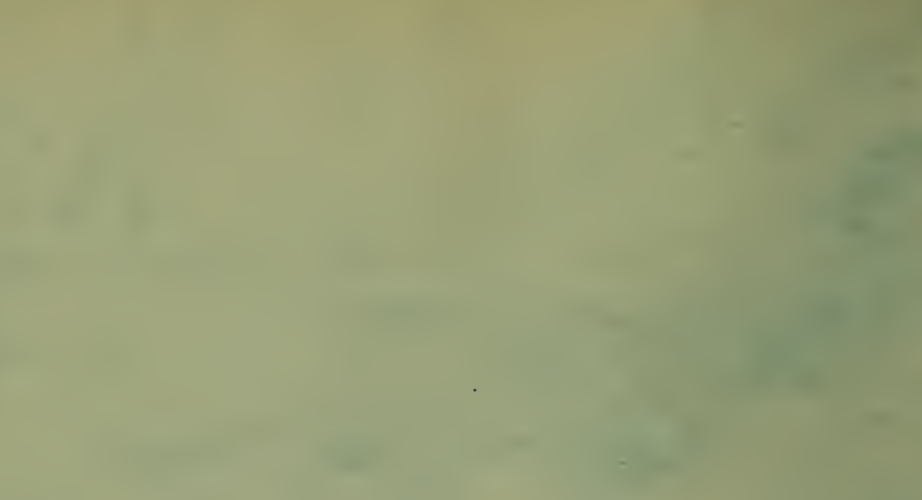

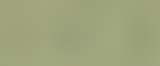

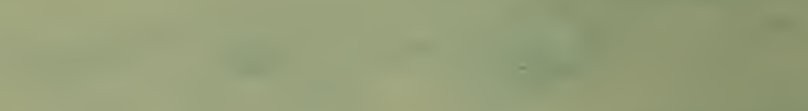

.

$-$

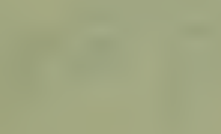

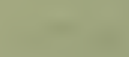
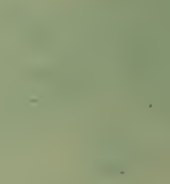

$$
\text { na }
$$

$$
\text { (2) }
$$

$$
x^{2}+2
$$$$
\text { ran }
$$$$
\text { 1. }
$$ 
- 



\title{
ÑOTIGE
}

$\mathrm{DU}$

\section{MUSEE NATIONAL}

\section{DE VERSAILLES,}

\author{
PAR
}

EUD. SOULIÉ,

Conservateur adjoint des Musées nationaux, chargé du service du Musée de Versailles.

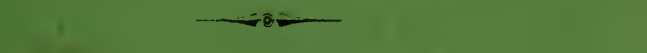

1re PARTIE.

\section{REZ-DE-CHAUSSÉE.}

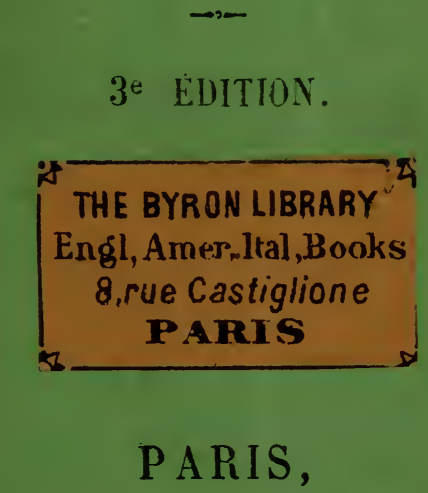

CHARLES DE MOURGUES FRÈRES, SUCCESSEURS DE VIYCHON, Imprimeurs des Husées Nationaux, RUE JEAN-JACQUES ROUSSEAU, 58. 
$\checkmark$

$x^{2}$

$x^{2}$

I.

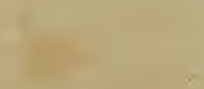




\section{MUSÉE NATIONAL}

DE VERSAILLES. 



\title{
NOTIGE
}

DU

MUSÉE NATIONAL

\section{DE VERSAILLES,}

PAR

\section{EUD. SOULIÉ,}

Conservateur adjoint des Musées nationaux, chargé du service du Musée de Versailles.

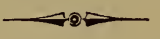

$1^{\text {re }}$ PARTIE.

REZ-DE-CHAUSSÉE.

\author{
$3^{\text {e }}$ ÉDITION. \\ Prix : 3 franes. \\ PARIS,
}

CHARLES DE MOURGUES FRÈRES, SUCCESSEURS DE VINCHON, Imprimeurs des Musées Nationaux,

RUE JEAN-JACQUES-ROUSSEAU, 58.

1880. 

A Monsieur. le comte de Nieuwerkerke, Direcleur général des Musées Impériaux, Intendant des Beaux-Arts de la Maison de l'Empereur, Membre de l'Institut.

Monsieur le Comte,

J'ai l'honneur de soumettre à votre approbation les épreuves de la $2^{\mathrm{e}}$ édition de la Notice du Musée Impérial de Versailles.

Cette première partie, qui comprend la description du rez-de-chaussée et de tous les objets d'art qui s'y trouvent, est précédée d'un Avertissement explicatif de la méthode suivie dans cette Notice, et d'un Abrégé chronologique des prineipaux faits relatifs a l'histoire du palais de Versailles, qui ne se trouvait pas dans la $1^{\text {re }}$ édition.

Je me suis efforcé de compléter et d'améliorer cette nouvelle édition; mais l'étendue des matières ajoutées m'engage à vous proposer de décider que la Notice de Versailles formera, comme celle des tableaux du Louvre, trois parties : rez-de-chaussée. - Premier étage. - Deuxième êtage. En effet, il est impossible de faire entrer dans un seul volume portatif l'explication de plus de 5,000 objets d'art ou d'histoire, dont se compose l'ensemble du Musée de Versailles tant à l'intérieur qu'à l'extérieur.

J'ai l'honneur d'être avec respect, Monsieur le Comte,

Votre très-obéissant serviteur.

Le Conservateur adjoint des Musées impiriawx, chargé du service du Musée de Versaillos,

EUD. SOULIÉ.

Versailles, 28 mai 1859.

Approuré :

Le Directeur général des Musées Impériaux, Intendant des Beaux-Arts de la Maison de l'Empereur,

Ct DE NHEWEREARER. 



\section{AVERTISSEMENT.}

Le Musée de Versailles, consacré a toutes les Gloires de LA France, est la collection la plus nombreuse et la plus variée d'ouvrages d'art qu'une nation ait jamais ouverte aux souvenirs de son histoire. Siéges et batailles, conquêtes, croisades, faits historiques, cérémonies, personnages illustres par le sang, le génie, le courage, la science ou la beauté; tableaux, portraits, statues, tombeaux ; c'est, comme on l'a voulu, une sorte de Panthéon de nos illustrations, dont l'intérêt s'accroît encore par celui du palais magnifique qui, pendant plus d'un siècle, a été le siége de la monarchie française.

Le château de Versailles, bâti par Jacques Lemercier, pour le roi Louis XIII, n'était d'abord qu'un simple rendez-vous de chasse. Les travaux ordonnés par Louis XIV furent successive- 
ment dirigés par Louis Levau, François Dorbay et Jules HardouinMansart. L'ancienne façade sur la cour fut respectée; mais les deux ailes en avant du château firent place à deux corps de bâtiment terminés par des pavillons ornés de colonnes et de statues, et, du côté des jardins, de nouvelles constructions vinrent envelopper le château de brique. En 1682, Louis XIV fixe à Versailles le siége de la royauté. Dans les années suivantes, Mansart élève aux abords du château les deux ailes des Ministres et les bâtiments de la Grande et de la Petite-Écurie, ajoute les deux grandes ailes sur les jardins, rebâtit l'Orangerie et construit la Chapelle. Sous le règne de Louis XV, Ange-Jacques Gabriel fit la Salle de spectacle et reconstruisit l'aile droite sur la cour, du côté de la Chapelle, d'après de nouveaux plans qui auraient fait disparaître complétement le château de Louis XIII. Dans la suite, ces projets furent abandonnés; on a élevé seulement depuis 1814 le pavillon de gauche, semblable à celui de Gabriel, mais en conservant la vieille aile.

Le palais de Versailles était resté inhabité depuis 1789, lorsqu'en 1833, le roi Louis-Philippe eut la pensée de consacrer l'ancienne demeure des rois à l'installation d'un musée historique, en rassemblant dans son enceinte des collections d'objets dart de toute nature offrant un caractère historique. On recueillit dans les dépôts de la Couronne et dans les résidences royales les peintures, statues, bustes ou bas-reliefs représentant des faits ou des personnages célèbres de nos annales, et, afin de combler les lacunes qu'offraient ces éléments divers, un nombre considérable de tableaux, de statues et de bustes fut commandé aux artistes. Pour recevoir cette immense quantité d'objets d'art, de grands 
travaux furent exécutés dans l'intérieur du palais, et ces travaux, dirigés par M. Nepveu, architecte, changèrent en vastes salles et en galeries presque tous les appartements d'habitation de l'ancien château, entièrement transformé en Musée.

Depuis l'ouverture des Galeries historiques de Versailles, en 1837, jusqu'à la $1^{\text {re }}$ édition de cette Notice (18ă4-1855), aucun catalogue complet de ce Musée n'avait été publié. La première Notice des peintures et sculptures du palais de Versailles, Paris, Crapelet, 1837, était une simple nomenclature qui ne donnait au public d'autre renseignement què celui inscrit au-dessous de l'objet même, et ne renfermait pas tous les monuments dont se composait à cette époque le Musée. Une autre Notice historique des peintures et sculptures du palais de Versailles, publiée en quatre parties, de 1837 à 1839, n’offre, malgré son étendue, qu'un ensemble encore très-incomplet. Les trois premières parties comprennent la peinture (Sujets - Résidences royales Portraits ). Le nombre des tableaux indiqués dans ces trois parties s'élève à 2,737 ; la série des portraits n'est pas terminée et ne dépasse pas le règne de Louis XVI. La quatrième partie contient les sculptures, au nombre de 602, et s'arrête également au règne de Louis XVI; les sculptures recommencent une nouvelle série de numéros, distincte de celle de la peinture. Ces quatre parties réunies formeraient un volume de 2,146 pages.

Une autre publication officielle ayant pour titre : Galeries historiques du Palais de Versailles, avait été commencée à l'Impirimerie royale en 1839 et a été interrompue en 1848. Les neuf volumes qui ont paru comprennent 2,497 numéros, et ne terminent pas la partie de la peinture, qui s'arrête aux portraits du 
règne de Louis XIII. Les cinq premiers volumes de cette collection, comprenant les tableaux historiques, ont été réimprimés en 1842, sous forme de catalogue, par la Direction des Musées.

Dans tous ces travaux, l'ordre chronologique avait servi de base pour le classement des peintures et des sculptures, sans égard à l'emplacement qu'elles occupent. Les divisions primitives du palais n'ayant pas permis de suivre rigoureusement la succession historique des événements et des personnages, on avait voulu rétablir l'unité dans un Catalogue général, sorte d'abrégé de l'histoire de France. Rédigées dans ce sens, les Notices n'entraient dans aucun détail sur la dimension, l'importance ou l'auteur de chaque objet d'art. Un cartouche peint, portant seulement le nom d'un connétable ou d'un maréchal de France, figurait parmi les portraits avec une note généalogique et biographique, au même titre qu'une peinture ancienne et due à un artiste célèbre; le même système avait été suivi pour les sculptures.

Le Musée de Versailles se trouve dans des conditions tout-àfait exceptionnelles; il a été formé, non pas au point de vue de lart, mais au point de vue de l'histoire. Il se compose d'éléments divers, tels que tableaux anciens et modernes, modèles de tapisseries, copies, dessins, gouaches, sculptures, moulages, médailles, etc. La classification par écoles et par maîtres, adoptée pour les catalogues des autres Musées, ne peut aucunement lui convenir. L'ordre chronologique a le défaut d'exclure des renseignements du plus grand intérêt en ce qui concerne l'art et l'histoire particulière du palais. Dans un catalogue purement historique, il est impossible de faire entrer les Grands Appartements, 
la Grande Galerie, les Salons de la Paix et de la Guerre, la Chapelle, le Salon d'Hercule, la Salle de Spectacle, où se développe l'histoire la plus complète de l'art de la décoration depuis Lebrun et Coyzevox jusqu'à Durameau et Pajou; le Parc, dont les nombreuses statues de marbre et de bronze forment un véritable Musée de la sculpture française pendant la seconde moitié du xvir siècle. D'autres questions, soulevées non par tel ou tel objet d'art, mais par l'endroit même où il est placé, se présentent dans un palais aussi rempli de souvenirs que celui de Versailles. Au milieu de tous ces grands faits de l'histoire générale, on ne peut oublier les faits particuliers qui se rapportent à l'histoire même du palais, à l'ancienne destination des appartements, aux personnages qui les ont habités, aux événements, aux fêtes, aux cérémonies dont ils ont été le théâtre; et ces renseignements sont également exclus d'un catalogue chronologique.

Pour satisfaire à toutes les considérations qui précèdent, nous avons pensé qu'une Notice relatant d'abord, par ordre chronologique, les principaux faits relatifs à l'histoire du monument, puis décrivant chaque salle à mesure qu'elle se présente, rappelant les souvenirs qui s'y rattachent, et signalant enfin toutes les peintures et sculptures historiques qui y sont placées, était le cadre le plus simple, le plus clair et le plus large pour satisfaire en même temps à l'intérêt de l'histoire et à celui de l'art. Une table générale, par ordre chronologique, reliera les divers objets ,disséminés dans ce vaste Musée, et présentera à la fois tous les monuments peints ou sculptés qui se rapportent à chaque règne; enfin une table alphabétique facilitera les recherches relatives aux noms de lieux, de personnages et d'artistes cités dans le courant du catalogue. 
Nous n'avons adopté d'autres divisions que celles indiquées par la disposition même du monument, composé d'un corps central et de deux grandes ailes. Le rez-de-chaussée, comprenant l'aile du nord, la partie centrale et l'aile du midi, forme notre première partie. La seconde est consacrée à la description du premier étage, et la troisième au deuxième étage ou attique.

Des plans portant pour chaque salle des numéros correspondant à ceux de notre Notice, seront joints à ce catalogue.

Comme disposition, nous nous sommes rapproché autant que possible de la forme adoptée pour les Notices du Musée du Louvre.

Les renseignements relatifs à chaque objet d'art se présentent dans l'ordre suivant :

$1^{\circ}$ - Le sujet, la date, le nom du personnage peint ou sculpté; cette indication étant le point essentiè au Musée de Versailles, suit immédiatement le numéro du catalogue.

$2^{\circ}$ - Le nom de l'artiste, la dimension de l'ouvrage et sa matière.

$3^{\circ}$ - Une notice historique ou biographique relative au sujet ou au personnage représenté.

$4^{\circ}$ - La description de l'objet d'art, lorsqu'elle est rendue nécessaire par quelque particularité qui n'a pu trouver place dans la notice historique; l'indication du Salon auquel l'ouvrage a été exposé ; du monument pour lequel il a été exécuté primitivement; de l'original d'après lequel il a été copié ou moulé; des gravures qui ont été faites d'après l'objet mentionné. 
Nous avons essayé de donner dans cette Notice, sous la forme la plus simple et la plus concise, tous les renseignements qui nous ont paru utiles au public, sur la nombreuse collection historique du Musée de Versalles, sur les objets d'art qui décorent l'intérieur et l'extérieur du Palais, et sur l'ancienne destination des appartements. Autant et plus que les autres Musées, celui de Versailles est destiné à se compléter en recevant successivement les monuments consacrés aux gloires du passé qui n'y ont pas encore trouvé place, et ceux que le présent et l'avenir lui préparent. Nous espérons que l'étendue de notre travail nous fera pardonner des erreurs et des omissions qui devront peu à peu disparaître. 



\title{
ABRÉGÉ CHRONOLOGIQUE
}

\author{
$\mathrm{DE}$
}

\section{L'HISTOIRE DU PALAIS DE VERSAILLES.}

1624.

L'acquisition de la seigneurie de Versailles, faite par Louis XIII, est de l'année 1632 , mais on sait que dès 1624 le roi avait commencé à faire bâtir à Versailles « un rendez-vous de chasse qu'il aroit élevé sur le lieu le plus éminent et où étoit situé ci-devant un moulin à vent » (1). C'est au commencement de l'année 1627, dans une assemblée de notable tenue au palais des Tuileries, que Bassompierre, reprochant au roi la suspension de l'achèvement des bâtiments royaux, disait: « que son inclination n'est puint portée à bâtir, et que les finances de la chambre ne seront point épuisées par ses somptueux édifices, si ce n'est qu'on lui reuille reprocher le chétif chàteau de Versailles, de la construction duquel un simple gentilhomme ne voudroit pas prendre vanité ») (2).

1630.

Le 11 novembre 1630, après une conférence tenue au Lusembourg, et dans laquelle la reine mère Marie de Médicis avait cru obtenir délinitivement de son fils l'éloignement du cardinal de Richelieu, et son remplacement, comme premier ministre, par le garde des sceaux Ma.

(1) Voir BLondex, Architecture francoise, 175\%, in-fol., tome IV, et Louis XIII et Versailles, par J. A. Le RoI, conservateur de la bibliothéque de la ville de Versailles, Versailles, 1850 , in $-8^{\circ}$. Presque tout ce qui, dans cet abrégé, est relatif au règne de Louis XIII, est extrait de ce dernier ouvrage.

(2) Mémoires du maréchal de Bassompierre, Cologne, 1665, tome III, page 53. 
rillac, Louis XIII s'était rendu à Versailles. " Il commanda, dit Charles Bernard, au cardinal et au garde des sceaux, chacun à part, de l'y suivre. Il n'aroit encore mené en ce lieu pas un conseil, ayant fait bàtir cette petite maison pour se distraire entièrement des affaires... Cependant, les deux personnages qui étoient les premiers des conseils du Roi, pour obéir au commandement de Sa Majesté, le suivirent et eurent un divers événement de leur arrivée : le garde des sccaux ayant eu commandement d'aller loger à Glatigny, le Roi lui ayant fait dire qu'il lui feroit le lendemain saroir sa volonté, au lieu que le cardiıal fut logé dans le chàteau de Versailles, sous la chambre du Roi, en celle où l'on aroit coutume de loger M. le comte de Soissons, et dès le soir il entra en conseil arec Sa Majesté ) (1).

Le lendemain 12 novembre, Louis XIII retiraít les sceaux à.Marillac pour les donner à Charles de l'Aubespine, marquis de Châteauneuf, qui prêta serment à Versailles, entre les mains du roi, le 14. Marillac, son frère le maréchal, et les partisans de la reine mère furent emprisonnés ou disgraciés. Cet événement est connu dans l'histoire sous le nom de Journée des dupes.

\section{2.}

Le roi, dit la Gazette de France, étant parti de Metz le 9 février, arriva à Versailles le 16 arec une diligence telle que grande partie de sa suite n'en pût être. "Et pour vous faire roir, ajoute la Gazette; que la Reine mème et les princesses qui l'accompagnent n'usent pas toujonrs du privilége dû à leur qualité et à lenr sexe, je ne vous en alléguerai qu'un exemple de la duchesse de Montbazon, laquelle, au sortir de Malatour, étant attaquée d'une violente esquinancie (l'une des plus aiguës et périlleuses maladies, et qui a le plus besoin de repos), ne daigna pour cela sortir du carrosse de la Reiue où elle étoit, mais s'y fit saigner en présence de Sa Majesté, et nen firent pas moindre journée, pour apprendre aux autres à n'ètre point délicates et paresseuses en telle occurence. ") Le roi ayant śjourné seulement deux jours à Versailles, repartit pour Saint-Germain; il revint en ce lieu de plaisance le $20, \mathrm{y}$ passa les jours gras et y resta jusuu'ar 27 férrier.

8 avril. - Contrat d'acquisition par lequel Jean-François de Gondi,

(1) Histoire de Louis XIII, par Charles DERTARv, 16i5, in-fol. 
archevèque de Paris, reconnaît avoir vendu, cédé et transporté à Lonis XIII la terre et seigneurie de Versailles, “ consistant en un vieil château en ruines et une ferme de plusieurs édifices. » Jusqu'alors, le château construitpar Jacques Lemercier, architecte du roi, était, dit Blondel, «flanqué de quatre pavillons bâtis de pierres et de briques, avec un balcon de fer qui tournoit tout autour et qui dégageoit les appartements du premier étage. Une fausse braie entouroit aussi ce bâtiment, et elle étoit précédée d'un fossé à fond de cuve, revêtu de briques et de pierres de taille, terminé par une balustrade. Ce petit édifice étoit environné de bois, de plaines et d'étangs dont la nature faisoit seule les frais. ”Dès que le roi eut fait l'acquisition de la seigneurie et du vieux château de Versailles, de nombreux changements furent opérés dans les dépendances. Deux ailes, terminées par quatre pavillons, furent d'abord construites en avant du château, du côté de l'entrée. De ces deux ailes, celle du sud était destinée aux écuries, et celle du nord au logement des personnes de la suite. Une grille, flanquée de deux petits pavillons de portiers, se trouvait en avant; deux balustrades, soutenues par des murs en briques, partaient de chaque côté de cette grille et venaient se terminer en demi-cercle à deux obélisques qui marquaicnt l'entrée de l'avant-cour. Louis XIII fit ensuite abattre le vieil château en ruines, et à la place on éleva une orangerie remplacée depuis par celle construite sur les dessins de Mansart. Dans les années suivantes, l'établissement d'un jardin potager, d’une ménagerie, l'agrandissement successif du parc et des jardins, signalèrent la présence de plus en plus fréquente de Louis XIII à Versailles. Le roi avait chargé aussi le célèbre ingénieur hydraulique Pierre Francine de rechercher les moyens d'amener à Versailles une eau suffisante aux besoins du service (1).

Ce fut encore à Versailles que Louis XIII vint clirectement au mois de novembre 1632, à son retour du midi. Parti de Toulouse le 31 octobre, le lendemain de l'exécution du duc de Montmorency, il arriva à Versailles le 20 novembre, sur les deux heures après midi, accompagné du comte de Soissons et autres seigneurs qui étaient allés au-devant de Sa Majesté (2). La reine Anne d'Autriche, qui avait accompagné Louis XIII dans le midi et était revenue avec la cour par l'ouest, vint voir le roi à

(1) LE RoI, Louis XIII et Versailles. - Notice historique sur le potager de Versailles.

(2) Mcrcure francois, 1632, page 882. 
Versailles, le 14 décembre. "Sa Majesté, dit la Gazette de France, la reçut arec un contentement indicible de part et d'autre. ")

1633.

Louis XIII passe à Versailles une grande partie du mois de janvier, et le carnaval de cette année. Il reçoit pendant ce séjour le serment de Cinq-Mars, comme lieutenant du roi en Bourbonnais.

1634.

Le 2 octobre, le marquis de Saint-Germain, ambassadeur extraordinaire de Savoie près le roi d'Angleterre, revenant de son ambassade, vint à Saint-Germain-en-Laye où il eut audience du roi et lui offrit de la part de la duchesse de Savoie, sœur de Louis XIII, quatre ameublements de velours à fonds d'argent, l'un bleu, l'autre gris de ciel, le troisième vert et le quatrième nacarat, pour mettre dans son château dc Versailles. Le même mois, Louis XIIl rend à Versailles une déclaration par laquelle, oubliant les fautes passées de son frère Gaston, il le reçoit en ses bonnes gràces et le rétablit en tous ses biens et apanages.

1635.

( De Versailles, le $\mathbf{1 3}$ avril. - Le Roi partit hier de Saint-Germain pour se rendre ici; passa par Ruel, où il fut deux heures enfermé avec le Cardinal-Duc. La Reine vint hier ici accompagnée de la duchesse de Montbazon et de ses filles. Monsieur y est aussi arrivé de Paris en mème temps.... Sa Majesté est allée au-devant de la Reine, et après lui avoir fait roir la maison, lui a fait une très-belle collation et aux dames die sa suíte, près desquelles il y avoit des gentilshommes ordonnés de sa part pour les servír. Après cette collation la Reine et toutes les dames sont allées à cheval dans le parc voir chasser le renard aux chiens du roi qui ont fort bien chassé, et comme ce divertissement n'étoit que pour la Reine et les dames il n'y aroit aussi qu'elles a cheval; le Roi, Monsieur et tous les seigneurs étoient à pierl près d'elles. Cette chasse finie, Leurs Majestés ont pris la route de Saint Germain et ayant eu le plaisir de voir prendre cinq ou six lièvres aux lévriers, un sanglier henreusement rencontré et pris sur le chemin contribua à leur divertissement. Puis le Roi ayant accom- 
DE L'HISTOIRE DU PALAIS DE VERSAILLES.

pagné la Reine jusqu'à Marli, village à une lieue de Saint-Germain, s'est retiré en ce lieu d'où Sa Majesté part aujourd'hui pour s'en retourner coucher à Saint-Germain. ) -(Gazette de France.)

1636.

25 février, - Le roi donne à dîner à Versailles à Êdouard Farnèse, duc de Parme.

1637.

20 février. - Le roi reçoit à Versailles son frère Gaston, avec lequel il venait de se réconcilier de nouveau à 0rléans.

30 octobre. - Louis XIII donne la charge de lieutenant civil à Laffemas qui lui est présenté à Versailles par Claude Bouthillier de Chavigny, surintendant des finances.

\section{8.}

27 mai. - « Le Roi, dit la Gazette, fit voir sa maison de Versailles à Mademoiselle (de Montpensier), suivie de Mademoiselle de Bourbon (AnneGeneviève, fille du prince de Condé); de la princesse lỉarie (1), de Mme d'Hautefort, dame d'atour, et des filles de la Reine, lesquelles à cheval en capeline, eurent le plaisir de la chasse du renard dans le parc de cette belle maison, à l'issue de laquelle le Roi leur donna une magnifique collation où elles furent servies par tous les seigneurs qui se trouvoient lors près du Roi. "

5 septernbre. - Naissance de Louis XIV au château de Saint-GerInain; en souvenir de cet événernent si longtemps désiré, Lonis XIII donne à l'un des bosquets de Versailles le nom de Bosquet.Dauphin.

1639.

Novembre et décembre. - Séjour du roi à Versailles.

(1) C'est ainsi que l'on désignait $\mathrm{IJ}^{\mathrm{me}}$ de Combalet, nièce du cardinal de Richelieu, qui venait d'être nommée par le roi duchesse d'Aiguillon. 
1640.

Le roi séjourne à Versailles en janvier et en décembre.

1641.

Mars. - Séjour du roi à Versailles.

30 décembre. - Mazarin nommé cardinal par le pape Urbain VIIl, se rend à Versailles pour en remercier le roi qui, dit la Gazette, "lui fit de grandes caresses et en témoigua un contentement indicible. »

1642.

9 janvier. - " Le Roi courut en même temps, dans les buissons de Versailles, six cerfs avec autant de meutes différentes, assavoir : deux de Sa Majesté, celle de Monsieur, et celles du duc d'Angoulême, de l'évêque de Metz et du sieur de Souvré, premier gentilhomme de la chambre; au retour de laquelle chasse, le Roi ne se sentant nullement fatigué, commanda à plusieurs seigneurs de sa cour de souper à sa table. ) - (Gazette de France.)

12 août, - Le roi reçoit à Versailles le comte de Mussan, envoyé du cardinal Maurice de Savoie, régent pendant la minorité de son neveu, Charles-Emmanuel.

Décembre. - Après la mort du cardinal de Richelieu à Paris, le 4 décembre, Louis XIII se rend à Versailles où il reçoit, le 27, le serment du comte de Noailles, comme gouverneur en chef de la province d'Auvergne.

1643.

28 janvier. - Louis XIII reçoit à Versailles le cardinal Alexandre Bichi, ancien nonce du papa et protecteur des affaires de France à Rome.

Février. - Le roi demeure à Versailles du 8 au $\mathbf{1 1}$ février, et le $\mathbf{1 0}$ il honore de sa table le cardinal Mazarin, l'évêque de Metz (Henri de Bourbon-Verneuil), le maréchal de Guiche et le secrétaire d'État Chavigny. Le 15, le roi donne à souper à sa table à Nonsieur, duc d'Orléans 
son frère, à l'évêque de Metz, au maréchal de Schomberg et à six autres seigneurs. Ce séjour fut le dernier de Louis XIII, à Versailles. De retonr à Saint-Germain, le 18 février, il y mourut le $\mathbf{1 4}$ mai 1643.

\section{1.}

C'est huit ans après la mort de son père que Louis XIV, alors dans sa treizième année, vient pour la première fois au château de Versailles. "Le 18 avril, dit la Gazette, le Roi étant allé prendre autour du château de Versailles le divertissement de la chasse, et le maréchal de Villeroy, gouverncur de Sa Majesté, qu’il accompagnoit, ayant demandé à dîner au président de Maisons, surintendant des finances, capitaine de ce château et de celui de Saint-Germain, le Roi voulut honorer de sa présence ce repas, auquel il parut qu'une personne d'ordre l'est partout, car encore que Sa Majesté eut défendu à ses officiers d'y aller, elle fut si magnifiquement traitée avec toute sa cour, en des tables qui se trouvoient servies à mesure que l'on s'y présentoit, que tous en furent extraordinairement satisfaits. » Le 18 juin, le jeune roi dìne encore à Versailles, et le 28 du même mois, " dès la pointe du jour, dit la Gazette, le roi fut voir son château de Versailles et prit autour de là le divertissement de la chasse. ")

1652.

Le 27 avril, la reine mère Anne d'Autriche et Louis XIV, arrivant de Corbeil, où ils avaient eu, le 23, une entrevue avec Charles II, roi d'Angleterre, qui, après la perte de la hataille de Worcester, s'était réfugié en France, dînent à Versailles avant de rentrer au château de Saint-Germain. Le 14 novembre, «le Roi, accompagné de Monsieur, son frère, et d'une partie de la cour, alla prendre le divertissement de la chasse à Versailles. ) - (Gazette de France.)

1653.

Chasses du roi dans les mois de janvier, d'avril et de mai. Le 15 août, Louis XIV se rend à Versailles avec le cardinal Mazarin, et revient lc lendemain avec lui au Louvre. 


\section{$1654-1661$.}

Pendant les années suivantes, le roi continue à chasser une ou deux fois par an à Versailles, tantòt avec son frère, tantôt avec le cardinal Mazarin. Le 25 octobre 1660, Louis XIV, marié le 9 juin précédent avec l'infante Marie-Thérèse d'Autriche, se rend arec la reine à Versailles. Le 9 mars 1661, Mazarin meurt à Vincennes, et dès le lendemain Louis XIV annonce sa résolution de gouverner par lui-même. Le 16 mars Colbert est installé comme intendant des finances, et dès cette époque de grands travaux sont entrepris dans les résidences du Louvre, des Tuileries, de Fontainebleau, de Saint-Germain et de Versailles.

\section{2.}

Versailles commence à devenir un des séjours favoris du roi. Le $1 \mathrm{er}$ mars il s'y rend avec la reine et il y chasse le 15. Le 19 juillet, Madlame Henriette, duchesse d'Orléans, et Mademoiselle de Montpensier l'y accompagnent à cheval, " dans un équipage des plus lestes, 》 dit la Gazette. Le lendemain, "le Roi prit de 'rechef le divertissement de la chasse à Versailles, où se trouraient les reines (Anne d'Autriche et Marie-Thérèse), arec plusieurs des principales personnes de la cour, que Sa. Majesté régala magnifiquement. » Le 17 septembre, "le Roi, avec lequel étoient Monsieur, Madame, et dirers autres seigneurs et dames, allèrent à la promenade à Versailles, où Sa Mlajesté régala splendidement la compagnie à dìner, et sur le soir il $\mathbf{y}$ eut grand bal, qui fut encore accompagné d'une magnifique collation. „) Le 1 er octobre, promenade ciu roi à Versailles; le 4 novembre il y court le lièvre et y dîne; le 13 il y chasse encore; entin, le 30 décembre la jeune princesse Anne-Elisabeth de France, fille du roi, étant morte au Louvre, Louis XIV se retire à Versailles.

\section{3.}

Les chasses et les promenades du roi à Versailles deviennent trop fréquentes pour être désormais toutes citées. Le 3 février, le roi s’y rend avec la reine et y "traite la compagnie à diner, puis, dit la $G a$ sette, chacun se divertit à visiter les beaux appartements de ce châleau très-magnifiquement meublés. ») Louis XIV et Mlarie-Thérèse y séjournent 
du 12 au 16 mars, et la reine mère Anne d'Autriche y vient le 15. Le 11 avril, le roi et la reine, " accompagnés de la comtesse de Soissons, de la duchesse de Bouillon et de quelques autres dames, allèrent prendre le divertissement de la chasse à Versailles, où le Roi traita la compagnie. ») Le 29 mai, Louis XIV s'était rendu à Versailles avec la reine Marie-Thérèse, qui venait d'avoir la rougeole. Le soir même de son arrivée, le roi ressentit les atteintes de la même maladie, et le lendemain la rougeole parut. Le roi demeura à Versailles jusqu'à son entière guérison et n'en repartit que le 9 juin. Le roi et la reine séjournent encore à Versailles du 11 au 20 aoút. Le 3 novembre, "le Roi, avec lequel étoient Monsieur, le duc d'Enghien (fils du grand Condé), le duc de Beaufort et divers autres seigneurs, alla à Versailles à la chasse du cerf, qui fut suivie d'un superbe dîner. 》 Lc 22 du même mois, " le Roi fut à la promenade à Versailles; où Sa Majesté régala splendidement à dîner le duc de Mecklenbourg, ajoutant aux bontés qu'elle lui a témoignées, celle de lui faire voir ses bâtiments et toutes les raretés de ce beau lieu.»" - (Gazetle de 1663.)

\section{4.}

30 janvier. Le roi se rend à Versailles avec la reine et la reine mère, le duc d'Orléans, le duc d'Enghien, la comtesse de Soissons et d'autres dames de la cour.

Du 5 au 14 mai, séjour de la cour. C'est pendant ce séjour que se donna la première grande fête de Versailles, dont le sujet, lẹs Plaisirs de l'île enchantée (1), était emprunté au poème de l'Arioste, et à l'exécution de laquelle concoururent Benserade et le président de Périgny pour les récits en vers, Molière et sa troupe pour la comédie, Lulli pour la musique et les ballets, et le machiniste italien Vigarani pour les décorations, les illuminations et les feux d'artifice. Celte fête dura trois jours. Le 7 mai, il y eut, pour la première journée, course de bagues en présence des deux reines, dans un cirque de verdure élevé à l'entrée de

(1) Une relation anonyme de cette fête accompagne la $1^{\text {re }}$ édition des neuf planches dessinées et gravées par Israel silvestre pour le Cabinet du Roi.-Paris, Imprimerie royale, 1673, in-fol. Ces planches existent encore à la Calcographie du Louvre. Une autre relation, faite par l'abbé de Marigny sous forme de lettre, se trouve dans ses Euvres en prose et en vers, Paris, 1674, in-12. 
la grande allée que l'on nomme aujourd'hui le tapis vert. Louis XIV y représentait le paladin Roger, et les personnages de sa suite figuraient les autres chevaliers enchantés dans l'île d'Alcine. La course fut précédée de récits en vers, débités par les acteurs de la troupe de Molière, suivie d'un concert et d'un ballet dirigés par Lulli, et terminée par le festin royal. Le lendemain $8 \mathrm{mai}$, on représenta, sur un théâtre élevé au milieu de la même grande allée, la Princesse d'Elide, dans laquelle Molière jouait les rôles de Lyciscas et de Moron. Cette comédie était mêlée de danses, de concerts, et se termina par un ballet. Le 9 , troisième journée de la fête, " la cour eut le plaisir d'un ballet qui se fit dans le palais d'Alcine, sur les dix heures du soir. ") Le bassin qui se trouve au bas de la grande allée n'était pas alors décoré du groupe représentant Apollon sur son char, et on y avait élevé un théâtre figurant le palais d'Alcine. Le ballet, qui avait pour sujet la fin des enchantements d'Alcine, fut terminé par un feu d'artifice représentant l'embrasement du palais.

Les divertissements continuèrent les jours suivants. Le 10 mai, il y eut une course de têtes dans les fossés du château; toute la cour était placée sur le balcon de fer qui régnait autour du palais. Le 11, le roi mena toute la cour à la Ménagerie, dont on admira le nombre d'oiseaux de toute sorte, et le soir il fit représenter dans son salon, sur un thétre portatif de son invention, la comédie des Fâcheux, par Molière. Le 12, après dîner le roi fit tirer une loterie où se trouvaient des pierreries, des ameublements et des pièces d'argenterie. Il y eut ensuite une nouvelle course de têtes, puis le soir, ajoute la relation, « une comédie nommée Tartuffe, que le sieur de Molière avoit faite contre les hypocrites. Mais quoiqu'elle eût été trouvée fort divertissante, le Roi connut tant de conformité entre ceux qu'une véritable dévotion met dans le chemin du ciel et ceux qu'une vaine ostentation des bonnes œurres n'empêche pas d'en commettre de mauvaises, que son extrême délicatesse des choses de la religion ne pût souffrir cette ressemblance du vice avec la vertu, qui pouvoient être pris l'un pour l'autre. Et quoiqu'on ne doutât point des bonnes intentions de l'auteur, Sa Majesté le défendit pourtant en public et se priva lui-même de ce plaisir pour n'en pas làisser abuser à d'autres moins capables d'en faire un juste discernement. ") Le 13 , le roi voulut encore courir les têtes, et on joua le même soir le Mariage forcé, de Molière. Le lendemain, la cour partit pour Fontainebleau.

10 juillet. - Le cardinal Chigi, légat du pape, visite Versailles, dont le bàilli de Souvré lui fait les honneurs; il admire les appartements 
beaux et richement meublés, et la grande diversité d'animaux rassemblés à la Ménagerie. - (Gazette de 1664.)

12 octobre. - Toute la cour se rend à Versailles où l'on prend, dit la Gazette, le divertissement de la chasse et tous ceux que peut fournir la beauté du lieu et de la saison. La reine y était allée en chaise à cause de sa grossesse; elle accoucha à Paris, le 16 novembre, d'une princesse nommée Marie-Anne, qui mourut le 26 décembre suivant.

1665.

13 mars. - Le roi et la reine, accompagnés de Mademoiselle de Montpensier et de grand nombre de dames de qualité, vont à Versailles prendre le divertissement de la chasse du cerf; toute la compagnie est ensuite régalée d'une magnifique collation, à laquelle prend part le comte de Lira, envoyé d'Espagne.

13 juin. - Divertissement organisé dans le petit parc de Versailles par Vigarani. Le roi , la reine et Madame Henriette, accompagnés de toutes les dames de la cour, y assistent. "Après que le Roi eut fait voir à la Reine les beaux appartements de cette délicieuse maison, ils descendirent dans un grand salon où se trouroit une collation de toutes sortes de fruits et de confitures en cinq grandes machines dont l'une étoit de diverses figures de glace et de différentes couleurs. „) Puis toute la cour s'étant placée dans un grand théâtre élevé dans l'allée du milieu du parc, la troupe du roi représenta le Favori, tragi-comédie, composée par Mme de Villedieu, et entremélée d'intermèdes et d'entrées de ballets avec des concerts de voix et d'instruments. "Ensuite il y eut au même lieu grand bal, puis on entra dans un labyrinthe de plusieurs allées, au milieu desquelles étoient dressées quatre grandes tables qui furent tenues par le Roi, la Reine, Monsieur et Madame. A trois heures du matin, la cour retourna à Saint-Germain. »)

Juillet. - La cour s'était rendue à Versailles le 7. Le 9, Madame Henriette, duchesse d'Orléans, y accoucha d'une fille qui, étant venue avant terme, mourut immédiatement. Madame y resta trois semaines, pendant lesquelles la reine d'Angleterre, sa mère, qui demeurait à Colombes, vint la voir plusieurs fois.

Septembre. - Arrivée de la cour à Versailles le 13. Le 14, le roi, la reine et leur suite se rendent en calèches dans le parc; la reine, Ma- 
dame, Mademoiselle de Montpensier, Mademoiselle d'Alençon et les autres dames, rêtues en amazones, prennent le divertissement de la chasse suivi d'une comédie entremêlée de ballets. Retour au Louvrele 17.

Du 11 au 15 octobre. - Séjour de la cour.

Novembre. - «Le 2, le Roi et la Reine, arec lesquels étoient monseigneur le Dauphin, Monsieur, Madame, Mademoiselle d'Alençon et plusieurs autres princesses et dames de haute qualité allèrent à Versailles, et le lendemain y firent la fète de St-Hubert par une chasse solennelle où Madame et la plupart des princesses étoient à cheval. La cour revint à Paris le 7, après avoir encore pris le jour précédent le divertissement de la chasse au cerf. ») - (Gazette de 1665.)

1666.

Janvier. - Anne d'Autriche meurt à Paris le 19; le roi et la reine se retirent à Versailles où ils sont visités le 22 par la reine d'Angleterre, Nonsieur, Madame et toute la cour.

Avril. - Séjour de la cour du 3 au 15. Le 6 avril, le roi prend le divertissement du vol des oiseaux de la grande fauconnerie.

Octobre. - Le roi se rend à Versailles le 3. Le 14, dit la Gazette, "Sa Hajesté visita la verrerie royale du faubourrs Saint-Antoine, où elle vit travailler avec beaucoup de satisfaction le sieur de la Grange qui en est le maître, et d'autres gentilshommes, à quantité de vases des plus rares; puis, elle entra au cabinet où sont les pièces curieuses dont elle choisit grand numbre pour son château de Versailles. ) Le 15, le roi se rendant de Vincennes à Saint-Germain, dîne à Versailles.

\section{7.}

Le 6 janvier, fête de l'Épiphanie, "le Roi alla au château de Versailles, où il traita à dîner Monsieur et Madame et les autres principales dames de la cour arec une magnificence extraordinaire. Le 24, sadite Majesté, arec laquelle étoient Monsieur, Madame, et les principaux seigneurs de la cour, alla au chàteau de Versailles où elle traita magnifiquement Leurs Altesses Royales et plusieurs dames de qualité qui eurent ensuite le divertissement du bal accompagné d'une collation des plus galantes. ) - (Gazette de France.)

Février. - "Le Roi, ayant choisi Versailles comme le lieu le plus 
agréable pour les divertissements des derniers jours de carnaval, y arriva le 20 février avec toute la cour et y traita à dîner Monsieur, Madame, Mademoiselle (de Montpensier) et plusieurs autres princesses et dames avec une magnificence extraordinaire. Le soir, il y eut bal daris le vestibule du château, qui fut commencé par Sa Majesté avec la Reine et continué par Monsieur avec Madame, puis par le duc d'Enghien avec la duchesse son épouse (Anne de Bavière) et par les autres seigneurs et dames, vêtus et masqués d'une manière des plus superbes, notamment le Roi qui avoit un habit, moitié à la persienne et moitié à la chinoise, chargé de pierreries, et ce divertissement fut suivi d'un souper servi encore avec une somptuosité vraiment royale.

“ Le lendemain, tout ayant été préparé pour les courses, dans la place devant l'Orangerie où Sa Majesté avoit fait, en quatre jours, préparer le camp environné de balustrades, sur lesquelles étoient disposées des têtes en divers endroits, la Reine s'y rendit sur les quatre heures du soir, aussi richement que galamment déguisée, avec un habit éclatant de pierreries et de broderies, accompagnée de Mademoiselle (de Montpensier), non moins magnifiquement habillée à la turque, de la duchesse d'Enghien et des autres princesses et dames en un équipage des plus avantageux. Aussitôt que Sa Majesté se fut placée en un fauteuil, ainsi que sa compagnie, à droite et à gauche sur des bancs, l'on aperçut une nombreuse troupe de chevaliers qui entroient par la porte du petit parc aux fanfares des trompettes et au bruit de deux timballiers, le duc de Saint-Aignan, des mieux vêtus à la persienne et très-bien monté, étant à la tête en qualité de maréchal de camp général, précédant les principales beautés de la cour, toutes admirablement équipées et sur des chevaux choisis, conduites par Madame, avec une veste des plus superbes et sur un cheval blanc houssé de brocart, semé de perles et de pierreries, ainsi que son habit. Le Roi marchoit après, ne se faisant pas moins connoître à cette haute mine qui lui est paríiculière qu'à son riche vêtement à la hongroise, couvert d'or et de pierreries, avec un casque de même, ondoyé de plumes, et à la fierté de son cheval, qui sembloit plus superbe de porter un si grand monarque que de la magnificence de son caparaçon et de sa housse pareillement couverte de pierreries. Monsieur joignoit Sa Majesté, richement vêtu à la turque et monté sur un cheval blanc, caparaçonné et houssé, avec quantité de perles. Le duc d'Enghien étoit à côté de Son Altesse Royale, superbement habillé en indien et monté à l'avantage ainsi que les autres seigneurs qui suivoient en dix quadrilles. » 
Les deux troupes firent le tour du camp, passant devant la reine pour la saluer, puis les dames s'étant rangées hors la barrière d'un côté, et les chevaliers de l'autre, le roi fit la première course et après lui les autres chevaliers. "Les courses terminées, les deux troupes se retirèrent en bel ordre par la même porte qu'elles étoient entrées; toute la compagnie se retira aussi des plus satisfaite de ce divertissement qui fut vu d'un nombre infini d'étrangers entre lesquels il y avoit quantité de seigneurs allemands placés sur de grandes balustrades et terrasses qui sembloient avoir été préparées à cet effet, quoique ce soient les ornements ordinaires de ce beau lieu.

«Le 22 février, les réjouissances furent terminées par un bal qui dura depuis neuf heures du soir jusqu'a six heures du matin avec un merveilleux concours des plus beaux masques pour lesquels, par l'ordre du Roi, il y eut toujours quatre tables servies soir et matin avec une singulière magnificence. " La cour ne retourna de Versailles à Saint-Germain que le 28 février, "y ayant eu, durant huit jours, plus de vingt tables outre les quatre principales, incessamment servies avec une égale abondance et politesse. ) - (Gazette de 1667.)

Novembre. - «Le 9, Leurs Majestés retournèrent à Paris pour passer l'hiver en leur beau palais des Tuileries, après avoir fait au château de Versailles les réjouissances de la fète de Saint-Hubert avec beaucoup plus de solennité que les autres années, ayant pris pendant six jours le divertissement de la chasse, où la Reine et Madame étoient à cheval, superbement vêtues en amazones, ainsi que toutes les dames, et ensuite, ceux des concerts, de la comédie et du bal avec une pastorale nouvelle, sur des théâtres des plus magnifiques, le tout précédé et suivi de festins où toute la cour étoit traitée arec une somptuosité digne de la magnificence royale. » - (Gazette de 1667.)

\section{8.}

Après la rapide et glorieuse campagne de la Franche-Comté, suivie du traité d'Aix-la-Chapelle, qui assuraít à la France la possession des conquêtes de Flandre, Louis XIV " pour réparer en quelque sorte, dit Félibien, ce que la cour avoit perdu dans le carnaval pendant son absence, résolut de faire une fête dans les jardins de Versailles. » Cette fète dut se composer d'une collation, d'une comédie, d'un souper, d'un bal et d'un feu d'artifice. Elle commença le mercredi 18 juillet, rers 
sept heures du soir. Après une collation servie dans une des allées du parc, la cour se rendit dans une salle de spectacle construite à l'endroit où se trouve aujourd'hui le bassin de Saturne ou de l'Hiver. Le spectacle se composait d'une pastorale en trois actes, les Fétes de l'amour et de Bacchus, dont les paroles étaient de Quinault et la musique de Lulli, et de la comédie de Georges Dandin, jouée par Molière et sa troupe. Les actes de la pastorale servaient d'intermèdes à ceux de la comédie et s'y reliaient par des chants et des entrées de ballet. Après la comédie, on passa d'abord dans une salle de festin, située à l'endroit ou se trouve aujourd'hui le bassin de Flore ou du Printemps; puis dans une salle de bal construite sur l'emplacement du bassin de Cérès ou de l'Été. A deux heures du matin, le bal finit et le spectacle des illuminations et des feux d'artifices commença. Le pourtour du parterre de Latone, la grande allée, la terrasse et la façade du château étaient décorés de candélabres, de vases, de statues et de termes, éclairés d'une manière ingénieuse, qui les faisait paraître enflammés à l'intérieur. Le bassin de Latone, dont la disposition a été changée depuis, était rempli de feux grégeois au milieu desquels des figures de paysans et d'animaux lançaient de l'eau. Deux feux d'artifices furent tirés à la fois l'un à droite, du côté du grand étang qui devint plus íard la pièce d'eau des Suisses, l'autre à gauche, vers l'endroit où se trouvent aujourd'hui les réservoirs et qui était alors occupé par une pompe ou tour d'eau qui faisait jouer les fontaines du parc. Les fusées de ces deux feux d'artifices se croisaient au-dessus du château, et lorsque toutes ces lumières s'éteignirent, dit Félibien en terminant le récit de cette fête «l'on s'aperçut que le jour, jaloux des avantages d'une si belle nuit, commençoit à poindre. ) (1).

1669.

Juin. - « Le 29, Leurs Majestés, accompagnées de tous les seigneurs et dames de la cour, allèrent coucher au château de Versailles.

(1) Il existe trois relations de cette fête. La première, composée par Félibien, pour accompagner les cinq estampes gravées par Lepautre et le plan dessiné et gravé par Lapointe, dont les planches existent encore à la Calcographie du Louvre. La seconde, écrite par ordre de la reine pour être envoyée au marquis de Fuentes, à Madrid, est due à l'abbé de Montigny, depuis évêque de Laon; elle est manuscrite et se trouve à la bibliothè que de l'Arsenal, dans les papiers de Conrart. La troisième est en langue espagnole et a pour titre : Descripcion del esplendido banquete que Sa Magestad christianissima el rey Luis XIV dio a las senoras de su corte en el real sitio de Versalla (por Pedro de la Rosa). - Paris, 1668, in-4. 
Le lendemain, elles y prirent le divertissement de la promenade du parc, et après une superbe collation qui leur y fut servie, la continuèrent sur le canal, dans une berge magnifiquement ajustée et suivie de deux grands bateaux où se faisoit un très-beau concert de voix et d'instruments, à l'issue duquel et d'un splendide souper, Leurs Majestés retournèrent à la promenade dans leurs calèches. »

Août. - "Le 11, Leurs Majestés, avec lesquelles étoient Monsieur, Mademoiselle d'Orléans, Madame de Guise et plusieurs des principales dames de la cour, allèrent à Versailles où le prince de Toscane se rendit aussi, accompagné du duc de Guise. Cette illustre compagnic s'y promena en calèches, puis alla dans la grotte (1) où elle eut le divertissement d'une excellente musique avec un beau régal de fruits et de confitures, en de grands bassins posés sur des guéridons, dans tous les angles de ce lieu, qui étoit éclairé d'une infinité de lumières à l'entour de la corniche. De là, tout ce beau monde étant allé à l'Orangerie, qui étoit aussi très-bien éclairée, les divertissements y furent continués par la comédie françoise, représentée sur un théâtre des plus galants, puis on passa en un vestibule de verdure où il y eut bal, auquel les dames parurent extraordinairement parées. Ensuite la compagnie fut régalée d'une superbe collation sur une table qui prit la place du théâtre, et tous les divertissements se terminèrent par un très-beau feu d'artifice dans le parc et un concert de trompettes et de timbales. »

2 novembre. - « Leurs Majestés, avec lesquelles étoient Monsieur et Madame, et grand nombre de seigneurs et dames, allèrent à Versailles pour y célébrer la fête de Saint-Hubert, comme elles firent le lendemain par la chasse au cerf et une chère merveilleuse, e.t les autres réjouissances ordinaires en pareille occasion » - (Gazette de 1669).

1670.

20 juin. - Le roi et la reine, accompagnés du dauphin, de son jeune frère le duc d'Anjou, et de Nadame Henriette, qui était arrivée de son voyage d'Angleterre le 18 , se rendent à Versailles. Neuf jours après,

(1) Cette grotte se trouvait sur l'emplacement qu'occupe actuellement le vestibule de la chapelle. Elle a été gravée par Lepautre et Chaureau en dix planches, qui se trouvent à la Calcographie du Louvre. 
Madame, de retour à Saint-Cloud, y meurt subitement dans la nuit du 29 au 30 juin. " Leurs Majestés, dit la Gazette, ne furent pas plutôt averties de son indisposition, qu'elles se rendirent auprès d'elle et lui firent connoître, par les témoignages de la plus graude tendresse, la part qu'elles prenoient en ses douleurs. " Le 1er juillet, dit encore le même recueil, "Leurs Majestés et monseigneur le Dauphin vinrent de Versailles au Palais-Royal voir Monsieur qui s'y étoit retiré. ») Le 23 juillet, Monsieur «fut trouver Leurs Majestés à Versailles, » et le 21 août la reine assista incognito au service fait pour Madame à Saint-Denis, et où Bossuet prononça sa célèbre oraison funèbre.

23juillet.— «Leurs Majestés, avec lesquelles étoit Monsieur, allèrent (de Saint-Germain) à Versailles, et à leur descente le Roi ayant pris le duc de Buckingham dans sa calèche, lui donna le divertissement de la promenade dans les jardins de ce beau lieu. Ensuite la compagnie se mit sur le caual où elle fut régalée d'un charmant concert d'instruments et de voix, puis on alla dans la grotte où il y eut encore concert, après lequel on servit une collation des plus magnifiques. ")

6 septembre. - «Leurs Majestés, accompagnées de toute la cour, allèrent l'après-dîner au château de Versailles, et le roi y régala derechef le duc de Buckingham d'une manière qui fit assez voir combiẹn Sa Majesté l'estime. D'abord on prit le plaisir de la promenade dans le petit parc; puis toute la compagnie alla sur le grand canal où elle trouva une splendide collation apprêtée sur une île d'une manière des plus galantes. A l'issue de ce régal on retourna dans le petit parc, et la nuit étant survenue on se rendit à l'entrée d'un bois où avoit été dressé un théàtre des plus surprenants, dans un grand salon auquel on fut conduit par une longue allée éclairée de quantité de lustres. La compagnie y eut le divertissement de la comédie par la troupe royale, accompagnée dans les entr'actes d'une excellente musique et symphonie, et au sortir de ce lieu elle entra dans l'allée des cascades où les plaisirs furent continués par un feu d'artifice des plus beaux qui se fussent encore vus. Leurs Majestés passèrent ensuite dans la salle et le vestibule du château, où les attendoit un très-magnifique souper qui dura jusqu'à trois heures après minuit. Le lendemain le roi régala encore le duc de Buckingham d'une excellente musique de voix dans la salle proche la vieille chapelle (1).»

(1) Cette vieille chapelle était sans doute celle du château de Louis XIII, remplacée, en 1672, par une autre chapelle qui se trouvait près de l'escalier de la 
Le 25 décembre, le roi et la reine étaient partis des Tuileries pour passer à Versailles les fêtes de Noël; le 27, le comte de Windischgratz, envoyé extraordinaire de l'empereur d'Allemagne, y fut reçu en audience par le roi.

\section{1.}

Février. - Séjour de la cour du 10 au 23, pendant lequel, dit la Gazette, Leurs Majestés " prennent le divertissement de la chasse et de petits ballets, accompagnés de concerts des plus délicieux. ”

Avril. - Séjour de la cour du 1er au 23. Le 4 avril, le roi et la reine tiennent sur les fonts une fille de l'ambassadeur et de l'ambassadrice de Savoie, baptisée dans la chapelle du château par Bossuet, alors évêque de Condom.

Septembre. - Séjour de la cour du 31 août au 30 septembre. Le 12 septembre, “ Leurs Majestés, avec lesquelles étoient monseigneur le Dauphin, Monsieur et tous les seigneurs et dames de la cour, prirent le divertissement de la comédie par la troupe royale, dans l'une des cours de ce château. Ensuite elles entrèrent dans le parc qui étoit de tous côtés éclairé d'une infinité de lumières de différentes façons, et si ingénieusement placées qu'elles produisoient le plus bel̀ effet du monde, et se rendirent ainsi vers le théâtre d'eau, depuis peu ajouté aux autres beautés qui rendent ce lieu si délicieux, où elles furent agréablement diverties par les différentes figures qu'un art ingénieux y fait prendre à l'eau et par une agréable musique et symphonie. De là elles allèrent dans la grotte où le souper fut servi avec une magrificence merveilleuse, de manière qu'il ne manqua rien pour combler de plaisir tous les sens de cette royale compagnie, ainsi que le lendemain que cette belle fête fut continuée.»

Novembre. - Séjour de la cour du 2 au 18. La fête de Saint-Hubert fut célébrée " par de continuelles chasses, où les dames se trouvèrent en un ajustement des plus lestes, et ce divertissement fut suivi deux fois de celui d'une pastorale des Amours de Diane et d'Endymion, composée

Reine, puis, en 1682, par celle construite sur l'emplacement actuel du salon d'Hercule, et enfin, en 1710, par la magnifique chapelle qui existe encore. Il y a dcnc eu à Versailles quatre chapelles construites successivement sur des emplacements différents, une sous Louis XIII et trois sous Louis XIV. 
de récits et d'entrées de baliet, larquelle fut représentée sur un magnifique théatre, dans l'appartement neuf de la reine. ") Le 6 novembre, le roi et la reine signent à Versailles le contrat de mariage de Monsieur, duc d'Orléans, arec sa seconde femme, Élisabeth-Charlotte de Bavière.

\section{2}

Du 16 janvier au 1er férrier, séjour de la cour.

Le 3 août, Louis XIV, revenant de la conquête de la Hollande, « alla, dit la Gazette, visiter ses bàtiments de Versailles, qu'il trouva fort avancés. ) Ces bâtiments étaient ceux du grand escalier détruit sous Louis XV, du petit escalier ou escalier de la reine, qui existe encore, et d'une chapelle qui se trouvait près de ce petit escalier.

Du 1 er septembre au 10 octobre. - Séjour de la cour au chàteau de Versailles qui, de rendez-vous de chasse et de fêtes, devient une véritable résidence royale. Louis XIV y reçoit les ambassadeurs comme à SaintGermain et à Paris. " La cour, dit la Gazette, continue de prendre ici les divertissements de la saison, entre lesquels celui de la comédie a ses jours. Le 17 septembre, la troupe du roi y en représenta une des plus agréables, intitulée les Femmes savantes, et qui fut admirée d'un chacun. Le 20, les Italiens y jouèrent l'une de leurspièces les plus comiques; le 21, la seule troupe royale y continua ses représentations avec beaucoup d'applaudissements. )

30 octobre. - François de Harlay de Champvallon, archevêque de Paris, bénit la première chapelle construite à Versailles par Louis XIV.

Novembre et décembre. - Le duc d'Anjou, troisième fils de Louis XIV, étant mort à Saint-Germain le 4 novembre, le roi et la reine se retirent le lendemain à Versailles, et leur séjour s'y prolonge jusqu'au 20 décembre. Quelques jours avant son retour à Saint-Germain, «le roi, dit la Gazette, vit arec beaucoup de plaisir les nouvelles découvertes qui ont été faites sur l'aimant, sur la pesanteur de l'air et sur l'anatomie; le sieur Denys, que Sa Majesté avait mandé pour luí donner ce divertissement, y ayant satisfait par une si prodigieuse quantité d'expériences, qu'elle en témoigna être fort contente. »

1673.

Mars. - Séjour de ta cour du $\mathbf{4}$ au 24. 
Du 13 octobre au 30 novembre. - Louis XIV qui, après la prise de Maëstricht, au mois de juin, avait fait un voyage en Lorraine et en Alsace, arrive à Versailles le 13 octobre, et y reçoit les jours suivants les félicitations du grand conseil de l'Université et de l'Académie française sur son heureux retour. Le 5 novembre, la princesse de Modène, MarieBéatrix-Éléonore d'Este, qui avait épousé, le 30 septembre précédent, le duc d'York, depuis Jacques II, roi d'Angleterre, vient avec sa mère à Versailles rendre ses devoirs à la reine Marie-Thérèse, "ayant été amenées de Paris, dit la Gazette, dans les carrosses du Roi par le maruuis de Dangeau. Le sieur de Bonneuil, introducteur des ambassarleurs, les présenta, et Sa Majesté, accompagnée de toutes les princesses et duchesses, les reçut dans un salon où, après avoir salué la duchesse d'York, elle la fit seoir dans un fauteuil, à sa gauche. Ensuite de la conversation, le roi la vint prendre pour lui faire voir les appartements neufs du château, et la duchesse de Modène y étant survenue, ils descendirent dans les jardins, et ces deux princesses montèrent seules dans la calèche de Sa Majesté. Elle les mena ainsi promener et leur fit pareillement voir une grande partie des jets d'eau et le canal, où l'artillerie du vaisseau qui est dessus fit grand bruit à leur passage. " Le 16 novembre, le prince de Condé, ayant laissé en fort bon état les.troupes qui sont demeurées en Flandre, alla à Versailles « saluer le roi, qui l'a reçu avec tous les témoignages d'amitié qui se peuvent imaginer. » - (Gazette de 1673.)

\section{4.}

Du 8 férrier au 19 avril. - Séjour de la cour. Le père Bourdaloue prêche pendant le carême.

Juillet à octobre. - " Le roi, dit Félibien, après la réduction de la Franche-Comté sous son obéissance, pour donner à toute la cour quelques moments de repos et de plaisir en suite des longues fatigues d'un royage que la saison avoit rendu très-pénible, ordonna, aussitòt qu'il fut arrivé à Versailles (le 30 juin), que l'on préparât des fètes et des réjouissances et que de temps en temps il y eut quelques divertissements nouveaux. ) Ces fètes remplirent six journées pendant les mois de juillet et d'août (1). Le 4 juillet, première journée des fêtes, après une collation_dans le

(1) Elles ont été gravées par Lepautre et Chauveau en six planches, qui se trouvent à la Calcographie du Louvre. Félibien en a écrit la relation. 
bosquet du Marais, on représenta dans la cour de marbre Alceste ou le Triomphe d'Alcide, opéra de Quinault et de Lulli. Le 11 juillet, on chanta dans une des allées de Trianon, l'Églogue de Versailles, scène de musique vocale et instrumentale dans le goût des intermèdes de Molière et qui était aussi l'œuvre de Quinault et de Lulli ; puis, la cour revint souper dans un bosquet du parc de Versailles, que l'on nommait la salle du Conseil. Le 19 juillet, représentation de la comédie du Malade imaginaire, dernier ouvrage de Molière, mort l'année précédente; le théâtre avait été dressé sur la terrasse du château, devant la grotte. Le 28, collation au théâtre d'eau, représentation de l'opéra de Cadmus et Hermione, par Quinault et Lulli, sur un théâtre dressé dans le parc, feu d'artifice sur le canal et souper servi dans la cour de marbre, autour de la fontaine qui la décorait alors. Le 18 août, cinquième journée des fêtes, " le sieur de Gourville, envoyé par le prince de Condé, présenta à Sa Majesté cent sept drapeaux ou étendards qui ont été gagnés sur les Impériaux, les Espagnols et les Hollandois, en la défaite de l'arrièregarde de leur armée par ce prince, en la bataille de Senef. Le soir, Leurs Majestés prirent, dans l'Orangerie, le divertissement d'une pièce nouvelle de théâtre, intitulée Iphigénie, composée par le sieur Racine laquelle fut admirablement bien représentée par la troupe royale et très-applandie de toute la cour. Ensuite, elles eurent aussi le divertissement d'un grand feu d'artifice sur le canal. ») Enfin, le 31 août, sixième et dernière journée de ces fêtes, la cour eut peudant la nuit un spectacle extraordinaire et réellement magique. « Sa Majesté, dit Félibien, étant sortie du château environ à une heure de nuit, mais d'une nuit la plus noire et la plus tranquille qui ait été depuis longtemps, l'on vit, dans cette grande obscurité, tous les parterres tracés de lumières. La grande terrasse qui est devant le château étoit bordée d'un double rang de feux espacés à deux pieds l'un de l'autre. Les rampes et les degrés du fer à cheval, et généralement toutes les fontaines qui sont dans le petit parc étoient environnées de pareilles lumières qui, réfléchies dans les bassins, y faisoient encore autant de clartés. ) Les deux bords et toutes les extrémités du grand canal étaient ornés de statues et de décorations d'architecture « derrière lesquelles, dit la Gazette, on avoit disposé un nombre infini de feux qui les faisoient paroître transparentes et qui les rendoient éclatantes et lumineuses dans une nuit obscure. Le Roi, la Reine et toute la cour firent plusieurs tours sur le canal dans des gondoles et dans des chaloupes richement ornées, suivies des bateaux où étoit la musique. ” Ce séjour à Versailles, le plus long que le roi eut encore fait, dura quatre 
mois et ne cessa qu'à la fin d'octobre. Les fêtes de 1674 sont les dernières de ce genre données par Louis XIV à Versailles.

1675 .

Juillet et aoùt. - C'est encore à Versailles que Louis XIV se rend le 21 juillet, à son retour de la campagne de Flandre. Il y reçoit, le 24, la duchesse de Toscane, fille de son oncle Gaston, duc d'Orléans. Le lundi 29, " Je roi , dit la Gazette, reçut à Versailles, à neuf heures dn soir, la nouvelle funeste de la mort de Henri de la Tour d'Auvergne, vicomte de Turenne, général de ses armées en Allemagne. » Le 26 août, la cour part de Versailles pour Fontainebleau.

1676.

Du 13 juillet au 9 novembre, - Séjour de la cour à Versailles.

1677.

Du 31 mai au 26 août.- Séjour de la cour. Le 29 juin, “ le Roi et la Reine, dit la Gazette, firent l'honneur au duc et à la duchesse de Saint-Simon de nommer, sur les fonts de baptême, le vidame de Chartres, leur fils (1). Le cardinal de Bouillon, grand aumônier de France, fit la cérémonie dans la chapelle du château. »

Octobre et novembre. - La cour se rend de Fontainebleau à Versailles le 30 septembre, et y demeure jusqu'en novembre.

1678.

Du 15 octobre au 12 décembre. - Séjour de la cour à Versailles. 1679.

Le contrat de mariage de Mademoiselle (Harie-Louise d'Orléans) avec Charles II, roi d'Espagne, ayant été signé à Saint-Germain, le roi et la

(1) Le futur auteur des Mémoires, né à Paris le 16 janvier 1075, était alors dans sa troisième année. 
reine, accompagnés du dauphin, de Monsieur, de Madame et de Mademoiselle se rendent le 6 août à Versailles, " où ils trouvèrent, dit la Gazette, le marquis de los Balbazès, ambassadeur d'Espaģne, et l'ambassadrice, sa femme. Le Roi fit l'honneur à l'ambassadeur de le mener partout et de lui montrer lui-même ce qu'il y a de plus remarquable dans les jardins et dans les appartements du chàteau. ) Le 10 septembre, la nouvelle reine d'Espagne dîne à Versailles avant son départ.

\section{0.}

Du 31 août au 2 décembre. - Le roi et la reine, accompagnés du dauphin et de la dauphine (Marie-Anne-Christine-Victoire de Bavière, mariée à Chàlons le 7 mars précédent, au fils de Louis XIV), arrivent le 30 août à Versailles. La cour y séjourne jusqu'an 2 décembre.

1681.

Du 29 avril au 28 juillet. - Séjour de la cour. Le roi y reçoit au commencement de mai les ambassadeurs du grand-duc de Moscovie, Potemkin et Polskow.

\section{2.}

Depuis l'année 1675, de grands travaux commencés par Levau et Dorbay et continués par J.-H Mansart, avaient été entrepris à Versailles pour en faire la résidence habituelle du roi. Pendant cette période, on achève les grands appartements et l'escalier du roi ou des ambassadeurs; on commence la grande galerie; on ajoute au château, du côté du midi, l'aile dite des Princes; on termine les ailes des ministres, et en 1680 Milansart construit la grande et la petite écurie. Enfin, en 1681, on transporte la chapelle sur l'emplacement actuel du salon d'Hercule et du vestibule qui se trouve au-dessous. Le 30 avril 1682, l'archevêque de Paris, François de Harlay qui, neuf ans auparavant, avait béni la première chapelle construite par Louis XIV, vient faire la bénédiction de cette nouvelle chapelle dédiée sous le titre de Saint-Louis, et, le 6 mai suivant, Louis XIV établit sa demeure à Versailles.

Dans les derniers jours de juin, "le roi alla voir les travaux que le sieur de Ville, gentilhomme et échevin de Liége, fait faire sur la Seine afin d'élever de l'eau de celte rivière à quatre cent soixante-dix pieds 
de haut pour être conduite à Versailles, et la première épreuve en fut faite en présence de Sa Majesté avec beaucoup de succès. ) - (Gazette de 1682.)

6 août. - Naissance de Louis de France, duc de Bourgogne, petit-fils de Louis XIV.

1683.

30 juillet. - Mort de la reine Marie-Thérèse d'Autriche.

19 décembre. - Naissance de Philippe de France, duc d'Anjou, depuis roi d'Espagne sous le nom de Philippe $\mathbf{V}$.

1684.

10 arril. - Le duc du Maine épouse, au nom de Victor-Amédée II, duc de Savoie, Anne-Marie d'Orléans, nièce du roi.

27 novembre. -- Audience donnée par le roi anx ambassadeurs du roi de Siam.

1685.

11 mars. - Audience donnée aux députés d'Alger.

15 mai. - Le doge de Gènes, Francesco-Maria Imperiale Lercaro, vient à Versailles faire réparation au roi au nom de la république de Gènes.

21 mai. - Audience donnée aux ambassadeurs de Moscovie.

千 et 5 juin. - Carrousel du dauphin.

24 juillet. - Nariage du duc de Bourbon, petit-fils du grand Condé, arec Mademoiselle de Nantes (Louise-Françoise de Bourbon), fille légitimée de Louis XIV et de Mlme de Montespan.

1686.

28 et 29 mai. - Carrousel du dauphin.

2 juin. - Réception des ducs de Chartres et de Bourbon, du prince de Conty et du duc du Maine daus l'ordre du Saint-Esprit.

6 juin. - Établissement de la maison royale de Saint-Cyr. 
31 août. - Naissance de Charles de France, duc de Berry, troisième petit-fils du roi.

18 novembre. - 0pération de la fistule faite au roi.

1687.

18 janvier. - Baptême des ducs de Bourgogne, d'Anjou et de Berry.

1688.

29 juin. - Mariage de François-Louis de Bourbon, prince de Conty, avec Marie-Thérèse de Bourbon-Condé.

31 décembre. - Grande promotion de chevaliers de l'ordre du SaintEsprit.

\section{9.}

8 janvier. - Réception de Jacques II, roi d'Angleterre.

3 décembre. - Louis XIV donne l'ordre de porter à la Monnaie pour étre fondus tous les objets en argenterie qui meublaient et décoraient le château de Versailles. Il existe aux Archives impériales un inventaire général des meubles de la Couronne, dressé en 1706, sur lequel sont décrites toutes les pièces d'argenterie fondues par ordre du roi. La pièce fondue est rayée sur le manuscrit, avec cette mention en marge: « Déchargé, ayant été porté à la Monnoie, suivant le récépissé du sieur Rousseau, directeur général des Monnoies. " La date la plus ancienne de ces récépissés est du 12 décembre 1689 et la plus récente du 19 mai 1690. Les articles rayés montent à près de douze cents, qui représentent au moins le double d'objets détruits, tous plus précieux encore par l'art et le travail que par la matière et qui formaient le mobilier le plus somptueux qui ait jamais existé : cabinets, tables, guéridons, coffres, fauteuils, siéges, tabourets, bancelles à dossier, deux balustrades d'alcòve, garnitures de cheminée, bordures de miroirs, torchères, girandoles, bras, chandeliers, nefs, bassins, vases, urnes, aiguières, buires, flacons, cuvettes, plateaux, salières, pots à fleurs, cassolettes, caisses d'orangers, brancards, seaux, etc. Le nombre des figurines et des bas-reliefs en vermeil et en argent ciselé est considérable; on fond même une figure de Louis XIII à cheval. Tous les objets en filigrane sont rayés sur l'inventaire avec cette note: " Le présent chapitre des filigranes d'argent composé de six cent 
soixante-huit numéros est déchargé en entier, attendu que du contenu en iceluy il en a été fondu par ordre du roy 2167 mars 5 onces 4 gros, suivant le récépissé du sieur Rousseau, directeur général des Monnoies du 17 mars 1690. „ Ce chapitre se composait de coffres, bahuts, boîtes, vases, saluts, chandeliers, aiguières, siéges, cabinets, etc.

1690.

20 avril. - Mort de la dauphine Marie-Anne Christine-Victoire de Bavière.

1691.

15 mars. - Madame de Montespan retirée au monastère de SaintJoseph fait annoncer au roi par Bossuet sa résolution de ne plus revenir à la cour; son appartement est donné au duc du Maine.

16 juillet. - Mort de Louvois à l'hôtel de la surintendance de Versailles.

1692.

18 février. - Mariage du duc de Chartres (Philippe d'Orléans, depuis duc d'Orléans et régent du royaume), avec Mademoiselle de Blois (Françoise-Marie de Bourbon, fille légitimée de Louis XIV et de IIme de Nontespan).

19 mars. - Mariage du duc du Maine (Louis-Auguste de Bourbon, fils légitimé de Louis XIV et de Mme de Montespan), avec Mademoiselle de Charolais (Anne-Louise-Bénédicte de Bourbon-Condé).

\section{3.}

21 janvier. - Louis XIV reçoit à Versailles le prince royal de Danemark, depuis Frédéric IV, roi de Danemark.

10 avril. - Création de l'ordre militaire de Saint-Louis.

1695.

4 janvier. - Le maréchal duc de Luxembourg (François-Henri de Montmorency) meurt au château de Versailles.

18 décembre. - Louis XIV reçoit dans la chapelle le serment du mar- 
quis de Dangeau pour la charge de grand maltre des ordres de NotreDame-du-Mont-Carmel et de Saint-Lazare.

$$
1696 .
$$

17 mars. - Mort d'Élisabeth d'Orléans, duchesse de Guise, fille de Gaston de France, duc d'Orléans.

\section{7.}

7 décembre. - Nariage du duc de Bourgogne, petit-fils de Louis XIV, avec Marie-Adélaïde de Savoie.

1698.

25 mai. - Louis XIV reçoit à Versailles le prince Jean-Gaston de Médicis, depuis grand-duc de Toscane.

1699.

16 février. - Audience donnée à l'ambassadeur du roi de Maroc.

21 novembre. - Louis XIV reçoit, à Versailles, le duc et la duchesse de Lorraine. Le 25 novembre, le duc Léopold prête foi et hommage au roi pour le duché de Bar.

1700 .

16 novembre. - Le duc d'Anjou est déclaré roi d'Espagne.

1701.

21 septembre - Louis XIV reconnaît roi d'Angleterre sous le nom de de Jacques III et reçoit à Versailles Jacques-François-Édouard Stuart, prince de Galles, fils de Jacques II, roi d'Angleterre, mort au vieux château de Saint-Germain-en-Laye le 16 septembre précédent.

1703.

4 août.-Naissance de Louis d'Orléans, depuis duc d'Orléans.

1704.

12 mai. - Louis XIV reçoit, à Versailles, Charles de Gonzague, duc de Mantoue. 
25 juin. - Naissance du duc de Bretagne, fils atné du duc de Bourgogne.

3 août. - Le duc de Mantoue prend congé du roi.

1705.

13 avril. - Mort du duc de Bretagne, fils ainé du duc de Bourgogne.

1706.

26 septembre. - Louis XIV reçoit l'électeur de Cologne, Josę̧ihClément de Bavière.

1707.

8 janvier. - Naissance de Louis de France, duc de Bretagne, second fils du duc de Bourgogne. Ce prince mourut en 1712.

1710.

15 férrier. - Naissance du duc d'Anjoù (Louis XV), troisième fils du duc de Bourgogne.

4 mars. - Louis XIV reçoit l'élecleur de Bavière, Maximilien-MarieEmmanuel.

5 juin. - Bénédiction de la chapelle du château par le cardinal de Noailles, archerêque de Paris. Cette chapelle, commencéc en 1699 sur les dessins de J.-H. Mansart, fut le dernier grand ourrage de Louis XIV à Versailles.

5 juillet. - Mariage de Charles de France, duc de Berry, arec Mademoiselle de Chartres (IIarie-Louise-Élisabeth d'Orléans).

1711.

4 janvier. - Louis XIV reçoit l'électeur de Cülogne, Joseph-Clément dè Bavière.

27 avril. - Le roi reçoit les compliments de condoléance sur la mort du dauphin, arrivée à Meudon le 14 avril précédent.

18 novembre. - Secousse de tremblement de terre à Versailles. 
1712.

12 février. - Mort de Marie-Adélaïde de Savoie, duchesse de Bourgogne, puis dauphine de France. Le duc de Bourgogne, dauphin de France, meurt à Marly le 18 février; son corps est rapporté à Versailies et exposé arec celui de la dauphine jusqu'au 23 février.

8 mars. - Mort de Louis de France, duc de Bretagne, dauphin, second fils du duc et de la duchesse de Bourgogne et frère aîné de Louis $\mathrm{XV}$, qui prend le titre de dauphin.

\section{3.}

Mars. - Louis XIV reçoit le 10 mars l'électeur de Cologne et le 12 l'électeur de Bavière, son frère.

8 juillet. - Double mariage de Louis-Henri de Bourbon-Condé, duc de Bourbon, avec Marie-Anne de Bourbon-Conty; et de Louis-Armand de Bourbon, prince de Conty, avec Louise-Élisabeth de Bourbon-Condé.

1715.

19 février. - Louis XIV reçoit dans la grande galerie Méhemet-RizaBeg, ambassadeur extraordinaire de Perse.

22 mars. - L'électeur de Bavière prend congé de Louis XIV pour retourner dans ses états.

28 mai. - Frédéric-Auguste, prince électoral de Saxe qui avait été présenté à Louis XIV à Fontainebleau, le 27 septembre 1714, par Madame, duchesse douairière d'Orléans, sous le nom de comte de Lusace, prend congé du roi à Versailles.

13 août. - Audience de congé de l'ambassadeur de Perse.

1 er septembre. - Mort de Louis XIV, à 8 heures $1 / 4$ du matin. Son cercueil est exposé pendant huit jours dans le salon de Mercure ou chambre de parade, et transporté à Saint-Denis le $\mathbf{9}$.

9 septembre. - Louis XV part de Versailles pour Vincennes.

1717.

Du 24 au 26 inai. - Le czar Pierre le Grand visite Versailles et y 
occupe les petits appartements du duc de Bourgogne, habités depuis par les reines Marie Leczinska et Marie-Antoinette.

3 juin. - Le czar se rend de nouveau à Versailles et y séjourne jusqu'au 11.

\section{8.}

29 mars. - Le duc de Lorraine, Léopold-Charles, et la duchesse de Lorraine, Élisabeth.Charlotte d'Orléans, sœur du régent, visitent Versailles, Trianon et la Ménagerie.

1722.

15 juin. - Louis XV revient fixer sa résidence à Versailles; le 17, la jeune infante d'Espagne, qu'il devait épouser, est installée dans l'appartement de la reine.

9 août. - Le roi reçoit dans la chapelle le sacrement de confirmation par les mains du cardinal de Rohan, grand aumônier de France; il fait sa première communion le 15 à la paroisse de Versailles.

13 août. - Arrestation et exil du maréchal de Villeroy, gouverneur de Louis XV.

21 août. - Le cardinal Dubois est déclaré premier ministre et prête serment le lendemain entre les mains du roi.

26 décembre. - Le roi signe le contrat de mariage de l'infant d'Espagne Don Carlos, avec la princesse Philippe-Elisabeth d'Orléans, fille du régent.

1723.

16 février. - Louis XV parvient à sa majorité et reçoit les compliments du régent et de la cour.

10 août. - Mort du cardinal Dubois à l'hôtel de la surintendance.

2 décembre. - Mort du régent. Le duc de Bourbon est chargé du détail des affaires et des fonctions de la charge de principal ministre.

1724.

2 février. - Nomination de cinquante-huit chevaliers de l'ordre du Saint-Esprit et de sejt maréchaux de France. 
DE L'HISTOIRE DU PALAIS DE VERSAILLES.

XLV

3 juin. - Réception, dans la chapelle, des nouveaux chevaliers de l'ordre du Saint-Esprit.

\section{5.}

5 arril. - Départ de l'infante d'Espagne dont le mariage avec le roi est rompu.

12 mai. - Naissance de Louis-Philippe d'Orléans, duc de Chartres, petit-fils du régent.

27 mai. - Déclaration du mariage projeté entre le roi et la princesse Marie Leczinska, tille de Stanislas, roi de Pologne.

9 août. - Signature du contrat de mariage de Louis XV avee Marie Leczinska.

$1^{\text {er }}$ décembre. - Le roi et la reine arrivent de Fontainebleau à Versailles.

1726.

30 mars. - Réception de la reine douairière d'Espagne, LouiseElisabeth d'Orléans, veuve de Don Louis.

8 avril. - Le duc de Bourbon présente à Louis XV le prince de Birkenfeld, lieutenant général des armées du roi, qui était absent depuis dix années qu'il avait passées dans ses états d'Allemagne. La princesse de Birkenfeld est présentée au roi par la duchesse de Ventadour.

16 juin. - Le roi, après avoir exilé le duc de Bourbon à Chantilly, supprimé le titre et les fonctions de principal ministre, et nommé l'abbé Fleury ministre d'État, confirme dans son conseil d'État, la résolution qu'il avait prise de gouverner par lui-même.

23 juillet. - Louis XV se trouve mal pendant la messe, dans la chapelle du château de Versailles. Cet accident est suivi d'une fièvre violente qui inspire pendant quelques jours les plus grandes inquiétudes.

30 juillet. - Le roi donne audience aux ambassadeurs et reçoit leurs compliments sur sa convalescence.

3 août. - La reine est attaquée d'une fièvre qui fait craindre pour sa vie; elle reçoit les sacrements le 13 , et, le 18 , elle entre en convalescence.

24 septembre. - La reine douairière d'Espagne se rend en grand cortége du chàteau de Vincennes à Versailles pour complimenter la reine sur le rétablissement de sa santé. 
1727.

14 août. - Naissance de Louise-Elisabeth de France et de AnneHenriette de France, filles jumelles de Louis XV.

1728.

28 juillet. - Naissance de Louise-Marie de France, fille de Louis XV. Cette princesse mourut en 1733.

1729.

28 août. - Audience des envoyés de Tripoli.

4 septembre. - Naissance de Louis de France, dauphin.

5 octobre. - Concert et ballet dans la cour de marbre, à l'occasion de la naissance du dauphin.

5 décembre. - Illumination et feu d'artifice dans la cour des ministres.

1730.

1er février. - Le duc de Lorraine (François III, depuis empereur d'Allemagne sous le nom de François Ier), prête foi et hommage au roi pour le duché de Bar et autres domaines mouvants de la couronne.

30 juillet. - Naissance de N. de France, duc d'Anjou, second fils de Louis XV. Ce prince mourut en 1733 sans avoir été nommé.

1732.

22 janvier. - Mariage de Louis-François de Bourbon, prince de Conty, avec Louise-Diane d'Orléans (Mademoiselle de Chartres); dernière fille du régent. Elle avait été baptisée trois jours avant dans la chapelle, à l'âge de seize ans.

23 mars. - Naissance de Marie-Adélaïde de France (Madame Adélä̈de).

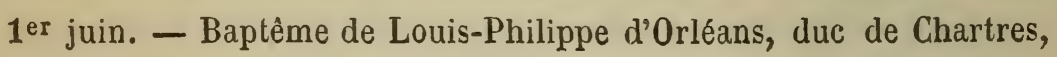
tenu sur les fonts par le roi et la reine.

5 juillet. - Baptême de Louis-Jean-MIarie de Bourbon, duc de Penthièvre, tenu sur les fonts par le roi et la reine.

2 septembre. - Lit de justice tenu par le roi. 


\section{3.}

11 mai. - Naissance de Marie-Louise-Thẻrèse-Victoire de France (Nadame Victoire).

1734.

6 juin. - La Ville de Paris présente au dauphin ses premières armes, consistant en une épée, un fusil et deux pistolets.

27 juillet. - Naissance de Sophie-Philippine-Elisabeth-Justine de France (Madame Sophie).

1735 .

19 janvier. - Le roi donne audience dans la cour de marbre à Hadji Mehemet Effendi, envoyé de Tripoli.

1736.

15 janvier. - Le dauphin est remis entre les mains des hommes.

16 mai. - Naissance de N. de France, fille de Louis XV, morte en 1744 sans avoir été nommée.

7 juin. - Le roi Stanislas, de retour de Pologne, vient en cérémonie à Versailles rendre visite au roi.

26 septembre. - Le plafond du salon d'Hercule commencé par Francois Lemoine en 1729, est découvert et Louis XV, après l'avoir examiné, donne à Lemoine le titre de premier peintre du roi.

30 novembre. - Le cardinal de Fleury fait dans la chapelle de Versailles la cérémonie de présenter à la reine la Rose d'or bénite par le pape Clément XII, et apportée de sa part par l'abbé Lercari, commissaire apostolique.

\section{7.}

27 avril. - Baptême du dauphin et des trois filles aînées de Louis XV, par le cardinal de Rohan, grand aumônier de France.

15 juillet. - Naissance de Louise-Marie de France (Madame Louise), dernière fille de Louis XV. 
1739.

26 janvier. - Bal donné par le roi dans le salon d'Hercule.

21 février. - Le marquis de la Mina présente au roi et au dauphin le collier de la Toison d'or de la part du roi d'Espagne Philippe V.

26 août. - Mariage par procuration de Louise-Elisabeth de France, fille aînée de Louis XV, avec l'infant Don Philippe (1).

21 décembre. - Traité de commerce, navigation et marine conclu à Versailles entre le roi et les états généraux des Provinces-Unies,

1742.

11 janvier. - Audience de Saïd-Méhémet-Pacha, ambassadeur ex traordinaire du Grand Seigneur.

1743.

13 juin. - Le roi pose la première pierre de l'église cathédrale de Saint-Louis.

17 décembre. - Mariage de Louis-Philippe d'Orléans, duc de Chartres, depuis duc d'Orléans, avec Louise-Henriette de Bourbon-Conty.

1744.

18 novembre. - Rentrée du roi à Versailles après la campagne de Flandre et sa maladie de Metz. Un arc de triomphe avait été élevé à l'entrée de l'avenue de Paris par les habitants de Versailles; c'est à ce retour que le roi reçut le surnom de Louis le Bien-Aimé.

8 décembre. - Mort de la duchesse de Châteauroux, dame du palais de la reine.

29 décembre. - Mariage de Louis-Jean-Narie de Bourbon, duc de Penthièvre, arec Marie-Thérèse-Félicité d’Este, princesse de Hodène.

(1) La décoration élevée sur la terrasse du château de Versailles, à l'occasion de ce mariage, a été gravée par C. N. Cochin (Calc. imp., n²962). 


\section{5.}

2 février. - Le comte de Montijo, le duc de Modène, le prince de Campo-Florido et le marquis Scotti sont nommés chevaliers de l'Ordre du Saint-Esprit.

23 février. - Mariage dans la chapelle de Louis de France, dauphin, avec Marie-Thérèse-Antoinette-Raphaëlle, infante d'Espagne(1).

\section{6.}

22 juillet. - Mort de la dauphine, infante d'Espagne. Elle était accouchée la veille d'une fille nommée Marie-Thérèse de France, qui mourut en 1748 .

1747.

9 février. - Mariage du dauphin avec Marie-Josèphe de Saxe (2).

1748.

24 mar's. - Madame Victoire, fille du roi, arrive à Versailles de l'abbaye de Fontevrault où elle avait été élevée.

21 novembre. - Madame Infante et l'infante Isabelle, sa fille, arrivent à Versailles avant de se rendre à Parme pour prendre possession des états de l'infant Don Philippe.

1750.

26 août. - Naissance de Marie-Zéphirine de France, fille du dauphin. Cette princesse mourut en 1755.

1751.

Juin. - Visite du duc de Deux-Ponts, sous le nom de comte de Sponheim.

(1) Dessiné et gravé par G. N. Cochin (Calc. imp., n॰ 2978).

(2) L'illumination faite à l'occasion du second mariage du dauphin a été gravée par Ingram, d'après C. N. Cochin (Calc. imp., n॰2985). 
13 septembre. - Naissance de Louis-Joseph-Xavier de France, duc de Bourgogne, petit-fils de Louis XV. Ce prince mourut en 1761.

20 septembre. - Bal donné par les gardes du corps pour célébrer la naissance du duc de Bourgogne.

19 décembre. - Jeu du roi dans la grande galerie et illumination de la décoration élevée sur la terrasse du château.

29 décembre. - Grande réception dans la galerie et feu d'artifice sur la terrasse (1).

1752.

16 juin. - Le duc de Deux-Ponts, après avoir passé quelque temps à la cour sous le nom de comte de Sponheim, prend congé du roi et de la famille royale.

Du 12 au 24 septembre. - Séjour de Stanislas Leczinski.

1753.

3 mai. - Mariage de Louis-Joseph de Bourbon, prince de Condé, avec Charlotte-Godefride-Élisabeth de Rohan-Soubise.

8 septembre. - Naissance de Xavier-Marie-Joseph de France, duc d'Aquitaine, second fils du dauphin. Ce prince mourut en 1754.

Du 21 septembre au 6 octobre. - Séjour de Stanislas Leczinski.

1754.

23 août. - Naissance de Louis-Auguste de France, duc de Berry (Louis XVI).

1755.

Du 19 août au 4 septembre. - Séjour de Stanislas Leczinski.

17 novembre. - Naissance de Louis-Stanislas-Xavier de France, comte de Provence (Louis XVIII).

(1) La décoration élevée sur la terrasse du château de Versailles pour l'illumination et le feu d'artifice tiré à la naissance du duc de Bourgogne, a été gravée par Narvie et Ouvrier, d'après C. N. Cochin (Cal. imp., n॰2987). 
1756.

8 février. - La marquise de Pompadour nommée dame du palais de la reine est présentée à la reine. Mme de Pompadour, maîtresse du roi depuis le commencement de l'année 1745 , avait été présentée à Versailles le 15 septembre 1745 au roi, à la reine et à la famille royale par la princesse douairière de Conty.

18 février. - Secousse de tremblement de terre à Paris et à Versailles.

1 er mai.-Convention et acte de neutralité conclu à Versailles entre le roi de France et la reine de Hongrie pendant la durée de la guerre entre la France et l'Angleterre. Le même jour on conclut à Versailles un traité d'amitié et d'alliance entre le roi et l'impératrice reine par lequel les deux souverains se promettent mutuellement, le cas de la guerre avec l'Angleterre excepté, de garantir et défendre mutuellement leurs états en Europe. Madame de Pompadour fit graver par Guay sur sardonyx (1) une allégorie à cette alliance des maisons de France et d'Autriche.

30 mai - Secousse de tremblement de terre à Versailles.

21 août. - Lit de justice tenu par le roi (2); il y rend trois édits pour subvenir aux dépenses de la guerre.

Du 12 au 20 septembre. - Séjour du roi Stanislas.

1757.

5 janvier. - Le roi sortant de chez Mesdames de France et au moment de monter dans son carrosse pour se rendre à Trianon, est frappé à cinq heures trois quarts du soir par Damiens, d'un coup de couteau.

4 mars. - Le roi tient le sceau pour la première fois depuis son avénement à la couronne.

Du 8 août au 5 septembre. - Séjour du roi Stanislas.

4 septembre. - Arrivée de Madame Infante, duchesse de Parme, à Versailles.

9 octobre. - Naissance de Charles-Philippe de France, comte d'Artois (Charles X).

(1) No 359 du Catalogue général et raisonné des camées et pierres gravées de la Bibliotheque impériale, par M. СнавоuILLET, conservateur adjoint du cabinet des médailles et antiques.

(2) Le plan de ce lit de justice a été gravé par Martinet (Cal imp., n² 2989). 
1758.

12 septembre. - Arrivée de Stanislas Leczinski.

30 novembre. - Le comte de Lusace arrive de l'armée de Westphalie.

30 décembre. - Traité de Versailles entre la France et l'Autriche.

1759.

2 février. - Présentation de la princesse douairière d'Anhalt-Zerbst, sœur du roi de Suède et mère de la grande-duchesse de Russie.

20 septembre. - Lit de justice tenu par le roi (1).

23 septembre. - Naissance de Marie-Adélaïde-Clotilde-Xavière de France, seconde fille du dauphin, depuis reine de Sardaigne.

18 novembre. - Baptême de Louis-Philippe-Joseph d'Orléans, duc de Chartres, tenu sur les fonts par le roi et la reine.

6 décembre. - Mort de Louise-Élisabeth de France, duchesse de Parme, nommée Madame Infante, fille ainée de Louis XV.

1760.

20 janvier. - Secousse de tremblement de terre đ̀ Versailles et à Paris.

1761.

15 février. - Arrivée à la cour du comte de Lusace; il repart pour l'armée le 23.

22 mars. - Mort du duc de Bourgogne, fils ainé du dauphin.

15 octobre. - Le prince Clément de Saxe, frère de la Dauphine, arrive à Versailles.

18 et 19 octobre. - Baptême du duc de Berry (Louis XVI), du comte de Provence (Louis XVIII), du comte d'Artois (Charles X) et de leur sœur Mladame Clotilde.

(1) Le plan de ce lit de justice a été gravé par F. N. Martinet (Calc. imp., n` 2993). 
1762.

2fi avril. - Le comte de Lusace quitte la cour pour se rendre à l'armée.

Septembre. - Arrivée de la princesse Marie-Christine de Saxe, sœur de la dauphine, sous le nom de comtesse de Henneberg.

1763.

4 janvier. - Arrivée du comte de Lusace.

11 janvier. - Lit de justice tenu par le roi ; il y fait enregistrer des édits pour lesquels le parlement avait fait des remontrances.

17 janvier. - Bal dans la salle de spectacle du château (1).

18 janvier. - Déclaration du roi par laquelle il reconnaît le titre impérial comme attaché au trône de Russie.

8 février. - Présentation du prince héréditaire Louis de NassauSaarbruck au roi, à la reine et à toute la famille royale.

20 mars. - Départ du comte de Lusace.

\section{4.}

15 avril. - Mort de la marquise de Pumpadour, dame du palais de la reine.

3 mai. - Naissance d'Élisabeth-Philippine-Marie-Hélène de France (Madame Élisabeth), dernière fille du dauphin.

\section{5.}

Juin. - Le prince palatin Frédéric de Deux-Punts est présenté au roi.

11 juin. - Le prince de Nassau-Saarbruck prend congé de la cour.

24 septembre. - Baptême de Louis-Henri-Joseph, duc de Bourbon.

20 décembre. - Le dauphin étant mort à Fontainebleau, le roi

(1) Ce bal a été gravè sous le nom de Bal du Mai, par F. N. Martinet, d'après M. A. Slodtz (Calc. imp., ${ }_{5}^{\circ}{ }^{\circ}$ 3004). 
revient à Versailles le même jour, et donne au duc de Berry, l'aîné de ses petits-fils, le titre de dauphin.

1766.

22 avril. - Le prince héréditaire de Brunswick-Lunebourg arrivant d'Angleterre est présenté au roi et à la famille royale, sous le nom de comte de Blakenbourg.

30 mai - Le prince de Nassau-Saarbruck prend congé de la cour pour se rendre en Allemagne.

19 juin. - Le prince hérẻditaire de Brunswick prend congé de la cour.

1767 .

13 mars. - Mort de la dauphine Marie.Josèphe de Saxe.

Mars. - Arrivée du prince héréditaire de Brunswick, sous le nom de cointe de Blakenbourg, et du duc de Deux-Ponts.

7 avril. - Départ du prince de Brunswick.

7 juin. - Baptême de Louise-Marie-Thérèse-Bathilde d'Orléans, tenue sur les fonts par le roi et la reine.

1768.

30 janvier. - Le prince héréditaire de Nassau est présenté à la cour. 16 février. - Arrivée du duc de Deux-Ponts à la cour.

25 uin. - Mort de la reine Marie Leczinska.

13 juillet. - Arrivée du prince Frédéric-Hermann d'Anhalt.

21 novembre. - Réception de Christian VII, roi de Danemark.

6 décembre. - Le roi de Danemark prend congé de Louis XV.

8 décembre. - Baptême de Louise-MIarie-Adélaïde de Bourbon, fille du duc de Penthièvre.

20 décembre. - Le prince héréditaire de Saxe-Gotha prend congé du roi et de la famille royale sous le nom de comte de Roda.

1769.

5 avril._Mariage de Louis-Philippe-Joseph d'Orléans, duc de Chartres, avec Louise-MIarie-Adélä̈de de Bourbon (Mademoiselle de Penthièvre). 
22 avril. - La comtesse du Barry est présentée au roi et à la famille royale par la comtesse de Béarn.

25 juillet. - Le prince de Saxe, duc de Courlande, voyageant sous le nom de comte de Barby, est présenté au roi et à la famille royale.

1770.

10 mars. - Le prince de Nassau-Saarbruck est présenté au roi et à la famille royale.

20 mars. - Le prince de Saxe, duc de Courlande, prend congé du roi.

25 mars. - Le duc de Deux-Ponts est présenté au roi.

3 arril. - Baptême de Louise-Adélä̈de de Bourbon (Mademoiselle de Condé).

4 avril. - Le roi tient la cour des pairs pour le procès du duc d'Aiguillon, accusé d'abus de pouvoir par le parlement de Bretagne.

11 avril. - Madame Louise, fille du roi, quitte la cour pour entrer au monastère des Carmélites de Saint-Denis.

24 avril. - Mariage de Louis-Henri-Joseph de Bourbon, duc de Bourbon, avec Louise-Marie-Thérèse-Bathilde d'Orléans.

Mai. - Fêtes du mariage du dauphin avec Marie-Antoinette, archiduchesse d'Autriche. La bénédiction nuptiale leur est donnée le 16 dans la chapelle de Versailles par l'archevêque de Reims (Charles-Antoine de la Roche-Aymon), grand aumônier de France; le soir, jeu de lansquenet dans la grande galerie et souper servi au grand couvert dans l'appartement de la reine, occupé par la dauphine. Le lendemain, représentation de l'opéra de Persée, dans la nouvelle salle de spectacle qui sert pour la première fois. Le 19 mai, bal paré sur le theâtre de la salle de spectacle et feu d'artifice tiré sur la terrasse du château. Après le feu d'artifice, toutes les parties de la décoration qui le composaient furent enlevées et firent place à l'illumination du parc, terminée, à l'extrémité du canal, par une décoration représentant le temple du Soleil. Le canal était couvert de bateaux illuminés. Les grandes eaux jouaient au milieu des illuminations des bosquets. "Plusieurs theâtres de bateleurs, de danseurs et de voltigeurs étoient dispersés dans le parc, et le peuple, dont la multitude étoit prodigieuse, dansoit dans les différents bosquets ) (Gazette de France). Le 21 mai bal masqué dans le grand appartement du roi, et le 23 représentation d'Athalie avec les 
chœurs exécutés en musique. Le 31 mai, le dauphin et la dauphine envoient au lieutenant général de police l'argent de leur menus plaisirs pour secourir les blessés et les familles des cent trente-deux personnes tuées à la fête donnée la veille par la ville de Paris sur la place de Louis XV.

27 juin. - Lit de justice tenu par le roi, dans lequel il annulle la procédure faite contre le duc d'Aiguillon.

9 septembre. - Le prince Charles, second fils du roi de Suède, est présenté au roi et à la famille royale sous le nom de comte de Vasa.

9 décembre. - Lit de justice tenu par le roi. Le duc d'Aiguillon y siége comme pair.

10 décembre. -- Premier bal donné par la dauphine Mlarie-Antoinette, dans son appartement.

1771.

14 janvier. - Arrivée à la cour de la princesse Marie-Christine de Saxe, sous le nom de comtesse de Henneberg.

17 et 23 janvier. - Promenades de la dauphine en traîneaux; elle est accompagnée des duchesses de Chartres et de Bourbon et de la princesse de Lamballe.

9 février. - Le prince royal de Suède et le prince Adolphe son frère sont présentés au roi et à la famille royale sous les noms de comte de Gothland et de comte d'Euland. Ils soupent avec le roi et se trouvent le 12 au bal donné par la dauphine.

23 février. - Le prince Frédéric de Salm-Kyrbourg, nommé colonel à la suite d'un régiment d'infanterịe allemande au service de France, est présenté au roi et à la famille royale.

8 avril. - Arrivée du duc de Deux-Ponts.

13 avril. - Lit de justice tenu par le roi, dans lequel sont supprimés les offices de l'ancien parlement.

14 mai. - Mariage de Louis-Stanislas Xavier, comte de Provence (depuis Louis XVIII), arec la princesse Mlarie-Joséphine-Louise de Savoie.

Septembre. - Le margrave de Bade-Dourlach, sous le nom de comte 
d'Eberstein, et le prince héréditaire son fils, prennent congé du roi et de la famille royale.

24 novembre. - Bal donné par la dauphine.

1772.

30 janvier. - Promenade de la dauphine en traîneaux; elle est accompagnée de la comtesse de Provence et de la princesse de Lamballe.

24 mars. - Arrivée à la cour du prince de Nassau-Saarbruck.

1773.

29 mars. - Le roi visite les nouvelles casernes des gardes françaises, construites sur un des côtés de la place d'Armes.

16 novembre. - Mariage de Charles-Philippe, comte d'Artois (Charles X), avec la princesse Marie-Thérèse de Savoie, sœur de la comtesse de Provence.

1774.

4 janvier. - Promenade de la dauphine en traîneaux; elle est accompagnée du comte de Provence, de la comtesse d'Artois et de la princesse de Lamballe.

22 janvier. - La princesse Marie-Christine de Saxe se rend à la cour sous le nom de comtesse de Henneberg.

Le prince Xavier de Saxe est présenté au roi et à la famille royale sous le nom de comte de Lusace.

22 mars. - Le prince héréditaire de Hesse-Rheinfels-Rottembourg est présenté au roi et à la famille royale.

10 mai. - Louis XV meurt de la petite vérole à Versailles. Louis XVl et la reine, accompagnés du comte et de la comtesse de Provence (qui prennent le titre de Monsieur et de Madame), du comte et de la comtesse d'Artois, de Mesdames Clotilde et Élisabeth, partent le même jour pour le chàteau de Choisy. Mesdames Adelaïde, Victoire et Sophie, filles de Louis XV, qui ne l'avaient pas quitté pendant sa maladie, sont atteintes de la petite vérole à Choisy, et la cour se rend au château de la Muette.

6 juin. - Le roi assiste à Versailles à la levée des scellés qui avaient été apposés sur les papiers de Louis XV. Il dîne avec la reine et la fa- 
mille royale au Petit-Trianon que Louis XVI venait de donner à MarieAntoinette. Le 18 juin, le roi, Monsieur, le comte et la comtesse d'Artois se font inoculer à Mlarly, et le 1er août la cour part pour Compiègne, où elle reste jusqu'au 1 er septembre.

1er septembre. - Rentrée du roi à Versailles.

27 septembre. - Le prince régnant de Salm-SaIm est présenté au roi.

Décembre. - Louis XVI ordonne la replantation du parc de Versailles dont tous les arbres sont abattus.

1775.

7 mars. - Le duc Charles-Auguste de Saxe-Weimar-Eisenach et le prince Frédéric-Ferdinand, son frère, qui voyagent sous le nom de comtes d'Alstedt, sont présentés au roi, à la reine et la famille royale. Ils prennent congé le 9 mai.

5 mai. - Lit de justice tenu par le roi à l'occasion des brigandages exercés sur les grains.

3 juin. - Le prince de Carignan, le prince Victor et le prince Eugène son fils, qui voyagent sous les noms de marquis de Marène, de comte de Salussol et de comte de Villefranche, sont présentés au roi, à la reine et à la famille royale.

6 juillet. - Le roi reçoit, au retour de son sacre, le parlement, les Cours supérieures, l'Université et l'Académie française.

6 août. - Naissance de Louis-Antoine d'Artois, duc d'Angoulême.

26 août. - Monsieur épouse par procuration du prince de Piémont (Charles-Emmanuel-Ferdinand, depuis roi de Sardaigne), Marie-AdelaïdeClotilde-Xavière de France, sœur du roi.

30 décembre. - Mouvement de tremblement de terre à Versailles.

31 décembre. - Le roi reçoit le serment de fidélité des états de la souveraineté de Béarn.

1776.

15 février. - Le duc souverain régent de Wurtemberg, voyageant sous le nom de comte de Dourac, est présenté à la cour. 
DE L'HISTOIRE DU PALAIS DE VERSAILLES.

12 mars. - Lit de justice tenu par le roi, dans lequel il fait enregistrer l'édit qui supprime la corvée. Cet édit fut retiré le $\mathbf{1 1}$ août suivant.

5 août. - Naissance de Mademoiselle d'Artois. Cette princesse mourut en 1783 sans avoir été nommée.

\section{7.}

24 janvier. - Le prince palatin, duc de Deux-Ponts, sous le nom de comte de Sponheim, et la duchesse de Deux-Ponts, sont présentés à la cour; il prennent congé le $1 \mathrm{er}$ février.

19 avril. - L'empereur Joseph II, frère de la reine, voyageant sous le nom de comte de Falckenstein, arrive à Versailles.

1778.

24 janvier. - Naissance de Charles-Ferdinand d'Artois, duc de Berry.

20 mai. - Benjamin Franklin, Silas Deane et Arthur Lée, députés des États-Unis de l'Amérique septentrionale, sont présentés au roi, à la reine et à la famille royale.

15 septembre. - Le prince de Holstein - Gottorp, coadjuteur de l'évêché de Luheck, est présenté à la cour sous le nom de comte de Rastadt.

19 décembre. - Naissance de Marie-Thérèse-Charlotte de France, fille de Louis XVI.

Voici dans quels termes le roi raconte cet événement dans son journal manuscrit trouvé dans l'armoire de fer aux Tuileries et déposé aux Archives impériales :

“ La Reine s'étoit couchée la veille à onze heures sans rien souffrir. A minuit et demi elle a commencé à souffrir; à une heure et demie elle a sonné. On a été chercher madame de Lamballe et les honneurs; à trois heures madame de Chimay est venue me chercher. La Reine êtoit encore dans son grand lit; une demi-heure après elle a passé sur un lit de travail. Madame de Lamballe a envoyé chercher la famille royale et les princes et princesses qui étoient à Versailles, et a envoyé des pages à M. le duc l'Orléans, madame la duchesse de Bourbon et madame la princesse de Conti qui étoient à Saint-Cloud; M. le duc de Chartres, M. le duc de Bourbon et M. le prince de Conti étoient à Paris. Les dou- 
leurs de la Reine se ralentissant, elle s'est promenée dans la chambre jusqu'à près de huit heures qu'elle s'est remise sur le lit de travail. Il y avoit dans la chambre la famille royale, les princes et les princesses du sang, les honneurs et madame de Polignac dans le grand cabinet, ma maison, celle de la Reine et les grandes entrées; dans le salon de jeu et la grande galerie tout le reste du monde. 0 n est entré lorsque l'accoucheur a averti. La Reine est accouchée à onze heures et demie d'une fille. J'ai passé tout de suite dans le grand cabinet pour la voir emmailloter et la remettre entre les mains de madame de Guéménée, gouvernante. Le souslieutenant des gardes de service chez la Reine est parti tout de suite pour faire part de la.naissance au corps de ville qui étoit assemblé depuis la nouvelle du travail et un autre sous-lieutenant a reconduit ma fille chez elle. 0 n n'avoit pas pu saigner la Reine pendant le travail; quelques minutes après être accouchée le sang lui a monté à la tête et elle est tombée sans connoissance; on l'a saignée copieusement du pied, ce qui l'a fait revenir au bout de trois quarts d'heure, et depuis elle a toujours bien été. Je suis rentré chez moi à deux heures et demie où j'ai signé les lettres de ma main pour l'Empereur et l'Impératrice et le roi d'Espagne; les autres avaient été signées quelques jours avant. J'ai été de là à la messe en haut (1); après je suis descendu en bas pour le baptême. Ma fille a été tenue par Monsieur èt Madame représentant le roi d'Espagne et l'Impéra trice. Elle a été nommée Marie-Thérèse-Charlotte. Toute la famille royale et les princes et princesses du sang ont signé l'acte de baptême. Après j'ai entendu en bas le Te Deum chanté en musique et je suis rentré cliez moi. Le soir les premiers présidents des cours sont venus me complimenter. ") - (Revue rétrospective, tome v).

1779.

20 juillet. - Le prince régnant de Salm-Kyrbourg est présenté à la cour.

1780.

13 février. - Le prince héréditaire de Hesse-Darmstadt royageant sous le nom de comte d’Epstein, est présenté à la cour.

(1) C'est-à-dire dans la tribune de la chapelle. 
1781.

29 juillet. - Noureau voyage de l'empereur Joseph II sous le nom de comte de Falckenstein.

22 octobre. - Naissance de Louis-Joseph-Xavier-François de France, dauphin. Ce prince mourut au château de Meudon en 1789.

Louis XVI raconte ainsi cette naissance dans son journal :

“ La Reine avoit très-bien passé la nuit du 21 au 22 d'octobre. Elle sentit quelques petites douleurs en s'éveillant qui ne l'empêchèrent pas rle se baigner; elle en sortit à dix heures et demie; les douleurs continuèrent à être médiocres. Je ne donnai aucun ordre, pour le tiré que je devois faire à Saclé, qu'à midi. Entre midi et midi et demi, les douleurs augmentèrent; elle se mit sur son lit de travail, et à une heure et un quart, juste à ma montre, elle est accouchée très-heureusement d'un garçon. Pendant le travail il n'y avoit dans la chambre que madame de Lamballe, Monsieur, le comte d'Artois, mes tantes, madame de Chimay, madame de Mailly, madame d'Ossun, madame de Tavannes, et madame de Guéménée, qui alloient alternativement dans le salon de la Paix qu'on avoit laissé vide. Dans le grand cabinet il y aroit ma maison, celle de la Reine, et les grandes entrées, et les sous-gouvernantes qui entrèrent au moment des grandes douleurs et se tinrent dans le fond de la chambre, sans intercepter l'air.

“ De tous les princes que madame de Lamballe envoya avertir à midi, il n'y avoit que M. le duc d'0rléans, qui arriva avant les dernières douleurs (il étoit à la chasse, à Fausse-Repose). Il se tint dans la chambre ou le salon de la Paix. M. le prince de Condé, M. de Penthièvre, M. le duc de Chartres, madame la duchesse de Chartres, madame la princesse de Conti et mademoiselle de Condé, arrivèrent que la Reine étoit accouchée, M. le duc de Bourbon le soir et M. le prince de Conti le lendemain. La Reine a vu tous ces princes, le lendemain, les uns après les autres. Après que la Reine a été accouchée, on a porté mon fils dans le grand cabinet où je suis allé le voir habiller, et je l'ai remis entre les mains de madame de Guémenée, gouvernante. Après que la Reine a été délivrée je lui ai annoncé que c'étoit un garçon et on le lui a apporté sur son lit. Après qu'elle l'a eu vu quelque temps chacun a été chez soi. J'ai signé les lettres de part de ma main, pour l'Empereur, le roi d'Espagne et la princesse de Piémont, et j'ai ordonné qu'on fasse partir les autres que j’arois déjà signées. A trois heures, j'ai été à la chapelle où mon 


\section{LXII}

ABRÉGÉ GHRONOLOGIQUE

fils a été baptisé par le cardinal de Rohan, et tenu sur les fonts de baptême par l'Empereur et la princesse de Piémont représentés pạr Monsieur et par ma sœur Elisabeth. Il a été nommé Louis-Joseph-Xavier-Francois. Mes frères, mes sœurs, mes tantes, M. le duc d'Orléans, M. le duc de Chartres, M. le prince de Condé et M. de Penthièvre ont signé l'acte. Après le baptême j'ai entendu en bas le Te Deum, chanté par la musique, les princesses n'ayant pas eu le temps de s'habiller le soir.

“ Pendant que je voyois tirer le feu d'artifice dans la place d'armes, le premier président de la Chambre des Comptes est venu me complimenter. $)-($ Revue rétrospective, tome v.)

1782.

13 janvier. - Réception dans les grands appartements à l'occasion de la naissance du dauphin. Le roi et la reine soupent à leur grand couvert dans le salon d'Hercule. Le 21 janvier, le roi et la reine se rendent à Paris pour les fêtes données à l'Hôtel de Ville.

30 janvier. - Bal paré et masqué donné par les gardes du corps du roi, daus la salle de spectacle, à l'occasion de la naissance du dauphin.

3 mars. - Mort de Madame Sophie, fille de Louis XV.

20 mai. - Le grand-duc et la grande-duchesse de Russie, arrivés à Paris le 18, sous les noms de comte et de comtesse du Nord, sont présentés à la cour. Après un mois de séjour tant à Versailles qu’à Paris, ils partent le 19 juin, en passant par Choisy où la cour s'est rendue pour les recevoir.

\section{3.}

7 janvier. - Le prince Doria Pamphili, nonce extraordinaire du pape, remet, dans une audience solennelle, les langes bénits par Pie VI pour le dauphin.

14 janvier. - Le prince héréditaire de Hohenzollern-Sigmaringen est présenté à la cour.

20 janvier. - Signature des préliminaires de la paix entre la France et l'Angleterre.

3 septembre. - Signature des traités définitifs entre la Grande-Bretagne et les États-Unis, entre le roi d'Espagne et le roi d'Angleterre, et entre le roi de France et le roi d'Angleterre. 
23 septembre. - Le prince héréditaire de Hesse-Darmstadt est présenté à la cour.

9 décembre. - Le prince de Nassau-Usingen et le margrave d'Anspach sont présentés à la cour.

1784.

30 mars. - Visite du prince de Nassau-Saarbruck.

7 juin. - Arrivée à la cour de Gustave-III, roi de Suède, sous le nom de comte de Haga.

23 juin. - Pilâtre de Rozier s'enlève dans une montgolfière en présence du roi, de la cour et du comte de Haga.

1785.

27 mars. - Naissance de Louis-Charles de France, duc de Normandie, second fils de Louis XVI, ce prince déclaré dauphin en 1789, mourut au Temple en 1795.

6 juin. - Le prince de Nassau-Usingen prend congé du roi, de la reine et de la famille royale.

29 juin. - La Pérouse, capitaine de vaisseau, commandant la Boussole et l'Astrolabe, prend congé du roi auquel il est présenté par le maréchal de Castries, ministre et secrétaire d'État de la marine.

15 août. - Le cardinal de Rohan, grand aumônier de France, est arrêté par ordre du Roi dans la grande galerie.

31 août. - Baptême du duc d'Angoulême et du duc de Berry.

1786.

13 mai. - Arrivée de l'archiduc Ferdinand, gouverneur général de la Lombardie autrichienne, frère de Marie-Antoinette, et de l'archiduchesse Marie-Béatrix d'Este, sous les noms de comte et de comtesse de Nellenbourg. Ils partent le 17 juin.

9 juillet. - Naissance de Marie-Sophie-Hélène-Béatrix de France, seconde fille de la reine. Cette princesse mourut le 29 juin 1787.

29 juillet. - Arrivée du duc, et de la duchesse de Saxe-Teschen, sous les noms de comte et de comtesse de Bély. Ils partent le 28 août. 
26 septembre. - Traité de commerce et de navigation entre la France et l'Angleterre.

\section{7.}

22 février. - Le roi ouvre l'assemblée des notables.

6 août. - Lit de justice tenu par le roi. Il y fait enregistrer par le parlement l'impôt du timbre et la subvention territoriale.

1788.

8 mai. - Lit de justice tenu par le roi pour l'enregistrement de différentes lois relatives aux fonctions des tribunaux et à l'établissement d'une cour plénière.

18 mai. - Baptême du duc de Chartres (depuis Louis-Philippe 1er, roi des Français), et du duc de Montpensier, son frère.

10 août. - Audience solennelle des ambassadeurs de Tippo-Saïb dans le salon d'Hercule.

23 août. - Le corps de ville de Paris présente au dauphin ses premières armes, consistant en une épée, un fusil et une paire de pistolets.

10 novembre. - Le roi ouvre la seconde assemblée des notables.

17 avril. - Baptême de Mademoiselle (Eugénie-Adélaïde-Louise d'0rléans).

1789.

2 mai. - Le roi reçoit les députés des trois ordres aux états généraux.

3 mai. - Procession des états généraux.

5 mai. - Ouverture des états généraux.

4 juin. - Le duc de Normandie est déclaré dauphin, son frère ainé étant mortle même jour au chàteau de Meudon.

12 juillet. - Arrivée du prince héréditaire de Nassau-Saarbruck.

25 août. - Le roi reçoit le serment de Bailly, nommé maire de Paris après la prise de la Bastille.

1er octobre. - Repas donné par les gardes du corps dans la salle de spectacle de Versailles. 
6 octobre. - Après l'invasion du château par la populace et le massacre des gardes du corps, le roi, la reine et le dauphin quittent Versailles pour se rendre à Paris.

\section{1.}

26 mai. - Décret constitutionnel sur la Liste civile, qui assigne à la famille royale les Tuileries et le Louvre pour demeure, et ordonne que ce palais recerra le dépôt des monuments des sciences et des arts.

1792.

19 septembre. - Décret de l'Assemblée nationale qui ordonne que les tableaux et autres monuments des beaux-arts placés dans les maisons royales seront transportés au dépôt du Louvre.

20 octobre. - Lettre de Roland à la Convention nationale par laquelle il demande l'autorisation de vendre les meubles du château de Versailles. Le député Manuel propose, non-seulement de vendre les meubles, mais aussi (" d'afficher la maison à vendre ou à louer. ) La Convention autorise à faire vendre les meubles, et renvoie au comité d'aliénation pour la vente de la maison.

3 novembre. - Pétition présentée à la Convention nationale au nom des sections du district de Versailles pour réclamer la restitution des tableaux des écoles anciennes qui faisaient partie de l'ancienne collection de la couronne, et la formation au château de Versailles d'un lycée devant renfermer les peintures italiennes, les statues antiques, les collections de pierres gravées, d'estampes, de médailles, une bibliothèque, etc. $\mathbf{A}$ ce lycée viendraient s'adjoindre une université, une école de musique et une école d'équitation. Des représentations de pièces antiques seraient données sur le théâtre du château, et des fêtes civiques dans l'Orangerie, dont on convertirait les escaliers en gradins d'amphithéâtre.

\section{3.}

28 février. - Deux députés de l'administration du district de l'0ise annoncent à la Convention qu'ils ont trouvé au chàteau de Versailles, dans un secrétaire de Louis XVI, un livre rouge en trois volumes in $-4^{\circ}$. Dans ce livre sont consignées les différentes sommes distribuées aux personnes de la cour. L'impression de ce livre est décrétée. 
8 juillet. - Barrère propose, au nom du Comité de salut public, d'établir dans le palais de Versailles une école centrale ou gymnase public.

24 novembre. - Arrêté du département de Seine-et.-0ise pour l'installation au palais de Versailles d'un Musée spécial de l'École française. Ce Musée étant entré plus tard dans les attributions du ministre de l'intérieur Benezech, fut composé principalement des peintures et sculptures présentées par les membres de l'ancienne Académie royale pour leur réception. Il occupait les grands appartements, la grande galerie et le premier étage de l'aile du nord, du côté des jardins. Un cabinet d'histoire naturelle, créé vers la même époque, occupait neuf pièces du rezde-chaussée de l'aile du nord.

1794.

4 juin. - La Convention décrète que les maisons et jardins de SaintCloud, Bellevue, Mouceaux, le Raincy, Versailles, Bagatelle, Sceaux, l'Ile-Adam et Vanvres, ne seront pas vendus et seront conservés et entretenus aux frais de la République, pour servir aux jouissances du peuple et former des établissements utiles à l'agriculture et aux arts.

\section{5.}

24 décembre. - Loi qui ordonne la vente des maisons et parcs de Saint-Gloud, Meudon, Vincennes, Madrid, Bagatelle, Choisy, Marly, Saint-Germain, Maisons-Carrières, le Vésinet, Rambouillet, Chambord, Chantilly, Chanteloup, le Pin, etc., à l'exception seulement des maisons principales de Versailles, Fontainebleau et Compiègne, destinées à des établissements publics.

1798.

6 janvier. - Message du Directoire au Conseil des Anciens et au Conseil des Cinq-Cents, sur la nécessité de prendre une détermination relativement à Versailles. "Une très-petite partie du ci-devant château renferme un dépôt littéraire qui pourrait être mieux placé; d'autres salles sont occupées par un Muséum spécial de l'École française; la somptueuse galerie êt les appartements sont vides. En général les bâtiments, l'Orangerie et les jardins sont bien entretenus. Le grand canal est en prairie... Les bâtiments exigent des réparations urgentes qui iront en croissant chaque année... Ce serait à regret que le gou- 
vernement verrait le vandalisme voter l'anéantissement de cet ensemble de chefs-d'œurre. ) - (Moniteur universel.)

1799.

17 octobre. - Exposition, dans la salle des gardes du corps, des ouvrages des artistes demeurant à Versailles.

1800.

Janvier. - Installation d'une annexe de l'Hôtel des Invalides. Les invalides, au nombre de près de deux mille, étaient établis dans les appartements de Louis XV et dans les ailes du midi, tant du jardin que de la cour des ministres.

1801.

5 arril. - Distribution, dans le salon d'Hercule, des prix de l'École du modèle vivant, instituée au palais national de Versailles.

\section{4.}

3 janvier. - Le pape Pie VII, après s'être rendu directement à la cathédrale de Versailles, visite le château et donne la bénédiction pontificale du haut du balcon de la grande galerie.

\section{5.}

5 février. - Bal donné dans le salon d'Hercule en réjouissance du couronnement de l'Empereur.

\section{7.}

18 novembre. - Visite de la reine de Westphalie (Frédérique-Catherine de Wurtemberg).

1808.

11 mars. - Visite de l'empereur Napoléon Ier.

7 avril. - 0n remplit d'eau le grand canal, mis à sec en 1789 pour le réparer. 
1809.

6 décembre. - Visite de Frédéric-Auguste, roi de Saxe.

1814.

11 mai. - L'empereur de Russie, Alexandre Ier, le roi de Prusse, Frédéric-Guillaume III, deux frères de l'empereur de Russie et deux des fils du roi de Prusse, viennent visiter le château et les jardins de Versailles.

9 août. - Visite de Louis XVIII.

17 août. - Visite de la duchesse d'Angoulême.

1815.

14 août. - Visite du duc et de la duchesse d'Angoulême et du duc de Berry.

1816.

25 juin. - Visite de Louis XVIII, accompagné de Monsieur, du duc et de la duchesse d'Angoulême, et du duc et de la duchesse de Berry.

1 er novembre. - Visite du duc de Cambridge (Adolphe-Frédéric d'Angleterre).

1817.

26 juin. - Le roi, accompagné de Ṁonsieur, visite « le noureau jardin de fleurs qui porte le nom de Bosquet $d u$ Roi, et qui, formé depuis le mois de février, remplace le bassin de l'ancienne île d'amour. ") - (Moniteur universel.)

1820.

18 avril. - Bénédiction, par le prince de Croy, évêque de Strasbourg, de la chapelle de Versailles, nouvellement restaurée. 
1826.

6 août. - Visite de Charles $\mathrm{X}$, accompagné de la famille royale.

1833.

29 août. - Rapport au roi par M. le comte de Montalivet, intendant général de la Liste civile, sur la nouvelle destination à donner au palais de Versailles, en y établissant un Musée historique. La création de ce musée est ordonnée par Louis-Philippe le 1er septembre.

1837.

10 juin. - Inauguration du Musée de Versailles.

“ Le roi avait convié à cette grande solennité les membres de la chambre des pairs, de la chambre des députés, du conseil d'état, de la cour de cassation, de la cour des comptes, de la cour royale de Paris; les tribunaux de première instance et de commerce de la Seine et de Seine-et-0ise; le conseil royal de l'instruction publique, et un grand nombre de membres des cinq académies qui composent l'Institut de France.

« La ville de Paris était représentée par le préfet de la Seine, par un certain nombre de membres du conseil général et du conseil de préfecture, et par les douze maires de Paris.

“ La garde nationale de la Seine avait pour représentant son commandant en chef, le maréchal comte de Lobau, le général Jacqueminot, chef d'état-major; les colonels et lieutenants-colonels des dix-sept légions de Paris et de la banlieue.

Le roi avait également invité à cette fète nationale le préfet, les principales autorités et les officiers supérieurs des gardes nationales du département de Seine-et-0ise.

“ L’armée était représentée par les maréchaux de France, les amiraux, un grand nombre de lieutenants généraux, de maréchaux de camp, de 
vice-amiraux, de contre-amiraux, d'officiers généraux en retraite; par les états-majors de la première division militaire, des places de Paris et de Versailles; par les colonels, lieutenants-colonels des régiments qui forment la garnison de ces deux villes; enfin par l'état major et les offlciers supérieurs de l'école royale militaire de Saint-Cyr.

“ Indépendamment des membres de l'Institut de France, le roi avait bien voulu inviter un grand nombre d'hommes de lettres, d'artistes, et particulièrement les peintres et les sculpteurs qui avaient concouru par leurs travaux à enrichir le nouveau musée.

« Le roi et la reine sont partis à trois heures de Trianon pour se rendre au palais de Versailles.....

“ Depuis dix heures du matin toutes les salles du musée de Versailles étaient ouvertes aux personnes invitées, qui avaient pu les parcourir en attendant l'arrivée du roi.

“ Leurs Majestés ont été accueuillies par les témoignages du plus vif dévouement; elles se sont rendues aux galeries du premier étage par l'escalier de marbre, ont traversé la grande salle des Gardes, aujourd'hui salle de Napoléon, la salle de 1792, les quatre salles consacrées aux campagnes de $1793,1794,1795$ et 1796 ; elles sont entrées ensuite dans la grande galerie des Batailles, où l'on voit, retracés sur la toile, tous les hauts faits de la valeur française, depuis la bataille de Tolbiac jusqu'à celle de Wagram. La foule des invités, qui se pressait autour du roi ne pouvait se lasser d'admirer les belles proportions, les riches ornements de cette galerie entièrement nouvelle.

« Après avoir parcouru d'autres salles, parmi lesquelles on a surtout remarqué la salle des états généraux, la salle de 1830 , où figurent les principaux événements de la révolution de Juillet, leurs Majestés ont traversé la galerie des sculptures et se sont. arrêtées dans la chambre du lit de Louis XIV, pour examiner toutes les parties de l'ancien ameublement restaurées arec une grande magnificence.

" Le banquet royal auquel quinze cents personnes étaient conviées, a eu lieu dans la grande galerie de Louis XIV et dans les salons de la Guerre, d'Apollon, de Ilercure, de Mars, etc. La table du roi était de six cents couverts et oflrait l'aspect le plus splendide. Les princes présidaient aux autres tables, aussi magnifiquement servies que celle du roi. Un ordre admirable a régné dans le service.

“ Après le diner on s'est répandu de nouveau dans les galeries pour les visiter en détail, en attendant l'heure du spectacle. 
“ Leurs Majestés sont entrées dans la salle de spectacle à huit heures, et se sont placées à l'amphithéâtre au-dessus du parterre. Le roi occupait le milieu, ayant à sa droite la reine, et à sa gauche la reine des Belges, madame la duchesse d'0rléans et la princesse Marie. La reine avait à sa droite le roi des Belges, madame la grande-duchesse douairière de Mecklembourg, madame la princesse Adélä̈de et la princesse Clémentine.

“ Le prince royal (duc d'0rléans) occupait un siége derrière madame la duchesse d'Orléans; M. le duc de Nemours, M. le prince de Joinville, M. le duc d'Aumale et M. le duc de Montpensier avaient pris place derrière le roi ct la reine.

« La salle éblouissante de lumières, et décorée avec une magnificence que rien ne saurait égaler, était presque entièrement pleine avant l'arrivée du roi. L'entrée de Leurs Majestés a été saluée par les plus vives acclamations.

“ A huit heures, le spectacle a commencé par le Misanthrope joué avec les costumes du temps, par mademoiselle Mars et les principaux acteurs de la Comédie française. Les acteurs de l'Académie royale de musique ont ensuite exécuté des fragments du troisième et du cinquième acte de Robert le Diable: Leurs Majestés ont plus d'une fois daigné applaudir au talent de Duprez, de Levassor et de mademoiselle Falcon Le spectacle a été terminé par un intermède de $\mathrm{H}$. Scribe, destiné à célébrer l'inauguration du musée et à mettre en parallèle une fête donnée à Versailles par Louis XIV avec la fête toute nationale donnée en ce jour même par le roi des Français.

“ L'assemblée toute entière a témoigné le plus vif enthousiasme au moment où l'art du décorateur a fait succéder à l'aspect du vieux Versailles celui de Versailles rendu à son antique splendeur, et consacré par Louis-Philippe à toutes les gloires qui honorent le pays.

“ Le spectacle s'est terminé à minuit et demi. Quand le roi a quitté sa place, les acclamations ont éclaté avec une nouvelle force. Alors a commencé la promenade aux flambeaux dans les vastes salles du palais et dans la grande galerie des Batailles. Le roi était précédé de valets de pied portant des torches, suivi de sa famille et de toutes les personnes qui avaient pris part au banquet ou à la représentation.

“ Leurs Majestés sont reparties pour Trianon à deux heures du matin.

(Moniteur universel du 12 juin 1837.) 


\section{0.}

4 mai. - Banquet royal dans la galerie de Loủ 3 XIII, le jour de la fète du roi. Après le dîner, le roi, la reine, la famille royale et LL. AA. les ducs de Saxe-Cobourg et de Wurtemberg visitent aux flambeaux toutes les galeries historiques du palais.

1844.

9 juin. - Fête donnée dans la salle de spectacle en l'honneur de l'industrie nationale. Le roi, la reine, la famille royale, le comte de Syracuse, le prince Paul et le duc Alexandre de Wurtemberg assistent à une représentation composée de deux actes d'OEdipe ả Colonne, d'un acte de la Favorite et de deux actes de la Muette, exécutés par les artistes de l'Académie royale de musique. Huit cents invitations avaient été adressées aux représentants de l'industrie française à l'Exposition ouverte le 1er mai précédent aux Champs-Élysées.

1849.

1er septembre. - Visite du prince Louis-Napoléon, président de la République.

1850.

12 avril. - Visite du prince-président de la République et de S. A. I. et $R$. madame la grande-duchesse douairière de Bade.

$18 \check{1} 1$.

28 juin. - Visite du prince-président de la République.

1853.

25 mai. - Visite de S. A. R. le duc de Gênes. 
DE L'HISTOIRE DU PALAIS DE VERSAILLES.

LXXIII

2 juin. - Visite de LL. MM. l'Empereur et l'Impératrice.

20 juin. - Dîner de LL. MM. l'Empereur et l'Impératrice dans la galerie de Louis XIII.

1854.

4 mars. - Visite de S. M. l'Empereur et de S. A. R. le duc de Saxe-Cobourg-Gotha.

16 avril. - Visite de S. A. R. le duc de Cambridge.

1855.

10 juin. - Visite de S. M. le roi de Portugal et de S. A. R. le duc de Porto.

21 août. - LL. MM. la reine Victoria, l'Empereur et S. A. R. le prince Albert, LL. AA. RR. le prince de Galles et la princesse royale d'Angleterre, visitent les appartements et le Musée de Versailles, et assistent au jeu des grandes eaux.

25 août. - Fête de nuit donnée à la reine d'Angleterre.

“Versailles s'était paré pour recevoir dignement les hôtes augustes de l'Empereur. La grande cour du château resplendissait comme en plein jour. Le profil imposant et sévère de cette grande et belle architecture se dessinait en lignes de feu.

“ Leur's Majestés sont entrées par l'escalier de marbre, tandis que les invités montaient par l'escalier des princes. Des salons d'attente et de repos, des boudoirs tendus de damas bleu et remplis de jardinières élégantes avaient été disposés pour la reine d'Angleterre et le prince Albert dans les anciens appartements de Marie-Antoinette.

" La galerie des glaces offrait le plus éblouissant coup d'œil. Aux quatre angles s'élevaient quatre orchestres. Des guirlandes pendaient de la voûte et se reliaient entre elles, formant la plus légère et la plus charmante décoralion; des milliers de lustres, de girandoles, de torchères, réflétés à l'infini par les glaces versaient des torrents de lumière sur les brillants costumes des invités.

“ Le grand parterre d'eau était encadré sur toutes les faces d'une érlatante série de portiques, style renaissance, se découpant sur le fond du pare en feux de couleur et reliés par des treillages émeraude. Au 
centre s'élevait un portique de deux tiers plus grand que les autres, en guise d'arc de triomphe, strmonté du double écusson de France et d'Angleterre. Aux deux coins de droite et de gauche s'arrondissaient deux autres portiques ornés des monogrammes étincelants de Leurs Majestés. Sous ces arches brillantes l'eau s'élançait en gerbes et retombait en cascades. Les deux bassins ne formaient qu'une vaste nappe embrasée sur laquelle nageaient des dauphins d'or montés par des amours portant des torchères à globes, et des guirlandes vénitiennes.

( A dix heures, les portes des grands appartements se sont ouvertes et Leurs Majestés suivies de toute la cour ont fait leur entrée dans la galerie des glaces. La reine d'Angleterre donnait le bras à l'Empereur, l'Impératrice au prince Albert, la princesse Mathilde au prince de $\mathrm{Ba}$ vière, la princesse royale au prince Napoléon. )

Après le feu d'artiflce, dressé à l'extrémité de la pièce d'eau des Suisses, et dont la décoration représentait le château de Windsor, l'Empereur a ouvert le bal avec la reine d'Angleterre. " A onze heures, la cour s'est rendue pour le souper dans la salle de spectacle. La table de Leurs Majestés avait été dressée dans la loge d'honneur d'où l'on. dominait les autres loges garnies de dames, l'orchestre et le parterre transformés en salle de festin. ) - (Extrait du Moniteur universel.)

19 octobre. - Visite de S. MI. l'Empereur et de LL. AA. RR. le duc et la duchesse de Brabant.

29 novembre. - Visite de S. M. le roi de Sardaigne.

\section{6 .}

- 9 mai. - Visite de S. M. le roi de Wurtemberg.

20 mai. - Visite de S. A. I. et R. l'archiduc d'Autriche FerdinandMaximilien. L'Empereur se rend à Versailles avec S. A. R. le prince Oscar de Suède et après un déjeûner servi dans la galerie de Louis XIII, S. M. et LL. AA. passent une revue au camp de Satory.

23 juin. - Visite de S. Ém. le cardinal Patrizi, légat a latere, chargé de représenter le pape Pie IX au baptême du prince impérial.

11 novembre. - Visite de S. A. I. et R. le prince héréditaire de Toscane.

19 décembre. - Visite de S. A. R. le prince Frédéric-Guillaume de Prusse. 
1857.

8 mai. - Visite de S. A. I. le grand-duc Constantin.

31 mai, 3 et 8 juin. - Visites de S. M. le roi de Bavière.

1858.

8 férrier. - Visite de S. A. R. le prince Christian de Danemark.

27 mars. - Visite de S. A. R. le prince Georges de Saxe.

12 et 19 mai. - Visites de S. M. la reine des Pays-Bas.

21 mai. - Visite de S. A. R. le prince de Wurtemberg. 


\section{PLAN DU REZ-DE-GHAUSSÉE \\ DU MUSÉE IMPÉRIAL DE VERSAILLES.}

Aile du Nord.

1 Vestibule de la chapelle.

2

3

4

5

6

15 Vestibule de la salle de spectacle. Bustes.

16 Galerie. Statues et bustes depuis Clovis II jusqu'à Louis XIV in-

17

18

19

20

21

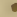

\section{Partie centrale.}

22

23

24

23 Arcades du Nord. Statues et buste de maréchaux de France.

26 Escalier et vestibules. Statues et bustes des officiers généraux tués sur le champ de bataille.

27 Vestibule. Statues et bustes. Ta-

31 Testibules. Bustes.

32 Vestibule de Louis XIII. Statues.

33 Salle des Rois de France.

Vues des anciennes résidences royales et de Paris.

38 Escalier de marbre et vestibules. Statues et bustes.

39 Arcade du Midi. Statues et bustes.

40 Vestibule. Statues et bustes.

41 Vestibule. Statues 'et bustes.

42 Salle des Amiraux.

43 Salle des Connétables.

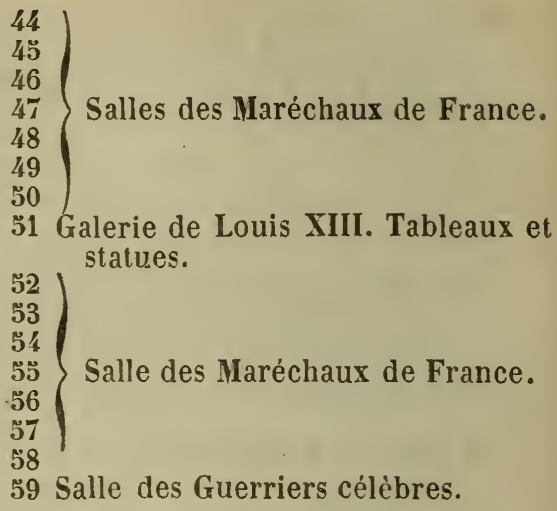

59 Salle des Guerriers célèbres.

Mile du Midi (Partie basse).

60 Galerie. Statues et bustes depuis Louis IV (d'Outremer) jusqu'à Louis XVI inclusivement.

61 Vestibule. Statues et bustes des personnages de la branche de Bourbon-Condé.

62 Vestibule de l'Orangerie. Statues et bustes.

63 Vestibule de l'escalier de Provence. Statues et bustes.

64 Vestibules. Mausolées.

Aile du midi (Rez-de-chaussée).

65 Salles des Marines.

66 Vestibule. Statues et bustes.

67

68

69 Salles des campagnes de 1796 à $70\} 180$ ร.

71

73 Vestibule de Napoléon. Statues et bustes des membres de la Famille Impériale.

74

75 76

77 Salles des campagnes de 1803 à $78\} 1810$.

79

$80)$

81 Galerie. Statues et bustes depuis Louis XVI jusqu'à Louis-Philippe Ier.

82 Vestibule de l'Escalier des Princes. Statues et bustes. 


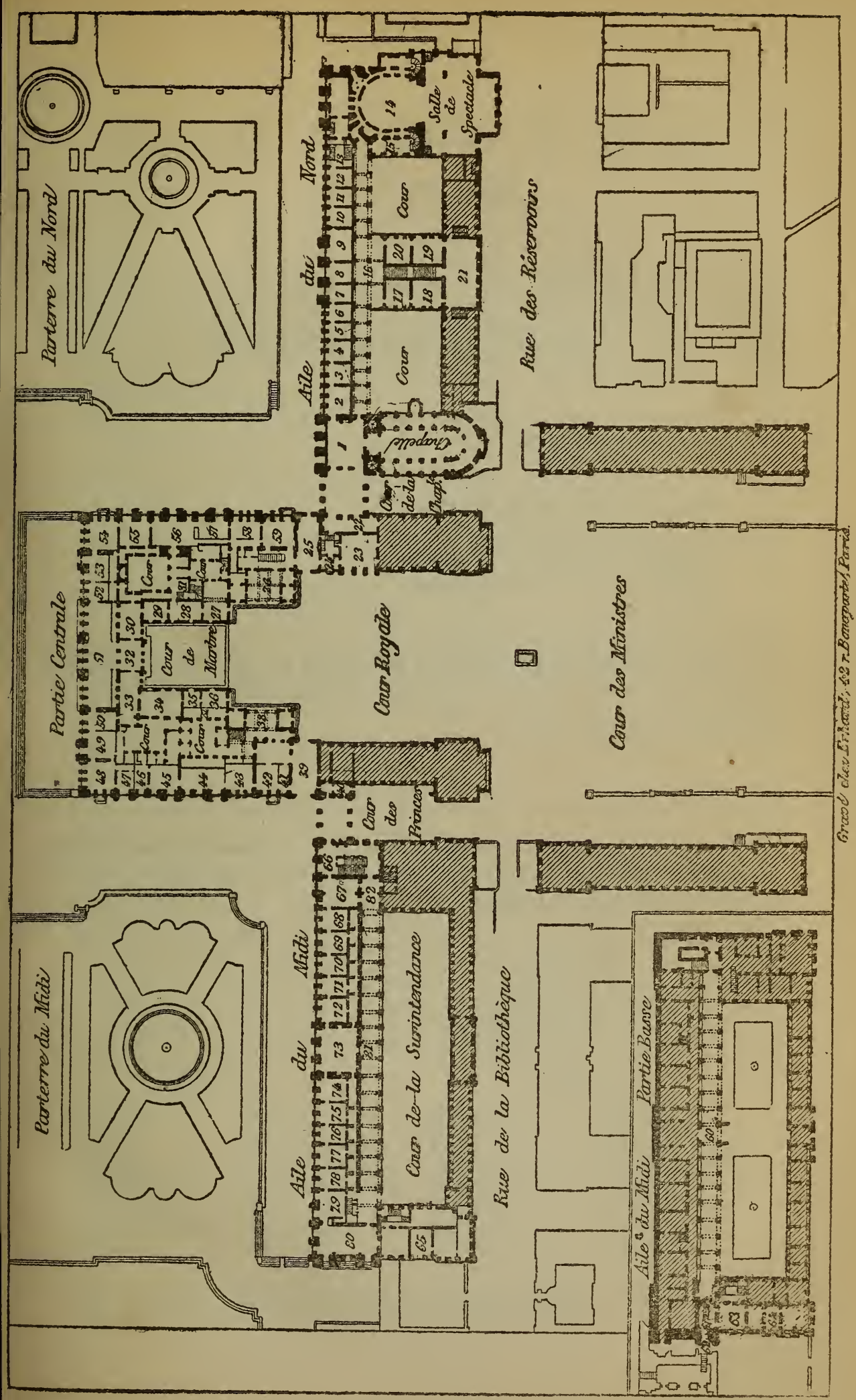




\section{EXPLICATION DES ABRÉVIATIONS.}
H.
- Hauteur.
L.
- Largeur.
Long.
- Longueur.
Diam.
- Diamètre.
Calc. imp.
- Calcographie impériale.

Nota. - Presque tous les tableaux étant peints sur toile, on n'a désigné la matière que dans le cas où les peintures seraient exécutées sur bois ou sur cuivre.

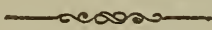

Les objets qui portent des numéros bis et ter ont été placés dans les Salles pendant l'impression de cette Notice, et se trouven mentionnés à la fin du volume sous le titre d'Additions et Corrections 


\section{ENTRÉE ET COUR DU MUSÉE}

\section{DE VERSAILLES.}

La grille d'entrée est divisée en onze travées par des pilastres en fer dont les ornements sont dorés. La porte du milieu est surmontée des armes de France; dans les pilastres latéraux " on a figuré, dit Félibien, une grande lyre avec un soleil, et trois fleurs-de-lys au-dessus; leurs intervalles sont remplis de barreaux qui ont en haut comme des houppes et des fers de piques dorés. "

Les groupes en pierre placés de chaque côté de cette grille d'entrée ont $3 \mathrm{~m}$. $60 \mathrm{c}$. de hauteur et représentent :

A droite. - La Victoire de la France sur l'Empire, par G. Marsy (1).

La Victoire élevant de la main gauche une couronne, prend de la droite des couronnes et des palmes qu'un génie lui présente; près d'elle est un captif, et à ses pieds un aigle terrassé, symbole de l'Empire.

A gauche. - La Victoire de la France sur l'Espagne, par Girardon.

La Victoire tient une couronne de la main gauche et appuie la droite sur l'épaule d'un captif qui a les bras liés derrière le dos; à ses côtés est un génie tenant une palme, et à ses pieds un lion couché, symbole de l'Espagne.

Deux autres groupes ont été placés à l'extrémité de la balustrade; ils ont $2 \mathrm{~m} .43 \mathrm{c}$. de hauteur, et représentent:

A droite. - La Paix, par TuBY.

La Paix tient un caducée de la main gauche et de la droite une torche avec laquelle elle met le feu à un monceau d'armes; un génie lui présente une palme et une branche d'olivier; derrière elle un autre génie terrasse la Discorde.

A gauche. - L'Abondance, par Coyzevox.

Elle est figurée par une femme tenant deux cornes d'abondance et posant le pied sur une gerbe d'épis; devant elle un génie presse une grappe de raisin; derrière elle un autre génie terrasse une figure de femmetirant la langue, emblême de la stérilité.

La Cour d'entrée se nommait autrefois Avant-Cour ou Cour des Ministres, à cause des deux corps de bâtiments qui la bordent et qui étaient occupés par les ministres et secrétaires d'État. "C'est dans cette cour, dit l'Almanach de Versailles de 1789, que quatre compagnies du régiment des gardes françaises et deux du régiment des gardes suisses font la parade, au bruit des fanfares d'une musique guerrière." On voit encore de chaque côté de cette cour les lignes de pavés sur lesquelles se rangeaient les gardes françaises et suisses. Une des premières expériences aérostatiques de Montgolfier fut faite dans cette cour, devant le roi et la famille royale, le 4 septembre 1783 ; et le 23 juin 1784, Pilâtre de Rozier s'y éleva dans une montgolfière nommée Marie-Antoinette, en présence de Louis XVI et de Gustave III, roi de Suède, qui voyageait en France sous le nom de comite du Haga. - Cette cour est décorée de seize statues en marbre de $4 \mathrm{~m}$. de proportion, qui, à l'exception de celles des quatre maréchaux de l'Empire, avaient été exécutées sous Louis XVIII pour la décoration du pont Louis XVI, à Paris. Elles représentent:

\begin{tabular}{|c|c|c|c|}
\hline \multicolumn{2}{|c|}{ A droite: } & \multicolumn{2}{|c|}{ A gauche: } \\
\hline & par C. RAMEX. & Suger & par STouf. \\
\hline & par Moutoni. & uesclin, & par BR \\
\hline $\operatorname{colc}$ & par MILHOMME. & Sully, & $\operatorname{ar} 1$ \\
\hline Masséna & par ESPERGIEUX. & Mortier, & par CALAMATTA \\
\hline Tourville, & par MARIN. & Suffren, & par LESUEUR. \\
\hline Duguay-Trouin, & par DUPASQUIER. & Duquesne, & par ROGUIER. \\
\hline Turenne, & & Condé, & \\
\hline
\end{tabular}

(1) Ce groupe coûta 3,020 livres, et fut soldé aux héritiers de Gaspard Marsy le 7 mars 1683. Celui de Girardon fut payé, en $1682,3,650$ livres; celui de Tuby, en 1683, 2,847 livres; et celui de Coyzevox, en 1682, 2,832 livres. 
Au centre. - Louis $\boldsymbol{X I V}$, statue équestre en bronze, par L. Petitot et CARTELLIER (1).

A la place occupée par cette statue équestre se trouvait l'entrée d'une seconde grille que décoraient les deux groupes en pierre, de Coyzevox et de Tuby, représentant l'Abondance et la Paix, placés actuellement aux angles de la balustrade du côté de la place d'Armes. Cette grille rejoignait par des parties circulaires les angles des deux pavillons qu'ont remplacés ceux sur lesquels est tracée l'inscription : A TOUTES LES GLOIRES DE LA FRANCE. Le pavillon de droite ainsi que l'aile en retour ont été reconstruits en 1772 par GABRIEL; celui de gauche a été élevé de 1814 à 1829, mais la vieille aile a été conservée. La tourelle placée dans un angle à gauche a été ajoutée lors des travaux du musée historique. La partie comprise entre ces deux ailes portait le nom de Cour Royale, jusqu'à l'ancienne cour du château de Louis XIII, qui a gardé le nom de Cour de Marbre.

La Cour de Marbre était autrefois élevée de cinq marches et se trouvait au-dessus ciu niveau des appartements du rez-de-chaussée; elle a été abaissée lors des travaux exécutés pour la conversion du palais en musée historique.

Le 4 juillet 1674, première journée des fêtes ordonnées par Louis XIV au retour des conquêtes de la Franche-Comté, il y eut dans la Cour de Narbre une représentation d'Alceste, opéra de Quinault, mis en musique par Lulli, et le $28 \mathrm{du}$ même mois, quatrième journée de ces fêtes, un souper fut servi à minuit, autour de la fontaine qui décorait alors cette cour. Les gravures de ces fêtes, exécutées par Lepautre (n ${ }^{\text {os }} 2879$ et 2882 du Catalogue de la Calcographie impériale), reproduisent exactement l'aspect de la Cour de Marbre à cette époque. Le 5 octobre 1729, à sept heures du soir, on exécuta sur un théàtre dressé dans la Cour de Marbre un grand concert et un ballet pour célébrer la naissance du dauphin, fils de Louis XV. La décoration représentait le Parnasse, et le roi vit cette fête du balcon de sa cliambre.

Les façades qui entourent la Cour de Harbre sont celles du château, bâti par LEMERCIER pour Louis XIII, auxquelles ont été ajoutés, sous Louis XIV, des combles en plomb couronnés de sculptures, des statues, des trophées, des vases en pierre et des bustes en marbre. Les statues en pierre qui sont posées sur la balustrade "expriment, dit Félibien, les unes les vertus héroïques du roi, et d'autres les quatre parties du monde." Ce sont :

A droite :

La Magnificence, par G. MARSY.

La Justice,

La Sagesse,

La Prudence.

La Diligence,

La Paix,

L'Europe,

L'Asie,

La Renommée, par Coyzevox.

par GIRARDON.

par MASSOU.

par RAON.

par REGNAUDIN.

par LEGROS.

par MASSOU.

par LECOMTE.
A gauche :

$\begin{array}{ll}\text { L'Abondance, } & \text { par G. MARSY. } \\ \text { La Force, } & \text { par CoYzEVOX. } \\ \text { La Générosité, } & \text { par LEGROS. } \\ \text { La Richesse, } & \text { par LEHONGRE. } \\ \text { L'Autorité, } & \text { par LEHONGRE. } \\ \text { La Gloire, } & \text { par REGNAUDIN. } \\ \text { L'Amérique, } & \text { par REGNAUDIN. } \\ \text { L'A frique, } & \text { par LEHONGRE. } \\ \text { La Victoire, } & \text { par LESPINGOLA. }\end{array}$

De chaque côté de l'horloge sont deux figures demi-couchées. A droite: Mars, par G. MARSY ; et à gauche : Hercule, par GIRARdon.

Le balcon dupremier étage est soutenu par huit colonnes de marbre de Rance. Sur des consoles de pierre sont posés quatre-vingt-quatre bustes en marbre imités de l'antique.

Le comble est couronné par une crête en bronze représentant les attributs de la royauté.

Les deux passages latéraux qui conduisent au parc, et qui étaient autrefois fermés par des grilles, se nommaient, celui de droite: Cour de la Chapelle, et celui de gauche: Cour des Princes.

(1) Le cheval, modelé par Cartellier et fondu par Crozatier, était destiné pour une statue équestre de Louis XV, qui devait décorer le rond-point des champsElysées à Paris. La figure de Louis XIV a été exécutée par M.L. Petitot et fondue également par Crozatier; la hauteur totale de cette statue équestre est de $8 \mathrm{~m} .52 \mathrm{c}$. 


\section{CHAPELLE.}

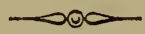

La Chapelle est le dernier ouvrage de Jules-Hardouin MANSART. La première pierre en fut posée le 20 mars 1699; Mansart mourut en 1708, et Robert de Cotte, son beau-irère, la termina d'après ses dessins. Elle fut bénite le 5 juin 1710 par le cardinal de Noailles, et le même jour Louis XIV y entendit la messe pour la première fois. Les principales cérémonies auxquelles elle servit depuis cette époque sont : en $\mathbf{1 7 1 0}$ le mariage du duc de Berry, petit-fils de Louis XIV avec Mademoiselle, fille du duc d'Orléans, depuis régent; en 1713 le mariage du duc de Bourbon avec $\mathrm{M}^{1 \mathrm{le}}$ de Conty et celui du prince de Conty avec $\mathrm{M}^{1 \mathrm{lle}}$ de Bourbon ; en 1724 la réception de cinquante-huit chevaliers de l'ordre du Saint-Esprit; en 1732 le mariage de $M^{\text {lle }}$ de Chartres avec le prince de Conty; en 1736 la cérémonie de la présentation de la Rose d'or envoyée par le pape à la reine Marie Leczinska; en 1737 le baptême du dauphin et des trois filles aînées de Louis XV; en 1739 le mariage de Madame, première fille de Louis XV avec l'infant d'Espagne, don Philippe; en 1743 le mariage du duc de Chartres avec $\mathrm{M}^{1 \mathrm{ll}}$ cie Conty; en $\mathbf{1 7 4 4}$ le mariage du duc de Penthièvre avec la princese de Modène; en 1745 le premier mariage du dauphin avec l'infante d'Espagne (1) et en 1747 son second mariage avec la princesse de Saxe; en 1753 le mariage du prince de Condé avec $M^{11 e}$ de Rohan; en 1769 le mariage du duc de Chartres et de $\mathrm{M}^{\text {lle }}$ de Penthièvre; en 1770 le mariage du duc de Bourbon avec $\mathrm{M}^{\text {lle }}$ d'Orléans et celui du dauphin (Louis XVI) avec l'archiduchesse Marie-Antoinette; en 1771 le mariage du comte de Provence avec la princesse de Savoie; en 1773 le mariage du comte d'Artois avec la sœur de la comtesse de Provence; en 1775 le mariage de $\mathrm{M}^{\text {me }}$ Clotilde, sœur de Louis XVI, avec le prince de Piémont, depuis roi de Sardaigne.

En 1793 tous les attributs royaux qui entraient dans les ornements de la Chapelle furent détruits. Le 26 fructidor an Ix (8 août 1802), la croix fut rétablie sur le comble, les grilles du chœur furent reposées et on recommença, depuis cette époque, à y célébrer le service divin.

L'extérieur de ce monument est composé d'un soubassement surmonté d'un ordre de pilastres corinthiens et d'un attique. L'appareil des pierres est fait avec un soin et une précision remarquables. Sur les archivoltes des grandes fenêtres en arcade sont des enfants portant les attributs du culte catholique. Ces basreliefs ont été sculptés par Bourdict, Tuby, Defer, OfFement, ARMand, Raon, Vigier, Dedieu, Grettepin, Francois, Vorriot et Rousseau de Corbeil. $\mathrm{Au}$-dessus des pilastres règne une balustrade ornée de vingt-huit statues de pierre de Tonnerre, de 3 mèt. de proportion. Les dix premières, placées du côté de l'entrée du parc, sont : $S$. Thomas et $S$. Jacques le Mineur par Manik̀ne, $\boldsymbol{S}$. Jacques le Majeur et $\boldsymbol{S}$. André par THEodon, S. Paul et S. Pierre par Porrier, $S$. Jérôme et $\boldsymbol{S}$. Augustin par Coustou, S. Grégoire et $\boldsymbol{S}$. Ambroise par LEPAUTRE; au chevet, les quatre Evangélistes par VAN CLìve, et en retour, du côté du nord, $S$. Basile et $\boldsymbol{S}$. Athanase par Poultier, S. Chrysostôme par Flamen, S. Grégoire de Naziance par Hurtrel, S. Philippe et S. Barthélemi par Flamen, $S$. Simon et $S$. Jude par Lemoine, $S$. Barnabé par Bourdict, $S$. Mathias par LAPIERRE. Au-dessus de la partie en saillie qui contient les chapelles de S. Louis et de la Vierge, sont quatre Vertus chrétiennes : la Foi par SlODTZ, la Justice par Garnier, la Charité par LelorRain, et la Religion par BARRoIS. Enfin, sur le tympan de la face du côté du parc, sont deux figures demicouchées représentant la Foi et la Religion sculptées par G. Coustou. Le comble est décoré d'ornements en plomb autrefois dorés; aux deux extrémités sont deux groupes d'anges, par G. Coustou et LePaUtRE. Au milieu, s'élevait une lanterne revêtue d'ornements en plomb également dorés; cette lanterne, qui menaçait ruine, fut supprimée en 1765.

(1) Une gravure de G. N. Cochin (Calc. imp., n॰ 2978) représente cette cére̊monie. 
CHAPELLE.

L'intérieur de la Chapelle se divise en deux parties distinctes. Dans la partie basse se trouvent le maître-autel, la chapelle de S. Louis et la sacristie. La tribune du roi, celle du pourtour et la chapelle de la Vierge occupent la partie haute.

\section{PARTIE BASSE.}

Le rez-de-chaussée de la Chapelle est composé d'un porche placé sous la tribune du roi, de la nef et des bas-côtés. Le carrelage, divisé en compartiments, est une mosaïque de marbres de différentes couleurs. Ce rez-de-chaussée comprend la hauteur d'un soubassement en pierre de liais, qui sert de stylobate continu à l'ordre corinthien qui règue au premier étage. Les piédroits des arcades en plein cintre de la nef sont ornés sur leurs quatre faces de trophées en bas-relief à peine saillant et du travail le plus délicat; entre les archivoltes de ces arcades, des anges tiennent les divers attributs de la Passion. Les sculptures à droite de l'entrée sont dues à Bertrand, Dumont, Cornu, lelorrain, Thierry, Poultier, G. Coustou; celles de gauehe à Frénin, Lemorne, Manière, Lapierre, Lepautre, PoIrIER et VAN CLÈve. Une chaire en bois sculpté et doré était placée contre le troisième pilier de gauche et fut détruite en 1793. Aucun prédicateur célèbre ne s'y ẻtait fait entendre sous Louis XIV; les célèbres sermons de Bossuet, de Mascaron, de Bourdaloue, de Fléchier et de Massillon sont tous antérieurs à 1710. Les seuls souvenirs que cette chaire aurait pu rappeler étaient ceux de l'abbé Maury et de l'abbé Fauchet qui y prêchèrent devant la cour, le premier en 1775, 1781 et 1785, et le second en 1779 et en 1782.

Le maître-autel, adossé à l'arcade qui fait face à la porte d'entrée, est construit en marbre et en bronze doré. Il est surmonté d'une Gloire céleste adorée par les anges et les chérubins; ces sculptures sont de VAN GLEvE. Le bas-relief de l'autel, par G. Coustou, représente J.-C. mort sur les genoux de la Vierge.

Dans les bas-côtés, les piliers, les pendentifs et les lunettes de la voûte sont également couverts de sculptures. Au bas des croisées étaient placés alternativement des autels et des confessionnaux en bois doré. Les confessionnaux n'existent. plus; les autels, construits sous le règne de Louis XV, sont en marbre et ornés de bas-reliefs en bronze; les figures d'anges en bronze qui les surmontent sont toutes de G. Coustou.

Les autels et les chapelles sont, en commençant par le bas-côté à droite de l'entrée:

$1^{\circ}$ Autel de Sainte Adélaïde. - Bas-relief: Sainte Adèlaïde quittant S. Odilon, évêque de Cluny, par ADAM l'aîné en 1745 (1).

$2^{\circ}$ Autel de Sainte Anne. - Bas-relief : Sainte Anne instruisant la Vierge, par VINACHE.

30 Autel de S. Charles Borrumée. - Bas-relief : S. Charles Borromée pendant la peste de Milan, par BouchaRdoN.

$4^{\circ}$ Chapelle du Sacré Cœur de Jésus. - Cette chapelle fut construite d'après les dernières volontés du Dauphin, fils de Louis XV, et terminée en 1772 sur les dessins de A.-J. GABRIEL. Les ornements de bronze doré sont attribués aux frères ADAM.

Dans l'arcade en face de cette chapelle et adossé au maître-autel, est un tablean de Silvestre représentant la Cène. La bordure en marbre est surmontée de deux anges en bronze, par LEPAUTRE.

5" Autel de S. Philippe. - Bas-relief : Martyre de S. Philippe, par LADATTE en $1738(2)$.

$6^{\circ}$ Chapelle de S. Louis. - Bas-relief : $\boldsymbol{S}$. Louis servant les pauvres, par M.-A. SLODTZ, - Tableau d'autel : S. Louis soignant les blessés après la bataille de la Massoure, par Jouvenet.

$7^{\circ}$ Autel de Sainte Victoire. - Bas-relief : Martyre de Sainte Victoire, par ADAM le cadet en 1737 (3).

La sacristie renferme quatre tableaux de l'école de Lebrun représentant les

(1) Le modèle de ce bas-relief a été exposé au Salon de 1738.

2 Ce bas-relief a été exposé au Salon de 1738.

(3) Ce bas-relief a été exposé au Salon de 1737. 
Evangélistes, une copie d'après les Pèlerins d'Emmaüs, du Titien, et treize petits bustes en terre cuite par SARAZIN, représentant Jésus-Christ et les Apôtres.

\section{PARTIE HAUTE.}

A la hauteur du premier étage se trouvent la tribune du roi et celle du pourtour placée au-dessus des bas-côtés. Le chevet est occupé par le buffet d'orgue et par la partie réservée aux musiciens de chapelle. Le milieu des fenêtres du premier étage et de l'attique était décoré de vitraux peints par MIrCHU, représentant le chiffre de Louis XIV et les armes de France; ces vitraux, qui avaient été détruits, ont été rétablis, sous la direction de M. RoBERT, par les artistes de la manufacture de Sères, en 1852.

La tribune du roi, placée en face du maître-autel, s'étend dans toute la largeur de la nef. Les parties circulaires des angles supportaient autrefois deux lanternes en bois doré, garnies des glaces, qui servaient d'oratoires au roi et à la reine. Le roi se plaçait dans celle de gauche et la reine dans celle de droite. Le roi ne descendait dans le bas de la chapelle que lorsqu'un évêque officiait. La porte d'entrée est surmontée d'un bas-relief sculpté par MaNıère et représentant les armes de France soutenues par deux anges. Au-clessus des deux portes qui donnaient sur les escaliers à vis, sont deux bas-reliefs : à droite, la Présentation au Temple, par PoIRIER; à gauche, J.C. dans le Temple, instruisant les docteurs de la loi, par G. Coustou.

La tribune du pourtour est divisée en quinze travées par les colonnes et les piliers qui soutiennent l'attique. Les arcades des grandes travées sont surmontées de figures assises, sculptés en bas-relief et représentant des Vertus caractérisées par leurs symboles; les plafonds, peints à l'huile sur un enduit de plâtre, ont pour sujets les douze apôtres. Ce sont en entrant par la tribune à droite:

$1^{\text {re }}$ travée. - La Charité et la Religion, bas-relief, par LELoRRaIN - S. Barnabé, plafond par BON BOUlOGNE.

$2^{\mathrm{e}}$ travée - La Prudence et la Justice, bas-relief, par PoIrIER. - S. Jude, plafond, par BON BOULOGNE.

$3^{\mathrm{e}}$ travée. - Le Secret et la Patience, bas-relief, par Bertrand. - S. Barthélemi, plafond, par Bon BouloGNe.

$4^{\mathrm{e}}$ travée. - L'Humilité et la Sagesse, bas-relief, par LAPIERRE. - S. Jacques le mineur, plafond, par BON BOULOGNE.

$5^{\mathrm{e}}$ travée. - La Modération et la Mortification, bas-relief, par Frémin. S. Jacques le majeur, plafond, par BoN BouloGNE.

$6^{\text {e }}$ travée. - Deux anges portant des instruments de musique, plafond, par BON BOULOGNE.

$7^{\text {e }}$ travée. - La Libéralité et le Zèle, bas-relief, par LeLorraIn. - S. Paul ravi au troisième ciel, par LoUIs BoolOGNE.

$8^{\mathrm{e}}$ travée. - La Clémence et la Miséricorde, par Slodtz (1).-Un concert d'anges chantant le Domine salvum fac regem, plafond, par LOUIS BOULOGNE.

$9^{\mathrm{e}}$ travée. - La Vigilance et l'Eternité, bas-relief, par ThIERRY. - S. Pierre, plafond, par Louis BOULOGNE.

$10^{\mathrm{e}}$ travée. - Trois anges formant un concert, plafond, par LOUIS BouloGNE. $11^{\mathrm{e}}$ travée. - L'Adoration et la Contemplation, bas-relief, par MANIÈRE. S. André, par LOUis BOUlogNe.

Dans cette travée est un autel dédié à Sainte Thérèse. Le tableau, peint par SANTERRE, représente Sainte Thérèse en extase; la bordure en marbre est surmontée de deux anges en bronze, par LEPAUTRE. La mort de Sainte Thérèse, bas-relief en bronze, par VINACHE (2), est dans la partie inférieure de l'autel.

$12^{\mathrm{e}}$ travée. - La Piété et l'Obéissance, bas-relief, par Lemoine. - S. Philippe, plafond, par LouIs BouloGNE.

$13^{\mathrm{e}}$ travée. - La Modestie et la Pureté, bas-relief, par Lepautre.-S. Simon, plafond, par LOUIS BOULOGNE.

(1) Ce bas-relief est caché par le buffet d'orgue qui occupe l'arcade du milieu.

(2) Le modèle de ce bas-relief a été exposé au Salon de 1739. 
De cette travée on entre dans la chapelle de la Vierge, placée au-dessus de celle de S. Louis. Les peintures du plafond sont de LouIS BouloGNE; il a représenté dans le milieu l'Assomption de la Vierge; dans les voussures des trois arcades, l'Amour divin, la Pureté et l'Humilité; dans les pendentifs quatre anges portent divers attributs tirés des litanies de la Vierge : Rosa mystica - Foderis arca-Stella matutina. - Turris Davidia. Le tableau de l'autel représentant l'Annonciation est aussi de LOUIS BOUlOGNE; dans la partie inférieure, un basrelief en bronze, par G. Coustou, a pour sujet la Visitation.

$14^{\mathrm{e}}$ travée. - La Tempérance et la Foi, bas-relief, par Potltier. - S. Mathicu, par LouIS BOULOGNE.

$13^{\mathrm{e}}$ trarée. - L'Espérance et la Foi, bas-relief, par Coustod. - S. Thomas, par LOUIS BOULOGNE.

Le plafond du milieu de la voûte est décoré d'un riche fond d'architecture, peint par Mieusnier. du centre, A. Coypel a représenté le Père Eternel dans sa gloire et de chaque côté deux groupes d'esprits célestes portant la Colonne et la Croix, instruments de la Passion de J.-C. Dans les voussures des fenêtres de l'attique sont les quatre Évangélistes, et aux extrémités du plafond Charlemagne et $\boldsymbol{S}$. Louis; ces figures sont exécutées en camaïeux imitant des bas-reliefs de bronze doré. Sur les pendentifs, le même artiste a peint les douze prophètes; à droite : Malachie, Joël, Jacob, David, Jérémie et Aggée. - A gauche : Zacharie, Michée, Abraham, Moïse, Isaie et Daniel.

Dans la voûte du chevet. - La Résurrection de J. C., par LAFossE.

Au-dessus de la tribune du roi. - La Descente du Saint-Esprit, par JoUVENET. 


\section{MUSÉE IMPÉRIAL}

\section{DE VERSAILLES.}

REZ-DE-CHAUSSÉE.

\section{Aile du Nord.}

\section{VESTIBULE DE LA CHAPELLE, No 1.}

Ce Vestibule servait d'entrée à la Chapelle et aux appartements de l'aile droite. Il est partagé dans la longueur et la profondeur par deux files de douze colonnes d'ordre ionique.

\section{Allégorie au passage du Rhin par Louis XIV.}

Par N. et G. Coustoc; bas-relief en marbre. - H. 3,78. - I. 2,96 .

Louis XIV, couronné par la Victoire, foule aux pieds le Rhin sous la figure d'un vieillard terrassé. Dans le fond, des cavaliers exécutent le passage du fleuve.

Ce bas-relief a remplacé celui du Puget représentant Alexandre et Diogène, transporté au Louvre. Il est de forme ovale et a été agrandi dans les angles. Il était destiné à être mis à la place du modèle en plâtre par Coyzevox qui se trouve dans le salon de la Guerre.

\section{SALLE No 2.}

Cette salle et les suivantes, jusqu'à la salle $n^{\circ} 7$ inclusivement, formaient l'appartement habité, à la fin du règne de Louis XIV, par le duc du Maine; sous Louis XV par le duc d'Orléans, fils du régent, puis par sa sœur Charlotte-Aglaé d'Orléans, duchesse de Modène, et sous Louis XVI par Louis-Joseph de Bourbon, prince de Condé.

2. Clovis $I^{e r}$, roi des Francs. (Voir n ${ }^{\circ} 656$.)

Par Dejuinne. - H. 1,44. - L. 0,89. 


\section{Baptême de Clovis à Reims. - 25 décembre 496.}

Par Dejuinne en 1837. - H. 1,43. - L。 1,80.

Clovis, après la bataille de Tolbiac, obtint de ses guerriers la promesse de le suivre au baptême, et ne tarda pas lui-même à s'y présenter. Le roi, dit Grégoire de Tours, pria saint Remi, évêque de Reims, de le baptiser le premier. Le nouveau Constantin s'avance vers le baptistère, et le saint évêque lui dit alors d'une bouche éloquente : " Doux Sicambre, courbe la tête; adore ce que tu as brûlé, brûle ce que tu as adoré ». Plus de trois mille hommes de l'armée de Clovis reçurent après lui le baptême.

\section{Entrée triomphale de Clovis à Tours. - 508.}

Par M. Robert-Fledry en 1837. - H. 0,79. - L. 0,89.

Clovis, à qui l'empereur Anastase avait décerné les honneurs consulaires, revêtit dans la basilique de Saint-Martin de Tours la tunique de pourpre et la chlamyde, et posa la couronne sur sa tête. " Ensuite, dit Grégoire de Tours, étant monté à cheval, il jeta de sa propre main de l'or et de l'argent au peuple assemblé, et depuis ce jour il fut appelé Consul ou Auguste ».

\section{Funérailles de Dagobert à Saint-Denis. - Jan- vier 638 .}

Par M. TASSaert en 1837. - H. 0,81. - L. 0,89.

Dagobert mourut dans l'abbaye de Saint-Denis, dont il est regardé comme le fondateur. Ses restes furent déposés dans l'église en grande pompe, et ensevelis à la droite du tombeau des saints martyrs Denis, Rustique et Eleuthère. Depuis cette époque, l'église de Saint-Denis a été le lieu ordinaire de la sépulture des rois de France et des princes de leur famille.

6. Sacre de Pépin-le-Bref à Saint-Denis. - 28 juillet. 754.

Par M. François Dubois en 1837. - H. 0,60. - L. $0,89$.

Le pape Etienne II donne la couronne et l'onction sacrée à Pépin, à la reine Berthe ou Bertrade et à leurs deux fils aînés Charles et Carloman. - Pépin est le premier roi de France qui ait été sacré.

7. Charlemagne ou Charles $\boldsymbol{I}^{\text {er }}$, roi des Francs, empereur d'Occident. (Voir $\mathrm{n}^{\circ} 674$.)

Par M. AMIEL. - H. 0,75. - L. 0,64. 
8. Charlemagne traverse les Alpes. - $\mathbf{7 7 3}$.

Par Eugène RoGer en 1837. - H. 0,69. - L. 1,06.

Appelé par le pape Adrien I ${ }^{\mathrm{er}}$, qui avait invoqué son secours contre Didier, roi des Lombards, Charlemagne entre en Italie par le mont Cenis, dans l'automne de 773. Eginhard parle « des immenses difficultés que les Francs trouvèrent à passer les Alpes, et des pénibles travaux qu'il leur fallut supporter.pour franchir ces sommets de monts inaccessibles, ces rocs qui s'élancent vers le ciel et ces rudes masses de pierre. »

9. Charlemagne couronné roi d'Italie à Milan. - 774 . Par M. JaCQUAND en 1837. - H. 0,67. - L. 1,06.

Après avoir conquis le royaume des Lombards, Charlemagne prit le titre de roi d'Italie et ceignit la couronne de fer dans la cathédrale de Milan.

\section{Charlemagne présente ses premiers Capitulaires à l'assemblée des Francs. - 779 .}

Par Ary SGHeFfer. - H. 3,60. - L. 2,85.

L'empereur, assis sur son trône, la couronne en tête, le sceptre de justice à la main, fait lire les Capitulaires par Eginhard, son secrétaire. Ces édits ou règlemènts étaient rédigés par Charlemagne et soumis chaque année à l'examen des grands du royaume.

Ce tableau a été exécuté en 1827 pour une des salles du conseil d'État au Louvre.

\section{Alcuin présenté à Charlemagne. - 780 .}

Par M. Jules Laure, d'après M. Schnetz. - H. 0,64. - L. 1,06.

Charlemagne, environné des principaux personnages de sa cour, reçoit Alcuin, moine anglais, qui lui présente des manuscrits. Un ambassadeur du calife Aaroun-al-Raschid assiste à cette cérémonie. " Alcuin, dit M. Guizot, devint le conseiller et le premier ministre intellectuel de Charlemagne. »

Ce tableau est une copie réduite du plafond peint par M. Schnetz dans une des salles du Louvre.

12. Bataille de Fontenay ou de Fontenailles. - 25 juin 841.

Par Tony Johannot en 1837. - H. 0,61. - L. 1,05.

Cette bataille fut livrée par Charles-le-Chauve et Louis-le-Germanique contre Lothaire leur frère. Les deux armées se rencontrèrent à Fontenay ou Fontenailles, près d'Auxerre. « La bataille, 
dit l'historien Nithard, qui combattait dans l'armée de Charles-leChauve, s'engagea sur les bords de l'Andrie, petite rivière de Bourgogne. Louis et Lothaire en vinrent aux mains dans un endroit nommé les Bretignelles, et là Lothaire vaincu prit la fuite. La portion de l'armée que Charles attaqua dans le village du Fay s'enfuit aussi.... Les deux rois furent done vainqueurs. ») Le carnage fut immense; on dit que soixante-dix mille hommes furent tués.

\section{Mort de Robert-le-Fort au combat de Brisserte.- 25 juillet 886.}

Par M. Henri Lehmañ en 1837. - H. 0,68. - L. $1,05$.

Les Normands avaient pillé le Mans. Robert-le-Fort, comte de Paris, tige de la maison des Capétiens, poursuivit les pillards, les atteignit à Brisserte, à cinq lieues d'Angers, et les obligea à se renfermer dans l'église de ce village. Fatigué d'une longue marche, et se fiant au blocus étroit dont il enveloppait la place d'armes des barbares, Robert donna à ses soldats l'exemple de se dépouiller de leur armure et de prendre un peu de repos. Les Normands profitèrent de ce moment d'imprévoyarice et se jetèrent sur Robert et sa troupe. Désarmé, ils le tuèrent sans peine, et traînèrent son corps dans l'église. Cette église, reconstruite à plusieurs reprises, a néanmoins une nef très-ancienne, que l'on croit être celle même où les Normands s'enfermèrent.

\section{Bataille de Saucourt en Vimeu. - Juillet 881.}

Par M. DASSY en 1837. - H. 0,67. - L. 1,05.

Louis III voulant arrêter les ravages des Normands dans les provinces de Flandre et d'Artois, marche contre eux et les rencontre à Saucourt en Vimeu, village situé à trois lieues d'Abbeville. La défaite des Normands fut complète; leur chef Garamond resta parmi les morts.

\section{Lothaire défait l'empereur Othon II sur les bords de l'Aisne. - Octobre 978.}

Par Charles Durupt en 1837. - H. 0,64. - L. 1,05.

Othon II, empereur d'Allemagne, était venu, à la tête d'une armée de soixante mille hommes, camper sous les murs de Paris, puis avait été forcé de battre en retraite. Lothaire, qui l'avait poursuivi, profitant de ce que pendant la nuit des pluies avaient grossi la rivière de l'Aisne et empêché le passage de l'armée entière, attaque l'arrière-garde d'Othon et la précipite dans la rivière. 
16. Louis-le-Gros prend l'oriflamme à Saint-Denis. -1124 .

Par M. Jollivet en 1837. - H. 0,60. - L. 1,05.

Suger, abbé de Saint-Denis, remet aux mains de Louis-leGros, vassal de l'abbaye, l'oriflamme que le roi vient chercher en grande pompe avant de marcher contre l'armée de l'empereur Henri V, qui menaçait d'envahir la France.

17. Louis IX (saint Louis), roi de France. (Voir n 694.) Par A. DE Creuse. - H. 0,74. - L. 0,64.

18. Saint Louis reçoit à Ptolémaïs les envoyés du Vieux de la Montagne. - 1251.

Par M. Rovget. - H. 3,60. - L. 4,87.

Le chef mystérieux de quelques bourgades du mont Liban, que les uns nommaient le Prince des Assassins, et d'autres le Vieux de la Montagne, s'était rendu redoutable par le dévoûment fanatique de ses sicaires, qui, sur son ordre, allaient poignarder ceux qui refusaient de lui payer un tribut. Il n'osa cependant braver le pouvoir du roi de France, et lui envoya, en signe de soumission, sa chemise et son anneau.

Ce tableau a été exposé au Salon de 1819.

19. Saint Louis rendant la justice sous le chêne de Vincennes.

Par M. Rovget en 1826. - H. 3,60. - L. 2,61.

“ Maintefois ay veu, dit Joinville, que en été il alloit seoir au bois de Vincennes, après sa messe, et se accôtoioit à un chêne, et nous faisoit seoir autour de lui; et tous ceux qui avoient à faire venoient parler à lui, sans destourbier de huissier ni d'autre. Et alors il leur demandoit de sa bouche : Y a-t-il aucun qui ait partie? Et eux se levoient qui partie avoient, et il leur disoit : Taisez-vous tous, et on vous délivrera l'un après l'autre. Et alors il appeloit monseigneur Pierre de Fontaines et monseigneur Geoffroy de Villettes, et disoit à l'un d'eux : Délivrez-moi cette partie. Et quand il voyoit aucune chose à amender en la parole de ceux qui parloient pour autrui, lui-même l'amendoit de sa bouche. »

Ce tableau a été exposé au Salon de 1827.

20. Saint Louis médiateur entre le roi d'Angleterre et ses barons. - 23 janvier 1264.

Par M. Rovget en 1820. - H. 3,60. - L. 4, 85 .

Henri III, roi d'Angleterre, avait soulevé contre lui les barons 
anglais par le mépris qu'il faisait de leurs prérogatives et les préférences qu'il accordait à des favoris étrangers. Ils invoquèrent, d’un commun accord, la médiation du roi de France. Saint Louis ajourna les deux partis à son tribunal dans la ville d'Amiens. Henri III s'y rendit avec la reine Éléonore de Provence, l'archevêque de Cantorbéry et la foule de ses courtisans, pendant que Pierre de Montfort, fils du comte de Leicester, venait plaider la cause des barons anglais. Saint Louis, entouré de sa cour, entendit les griefs réciproques de la couronne et de l'aristocratie. Il prononça en faveur de Henri III, et annula les provisions d'OXford, sorte de traité dicté par les barons au roi d'Angleterre.

Ce tableau a été exposé au Salon de 1822.

\section{Mort de saint Louis devant Tunis. -25 août 1270.}

Par M. Rovget. - H. 3,60. - L. 2,70.

Le roi, atteint par l'épidémie qui ravageait son armée sous les murs de Tunis, se fit coucher sur un lit de cendres au pied de l'autel; là, entouré de ses deux fils, des princes et des princesses de sa famille, il rendit le dernier soupir vers trois heures de l'après-midi. Charles d'Anjou, roi de Sicile, qui venait de débarquer, vole à la tente du roi son frère, le trouve mort, et se prosterne à ses pieds qu'il arrose de larmes.

Ce tableau a été exposé au Salon de 1817.

22. Philippe $I I I$, roi de France. (Voir n $\left.{ }^{\circ} 695.\right)$

Par M. Jollivet. - H. 0,66. - L. 0,56.

\section{Prise du château de Foix. - 1272.}

Par M. Jollivet en 1837.- H. 0,68. - L. 1,40.

Les seigneurs de Foix et d'Armagnac s'étant soulevés contre les droits de Philippe-le-Hardi au comté de Toulouse, le roi convoque aussitôt à Tours les vassaux de la couronne, marche sur Toulouse, où il prend solennellement possession du comté qui vient de lui échoir, et va mettre le siége devant le château où Roger Bernard s'est renfermé. Le comte de Foix, n'osant se fier aux murs épais de sa forteresse, la remit, au bout de deux jours, entre les mains du roi.

SALLE $N^{\circ}$ 3. (Voir salle no 2.)

24. Charles $V$, roi de France. (Voir no ${ }^{702 .)}$

Par M. SaINT-EVRE. - H. 0,72. - L. 0,58. 
25. Fondation de la Bibliothèque du roi, à Paris. 1379.

Par M. SAINT-EvRE. - H. 0,75. - L. 1,21.

Le roi Charles $\mathrm{V}$, en même temps qu'il recherchait les livres, était aussi saige artiste et deviseur de beaux maconnages; parmi les embellissements dont il décora le Louvre, il y fit construire une tour dite Tour de la Librairie, où étaient renfermés les neuf cents volumes qu'il avait rassemblés à grands frais. Le catalogue des livres de Charles $\mathbf{V}$, fait par Malet, son bibliothécaire, existe en original à la Bibliothèque impériale. Cette bibliothèque fut transportée en Angleterre par le duc de Bedford, en 1429.

\section{Mort de Du Guesclin devant C'hâteauneuf de Ran- don. - 13 juillet 1380.}

Par Nicolas-Guy Brenet. - H. 3,83. - L. 2,64.

Le connétable Du Guesclin assiégeait Châteauneuf de Randon, à quatre lieues du Puy, lorsqu'il tomba malade. On rapporte que le commandant anglais de la forteresse s'était engagé à la rendre si, à jour fixe, il n'était point secouru. Ce jour même mourut Duguesclin; l'Anglais n'en vint pas moins déposer les clefs de la place sur son lit de mort : " Son nom, suivant la belle expression de Mézeray, acheva l'entreprise. »

Olivier de Clisson, frère d'armes de Du Guesclin, est debout et montre son ami mort; derrière lui est le maréchal de Sancerre, qui succéda à Du Guesclin dans le commandement de l'armée, et fut depuis connétable.

Ce tableau a été exposé au Salon de 1777.

27. Charles VI, roi de France. (Voir no 703.) .......... - H. 1,11. - L. 1,05.

28. Bataille de Rosebecque. - 27 novembre 1382.

Par Alfred et Tony Jоналnот. - H. 3,83. - L. 2,64.

Les Français, ayant à leur tête le roi Charles VI, à peine âgé de quatorze ans, trouvèrent devant eux, le 26 novembre 1382, l'armée flamande, rangée en bataille entre Rousselaer et Rosebecque. Philippe Arteveld commandait cinquante mille fantassins tous couverts de fer, serrés en phalange les uns contre les autres, et les bras entrelacés pour ne point interrompre leurs rangs. La gendarmerie française, avec ses armures de fer, avait mis pied à terre; pendant qu'elle soutenait au centre le choc des Flamands, elle débordait sur les deux ailes l'armée ennemie, qui se trouva ainsi enveloppée; ce ne fut plus alors un combat, mais un massacre. On trouva Philippe Arteveld gisant parmi les morts. 


\section{Bataille de Beaugé. - 22 mars 1421.}

Par M. Lavauden en 1837. - H. 0,82. - L. 1,05.

Le gros de l'armée du dauphin (depuis Charles VII), était réuni en Anjou, sous les ordres du maréchal de La Fayette et du comte de Buchan. Les Anglais vinrent livrer bataille, près de Beaugé, à cette armée qu'ils méprisaient; le duc de Clarence, prince du sang royal, les commandait. Il n'attend pas pour charger les Français que toute son armée soit rassemblée autour de lui, et s'élance à la tête de ses hommes d'armes, laissant de l'autre côté de la rivière ces redoutables archers des communes dont la part avait été si grande dans les victoires de l'Angleterre en France. Sa témérité ne tarda guère à être punie : il fut pris par un chevalier de l'armée française, et au milieu des efforts qu'il faisait pour se délivrer, il tomba sous les coups du comte de Buchan.

30. Charles VII, roi de France. (Voir no 704.)

par M. H. LehmanN. - H. 0,72 . - L. 0,57.

\section{Jeanne d'Arc présentée à Charles VII. - Février 1429.}

Par PAPETY, d'après M. Saint-Evre. - H. 0,93. - L. 1,05.

Toute la France du Nord jusqu'à la Loire était aux mains des Anglais, et Charles VII, réduit à la souveraineté des provinces du centre et du sud du royaume, recevait de ses ennemis le titre dérisoire de Roi de Bourges. C'est alors que parut Jeanne d'Arc; accueillie d'abord avec incrédulité aux lieux où elle était née, elle finit par prouver sa mission à force de sainteté, et le sire de Beaudricourt se décida à l'envoyer au roi, qui consentit à la voir. " Pour l'éprouver, dit M. de Barante, il ne se montra point d'abord, et se tint un peu à l'écart. Cependant elle ne se troubla point; et, bien que le roi ne fût point si richement vêtu que beaucoup d'autres qui étaient là, ce fut à lui qu'elle vint. Elle s'agenouilla devant lui, embrassa ses genoux. "Ce n'est pas moi qui suis le roi, Jeanne, dit-il, en montrant un de ses seigneurs : le voilà. - Par mon Dieu, gentil prince, c'est vous, et non un autre. " Puis elle ajouta : "Très noble seigneur dauphin, le roi des cieux vous mande par moi que vous serez sacré et couronné en la ville de Reims, et vous serez son lieutenant au royaume de France. ग,

\section{Sacre de Charles VII à Reims. - 17 juillet 1.429.}

Par Vincion en 1837. - H. 3,83. - L. 6,19.

Charles VII et Jeanne d'Arc enlevèrent Reims aux Bourguignons. Deux jours après le roi fut sacré dans la cathédrale par 
l'archevêque Renaud de Chartres. Les vieilles pairies laïques ou ecclésiastiques du royaume ou n'existaient plus ou étaient réunies sur la tête du duc de Bourgogne. Ce furent les principaux seigneurs de la cour du roi qui les représentèrent. Le sire d'Albret y représenta le connétable; les autres fonctions furent remplies par le comte de Clermont, le sire de la Trémoille, le duc d'Alencon, les évêques de Châlons et d'Orléans et le cardinal duc de Bar. René d'Anjou, roi de Naples et beau-frère du roi, Dunois, Lahire et Xaintrailles étaient aussi présents. Jeanne d'Arc, son étendard à la main, resta debout près du roi pendant la cérémonie. On sait qu'en face de ses juges, interrogée pourquoi elle avait eu l'audace de porter au sacre du roi son étendard, Jeanne répondit : “ Il avait été à la peine, c'était bien raison qu'il fût à l'honneur. » Le frère Richard, confesseur de Jeanne d'Arc, était du nombre des assistants ; son père et son frère, venus à pied de Donrémy, assistaient aussi à cette cérémonie.

Ce tableau a été exposẻ au Salon de 1838.

\section{Entrée de l'armée française à Paris. - 13 avril 1436.}

Par Berthelemy en 1787. - H. 3,83. - L. $2,62$.

L'expulsion des Anglais et le rétablissement de l'autorité du roi Charles VII dans Paris furent dus aux courageux efforts de Michel Lallier, bourgeois de Paris, qui ouvrit au connétable de Richemont une des portes de la ville. Une insurrection populaire obligea les Anglais à se réfugier dans la Bastille, qu'ils évacuèrent le 17 avril. Michel Lallier s'avança au-devant du connétable, sur le pont NotreDame, et lui offrit la soumission de la ville. Richemont lui répondit en remerciant au nom du roi Charles VII " ses bons amis les habitants de Paris ", et se rendit ensuite à Notre-Dame, où il entendit la messe tout armé.

\section{Bataille de Bratelen ou de Saint-Jacques. - 26 août 1444.}

Par Alfred Johannot. - H. 3,83. - L. $2,63$.

Cette bataille se livra sous les murs de Bâle, près de la Maladrerie de Saint-Jacques. Les Français étaient commandés par le dauphin (depuis Louis XI). Après une vigoureuse résistance les Suisses furent écrasés par le nombre; ils se firent tuer jusqu'au dernier plutôt que de se rendre.

Ce table $\mathrm{u}$ a étẻ exposé au Salon de 1838. 


\section{Entrée de Charles VII à Rouen. - 10 novembre 1449.}

Par Decaisne. - H. 0,67. - L. 1,05.

Charles VII, après avoir enlevé Rouen aux Anglais, fit son entrée dans cette ville, ayant à sa suite le comte de Dunois qui commandait l'armée, et Jacques Cœur qui avait prêté l'argent nécessaire pour la levée de cette armée.

\section{Bataille de Formigny. - 18 avril 1450.}

Par M. LAFAYE. - H. 0,74. - L. 1,41.

Elle s'engagea entre Carentan et Bayeux, près du village de Formigny. Un petit ruisseau coulait devant le front de bataille des Anglais, et sur ce ruisseau était un pont occupé par les Français. Le combat fut vif et dura trois heures : au bout de ce temps, le connétable de Richemont était vainqueur de l'armée anglaise. Le résultat de cette victoire fut l'expulsion des Anglais de la Normandie.

SALLE No 4. (Voir salle $n^{\circ}$ 2.)

\section{Entrée des Français à Bordeaux. - 23 juin 1451.}

Par Vinciros en 1838. - H. 3,84. - L. 2,68.

" Le comte de Dunois, dit M. de Barante, se présenta avec la brillante et nombreuse compagnie des seigneurs de France et des capitaines de son armée, devant les portes de Bordeaux. Le héraut de la ville commença par sommer trois fois à haute voix les Anglais de venir porter secours aux gens de Bordeaux. Nul ne comparaissant, les jurés de la ville, l'archevêque, son clergé, et les principaux seigneurs du pays, remirent les clefs au lieutenantgénéral du roi. „ L'entrée fut brillante et solennelle; on y vit le chancelier Juvénal des Ursins, Olivier de Coëtivy, sénéchal de Guyenne et grand nombre d'autres nobles et puissants seigneurs.

Ce tableau a été exposé au Salon de 1839.

38. Louis $\mathbf{X I}$, roi de France. (Voir n ${ }^{\circ}$ 705.)

Par M. Giвот. - H. 0,65. - L. 0,56.

39. Défense de Beauvais. - 22 juillet 1472.

Par M. Сівот. - H. 0,69. - L. 1,36.

Les habitants de Beauvais, seuls et sans secours, soutinrent le premier choc de l'armée de Bourgogne commandée par Charles- 
le-Téméraire. Les femmes surtout se distinguèrent par leur intrépidité; elles montaient sur la muraille pour apporter des traits, de la poudre et des munitions ; elles-mêmes roulaient de grosses pierres, et versaient l'eau chaude, la graisse fondue et l'huile bouillante sur les assiégeants. Il y en eut une entre autres, nommée Jeanne Lainé et que la tradition appelle Jeanne Hachette, qui au plus fort de l'assaut, saisit, quoique sans armes, la bannière d'un Bourguignon, au moment où il allait la planter sur la muraille. Après vingt-quatre jours de siége, Charles-le-Téméraire fut obligé de se retirer.

\section{Charles VIII, roi de France. (Voir n ${ }^{\circ}$ 706.)}

Par M. Saint-EVRE. - H. 0,65. - L. 0,57.

\section{Anne de Bretagne, reine de France.}

Par M. Rubio. - H. 0,71. - L. 0,64.

Fille aînée de François II, duc de Bretagne, elle était âgée de quatorze ans lorsqu'elle hérita de ce grand fief en 1490. Mariée à Charles VIII en 1491, elle gouverna la France pendant l'expédition d'Italie, en 1494. Après la mort de Charles VIII, elle s'était retirée en Bretagne, lorsque son mariage avec Louis XII la fit couronner une seconde fois reine de France en 1499. Elle mourut au château de Blois, le 9 janvier 1514, âgée de trente-huit ans.

\section{Mariage de Charles VIII et d'Anne de Bretagne. - 6 décembre 1491.}

Par M. SAINT-Evre. - H. 0,69. - L. 1,39.

Ce mariage fut célébré au château de Langeais en Touraine. Il eut pour résultat de préparer la réunion du duché de Bretagne à la France.

\section{Isabelle d'Aragon implore Charles VIII. - 14 octobre 1494.}

Par M. Th. Fragonard, d'après Allori. - H. 0,80. - L. 1,07.

Charles VIII traversant la Lombardie pour marcher à la conquête du royaume de Naples, voulut voir le jeune duc Jean Galéas, que son oncle Louis Sforce, dit le More, tenait renfermé dans le château de Pavie. Il le trouva s'éteignant dans les langueurs d'une cruelle maladie et sa compassion redoubla lorsque la princesse Isabelle, fille du roi de Naples et femmẻ du jeune duc, se jeta à ses pieds en le suppliant d'épargner son père et de protéger son époux.

Le tableau original de Christofano Allori est au Musée du Louvre. 


\section{Entrée de Charles VIII dans Acquapendente. - 7 décembre 1494.}

Par M. Hostein, d'après Chauvin. - H. 0,82. - L. 1,07.

Charles, VIII était sous les murs d'Acquapendente, la première ville des États pontificaux à la frontière de Toscane. Il n'y trouva point de garnison ennemie, mais bien le clergé tout entier qui sortit à sa rencontre en grand appareil, avec la croix, les reliques et le Saint-Sacrement.

Le tableau original est au palais de Fontainebleau.

\section{Bataille de Séminara. - 24 juin 1495.}

Par M. Jollivet. - H. 0,74. - L. 1, 07.

Une armée commandée par Ferdinand II, roi de Naples, et Gonzalve de Cordoue, avait pénétré dans la Calabre et surpris un petit corps de troupes françaises. Le sire d Aubigny, qui commandait dans cette province, marche rapidement à la rencontre de l'ennemi et lui présente la bataille. Dès le commencement de l'action, la cavalerie espagnole, chargée par les gendarmes français fit une évolution en arrière pour revenir ensuite à la charge, selon l'usage des Maures, avec qui elle était accoutumée à combattre. L'infanterie napolitaine prit cette mesure pour le signal de la fuite et se débanda. Ferdinand essaya en vain de la rallier.

\section{Bataille de Fornoue. - 6 juillet 1495.}

Par M. FERON en 1837. - H. 3,84. - L. $2,68$.

Charles VIII traversait toute l'Italie pour retourner dans son royaume. Après avoir passé, non sans de grandes difficultés, les Apennins au col de Pontremoli, il se trouve au débouché de ce col en présence de l'ennemi et l'attaque à Fornoue, sur la rive droite du Taro. L'armée des confédérés, au nombre de quarante mille hommes, était réunie sous les ordres de Francois de Gonzague, marquis de Mantoue, l'un des condottieri les plus renommés de l'Italie. Neuf mille Français, excédés de fatigue, n'hésitèrent pas à chercher un passage à travers cette masse épaisse d'hommes et de chevaux. La tactique italienne, appuyée du nombre, eut beau déployer toutes ses ressources, la furie francaise, à laquelle rien ne pouvait résister, l'emporta. Bayard, alors âgé de dix-huit ans, servait dans la compagnie des hommes d'armes du comte de Ligny. " Il fit à la bataille de Fornoue, disent les mémoires de la Trémouille, des prodiges de valeur, eut deux chevaux tués sous lui et prit une enseigne qu'il présenta au roi. »

Ce tableau a été exposé au Salon de 1838. 


\section{Clémence de Louis XII. - Avril 1498.}

Par Jean Gassies en 1824. - H. 3,84. - L. 5,41.

Lorsque la couronne passa sur la tête de ce prince, tous ceux qui avaient servi contre lui le roi son prédécesseur occupaient les plus hauts emplois à la cour ; La Trémouille, entre autres, avait l'office de premier chambellan. "Le roi, dit-il lui-même dans ses Mémoires, le manda de son propre mouvement, le confirma en tous ses états, offices, pensions et bienfaits, le priant de lui être aussi loyal qu'à son prédécesseur, avec promesse de meilleure récompense. » A ce noble traitement Louis XII ajouta cette parole si belle et si connue: "Le roi de France ne venge pas les injures du duc d'Orléans. " Il traita avec la même générosité les autres courtisans. Ayant mis une croix au nom de deux officiers qui l'avaient desservi, ils se crurent perdus, lorsque Louis les fit venir et leur dit : " J'ai marqué ainsi vos noms pour me rappeler celui qui a pardonné à ses ennemis en mourant pour eux sur la croix. ')

Ce tableau a été exposé au Salon de 1824.

\section{Bataille d'Agnadel. - 14 mai 1509.}

Par M. Jollivet. - H. 3,84. - L. 2,67.

“ La bataille d'Agnadel, dit le président Hénault, fut gagnée par Louis XII en personne contre les Vénitiens : il avait sous lui les maréchaux de Chaumont et de Trivulce, le duc de Bourbon, La Trémouille, etc.; le comte de Dunois, qui avait été fait duc de Longueville en 1505, commandait l'arrière-garde. L'Alviane commandait les Vénitiens. " Ce fut l'infanterie des Brisighella, que distinguaient ses casaques mi-partie rouges et blanches, qui soutint seule tout l'effort de la bataille. Encouragés par l'intrépidité de leur chef, ils se firent tuer presque jusqu'au dernier : on en compta six mille couchés par terre. Vingt canons tombèrent au pouvoir des Francais, et l'Alviane, blessé au visage, fut amené prisonnier à Louis XII.

Ce tableau a étê exposé au Salon de 1837.

\section{Prise de Brescia. - 19 février 1512.}

Par M. LaRivière en 1837. - H. 3,84. - L. 2,08.

Gaston de Foix était devant Brescia, où le comte Avogaro venait de relever l'étendard de Venise. Dans le terrible assaut qui emporta cette place, il paya de sa personne comme le plus simple chevalier, mais ce fut à Bayard qu'appartint la palme du courage pendant le combat, comme celle de la générosité après la victoire. “ Les François, raconte son écuyer qui a écrit son histoire, cryoient: 
France ! France ! ceulx de la compagnie du bon chevalier cryoient: Bayart ! Bayart ! Les ennemys cryoient: Marco ! Marco ! Mais s'ils avoyent grant cour de deffendre, les François l'avoyent cent fois plus grant pour entrer dedans; et vont livrer ung assault merveilleux, par lequel ilz repoussèrent ung peu les Véniciens. Quoi voyant le bon chevalier, commença à dire : Dedares! dedans! compaignons! ilz sont nostres; marchez, tout est deffaict. Luy-mesme entra le premier et passa le rampart, et apres luy plus de mille; de sorte qu'ilz gaignèrent le premier fort, et y en demoura de tous les costez, mais peu des François. Le bon chevalier eut un coup dedans le haut de la cuysse, et entra si avant que le bout rompit, et demoura le fer et ung bout du fust dedans. Bien cuyda estre frappé à mort de la douleur qu'il sentit ; si commencea à dire au seigneur de Molart: Compaignon, faites marcher voz gens; la vile est gaignée; de moy je ne saurois tirer oultre, car je suis mort. ")

Ce tableau a été exposé au Salon de 1838.

SALLE No

50. Amboise (Charles d'), amiral de France. (Voir no 912.) Par M. NaIgeon, d'après Solario. - H. 0,65. - L. 0,56.

\section{Prise de Bologne. - 21 mai 1511.}

Par MM. LaRivière et NaIgeon. - H. 0,66. - L. 1,40.

Le maréchal de Trivulce, s'étant avancé sur Bologne, Jules II, à son approche avait fui en toute hâte vers Ravenne, et laissé son neveu, le duc d'Urbin, en face des Français. Le courage manqua à ce capitaine et à ses soldats, comme il avait manqué au pontife. Ils furent en un instant dispersés par l'armée française, et tel fut l'entraînement de la déroute qu'il ne resta aux mains du vainqueur que l'artillerie et les bagages. Cette victoire dont le principal trophée fut des bêtes de somme, reçut des Français le nom dérisoire de journée des âniers.

\section{Mort de Gaston de Foix à la bataille de Ra- venne. - 11 avril 1512.}

Par Ary Scheffer en 1824. - H. 3,80. - L. 5,67.

La cavalerie espagnole avait été rompue et dispersée, et l'infanterie elle-même, qui avait déjà entamé le corps des lansquenets, rudement chargée, cédait le champ de bataille, lorsque Gaston de Foix, irrité du massacre qu'elle avait fait des siens et de l'opiniâtre résistance qu'elle lui opposait encore, ordonne contre elle une 
dernière charge. Il est blessé et renversé de cheval, et un soldat espagnol lui traverse le corps de son épée. L'honneur de la journée n'en resta pas moins aux Français, mais trop chèrement acheté par la perte du héros qui seul pouvait alors soutenir et faire triompher leur cause en Italie.

Le corps de Gaston de Foix est entouré par Bayard, Lautrec et La Palice. Le cardinal de Médicis, depuis Léon $X$, se trouve avec les généraux espagnols et vénitiens faits prisonniers pendant la bataille. Dans le fond les soldats courent à l'assaut de la ville de Ravenne.

Ce tableau a été exposé au Salon de 1824.

\section{Louise de Savoie, duchesse d'Angoulême, ré- gente de France.}

Par M. LARIVIÈRE. - H. 0,85. - L. 0,72.

Elle avait épousé en 1487, Charles d'Orléans, comte d'Angoulême, et fut mère de François I ${ }^{\text {er }}$, qui la nomma régente du royaume en 1515 . Elle gouverna de nouveau la France en 1525 et 1526, pendant la captivité de son fils, et mourut le 25 septembre 1531 à Gratz en Gâtinais.

\section{François $I^{\text {er }}$, roi de France. (Voir no ${ }^{\circ}$ 709.)}

Par M. NaIgeon, d'après le Titien. - H. 0,66. - L. 0,57.

La portrait original est au Musée du Louvre.

\section{François I $I^{\text {er }}$ armé chevalier par Bayard. - 14 octobre 1515.}

Par Fragonard, - H. 0,83. - L. 1,13.

Le soir de la bataille de Marignan, Francois Ier voulut recevoir l'ordre de chevalerie de la main de Bayard, qui s'était montré le plus brave. Le roi conféra à son tour le même honneur au brave Fleuranges.

Ce tableau est une petite répétition du plafond peint par le même artiste pour une des salles du Louvre.

\section{Entrevue du Camp du Drap d'or. - 7 juin 1520.} Par M. Auguste Debay. - H. 3,80. - L. 5,76.

Cette entrevue eut lieu entre Ardres et Guines, et conserva le nom de Camp du Drap d'or, en souvenir du luxe et de la magnificence que les souverains et les grands de leur cour y déployèrent. «Le jeudy, jour de la feste Dieu, dit le journal de l'entrevue, le roy de France et le roy d'Angleterre se virent et parlementerent ensemble après midi environ, en la terre dudit roy d'Angleterre, en une petite vallée nommée Valdoré. Le roy (François I ${ }^{\text {er }}$, estoit monté sur un beau coursier, et estoit vêtu d'une saye de drap d'or 
frisé, ayant une manteline de drap d'or battu fort enrichie de pierreries. La piece de devant de ses manches bien garnie de fines pierreries, comme gros diamans, rubis, esmeraudes, grosses perles en forme et facon de houppes; et pareillement sa barrette et son bonnet de veloux et garnie de plumars et pierreries tant que tout en reluisoit. Le roy d'Angleterre étoit habillé de toile d'argent ayant force pierreries et bien riches sur luy et emplumé de plumes blanches : et eux aincy arrivés près l'un de l'autre, commencerent à marcher et descendre ladite vallée tout doulcement avec leurs connétables ayant leur épée nüe, et ainsi s'approcherent l'un de l'autre; et quand furent près, donnerent des éperons à leurs chevaux comme font deux hommes d'armes, quand ils veulent combattre à l'espée ; et au lieu d'y mettre les mains, chacun d'eux mit la main à son bonnet, et aussitôt l'un que l'autre, et s'embrasserent et accolerent moult doucement ayant les têtes nues. "

Ce tableau a été exposẻ au Salon de 1837.

\section{Entrevue de François $\boldsymbol{I}^{\text {er }}$ et du pape Clément VIII à Marseille. - 13 octobre 1533.}

Par Mim. Larivière et X. Depre. - H. 0,67. - L. 1,40.

Clément VII avait fait offrir sa nièce, Catherine de Médicis, ¡uur le jeune duc d'Orléans, depuis Henri II, et s'était engagé, malgré ses infirmités et son grand âge, à venir trouver François Ier à Marseille. Cette entrevue eut lieu comme elle avait été convenue, et le mariage du duc d'Orléans avec Catherine fut conclu.

58. François Ier et Charles-Quint visitent les tombeaux de Saint-Denis. - 13 janvier 1540.

Par M. Norblin, d'après Gros. -- H. 1,80. L. 1,13.

Charles-Quint se rendant dans les Pays-Bas, fut invité par le roi Francois Ier à traverser la France, et fit son entrée à Paris le $1^{\text {er jan- }}$ vier 15040 . Peu de jours après il visita l'église de Saint-Denis où le roi voulut le conduire lui-même.

François [ex, accompagné de ses deux fils, Henri, dauphin de Viennois, depuis Henri II, et Charles, duc d'Orléans, montre à Charles-Quint le tombeau de Louis XII. Ils sont reçus par le cardinal de Bourbon, abbé de Saint-Denis.

Le tableau original est au Musée du Louvre.

59. Bataille de Cerisoles. - 14 avril 1544.

Par M. Schnetz. - H. 3,80.-L. 5,53.

François de Bourbon, comte d'Enghien, ayant obtenu du roi la 
permission de livrer bataille à l'armée de Charles-Quint, marcha contre elle, la rencontra dans les plaines de Cerisoles, et quoiqu'elle fùt supérieure à la sienne, remporta une victoire complète. Dix mille ennemis restèrent sur la place; trois mille furent faits prisonniers.

Le jeune comte d'Enghien reçoit après la victoire les prisonniers espagnols et les drapeaux pris sur l'ennemi.

Ce tableau a été exposé au Salon de 1838.

\section{SALLE No 6. (Voir salle $n^{\circ}$ 2.)}

\section{Henri II, roi de France. (Voir n⿳0 710.)}

Par M. de Chatillox, d'après Clouet.-H, 0,66. - L. 0,57.

Le portrait original est au Musée du Louvre.

\section{Levée du siége de Metz. - Janvier 1553.}

Par M. Eug. Devéria. - H. 0,68. - L. 1,40.

Charles-Quint était venu, le 31 octobre $15 \% 22^{2}$, avec soixante mille hommes et une redoutable artillerie, mettre le siége devant la ville de Metz. François de Lorraine, duc de Guise, qui s'y était enfermé, lui opposa une résistance opiniâtre pendant deux mois. Enfin, vers la mi-janvier 1อ̆ö3, Charles-Quint se décida à lever le siége; il avait tiré onze mille coups de canon et perdu trente mille soldats.

\section{Henri II donne le collier de son ordre au maréchal de Tavannes, après le combat de Renty. - 13 août 1554 .}

Par Brenet en 1789.- H. 3,81. - L. 2,36.

Dans l'affaire de Renty contre Charles-Quint, le roi Henri II avait remarqué le courage du vicomte de Tavannes, qui, à la tête de ses gendarmes, avait décidé la victoire. Comme il approchait de la tente du roi, l'épée encore au poing et teinte de sang, le monarque court à lui, l'embrasse, et détache de soln cou le collier de l'ordre de Saint-Michel pour l'en décorer.

Ce tableau a été exposé au Salon de 1789.

\section{Prise de Thionville. - 23 juin 1558.}

Par $\mathrm{I}^{\mathrm{me}}$ Haudebourt-Lescot - - H. 0,\$5 . - L. 1,17.

La ville de Thionville, occupée par les Espagnols, fut attaquée par le duc de Guise, et capitula après une résistance vigoureuse dans laquelle le maréchal de Strozzi fut tué. 
64. Henri III, roi de France. (Voir no 713.)

Par M. Rubio. - H. 0,79.-L. 0,73.

65. Henri IV, roi de France. (Voir no ${ }^{\circ} 14$. )

Par P. Franque d'après Porbus. - H. 0,65. - L. 0,56.

Le portrait original est au Musée du Louvre.

66. Henri IV devant Paris. - Août 1590.

Par M. Rouget en 1824. - H. 3,81. - L. 5,39.

Paris emprisonné par un étroit blocus depuis le 7 mai, souffrait toutes les horreurs de la famine. Des paysans qui cherchaient à introduire des vivres dans la ville ayant été arrêtés, Henri IV, loin de les punir, leur donna sa bourse en disant: « Le Béarnais est pauvre, il vous donne ce qu'il a. »

Ce tableau a été exposé au Salon de 1824.

\section{Henri IV devant Paris. - Août 1590.}

Par TARdieu en 1824. - H. 3,81. - L. 2,61.

Pendant le siége de Paris, Henri IV laisse d'abord ses capitaines, puis ses soldats eux-mêmes introduire des vivres dans la ville affamée. "Cela, dit Péréfixe, fit subsister Paris plus d'un mois plus qu'il n'eût fait. »

\section{Combat de Fontaine-Française. - Juin 1595.}

Par M. Eug. Devéria. - H. 0,67. - L. 1,40.

On y vit Henri IV, l'épée à la main, courir de tous côtés pour arrêter les fuyards, les ramener à la charge contre les Espagnols, et, se multipliant à force de valeur, forcer à la retraite une ennemi dix fois plus nombreux.

69. Assemblée des Notables à Rouen. - 4 nov. 1596. Par M. Rouget en 1822. - H. 3,81. - L. 2,83.

Henri IV en fit l'ouverture dans la grande salle de l'abbaye de Saint-Ouen. Autour de lui étaient les ducs de Montpensier et de Nemours, le connétable de Montmorency, les ducs d'Épernon et de Retz, le maréchal de Matignon, les quatre secrétaires d'État, le cardinal légat, les cardinaux de Gondi et de Givry, et les présidents des parlements de Paris, de Bordeaux et de Toulouse. Les dernières paroles prononcées par le roi dans cette circonstance méritent d'être citées : « Je ne vous ai point appelés, comme faisoient mes prédécesseurs, pour vous faire approuver mes volontés; je vous ai assemblés pour recevoir vos conseils, pour les suivre, 
bref, pour me mettre en tutelle entre vos mains, envie qui ne prend guère aux rois, aux barbes grises et aux victorieux. Mais la violente amour que je porte à mes sujets, et l'extrême envie que j'ai d'ajouter ces deux titres de libérateur et restaurateur de cet état à celui de roi, me font trouver tout aisé et honorable. »

\section{Signature du traité de paix de Vervins. -2 mai 1598.}

Par M. SaINT-Evre en 1837. - H. 0,71, - L. 1,17.

Un congrès pour la réconciliation des couronnes de France et d'Espagne s'était ouvert dans la petite ville de Vervins, à la frontière de la Picardie et de l'Artois. Les négociations dans lesquelles Bellièvre et Sillery représentèrent les intérêts de la France durèrent trois mois et rétablirent la paix. Philippe II, roi d'Espagne, reconnut Henri IV comme roi de France.

\section{Entrée de Henri IV à Montmélian. - 16 no- vembre 1600.}

Par M. Ed. OdIER en 1837. - H. 3,81. - L. 2,34.

La forteresse de Montmélian, dans les états du duc de Savoie, assiégée par les Français, avait été forcée de capituler. Henri IV y fit son entrée, et les magistrats vinrent lui présenter les clefs de la ville.

Ce tableau a été exposé au Salon de 1838.

\section{Henri IV fait construire les galeries du Louvre.}

Par Garnier. - H. 1,45. - 1,17.

Les travaux de la grande galerie du Louvre, ordonnés par Henri IV, furent commencés en 1594 et continués pendant la plus grande partie de son règne.

Le roi, accompagné de Sully, visite les travaux du Lnuvre et examine les plans qui lui sont présentés. Marie de Médicis, montée sur un cheval blanc, accompagne le roi.

Ce tableau a été exposẻ au Salon de 1819.

$$
\text { SALLE No 7. - (Voir salle no 2.) }
$$

La frise de cette salle est ornée de vingt-six médaillons peints par Pierre FranQue, représentant les principaux persomnages du règne de Louis XIII et de la régence d'Anne d'Autriche. Ce sont : le duc d'Epernon, le cardinal de Richelieu, le duc d'Aiguillon, le chancelier Du Vair, le duc de Montmorency, Marillac, le cardinal de La Valette, le duc de Rohan, le duc et la duchesse de Longueville, Gaston, duc d'Orléans, et ses deux femmes, le prince de Condé, la duchesse de Chevreuse, le duc de La Rochefoucauld, le maréchal de Guébriant, le duc de Guise, le maréchal de Gassion, le cardinal Mazarin, le comte d'Harcourt, le duc de 
Beaufort, la duchesse de Montpensier, le maréchal d'Hocquincourt, le chancelier Séguier et Guitaut.

73. Louis XIII, roi de France. (Voir n⿳0 716.)

Par M. de Lestaxg, d'après Ph. de Champagne. - H. 0,74. - L. 0,61.

Le portrait original est au Musée du Louvre.

74. Prise de Pignero!. - 30 mars 1630.

Par Hipp. Lecomte. - H. 0,45, - L. 0,35.

Le cardinal de Richelieu dirigea par lui-même le siége de la ville et de la forteresse de Pignerol, et les força de capituler.

75. Prise de Saverne. - 19 juin 1636.

Par M. Eug. Deveria. - H. 0,66. - L. 1,40.

Bernard de Saxe-Weimar, général au service de laFrance, s'empare de la ville de Saverne avec l'aide des troupes commandées par le cardinal de La Valette.

76. Prise de Landrecies. - 26 juillet 1637.

Par M. Hipp. Lecoute. - H. 0,61. - L. 0,49.

La ville de Landrecies fut investie le 19 juin 1637, et remise le 26 juillet entre les mains des Français.

17. Prise du Catelet. - 8 septembre 1638.

Par M. Hipp. Leсомте. - H. 0,61. - L. 0,49.

Du Hallier investit le 2อั août la place du Catelet, qui fut emportée d’assaut, quatorze jours après, par les deux régiments des gardes et de Picardie.

78. Prise de Collioure. - 13 avril 1642.

Par Hip. Lecoute. - H. 0,45. - L. 0,35.

Louis XIII voulut conduire lui-même l'expédition du Roussillon, et s'empara de la ville et de la citadelle de Collioure.

79. Bataille de Lérida. - 7 octobre 1642.

Par M. Hipp. Leconte. - H. 0,50. - L. 0,87.

Le maréchal d'Hocquincourt met en déroute les Espagnols qui venaient d'assiéger Lérida, ville forte de la Catalogne, sur la Sègre.

80. Anne d'Autriche, reine de France, régente du royaume. (Voir no 929 .)

Par M. Delaroche, d'après de Sève. - H. 0,74. - L. 0,61. 
81. Plan de la bataille de Rocroy. - 19 mai 1643.

Par M. Oscar GuÉ, d'après Martin (1). - H. 0,60. - L. 0,84.

\section{Bataille de Rocroy. - 19 mai 1643.}

Par M. JouY, d'après Martin. - H. 0,60. - L. 0,84.

Cinq jours après la mort de Louis XIII, le duc d'Enghien, âgé de vingt-deux ans, ayant sous ses ordres le maréchal de L'Hôpital, Gassion et La Ferté, marcha au secours de Rocroy assiégé par les Espagnols, leur livra bataille et remporta sur eux une victoire complète.

83. Plan du siége de Thionville. - 18 juin 1643.

Par M. Oscar Gúe, d'après Martin. - H. 0,45. - L. 0,35.

Le duc d'Enghien arriva le 18 juin devant Thionville, investie depuis deux jours par le marquis de Gesvres, qui fut tué dans un des assauts.

\section{Prise de Thionville. - 22 août 1643.}

Par M. Oscar Gué, d'après Martin. - H. 0,45. - L. 0,35.

La place de Thionville ne demanda à capituler qu'après deux mois d'une résistance opiniâtre et trente jours de tranchée ouverte. La garnison était réduite à douze cents hommes, de trois mille deux cents qu'elle avait au commencement du siége; le gouverneur avait été tué et la plupart des officiers étaient malades ou blessés.

85. Siége de Sierck. - 4 septembre 1643.

Par M. JouY, d'après Martin. - H. 0,45. - L. 0,35.

86. Siége de Sierck. - 4 septembre 1643.

Par M. JouY, d'après Martin.-H. 0, 45. - L. 0,35.

Le duc d'Enghien termina par la prise de la ville et du château de Sierck la campagne qu'il avait ouverte par la bataille de Rocroy.

87. Prise de Trino. - 23 septembre 1643.

Par Louis Dupré. - H. 0,61. - L. 1,40.

La ville de Trino, près de Casal, dans le Montferrat, fut investie le 14 aoùt, par le prince Thomas de Savoie, commandant général des armées de France en Italie. Le baron de Watteville, gouver-

(1) Les tableaux originaux de Martin, d'après lesquels ont été exécutées les copies qui se trouvent dans cette salle, sont placés dans la galerie du château de Chantilly. 
neur de la place pour le roi d'Espagne, la rendit après quatre jours de siége.

\section{Bataille de Fribourg, - 3-9 août 1644.}

Par M. LAFAYE, d'après Martin. - H. 0,50. - L. 0,86.

La bataille de Fribourg commença le 3 et ne finit que le 9 août. Le 3 , le duc d'Enghien et Turenne viennent attaquer et défont les Bavarois, commandés par le général Mercy; le 5, se donne un second combat plus rude encore que le premier; enfin, le 9 , les ennemis sont défaits pour la troisième fois par Turenne, et obligés d'abandonner leurs bagages et leur artillerie.

\section{Prise de Dourlach. - A oût 1644.}

Par M. LAFAYE, d'après Martin. - H. 0,45. - L. 0,35.

Le premier corps de l'armée du duc d'Enghien, commandé par Tubald, lieutenant-général de cavalerie suédoise, s'empare de la ville de Dourlach.

90. Prise de Baden. - Août 1644.

Par M. LAFAYE, d'après Martin. - H. 0,61. - L. 0,49.

Le second corps d'armée du duc d'Enghien, commandé par le général-major Roze, emporte la ville de Baden.

91. Prise de Lichtenau. - Août 1644.

Par MI. LAFAYE, d'après Martin. - H. 0,45. - L. 0,35.

La ville de Lichtenau, défendue par le major de Philipsbourg, ne céda qu'après deux jours de résistance au comte de Palluau, commandant le quatrième corps de l'armée du duc d'Enghien.

92. Siége de Philipsbourg. - 12 septembre 1644.

Par M. LaFaye, d'après Martin. - H. 0,61. - L. 0,49.

La tranchée avait été ouverte le 23 août. Turenne et Gramont conduisirent les attaques et forcèrent le gouverneur à capituler.

93. Bataille de Liorens. - 22 juillet 1645.

Par M. Pingret. - H. 1,87. - L. 2,10.

Le comte d'Harcourt, après s'être emparé d'Agramont et de Saint-Aunais, passe la Sègre et la Noguère, grossies par la fonte des neiges et bordées de bons retranchements, livre bataille aux Espagnols campés dans la plaine de Liorens, leur tue trois mille hommes et fait deux mille prisonniers. 
94. Louis XIV recoit son frère chevalier de l'ordre du Saint-Esprit. - 8 juin 1654.

Par M. X. Dupré, d'après Ph. de Champagne. - H. 3,27. - L. 3,96.

Le lendemain de son sacre, Louis XIV donna à son frère (Philippe de France, duc d'Anjou, depuis duc d'Orléans) le collier et le manteau de l'ordre du Saint-Esprit. Servien, Le Tellier, de Lionne et de Bonnelles, officiers des ordres, assistaient le roi lors de cette réception.

95. Prise de Montmédy. -6 août 1657.

École française; xvır siècle. - H. 1,33. - L. 2,10.

Le maréchal de La Ferté arriva devant Montmédy le 12 juin et fit ouvrir la tranchée devant la citadelle le 22. Louis XIV hâta la réduction de cette place par sa présence; il visita jusqu'à vingttrois fois les travaux de la tranchée et accorda à la garnison une capitulation très-avantageuse.

Louis XIV, à cheval et couronné par la Victoire, foule aux pieds le lion espagnol.

\section{Prise de Dôle. - 14 février 1668.}

Par J.-B. Martin. - H. 2,25. - L. 1,93.

Le 10 février Louis XIV était devant la place; la tranchée fut ouverte le 12 par trois endroits et poussée avec tant de vigueur que les assiégés capitulèrent deux jours après.

\section{Prise de Grave. - 14 juillet 1672.}

Par Bonnard, d'après Vander Meulen. - H. 2,25. - L. 1,93.

Le gouverneur de la place de Grave fut obligé de se rendre, après quelques jours d'attaque, au comte de Chamilly, le marquis de Joyeuse ayant défait vingt-quatre compagnies d'infanterie que le prince d'Orange avait envoyées pour s'y jeter.

98. Prise du fort de Joux. - Juin 1674.

Par Vander Meulen. - H. 2,25. - L. 1,55.

Le marquis de Duras s'empare du fort de Joux, en FrancheComté.

99. Prise de Condé. - 26 avril 1676.

Par J.-B. Martin. - H. 2,25. - L. 1,53.

Louis XIV se rend devant Condé le 21 avril, fait ouvrir la tranchée le même jour, et, pour hâter le siége, ordonne trois attaques. Les dehors sont emportés l'épée à la main, et la ville se rend 
SALLE $\mathrm{N}^{\circ} 8$.

discrétion presque en présence des armées d'Espagne et de Hollande, qui s'étaient avancées entre Mons et Saint-Guillain. Le roi sauva la ville du pillage.

\section{Bataille de Cassel. - 11 avril 1677.}

Par Bonvard, d'après Vander Meulen. - H. 2,25. - L. 1,55.

Le prince d'Orange se dirigeait, à la tête de trente mille hommes, au secours de la ville de Saint-Omer, assiégée par le duc d'Orléans. Ce dernier s'avance à sa rencontre, et les deux armées se trouvent en présence auprès du mont Cassel. Malgré les efforts du prince d'orange, la déroute fut complète. Les ennemis perdirent trois mille hommes; on leur fit quatre mille prisonniers; on leur prit treize pièces de canon, deux mortiers, quarante-quatre drapeaux, dix-sept étendards et tous leurs bagages.

\section{Prise d'Y $Y$ pres. - 19 mars 1678.}

Par VANDER Meulen. - H. 2,25. - L. 1,55.

Le roi fit ouvrir la tranchée le 18 mars de deux côtés à la fois, et les deux attaques se trouvant avancées jusqu'à quinze pas de la contrescarpe, il la fit attaquer. Le combat fut opiniâtre et sanglant; enfin la contrescarpe fut emportée, et le gouverneur capitula le lendemain à la pointe du jour.

\section{SALLE No 8.}

Cette salle occupe l'emplacement du grand escalier de l'aile du nord, détruit lors de l'établissement des galeries historiques. La frise est ornée de vingt-six médaillons peints par P. FRANQUE, représentant les principaux personnages du règne de Louis XIV. Ce sont: le grand Condé, le prince de Conty (Armand de Bourbon), Philippe de France, duc d'Orléans, et ses deux femmes, le duc de Longueville, Turenne, $M^{11 \mathrm{le}}$ de La Vallière, Vauban, Lamoignon, Colbert, Louvois, de Harlay, le maréchal de Luxembourg, $\mathrm{M}^{\mathrm{me}}$ de Montespan, Boufflers, Catinat, Uaguesseau, Fabert, Tourville, le maréchal de Noailles, le prince de Conty (François-Louis de Bourbon), le maréchal de Vivonne, le duc de Créquy et Le Tellier.

\section{Louis XIV, roi de France. (Toir n $\left.{ }^{\circ} 717.\right)$}

Par Henri Testelin. - H. 2,05. - L. 1,52.

Ce portrait, qui est signé "H. TESTELIN FE 1648 ", représente Louis XIV à l'âge de dix ans. Il est assis sur son trône, tient son sceptre de la main gauche, et de la droite une couronne de laurier. Au pied du trône sont les attributs de la Peinture et de la Sculpture.

\section{Louis $\mathrm{XIV}$. (Noir $\left.\mathrm{n}^{\circ} 717.\right)$}

École d'Hyacinthe Rigaud. - H. 2,05. - L. 1,52.

Ce portrait est une répétition de celui peint par Rigaud en 1701, mais avec des changements dans les accessoires. Devant le roi se trouve un globe sur lequel 
est tracé un soleil avec un sceptre et une main de justice croisés, accompagnés de cette devise: VNICO VNIVERSVS.

\section{Reddition de Spire. - 29 août 1644.}

Par M. Gallalt, d'après Martin (1). - H. 0,44. - L. 0,35.

Le duc d'Enghien avait envoyé le marquis d'Aumont pour attaquer la ville de Spire au cas qu'elle refusât de mettre hors de ses murailles les troupes lorraines qu'elle y tenait; les membres de la chambre impériale et le clergé vinrent faire leur soumission, les premiers portant de longues barbes sur des fraises bleues, les autres vêtus selon la coutume des ecclésiastiques.

\section{Prise de Worms. - Septembre 1644.}

Par M. Gallait, d'après Martin. - H. 0,61. - L. 0,81.

A l'approche de Turenne, les habitants de Worms lui ouvrirent les portes, et congédièrent la garnison lorraine qui y était.

\section{Prise d'Oppenheim. - Septembre 1644.}

Par M. Hipp. Lecoute, d'après Martin. - H. 0,44. - L. 0,35.

Turenne détacha le major Roze pour aller attaquer Oppenheim, petite ville située dans une plaine, mal fortifiée, mais défendue par un très-bon château; il n'y trouva aucune résistance et la ville se rendit à son arrivée.

\section{Reddition de Mayence. - 17 septembre 1644.}

Par M. Hipp. LEconte, d'après Martin. - H. 0,50. - L. 0,90.

Les députés de la ville vinrent au-devant du duc d'Enghien qui, après avoir ratifié la capitulation accordée par Turenne, prit possession de la ville, et y laissa une garnison française.

\section{Reddition de Bingen. - Septembre 1644.}

Par M. Hipp. Leconte, d'après Martin. - H. 0,44. - L. 0,35.

Bingen, petite ville avec un bon château sur le Rhin, fut comprise dans le traité de Mayence : on y envoya une garnison francaise.

109. Prise de Creutznach. - Septembre 1644.

Par M. Hipp. Leconte, d'après Martin. - H. 0,61. - L. 0,49.

Turenne occupa Creutznach en même temps que Bingen.

(1) Les tableaux originaux de Martin, d'aprèslesquels ont été exécutés les copies qui se trouvent rlans cette salle, sont placés dans la galerie du château de Chantilly. 


\section{Prise de Bacarah. -1644 .}

Par M. Hipp. Lecoute, d'après Martin. - H. 0,61. - L. 0,49.

Turenne prit possession de Bacarach, petite ville située sur le Rhin à peu de distance de Bingen.

\section{Siége de Landau. - Septembre 1644.}

Par M. Jour, d'après Martin. - H. 0,44. - L. 0,35.

Landau, ville située sur la rive gauche du Rhin, à quatre líeues de Philipsbourg, avait été investie parle marquis d'Aumont, qui en avait commencé le siége; mais d'Aumont ayant été blessé dangegereusement, Turenne alla continuer le siége, et le cinquième jour le duc d'Enghien y étant venu pour visiter les travaux, les Lorrains traitèrent avec Turenne et sortirent de la place.

\section{Prise de Neustadt. - 1644.}

Par N. Gallait, d'après Martin. - H. 0,44. - L. 0,35.

Turenne reçoit du duc d'Enghien l'ordre de s'emparer de la ville de Neustadt.

\section{Siége et prise de Rothembourg. - 1645.}

Par Rexoox, d'après Martin. - H. 0,44. - L. 0,35.

Turenne et le duc d'Enghien s'étant emparés de Wimpfen, petite ville sur le Necker, emportèrent ensuite d'assaut la ville et le château de Rothembourg.

\section{Plan de la bataille de Nordlingen. - 3 août 1645.}

Par Revoux, d'après Nartin. - H. 0,61. - L. 0,49.

115. Bataille de Nordlingen. - 3 août 1645.

Par Rexoux d'après Martin. - H. 0,61. - L. 0,49.

Le duc d'Enghien s'était avancé vers Nordlingen, ville impériale de la Souabe, où les Bavarois étaient retranchés. Il leur livre bataille et remporte une victoire complète. Mercy, général des ennemis, fut tué dans l'action, et Gleen, qui commandait les Impériaux, fut fait prisonnier.

116. Reddition de Nordlingen. - Août 1645.

Par Reroux, d'après Martin.;- H. 0,50. - L. 0,88.

Le duc d’Enghien se présente après la bataille devant la ville de Nordlingen, qui se rend sans opposer la moindre résistance. 


\section{Reddition de Dinkelsbühl. - Août 1645.}

Par Renoux, d'après Martin. - H. 0,44. - L. 0,33.

Les habitants de la ville de „Dinkelsbühl s'empressèrent après la bataille de Nordlingen, d'envoyer leur soumission au duc d'Enghien.

\section{Siége de Courtray. - 28 juin 1646.}

Par M. Pingret, d'après Martin. - H. 0,44. - L. 0,35.

Le duc d'Orléans, ayant sous lui les maréchaux de La Meilleraye, de Gramont et de Gassion, s'empare de Courtray.

\section{Siége de Bergues-Saint-Winox. - 31 juillet 1646.}

Par M. BRUYèRes, d'après Martin. - H. 0,44. - L. 0,35.

Le duc d'Orléans vint se présenter le 28 juillet devant BerguesSaint-Winox, grande ville sur la rivière de Colme, dont il entreprit le siége. Les assiégés ayant vu que les attaques avançaient beaucoup en peu de temps, demandèrent à capituler le 31 .

\section{Siége de Mardick. - 23 août 1646.}

Par M. BRoYères, d'après Martin. - H. 0,44. - L. 0,35 .

Le siége de Mardick fut long et très-meurtrier; il commença le 4 août et ne finit que le 23. L'arrivée de quelques vaisseaux hollandais fournit au duc d'Orléans le moyen de couper les communications avec Dunkerque, et la garnison, contrainte alors à capituler, resta prisonnière. Elle se montait ầ deux mille cinq cents hommes.

\section{Prise de Furnes. - 4 septembre 1646.}

Par M. Joux, d'après Martin. - H. 0,44. - L. 0,35 .

Le duc d'Enghien s'était dirigé sur Furnes, dans le dessein d'attaquer le marquis de Caracène, retranché à Vulpen avec un corps de cinq à six mille hommes; mais l'ennemi s'étant retiré, le prince arriva le 5 septembre, et la place ne fit aucune résistance. La garnison, montant à quinze cents hommes fut prisonnière.

\section{Siége de Dunkerque. - 12 octobre 1646.}

Par M. Jour, d'après Martin. - H. 0,61. - L. 0,81.

L'ouverture de la tranchée eut lieu le 24 septembre; le duc d'Enghien pressa vivement les attaques, souvent même il les commanda en personne. Le marquis de Lède, qui ne recevait aucun secours, 
écouta enfin les propositions qui lui étaient adressées. La capitulation était fort honorable ; elle portait qu'en cas qu'au bout de cinq jours, les armées d'Espagne ne viendraient pas secourir la place, on la remettrait entre les mains des Français, ce que le marquis de Lède exécuta le 12 octobre.

\section{Prise d'A ger en Catalogne. - Septembre 1647.}

Par M. PINGRET, d'après Martin. - H. 0,61. - L. 0,52.

Arnauld de Courbeville, détaché par le prince de Condé avec un corps de troupes s'empare de la petite ville d'Ager, qui fut emportée d'assaut.

124. Levée du siége de Constantine par l'armée espagnole. - Septembre 1647.

Par M. Pivgret, d'après Martin. - H. 0,44. - L. 0,35.

Constantine, ville sur la Sègre, était menacée par l'armée espagnole. Le prince de Condé marche au devant de l'ennemi; de son côté, le maréchal de Gramont, après avoir ravitaillé la ville, tenta d'opérer sa jonction avec l'armée du prince, et livra plusieurs combats partiels aux Espagnols. Le marquis d'Aytone se voyant sur le point dêtre attaqué de deux côtés, se retira après quelques escarmouches, et la place de Constantine fut conservée.

\section{Bataille de Lens. - 20 août 1648.}

Par M. Broyères, d'après Martin. - H. 0,61. - L. 0,52.

L'archịduc Léopold s'était rendu maître de Furnes, de Courtray, d'Étaire et de Lens. Le prince de Condé qui n'avait pu sauver cette place, se détermine à attaquer les ennemis campés dans la plaine de Lens et remporte une victoire complète. La cavalerie espagnole qui formait le corps de bataille fut taillée en pièces.

\section{Passage du Rhin. - 12 juin 1672.}

Par L. Testelis, d'après Lebrun. - H. 3,51 - L . 5,80.

Le 12 juin 1672, la cavalerie française arriva avec le roi et Condé; elle se précipita dans le fleuve dont les eaux étaient basses et le passa moitié à gué, moitié à la nage, sous la protection de quelques canons. Cinq mille Hollandais qui étaient sur l'autre rive essayèrent de résister; ils furent dispersés après un combat où périt le duc de Longueville. 


\section{Prise d'Utrecht. - 30 juin 1672.}

Par Bonnard, d'après Martin. - H. 2,15. - L. 1,56.

“ Aussitôt, dit Quincy, que le prince d'Orange se fut retiré avec ses troupes des environs d'Utrecht, les habitants de cette ville, après avoir tenu conseil, envoyèrent des députés qui vinrent offrir au roi de lui remettre cette place, et pour le prier de leur accorder des sauvegardes. Le roi les reçut fort bien, et, ayant accepté leurs offres, il détacha le marquis de Rochefort pour aller prendre possession, et lui donna ses mousquetaires avec quelques autres roupes d'élite. Le roi, parti de son camp de Damerongue, le suivit de près et fit son entrée dans Utrecht le 30 de juin. „ (Hist. milit. de Louis XIV.)

\section{Prise de Gray. - 28 février 1674.}

\section{Par Martin, d'après Vander Meulen. - H. 2,15. - L. 1,56.}

En s'approchant de Gray, place de la Franche-Comté, le duc de Navailles trouva la cavalerie des ennemis qui venait brûler les villages où il avait dessein de s'établir pour faire ce siége; il y eut une grande escarmouche, et les ennemis furent repoussés jusqu'à leurs postes. Le lendemain, il fit ouvrir la tranchée, et malgré l'inondation qui était grande, les soldats ayant de l'eau jusqu'à la ceinture, il fit attaquer le chemin couvert par le régiment de Lyonnais. Il s'en rendit maître après un combat de cinq heures. Les ennemis qui se virent pressés, demandèrent à capituler. On prit dans cette place seize cents hommes d'infanterie, quatre cents chevaux et six cents dragons.

\section{Siége d'Aire. - Juillet 1676.}

Par Martin, d'après Vinder Meulen. - H. 2,15. - L. 1,56.

\section{Prise d'Aire. - 31 juillet 1676.}

Par Martin, d'après Vander Meulen. - H. 2,15. - L. 1,56.

" Aire, l'une des deux places qui restoient pour lors à l'Espagne dans le pays d'Artois, est considérable par sa situation; elle est environnée de marais de trois côtés; les fortifications étoient excellentes du côté qui pouvoit être àttaqué. Le maréchal d'Humières, qui fut chargé de cette entreprise, y marcha le 18 juillet avec quinze mille hommes, trente pièces de canon et neuf mortiers, et s'en rendit maître en cinq jours. » (QuINCY.)

\section{Prise d'Y $Y$ pres. -19 mars 1678.}

Par Martin, d'après Vander Meulen. - H. 2,15. - L. 1,88.

Ce tableau est une copie du $n^{\circ} 101$, avec quelques changements. 


\section{Prise de Leewe. - 4 mai 1678.}

Par Martin, d'après Vander Meulen. - H. 2,15. - L. 1,88.

La Bretesche, colonel de dragons, surprend pendant la nuit le château et la ville de Leewe environnés d'un marais, et où la Geette forme un double fossé. Les soldats français traversèrent l'eau dans des bateaux de joncs recouverts de toile cirée.

\section{SALLE No 9.}

Cette salle et les suivantes jusqu'à la salle $n^{\circ} 12$, formaient l'appartement destiné aux princes de la branche de Conty. La frise est ornée de vingt-neuf médaillons peints par Pierre FRANQUE, représentant les principaux personnages de la fin du règne de Louis XIV. Ce sont : la grande dauphine, le maréchal de Duras, Seignelay, d'Estrées, Jean Bart, Barbezieux, Henri-Jules, prince de Condé et sa femme, le duc et la duchesse de Bourbon, le comte de Toulouse, le duc du Maine, le duc de Vendôme, le duc d'Anjou, le duc et la duchesse de Berry, la duchesse de Lorraine, le maréchal d'Harcourt, Chamillart, DuguayTrouin, Tessé, Phélypeaux, Villars, la duchesse de Bourgogne, Fénelon, Dangeau, Voisin, Torcy et le cardinal de Noailles.

\section{Louis de France, dauphin, surnommé le Grand Dauphin.}

Par Hyacinthe Rigaud. - H. 0,63. - L. 0,56.

Fils aîné de Louis XIV, né au château de Fontainebleau le 1 er novembre 1661. Il servit au siége de Dôle en 1674, épousa en 1680 Marie-Anne-Christine-Victorine de Bavière, et accompagna Louis XIV aux armées d'Alsace et de Flandre en 1681 et 1684. Généralissime des armées du roi en Allemagne et en Flandre depuis 1688 jusqu'en 1694, il fit les siéges de Philipsbourg, de Manheim, d'Heidelberg, et s'empara du Palatinat. Il mourut au château de Meudon le 14 avril 1711.

\section{Bataille de Réthel. - 15 décembre 1650.}

Par M. Dupressoir. - H. 0,50. - L. 0,90.

Les Espagnols étaient entrés en Champagne et y avaient pris Rhétel, lorsque le maréchal Du Plessis vint investir cette place et la força à capituler le 14 décembre. Le lendemain, il livra bataille aux ennemis, leur tua deux mille hommes, prit leur bagage et leur fit trois mille prisonniers.

\section{Siége de Stenay. -6 août 1650.}

Par M. Dupressoir. - H. 0,44. - L. 0,35.

Fabert ouvrit la tranchée le 3 juillet devant Stenay. Ce fut àce siége que Louis XIV fit sa première campagne. 
136. Arras secouru. - Août 1654.

Par M. Dupressoir. - H. 0,61. - L. 0,49.

" Turenne, La Ferté et d'Hocquincourt s'assemblèrent, dit la Mesnadière, pour concerter ensemble la ruine du camp ennemi, et l'attaque même de la circonvallation, s'il était besoin d'y penser... Etant arrivés à l'éminence nommée le Camp de César, ils résolurent de l'occuper pour établir le quartier du maréchal d'Hocquincourt. L'abbaye de Saint-Eloy en est fort proche ; elle étoit gardée par des gens détachés de l'armée ennemie; il les falloit dénicher de là, et on ne le pouvoit sans canon. On en fit rouler six pièces... L'abbaye fut à la fin emportée, après une assez longue résistance. $》$.

\section{Prise du Quesnoy. - 6 septembre 1654.}

Par M. Dupressoir. - H. 0,61. - L. 0,49.

Le Quesnoy n'arrêta Turenne qu'un jour, et cette place fut aussitôt prise qu'assiégée.

\section{Prise de Cadaquès. - 28 mai 1655.}

Par M. DUPREsSOIR. - H. 0,44. - L. 0,35.

Ie duc de Mercour bloque la ville de Cadaquès en Catalogne et la bat du côté de la mer, tandis que le prince de Conty l'attaque par terre. La place se rendit après six jours de siége.

\section{Prise de Besançon. - 6 février 1668.}

Par M. LAFAYE, d'après Martin. - H. 0,61. - L. 1,01.

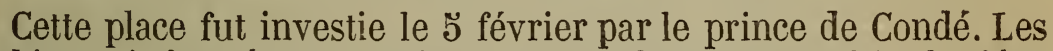
habitants informés que Louis XIV approchait pour en faire le siége en personne, se rendirent le jour même de son arrivée au camp.

Le tableau original est dans la galerie du château de Chantilly.

\section{Prise de Gray. - 17 février 1668.}

Par M. LAFAYE. - H. 0,44 - L. 0,35.

La ville de Gray, assiégée par Louis XIV, ne tint que quatre jours. Les habitants, voyant qu'ils ne pouvaient pas résister à une si forte armée, demandèrent à capituler.

\section{Prise du château de Sainte-Anne.-Février 1668.}

Par M. LAFAYE, - H. 0,44. - L. 0,35.

Les châteaux de Joux et de Sainte-Anne furent attaqués et pris 
en même temps par le duc de Luxembourg, que le roi avait détaché.

\section{Prise de Burick. - 4 juin 1672.}

Par M. DupressoIr. - H. 0,44. - L. 0,35.

Burick, attaqué par Turenne le 2 juin, se rendit deux jours après.

\section{Prise de Wesel. - 5 juin 1672.}

Par M. Dupressotr. - H. 0,61. - L. 0,49.

Après la prise de Burick, Turenne s'empare de Wesel.

\section{Prise d'Emmerich. -8 juin 1672.}

Par M. DupressoIr. - H. 0,61. - L. 0,49.

La ville d'Emmerich se soumet à l'approche du grand Condé.

\section{Prise de Schenck. - 19 juin 1672.}

Par M. Dupressoir. - H. 0,44. - L. 0,35.

Turenne, qui s'était emparé du fort de Knotzembourg, entreprit le siége de celui de Schenck, situé entre deux rivières, et que l'on regardait comme imprenable; deux jours d'attaque lui suffirent pour s'en rendre maître. La garnison qui était de deux mille hommes se rendit prisonnière de guerre.

\section{Prise de Nimègue. - 9 juillet 1672.}

Par M. Pingret. - H. 1, 13. - L. 0,98.

Turenne fit investir Nimègue le 3 juillet; cette place était forte et avait une garnison de quatre mille hommes d'infanterie et de quatre cents chevaux. Turenne somma le gouverneur de la rendre, et sur son refus, il prit aussitôt des mesures pour commencer le siége. La tranchée ayant été ouverte dans la nuit du 4 au 5 juin, les attaques furent poussées avec une si grande activité, que le 9 les assiégés demandèrent à capituler.

\section{Prise de Dôle. - 6 juin 1674.}

Par Jean PAUL. - H. 2,29. - L. 3,30.

Louis XIV se rendit, après la prise de Besançon, devant Dôle qu'il avait fait investir le 26 mai par le duc d'Enghien. Le gouverneur, sommé de rendre la place, ayant répondu par un refus, la tranchée fut ouverte le 28. Les assiégés firent une vigoureuse résistance; mais les troupes, encouragées par la présence du roi, forcèrent, après huit jours de défense, la ville à capituler.

Ce tableau était placé autrefois au château de Marly. 


\section{Combat de Sintzheim. - 16 juin 1674.}

Par M. PINGRET. - H. 1,12. - L. 1.21.

La bataille fut longtemps disputée ; de part et d'autre l'acharnement fut extrême. Enfin le maréchal de Turenne parvint à enlever toutes les positions de l'ennemi. "Cette action, dit Quincy, lui fut d'autant plus glorieuse qu'elle étoit hardie, et qu'il combattit, avec douze mille hommes très-fatigués d'une longue et pénible marche, près de quinze mille hommes qui sortoient de leurs quartiers et qui étoient postés dans un lieu presque inaccessible. Les ennemis eurent environ trois mille morts ou blessés. On leur prit plusieurs drapeaux ,et éteridards, et presque tous leurs bagages. »

\section{Bataille de Senef. - 11 août 1674.}

Par M. Dupressoir. - H. 0,50. - L. 0,90.

L'armée ennemie, forte de près de quatre-vingt-dix-mille hommes, commandée par le prince d'Orange, est attaquée à Senef par le prince de Condé, dont l'armée n'était guère que de cinquante mille hommes. Il bat l'arrière garde des ennemis, attaque ensuite le reste de l'armée et poursuit les ennemis jusqu'au village de Fay. Les Français demeurèrent maîtres du champ de bataille, firent un grand nombre de prisonniers et prirent tout le bagage.

\section{Prise de Huy. - 6 juin 1675.}

Par M. PINGRET. - H. 0,44. - L. 0,35.

La ville de Huy, entre Namur et Liége, ouvrit ses portes au marquis de Rochefort, et le château, après s'être défendu pendant quelques jours, capitula.

\section{Mort de Turenne. - 27 juillet 1675.}

Par M. Chabord en 1819. - H. 2,29. - L. $2,11$.

"Il monta à cheval, dit $\mathbb{M}^{\text {me }}$ de Sévigné, le samedi à deux heures, après avoir mangé; et comme il y avoit bien des gens avec lui, il les laissa tous à trente pas de la hauteur où il vouloit aller, et dit au petit d'Elbeuf : " Mon neveu, demeurez là ; vous ne faites que tourner autour de moi, vous me feriez reconnoître ". M. d'Hamilton, qui se trouva près de l'endroit où il alloit, lui dit : " Monsieur, venez par ici, on tirera du côté où vous allez ». " Monsieur, lui dit-il, vous avez raison, je ne veux point du tout être tué aujourd hui ; cela sera le mieux du monde ». Il eut à peine tourné son cheval, qu'il aperçut Saint-Hilaire (lieutenant de l'artillerie), le chapeau à la main, qui lui dit: "Monsieur, jetez les yeux sur cette batterie, que je viens de faire placer là ». M. de Turenne 
revint, et dans l'instant, sans être arrêté, il eut le bras et le corps fracassés du même coup qui emporta le bras et la main qui tenoit le chapeau de Saint-Hilaire. Ce gentilhomme, qui le regardoit toujours, ne le voit point tomber : le cheval l'emporte où il avoit laissé le petit d'Elbeuf; il étoit penché le nez sur larçon. Dans ce moment le cheval s'arrête, le héros tombe entre les bras de ses gens; il ouvre deux fois de grands yeux et la bouche, et demeure tranquille pour jamais. Songez qu'il étoit mort, et qu'il avoit une partie du cœur emportée ».

Le même coup qui frappa Turenne emporta le bras de SaintHilaire; et comme son fils tout en larmes le serrait entre ses bras, on connaît la réponse qu'il lui fit : “Ce n'est pas moi, c'est ce grand homme qu'il faut pleurer ».

\section{Prise de Bouchain. - 12 mai 1676.}

Par M. Pingret. - H. 0,44. - L. 0,35.

Après la prise de Condé, le duc d'Orléans vint faire le siége de Bouchain, qui se rendit après cinq jours de tranchée ouverte.

\section{Prise du château de l'Escalcette. - 8 nov. 1676.}

Par Renoux. - H. 0,44. - L. 0,35.

Escalcette était une place assez forte entre Messine et Taormine, que le duc de Vivonne assiéga en personne, malgré la rigueur de la saison extrêmement froide et pluvieuse. Les ennemis s'y défendirent pendant quinze jours; mais enfin, foudroyés de tous côtés par le canon des galères et par une batterie qu'on avait trouvé moyen de faire élever sur une montagne extrêmement haute, ils furent obligés de capituler.

154. Bataille de Cassel. -11 avril 1677. (Voir no 100.)

Par M. Gallait en 1837. - H. 1,93 . - L, $2,92$.

155. Reddition de la citadelle de Cambrai. - 18 avril 1677.

Par Vander Meulen.- H. 4,13. - L. 2,21.

" La capitulation ayant été signée, dit Quincy, la garnison sortit le lendemain 18, par la brèche, avec deux pièces de canon, deux mortiers et tous les autres honneurs de la guerre. Le roi, qui avoit fait mettre ses troupes en bataille et qui étoit présent pour la voir défiler, aborda le carrosse de don Pedro Zavala, gouverneur, qui aroit été blessé à la jambe d'un éclat de grenade, et qui étoit couché dedans. Il fit son compliment à Sa Majesté, qui lui donna beaucoup de louanges sur sa valeur et sur sa fermeté ".

Ce tableau faisait partie de la décoration du grand escalier des ambassadeurs, à 
Versailles; les ornements qui l'entourent sont de Lebrun. - Gravẻ par L. Surugue en 1725. (Calc. imp.)

\section{Prise de Saint-Omer. - 22 avril 1677.}

Par M. Pingret. - H. 0,61. - L. 1,03.

Le duc d'Orléans dirigea les travaux, anima les troupes par sa présence, et dès le 19 on s'était déjà emparé du chemin couvert. Les assiégés battirent la chamade et sortirent le 21 par capitulation.

\section{Prise de Gand. - 12 mars 1678.}

Par Renoux. - H. 0,61. - L. 0,49.

Louis XIV se rendit le 4 mars devant Gand, qui avait été investi dès le $1^{\text {er }}$ du mois. La ville se rendit au bout de cinq jours, et deux jours après, la citadelle suivit son exemple.

158. Prise de Philipsbourg. - 29 octobre 1688.

Par Renoux. - H. 0,50. - L. 0,90.

Le dauphin arriva au camp devant Philipsbourg le 6 octobre. En l'attendant on avait pris toutes les mesures relatives au siége, et attaqué le fort du Rhin dès le 3 au soir, mais on ouvrit en sa présence la tranchée de la principale attaque, la nuit du 10 au 11 octobre. Il montra beaucoup de sang-froid, voulant tout voir par luimême, et s'exposant au feu sans avoir l'air d'y prendre garde. Le comte de Stahremberg, qui défendait Philipsbourg, capitula le 30 octobre, et sortit de la place le $1^{\text {er }}$ novembre.

159. Prise de Manheim. - 10 novembre 1688.

Par M. Pingret. - H. 0,66. - L. 1,41.

Cette place était fortifiée très-régulièrement et située dans un lieu très-avantageux, au confluent du Nekre et du Rhin, à quatre lieues au-dessous d'Heidelberg. Les travaux du siége furent commencés le 4 novembre : on ouvrit la tranchée le 8 , et le 10 la ville capitula. La citadelle, attaquée le 11 , se rendit dans la même journée au grand dauphin.

\section{Combat de Leuze. - 18 septembre 1691.}

Par Joseph Parrocel. - H. 2,30. - L. 2,19.

Le maréchal de Luxembourg bat à Leuze le prince de Valdek qui commandait l'arrière-garde de l'armée ennemie; il n'avait que vingt-huit escadrons contre soixante-quinze. On tua aux ennemis quatorze ou quinze cents hommes; on leur fit plus de trois cents prisonniers et on leur prit quarante étendards. La maison du roi se distingua dans ce combat. 


\section{Prise de Roses. - 9 juin 1693.}

Par Renoux. - H. 0,61. - L. 0,49.

Roses fut attaqué par les armées de terre et de mer. Le maréchal de Noailles fit ouvrir la tranchée dans la nuit du $1{ }^{\mathrm{er}}$ au 2 juin; elle se rendit au bout de huit jours.

\section{Prise de Charleroi. - 11 octobre 1693.}

Par Vander Medlen. - H. 2,30. - L. 3,25.

La prise de Charleroi fut le fruit de la bataille de Nerwinde; le marquis de Villeroy, ayant été chargé d'en faire le siége, y fit ouvrir la tranchée le 15 septembre par le duc de Roquelaure, et poussa les attaques avec beaucoup de vigueur. La ville ne capitula qu'après trente-six jours de tranchée ouverte.

\section{Prise de Palamos. - Juin 1694.}

Par Revoux. - H. 0,44. - L. 0,35.

Le maréchal de Noailles arriva le 31 mai devant Palamos, place maritime assez forte; vivement attaquée par terre et par mer, elle fut défendue avec courage, et le dixième jour de la tranchée, les assiégés ayant été contraints de capituler, la garnison se rendit prisonnière de guerre.

164. Louis $X I V$ recoit le serment de Dangeau, grandmaître des ordres de Notre-Dame du MontCarmel et de Saint-Lazare.-18décembre 1695.

Par Antoine Pezex - H. 1,13. - L. 1,72.

Après la mort de Louvois, grand-vicaire de l'ordre de SaintLazare, Louis XIV avait rétabli le titre de grand-maître des ordres de Notre-Dame du Mont-Carmel et de Saint-Lazare de Jérusalem, et avait donné cette charge au marquis de Dangeau, le 9 décembre 1693. Cette nomination ayant été confirmée en 1695 par une bulle du pape, Dangeau prêta serment entre les mains du roi le dimanche 18 décembre 1695, qui était le lendemain de la fête de saint Lazare. "J'étois revêtu, dit-il dans son Journal, des habits et du grand manteau de l'ordre, qui est de velours amarante brodé d'or et doublé de vert. Après l'évangile j'allai faire mes révérences à l'autel et au roi, et puis je me mis à genoux devant son prie-Dieu et lui prêtai le serment sur les Évangiles ». Cette cérémonie se fit en présence du grand dauphin, du duc de Bourgogne qui était dans la tribune, du prince de Condé et du cardinal de Furstemberg en rochet et en camail. MM. de Rumont, de Bragelonne, de Montagnac, de Montauzé, de Collins, de Guénégaud, de Tillecourt, de Montalet, de 
Sauleux, de Genouillac et de La Barre, anciens chevaliers de l'ordre, accompagnaient le marquis de Dangeau.

La cérémonie se passe dans l'ancienne chapelle du château de Versailles (depuis le salon d'Hercule). - Gravé par Sébastien Leclerc.

\section{Prise de Brisach. - 6 septembre 1703.}

Par Franquelin. - H. 0,66. - L. 1,41.

Le duc de Bourgogne fait ouvrir la tranchée devant Brisach, se met à la tête des travailleurs, porte lui-même une fascine, et anime si bien le soldat par son courage, que la ville est forcée de se rendre après treize jours de tranchée ouverte.

\section{Prise de la ville de Lérida. - 13 octobre 1707.}

Par M. Auguste Codder en 1837. - H. 1,92. - L. $2,92$.

La tranchée fut ouverte dans la nuit du 2 au 3 octobre, et la brèche étant praticable, le duc d'Orléans commanda l'assaut dans la soirée du 12. Les assiégés se battirent avec le plus grand courage; mais le prince, malgré leur vive résistance, parvint à s'emparer de la place, qui fut entièrement abandonnée au pillage pendant vingtquatre heures.

Ce tableau a été exposé au Salon de 1838.

\section{Louis de France, duc de Bourgogne.}

Par Hyacinthe Rigadd, - H. 0,63. - L. 0,56.

Fils aîné du grand dauphin et petit-fils de Louis XIV, il nacruit à Versailles le 6 août 1682. Il épousa en 1697 Marie-Adélaïde de Savoie, commanda les troupes du camp de Compiègne en 1698, l'armée d'Allemagne en 1701, celles de Flandre et du Rhin en 1702 et 1703 , et se rendit maître de Brisach. Nommé général de l'armée de Flandre en 1708, il devint dauphin à la mort de son père en 1711, et mourut au château de Marly le 18 février 1712.

\section{Congrès de Rastadt. — Mars 1714.}

Par Jean Rudolf HUBER. - H. 1,12. - L. 1,48.

“Le comte du Luc, rapporte Descamps, appela Huber à Bade, où étoient pour lors assemblés les plénipotentiaires nommés pour terminer les différends et qui conclurent la paix. Notre peintre eut ordre de peindre dans un seul tableau les plénipotentiaires de la part de la France : le maréchal de Villars, M. de Saint-Contest, le comte du Luc et M. du Theil, secrétaire d'ambassade; ceux de la part de l'Empire étoient le prince Eugène, les comtes de Goës, de Seitern et M. de Bendenrieth, secrétaire de légation. "(Vies des peintres flamands.) 


\section{SALLE No 10. (Voir salle $n^{0} 9$. .)}

La frise de cette salle est ornée de vingt-cing médaillons peints par Pierre FRANQUE, représentantles principaux personnages de la fin du règne de Louis XIV et de la régence. Ce sont : la duchesse d'Orléans, femme du régent, le duc de Bourbon, le prince de Conty (Louis-Armand), Daguesseau, Villeroy, le maréchal d'Estrées, Saint-Simon, le maréchal de Berwick, Noailles, le cardinal de Rohan, le duc d'Orléans, fils du régent, et sa femme, le comte de Charolais, le prince de Conty (Louis-François), la princesse de Conty, le cardinal de Fleury, le comte de Clermont, Maillebois, Belle-Isle, le maréchal de Saxe, d'Argenson, Lowendal, Chevert, La Galissonnière et le maréchal de Richelieu.

\section{Philippe d'Orléans, duc d'Orléans, régent du royaume.}

Par M. Serrur, d'après Rigaud. - H. 0,72. - L. 0,57.

Il était fils de Monsieur, duc d'Orléans, frère de Louis XIV et naquit aú château de Saint-Cloud le 2 août 1674. Il porta d'abord le titre de duc de Chartres, accompagna le roi en 1691 au siége de Mons, et fut marié en $\mathbf{1 6 9 2}$ à Franęoise-Marie de Bourbon (Mademoiselle de Blois) fille légitimée de Louis XIV et de $\mathrm{II}^{\mathrm{m}} \mathrm{e}$ de Montespan. Il se trouva au combat de Leuze et au siége de Namur en 1692, commanda la cavalerie à la bataille de Nerwinde, en 1693, et devint duc d'Orléans à la mort de son père en 1701. Il commanda en Italie et en Espagne dans les années 1706 et 1707 et s'empara de Lérida. Reconnu régent ău royaume en 1715 pendant la minorité de Louis $\mathrm{XV}$, il devint à la majorité du roi, en 1723, principal ministre, grand-maitre et surintendant-général des postes, et mourut à Versailles le 2 décembre 1723.

\section{Louis $X V$, roi de France. (Noir n $\left.{ }^{\circ} 718.\right)$}

Par Hyacinthe Rigaud. - H. 0,79. - L. 0,72.

Il est représenté à l'âge d'environ six ans, revêtu du manteau royal et tenant le sceptre.

\section{Louis $X V$. (Toir n $\left.\mathrm{n}^{\circ} 718.\right)$}

Par Jean-Baptiste Vaxl00. - H. 0,72. - L. 0,57.

Il est représenté à l'âge d'environ quinze ans, la tête nue et cuirassé.

\section{Lit de Justice de Louis $\mathbf{X V}$. - 12 sept. 1715.}

Par Deméric. - H. 0,75. - L. 1,06.

Le parlement était assemblé dans la salle de la grand'chambre du Palais lorsque Louis XV arriva. Le roi étant assis, chacun prit place ; le régent et les princes du sang à sa droite, le grand chambellan était sur les marches du trône; le prévôt de Paris couché sur les degrés, les huissiers de la chambre du roi à genoux plus bas, 
leurs masses de vermeil sur le col, et les hérauts d'armes en costume avec leur cotte. La cour portait le deuil; après les princes venaient ensuite sur les gradins élevés de la salle, et au-dessous du trône, les pairs laïques à la droite et les pairs ecclésiastiques à la gauche du roi; le conseil d'État sous le gradin des pairs laïques et plus bas; devant les pairs ecclésiastiques les présidents des chambres, en robes rouges avec leurs fourrures. Les conseillers de toutes les chambres, en robes rouges, en face des pairs laïques, et plus bas ; enfin, en retour de la salle et en face des pairs ecclésiastiques, encore les conseillers. Derı ière eux, les gens du roi; après les spectateurs de marque et de considération. Les dames de la cour occupaient des lanternes ou loges.

M. Bonnardot a décrit ce tableau et le suivant dans son Iconographie $d u$ vieux Paris, tome III, pages 506 et suiv. de la Revue universelle des arts, 1856, in- $8^{\circ}$.

\section{Départ du Roi après le Lit de Justiee. - 12 sep- tembre 1715.}

Par Jean-Baptiste MarTin. - H. 0,88. - L. 1,25.

Le roi fut reconduit jusqu'à son carrosse au bas des degrés de la Sainte-Chapelle, par la même députation qui l'avait reçu à son arrivée. Le duc d'Orléans, le duc de Bourbon et tous les princes du sang marchaient immédiatement devant lui. Le premier chambellan, comme grand-écuyer, le porta dans son carrosse.

\section{Louis $\mathbf{X V}$ visite Pierre-le-Grand à l'hôtel de Les- diguières. - 10 mai 1717.}

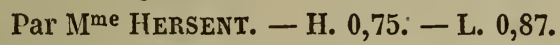

Pierre-le-Grand arriva à Paris le 7 mai, et voulut loger à l'hôtel de Lesdiguières. Le 10 février, le roi alla voir le czar, qui le reçut à la portière, et le conduisit jusque dans sa chambre, où ils trouvèrent deux fauteuils égaux. " On fut étonné, dit Saint-Simon, de voir le czar prendre le roi sous les deux bras, le hausser à son niveau, l'embrasser ainsi en l'air, et le roi, à son âge, et qui n'y pouvoit pas être préparé, n'en avoir aucune frayeur. » Le prince Kourakin servit d'interprète dans cette entrevue à laquelle assistaient le duc du Maine, le comte de Toulouse, le maréchal de Villeroy et l'évêque de Fréjus.

\section{Pierre-le-Grand et le Régent à la revue de la maison militaire du Roi. - 16 juin 1717.}

Par M. Lestang-Parade. - H. 0.70. - L. 1,40.

Le régent fit au czar les honneurs d'une revue dans la cour des 
Tuileries; deux régiments des gardes françaises et suisses, des mousquetaires, des gendarmes et des chevau-légers de la maison du roi défilèrent devant eux. Le czar était suivi du maréchal de Tessé et du prince Kourakin, qui l'accompagna partout dans son voyage en France.

\section{Camp de l'Armée francaise entre Saint-Sébastien et Fontarabie. - Juin 1719.}

Par Jean-Baptiste Martin. - H. 3,84. - L. $2,62$.

Le maréchal de Berwick était le 27 mai devant Fontarabie, dont il entreprit le siége. Le prince de Conty s'y rendit et accompagna le maréchal pendant toute la campagne.

Ce tableau représente la partie du camp où se trouvait le quartier du prince de Conty. Sur le devant, des officiers et des soldats prennent leur repas; à gauche, un officier fait distribuer des vivres par des domestiques.

\section{Méhémet Effendi, ambassadeur turc, arrive aux Tuileries. - 21 mars 1721.}

Par Charles Pariocel. - H. 2,28. - L. 3,29.

"Le vendredi 21 du mois de mars, dit Saint-Simon, le prince de Lambesc et Rémond, introducteurs des ambassadeurs, allèrent dans le carrosse du roi prendre l'ambassadeur à son hôtel; et aussitôt ils se mirent en marche pour aller à l'audience du roi : la compagnie de la police avec ses timbales et ses trompettes à cheval, le carrosse de l'introducteur, celui du prince de Lambesc, entourés de leurs livrées, précédés de six chevaux de main et de huit gentilshommes à cheval, trois escadrons d'Orléans, douze chevaux de main menés par des palefreniers du roi à cheval, trentequatre Turcs à cheval, deux à deux, sans armes, puis Merlin, aide-introducteur, et huit des principaux Tures à cheval, le fils de l'ambassadeur à cheval, seul, portant sur ses mains la lettre du Grand-Seigneur dans une étoffe de soie, six chevaux de main, harnachés à la turque, menés par six Tures à cheval, quatre trompettes du roi à cheval. L'ambassadeur suivoit entre le prince de Lambesc et l'introducteur, tous trois de front à cheval, environnés de valets de pied tures et de leurs livrées, cotoyés de vingt maîtres du régiment Colonel-Général, ce même régiment précédé des grenadiers à cheval; puis le carrosse du roi etla connétablie. L'ambassadeur', avec tout ce qui l'accompagnoit et toute sa suite à cheval, entra par le Pont-Tournant dans le jardin des Tuileries, depuis lequel, jusqu'au palais des Tuileries, les régiments des gardes françoises et suisses étoient en haie des deux côtés, les tambours rappelant et les drapeaux déployés. L'ambassadeur et tout ce qui l'accompagnoit passa ainsi à cheval le long de la 
grande allée, entre ces deux haies, jusqu'au pied de la terrasse, où il mit pied à terre. ')

Ce tableau était placé autrefois dans les appartements de Versailles et avait été agrandi pour faire pendant à un tableau de Vander Meulen. (Essai sur la vie de Charles Parrocel, par Cochin, tome II, page 408, des Mémoires inédits sur les membres de l'Académie de peinture et de sculpture. -1854, in- $8^{\circ}$.)

\section{Cavalcade du Roi après le sacre. - 26 octobre 1722.}

Par Pierre-Denis Martin. - H. 0,88. - L. 1,25.

Le lendemain de son sacre, Louis XV monta à cheval pour accomplir la cérémonie de la grande cavalcade. Il était accompagné du régent, des grands officiers de sa maison, des maréchaux de France et des officiers de l'ordre du Saint-Esprit. Le cortége sortit de l'archevêché dans l'ordre suivant : les hautbois, tambours et trompettes marchaient en tête ; venaient ensuite le comte de Monsoreau, grand-prévôt de l'hôtel, puis les gardes-du-corps avec leurs officiers. Le cortége se rendit d'abord à Saint-Marcou et ensuite à Saint-Rémy, où le roi mit pied à terre.

Ce tableau est signé : Martin le Jeune, Peintre Ordinaire et Pensionnaire du Roy. 1724.

\section{Bataille de Parme. - 29 juin 1734.}

Par Pierre-Denis Martin. - H. 0,75. - L. 1,06.

Le maréchal de Coigny défait, près de Parme, les Impériaux, qui y perdirent huit mille hommes avec leur général Mercy. La prise de Modène fut une suite de cette victoire.

Ce tableau, qui représente un engagement de cavalerie, est signé : $\boldsymbol{P}$. $\boldsymbol{D}$. Martin dit le Jeune, Peintre Ordinaire et Pensionnaire du Roy. 1737.

\section{Prise de Philipsbourg. - 18 juillet 1734.}

Par M. Auguste Couder en 1838. - H. 2,27. - L. 1,25.

Après la mort du maréchal de Berwick, le siége de Philipsbourg fut continué par les maréchaux d'Asfeld et de Noailles; et, après six semaines de tranchée ouverte, malgré les obstacles qu'opposaient des pluies continuelles, l'inondation des tranchées et la présence de l'armée impériale, les assiégés capitulèrent et rendirent la ville.

Un parlementaire est amené les yeux bandés aux deux généraux.

\section{Prise de Prague. - Novembre 1741.}

Par M. Auguste CovdER en 1838. - H. 2,27. - L. 1,35.

Maurice, comte de Saxe, s'empara de la ville de Prague, et en remit les clefs à l'électeur de Bavière, qui y fit son entrée le 26 novembre. 
182. Prise de Menin. - 4 juin 1744.

Par Pierre Lenfant. - H. 3,34. - L. 3,53.

Louis XV, à cheval, ordonne l'attaque du chemin couvert.

Ce tableau était placé à l'hôtel de la Guerre, à Versailles.

\section{Prise d'Ypres. - 27 juin 1744.}

Par M. VAN YsendycK. - H. 0,76. - L. 1,13.

Le prince de Clermont commanda les principales attaques de ce siége; la ville, investie le 16 juin, capitula le 27.

\section{Prise de Furnes. - 11 juillet 1744.}

Par M. Raverat. - H. 0,71. - L. 1,13.

Après la prise d'Ypres, le prince de Clermont fit le siége de Furnes, qui arbora le drapeau blanc après cinq jours de tranchée ouverte.

\section{Bataille de Coni. - 30 septembre 1744.}

Par M. SERrur. - H. 0,82. - L. 1,13.

La tranchée était à peine ouverte devant Coni, que le roi de Sardaigne se présenta pour en faire lever le siége, et livra bataille. Les F rançais et les Espagnols combattirent en cette occasion comme des alliés qui se secourent, et comme des rivaux qui veulent chacun donner l'exemple. Le roi de Sardaigne perdit près de cinq mille hommes et le champ de bataille. Le prince de Conty, qui était général et soldat, eut sa cuirasse percée de deux coups, et deux chevaux tués sous lui. La prise de Coni fut le résultat de la bataille.

\section{Entrée de Louis XV à Strasbourg. - 5 oc- tobre 1744.}

Par M. SERrur. - H. 0.70. - L. 1,40.

Le roi entra dans la ville au bruit de toutes les cloches et de l'artillerie des remparts, et se rendit à l'église cathédrale au milieu d'une double haie des troupes de la garnison. Les rues.étaient sablées, jonchées de verdure, et tapissées, à droite et à gauche, des plus belles tapisseries que les habitants de tous états avaient fournies à l'envi.

187. Siége de Fribourg. - 11 octobre 1744.

Par Pierre Lenfant. - H. 3,34. - L. 2,53.

Le maréchal de Coigny avait fait investir Fribourg en Brisgau, 
depuis le 19 septembre, lorsque le roi, arrivé de Strasbourg, prit le commandement de l'armée. Le siége de Fribourg fut long et pénible, surtout à cause de l'abondance des eaux du Treisam qu'il fallait arrêter et détourner. Le maréchal de Coigny rendait compte au roi tous les jours du progrès des travaux, et en recevait les ordres.

\section{Bataille de Fontenoy. - 11 mai 1745.}

Par Pierre Lenfant. - H. 3,91. - L. 2,79.

Louis XV à cheval et suivi du dauphin donne ses ordres au maréchal de Saxe. Dans le fond, la cavalerie française charge la colonne anglaise.

Ce tableau et le précédent étaient placés autrefois à l'hôtel de la Guerre, à Versailles.

SALLE No 11 (Voir salle no 9.)

\section{Sacre de Louis $X V$. -25 octobre 1722.}

Par M. Émile SignoL. - H. 3,23. - L. 5,39.

Louis XV fut sacré à l'âge de treize ans. La cérémonie eut lieu à Reims, dans l'église cathédrale. Le cardinal duc de Rohan, archevêque de Strasbourg et grand aumônier de France, officia. Il était assisté des évêques de Laon et de Beauvais.

\section{Louis $X V$, roi de France. (Voir no 718.)}

Par Carle VanLOO. - H. 0,72. - L. 0,56.

Il porte une cuirasse couverte en partie par le manteau royal.

\section{Louis $X V$. (Voir n⿳⺈ 718.)}

Par Louis-Michel VanLOo. - H. 0,72. - L. 0,56.

Il est revêtu du grand manteau royal.

\section{Louis de France, Dauphin.}

Par Nicolas-Simon-Alexis BeLLE. - H. 0,78. - L. 0,72.

Fils aîné de Louis XV, né à Versailles le 4 septembre 1729, il épousa en 17450 Marie-Thérèse-Antoinette-Raphaëlle, fille de Philippe $\mathrm{V}$, roi d'Espagne, et accompagna Louis XV à la bataille de Fontenoy. Il fut remarié en 1747 à Marie-Josèphe de Saxe, et mourut à Fontainebleau le 20 décembre 1765.

Il est représenté à l'âge d'environ un an, assis sur un coussin. 
193. Siége de Tournay; camp de la rive droite de l'Escaut. - 26 avril 1745.

Par Ignace PARrocel. - H. 0,90. - L. 1,58.

Le maréchal de Saxe investit Tournay sur les deux rives de l'Escaut, tandis que l'armée ennemie se dirigeait du côté de Mons el de Maubeuge qu'elle croyait menacés.

194. Siége de Tournay; camp de la rive gauche de l'Escaut. - 26 avril 1745.

Par Ignace PARRocEL. - H. 0,90. - L. 1,58.

195. Bataille de Fontenoy; attaque du village d'Antoin. - 11 mai 1745.

Par Pierre Lenfant. - H. 1,73. - L. 1,58.

Le village d'Antoin est attaqué par deux colonnes hollandaises et défendu par la cavalerie française.

Ce tableau était placé autrefois à l'hôtel de la Guerre, à Versailles.

196. Bataille de Fontenoy. - 11 mai 1745.

Par Hyacinthe de LA PEGNA. - H. 1,90. - L. 3,53.

A gauche, Louis XV et le dauphin sont à cheval devant les piliers de la justice de Notre-Dame-aux-Bois. Plùs loin, sont deux redoutes défendues par les Français et le bois de Barry. Au centre, la colonne anglaise mise en déroute par des charges de l'infanterie et la cavalerie francaise, et par une batterie de quatre pièces de canon; puis le village de Fontenoy relié par trois redoutes au village d'Antoin, qui est dans l'angle de droite. Les Hollandais et les Autrichiens sont mis en fuite par le feu de ces trois redoutes et par celui des lignes françaises.

197. Bataille de Fontenoy; prise du village de Vezon. 11 mai 1745.

Par Pierre Lenfant. - H. 1,73. - L. $1,79$.

Le colonel Grassin de Glatigny s'était tenu, pendant la bataille, dans les bois de Barry avec son régiment. Il se porta, après le combat, sur le flane de la cavalerie ennemie formée devant Vezon; il l'obligea, par son feu de s'éloigner de ce village. Il y prit huit cents hommes y compris les biessés, vingt-deux pièces de canon, tous les chariots d'artillerie, l'hôpital ambulant et beaucoup de bagages.

Ce tableau était placé autrefois à l'hôtel de la Guerre, à Versailles. 


\section{Combat de Melle. - 9 juillet 1745.}

Par Ignace PARROGEL. - H. 0,90. - L. 1,79.

Six mille Anglais envoyés au secours de Gand, sont défaits prés de l'abbaye de Melle par une colonne française sous le commandement du lieutenant-général Du Chayla.

\section{Prise de Gand. - 11 juillet 1745.}

Par M. Gigodx. - H. 0,66. - L. 1,40.

Le comte de Lowendal fait attaquer la place du côté de la porte Saint-Pierre, pendant que Du Chayla la surprend par la rive gauche de l'Escaut. Les habitants de Gand, qui s'étaient couchés Autrichiens, se réveillèrent le lendemain sous la domination française.

\section{Siége d'Oudenarde. - 17 juillet 1745.}

Par Ignace Parrocel. - H. 1,73. - L. 3,53.

Après la prise de Gand, le comte de Lowendal fit ouvrir la tranchée devant Oudenarde le 17 juillet. La ville capitula le 21.

\section{Siége d'Ostende. - A oût 1745.}

Par M. Rioult. - H. 0,75. - L. 1,14.

Louis XV donne l'ordre pour l'attaque du chemin couvert.

202. Siége de Bruxelles. - Février 1746.

Par M. Rubio. - H. 0,68. - L. 1,14.

Le 30 janvier 1746, le maréchal de Saxe mit le siége devant la ville de Bruxelles, qui se rendit le 20 février.

203. Entrée de Louis XV à Anvers. - 4 juin 1746. Par M. Hippolyte LecomTe. - H. 0,66. - L. 1,40.

Après la prise de Louvain, de Malines et d'Anvers, Louis XV fit son entrée dans cette dernière ville. Tout le clergé et les magistrats allèrent au-devant du roi hors des portes de la ville.

204. Siége de Mons. - Juillet 1746.

Par 1 ierre Lenfant. - H. 1,73. - L. 3,31.

Le prince de Conty fit investir Mons le 7 juin par le duc de Boufflers et le comte d'Estrées. La place se rendit le 10 juillet.

Ce tableau était placé autrefois à l'hôtel de la Guerre, à Versailles. 


\section{Siége de Saint-Guilhain. - Juillet 1746.}

Par Verdussen. - H. 0,89. - L. 1,14.

Le maréchal de Saxe avait fait investir la place de Saint-Guilhain le 14 juillet. La tranchée fut ouverte du 21 au 22 , et les grenadiers s'emparèrent de l'ouvrage avancé dans la nuit du 23 au 24. L'attaque fut continuée pendant le jour, et les assiégés, forcés dans leurs retranchements, demandèrent à capituler le 25.

206. Siége de Charleroi. - 2 août 1746.

Par Ignace ParRoceL. - H. 0,89. - L. 1,79.

Le prince de Conty commanda ce siége; la tranchée fut ouverte dans la nuit du 28 au 29, et la capitulation fut signée le 2 août, après trois attaques vigoureuses.

207. Siége de la ville de Namur. - Septembre 1746.

Par Ignace PARrocel. - H. 1,90. - L. 3,31.

Namur fut investi le 9 septembre. Cinquante-neuf bataillons et cinquante-six escadrons attaquèrent la ville. Cinq batteries de canon ouvrirent le siége par un feu aussi vif que meurtrier. La ville capitula le 19 septembre.

SALLE No 12. (Voir salle no 9.)

208. Louis $\mathbf{X}$, roi de France. (Voir n 718. )

Par Louis-IIichel VANLOO. - H. 0,73. - L. 0,56.

Il est représenté à l'âge d'environ soixante ans, en habit de velours bleu.

209. Louis de France, Dauphin. (Noir no 192.)

Par Anne-Baptiste Nivelon. - H. 0,78. - L. 0,71.

210. Siége de Tournay, -14 mai 1745.

Par Pierre Lesfant. - H. 3,70. - L. 2,46.

Le lendemain de la bataille de Fontenoy, les troupes francaises vinrent reprendre le siége de Tournay. Le 14 mai, Louis XV se rendit à la tranchée, accompagné du dauphin et du comte d'Argenson, ministre de la guerre. Il examina tous les travaux du siége, et la ville se rendit le 22.

Ce tableau était placé autrefois à l'hôtel de la Guerre, à Versailles.

211. Bataille de Rocoux. - 11 octobre 1746.

Par Camille Roedeplan. - H. 1,71. - L. 4,00.

Le maréchal de Saxe bat l'armée aux ordres du prince Charles 
de Lorraine à Rocoux, situé à une lieue de Liége. Les alliés eurent dans ce combat sept mille hommes tant tués que blessés; on leur fit mille prisonniers et on leur enleva cinquante pièces de canon et dix drapeaux.

\section{Bataille de Lawfeld. - 2 juillet 1747.}

Par Pierre Lenfant. - H. 3,70. - L. 2,46.

Le maréchal de Saxe prend les ordres du roi Louis XV pour livrer la bataille de Lawfeld.

Ce tableau était placé autrefois à l'hôtel de la Guerre, à Versailles.

\section{Bataille de Lawfeld. - 2 juillet 1747.}

Par Ch. PARROCEL. - H. 1,71. - L. 4,00.

Le combat s'engagea par la gauche des alliés, composée des Anglais, des Hanovriens, des Hessois et des Hollandais, commandés par le duc de Cumberland. L'aile gauche fut mise en déroute par le comte de Clermont; le maréchal de Saxe, après avoir forcé les ennemis retranchés dans la ville de Lawfeld, les rejeta dans Maestricht.

Ce tableau, laissé par Charles Parrocel à l'état d'ébauche, a été terminé par Pierre Eranque.

214. Siége et prise du fort Saint-Philippe au PortMahon. - 28 juin 1756.

Par M. Wachsmuth. - H. 0,80. - L. 1,13.

Le maréchal de Richelieu tenta l'entreprise la plus hardie, ce fut de donner à la fois un assaut à tous les ouvrages qui défendaient le corps de la place de Port-Mahon. Il fut secondé par le maréchal de Maillebois, et les troupes s'y portèrent avec d'autant plus de courage, qu'elles avaient affaire à près de trois mille Anglais, secondés de tout ce que la nature et l'art avaient dû faire pour les défendre. Le 28 juin la place se rendit, et le 29 juin l'armée française prit possession du fort Saint-Philippe.

\section{Bataille d'Hastembeck. - 26 juillet 1757.}

Par M. Rioult. - H. 0,73. - L. 1,40.

Le maréchal d'Estrades suivait pas à pas lạ retraite du duc de Cumberlanả qui espérait se fortifier dans l'électorat de Hanovre; il le joint à Hastembeck, lui livre bataille et remporte une victoire complète sur les Anglais et les Hanovriens réunis. 


\section{Bataille de Lutzelberg. - 10 octobre 1758.}

Par M. Demahis. - H. 0,75. - L. 1,13.

Le prince de Soubise rencontre l'ennemi à Lutzelberg, près de Cassel. Les Hanovriens et les Hessois furent vaincus par une manœuvre de Chevert, qui, à la tête des Saxons et des Palatins, vint les prendre en flanc.

\section{Bataille de Johannisberg. - 30 aout 1762.}

Par M. Amédée FAURE. - H. 0,70. - L. 1,13.

Le prince de Condé bat à Johannisberg, près de Fridberg, au nord de Francfort, le prince Ferdinand qui commandait l'armée des alliés. L'action, commencée à dix heures du matin, dura quatre heures. Les vaincus abandonnèrent aux Francais quinze cents prisonniers, quinze pièces de canon, douze cents chevaux et un régiment entier d'Anglais qui fut obligé de rendre les armes.

\section{Louis XVI, roi de France. (voir no 719.)}

Par Antoine-Francois Callet. - H. 0,73. - L. 0,56.

219. Publication du traité de paix de Versailles entre la France et l'Angleterre. - 25 nov. 1783.

Par M. VAN YseNdyck. - H. 0,73. - L. 1,40.

Le 30 novembre 1782, les préliminaires de la paix entre l'Angleterre, les Etats-Unis et la France leur alliée, furent arrêtés à Paris. Des traités définitifs entre les cours de France, d'Espagne, d'Angleterre et de Hollande, furent enfin signés les 3 et 22 septembre 1783, et la paix fut publiée dans Paris le 2oั novembre 1783, avec tout le cérémonial usité en pareille circonstance. Le prévôtdes marchands et les échevins, le lieutenant-général de police, les lieutenants procureurs du Chàtelet et les autres officiers y assistèrent. Ils parcoururent la ville précédés des archers du guet, des huissiers à cheval et à pied, accompagnés du roi d’armes, des six hérauts et du corps de musique de la ville. Le cortége, suivant l'usage, partit de l'Hôtel-de-Ville à midi, sarrêta sur toutes les places publiques, devant le Palais-Royal, aux Tuileries, sur la place Vendôme, traversa les boulevards et rentra à cinq heures.

220. Louis XVI donnant des instructions à La Pérouse. -29 juin 1785.

Par Nicolas-André MioxsiaU en 1817. - H. 1,72. - L. 2,27.

Avant le départ de l'expédition des frégates la Boussole et l'Astrolabe, Louis XVI reçut, dans son cabinet à Versailles, La Pé- 
rouse, en présence du maréchal de Castries, ministre de la marine, et lui donna lui-même ses dernières instructions.

\section{Louis XVI visite le port de Cherbourg. -23 juin 1786.}

Par Louis-Philippe CrépIN en 1817. - H. 1,71. - L. $2,68$.

Louis XVI était parti de Rambouillet le 21 juin pour se rendre à Cherbourg, y visiter les travaux et revenir par Caen et Le Havre. Le 23 juin le roi se rendit au port à l'heure de la marée montante. "Il était, dit une relation du temps, vêtu d'un habit écarlate, ayant la broderie des lieutenants-généraux ». Il parcourut la rade, débarqua à l'île Pelée pour y prendre connaissance des fortifications, de là 'se rendit à la fosse du Gallet, et il rentra enfin après avoir tenu la mer plus de quinze heures consécutives. Le retour du roi fut signalé par une triple salve des forts et de l'escadre, et à son débarquement il fut porté dans un canot par les marins et le peuple, au milieu des acclamations universelles.

Ce tableau a été exposé au Salon de 1817.

\section{Louis XVI abandonne les droits du domaine sur les lais de mer aux habitants de la Guyenne. $-1786$.}

Par M. Berthon. - H. 1,72, - L. 2,68.

Les eaux de la mer s'étant retirées sur l'un des points de la côte de la Guyenne, avaient laissé à découvert une portion de terrain qui, selon le principe du droit alors existant, était dévolu à la couronne. Cependant les riverains prétendaient, en vertu de quelques exceptions, avoir un droit particulier sur la propriété de ces terres. La cause ayant été portée au conseil du roi, Louis XVI décida contre lui-même en faveur des habitants de la côte.

Ce tableau a été exposé au Salon de 1817.

\section{Louis XVI distribue des secours aux pauvres pendant l'hiver de 1788.}

Par M. Hersent en 1817. - H. 1,71. - L. 2, 27.

La fin de l'année 1788 fut remarquable par un hiver des plus rigoureux; depuis celui de 1709 on n'en avait pas vu d'aussi cruel. On vit plusieurs fois Louis XVI parcourir les environs de Versailles pour y chercher l'indigence et la soulager lui-même.

Gravé par Pierre Adam. 


\section{ESCALIER DE L'AILE DU NORD, No 13.}

Cet escalier a été établi lors de la suppression du grand escalier de l'aile droite (voir salle no 8), à l'extrémité des appartements occupés, au rez-dle-chaussée, par les princes de la maison de Conty, et au premier étage par mademoiselle de Sens, première dame d'honneur de la reine Marie Leczinska. Il a été reconstruit en 1851 sur les dessins de M. QUESTEL.

\section{Louis XIV. (Voir no 717.)}

Par Jean Warix; buste en marbre. - H. 0,80.

Warin fit ce buste en 1665 dans le même temps que le Bernin exécutait celui placé dans le salon de Vénus, et le présenta à Louis XIV le 2 septembre 1666.

\section{Colbert (Jean-Baptiste), contrôleur-général des Finances.}

Par Coyzevox ; buste en marbre. - H. 0,70.

Né à Reims en 1619 , il fut employé dans les bureaux du cardinal Mazarin et particulièrement attaché à sa personne. Conseiller d'Etat en 1648, et secrétaire des commandements de la reine Anne d'Autriche en 165't, il fut intendant des finances en 1661, surintendant des bâtiments en 1664, ministre secrétaire d'Etat et contrôleur-général des finances en 1669 . 11 mourut le 6 septembre 1683 et fut enterré dans l'église Saint-Eustache. - Le nom de Colbert est associé à presque toutes les grandès fondations du règne de Louis XIV.

\section{Mansart (Jules-Hardouin), archilecte.}

Par M. GourdeL, d'après Lemoyne; buste en marbre. - H. 0,74.

Né à Paris en 1645 , il était fils de Jules Hardouin, peintre du cabinet du roi, qui avait épousé une sœur de François Mansart, et prit le nom de son oncle. Architecte du roi, puis surintendant des bâtiments en 1699, il fut chevalier de l'ordre de Saint-IIichel, et mourut à Marly le 11 mai 1708. - J.-H. Mansart dirigea la construction des châteaux de Marly, du Grand-Trianon, de Versailles, de Clagny, de la maison de Saint-Cyr, de la place Vendôme et de celle des Victoires, de l'hôtel des Invalides, etc.

Le buste original est au Musée du Louvre.

\section{Félibien (André), historiographe des bâtiments duRoi.}

Par M. OudiNE; buste en marbre. - H. 0,74.

Né à Chartres en 1619, il fut secrétaire de l'ambassade de Rome en 1647, historiographe du roi et de ses bâtiments, arts et manu- 
factures en 1666, et conseiller honoraire de l'Académie royale de Peinture et de Sculpture en 1667. Secrétaire de l'Académie d'Architecture en 1671, il devint garde des Antiques, membre de l'Adémie des Inscriptions et Belles-Lettres, contrôleur-général des Ponts-et-chaussées et administrateur de l'hôpital des QuinzeVingts. Il mourut à Paris le $\mathbf{1 1}$ juin 1695. Il est auteur des Entretiens sur les Vies des Peintres anciens el modernes, de la Description du château de Tersailles, et de plusieurs autres ouvrages sur les arts.

Le buste original est à la Bibliothèque de Sainte-Geneviève, à Paris.

\section{SALLE DE SPECTACLE, No 14.}

Cette salle, commencée en 1753, sur les dessins de GABRIEL, fut achevée en 1770 et inaugurée la même année par les fêtes du mariage du dauphin (Louis XVI); le 17 mai on y représenta Persée, opéra de Quinault, mis en musique par Lulli ; le 19, il y eut dans la nouvelle salle de spectacle un bal paré, ouvert par le dauphin et la dauphine, et le 23 une représentation d'Athalie, avec les chœurs exécutés en musique. Le mois suivant on y joua l'opéra de Castor et Pollux, et les tragédies de Tancrède et de Sémiramis, par Voltaire. En 1771, pour le mariage du comte de Provence, représentation de l'opéra de la Reine de Golconde le 17 mai, bal paré le 20, ballet héroïque des Projets de l'amour le 29, et représentation de la tragédie de Gaston et Bayard le 31. En 1773, pour le mariage du comte d'Artois, représentation de l'opéra d'Isménie le 18 novembre, et bal paré le 9 décembre. En 1777, pendant le séjour de l'empereur Joseph II, représentation de l'opéra de Castor et Pollux.

Le 30 janvier 1782, les gardes du corps du roi donnèrent, à l'occasion de la naissance du dauphin, un bal paré et masqué dans la salle de spectacle. Le roi et la famille royale assistèrent à ce bal où la reine dansa la première contredanse avec un garde du corps.

Le jeudi $1^{\text {er }}$ octobre 1789 , les gardes du corps ayant offert un banquet aux officiers des régiments d'infanterie de Flandre et des Trois-Evêchés, et aux officiers de la garde nationale de Versailles, avaient obtenu de donner cette fête militaire dans la salle de spectacle. Une table de trois cents couverts, en forme de fer à cheval, était dressée sur la scène, dont la décoration représentait une forêt. Dans l'orchestre étaient les trompettes des gardes du corps et la musique du régiment de Flandre. Le parterre était occupé par les soldaîs des régiments de Flandre et des Trois-Evêchés. Les loges étaient remplies d'un grand nombre de spectateurs qui avaient été admis sans billets. Le repas commença vers quatre heures du soir. A la fin du second service, le roi ct la reine, accompagnés du dauphin et de sa sœur, se montrèrent dans la loge royale et vinrent ensuite sur la scène où ils firent le tour de la table. Après leur départ le repas continua, puis les convives, les musiciens et les spectateurs se transportèrent dans la cour de Marbre, où le roi et la reine parurent au balcon. C'est à la suite de ce banquet que Louis XVI fut obligé de quitter Versailles le 6 octobre suivant.

Le 10 août 1837, on représenta dans la salle de spectacle nouvellement restaurée, en présence du roi Louis-Philippe et de la famille royale, le Misanthrope, des fragments de l'opéra de Robert le Diable, et un intermède de M. Scribe, destiné à célébrer l'inauguration du Musée de Versailles.

Le 25 juillet 1855, jour de la fête offerte à Versailles par l'Empereur à la reine d'Angleterre, la salle de spectacle fut destinée au souper qui termina cette fête. Dans la loge d'honneur était dressée une table à laquelle prirent place LL. MM. l'Empereur, l'Impératrice, la reine d'Angleterre, LL. AA. II. le prince Napoléon, la princesse Mathilde, et LL. AA. RR. le prince Albert, le prince de Galles, la princosse royale d'Angleterre et le prince de Bavière. 
Cotte salle, construite entièrement en menuiserie, était peinte autrefois en marbre vert antique; les loges étaient garnies de velours bleu avec des franges d'argent. Pour les bals parés, la scène se transformait, au moyen d'une décoration en charpente, en une seconde salle ornée de trois étages de galeries qui reproduisaient exactement la première. Les huit colonnes corinthiennes placées de chaque côté de l'avant-scène, formaient alors le milieu d'un immense amphithéâtre. Cette décoration n'existe plus qu'à l'état de fragments, et lors de la restauration faite en 1836, la salle a été repeinte en marbre rouge.

A la hauteur des secondes loges de la salle est une galerie circulaire formée par quatorze colonnes d'ordre ionique; le fond de cette galerie est décoré d'arcades ornées de glaces. Des bas-reliefs dorés sont placés sur les socles et les balustrades; ceux de la partie inférieure représentent les douze Dieux et Déesses de la Fable; dans la partie supérieure sönt des jeux d'enfants. Sur l'entablement, au-dessus de l'avant-scène, est un écisson supporté par des génies; dans les angles sont des groupes d'enfants et des trophées. Toutes ces sculptures ont été exécutées par PAJOU.

Le plafond du milieu de la salle, peint par DuraneaU, a pour sujet Apollon préparant des couronnes aux hommes illustres dans les arts. Le même artiste a représenté dans les plafonds des secondes loges, entre les colonnes, des Amours portant les attributs des douze Dieux.

Le grand foyer est décoré d'un soubassement au-dessus duquel règne un ordre de pilastres ioniques avec un entablement qui supporte un cintre en berceau divisé en compartiments ornés de peintures. Les bas-reliefs qui le décorent sont de PAJOd et représentent :

Au-dessus de la porte d'entrée, - La Jeunesse et la Santé.

Au-dessus de la cheminée. - L'A bondance et la Paix.

Dans les trumeaux du côté de la salle. - La Poésie épique.-A pollon et quatre enfarts figurant les arts. - La Poésie dramatique.

Dans les trumeaux du côté des fenêtres. - La Poésie pastorale. - Vénus avec les Amours. - La Poésie lyrique.

Au-dessus du grand foyer, et à la hauteur du premier étage, est un petit salon de forme ovale qui précédait l'ancienne loge royale. Au-dessus de la porte et de la cheminée sont placés deux tableaux de l'école de Boucher, représentant un Amour et une Tête de femme.

\section{VESTIBULE DE LA SALLE DE SPECTACLE, No 15.}

\section{Molière (Jean-Baptiste Poquelin, dit), poète co- mique.}

Par Hocdon; buste en plâtre. - H. 0,62.

Né à Paris le 15 janvier 1622, fils de Jean Poquelin, valet de chambre et tapissier du roi, il fut élevé par les jésuites au collége de Clermont, où il eut pour condisciples le prince de Conty, Chapelle et Bernier, et étudia la philosophie sous Gassendi. Appelé à remplir près du roi Louis XIII l'emploi de valet de chambre tapissier, il abandonna ces fonctions pour la carrière dramatique, prit le nom de Molière et forma à Paris une société qu'on nommait l' $I l$ lustre théâtre, qui donna des représentations en 16450 , au faubourg Saint-Germain et au quartier Saint-Paul. A près avoir parcouru la province pendant douze ans, il revint à Paris en 160 8, fut présenté à Louis XIV et à la reine-mère par le duc d'Anjou, et ouvrit d'a- 
bord à la salle de l'hôtel du Petit-Rourbon, puis au Palais-Royal, un théâtre sur lequel il fit représenter, depuis les Précieuses ridicules (1658) jusqu'au Malade imaginaire (1673), une trentaine d'ouvrages dans lesquels il jouait lui-même le principal rôle. Il mourut à Paris le 17 février 1673, à cinquante-un ans.

Le buste original est dans le foyer de la Comédie-Française, à Paris.

\section{Racine (Jean), poète tragique.}

Par BoIzor; buste en plâtre. - H. 0,68.

Né le 21 décembre 1639, à la Ferté-Milon, il fut élève du collége d'Harcourt et termina ses études à Port-Royal-des-Champs. Son premier essai poétique fut une ode qu'il composa pour le mariage de Louis XIV, en 1660; il fit jouer la Thébaïde en 1664, et donna de 1665 à 1677, Alexandre, Andromaque, les Plaideurs, Britannicus, Bèrénice, Bajazet, Mithridate, Iphigénie et Phèdre. Membre de l'Académie française en 1673, et historiographe du roi en 1677, il composa pour la maison royale de Saint-Cyr les tragédies d'Esther et d'Athalie (1689-91), et mourut le 22 avril 1699. - Racine, de concert avec Boileau, a composé les inscriptions des tableaux allégoriques de la grande galerie de Versailles peints par Lebrun.

Le buste original est dans le foyer de la Comédie-Française, à Paris.

\section{La Fontaine (Jean de), poète et fabuliste.}

Par DESeINe; buste en plâtre. - H. 0,61.

Né à Château-Thierry le 8 juillet 1621, il se fit recevoir, à l'âge de dix-neuf ans, dans la congrégation de l'Oratoire, en sortit au bout de dix-huit mois et remplaça son père dans la charge de mâ̂tre des eaux-et-forêts. Amené à Paris par la duchesse de Bouillon, vers 1660, il eut pour protecteurs le surintendant Fouquet, Henriette d'Angleterre, le prince de Condé et le duc de Bourgogne, et fut reç à l'Académie française en 1684. Il publia son premier ouvrage, l'Eunuque de Térence, en 1654 , la jremière partie de ses Contes en 1664, et les Fables qui ont rendu son nom immortel, en 1668. Il vécut dans la maison de madame de La Sablière pendant vingt ans, puis dans celle de madame Hervart, et mourut à Paris le 13 avril 169 ö.

Le buste original est dans le vestibule, $\mathrm{n}^{\circ} 31$.

\section{Quinault (Philippe), poète lyrique.}

Par Caffieri; buste en plâtre. - H. 0,61 .

Né à Paris le 3 juin 163s̆, il fut avocat au parlement, auditeur de la Chambre des Comptes, et acheta une charge de valet de 
chambre du roi. Protégé dans sa jeunesse par Tristan l'Hermite, qui lui avait inspiré le goût de la poésie, Quinault composa pour Louis XIV un grand nombre de poèmes lyriques qui furent mis en musique par Lulli. Membre de l'Académie française en 1670, chevalier de l'ordre de Saint-Michel en 1673, et membre de l'Académie des Inscriptions et Belles-Lettres en 1674, Quinault mourut à Paris, le 26 novembre 1688.

Le buste original est à la bibliothèque de Sainte-Geneviève, à Paris.

\section{Lulli (Jean-Baptiste), surintendant de la mu- sique du roi.}

Par Cotron; buste en plâtre. - H. 0,75.

Né à Florence en 1633 , il vint à Paris dès l'âge de treize ans à la suite du chevalier de Guise, et fit d'abord partie des violons de la musique de mademoiselle de Montpensier. Auteur de la musique des intermèdes des pièces de Molière représentées sur le théâtre particulier de la cour, il fut nommé en 1661 surintendant de la musique du roi, et obtint en 1672 le privilége de l'Académie royale de musique. Lulli composa en quinze ans dix-neuf grands opéras, dont les paroles étaient le plus souvent fournies par Quinault, et mourut à Paris le 22 mars 1687.

Le buste original fait partie du monument élevé par la famille de Lulli dans l'église des Petits-Pères, à Paris.

\section{3, Le Sage (Alain-René), écrivain et auteur dramatique.}

Par M. Desboeufs en 1842 ; buste en plâtre. - H. 0,70.

Né à Sarzeau, près Vannes, le 8 mai 1668, il étudia chez les jésuites de cette ville en 1682, occupa une place dans les fermes en Bretagne, et vint à Paris en 1692. Recu avocat au parlement, il fit représenter en 1707, Crispin rival de son maître, publia la même année le Diable boiteux, composa en 1708 la comédie de Turcaret, et de 1715 à 1730 le roman de Gil Blas. Il se retira à Boulogne-sur-Her en 1745̆, et y mourut le 17 novembre 1747, à soixante-dix-neuf ans.

\section{La Chaussée (Pierre-Claude Nivelle de), au- teur dramatique,}

Par CAFfieri en 1786; buste en plâtre. - H. 0,70.

Né à Paris en 1692, il se fit connaitre en 1732 par une Epître à Clio, et ne commença à travailler pour le théâtre qu'à l'âge de quarante ans. Iembre de l'Académie française en 1736, il fit jouer 
VESTIBULE DE LA SALLE DE SPECTACLE, N 10 .

successivement, la Fausse Antipathie, le Prëjugé à la mode, l'École des Amis, l'Ecole des mères, etc. Il mourut à Paris le 14 mai 1754.

Le buste original est placé dans le foyer de la Comédie-Française, à Paris.

\section{5, Gluck (Christophe), musicien et compositeur.}

Par Francin; buste en plâtre. - H. 0,65.

Né en 1712 dans un village du Haut-Palatinat, sur les frontières de Bohême, il commença ses études à Vienne, et les continua à Milan, sous Martini. Il fit représenter, sur le théâtre de Milan, son premier ouvrage, Artaxerce, en 1741. Après avoir fait exécuter plusieurs opéras en Italie, il se rendit à Londres en 1745̆, et retourna ensuite à Vienne. Il vint à Paris en 1773, fut maître de musique de Marie-Antoinette, et donna ses opéras d'Iphigénie, d'Orphée et d'Armide, à l'occasion desquels s'éleva la querelle des Gluckistes et des Piccinistes. Gluck retourna à Vienne en 1780 , et y mourut le 15 novembre 1787.

La buste original exécuté par Francin, d'après un modèle de Houdon, est placé au Mlusée du Louvre.

\section{Beaumarchais (Pierre-Auguste Caron de), auteur dramatique.}

Par Du Pasquier en 1800; buste en plâtre. - H. 0,48.

Né à Paris le 24 janvier 1732, il était fils d'un horloger, et se distingua d'abord dans l'état de son père, en inventant une nouvelle espèce d'échappement. Il se livra ensuite à l'étude de la musique, et fut appelé à la cour pour donner des leçons de harpe et de guitare à Mesdames, filles de Louis XV. Il prit part aux opérations de finances de Pàris Duverney, soutint plusieurs procès pour lesquels il écrivit des Mémoires, et fit représenter, en 1767, Eugénie, son premier ouvrage dramatique. Il donna le Barbier de Séville en 1775, le Mariage de Figaro en 1784, et fut nommé, en 1789, membre provisoire de la commune de Paris. Beaumarchais mourut à Paris, le 19 mai 1799.

\section{Grétry (André-Ernest-Modeste), musicien et compositeur.}

Buste en plâtre. - H. 0,48.

Né à Liége le 11 février 1741, il fut d'abord enfant de chœur, se rendit à Rome à lâge de dix-huit ans, et y reçut les conseils de Casali et de Piccini. Il passa, à son retour, par Genève, se rendit à Paris, et donna, en $\mathbf{1 7 6 9}$, le Huron, dont les paroles étaient de Marmontel. Depuis cette époque, jusqu'en 1800, il donna, tant à l'Opéra-Comique qu'au Grand-Opéra, quarante- 
quatre ouvrages, et fut surnommé le Nolière de la musique. Il mourut à Montmorency le 24 septembre 1813.

\section{Ducis (Jean-François), poète tragique.}

Par TAUnaY; buste en plâtre. - H. 0,58.

Né à Versailles le 22 août 1733 , il fit ses études au collég'e de cette ville, puis destiné au barreau, il entra chez un procureur au Châtelet de Paris. Secrétaire du maréchal de Belle-Isle en 175̋6, il fut attaché en 1757 au ministère de la guerre, et fit un voyage en Allemagne comme secrétaire du comte de Montazet. Sa première tragédie, Amélise, fut représentée avec peu de succès en 1764, et c'est en 1769 qu'il commença par Hamlet la série de ses imitations de Shakespeare. Il donna successivement Roméo et Julielte en 1772, OEdipe chez Admète en 1778, le roi Lear en 1783, Jean sans Terre en 1791 et Othello en 1792. Il avait remplacé Voltaire à l'Académie française en 1778 et fut secrétaire des commandements du comte de Provence (depuis Louis XVIII). En 1795 il fit représenter Abufar, et en 1797 OEdipe à Colonne. Outre ses tragédies, Ducis a composé des épîtres et des poésies fugitives; on cite aussi sa correspondance avec Thomas. Chevalier de la Légion d'honneur en 1814, Ducis mourut à Versailles le 31 mars 1816, dans la quatre-vingt-troisième année de son âge.

Le buste original est dans le foyer de la Comédie-Française, à Paris.

\section{Baillot (Pierre-Marie-François de Sales), violo- niste et compositeur.}

Par M. BriaN; buste en marbre. - H. 0,61.

Né à Passy le $1^{\text {er }}$ octobre 1771, il reçut à Rome les leçons de Pollani et, à Paris, celles de Viotti. Professeur au Conservatoire en 1795 , il se rendit en Russie de $180 \preceq$ à 1808, et, à son retour, fut attaché à la musique de l'empereur, puis à la chapelle du roi. Baillot est l'auteur de l'Art du Violon et le fondateur de l'école française de violon. Il mourut à Paris le 15 septembre 1842.

\section{GALERIE No 16.}

Cette galerie servait autrefois de dégagement et de couloir de service pour les appartements du rez-de-chaussée de l'aile du Nord; à la place des niches pratiquées ris-à-vis des fenêtres, se trouvaient les baies des portes communiquant aux salles $n^{08} 2$ à 12 ; au milieu de cette galerie était l'entrée cie l'escalier de l'aile droite dont l'emplacement est occupé aujourd'hui par la salle n' 8 .

Le plus grand nombre des sculptures placées dans cette galerie a été moulé dans l'église de Saint-Denis. Le transport des tombeaux de Saint-Denis au Musée des Monuments français en 1793, et leur réintégration en 1816 avaient occasionné 
de nombreuses confusions et de graves erreurs dont la rectification est due à M. le baron de Guilhermy.

Les deux statues placées de chaque côté de la porte d'entrée ont été moulées d'après des figures provenant du portail de l'ancienne église de Notre-Dame de Corbeil, et placées depuis à Saint-Denis sous les noms de Clovis Ier et de sainte Clotilde; ces figures, qui ont été exécutées vers le XIIe siècle, représentent des personnages de l'Ancien ou du Nouveau-Testament. Les dix figures dont les pieds reposent sur des animaux fantastiques et qui se voient au milieu de la galerie, n'offrent pas plus d'authenticité. Celles qui portent en caractères gothiques les noms de Hugues Capet, Robert II, Louis VI et Louis VII, ont été moulées à la façade septentrionale de l'église de Saint-Denis; les quatre autres, de plus petite proportion, et qu'on a cru représenter saint Germain, sainte Geneviève, Childebert et Utrogothe, proviennent du portail de l'église de Saint-Germain-l'Auxerrois, à Paris.

\title{
240. Clovis $I I$, roi des Francs. (Voir no 663.)
}

\author{
Statue en plâtre. - H. 1,85.
}

La figure originale placée à Saint-Denis est une de celles exécutées par ordre de saint Louis, qui consacra à ses prédécesseurs seize tombeaux uniformément construits en pierre de liais et surmontés chacun d'une statue couchée; ces tombeaux furent achevés en 1264. "Il serait difficile d'admettre, dit M. le baron de Guilhermy, surtout pour les personnages les plus anciens, que les artistes qui les ont faites se soient guidés d'après quelques traditions sur la physionomie, sur la complexion ou même sur le costume des rois et reines dont il s'agissait de tailler la représentation. Ces figures exécutées en excellente pierre de liais, et qui se seraient conservées intactes si des barbares ne s'étaient avisés de les mutiler, ne sont donc pas des portraits. " (Monographie de l'Eglise royale de Saint-Denis. - 1848).

\section{Charles Martel, maire du palais.}

Buste en plâtre. - H. 0,60 .

Il fut maire du palàis sous le règne de Thierry IV, repoussa les invasions des Sarrasins et livra en 732 la bataille de Poitiers où il défit l'armée commandée par Abdérame. Le pape Grégoire III lui donna le titre de patrice de Rome, et après la mort de Thierry IV il gouverna la France pendant un interrègne de quatre années. Il mourut au palais de Quierzi-sur-Oise, le 22 octobre 741, et fut enterré à Saint-Denis.

Ce buste est moulé d'après la statue que saint Louis fit mettre sur le tombeau de Charles-Martel à Saint-Denis (Voir n² 240).

\section{Pépin-le-Bref, roi des Francs. (Voir nº63.)}

Statue en plâtre. - H. 1,84.

La figure originale est à Saint-Denis (Voir n²40).

\section{Berthe ou Bertrade, reine des Francs.}

Statue en plâtre. - H. 1,84.

La reine Berthe fut sacrée, en 75̋4, avec Pépin-le-Bref, son 
mari, dans l'église de Saint-Denis, et mourut à Choisy le 12 juillet 782.

La figure originale est à Saint-Denis (Noir $n^{0} 240$ ). Elle portait à tort le nom d'Ermentrude.

\section{Ermentrude, reine des Francs.}

Statue en plâtre. - H. 1,87.

Elle fut la première femme de Charles-le-Chauve, et mourut en 869 .

La figure originale est à Saint-Denis (Voir n² 240). Elle portait à tort le nom de Berthe.

\section{Louis $I I I$, roi de France. (Voir n678.)}

Statue en plâtre. - H. 1,86.

La figure originale est à Saint-Denis (Voir n²40). Elle portait à tort le nom de Carloman.

246. Carloman, roi de France. (Voir n 678.)

Statue en plâtre. - H. 1,83.

La figure originale est à Saint-Denis (Voir n² 240 ). Elle portait à tort le nom de Louis III.

247. Eudes, roi de France. (Voir n 680 .)

Statue en plâtre. - H. 1,85.

La figure originale est à Saint-Denis (Voir n²40).

248. Lothaire, roi de France. (Voir no 684 .)

Statue en plâtre. - H. 1,84.

Cette figure, dont l'original n'existe pas, est une imitation de celle de Hugues Capet placée à Saint-Denis.

249. Hugues Capet, roi de France. (Voir no 686 .)

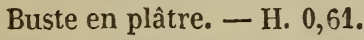

La statue originale est à Saint-Denis (Voir n²40).

250. Robert II, surnommé le Pieux, roi de France. (Voir n० 687.)

Statue en plâtre. - H. 1,84.

La figure originale est à Saint-Denis (Voir n² 240 ).

251. Constance d'Arles, reine de France. Statue en plâtre. - H. 1,85.

Constance, fille de Guillaume de Taillefer, comte de Provence, 
fut mariée en 998 à Robert-le-Pieux, et mourut au château de Melun en 1032.

La figure originale est à Saint-Denis (Voir no ${ }^{\circ} 40$ ).

\section{Henri $I^{e r}$, roi de France. (Voir n 688.)}

Statue en plâtre. - H. 1,83.

" La statue de ce prince, dit M. de Guilhermy, parait avoir été détruite en 1793 ; elle ne figure pas dans les catalogues des Petits-Augustins. Celle qui porte aujourd'hui le nom de Henri ${ }^{\text {er }}$ n'est autre chose que l'effigie de Carloman, frère de Charlemagne. " - Le moulage placé à Versailles rappelle la figure gravée dans Montfaucon (tome $I^{\mathrm{er}}$, pl. XXXIV), sous le nom de Henri I ${ }^{\mathrm{er}}$.

253. Louis VI, dit le Gros, roi de France. (Voir ${ }^{\circ}{ }^{690 .)}$ Statue en plâtre. - H. 1,84.

Moulage d'une figure moderne placée à Saint-Denis.

\section{Philippe de France.}

Statue en plâtre. - H. 1,80 .

Fils aîné de Louis-le-Gros, il fut couronné à Reims du vivant de son père. Il mourut à Paris d'une chute de cheval, le 13 octobre 1131, à l'âge de quinze ans. c On l'enterra, dit Suger, dans l'église du bienheureux Denis, dans le lieu réservé à la sépulture des rois, et à la gauche de l'autel de la Sainte-Trinité. »

La statue du prince Philippe et celle de la reine Constance de Castille sont les dernières de celles que saint Louis fit ériger dans l'église de Saint-Denis (Voir no 240).

\section{Louis VII, dit le Jeune, roi de France. (Voir nº 691.)} Statue en plâtre. - H. 1,84.

Moulage d'une figure moderne placée à Saint-Denis.

\section{Constance de Castille, reine de France.}

Statue en plâtre. - H. 1,81.

Fille aînée d'Alphonse VIII, roi de Castille, elle fut mariée à Orléans en $115 \mathrm{u}$ à Louis-le-Jeune et mourut en 1160.

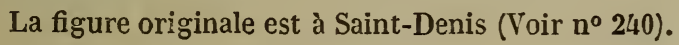

\section{Philippe II (Philippe-Auguste), roi de France. (Voir $\left.n^{\circ} 692.\right)$}

Par M. Aug. Dumont; statue en plâtre. - H. 2,10.

Modèle de la figure placée sur une des colonnes de la barrière du Trône à Paris.

258. Louis VIII, dit le Lion, roi de France. (Voir no ${ }^{693 .)}$

Par M. OUdiNé; buste en marbre. - H. 0,55.

Ce buste a été exécuté d'après une tête placée à Saint-Denis sous le nom de Louis VIII, mais qui n'offre aucun caractère d'authenticité. 
259. Robert de France, comte d'Artois. (Voir n ${ }^{\circ 57 .)}$ Par Pradier; statue en plâtre. - H. 2,25.

260. Plitippe III, surnommé le Hardi, roi de France. (Voir $\mathrm{n}^{\circ}$ 695.)

Par M. Heśson; buste en marbre. - H. 0,60.

La statue qui existe à Saint-Denis, et d'après laquelle ce buste a été exécuté, ouvre, suivant l'opinion de M. de Guilhermy, la série authentique des portraits de nos rois.

\section{Isabelle d'A ragon, reine de France.}

Par M. Auguste BARRE; buste en marbre. - H. 0,56.

Mariée en 1262 à Philippe-le-Hardi, alors duc d'Anjou, elle le suivit à la sixième croisade en 1270 , et mourut au retour, à Cosenza en Calabre, le 28 janvier 1271, âgée de vingt-quatre ans.

La statue originale est à Saint-Denis.

262. Pierre de France, comte d'Alençon.

Par MatTE; buste en marbre. - H. 0,52.

Cinquième fils de saint Louis, il l'accompagna au siége de Tunis en 1270, et fut tué à la Catona en 1283.

Ce buste a été exécuté d'après une statue provenant de l'église des Cordeliers de Paris et placée ensuite au Musée des Monuments français, puis à Saint-Denis, sous le nom de Pierre de France.

\section{Blanche de France.}

Buste en plâtre. - H. 0,56.

Blanche, fille de saint Louis, naquit à Jaffa en Syrie en 1232 et fut mariée à Burgos en 1269 à l'infant de la Cerda. Elle fit bâtir l'église et une partie du couvent des Cordeliers du faubourg Saint-IIarcel, où elle mourut le 22 juin 1320, âgée de soixantehuit ans.

La statue originale, provenant de l'église des Cordeliers de Paris, a été transportée au Musée des Monuments français, puis à Saint-Denis.

264. Philippe IV (Philippe-le-Bel), roi de France. (Voir $n^{\circ}$ 696.)

Par M. BRION; buste en marbre, - H. 0,62.

La statue originale est à Saint-Denis.

265. Charles de France, comte de Valois.

Buste en plâtre. - H. 0,57.

Troisième fils de Philippe-le-Hardi, il naquit en 1270. Il fit la 
guerre contre les Anglais ei les Flamands dans les années 1296 , 1297 et 1299, et reprit aux Anglais en 1322, tout le pays situé entre la Dordogne et la Garonne. Il mourut en 1325 à Nogentle-Roi et fut enterré à Saint-Denis. - Charles de France fut le chef de la branche des Valois.

La figure originale, provenant de l'église des Jacobins de Paris, figurait au Musée des Monuments français sous le nom de Robert de France, fils de saint Louis, et se trouve actuellement à Saint-Denis.

\section{Catherine de Courtenay, impératrice titulaire de Constantinople.}

Buste en plâtre. $=$ H. 1,57.

Fille unique de Philippe de Courtenay, empereur de Constantinople, elle prit le titre d'impératrice en 1300 , et elle épousa Charles de France, comte de Valois, dont elle fut la seconde femme. Le continuateur de Guillaume de Nangis dit qu'elle mourut au village de Saint-Ouen, le 8 octobre 1307, et qu'elle fut enterrée le jeudi suivant en l'église des Jacobins de Paris, en présence du roi.

Ce buste a été moulé d'après une figure en marbre noir, provenant de l'abbaye de Maubuisson, transportée au Musée des Monuments français sous le nom de Blanche de Castille, puis à Saint-Denis.

\section{Louis de France, comte d'Evreux.}

Buste en plâtre. - H. 0,55.

Il était fils de Philippe-le-Hardi, et se trouva à la bataille de Mons-en-Puelle en 1304. Il accompagna en 1315 Louis-le-Hutin, son neveu, dans l'expédition de Flandre, et mourut à Paris, le 19 mai 1319 , âgé de quarante-trois ans.

La statue originale, provenant de l'église des Jacobins de Paris, a été transportée du Musée des Monuments français à Saint-Denis, où elle portait par erreur le nom de Charles de France.

\section{Marguerite d'Artois, comtesse d'Évreux.}

Buste en plâtre. - H. 0,55 .

Marguerite d'Artois, dame de Brie-Comte-Robert, fille ainée de Philippe d'Artois, seigneur de Conches, épousa en 1300 Louis de France, comte d'Evreux, et mourut en 1311. Son tombeau et celui de son mari étaient placés au milieu du chœur de l'église des Jacobins de Paris.

La statue originale provient également des Jacobins: transportée du Musée des Monuments français à Saint-Denis, elle y était faussement désignée sous le nom de Blanche de Navarre, seconde femme de Philippe de Valois. 
269. Louis $\mathbf{X}$, dit le Hutin, roi de France. (Voir nº97.)

Par M. LESCORNÉ; buste en marbre. - H. 0,60.

La staiue originale est à Saint-Denis.

\section{Clémence de Hongrie, reine de France.}

Buste en plâtre. - H. 0,60 .

Fille de Charles d'Anjou, surnommé Martel, roi de Hongrie, elle épousa en 1315 Louis-le-Hutin, dont elle fut la seconde femme, et fut couronnée avec lui à Reims, la même année. Elle mourut à Paris, à l'hôtel du Temple, le 12 octobre 1328, et fut enterrée dans le chœur de l'église des Jacobins.

La statue originale provenant des Jacobins de Paris, a été transportée à Saint-Denis où elle a été aussi désignée sous le nom de Bonne de Luxembourg.

\section{Philippe $V$, surnommé le Long, roi de France. ( Voir $\left.\mathrm{n}^{\circ} 698.\right)$}

Par M. LANNo; buste en marbre. - H. 0,71.

La statue originale est à Saint-Denis.

\section{Charles IV, dit le Bel, roi de France. (Voir n• 698.)}

Par GaYrard père; buste en marbre. - H. 9,57.

La statue originale est à Saint-Denis.

\section{Jeanne d'Évreux, reine de France.}

Buste en plâtre. - H. 0,54.

Jeanne d'Évreux, qui avait épousé en 1324 Charles-le-Bel, fut couronnée à Paris en $\mathbf{1 3 2 6}$, et mourut à Brie-Comte-Robert en 1371, quarante-trois ans après son mari. Elle fut enterrée à Saint-Denis.

La figure originale est à Saint-Denis.

\section{Charles d'Évreux, comte d'Étampes.}

Buste en plâtre. - H. 0,54.

Fils de Louis de France, comte d'Évreux, il fut un des seigneurs français qui marchèrent en 1333 au secours du duc de Brabant, contre le comte de Flandre. Il prit aussi le parti de Jean II de Châlons, comte d'Auxerre, dans la guerre qu'il eut avec Eudes IV, duc de Bourgogne. Il y périt en faisant le siége de Pimorin, le $ّ$ septembre 1336, et fut enterré dans l'église des Cordeliers de Paris. - Charles-le-Bel érigea en sa faveur le comté d'Etampes en duché-pairie.

La statue originale était dans l'église des Cordeliers; transportée au Musée des 
Monuments français, puis à Saint-Denis, elle portait par erreur le nom et le titre de Louis de France, père de Charles d'Evreux.

\section{Marie d'Espagne, comtesse d'Etampes, puis d'Alençon.}

Par M. Meraier; buste en marbre. - H. 0,55.

Fille de Ferdinand d'Espagne, dit de la Cerda, elle fut mariée en 1335 à Charles d'Evreux, comte d'Etampes, et en 1336 à Charles de Valois, comte d'Alençon. Elle mourut en 1389.

La statue originale, provenant de l'église des Jacobins de Paris, a été transportée au Musée des Monuments français, puis à Saint-Denis, où elle portait par erreur le nom de Jeanne de Bourgogne, femme de Philippe-le-Long.

\section{Philippe VI (Philippe de Valois), roi de France.} ( Voir no 700.)

Statue couchée ; marbre. - Long. 1,74.

Le corps de ce prince fut enterré à Saint-Denis, son cœur à Bourg-Fontaine, et ses entrailles dans le couvent des Jacobins de Paris.

Cette figure est celle qui se trouvait dans la chapelle des Bourbons, au courent des Jacolsins de la rue Saint-Jacques; elle est décrite et gravée dans les Antiquités nationales de Millin, tome IV, no $39, \mathrm{pl}$. 6. Philippe VI est vêtu d'un ample manteau qui recouvre une tunique, et presse sur son sein, avec la main gauche, un espèce de paquet par lequel les sculpteurs de ce temps désignaient les entrailles. La main droite qui tient le sceptre a été refaite précisément à l'endroit où Millin indique une cassure; la couronne a été égaleınent refaite. M. de Guilhermy signale cette figure comme devant représenter Philippe de Valois et non Jean le Bon. (Monographie de Saint-Denis, p. 281.)

\section{Blanche de Navarre, reine de France.}

Buste en plâtre. - H. 0,53 .

Elle était fille de Philippe d'Évreux, roi de Navarre, et avait été accordée en 1345 à Pierre, infant de Castille; mais cette alliance n'eut pas lieu. Blanche d'Evreux épousa en 1349 Philippe de Valois, dont elle fut la seconde femme; elle mourut à Neauphlele-Châtel en 1398, et fut enterrée à Saint-Denis.

La statue originale est à Saint-Denis et portait à tort le nom de Clémence de Hongrie.

\section{Marguerite de France, comtesse de Flandre.}

Buste en plâtre. - H. 0,52 .

Fille du roi Philippe $\mathrm{V}$ et veuve de Louis II, comte de Flandre, tué à la bataille de Crécy, en 1346. Elle mourut le 9 mai 1382, âgée de soixante-douze ans, et fut enterrée à Saint-Denis, dans la chapelle de Saint-Michel, qu'elle avait fondée.

La statue originale est à Saint-Denis. Ce buste a été faussement désigné sous le nom de Marguerite de Flandre, duchesse de Bourgogne. 
279. Chanac (Guillaume de), évêque de Paris. Statue couchée; marbre. - Long. 1,94.

D'abord archidiacre et ensuite évêque de Paris, en 1332, patriarche d'Alexandrie en 1342, Guillaume de Chanac fonda à Paris un collége connu sous le nom de collége de Pompadour, ou de Saint-Michel. Il y mourut le 3 mai 1348, âgé d'environ cent ans.

Cette statue provient de l'église de Saint-Victor, à Paris. - Lenoir, no 50, pl. 67.

280. Jean II, dit le Bon, roi de France. (Voir no 701.)

Buste en plâtre. - H. 0,66 .

La statue originale est à Saint-Denis.

281. Jean d'Artois, comte d'Eu.

Statue coucliée; plâtre. - Long. 1,80.

Il fut fait chevalier en 13500 , au sacre du roi Jean, qui lui donna le comté d'Eu, combattit à Poitiers en 13206 , et accompagna le roi Charles $\mathrm{V}$ dans les guerres de Picardie. Le comte d'Eu servit encore en Flandre, sous Charles VI, en 1382, commanda l'arrière-garde à la bataille de Rosebecque en 1386 , et mourut la même année à soixante-cing ans. Il fut enterré dans l'église de Notre-Dame d'Eu.

La figure originale est dans l'église d'Eu.

282. Isabelle de Melun, comtesse d'Eu.

Buste en plâtre. - 0,53.

Elle était veuve de Pierre de Dreux, seigneur de Montpensier, lorsqu'elle épousa, en 1352, Jean d'Artois, comte d'Eu.Elle mourut au château de Monceaux (comté d'Eu) en décembre 1389.

La statue originale est dans l'église d'Eu.

\section{Charles $V$, roi de France. (Voir no 702.$)$}

Statue en plâtre. - H. 1,88.

Les statues en pierre de Charles $\mathrm{V}$ et de Jeanne de Bourbon étaient placées au portail de l'église des Célestins de Paris; transportées au Musée des Monuments français, puis à Saint-Denis, sous les noms de saint Louis et de Marguerite de Provence, elles ont repris leur véritable dénomination.

284. Charles V, roi de France. (Voir no 702.$)$

Buste en plâtre. - H. 0,53 .

La statue originale est à Saint-Denis. 
285. Jeanne de Bourbon, reine de France.

Statue en plâtre. - H. 1,85.

Fille de Pierre, duc de Bourbon, elle épousa à Tain près de Lyon, en 13ä0, le roi Charles V, et mourut à Paris en 1377, à l'âge de quarante ans. Elle fut enterrée à Saint-Denis.

La figure originale, provenant du portail des Célestins, est à Saint-Denis. (Voir $n^{\circ} 283$. )

286. Jeanne de Bourbon, reine de France.

Par M. Mercier; buste en marbre. - H. 0,60.

La statue originale est à Saint-Denis.

\section{Marie de Bourbon, abbesse de Saint-Louis de Poissy.}

Buste en plâtre. - H. 0,57.

Fille puinée du duc Pierre de Bourbon et sœur de la reine Jeanne, elle fut nommée en 1380 prieure du monastère de Poissy, où elle avait reçu le voile en $135 \% 1$. Elle mourut le 10 janvier 1401 et fut inhumée dans le chœur de l'église conventuelle.

La figure originale provenant du monastère de Saint-Louis de Poissy est à Saint-Denis.

288. Philippe d'Artois, comte d'Eu, connétable de France. (Voir n $\left.{ }^{\circ} 946.\right)$

Statue couchée; plâtre. - Long. 1,85.

La figure originale est dans l'église d'Eu.

289. Isabelle d'Artois.

Buste en plâtre. - H. 0,58.

Isabelle, fille de Jean d'Artois, comte d'Eu, mourut en 1379, à l'âge de dix-huit ans.

La statue originale est dans l'église d'Eu.

290. Du Guesclin (Bertrand), connétable de France. (Voir no 944.)

Buste en plâtre. - H. 0,53.

La statue originale est à Saint-Denis.

291. Braque (Nicolas de), trésorier de France. Buste en plâtre. - H. 0,54.

Maître des comptes et de l'hôtel du roi, il siégea aux États- 
GALERIE No 16.

Généraux de Paris, en 13อ̆6, fut chambellan et gouverneur du château de Vincennes, ambassadeur plénipotentiaire sous Charles V, et reçut en 1384 plusieurs donations de Charles VI.

Le buste original provenant du couvent des Pères de la Merci se trouvait au Musée des Monuments français, sous le $\mathbf{n}^{\circ} 67$.

\section{Léon $\boldsymbol{V}$ de Lusignan, roi d'Arménie.}

Buste en plâtre. - H. 0,55.

Léon de Lusignan, dernier roi de la petite Arménie, après avoir perdu ses états, vint en France en 1378, et mourut au palais des Tournelles, à Paris, le 29 novembre 1393.

Charles VI avait fait inhumer Léon de Lusignan dans l'église des Célestins, et a statue provenant de ce tombeau est placée aujourd'hui à Saint-Denis.

293. Charles VI, roi de France. (voir no 703.)

Buste en plâtre. - H. 0,56 .

La statue originale est à Saint-Denis.

294. Isabeau ou Isabel de Bavière, reine de France. Buste en plâtre. - H. 0,58.

Fille d'Étienne II, duc de Bavière, elle épousa en 1385, à Amiens, le roi Charles VI, et mourut le 30 septembre 1435 , à soixantequatorze ans. Elle fut enterrée à Saint-Denis.

La statue originale est à Saint-Denis.

\section{Louis de France, duc d'Orléans.}

Statue couchée; plâtre. - L. 1,78.

Il porta d'abord le titre de comte de Valois, et accompagna, en 1382, son frère Charles VI à la bataille de Rosebecque. Duc d'Orléans en 1392, surintendant des finances et gouverneur du royaume en 1402, il fut assassiné par ordre de Jean-sans-Peur, le 23 novembre 1407, dans la rue Barbette, à Paris.

Le roi Louis XII, qui était petit-fils de ce prince, lui érigea, en 1504, dans l'église des Célestius, un mausolée dans lequel il fit inhumer aussi les corps de son aïeule, Valentine de Milan, de son père, Charles, duc d'Orléans, et de son oncle, Philippe, comte de Vertus. Les statues provenant de ce monument sont placées à Saint-Denis.

\section{Valentine de Milan, duchesse d'Orléans.}

Statue couchée; plâtre. - L. 1,73.

Fille de Jean Galéas Visconti, duc de Milan, elle épousa, à Melun, en 1389, Louis de France, alors duc de Valois. Après l'assassinat de son mari, elle alla, entourée de ses enfants en deuil, 
demander justice au roi Charles VI, et mourut au château de Blois le 4. novembre 1408.

La statue originale est à Saint-Denis (Voir no 295).

297. Pierre de Navarre, comte de Mortain.

Buste en plâtre. - H. 0,53.

Charles VI érigea la terre de Mortain en comté, en faveur de Pierre de Navarre, fils du roi Charles-le-Mauvais. Il accompagna le roi au siége de Bourges, en 1412, et mourut dans cette ville le 29 juillet de la même année.

Pierre de Navarre, et sa femme Catherine d'Alençon, furent enterrés dans l'église des Chartreux, oà se voyaient leurs statues couchées. Ces deux figures sont au Musée du Louvre.

\section{Dormans (Jean de), chanoine de Paris.}

Statue couchée; pierre (1).:- Long. 1,72.

Il fut chanoine de Paris et de Chartres, et chancelier de l'église de Beauvais. Il mourut à Sens en 1380 .

Piganiol de la Force rapporte que dans la chapelle du collége de Beauvais, à Paris, fondée en 1370 par le cardinal Jean de Dormans, on voyait six statues de pierre de la famille de Dormans.

\section{Dormans (Renaud de), chanoine de Paris.}

Statue couchée; pierre (1). - Long. 1,80.

Il fut archidiacre de Châlons-sur-Marne, chanoine de Paris, de Chartres et de Soissons, et maître des requêtes. Il mourut à Paris en mai 1386.

Cette figure et la précédente proviennent de la chapelle du collége de Beauvais, à Paris.

300. Bureau de la Rivière (Charles).

Buste en plâtre. - H. 0,55 .

Premier chambellan des rois Charles V et Charles VI, il fut, en 1388, un des principaux ministres. Bureau de la Rivière mourut le 16 août 1400 , et fut enterré à Saint-Denis aux pieds du roi Charles V, qui l'avait ainsi ordonné de son vivant.

La statue de Bureau de la Rivière fut détruite en 1793. Celle qui se trouve à Saint-Denis avait été refaite au Musée des Monuments français avec divers fragments.

301. Sancerre (Louis de Champagne, comte de), connétable de France. (Voir no 948 .)

Buste en plâtre. - H. 0,53.

La statue originale est à Saint-Denis.

(1) Le masque et les mains des nos 298 et 299 sont en marbre. 


\section{Charles VII, roi de France. (Voir n ${ }^{\circ 03 .)}$}

Buste en plâtre. - H. 0,63 .

La statue originale est à Saint-Denis.

303. Marie d'Anjou, reine de France.

Buste en plâtre. - I1. 0,65.

Fille de Louis d'Anjou, roi de Sicile, elle fut mariée en 1422 à Charles VII, et mourut en 1463 à l'abbaye de Châteliers, en Poitou. Son corps fut transporté à Saint-Denis.

La statue originale est à Saint-Denis.

\section{Charles d'Orléans, duc d'Orléans et de Milan.}

Statue couchée; plâtre. - Long. 1,85.

Fils aîné de Louis, duc d'Orléans, et de Valentine de Milan, il naquit à l'hôtel Saint-Pol, à Paris, en 1391, et porta d'abord lẹ titre de comte d'Angoulême; il prit celui de duc d'Orléans après la mort de son père, et à la suite de la bataille d'Azincourt, où il fut fait prisonnier, il resta vingt-cing ans en Angleterre. A son retour en France, en 1440, le duc d'Orléans porta la guerre en Italie pour faire valoir ses droits au duché de Milan; il assistait, en 1464, aux états de Tours. Le duc d'Orléans cultivait la poésie avec une grande supériorité; c'est, dit M. Villemain, le plus heureux génie qui soit né en France à cette époque. Il mourut à Amboise le 4 janvier 1465 .

La figure originale est à Saint-Denis (Voir $n^{\circ} 295$ ).

\section{Philippe d'Orléans, comte de Vertus.}

Buste en plâtre. - H. 0,55 .

Quatrième fils de Louis, duc d'Orléans, il fit les guerres de 1414, sous Charles VI, en Picardie et en Artois, commanda en 1418 l'armée du roi, en Poitou, et mourut en 1420, à l'âge de vingt-quatre ans.

La statue originale est à Saint-Denis (Voir $n^{\circ} 295$ ).

306. Charles d'Artois, comte d'Eu.

Statue couchée; plâtre. - Long. 1,76.

Il se trouva, en 1415 , à la bataille d'Azincourt, où il fut fait prisonnier, et resta captif en Angleterre pendant vingt-trois ans. Charles d'Artois prit part aux guerres de Charles VII contre les Anglais, en 1441, 14 כั0 et 14อ33; créé lieutenant général en Normandie et en Guyenne en 145ัo, pair de France en 1458, il fut 
gouverneur de Paris en 146วั, et mourut le 15 juillet 1472. Il fut enterré dans le chœur de l'abbaye d'Eu.

La figure originale est dans l'église d'Eu.

\section{Jeanne de Saveuse, comtesse d'Eu.}

Par M. Oddine; buste en marbre. - H. 0,55.

Mariée en 1448 à Charles d'Artois, comte d'Eu, dont elle fut la première femme, elle mourut au chàteau de Sancerre le 2 janvier 1449.

La figure originale est dans l'église d'Eu.

\section{Hélène de Melun, comtesse d’Eu.}

Buste en plâtre. - H. 0,52 .

Seconde femme de Charles d'Artois, comte d'Eu; elle fut mariée en $145 \%$ et mourut le 25 juillet 1472 .

La figure originale est dans l'église d'Eu.

\section{Du Châtel (Guillaume).}

Buste en plâtre. - H. 0,55 .

Guillaume Du Châtel, pannetier de Charles VII et écuyer du dauphin, fut tué au siége de Pontoise le 20 juillet 1441. Charles VII le fit enterrer dans l'église de Saint-Denis. - Il était neveu de Tanneguy Du Châtel, prévôt de Paris.

La statue originale est à Saint-Denis.

\section{Louis XI, roi de France. (Voir n 704.$)$}

Par Michel Borridin; statue à genoux; plâtre. - H. 1,30.

Louis XI avait été enterré dans l'église collégiale de Notre-Dame-de-Cléry. Au $\mathrm{XVI}^{\mathrm{e}}$ siècle les calvinistes détruisirent son tombeau en bronze et jetèrent les restes de son corps dans la Loire. Louis XIII lui fit élever dans la même église un nouveau monument en 1622. - On lit sur le coussin de la statue : MICHAEL BOVRDIN AVRELIANENSIS 1622.

\section{Mausolée de Ferdinand $V$ et d'Isabelle de Castille.}

Plâtre. - H. 2,12. - L. 3,34. - Long. 3,92.

Ferdinand V, roi d'Aragou et de Sicile, épousa en 1469 Isabelle, héritière du royaume de Castille, et réunit ainsi sous ses lois presque toute l'Espagne. Sous le règne de Ferdinand et d'Isabelle, les Maures perdirent tout ce qui leur restait encore de leurs conquêtes en Espagne, et après la prise de Grenade, en 1492, la Péninsule tout entière retomba sous la domination des Chrétiens. Ferdinand V mourut en 15016 et Isabelle en 1 כ̋0'.

Les angles de la base sont ornés de quatre griffons; au centre de chacune des 
faces se trouve un bas-relief circulaire représentant : saint Jacques combattant les Maures; - le baptême de J.-C. ; - saint Georges terrassant le dragon; J.-C. sortant du tombeau. Ces bas-reliefs sont accompagnés des figures des douze apôtres. Aux angles de la frise sont les quatre docteurs de l'église: saint Ambroise, saint Augustin, saint Jérôme et saint Grégoire-le-Grand; au centre de la façade principale deux anges souliennent un cartouche sur lequel est tracée une inscription; dans les trois autres côtés les anges portent un écusson écartelé aux armes de Castille et d'Aragon, le reste de la frise est décoré de figures et d'ornements symboliques. Sur la plate-forme supérieure sont les statues couchées de Ferdinand et d'Isabelle; leur tête repose sur des coussins, à leurs pieds sont des lions.

Ce monument du XVI ${ }^{\mathbf{e}}$ siècle a été moulé d'après le tombeau placé dans la chapelle royale de l'église de l'Ange-Gardien, à Grenade. "La Real Capella, dit Antonio Conca, forme pour ainsi dire une autre église, parce que ce furent les rois catholiques qui la firent construire et que c'est aussi le lieu de leur sépulture. Il y règne partout une grande profusion d'ornements sculptés. Ceux de l'autel, et particulièrement les statues, qui sont en grand nombre et fort estimées, ont pour auteur Philippe de Bourgogne... Il faut surtout examiner le mausolée des rois catholiques don Ferdinand et dona Isabelle exécuté en albàtre, orné de statues d'anges et de saints et d'un grand nombre de figures en rondebosse. (Descrizione odeporica della Spagna. - 1797.)

On lit sur le cartouche de la façade principale:

MAIIOMETICE. SECTE. PROSTRA
TORES. ET. HERETICE. PERVICACIE.
EXTINGTORES. FERNANDUS. ARAGO
NVM. ET. HELISABETHA. GASTELLE.
VIR. ET VXOR. VNANIMES. GATHO
LIGI APPELLATI. HARMOREO. GLA
VDVNTVR. HOC. TVMVLO.

Voici le sens de cette inscription : Destructeurs de la secte de Mahomet, exterminateurs du fanatisme des hérétiques, Ferdinand d'Aragon et Isabelle de Castille, époux et épouse animés du. même zèle, surnommés les Catholiques, sont renfermés sous ce tombeau de marbre.

\section{Louis XII, roi de France. (Voị no 706.)}

Par Jean Juste; statue à genoux; plâtre. - H. 1,34.

La figure originale fait partie du tombeau érigé par François Ier à Louis XII et à Anne de Bretagne, dans l'église de Saint-Denis. Ce monument fut exécuté à Tours, vers 1530, par Jean Juste, artiste de cette ville; c'est à tort que quelques auteurs ont prétendu qu'il fut fait à Venise par Paul Ponce Trebati, sculpteur italien.

\section{Anne de Bretagne, reine de France. (Voir no 41.)}

Par Jean Juste; statue à genoux; plâtre. - H. 1,34.

La figure originale est à Saint-Denis (Voir $n^{\circ} 312$ ).

\section{Georges d'Amboise, cardinal, archevêque de Rouen.}

Statue à genoux ; plâtre. - H. 1,49.

Georges d'Amboise naquit au château de Chaumont sur Loire 3n 1460 et fut évêque de Montauban en 1484, à l'âge de quatorze ans. Aumônier du roi Louis XI, archevêque de Narbonne et ensuite 
de Rouen en 1493, il fut nommé cardinal par le pape Alexandre VI. Premier ministre de Louis XII en 1498, légat du pape en France en 1499, il mourut dans le couvent des Célestins, à Lyon, le 25 mai 1510 , à l'âge de cinquante ans.

La figure originale est dans la cathédrale de Rouen.

\section{Francois $I^{\text {er }}$, roi de France. (Voir $n^{\circ}$ 708.)}

Par P. Bontemps; statue à genoux; plâtre. - H. 1,52.

Cette figure est placée, ainsi que les quatre suivantes, sur la plate-forme supérieure du monument que Henri II fit élever en 1552 dans l'église de Saint-Denis, à François Ier, à la reine Claude et à leurs enfants.

\section{Claude de France, reine de France.}

\section{Statue à genoux ; plâtre. - H. 1,37.}

Claude de France, fille de Louis XII et d'Anne, duchesse de Bretagne, apporta en dot à Francois I ${ }^{\text {er }}$, alors comte de Valois, le duché de Bretagne, les comtés de Blois, de Coucy, de Montfort, ainsi que ses droits au duché de Milan. Elle fut couronnée reine de France à Saint-Denis en 1517 et mourut au château de Blois le 20 juillet 1524, à l'âge de vingt-cinq ans.

La figure originale est à Saint-Denis (Voir $\mathrm{n}^{\circ} 315$ ).

\section{François de France, dauphin de Viennois et duc de Bretagne.}

Par P. Bontenps; statue à genoux; plâtre. - H. 1,30.

Fils aîné de Francois Ier et de la reine Claude, il fut couronné duc de Bretagne à Rennes en $\mathbf{1 5 2 2}$, et mourut au château de Tournon le 12 août 1536, à l'âge de dix-huit ans.

La figure originale est à Saint-Denis (Voir no 315 ).

\section{Charles de France, duc d'Orléans.}

Par P. Bontemps; statue à genoux; plâtre. - H. 1,33.

Francois Ier, son père, lui donna, en 1540 , pour apanage, les duchés d'Orléans et d'Angoulême. Il commanda, en 1542, l'armée envoyée dans le Luxembourg contre Charles-Quint, et mourut, le 9 septembre 1545, à l'abbaye de Forestmoutier, près d'Abbeville, à l'àge de vingt-trois ans.

La figure originale est à Saint-Denis (Voir $n^{\circ} 315$ ).

\section{Charlotte de France.}

Statue à genoux; plâtre. - H. 1,24.

Fille de François $\mathrm{I}^{\mathrm{er}}$ et de la reine Claude, elle mourut au château de Blois, le 8 septembre 1524, à l'âge de huit ans.

La figure originale est à Saint-Denis (Voir $n^{\circ} 315$ ). 


\section{Georges d'Amboise, $I I^{e} d u$ nom, cardinal et archevêque de Rouen.}

Statue à genoux; plâtre. - H. 1,55.

Neveu du premier cardinal d'Amboise, il fut nommé archevêque de Rouen après la mort de son oncle, en 15110 , et mourut le 2 כั aoùt 150 ö0. Il fut enterré, dit le père Anselme, auprès de son oncle, derrière le chœur de l'église cathédrale de Rouen, où se voit leur sépulture.

La figure originale est dans la cathédrale de Rouen.

321. Villiers de lisle-Adam (Philippe), $42^{\mathrm{e}}$ grandmaître de l'ordre de Malte. (Voir no 466.)

Statue couchée; plâtrẹ. - Long. $1,90$.

La figure originale est dans l'église de Saint-Jean, à Malte.

322. Jouy (Jean d'Escoubleau, sire de), gentilhomme ordinaire de la chambre du roi.

Statue à genoux; marbre. - H. 1,37.

Il fut chevalier de l'ordre de Saint-Michel, maître de la garderobe du roi François Ier, et mourut en 1562.

Cette figure et la suivante étaient placées autrefois dans la chapelle seigneuriale de Jouy.

323. Jouy (Antoinette de Brives, dame de).

Statue à genoux; marbre. - H. 1,26.

Elle fut mariée en 1528 à Jean d'Escoubleau, sire de Jouy, maître de la garde-robe du roi François I ${ }^{\text {er. }}$

324. Henri II, roi de France. (Voir no 709.)

Par Germain Pilon; statue couchée; plâtre. - Long. 2,07.

Cette figure et celle de Catherine de Médicis, exécutées en marbre par Germain Pilon, étaient restées après sa mort, entre les mains des héritiers de l'artiste, et ce ne fut qu'à l'époque du décès cie Catherine de Médicis, qui les avait fait faire, qu'elles furent apportées à Saint-renis par ordre du parlement de Paris.

325. Catherine de Médicis, reine de France.

Par Germain Pilov; statue couchée; plâtre. - L. 1,92.

Catherine de Médicis, fille de Laurent II, duć d'Urbin, née à Florence le 13 avril 1อ̆19, avait été naturalisée française l'année même de sa naissance. Son mariage avec Henri II, roi de France, alors duc d'Orléans, fut conclu à Marseille en 1533, lors de l'en- 
trevue du pape Clément VII et de François I ${ }^{\text {er }}$. Elle fut couronnée à Saint-Denis le 10 juin 1549 et fut trois fois régente : la première en 1552 , pendant un voyage de Henri II en Lorraine; la seconde pendant la minorité de Charles IX, depuis l'année 1560 jusqu'en 1563; et la dernière après la mort de Charles IX, jusqu'au moment de l'arrivée de Henri III. Elle mourut au château de Blois le $\breve{5}$ janvier 1589, à l'âge de soixante-dix ans.

La figure originale est à Saint-Denis (Voir $\mathrm{n}^{\circ} 324$ ).

\section{Birague (René de), chancelier de France, car- dinal, évêque de Lavaur.}

Par Germain PILon; statue à genoux; plâtre. - H. 1,40.

Birague, né à Milan en 1506 , d'une famille de cette ville attachée à la France, fut nommé, par François I ${ }^{\mathrm{er}}$, conseiller au parlement de Paris et membre de son conseil privé; après la conquête du Piémont, il fut surintendant de la justice et président du sénat de Turin. Garde des sceaux en 1570, chancelier de France en 1573 , il fut créé cardinal en 1578 , et reçut l'ordre du Saint-Esprit. Evêque de Lavaur, abbé de Flavigny, il mourut à Paris le 24 novembre 1583, à l'âge de soixante-seize ans.

Le tombeau du chancelier de Birague et de sa femme était placé autrefois dans l'église de Sainte-Catherine du Val des Ecoliers; il se trouve aujourd'hui au Musée du Louvre. La statue de Birague est en bronze, et celle de Valentine est en marbre blanc. - V. nos 113 et 117 de la Description des sculptures modernes, par M. Barbet de Jouy.

\section{Birague (Valentine Balbiano, dame de).}

Par Germain PILoN; statue couchée; plâtre. - Long. 1,75.

Elle fut mariée à René de Birague et mourut en 1572. Birague entra alors dans les ordres, et devint cardinal et évêque de Lavaur.

\section{Diane de Poitiers, duchesse de Valentinois.}

Par Michel Bourdin; statue à genoux; plâtre. - H. 1,40.

Fille de Jean de Poitiers, comte de Saint-Vallier, née en 1500 , elle épousa à l'âge de treize ans Louis de Brezé, grand-sénéchal de Normandie. Veuve en $\mathbf{1 5 3 1}$, elle fut la maîtresse de Henri II qui la fit duchesse de Valentinois en 15\%48. A la mort de Henri II, en 1559 , elle se retira au château d'Anet, et y mourut le 26 avril 1566 .

La statue originale faisait partie du monument élevé à Diane de Poitiers par ordre de Louise de Brezé, sa fille, dans une chapelle du château d'Anet. Ce monument, transporté au Musée des Monuments français, puis dans un pavillon du parc du Neuilly, a été mutilé en 1848 et se trouve aujourd'hui au Musée de Versailles, vestibule $n^{\circ} 64$. 


\section{Loubenx de Verdale (Hugues de), $50^{\circ}$ grand- maître de l'ordre de Malte.}

Statue couchée; plâtre. - Long. 1,9'.

Chevalier d'une maison distinguée de Languedoc, au diocèse de Lavaur, grand-commandeur et prieur de Toulouse, il fut élu grand-maître en 1582. Les séditions qui éclatèrent dans le couvent de l'ordre l'obligèrent à se rendre deux fois à Rome, et il fut nommé cardinal par Sixte-Quint. Il mourut à Rome le 4 mai 1595.

La figure originale est dans l'église de Saint-Jean, à Malte.

\section{Angennes (N. d'), seigneur de Rambouillet.}

Statue à genoux; marbre. - H. 1,33.

Ce personnage est représenté agenouillé sur un coussin, la tête nue et les mains jointes; il est revêtu d'une cotte de mailles que recouvre une casaque aux armes de la maison d'Angennes : de sable au sautoir d'argent. Ses gantelets sont posés devant lui sur le coussin, et son casque est par terre à sa droite.

Cette figure était désignée au Musée des Monuments français sous le no 168 du catalogue de 1810, comme celle de Guillaume de Montmorency, mort en 1531, provenant du tombeau de ce personnage placé dans l'église de Saint-Martiı de Montmorency. Les armoiries de la cotte d'armes et la description du tombeau de Guillaume de Montmorency, qui se trouve gravé par Picart dans l'Histoire généalogique de la maison de Montmorency, par Duchesne (p. 364), démontrent l'erreur de cette attribution. M. de Guilhermy a reconnu ces armoiries pour être celles de la maison d'Angennes, dont plusieurs membres étaient enterrés dans l'église paroissiale de Rambouillet. La terre de Rambouillet ayant passé de la maison d'Angennes à divers possesseurs, des changements furent faits dans l'église, et la Description de Paris et de ses environs, par Piganiol de la Force (tome IX, p. 333), constate qu'en 1765 ces changements empêchèrent de reconnaître les sépultures des seigneurs de la maison d Angennes. "Il n'y en a qu'un seul, ajoute Piganiol, dont on voit ici un tombeau de pierre, sur lequel est un homme à genoux et armé, ayant ses gantelets par terre devant lui, ce qui signifie qu'il mourut de mort naturelle et point en guerre... L'on ne trouve rien dans les registres de cette église qui fasse connoitre nommément ce seigneur... Il y a toute apparence que c'est la représentation de Nicolas d'Angennes, seigneur de Rambouillet, etc., conseiller d'état, lieutenant-général des armées des rois Charles IX et Henri III, capitaine des gardes de ce dernier et chevalier de l'ordre du Saint-Esprit. Il vivait encore le 5 février 1611, âgé de quatre-vingts ans. " Le style de cette figure, qui serait plutôt celıi du XVIe siècle, l'absence des insignes des ordres de Saint-Michel et du Saint-Esprit, autorisent à supposer que cette statue est celle du père ou de l'aïeul de Nicolas d'Angennes.

\section{Crèveccur (Marguerite de).}

\section{Statue à genoux; marbre. - H. 1,25.}

Cette figure était placée au Musée des Monuments français, sous le n 161 , comme représentant la femme de Jacques Cour, exécutée par Philippe Buyster et provenant de l'église de Saint-Germain-l'Auxerrois. Allexandre Lenoir dit 
n'avoir pas d'autres renseignements sur cette statue qu'il avait classée parmi les monuments du XVIIe siècle. Transportée à Versailles, elle y a été désignée comme celle d'Isabelle Bureau, femme de Geoffroy Cœur, échanson de Louis XI. Il existait à Saint-Germain l'Auxerrois une statue de marbre blanc de Marguerite de Crèvecœur, morte le 23 décembre 1629, successivement mariée à Francois Milon, président en la chambre des comptes, puis à Nicolas Chevalier, président en la cour des aides, chancelier de la reine; elle était représentée à genoux lisant dans un livre que tenait devant elle un enfant. $M$. de Guilhermy, qui a trouvé cette indication dans le tome VII des Epitaphes de la ville de Paris (Mss. V, no 1278, Bibliothèque impériale), pense que cette figure est celle transportée au Musée des Monuments français, puis à Versailles, et dont le nom aura été altéré.

\section{Garzez (Martin), $51^{\mathrm{e}}$ grand-maître de l'ordre de Malte.}

Buste en plàtre. - H. 0,60.

Martin Garzez, de la langue d'Aragon, châtelain d'Emposte, fut élu grand-maître en 1595 . Il mourut le 7 février 1601, âgé de soixante-quinze ans.

Le buste original est dans l'église de Saint-Jean, à Malte.

333. Wignacourt (Alof de), 52e grand-maître de l'ordre de Malte.

Buste en plâtre. - H. 0,58.

Né en 1547 d'une ancienne maison des Pays-Bas fixée en Picardie, il était grand-croix et grand hospitalier de France, lorsqu'il fut élu grand-maître en 1601. Sous son administration, les galères de la religion se signalèrent par des courses heureuses sur les côtes d'Afrique et de Morée. Il fit construire à Malte, en 1616, l'aqueduc qui unit la cité Valette à la cité Notable, et mourut le 14. septembre 1622, à soixante-quinze ans.

Le buste original est dans l'église de Saint-Jean, à Malte.

334. Vasconcellos (Louis Mendez de), 53e grandmaître de l'ordre de Malte.

Buste en plâtre. - H. 0,70 .

Il était bailli d'Acre lorsqu'il fut élu grand-maître en 1622; il mourutl'année suivante, le 7 mars, âgé de plus de quatre-vingts ans.

Le buste original est dans l'église de Saint-Jean, à Malte.

\section{Paule (Antoine de), $54^{\mathrm{e}}$ grand-maître de l'ordre de Malte.}

Buste en plâtre. - H. 0,69 .

Issu d'une ancienne maison de Toulouse, il naquit en Gascogne vers 15๊2. Il était prieur de Saint-Gilles lorsqu'il fut élu grand- 
maître en 1623. Appelé l'année suivante devant le tribunal pontifical, il fut souvent en lutte avec le pape Urbain VIII au sujet des commanderies d'Italie. Sous son ministère il y eut, en 1631, un chapitre général de l'ordre. Antoine de Paule mourut le 10 juin 1636, âgé de plus de quatre-vingt-cinq ans.

Le buste original est dans l'église de Saint-Jean, à Malte.

336. Lascaris-Castellar (Jean-Paul de), 55e grandmaître de l'ordre de Malte.

Buste en plâtre. - H. 0,57.

Issu des comtes de Vintimille et de l'ancienne maison des empereurs de Constantinople, il était bailli de Manosque lorsqu'il fut élu grand-maitre en 1636. Il envoya une escadre au secours de Candie, assiégé par les Ottomans, et mourut le 14 août 165\%7, à l'àge de quatre-vingt-dix-sept ans.

Le buste original est dans l'église de Saint-Jean, à Malte.

337. Redin (Martin de), 56 ${ }^{\mathrm{e}}$ grand-maître de l'ordre de Malte.

Buste en plâtre. - H. 0,75.

Prieur de Navarre et vice-roi de Sicile, il fut élu grand-maître en 165̌7. Il fit construire des tours sur les côtes de Malte pour mettre l'île à l'abri des descentes des Infidèles. Il était âgé de soixante-dix ans quand il mourut, en 1660.

Lebuste original est dans l'église de Saint-Jean, à Malte.

338. Clermont (Annet de), $57^{\mathrm{e}}$ grand-maître de l'ordre de Malte,

Buste en plâtre. - H. 0,62 .

Annet de Clermont de Chattes-Gessan, bailli de Lyon, fut unanimement élu grand-maître au mois de février 1660. Il ne jouit de cette dignité que pendant trois mois, étant mort le 2 juin, à l'âge de soixante-treize ans.

Le buste original est dans l'église de Saint-Jean, à Malte.

339. Raphaël Cotoner, 58 grand-maître de l'ordre de Malte.

Buste en plâtre. - H. 0,70.

Il était bailli de Majorque lorsqu'il fut élu grand-maître en 1660. Il secourut Candie dont les Turcs faisaient le blocus, et mourut le 20 octobre 1663, àgé de soixante-trois ans.

Le buste original est dans l'église de Saint-Jean, à Malte. 


\section{PREMIÈRE SALLE DES CROISADES, No 17.}

Les cinq salles des Croisades et la partie de la galerie de sculpture $\mathbf{n}^{\circ} \mathbf{1 6}$ qui leur sert de vestibule, occupent au rez-de-chaussée le gros pavillon de l'aile du Nord, qui portait aussi le nom de pavillon de Noailles. Il était destiné à loger les principaux personnages de la suite du roi, de la reine et desprinces. La première salle des Croisades et la partie du vestibule qui la précède, formaient un appartement occupé sous Louis XIV par le maréchal d'Estrées, et, sous Louis XV, d'abord par madame de Conflans, gouvernante des enfants de la maison d'Orléans, puis par la duchesse de Lauraguais, dame d'atour de la dauphine.

Le plafond et la frise de cette salle sont décorés des armoiries des rois, princes, seigneurs et chevaliers qui prirent part aux trois premières croisades, de 1096 a 1191, savoir :

1096.

Aymery Ier, vicomte de Narbonne.

Aruaud de Grave.

Isarn, comte de Die.

Pierre de Champchevrier.

Humbert de Marssane.

Patri, seigneur de Chourses.

Hervé de Léon.

Chotard d'Ancenis.

Renaud de Briey.

Folcran, châtelain de Berghes.

Hugues de Gamaches.

Riou de Lohéac.

Conan, fils du comte de Lamballe.

Hélie de Malemort.

Foulques de Grasse.

1101.

Renaud II, seigneur de Château-Gontier.

1102.

Aycard de Marseille.

1106.

Hugues du Puiset, vicomte de Chartres.

Rivallon de Dinan. 1113.

Robert de Roffignac

1119

1120.

Foulques V, comte d'Anjou, depuis roi de Jérusalem.

Guillaume de Biron.

1124.

1130.

Hugues Rigaud, chevalier du Temple. 1136.

Robert le Bourguignon, gra.d-maître de l'ordre du Temple. 1144.

Baudouin IlI, roi de Jérusalem. 1147.

Pierre de France, depuis seigneur de Courtenay.

Pons et Adhémar de Beynac.
Evrard des Barres, grand-maître de l'ordre du Temple.

Guillaume III, comte de Varennes.

Artaud de Chastelus.

Jean, seigneur de Dol.

Hugues de Domène.

Guiffray, seigneur de Virieu.

Hesso, seigneur de Reinach.

1153.

Guillaume de Chanaleilles, grand-maitre de l'ordre du Temple.

Bertrand de Blanquefort, grand-maittre de l'ordre du Temple.

1159.

Hugues IV, vicomte de Châteaudun. 1160.

Auger de Balben, grand-maitre de l'ordre de Saint-Jean de Jérusalem. 1161.

Gerbert d'Assalyt, grand-maitre de l'ordre de Saint-Jean de Jérusalem. 1162.

Amaury I ${ }^{\text {er }}$, roi de Jérusalem. 1168.

Philippe de Naplouse, grand-maitre de l'ordre du Temple. 1169.

Castus, grand-maître de l'ordre de Saint-Jean de Jérusalem. 1170.

Joubert de Syrie, grand-maitre de l'ordre de Saint-Jean de Jérusalem. 1171.

Odon de Saint-Chamant, grand-maître de l'ordre du Temple. 1173.

Baudouin IV, roi de Jérusalem, 1179.

Arnaud de Toroge, grand-maître de l'ordre du Temple. 1184.

Terric, grand-maître de I'ordre du Temple. 


\section{5.}

Baudouin V, roi de Jérusalem. 1187.

Conrad de Montferrat, marquis de Tyr. Garnier de Naplouse, grand-maître de l'ordre de Saint-Jean de Jérusalem.

Frère Guérin, chevalier de l'ordre de Saint-Jean de Jérusalem. 1188.

Gérard de Riderfort, grand-maître de l'ordre du Temple. 1190.

Guy II de Dampierre.

Guillaume, seigneur d'Estaing.

Albert II, seigneur de la Tour du Pin.

Jean et Gauthier de Chastenay.

Hugues et Renaud de la Guiche.

Alain VII, vicomte de Rohan.

Hugues et Liébaut de Bauffremont.

Dreux de Nettancourt.

Gilles de Raigecourt.

Henri et Renaud de Cherisey.

Ulric de Dompierre, seigneur de Bassompierre.

Hugues de Clairon.
Hugues de Foudras.

Renaud et Herbert de Moustier.

Jean et Guil!aume de Drée.

Guigues de Moreton.

Guillaume et Pierre de Vallin.

André d'Albon.

Raoul de Riencourt.

Foulques de Pracomtal.

Bernard de Castelbajac.

Foulques de Beauvau.

Albéric d'Allonville.

Thibaut des Escotais.

Hervé de Broc.

Harduin de la Porte.

Mathieu de Jaucourt.

Foucauld de la Rochefoucauld.

Guillaume et Humbert Leclerc.

Miles de Frolois.

Elie de Cosnac.

Gilon de Versailles.

Geoffroy de la Planche.

G. de Bueil.

Simon de Vignacourt.

1191.

Géraud de Boysseulh.

\section{Levée du siége de Salerne. - Vers 1016.}

Par Eugène Roger en 1839. - H. 0,98. - L. 1,03.

$\mathrm{Au}$ commencement du $\mathrm{xI}^{\mathrm{e}}$ siècle une petite flotte de Sarrasins vint assaillir la ville de Salerne, et les habitants, cachés derrière leurs murs, attendaient avec effroi le pillage et la mort. Quarante chevaliers normands, qui revenaient du pèlerinage de TerreSainte, demandent au prince Guaimar III des chevaux et des armes, se font ouvrir les portes, et, malgré leur petit nombre, chargent intrépidement les Sarrasins qu'ils mettent en fuite.

\section{Robert Guiscard, duc de Pouille et de Calabre.} Par BLONDEL. - H. 1,04. - L. 0,76.

Robert Guiscard fut proclamé, en 10วั8, duc de Pouille et de Calabre. Après avoir vaincu l'empereur Alexis Comnène, à Durazzo, et soutenu le pape Grégoire contre l'empereur Henri IV, ll entreprit en 108 o la conquête de l'île de Céphalonie, et y mourut le 17 juillet de la même année.

342. Roger I ${ }^{\text {er }}$, comte de Sicile.

Par BLONDEL. - H. 1,04. - L. 0,80.

Il s'empara de Messine avec cent soixante chevaliers, et reçut de son frère, Robert Guiscard, l'investiture de la Sicile, avec le titre de comte. Il prit après la mort de Robert, le titre de grand 
comte de Calabre et de Sicile; et par une bulle donnée à Salerne, en 1098, le pape Urbain II le déclara, lui et ses successeurs, légats perpétuels du Saint-Siége en Sicile. Il mourut en juillet 1101.

\section{Bataille de Civitella. - 18 juin 1053.}

Par M. Adolphe Roger. - H. 1,96. - L. 1,03.

Guillaume Fier-à-Bras, Drogon et Umfroy, fils de Tancrède de Hauteville, gentilhomme de la basse Normandie, suivis peu après de leurs jeunes frères, Robert Guiscard et Roger, entreprirent la conquête du duché de Pouille. Le pape Léon IX, inquiet pour le Saint-Siége et pour l'Italie entière, arma contre eux, par ses pieuses exhortations, les deux empires d'Orient et d'Occident. Il n'avait pas moins de cinquante mille hommes 'et marcha lui-même à leur tête. Les Normands ayant rencontré à Civitella, dans la Capitanate, l'armée pontificale, la mirent en pleine déroute. Léon IX resta prisonnier entre leurs mains. Umfroy et Robert Guiscard lui témoignèrent un respect qui allait jusqu'à l'adoration; mais, à genoux devant lui, ils lui dictèrent leurs conditions.

\section{Combat de Céramo. - 1061.}

Par M. LAFAYE en 1839. - H. 0,71. - L. 0,79.

Le plus prodigieux des faits d'armes du comte Roger, en Sicile, est le combat de Céramo, où, suivant la chronique de Gaufred Malaterra, il mit en fuite, avec cent trente-six hommes, trentecinq mille Sarrasins.

\section{Henri de Bourgogne reçoit l'investiture du comté de Portugal. - 1094.}

Par M. JacQuand. - H, 0,71. - L. 0,79.

Henri de Bourgogne, arrière-petit-fils du roi de France Robert, était allé, avec un grand nombre de chevaliers français, offrir à don Alphonse IV, roi de Castille, son épée contre les Infidèles. En récompense de ses services, le roi Alphonse lui donna en mariage sa fille, et lui accorda en même temps l'investiture du comté de Portugal, que ses armes lui avaient soumis. Henri de Bourgogne plaça ainsi sur un nouveau trône la maison royale de France. Son fils Alphonse prit le titre de roi de Portugal.

\section{Raymond IV, dit de Saint-Gilles, comte de Tou- louse.}

Par Blondel. - H. 0,04. - L. 1,80.

Il fut un des chefs de la première croisade en 1095, et monta 
l'un des premiers à l'assaut de Jérusalem. Raymond de SaintGilles avait fait le vœu de mourir en Terre-Sainte, et finit ses jours au château du Mont-Pèlerin, devant Tripoli, qu'il assiégeait en 1105 .

\section{Marc Bohémond $\boldsymbol{I}^{\text {er }}$, prince d'Antioche.}

Par BLONDEL. - H. 1,04. - L. 0,77.

Fils de Robert Guiscard, il hérita en 1085 des duchés de Pouille et de Calabre, fut un des principaux chefs de la première croisade, et reçut la principauté d'Antioche. Il mourut à Canose, dans la Pouille, en 1108.

\section{Eudes I ${ }^{\text {er }}$, surnommé Borel, duc de Bourgogne.}

Par BLONDEL. - HI. 1,04. - L. 0,61.

Il parvint au duché de Bourgogne en 1078, se croisa en 1098, et mourut à Tarse, en Sicile, en 1103.

\section{Alexis Comnène reçoit à Constantinople Pierre l'Ermite. - 1096.}

Par M. SaINT-Èvre en 1839. - H. 0,98. - L. 1,36.

" Pierre l'Ermite, dit Michaud, fut admis à l'audience de Comnène et raconta sa mission et ses revers. En présence de toute sa cour, l'empereur vanta le zèle du prédicateur de la croisade, et comme il n'avait rien à craindre de l'ambition d'un ermite, il le combla de présents, fit distribuer à son armée de l'argent et des vivres, et lui conseilla d'attendre, pour commencer la guerre, l'arrivée des princes et des illustres capitaines qui avaient pris la croix ».

350. Adoption de Godefroy de Bouillon par Comnène. $-1097$.

Par M. Alexandre Hesse. - H. 1,96. - L. 3,10.

" En voyant le magnifique et honorable duc, dit Albert d'Aix, chroniqueur contemporain, ainsi que tous les siens dans tout l'éclat et la parure de leurs précieux vêtements de pourpre et d'or, recouverts d'hermine blanche comme la neige, de martre, de petit-gris et de diverses autres fourrures, telles que les portent les seigneurs de France, l'empereur admira vivement leur pompe et leur splendeur. D'abord il admit le duc avec bonté à recevoir le baiser de paix; puis, et sans aucun retard, il accorda le même honneur à tous les grands de sa suite et à ses parents ». 
Il voulut adopter Godefroy pour son fils, et à son tour le duc se déclara vassal de l'empereur.

Ce tableau a été exposé au Salon de 1842.

\section{Passage du Bosphore. - 1097.}

Par M. Émile Signol. - H. 3,25. - L. 5,58.

L'empereur Alexis Comnène n'était occupé que de soumettre à son empire les princes de la Croix et ne songeait plus que les drapeaux musulmans flottaient sur Nicée. Cependant, Godefroy de Bouillon et les plus sages d'entre les chefs ne perdaient pas de vue la croisade; eux-mêmes demandaient qu'on leur fournit des barques pour traverser le Bosphore et reprendre la route de Jérusalem. Godefroy donna l'exemple et s'embarqua avec ses chevaliers dans le golfe de Buyuk-Déré, accompagné du duc Baudouin, son frère, et de sa famille, qui venaient de servir d'otages au roi de Hongrie, qui n'avait laissé passer l'armée chrétienne qu'à ce prix.

Deux ministres de l'empereur Alexis sont près de Godefroy de Bouillon et l'accompagnent, tandis que le héros ne quitte pas des yeux le rivage de l'Asie. Au milieu du tableau est le groupe des femmes de la famille de Baudouin, qui viennent de subir comme otages une captivité en Hongrie. L'espoir et l'enthousiasme brillent dans les yeux des chrétiens auxquels le ciel semble sourire.

Ce tableau a été exposé au Salon de 1855.

\section{Bataille sous les murs de Nicée. - 1097.}

Par M. SERRur en 1839. - H. 0,98. - L. 1,48.

Le sultan Kilig-Arslan s'était avancé à la tête d'une formidable armée de cavaliers pour délivrer Nicée que les Croisés assiégeaient. La bataille qui se livra sous les murs de la ville dura depuis le matin jusqu'à la nuit. Les Turcs vaincus s'enfuirent dans les montagnes, laissant dans la plaine quatre mille morts.

\section{Baudouin s'empare de la ville d'Edesse. - 1097.}

Par M. Robert-Fleury en 1839. - H. 1,96. - L. 1,36.

Baudouin, frère de Godefroy de Bouillon, étant arrivé sur le territoire d'Edesse, métropole de la Mésopotamie, tout le peuple, à la vue de la bannière de la croix, se porte à sa rencontre, tenant à la main des branches d'olivier et chantant des cantiques.

354. Combat de Robert, duc de Normandie, avec un guerrier sarrasin. - 1098.

Par M. DAssy. - H. 0,71. - L. 0,79.

Les Croisés, vainqueurs à Nicée, avaient mis le siége devant Antioche. Pendant ce siége plusieurs chefs signalèrent leur bra- 
voure dans des combats particuliers. "Le duc de Normandie, dit Michaud, soutint seul un combat contre un chef des Infidèles qui s'avancait au milieu des siens ; d'un coup de sabre il lui fendit la tête jusqu’à l'épaule et l'étendit à ses pieds, en s'écriant : " Je dévoue ton âme impure aux puissances de l'enfer ».

\section{Combat de Harenc. - 7 février 1098.}

\section{Par J. M. Got. - H. 0,98. - L. 1,02.}

Pendant le siége d'Antioche, de nombreuses troupes d'Infidèles sorties d'Alep, de Césarée et de Damas, s'avancèrent pour délivrel' la ville, et vinrent camper aux environs dun lieu nommé Harenc, à quatorze mille d'Antioche. A l'entrée de la nuit les Croisés, avertis de leur approche, sortirent de leurs retranchements au nombre de sept cents, rencontrèrent l'ennemi et le chassèrent devant eux jusquau camp de Harenc. Les Infidèles perdirent dans cette journée près de deux mille des leurs.

\section{Prise d'Antioche. - 3 juin 1098.}

Par M. Gallait. - H. 0,77. - L. 1,35.

Après un siége de huit mois, une échelle, suspendue aux créneaux de l'une des tours, introduisit dans la ville chefs et soldats, et le cri Dieu le veut! retentissant dans les rues au milieu de la nuit, annonça aux Musulmans leur dernière heure. Il y en eut dix mille d'égorgés.

\section{Bataille sous les murs d'Antioche. - 1098.}

Par M. Schopin. - H. 0,97. - L. 1,37.

Les Croisés, trois jours après la prise d'Antioche, y furent assiégés à leur tour par l'armée de Kerbogah, général du sultan de Perse. La découverte de la lance dont fut percé le côté du Sauveur sur la croix exalta le courage des Chrétiens. Ils sortirent de la ville avec confiance, se jetèrent sur le camp de Kerbogah, et en une heure anéantirent sa superbe armée.

\section{Prise d'Albare. - 1098.}

Par M. Pingret. - H. 0,71. - L. 0,79.

Lorsque les Croisés eurent pris possession d'Antioche, ils se dispersèrent dans les terres et les villes voisines, assiégeant les places rebelles et les soumettant à leur autorité. La ville d'Albare était renommée par ses grandes richesses; ils l'attaquèrent et passèrent au fil de l'épée les Turcs et les Sarrasins qui y furent trouvés. 


\section{Prise de Marrah. - 1098.}

Par Decaisne en 1844. - H. 1,96. - L. 1,02.

Après s'être emparès d'Albare, les comtes de Toulouse, de Flandre et de Normandie, le duc Godefroy, son frère Eustache et Tancrède allèrent investir la ville de Marrah. Les assiégés réussirent à repousser les premiers assauts, mais Bohémond étant arrivé à la tête de nouvelles troupes, les Croisés s'emparèrent deplusieurs tours, puis occupèrent la ville.

\section{Prise de Jérusalem. - 15 juillet 1099.}

Par M. Émile Signol en 1847. - H. 3,24. - L. 5,57.

Jérusalem fut pris le Vendredi-Saint, anniversaire de la mort du Christ. Les Croisés avaient tenté la veille un premier assaut et avaient été repoussés; celui du lendemain ne fut donné qu'après une nuit de larmes, de confession et de prières. A peine la ville venait-elle d'être conquise qu'on vit accourir les chrétiens de Jérusalem au-devant des vainqueurs; ils partageaient avec eux les vivres qu'ils avaient pu dérober à la recherche des Musulmans. Tous remerciaient ensemble le Dieu qui avait fait triompher les armes des soldats de la croix. Pierre l'Ermite qui, cinq ans auparavant avait promis d'armer l'Occident pour la délivrance des fiàèles de Jérusalem put jouir alors du spectacle de leur reconnaissance et de leur joie.

Ce tableau a été exposé aux Salons de 1848 et de 1855.

\section{Godefroy de Bouillon élu roi de Jérusalem. - 23 juillet 1099.}

Par M. Madrazzo en 1839. - H. 1,96. - L. 1,36.

Dix jours après la prise de Jérusalem, le conseil des princes décerna la couronne à Godefroy de Bouillon, comme au plus digne. Par une pieuse humilité, Godefroy refusa le diadème et les marques de la royauté : il ne voulut pas, disent les Assises de Jérusalem, " estre sacré et corosné roi de Jérusalem, parce que il ne vult porter corosne d'or, là où le Roy des Roys, JésusChrist, le fils de Dieu, porta la corosne d'espines le jour de sa Passion. "

\section{DEUXIÈME SALLE DES CROISADES, № 18.}

L'appartement que cette salle a remplacé fut habité sous Louis XV, par la maréchale d'Estrées, puis par $M^{\text {nie }}$ de Goesbriant, dame de compagnie de Mesdames Victoire, Sophie et Louise. 
Les armoiries qui décorent le plafond et la frise appartiennent aux cinq premières croisades de 1096 à 1248 ; ce sont celies de :

Hugues de Saligna. 1096. 1144.

Eustache de Monthoissier. 1175.

Amanjeu d'Astarac. 1179.

Guillaume de Sainte-Maure. 1190.

Poncet d'Anvin.

Guillaume de Prunelé.

Jodoin de Beauvilliers.

Payen et Hugues de Buat.

Juhel de Champagne.

Jean d'Andigné.

Gervais de Menou.

Humphroy de Biencourt.

François cle Vimeur.

Jean de la Bérandière.

Érmengard Daps, grand-maître de l'ordre cie Saint-Jean de Jérusalem.

Hélie de la Cropte.

Jean de Chaunac.

Jourdain d'Abzac.

B. de Cugnac.

Guillaume de Montléart.

Guillaume de Gaudechart.

Guignes et Herbert de la Porte (en Dauphiné).

Renaud de Tramecourt.

Wautier de Ligne.

Hamelin et Geoffroy d'Antenaise.

Isnard d'Agout.

Guethenoc de Bruc.

Raoul de l'Angle.

Bertrand de Foucaud.

B. de Mellet.

Gilles de Hinnisdal.

Guillaume de Lostanges.

Jean d'Osmond.

Juhel de la Motte.

Bernard de Durfort.

Eudes de Tournon.

Thierry, seigneur de Misnie.

Pons de Bastet, seigneur de Crussol.

Paoul de Saint-Georges. 1191.

Godefroy de Duisson, grand-maître de l'ordre de Saint-Jean de Jérusalem.

$$
1196 .
$$

Gilbert Horal, grand-maître de l'ordre du Temple.

1201.

Philippe du Plaissiez, grand-maître de l'orire du Temple. 1202.

Alphonse de Portugal, grand-maitre de l'ordre de Saint-Jean de Jérusalem.
Baudouin, comte de Flandre, empereur de Constantinople.

Thierry et Guillaume de Los.

Geoffroy de Beaumont au Maine.

Hugues de Chaumont.

Geoffioy, seigneur de Lubersac.

Guillaume de Digoine.

Thomas Berton.

Guillaume de I)ampierre.

Otbert de Roubaix.

Guillaume de Straten.

Philippe de Caulaincourt.

Milon de Bréban, seigneur de Provins.

Hugues de Beaumez.

Gautier de Vignory.

Baudouin de Comines.

Gilles de Landas.

1204.

Geoffroy le Rath, grand-maître de l'ordre de Saint-Jean de Jérusalem. 1217.

Guillaume de Chartres, grand-maittre de l'ordre du Temple. 1218.

Colin d'Espinay.

Foulques de Quatrebarbes.

Guy de Hauteclocque.

Foulques d'Orglandes.

Barthélemy de Nédonchel.

Robert de Maulde.

Guillaume de la Faye.

Gilles de Croix.

Jean de Dion.

Baudouin de Mérode. 1219.

Jean de Hédouville.

Guillaume de Saveuse.

Pierre de Montaigu, grand-inaitre de l'ordre du Temple. 1220.

Eudes de Ronquerolles. 1230.

Bertrand de Texis, grand-maitre de l'ordre de Saint-Jean de Jérusslem. 1231.

Guérin, grand-Inaître de l'ordre de Saint-Jean de Jérusalem. 1236.

Bertrand de Comps, grand-maître de l'ordre de Saint-Jean de Jérusalem. 1239.

Raussin de Rarécourt.

Richard de Chaumont en Charolois. 1240.

André de Saint-Phalle.

Guillaume de Messey.

Adam de Sarcus.

Girard de Lezay. 
1241.

Pierre de Villebride, grand-maître de l'ordre de Saint-Jean de Jérusalem. 1244.

Guillaume de Châteauneuf, grandmaître de l'ordre de Saint-Jean de Jérusalem.

1247.

Guillaume de Sonnac, grand-maître de l'ordre du Temple.

Robert de Dreux, I ${ }^{\text {er }}$ du nom, seigneur de Beu.
Guillaume de Courtenay, II ${ }^{\mathbf{e}} \mathrm{du}$ nom, seigneur d'Yerre.

Guillaume de Goyon.

Alain de Lorgeril.

Hervé de Saint-Gilles.

Olivier de Rougé.

Payen Féron.

Geoffroy de Goulaine.

Guillaume de Kergariou.

Hervé Chrétien.

\section{Eustache III, comte de Boulogne.}

Par M. OdIER. - H. 1,04. - L. 0,77.

Il succéda, vers 1093, à son père Eustache II, au comté de Boulogne; frère aîné de Godefroy de Bouillon et de Baudouin I ${ }^{\text {er }}$, il marcha avec eux à la première croisade, et mourut en 1125 '.

\section{Baudouin II, dit du Bourg, roi de Jéruisalem.}

Par M. OdiER. - H. 1,04. - L. 0,77.

Baudouin, fils aîné de Hugues, comte de Rethel, accompagna à la croisade, en 1096, Godefroy de Bouillon, dont il était le parent. Il remplaça Baudouin Ier, frère de Godefroy, dans le comté d'Edesse, et après la mort de ce prince, en 1118, lui-même fut élu et couronné roi de Jérusalem. Il mourut le 21 août 1131.

364. Alain Fergent, duc de Bretagne.

Par M. OdIER. - H. 1,04. - L. 0,81.

Il succéda à son père Hoël $\mathrm{V}$ au duché de Bourgogne en 1084. Il se croisa en 1096 et mourut en Bretagne, en 1119.

\section{Bataille d'Ascalon. - 12 août 1099.}

Par M. Schnetz en 1847. - H. 3,15. - L. 5,56.

Le royaume de Jérusalem venait à peine d'être institué qu'on apprit les grands préparatifs du calife fatimite d'Egypte pour reconquérir la ville sainte. Le visir Afdal avait déployé l'étendard du prophète, et une multitude immense de combattants était accourue de toutes les provinces soumises à l'islamisme pour se joindre à l'armée égyptienne. Les Croisés sortirent de Jérusalem au nombre de vingt mille, marchèrent au-devant de l'ennemi et le rencontrèrent dans la plaine d'Ascalon. La bataille fut courte et la victoire facile; ce ramas indiscipliné de fantassins mal armés et de cavaliers du désert ne put tenir contre les armures de fer et la vaillance exercée de l'armée chrétienne. Le camp du visir fut 
livré au pillage, et le plus précieux trésor qu'y trouvèrent les Croisés furent des outres pleines d'eau pour désaltérer la soif ardente qui les dévorait.

Ce tableau a étẻ exposé au Salon de 1848.

366. Godefroy de Bouillon dépose dans l'église du Saint-Sépulcre les trophées d'Ascalon. - Août 1099.

Par Granet en 1839. - H. 1,75. - L. 3,05.

Après la victoire d'Ascalon, les Croisés rentrèrent en triomphe dans Jérusalem, et Godefroy alla suspendre aux colonnes de l'église du Saint-Sépulcre l'étendard du grand visir et son épée qu'il avait laissée sur le champ de bataille, pendant que les Croisés offraient à genoux leurs actions de grâces au Dieu qui avait béni leurs armes.

Ce tableau été exposé au Salon de $\mathbf{1 8 4 0 .}$

367. Funérailles de Godefroy de Bouillon sur le Calvaire. - 23 juillet 1100.

Par M. Сiвot en 1839. - H. 1,15. - L. 1,47.

" A la mort de cet illustre capitaine et très noble athlète du Christ, dit l'historien Albert d'Aix, tous les chrétiens, François, Italiens, Syriens, Arméniens, Grecs, la plupart des Gentils euxmêmes, Arabes, Sarrasins et Turcs, se livrèrent aux larmes penldant cinq jours et firent entendre de douloureuses lamentations. » On ensevelit ses restes avec toutes les pompes de l'église catholique, dans l'enceinte du Calvaire, près du sépulcre de JésusChrist, qu'il avait délivré.

368. Prise de Tripoli. -1100.

Par Debace en 1842. - H. 1,15. - L. 1,46.

Raymond de Saint-Gilles assiégeait Tripoli, ville située dans une riante plaine, au pied du Liban, et renommée par la richesse de son sol, par son commerce et par sa vaste bibliothèque. Mais la mort vint le frapper devant cette place, et le soin d'en poursuivre le siége resta à son fils Bertrand, qui venait d'arriver d'Europe avec une troupe de chevaliers et une flotte génoise. Il força en peu de temps la ville à capituler.

\section{Josselin de Courtenay, comte d'Edesse.}

par M. Odier. - H. 1,04. - L. 0,81.

Josselin de Courtenay, $\mathrm{II}^{\mathrm{e}} \mathrm{du}$ nom, passa en Terre-Sainte l'an 
1101, et fut un des plus héroïques défenseurs du royaume de Jérusalem. Prince de Tibériade en 1110 et comte d'Edesse en 1119 , il mourut en 1131 .

370. Combat de Jaffa. - 1102.

Par M. Serrur en 1844. - H. 0,70. - L. 0,78.

Les Chrétiens ayant à leur tête Baudouin et le patriarche de Jérusalem qui portait le bois de la vraie croix, rencontrent les $\mathrm{Mu}$ sulmans dans la plaine de Jaffa. Baudouin décida la victoire en se précipitant, un drapeau à la main et suivi de cent-soixante chevaliers, dans les rangs des ennemis. A l'approche de la nuit, les Infidèles s'enfuirent laissant sur le champ de bataille l'émir d'Ascalon et quatre mille des leurs.

\section{Prise de Baruth. - 17 mai 1109.}

Par M. Eug. LeportTevin en 1844. - H. 0,70. - L. 0,78.

Après la prise de Tripoli, le roi de Jérusalem vint mettre le siége devant Baruth, port de mer situé dans la province de Phénicie, entre Biblios et Sidon. Bertrand, comte de Tripoli, vint se joindre à cette expédition, et au bout de deux mois, la ville, bloquée par terre et par mer, fut prise d'assaut.

\section{Défense de la Célésyrie par Raymond Dupuy. - 1130.}

Par N. Сiвot en 1844. - H. 0,70. - L. 0,79.

Les chevaliers de Saint-Jean ayant à leur tête le grand-maître Raymond Dupuy, marchent contre Borsequin, qui était venu des bords du golfe Persique ravager la Célésyrie et le pays d'Antioche, et dispersent son armée.

\section{Raymond Dupuy fait prisonnier un corps de Turcs. -1130 (1). ........... - H. 0,70. - L. 0,79.}

374. Prédication de la deuxième croisade à Vezelay, en Bourgogne. - 31 mars 1146.

Par M. Emile Signol. - H. 3,14. - L. 2,34.

Louis VII avait convoqué à Vezelay un parlement de tous les

(1) Les sujets dont le titre est mentionné sans nom d'auteur et sans description avaient été désignés pour compléter la décoration des salles des croisades et ne sont pas encore exécutés. 
seigneurs du royaume; la foule qui s'y rendit, trop grande pour être contenue dans l'étroite enceinte de cette bourgade, se répandit en amphithéâtre au pied de la montagne où elle était située. Ce fut saint Bernard qui porta la parole dans cette assemblée. Il monta avec le roi dans une sorte de chaire qu'on avait élevée pour eux, et d'où il adressa au peuple des paroles enflammées. Bientôt il fut interrompu par le cri : la croix! la croix! qui s'éleva de toutes parts. Il commença aussitôt, ainsi que le roi, à distribuer aux assistants les croix quils avaient préparées; mais quoiquiils en eussent fait apporter une grande quantité, leur provision fut vite épuisée, et ils déchirèrent leurs habits pour en faire de nouvelles.

Ce tableau a été exposé au Salon de 1839.

375. Eléonore de Guyenne prend la croix avec les dames de sa cour. - 1147.

........... - H. 1,15, - L. 1,47.

376. Chapitre de l'ordre du Temple, tenu à Paris. -22 avril 1147.

Par GRanet. - H. 1,75. - L. 3,05.

Sous le magistère de Robert le Bourguignon, les chevaliers du Temple s'assemblèrent en chapitre au nombre de cent-trente, le pape Eugène III à leur tête, pour les affaires de la Terre-Sainte. Le roi Louis-le-Jeune assista à celte assemblée.

Ce tableau a été exposé au Salon de 184.5.

\section{Louis VII prend l'oriflamme à Saint-Denis. - 1147.}

Par Miadzaisse en 1839. - H. 1,15. - L. 1,47.

Louis VII se rendit en grande pompe à Saint-Denis pour y prendre sur l'autel la sainte bannière de l'oriflamme, et, selon la naïve expression de son historien, recevoir le congé du bienheureux patron de la France. Le pape Eugène III, qui était alors à la cour du roi Louis VII, remit au monarque le bourdon et la pannetière, symboles du pèlerinage qu'il allait accomplir.

378. Surprise du camp de Noradin, sultan d'Alep. - 1150. - H. 3,14. - L. 5,57, 


\section{TROISIÈME SALLE DES CROISADES, No 19.}

Cette salle et la partie du vestibule qui la précède formaient l'appartement occupé sous Louis XV par M. de Clermont, premier écuyer du duc d'Orléans, puis par la princesse de Carignan.

Les armoiries qui décorent cette salle appartiennent toutes à la sixième croisade; ce sont celles de :

Hervé Budes.

1248.

Olivier de Carné.

Pierre Freslon.

Rattier de Caussade.

Eudes de Quélen.

Jean de Québriac.

Raoul de la Moussaye.

Geoffroy de Boisbily.

Poland des Nos.

Hervé de Saint-Pern.

Macé de Kérouarts.

Bertrand du Coëtlosquet.

Raoul de Coëtnempren.

Robert Kersauson.

Huon de Coskaër, seigneur de Rosanbo.

Hervé et Geoffroy de Beaupoil.

Jean du Marhallach.

Hervé de Sesmaisons.

Henri et Hamon Lelong.

Olivier de la Bourdonnaye.

Hervé de Boisberthelot.

Guillaume de Gourcuff.

Guillaume Hersart.

Hervé du Couédic.

Robert de Courson.

Hervé de Kerguélen.

Raoul Audren.

Guillaume de Visdelou.

Pierre de Boispéan.

Macé le Vicomte.

Geoffroy du Plessis.

Aymeric du Verger.

Aymeric de Sainte-Hermine.

Aymeric de Rechignevoisins.

Geoffroy de Kersaliou.

Guillaume, seigneur de Mornay.

Guillaume de Chauvigny.

Gaillard de Pechpeyrou.

Sanchon de Corn.

Bertrand de Lentilhac.

Guillaume de Courbon.

Aymeric et Guillaume de Monialembert.

Hugues Gourjault.
Guillaume Séguier.

Dalmas de Boruillé.

Bertrand de Thésan.

Hugues de Sacle.

Aster ou Austor de Mun.

Enguerrand Bournel.

Payen Gauteron.

Alain de Boisbaudry.

Hugues de Fontanges.

Amblard de Plas.

Guy de Chabannes.

Gautier de Sartiges.

Roger de la Rochelambert.

Guillaume de Chavagnac.

Bernard de David.

Pierre de Lasteyrie.

Guillaume Amalvin et Gasbert de Luzech.

A. de Valon.

Pierre de Saint-Geniez.

Raymond et Bernard de la Popie.

F. de Roset.

J. de Feydit.

Bertrand de las Cases.

Hugues de Gasca.

Guillaume de Balaguier.

Motet et Raoul de la Panouse.

Bernard de Levezou.

Hervé Siochan.

Bernard de Cassaignes.

Amalvin de Preissac.

Bernard de Guiscard.

Pierre d'Yzarn.

Thibaut de Solages.

Pierre de Mostuéjouls.

Déodat et Arnaud de Caylus.

Dalmas de Vezins.

Hugues et Girard de Curières.

Rostain de Bessuéjouls.

Laurent de la Laurencie.

André de Boisse.

Guillaume de Bonneval.

Guillaume de la Rode.

Adhémar de Gain.

\section{Siége de Belbeys. - 1163.}

$$
\text { ............ H. 0,71. - L. } 0,79 \text {. }
$$




\section{Bataille d'Ascalon. - 18 novembre 1177.}

Par M. LARIVIÈRE. - H. 3,14. - L. 5,63.

Baudouin IV, roi de Jérusalem apprenant que les Sarrasins avaient envahi son territoire, sortit d'Ascalon du côté de la mer et suivit le rivage, afin de surprendre Saladin dans la plaine où il s'était arrêté. Il avait avec lui Odon de Saint-Amand, grand-maître du Temple, et quatre-vingts de ses chevaliers, le prince Raimond, Baudouin de Ramla et Balian, son frère, Renaud de Sidon et le comte Josselin, son oncle, sénéchal du royaume; Albert, évêque de Bethléem, portant le bois de la vraie Croix, marchait à leur tête. Le roi Baudouin étant malade se faisait porter sur un brancard. Tandis qu'ils s'avançaient, le spectacle des incendies qui sillonnaient le passage des Sarrasins excitait leur courage, et ils joignirent enfin l'ennemi vers la huitième heure du jour. Après une courte résistance, le désordre se mit dans les rangs des Infidèles, qui prirent la fuite en laissant sur le champ de bataille un grand nombre de morts.

Ce tableau a été exposé au Salon de 1844.

\section{Guy de Lusignan, roi de Jérusalem et de Chypre.} Par M. Picot. - H. 1,04. - L. 0,82.

Guy de Lusignan tenait ses droits au trône de Jérusalem de son mariage avec Sibylle d'Anjou, fille du roi Amaury. Il tomba prisonnier aux mains de Saladin à la bataille de Tibériade en 1187, et à peine rendu à la liberté vint mettre le siége devant Ptolémaïs en 1189. Richard-Coeur-de-Lion lui céda en 1192 la souveraineté de l'île de Chypre où il mourut en 1194 à l'âge de quarante-neuf ans.

\section{Conrad, marquis de Montferrat et de Tyr.}

Par M. Picot. - H. 1,04. - L. 0,77.

Il prit la croix en 1186, et recut le marquisat de Tyr en récompense de ses exploits pour la défense de cette ville contre Saladin. Son mariage avec Isabelle d'Anjou, fille d'Amaury, roi de Jérusalem, lui assurait des droits au trône de la ville sainte lorsque, au moment d'être investi de cette royauté devenue purement titulaire, il fut assassiné à Tyr, au rapport de quelques chroniques, par deux envoyés du Vieux de la Montagne, le 3 des calendes de mai (29 avril 1192).

383. Entrevue de Philippe-Auguste avec Henri II à Gisors. - 21 janvier 1188.

Par M. SAINT-Èvre en 1839. - H. 1,12. - L. 1,64.

Philippe-Auguste prit la croix à Gisors avec le roi d'Angle- 
terre, Henri II; les deux monarques abjurèrent leurs ressentiments devant le grand intérêt de la guerre sainte, et s'embrassèrent en versant des larmes.

\section{Frédéric Irr, surnommé Barberousse, empereur d'Allemagne.}

Par M. Picot. - H. 1,04. - L. 0,79.

Fils de Frédéric de Souabe, neveu de l'empereur Conrad III, il naquit en 1121. A la mort de son oncle, il fut élu empereur par la diète de Francfort en 1152. Après une lutte de dix-huit années contre le siége apostolique et la liberté des villes italiennes, il se croisa en 1189 dans une diète tenue le 27 mars à Mayence, ainsi que Frédéric, son fils, duc de Souabe, et soixante-huit seigneurs tant clercs que laïques. Après avoir battu deux fois le sultan d'Iconium et pris d'assaut sa capitale, il mourut en Cilicie le $\mathbf{1 0}$ juin 1190, en se baignant dans les eaux du Salef.

\section{Philippe-Auguste prend l'oriflamme à Saint- Denis. - 24 juin 1190.}

Par Révoll en 1841 - - H. 0,71. - L. 0,79.

Le roi, suivi d'un nombreux cortége, reçoit la pannetière et le bourdon de pèlerin des mains de Guillaume, archevêque de Reims, son oncle, légat du siége apostolique.

\section{Baiaille d'Arsur. - 1191.}

Par M. FÉron en 1843. - H. 3,14. - L. $2,32$.

Les Croisés, ayant à leur tête Richard-Cœur-de-Lion, le duc de Bourgogne et le comte de Champagne, étaient en marche vers Jérusalem. Ils débouchaient des montagnes de Naplouse dans la plaine d'Arsur, quand ils y trouvèrent deux cent mille Musulmans qui les attendaient pour leur disputer le passage. L'arrièregarde des Chrétiens, où étaient les Hospitaliers, s'ébranla la première, et bientôt tout le reste de l'armée, chevaliers de Bourgogne et de Champagne, Flamands, Angevins, Bretons, Poitevins, fut entraîné à leur suite. De la mer aux montagnes ce ne fut plus qu'un vaste champ de carnage. Richard se montrait partout faisant entendre son redoutable cri de guerre : Dieu, secourez le Saint-Sépulcrel et partout des ruisseaux de sang, des escadrons en désordre marquaient son passage. En peu de temps l'armée de Saladin fut ảispersée et eût été anéantie tout entière, si la forêt d'Arsur n'eût accueilli et protégé ses débris.

Ce tableau a été exposé au Salon de 1844. 


\section{Prise de Baruth. -1197.}

Par M. Alex. Hesse. - H. 1,73. - L. 3,43.

Guillaume de Tyr rapporte que " le roi Amaury, le Temple et l'Hôpital, le chancelier d'Allemagne et les barons du pays, donnèrent conseil d’aller assiéger Beryte (Baruth). Les Sarrasins qui étaient sortis du château, virent que les Chrétiens approchaient rudement par mer et par terre ; ils retournèrent en arrière et crurent rentrer au château, mais ils virent la porte fermée par les esclaves chrétiens qui, pour favoriser les armes des Croisés, étaient sur la porte et sur la maîtresse tour, et criaient: Dieu et SaintSépulcre! Les Sarrasins, voyant qu'ils avaient perdu le château, s'enfuirent, et le chàteau demeura aux Chrétiens. »

Ce tableau a été exposé au Salon de 1848.

\section{Défaite de Malek-el-Adel (Saphadin) entre Tyr et Sidon. - 1197. \\ ..........- H. 1,12. - L. 1,64 .}

389. Boniface de Montferrat, élu chef de la quatrième Croisade, à Soissons. - 1201.

Par DeCaisne en 1849. - H. 0,70. - L. 0,79.

Après la mort de Thibaud, comte de Champagne, les barons el les chevaliers qui avaient pris la croix offrirent le commandement au marquis de Montferrat. Il vint à Soissons où il reçut la croix des mains du curé de Neuilly, et fut proclamé chef de la Croisade dans l'église de Notre-Dame, en présence du clergé et du peuple.

\section{Traité conclu entre les Croisés et les Vénitiens dans l'église de Saint-Marc. - 1201.}

Par Revoux en 1839. - H. 3,14. - L. 2,33.

Une députation de Croisés, sous la conduite de Geoffroy de VilleHardouin, s'était rendue à Venise pour demander des vaisseaux à la République. Une assemblée générale du peuple fut convoquée dans l'église de Saint-Marc, et l'on commença par y célébrer la messe du Saint-Esprit; puis les députés furent introduits. "Alors Geoffroy de Ville-Hardouin, maréchal de Champagne, prenant la parole pour ses compagnons, et de leur consentement, dit : Seigneurs, les plus grands et les plus puissants barons de France nous ont envoyés vers vous pour vous prier, au nom de Dieu, d'avoir compassion de Hiérusalem, qui est en servage des Tures, et de vouloir les accompagner en cette occasion pour venger l'injure faite à notre Seigneur Jésus-Christ, ayant jeté les yeux sur 
vous comme ceux qu'ils savent être les plus puissants sur la mer, et nous ont chargés de nous prosterner à vos pieds, sans nous relever que vous ne nous ayez octroyé d'avoir pitié de la TerreSainte d'outre-mer. Là-dessus les six députés s'agenouillent à leurs pieds, pleurant à chaudes larmes, et le vieux doge Henri Dandolo, devenu aveugle, se lève avec le peuple entier qui s'écrie, en levant les mains : Nous l'octroyons! nous l'octroyons!»

\section{Baudouin $I^{\text {er }}$, comte de Flandre, empereur de Constantinople.}

Par M. Рісот. - H. 1,04. - L. 0,80.

Baudouin, IX ${ }^{\mathrm{e}}$ du nom, né à Valenciennes, en 1171, hérita du comté de Flandre en 1194, et prit la croix en 1200. Les Croisés s'étant emparés de Constantinople, donnèrent, en 1204, la couronne des empereurs d'Orient à Baudouin. Fait prisonnier dans une guerre qu'il avait entreprise contre les Bulgares, il mourut en 1206 dans la captivité, à l'âge de trente-cinq ans.

\section{Baudouin couronné empereur de Constantinople.} - 16 mai 1204.

Par M. Gallait en 1847. - H. 3,14. - L. 5,63.

Baudouin se rendit à Sainte-Sophie, accompagné des barons et du clergé. " Là, dit Michaud, pendant qu'on célébrait le service divin, l'empereur fut élevé sur un trône d'or et reçut la pourpre des mains du légat du pape, qui remplissait les fonctions de patriarche; deux chevaliers portaient devant lui le laticlave des consuls romains, et l'épée impériale, qu'on revoyait enfin dans la main des guerriers et des héros. Le chef du clergé, devant l'autel, prononça dans la langue grecque ces paroles : Il est digne de régner; et tous les assistants répétèrent en chœur: Il en est digne, il en est digne. Les Croisés faisant entendre leurs bruyantes acclamations, les chevaliers, couverts de leurs armes; la foule misérable des Grecs, le sanctuaire dépouillé de ses antiques ornements et rempli d'une pompe étrangère, présentaient à la fois un spectacle solennel et lugubre, et montraient tous les malheurs de la guerre au milieu des trophées de la victoire $»$.

Ce tableau a été exposé au Salon de 1848.

393. Jean de Brienne, roi de Jérusalem, empereur de Constantinople.

Par M. Рісот. - H. 1,04. - L. 0,77.

Simple cadet de la maison de Brienne, il prit part à la prise de Constantinople en 1204, et après la mort d'Amaury, roi de Jéru- 
salem, fut élu par les barons de la Palestine pour le remplacer. Il fut couronné à Tyr en 1210, et revint en France, en 1221, demander des secours pour la Terre-Sainte. Appelé en 1231 au trône impérial par les barons français de l'empire d'Orient, il joignit à la couronne qu'il avait portée, celle des empereurs de Constantinople. Il mourut le 23 mars 1237, âgé de quatre-vingt-neuf ans.

\section{André de Hongrie se fait associer à l'ordre de Saint-Jean-de-Jérusalem. - 1218.}

Par M. Saint-Evre. - H. 0,70. - L. 0,79.

André II, roi de Hongrie, petit-fils de Louis-le-Jeune, par sa mère Marguerite de France, passant par Saint-Jean-d'Acre, fut si édifié de la charité qu'exerçaient les Hospitaliers, qu'il demanda, dit Vertot, d'être associé dans l'ordre en qualité de confrère, et reçut l'habit de chevalier des mains de Guérin de Montaigu.

\section{QUATRIÈME SALLE DES CROISADES, № 20.}

L'appartement que cette salle a remplacé fut habité, sous Louis XV, par la princesse d'Egmont, puis par la duchesse de Boufflers, dame du palais de la reine.

Le plafond et la frise offrent les armoiries des Croisés et des chevaliers des ordres religieux depuis 1218 jusqu'en 1553, savoir :

1218.

Géraud de Bosredont. 1248.

Robert de Coustin.

Arnaud de Gironde.

Dieudonné d'Albignac.

Raoul et Guillaume du Authier.

Guy, Guichard et Bernard d'Escayrac.

Bernard de Montault.

Geoffroy de Courtarvel.

Pierre Isoré.

Robert et Henri de Grouchy.

Carbonnel et Galhard de la Roche.

Guillaume de Polastron.

André de Vitré.

Thomas de Taillepied.

Geoffroy de Montbourcher.

Thomas de Boisgelin.

Guillaume d'Asnières.

Guillaume de Maingot.

Arnaud de Noë.

Roux de Varaigne.

Pierre de l'Espine.

Pierre de Pomolain.
Guillaume de Brachet.

Audoin de Lestranges.

Hugues de Carbonnières.

Harduin de Pérusse.

Bertrand d'Espinchal.

Payen Euzenou.

Guillaume de Cadoine.

Guillaume et Guillaume-Raymond de Ségur.

Guiliaume et Aymon de la RocheAymon.

Pons Motier.

D. de Verdonnet.

Jean d'Audiffred.

1250.

Renaud de Vichy, grand-maître de l'ordre du Temple. 1252.

Bohémond VI, prince d'Antioche.

Guillaume-Raymond de Grossolles.

Geoffroy de Penne.

Pierre de Gimel.

Arnaud de Marquefave.

Pierre de Voisins. 


\section{QUATRIÉME SALLE DES GROISADES, No 20.}

Thomas Bérault, grand-mattre de l'ordre du Temple.

1259.

Hugues de Revel, grand-maitre de l'ordre de Saint-Jean de Jérusalem. 1267.

Sicard, vicomte de Lautrec. 1269.

Eudes de Bourgogne, sire de Bourbon, comte de Nevers, d'Auxerre et de Tounerre.

1270.

Ferry de Verneuil, maréchal de France. Jean Britaut.

Raoul le Flamenc, seigneur de Cany, depuis maréchal de France.

Pierre de Blémus.

Erard, seigneur de Valery, connétable de Champagne.

Roger, fils de Raymond Trencavel, dernier vicomte de Béziers et de Carcassonne.

Jean III, Jean IV et Raoul de Nesle.

Simon de Clermont, II du nom, seigneur de Néelle et d'Ailly.

Amaury de Saint-Cler.

Jean Malet.

Hugues de Villers.

Jean de Prie, seigneur de Buzançois.

Etienne et Guillaume Granche.

Gisbert ${ }^{\mathrm{er}}$, seigneur de Thémines.

Geoffroy de Rostrenen.

Pierre de Kergorlay.

Maurice de Bréon.

Guy de Severac.

Gilles de Boissavesnes.

Guillaume de Patay.

Gilles de la Tournelle.

Jean de Chambly.

Simon de Coutes.

\section{3.}

Guillaume de Beaujeu, grand-mattre de l'ordre du T'eınple.

$$
1278 .
$$

Nicolas Lorgue, grand-maitre de l'ordre de Saint-Jean de Jérusalem. 1289.

Jean de Villiers, grand-maitre de l'ordre de Saint-Jean de Jérusalem. 1291.

Le moine Gaudini, grand-mâttre de l'ordre du Temple. 1298.

Odon de Pins, grand-maitre de l'ordre de Saint-Jean de Jérusalem.
1300

Guillaume de Villaret, grand-maittrc de l'ordre de Saint-Jean de Jérusalem.

\section{5.}

Jacques Brunier, chancelier du Dauphiné.

Jean Aleman.

Guillaume de Morges.

Didier, seigneur de Sassenage.

Aymon et Guiscard de Chissey.

Raymond de Montauban, seigneur de Montmaur.

Geoffroy de Clermont, seigneur de Chaste.

1354.

Pierre de Corneillan, grand-maitre de Rhodes.

$$
1355 .
$$

Roger de Pins, grand - maître de Rhodes.

1374.

Robert de Juilly, grand-maittre de Rhodes.

1376.

Jean Fernandès de Hérédia, grandmaître de Rhodes.

1396.

Philippe d'Artois, comte d'Eu, connétable de France.

Jacques de Bourbon, II ${ }^{e}$ du nom, comte de la Marche.

1454.

Jacques de Milly, grand-maitre de Rhodes.

1461.

Pierre-Raymond Zacosta, grand-maitre de Rhodes.

1467.

Jean-Baptiste des Ursins, grand-maître de Rhodes.

1512.

Guy de Blanchefort, grand-maître de Rhodes.

1534.

Pierre du Pont, grand-maître de Malte. 1535.

Didier de Saint-Jaille, grand-maittre de Malte.

1536.

Jean d'Omèdes, grand-maître de Malte. 1553.

Claude de la Sangle, grand-maitre de Malte.

\section{Reprise du château de Jaffa. - 1192.}

Par M. Ed. Girardet en 1844. - H. 0,70. - L. 0,79.

Pendant une expédition de Richard-Cœur-de-Lion sur les fron-

6. 
tières de l'Egypte et de la Cilicie, Saladin était venu surprendre la citadelle de Jaffa. Le roi d'Angleterre, averti du danger qui menacait la ville, s'embarque à Saint-Jean-d'Acre et chasse les Musulmans du point dont ils s'étaient emparés.

\section{Réception de Jean de Brienne à Ptolémaïs. - 13 septembre 1210.}

\section{.......... - H. 3,17. - L. 5,57 .}

397. Débarquement de saint Louis en Égypte. 4 juin 1249.

Par M. RocGet en 1839. - H. 1,73. - L. 1,12.

Au mois de juin 1249, la flotte qui portait les Croisés parut à l'embouchure du Nil, devant Damiette. Une armée de Sarrasins bordait le rivage. Saint Louis donne l'exemple à ses guerriers; malgré le légat qui veut le retenir, il se jette à la mer, couvert de son armure et ayant de l'eau jusqu aux épaules. Le sire de Joinville, Baudouin de Reims, le comte de Jaffa, rivalisent d'ardeur avec leur roi; ils ont des premiers mis le pied sur le sable, et avec une poignée de chevaliers qui les ont suivis, ils s'y forment en bataille pour soutenir le choc de la.cavalerie ennemie qui vient les charger.

398. Saint Louis recoit à Damiette le patriarche de Jérusalem. - 1249.

Par M. Oscar GUE. - H. 0,70. - L. 0,70.

Robert, patriarche de Jérusalem, se trouva avec saint Louis au siége de Damiette, et lorsque la ville fut prise, il y entra nu-pieds avec le roi, et y célébra les saints mystères.

399. Gaucher de Châtillon défend seul l'entrée d'une rue dans le faubourg de Miniéh. - 1250.

Par M. Karl Girardet. - H. 1,1i, - L. 1,12.

Après la bataille de Mansourah, le roi saint Louis, escorié par quelques chevaliers seulement, entra dans la ville de Miniéh. L'intrépide Gaucher de Chàtillon défendit seul contre les Sarrasins l'entrée d’une rue étroite qui conduisait à l'asile du roi. Aucun des croisés ne put le secourir ni être témoin de sa fin héroïque.

Ce tableau a été exposé au Salon de 184'\%. 
400. Philippe III (Philippe-le-Hardi), roi de France. (Voir $\mathrm{n}^{\circ}$ 694.)

Par M. Laemlein. - H. 1,03. - L. 0,77.

401. Concile de Lyon. - 1274.

.......... - H. 1,11. - L. 1,35.

402. Guillaume de Clermont défend Ptolémaïs.-1291. Par PAPETY. - H. 1,73. - L. 1,35.

La ville de Ptolémaïs était assiégée par l'armée du sultan d'Égypte Kelaoun et allait être prise d'assaut, lorsque Guillaume de Clermont, maréchal des Hospitaliers, accourt avec ses chevaliers au lieu du carnage. Il relève le courage des assiégés, se précipite dans les rangs des Sarrasins, et, vers le soir, les assaillants se retiraient en désordre par la brèche qu'ils avaient faite.

Ce tableau a èté exposé au Salon de 1845.

403. Jacques Molay prend Jérusalem. - 1299.

Par M. JACQUAND en 1846. - H. 1,73. - L. 3,15.

Les chevaliers du Temple, ayant à leur tête Jacques Molay, surprennent à la pointe du jour la ville de Jérusalem. Ce fut la dernière occupation de la cité sainte par les Chrétiens.

Ce tableau a été exposé au Salon de 1846.

\section{Prise de Rhodes - 15 août 1310.}

Par M. Feron. - H. 1,11. - L. 1,49.

Les chevaliers de Saint-Jean, ayant à leur tête Foulques de Villaret, assiégèrent l'île de Rhodes pendant quatre ans. Enfin la place fut emportée d'assaut, et le jour de l'Assomption l'étendard de la religion fut arboré sur la brèche de Rhodes conquise.

405. Défense de Rhodes contre le sultan Othman. 1315.

…..... - H. 3,17. - L. 5,57.

406. Bataille navale d'Episcopia. - 1323.

Par II. Auguste MAYYr. - H. 1,11. - L. 1,49.

Le sultan Orkhan avait équipé une flotte de quatre-vingts navires avec laquelle il espérait surprendre Rhodes. Mais le commandeur Gérard de Pins, avec dix galères et quelques navires marchands rassemblés à la hâte, ne craignit point d'aller au-devant de son puissant ennemi. Le combat s'engagea près de la petite île 
d'Episcopia. Orkhan perdit le plus grand nombre de ses vaisseaux, pris ou coulés à fond.

\section{Prise du château de Smyrne. - 1344.}

Par DebacQ en 1845. - H. 1,73. - L. 1,35.

Les chevaliers de Rhodes, conduits par Biandra, grand-prieur de Lombardie, firent, en 1344, une tentative prèsla ville de Smyrne, et s'emparèrent du château qui commandait le port. Tout ce qui se trouva dans ce fort, Tures et Arabes, fut taillé en pièces.

\section{Bataille navale d'Embro. - 1346.}

Par M. Eugène Leportevir en 1841. - H. 1,21. - L. 1,35.

Les Tures étaient à l'ancre, dans la petite île d'Embro, à douze milles des bouches des Dardanelles, lorsque Biandra, prieur de Lombardie, les surprit. a Ce fut, dit Vertot, moins un combat qu'une déroute générale; les soldats qui étoient sur cette flotte l'abandonnoient pour chercher un asile dans lî̀le, et ceux qui étoient descendus à terre auparavant accouroient pour se rembarquer. Les uns et les autres ne faisoient que s'embarrasser; et dans ce désordre et cette confusion, le général de Rhodes leur prit cent dix-huit petits vaisseaux, légères frégates, brigantins, felouques ou barques armées, qu'il ramena triomphalement à Rhodes ».

\section{Les chevaliers de Saint-Jean rétablissent la reli- gion en Arménie. - 1347.}

Par M. Henri DeLaborde en 1844. - H. 0,70. - L. 0,79.

Le royaume chrétien d'Arménie était prêt de succomber sous l'invasion des Sarrasins, qui l'occupaient en grande partie. Le roi Constant avait envoyé demander du secours en Europe, le grandmaître Dieudonné de Gozon répondit à son appel. Il envoya les troupes de la religion en Arménlie, et les Sarrasins furent entièrement chassés de ce pays.

410. Prise d'Alexandrie. - 1366. ......... - H. 0,70. - L. 0,79.

411. Philippe d'Artois, comte d'Eu, connétable de France. (Voir n 947.)

Par M. LAemlein. - H. 1,03. - L. 0,80.

412. Jean Sans-Peur, duc de Bourgogne.

Par M. Laemlein. - H. 1,03. - L. 0,80.

Né à Dijon en 1371, il était fils de Philippe-le-Hardi, et portait 
le titre de comte de Nevers, lorsqu'il alla, en 1396, combattre les Turcs à la bataille de Nicopolis. Duc de Bourgogne en 1404, à la mort de son père, il fit lever en 1408 le siége de Maestricht aux Liégeois, et se ligua avec Henri V, roi d'Angleterre, pendant l'invasion de la France. Il fut assassiné sur le pont de MontereauFaut-Yonne, le 10 septembre 1419, dans une entrevue avec le dauphin, fils de Charles VI.

\section{Boucicault (Jean le Meingre, dit) maréchal de France. (Voir no 960 .)}

Par M. LaemLein. - H. 1,03. - L. 0,77.

\section{Levée du siége de Constantinople. - 1402.}

Par Granger en 1839. - H. 1,73. - L. 1.12.

Boucicault conduisit, en 14.02, une armée au secours de Constantinople assiégée par Bajazet. L'arrivée du maréchal rendit courage à l'empereur Paléologue. Par une suite de hardis coups de main les Francais chassèrent les Turcs d'un grand nombre de bourgs et de villages qu'ils occupaient sur le Bosphore, et le siége de Constantinople fut levé.

\section{Chapitre général de l'ordre de Saint-Jean-de- Jérusalem, tenu à Rhodes. - 1514.}

Par M. JAGQUAND. - H. 1,11. - L. 1,12.

A peine élevé à la grande-maitrise de l'ordre de Saint-Jean, Fabrizio Caretto convoqua le chapitre-général de l'ordre, afin de préparer les moyens de résister aux desseins du sultan Selim, sur l'île de Rhodes. Les ressources qu'il demandait lui furent toutes accordées, et Rhodes fut en état de soutenir l'effort de la puissance ottomane.

Ce tableau a été exposé au Salon de 1839.

\section{CINQUIÈME SALLE DES CROISADES, No 21.}

Cette salle, qui s'étend dans toute la largeur du pavillon de Noailles, formait autrefois deux appartements occupés, sous Louis XV, en 1735 par l'abbé de Pomponne et la marquise de Mailly, dame du palais de la reine, et en 1755 par le prince Constantin, premier aumônier du roi, et par le duc de Luxembourg, capitaine des gardes. Les murs de séparation ont été remplacés par des piliers.

Les portes en cèdre et le mortier en bronze placés au milieu de cette salle, proviennent de l'hôpital des chevaliers de Saint-Jean à Rhodes. Ces objets ont été donnés en 1836 au roi Louis-Philippe par le sultan Mahmoud. 
Les armoiries des principaux Croisés, depuis l'an 1096 jusqu'en 1557, décoreut les plafonds et les piliers; ce sont celles de :

1096.

Godefroy de Bouillon, roi de Jérusalen.

Hugues de France, surnommé le Grand, comte de Vermandois.

Eudes Ier, duc de Bourgogne.

Robert III, duc cie Kormandie.

Raymond V, comte de Toulouse.

Robert II, comte de Flandre.

Gérard de Martigues, maître ou recteur de l'hôpital de Saint-Jean de Jérusalem.

Alain IV, dit Fergent, duc de Bretagne.

Bohémond, prince d'Antioche.

Etienne de Champagne, comte de Blois.

Renaud et Etienne, dit Tête-Hardie, comtes de haute Bourgogne.

Louis, fils de 'Thierry Ier, comte de Bar.

Baudouin Ier, roi de Jérusalem.

Baudouin II, comte de Hainaut.

Henri Ier, comte d'Eu.

Etienne de Champagne, comte d'Aumale.

Eustache, comte de Boulogne.

Roger Ier, comte de Foix.

Gaston IV, vicomte de Réarn.

Hugues VI, sire de Lusignan.

Adhémar de Monteil.

Raymond Pelet.

Raymond Ier, vicomte de Turenne.

Tancrède.

Eustache d'Agrain, prince de Sidon et de Césarée, vice-roi et connétable du royaume de Jérusalem.

Bauciouin de Rethel, dit du Bourg, depuis roi de Jérusalem.

Philippe le Grammairien, comte d'Alencon (naison de Belesme).

Geoffroy de Preuilly, comte de Vendûme.

Rotrou II, comte du Perche.

Guillaume Taillefer III, comte d'Angoulême.

Drogon, seigneur de Nesle et de Falvy (souche des comtes de Soissons).

Raimbaud III, comte d'Orange.

Garnier, comte de Gray.

Astanove VII, comte de Fezensac.

Etienne et Pierre de Salviac de VielCastel.

Thomas de Coucy.

Gilbert, dit Payen, de Garlande.

Amanjeu II, sire d'Albret.

Ithier II, seigneur de Tocy et de Puisaye.

Raymond Bertrand, seigneur de l'Islejourdain.
Guillaume de Sabran.

Foulques de Maillé.

Calo II, seigneur de Caumont.

Roger de Choiseul.

Guillaume Ier, dit le Charpentier, vicomte de Melun.

Guy de Thiern, comte de Châlons-surSaône.

Gérard, sire de Créquy.

Host du Roure.

Jean et Colard de Houdetot.

Robert de Nevers.

Raimbaud Creton, seigneur d'Estourmel.

Pons et Bernard de Montlaur.

Arnoul, baron d'Ardres.

Guillaume III, comte de Isyonnais et de Forez.

Hugues de Saint-Omer.

Renaud de Pons.

Hugues du Puy, seigneur de Pereins, d'Apifer et de Rochefort.

Gérard de Bournonville.

Héracle, comte de Polignac.

Aimery IV, vicomte de Rochechouart.

Adam de Béthune.

Guy, sire de Laval.

Pierre Raymond de Hautpoul.

Gaucher ier, de Châtillon.

Raou!, seigneur d'Escorailles.

Gérardi, comte cie Roussillon.

Guillaume V, seigneur de Montpellier.

Gérard de Chérizy.

Pierre Ier, vicomte de Castillon.

Guérin de Rochemore.

Eléazar đ'e Montredon.

Pierre et Pons de Capileuil (Fay).

Bernard, comte de Saint-Valery.

Raoul, seigneur de Beaugency.

Guillaume de Briqueville.

Philippe de Montgommery.

Robert de Vieux-Pont.

Hugues, comte de Saint-Pol.

Anselme de Ribaumont.

Golfier de Lastours, dit le Grand, seigneur de Hautefort.

Manassès, comte de Guines.

Geoffroy II, baron de Donzi.

Guy, sire de la Trémoille.

Robert de Courcy.

Renaud de Beauvais.

Jean de Mathan.

Guillaume Raymond.

Guillaume de Pierre, seigneur de Ganges.

Clairambault de Vandeuil.

Guillaume Carbonnel de Canisy.

Bertrand Porcelet. 
Claude de Montchenu.

Jourdain IV, sire de Chabannais et de Confolent.

Robert de Sourdeval.

Philippe, seigneur de Montbel.

Foulcher d'Orléans.

Gauthier, seigneur de Breteuil.

Drogon ou Dreux de Monchy.

Guillaume de Bures, seigneur de Tibériade.

Baudouin de Gand, seigneur d'Alost.

Gérard, seigneur de Gournay.

Le seigneur de Cardaillac.

Le seigueur de Barasc.

Géraud, seigneur de Gourdon. 1099.

Josselin de Courtenay. 1100.

Guillaume IX, duc de Guyenne et comte de Poitiers.

Guillaume II, comte de Nevers.

Eudes Herpin, vicomte de Bourges.

Herbert II, vicomte de Thouars. 1101.

Bernard Aston, vicomte de Béziers.

Baudouin de Grandpré.

Hugues, dit Barloul II, seigneur de Broyes.

1102.

Guillaume VII, comte d'Auvergne.

Le baron de la Tour-d'Auvergne.

Jean, vicomte de Murat.

Arnaud d'Apchon.

1103.

Guillaume de Castelnau.

Robert Damas.

1106.

1107.

Robert, comte de Montfort-sur-Rille.

$$
1109 .
$$

Raymond II, comte de Substantion et de Melgueil.

1111.

Pierre, seigneur de Noailles.

Gérard de Briord. 1112.

1119.

Raymond du Puy, premier grandmaître de l'ordre de Saint-Jean-deJérusalem.

1120.

Gauthier de Beyviers.

Archeric, seigneur de Corsant.

Ulric de Baugé, seigneur de Bresse.

Pernold de Saint-Sulpis.

1128.

Hugues de Payens, premier grandnaître de l'ordre du Temple.

1133.

Humbert III, dit le Renforcé, sire de Salins.
Louis VII, dit le Jeune, roi de France. Conrad III, empereur d'Allemagne.

Robert de France, comte de Dreux.

Henri $I^{\text {er }}$, comte de Champagne et de Brie.

Archambaud VI, seigneur de Bourbon.

Thibaut de Montmorency.

Guy II, comte de Ponthieu.

Renaud, comte de Joigny.

Sebran Chabot.

Rainaud V, vicomte d'Aubusson.

Guerric $I^{\mathbf{e r}}$, seigneur de Coligny.

Guillaume VIII, comte et premier dauphin d'Auvergne.

Richard de Harcourt.

Guillaumd de Trie.

Hugues II, seigneur de Montmorin.

Hugues Ier, comte de Vaudémont.

Galeran III, comte de Meulent.

Maurice de Montréal.

Soffrey de Beaumont (en Dauphiné).

Gilles, dit Gillion, seigneur de Tra-signies.

Geoftroy Waglisp ou Gayclip, aieul de Du Guesclin.

Hugues V, seigneur de Beaumont-surVigenne.

Ebles III, vicomte de Ventadour.

Ithier de Magnac.

Manassès de Bulles.

Hugues VII, dit le Brun, sire de Lezignem.

Geoffroy de Rancon.

Guy IV, de Comborn, vicomte de Limoges.

Hugues Tyrrel, sire de Poix.

Renaud, comte de Tonnerre. 1148.

Amédée II, comte de Maurienne et de Savoie.

1149.

Bernard de T'ramelay, grand-maître de l'ordre du Temple.

1177.

Roger Desmoulins, grand-maître de l'ordre de Saint-'ean-de-Jérusalem.

1190.

Philippe-Auguste, roi de France.

Frédéric Barberousse, empereur d'Allemagne.

Richard Cour-de-Lion, roi d'Angleterre.

Hugues III, duc de Bourgogne.

Henri I er, comte de Brabant.

Raoul, comte de Clermont en Beauvoisis, connétable de France.

Albéric Clément, seigneur du Mez, maréchal de France.

Jacques d'Avesnes.

Dreux de Mello, IVe du nom, depuis connétable de France. 
Etienne de Champagne, Ier du nom, comte de Sancerre.

Guy de Senlis, IVe du nom, seigneur de Chantilly.

Adam III, seigneur de l'Isle.

Raymond Aymery II, baron de Montesquiou.

Clérembault, seigneur de Noyers.

Jean $I^{\text {er }}$ de Saint-Simon.

Guillaume de la Rochefoucault, vicomte de Châtellerault.

Laurent du Plessis.

Florent de Hangest.

Hugues, seigneur de Vergy.

Dreux II, seigneur de Cressonsart.

And é de Brienne, seigneur de Rameru.

Aléaume de Fontaines.

Osmond d'Estouteville.

Raoul de Tilly.

Mathieu III, comte de Beaumont-surOise.

Léon, seigneur de Dienne.

Juel, seigneur de Mayenne.

Hellin de Waurin.

\section{1.}

Henri de Walpot de Passenheim, premier grand - maître de l'ordre Teutonique.

Robert de Sablé, grand-maître de de l'ordre du Temple.

Guy de Lusignan, roi de Chypre. 1196.

Marguerite de France, reine de Hongrie.

Enguerrand, seigneur de Crèvecœur. 1202.

La république de Venise.

Geoffroy de Villehardouin.

Simon III, comte de Montfort.

Renaud, seigneur de Montmirail.

Richard, seigneur de Montbéliard.

Eustache de Saarbruck.

Eudes et Guillaume, seigneur de Champlite.

Eustache, seigneur de Conflans.

Pierre de Bermond, baron d'Anduze.

Guillaume d'Aunoy.

Guigues III, comte de Forez.

Eudes, seigneur de Ham (ancien Vermandois ).

Nicolas, seigneur de Mailly.

Baudouin d'Aubigny.

Henri, seigneur de Montreuil-Bellay.

Bernard III de Moreuil.

Gauthier, seigneur de Bousies.

Othon de la Roche, sire de Ray.

Anselme de Cayeux.

Enguerrand, seigneur de Fiennes.

Eustache de Canteleu.

Robert Nalvoisin.
1207.

Guérin de Montagu, grand-maitre de l'ordre de Saint-Jean-de-Jérusalem. 1215.

André, roi de Hongrie. 1218.

Henri, comte de Rodez et de Carlat. Milon III, comte de Bar-sur-Seine. Grimaldus, seigneur de Monaco.

Savary de Mauléon.

Pierre de Lyobard.

Jean, seigneur d'Arcis-sur-Aube. 1221.

Jean de Brienne, roi de Jérusalem, empereur de Constantinople.

Pierre II, seigneur de Courtenay, empereur de Constantinople.

1228.

Frédéric II, empereur d'Allemagne. 1233.

Hermann ou Armand de Périgord, grand-maître de l'ordre du Temple. 1248.

Louis IX (Saint-Louis), roi de France. Robert d'Artois, frère de Saint-Louis . Alphonse, comte de Poitiers.

Charles de France, comte d'Anjou.

Hugues IV, duc de Bourgogne.

Pierre de Courtenay.

Thibaut VI, comte de Champagne, roi de Navarre.

Pierre de Dreux, dit Mauclerc, duc de Bretagne.

Jean, sire de Joinville.

Archambaud IX de Dampierre, sire de Bourbon.

Humbert de Beaujeu, seigneur de Montpensier, connétable de.France.

Aymery VI, comte de Montfort-l'Amaury, connétable de France.

Hugues XI, dit le Brun, sire de Lezignem, comte de la Marche.

Henri Clément, maréchal de France.

Guillaume de Beaumont, maréchal de France.

Mathieu I er du nom, seignéur de Roye.

Gilles, sire de Rieux.

Boson de Talleyrand, seigneur de Grignols.

Gaston II de Gontaut, seigneur de Biron.

Roland de Cossé.

Henri, seigneur de Boufflers.

Jean Ier, sire d'Aumont.

Geoffroy V, baron de Châteaubriant.

Olivier de Termes.

Gauthier, vicomte de Meaux.

Pons de Villeneuve.

Hélie de Bourdeilles.

Jean de Beaufort en Artois. 
Guẻrin de Châteauneuf de Randon, seigneur d'Apehier.

Gaubert d'Aspremont.

Pliilippe II, seigneur de Nanteuil, du Plaissier, de Pomponne et de Lévignen.

Geoffroy de Sargines.

Ilugues de Trichâtel, seigneur d'Escouflans.

Josseran de Brancion,

Roger de Brosse, seigneur de Boussac.

Foulques de Merle.

Pierre de Villebéoll, grand chambellan de France.

Gauthier de Brienne, comte de Jaffa.

Hugues Bonafos de Teyssieu.

Jacques de Saulx.

Henri de Roucy, seigneur de Thosny et du Bois.

1270.

Philippe-le-Hardi, roi de France.

Jean Tristan, comte de Nevers.

Pierre, comte d'Alençon.

Guy de Lévis, III ${ }^{\mathrm{e}}$ dù nom, maréchal de Mirepoix.

Astorg d'Aurillac, baron d'Aurillac et vicomte de Conros.

Anselme de Torote, seigneur d'Offemont.

Guillaume III, vicomte de Meluu.

Mathieu III, seigneur de Montmorency.

Florent de Varennes, amiral de France.

Guy VII, sire de Montınorency-Laval.

Raoul de Sores, sire d'Estrées, maréchal de France.

Thibaut de Marly, seigneur de Mondreville.

Lancelot de Saint-Maard, maréchal de France.

Guillaume V, seigneur du Bec-Crespin, maréchal de France.

Héric de Beaujeu, maréchal de France.

Renaud de Pressigny, maréchal de France.

Guy de Châtillon, comte de Blois.

Jean de Rochefort.

Prégent, sire de Coëtivy.

Bernard II, seigneur de lá Tour-d'Auvergne.

Jean $1^{\text {er }}$, sire de Grailly.

Philippe, sire d'Auxy.

Bernard, seigneur de Pardaillan.

Jean de Sully.
Guy, baron de Tournebu.

Aubert et Baudouin de Longueval.

Raoul et Gauthier de Jupilles.

sacé de Lyons.

$$
1288 .
$$

Jean III, seigneur de Saint-Mauris-enMontagne.

Guillaume, baron de Montjoye.

1298.

Jacques de Molay, dernier grand-maître de l'ordre du Temple. 1310.

Foulques de Villaret, grand-maitre de l'ordre de Saint-Jean de Jérusalem. 1319.

Hélion de Villeneuve, grand-maître de l'ordre de Saint-Jean de Jérusalem.

1346.

Dieudomé de Gozon, grand-maître de l'ordre de Saint-Jean de Jérusalem

1365.

Raymond Bérenger, grand-maître de l'ordre de Saint-Jean de Jérusalem. 1396.

Jean de Bourgogne (Jean-sans-Peur), comte de Nevers, depuis duc de Bour gogne.

Jean de Vienne, amiral de France.

Jean le Meingre, dit Boucicault, maréchal de France.

1397.

Philibert de Naillac, grand-maître de l'ordre de Saint-Jean de Jérusalem. 1437.

Jean de Lastic, grand-maître de l'ordre de Saint-Jean de Jérusalem. 1476.

Pierre d'Aubusson, grand-maitre de l'ordre de Saint-Jean de Jérusalem. 1503.

Emeric d'Amboise, grand-maître de l'ordre de Saint-Jean de Jérusalem. 1514.

Fabrice Carette, grand-maître de l'ordre de Saint-Jean de Jérusalem. 1521.

Philippe de Villiers de l'Isle-Adam, grand-maître de l'ordre de Saint-Jean de Jérusalem.

1557.

Jean Parisot de la Valette, grand-maître de l'ordre de Saint-Jean de Jérusalem.

\section{Pierre l'Ermite.}

Par II. L. DE Lestang. - II. 1,70. - L. $0,79$.

Né d'unẹ famille noble du diocèse d'Amiens, il fit le pèlerinage 
de Jérusalem, et à son retour entraina l'Europe à la délivrance de la Terre-Sainte. Après la prise de Jérusalem, il se retira à Huy, aux environs de Liége, et y fonda le monastère de Neumoutiers, où il mourut le 7 juillet 111 .

\section{Adhémar de Monteil, évêque du Puy.}

Par Blondel. - H. 2,58. - L. 0,69.

Il commandait, avec Raymond, comte de Toulouse, les Croisés du midi de la France. Son titre de légat apostolique en fit en quelque sorte le chef spirituel de la croisade. Il mourut à Antioche en 1098.

Il est représentẻ en pied, tenant sa crosse de la main droite et une épée de la main gauche.

\section{Godefroy de Bouillon, roi de Jérusalem.}

Par 1. Émile SigroL en 1844. - H. 2,98. - L. 2,30.

Godefroy, due de la basse Lorraine, après avoir servi en Allemagne et en Italie, dans les armées de l'empereur Henri IV, fut un des chefs de la croisade contre les Infidèles, résolue en $1090 \%$ dans le concile de Clermont, en Auvergne, sous le pape Urbain II. Elu roi de Jérusalem quelques jours après la prise de cette ville, le 20 juillet 1099, il y mourut à l'âge de quarante ans, le 18juillet 1100.

Il est représenté à cheval, montrant aux Croisés la ville de Jérusalem.

\section{Baudouin I ${ }^{\text {er }}$, roi de Jérusalem.}

Par BloNdeL. - H. 1,67. - L. 1,12.

Frère de Godefroy de Bouillon, il l'accompagna en Terre-Sainte, se trouva aux siéges de Nicée et de Tarse, et s'empara de la ville d'Edesse dont il fut reconnu comte. Après la mort de son frère, il fut élu roi de Jérusalem en 1100 , prit aux Musulmans Ptolémaïs, Beryte et Sidon, et mourut en 1118 à Laris, en traversant le désert.

420. Tancrède, prince de Tibériade.

Par BLONDEL. - H. 1,67. - L. 0,78.

Il accompagna en Terre-Sainte son cousin Bohémond, et se trouva aux siéges de Tarse, d:Antioche et de Jérusalem. Godefroy de Bouillon lui donna, en 1100, la principauté de Tibériade, et il mourut en 1112 à Antioche. Les exploits presque fabuleux de Tancrède ont été célébrés dans un poème laissé par son écuyer Raoul de Caen, qui a pour titre: Gestes de Tancrède. 


\section{Hugues de France, comte de Vermandois.}

par Decaisne. - H. 0,94. - L. 0,65 .

Il était fils de Henri Ier, roi de France, et se croisa en 109ð. Ses exploits au siége de Nicée, en 1097, et à celui d'Antioche, en 1098, lui méritèrent le surnom de Grand. Il se croisa de nouveau en 1101, se signala à la bataille d'Héraclée, et mourut le 18 octobre 1101, à Tarse en Cilicie, des suites de ses blessures.

\section{Robert III, surnommé Courteheuse, duc de Normandie.}

Par Decaisne. - H. 0,91. - L. 1,03.

Duc de Normandie, en 1087, à la mort de son père Guillaumele-Conquérant, il fut un des premiers princes français qui prirent la croix, et se signala dans tous les combats de la première croisade. Il revint en 1111 prendre possession de son duché, entreprit de s'emparer du royaume d'Angleterre occupé par son frère Henri Ier, et mourut prisonnier dans le château de Cardiff, le 10 février 1134, après vingt-huit ans de captivité.

\section{Robert II, dit le Iérosolymitain, comte de Flandre.}

Par DeGaISNE. - H. 0,91. - L. 1,03.

Il succéda à son père en 1093, prit part à la première croisade en 1095 , ce qui lui fit donner le surnom de lérosolymitain, et refusa la couronne de Jérusalem. De retour dans ses états en 1100, il soutint en 1107, dans la ville de Douai, un siége contre l'empereur Henri V, s'allia en 1111 avec Louis-le-Gros contre Henri Ier, roi d'Angleterre, et l'aida à battre les Anglais devant Gisors. Ils faisaient ensemble le siége de Meaux, lorsque le pont sur lequel Robert combattait se rompit; il tomba dans la Marne et y périt, le 4 décembre 1111.

424. Prédication de la première Croisade, à Clermont en Auvergne. - Novembre 1095.

$$
\text { .......... - H. 4,06. - L. 4,92. }
$$

Ce tableau a été remplacé provisoirement par une tapisserie des Gobelins, représentant la bataille de Toloza entre les Espagnols et les Maures, en 1212, exécutée d'après un tableau de M. Horace Vernet, exposé au Salon de 1817.

\section{Tancrède prend possession de Béthléem. - 6 juin 1099.}

Par Révoil. - H. 0,70. - L, 0,79.

Les Croisés étant entrés dans la petite ville d'Emmaüs, Godefroy 
de Bouillon envoya Tancrède à la tête de cent cavalier's pour prendre possession de Bethléem. La bannière de la Croix flotta bientôt dans ces murs où était né le Sauveur.

426. Tancrède au mont des Oliviers. - 1099. .......... - H. 0,70. - L. 0,79.

427. Arrivée des Croisés devant Jérusalem. - 1099. .......... - H. 0,70. - L. 0,79 .

428. Procession des Croisés autour de Jérusalem. 14 juillet 1099.

Par M. Schnetz en 1841. - H. 4,06. - L. 4,92.

La veille de la prise de Jérusalem, les Croisés firent une procession autour de la ville. Pierre l'Ermite, évoquant devant eux le souvenir de chacun des saints lieux que foulaient leurs pas, enflamma leur foi et leur enthousiasme, et l'assaut eut lieu le lendemain.

Ce tableau a été exposé au Salon de 1841.

429. Godefroy de Bouillon tient les premières assises du royaume de Jérusalem. - Janvier 1100.

Par M. Jollivet. - H. 0,70. - L. 0,79.

Au commencement de l'année 1100 , Godefroy de Bouillou convoqua à Jérusalem les assises générales du royaume. Baudouin, conquérant d'Edesse, Bohémond, prince d'Antioche, Raymond de Saint-Gilles, seigneur de Laodicée, les seigneurs de Jaffa, de Ramla, de Tibériade, et tous les autres grands feudataires se l'endirent à cette assemblée d'où sortit un des monuments les plus complets de la législation féodale.

430. Du Puy (Raymond), premier grand-maître de - l'ordre de Saint-Jean-de-Jérusalem.

Par M. LaemLein. - H. 1,70. - L. 1,11.

Raymond Du Puy remplaça Gérard dans la préfecture de l'hôpital, l'an 1121. Il fit de nouvelles institutions pour perfectionner la règle que Gérard avait établie; elles furent confirmées en 1123 par le pape Calixte II, et en 1130 par Innocent II. Raymond Du Puy suivit Baudouin II dans ses guerres contre les infidèles, " et depuis ce temps, dit Moréri, il n'y eut aucune expédition ni aucun combat où les chevaliers de cet Ordre ne se trouvassent $"$. Il mourut vers 1160 . 


\section{Institution de l'ordre de Saint-Jean de Jéru- salem. - 15 février 1113.}

Par Decaisne en 1841. - H. 0,71. - L. 1,11.

Vers le milieu du $\mathrm{XI}^{\mathrm{e}}$ siècle, quelques pèlerins s'étaient associés pour fonder l'hôpital de Saint-Jean, et y donner en commun leurs soins aux pauvres et aux malades. Gérard, de la petite île de Martigues, en Provence, fut, sous le titre modeste de maître de l'Hôpital, le premier chef de cette association. Plus tard, après la conquête de Jérusalem, Raymond Du Puy, gentilhomme dauphinois, qui avait succédé à Gérard, conçut la pensée de rendre aux hospitaliers les armes que la plupart avaient quittées pour se vouer à leur mission de charité. Le chapitre de l'ordre ayant été convoqué dans l'église Saint-Jean, Raymond Du Puy fit part à ses frères de sa généreuse proposition. Les hospitaliers reprirent avec un pieux enthousiasme leurs épées, qu'ils s'engageaient à ne tirer que contre les ennemis de la foi. C'est ainsi que, dans ces premiers jours de l'ordre de Saint-Jean, on vit les mêmes hommes, fidèles à leur double mission, tour à tour veiller au lit des malades et monter à cheval pour combattre les Infidèles.

\section{Prise de Tyr. - 1124.}

Par M. Caminade. - H. 0,71. - L. 1,11.

L'arrivée d'une flotte vénitienne sur les côtes de Syrie fournit aux Croisés l'occasion et les moyens d'attaquer l'ancienne ville de Tyr. Ni l'approche d'une armée ennemie, qui venait de Damas au secours de la ville, ni la marche des Egyptiens sur Jérusalem, ne purent arracher aux Chrétiens leur proie : la bannière du roi de Jérusalem, alors prisonnier des Infidèles, flotta avec le lion de Saint-Marc sur les murs de Tyr.

Le comte de Tripoli, accompagné du doge de Venise et du patriarche de Jérusalem, reçoit les clés de la ville.

\section{Hugues de Payens, premier grand-maître de l'ordre du Temple.}

Par M. H. LehmanN. - H. 1,70. - L. 1,11.

Hugues de Payens fonda, avec huit autres chevaliers, une confrérie militaire pour la défense de la Terre-Sainte, qui prit son nom du Temple de Salomon. Il mourut en Orient, en 1136.

\section{Institution de l'ordre du Temple. - 1128.}

Par Granet en 1840. - H. 0,70. - L. 1,11.

Au même temps où l'ordre des Hospitaliers commençait sa glorieuse mission, neuf chevaliers français fondaient une autre 
confrérie militaire, consacrée à la défense des saints lieux et à la protection des pèlerins qui venaient les visiter. Etablis près du temple de Salomon ils en tirèrent leur nom de Templiers. Hugues de Payens et Geoffroy de Saint-Aldemar se rendirent à Rome et demandèrent au Pape Honorius III une règle et le titre d'ordre religieux. La règle leur fut donnée par saint Bernard, et le concile de Troyes en 1128, autorisa l'institution de l'ordre des pawvres soldats du Temple de Salomon.

\section{Le pape Eugène III recoit les ambassadeurs du roi de Jérusalem. - 1145.}

Par NIne Haudebourt en 1839. - H. 0,70. - L. $1,11$.

Après la prise d'Edesse par le sultan Zenghi, en 1144, Baudouin III, roi de Jérusalem, envoya au pape une ambassade que conduisait l'évêque de Gabale. Eugène III la reçut à Viterbe et appela aussitôt les princes d'occident à une nouvelle croisade.

\section{Louis VII, roi de France. (Voir n ${ }^{\circ} 690$. )}

Par M. Emile SignoL. - H. 2,55. - L. 1,31.

Il est représenté en pied tenant son sceptre de la main droite et l'oriflamme de la main gauche.

\section{Henri I $^{\text {, }}$ dit le Libéral, comte palatin de Champagne et de Brie.}

Par DeGaisne. - H. 0,90. - L. 1,21.

N'étant que comte de Meaux il accompagna, en 1147, le roi Louis VII à la croisade et y demeura jusqu'après le siége de Damas, en 1148. Il revint alors en Europe, et à la mort de son père Thibaud IV, en 1152 , lui succéda au comté de Champagne. En 1178, Henri se croisa de nouveau et mourut à Troyes le 17 mars 1181, sept jours après son retour de la Terre-Sainte.

\section{Saint Bernard, premier abbé de Clairvaux.}

Par M. L. DE LestaNG. - H. 1,70. - L. 1,13.

Il entra en 1113, à l'âge de vingt-trois ans, à l'abbaye de Citeaux, qui avait été fondée dans l'année 1098. Ordonné abbé en 1115 , il fut le premier abbé de Clairvaux; défenseur de l'église, il combattit les novateurs, fit condamner en 1140, au concile de Sens, le schisme d'Abeilard, et se déclara contre le moine Raoul qui demandait le massacre des Juifs. Saint Bernard prêcha en 1145 la deuxième croisade en France et en Allemagne. Il mourut à l'abbaye de Clairvaux, le 20 août 1153. 


\section{Prise de Lisbonne. - 25 octobre 1147.}

Par M. Deshoulins. - H. 0,70. - L. 1,11.

Au commencement du mois de juin 1147, les Croisés entrèrent dans le Tage, et allèrent secourir Alphonse, roi de Portugal, fils de Henri de Bourgogne, qui assiégeait alors Lisbonne. Les Musulmans résistèrent plus de quatre mois, et ce ne fut que le $250 c-$ tobre qu'Alphonse vainqueur entra dans sa nouvelle capitale.

\section{Louis VII force le passage du Méandre.- 1148.}

Par Tony Johannot en 1841. - I. 0,70. - L. 1, 11 .

L'armée française traversait l'Asie-Mineure pour se diriger sur la Syrie, lorsqu'elle rencontra les Tures sur les bords du Méandre. Louis VII protégea le passage de son armée, en se lançant à toute bride contre ceux des Tures qui assaillaient les siens par derrière; il les poursuivit jusque dans les montagnes, et, selon l'expression d'odon de Deuil, les deux rives du fleuve furent semées de cadavres ennemis.

\section{Louis VII dans les défilés de Laodicée en Syrie. $-1148$.}

Par BoIsSELIER en 1839. - H. 0,70. - L. 1,11.

En sortant de Laodicée, les Français s'étaient engagés imprudemment dans un défilé où les Tures surprirent leur armée, et du haut des montagnes l'écrasèrent malgré une longue et héroïque résistance. Dans cette mêlée, le roi perdit son escorte et fut poursuivi par un grand nombre d'ennemis qui se jetèrent après lui pour s'emparer de sa personne, tandis que d'autres, plus éloignés, lui tiraient des flèches. Mais, monté sur un rocher et adossé à un arbre, sa cuirasse le préserva de l'aitteinte des flèches, et avec son glaive tout sanglant " il fit tomber, dit Odon de Deuil, les mains et les têtes de beaucoup d'ennemis. Enfin ceux-ci, qui ne le connaissaient pas, voyant qu'il serait difficile de le saisir, et craignant qu'il ne survînt d'autres combattants, renoncèrent à l'attaquer et s'éloignèrent. »"

Ce tableau est une répétition de celui exposé par le même artiste au Salon de 1824, et placé dans la galerie de Diane à Fontainebleau.

\section{Assemblée des Croisés à Ptolémaïs. - 1148.}

Par Debace en 1839. - H. 0,70. - L. 1,11.

Une grande assemblée ayant été convoquée à Ptolémaïs pour y décider les moyens de raffermir le trône de Jérusalem, l'empe- 
reur Conrad, Louis VII, roi de France, le jeune roi de Jérusalem, Baudouin III, s'y rendirent accompagnés de leurs barons et de leurs chtvaliers. Les chefs du clergé y siégèrent avec toutes les pompes de l'église, et la reine Mélisende, avec la marquise d'Autriche, vinrent assister aux délibérations. On y résolut le siége de Damas.

\section{Prise d'Ascalon. - 1152.}

Par M. Convu en 1841. - H. 0,70. - L. 1,13.

Baudouin III ayant résolu de s'emparer d'Ascalon, tous les barons du royaume de Jérusalem accoururent sous sa bannière, le patriarche à leur tête, avec la vraie croix de Jésus-Christ. Le siége dura plus de deux mois. Les machines de guerre des Croisés furent un jour livrées aux flammes par les Musulmans; mais le vent du désert poussa l'incendie contre ceux qui l'avaient allumé ; cette circonstance détermina la reddition de la ville, et Baudouin vit arriver dans sa tente des messagers qui demandaient en suppliant à capituler. Peu d'heures après, on vit l'étendard de la croix flotter sur les tours d'Ascalon.

\section{Bataille de Putaha. - 1159.}

Par M. Féron. - H. 0,70. - L. 1,13.

Le sultan de Damas ayant franchi le Liban pour descendre en Palestine, Baudouin le vainquit dans une sanglante bataille à Putaha, entre le Jourdain et le lac de Somnaserh. Plus de six mille Infidèles demeurèrent sur la place, sans compter les blessés et les prisonniers.

\section{Combat près de Nazareth. - $1^{\mathrm{er}}$ mai 1187.} .......... - H. 0,70. - L. 1,14.

\section{Philippe II (Philippe-Auguste), roi de France,} (Voir $n^{\circ}$ 691.)

Par M. Émile SignoL. - H. 2,55. - L. 1,31.

Il est représenté en pied, tenant l'oriflamme de la main droite et son épée de la main gauche.

\section{Richard I ${ }^{\text {er }}$, dit Coeur-de-Lion, roi d'Angle- terre.}

Par BloNdeL. - H. 1,70. - L. 1,14.

Investi en 1169 par son père Henri II du duché d'Aquitaine, il lui succéda en 1189 et prit la croix l'année suivante. Il s'empara de l'île de Chypre, prit part au siége de Ptolémaïs avec 
CINQUIÈME SALLE DES CROISADES, No 21.

Philippe-Auguste, et après le départ du roi de France continua la lutte contre Saladin. Forcé de renoncer à la conquête de Jérusalem, il se rembarqua pour l'Europe en 1192, et fut retenu captif en Allemagne pendant quatorze mois. Après avoir repris son sceptre des mains de son frère Jean qui l'avait usurpé pendant son absence, il entra en lutte avec Philippe-Auguste, et fut tué le 6 avril 1199 devant le château de Chalus qu'il assiégeait. Ses restes furent ensevelis dans l'abbaye de Fontevrault.

\section{Albéric Clément, maréchal de France.}

Par Decaisne. - H. 0,90. - L. $1,02$.

Maréchal de France vers 1190, il accompagna Philippe-Auguste en Terre-Sainte, et fut tué au siége de Ptolémaïs, en juillet 1191.

\section{Siége de Ptolémaïs, - Juillet 1191.}

Par Fragonard. - H. 0,70. - L. 1,14.

Le siége de Ptolémaïs, qui dura près de deux ans (28 août 118913 juillet 1191), est comparé au siége de Troie dans les chroniques contemporaines. Le dernier effort de l'armée française se porta contre la tour maudite. La mine ayant ébranlé les fondements de cette tour, et le mur commençant à chanceler, Albéric Clément, maréchal du roi Philippe, s'écrie : “ Je mourrai aujourd'hui, ou, avec la grâce de Dieu, j'entrerai dans Acre. "Saisissant une échelle, il s'élance au haut de la muraille, et abat de son épée plusieurs Sarrasins. Mais trop de guerriers l'ont suivi, et ils sont entraînés à terre avec l'échelle qui ne peut les porter. Les Sarrasins, en la voyant tomber, poussent un cri de joie : Albéric, seul sur le mur, y trouva une mort glorieuse.

\section{Tournoi sous les murs de Ptolémaïs. - 1191. ............ - H. 0,70. - L. 0,80 .}

\section{Ptolémaïs remise à Philippe-Auguste et à Richard Cœur-de-Lion. - 13 juillet 1191.}

Par BLoNdel en 1840. - H. 4,06. - L. 4,94.

Philippe-Auguste et Richard prirent possession de la ville, et les deux bannières de France et d'Angleterre furent en même temps arborées sur les murailles. Les Sarrasins avaient enfin demandé à capituler, et passèrent désarmés devant les Croisés rangés en bataille.

Ce tableau a été exposé au Salon de 1841. 


\section{Marguerite de France mène les Hongrois à la croisade. -1196.}

Par M. PINGRET. - H. 0,70. - L. 0,79.

Marguerite de France, sœur de Philippe-Auguste, et reine de Hongrie, conduisit elle-même ses peuples à la croisade. Cette princesse, après la mort du roi Béla son époux, avait fait le serment de ne vivre que pour Jésus-Christ, et de finir ses jours dans la Terre-Sainte.

453. Prise de Constantinople. - 12 avril 1204.

Par MI. Eugène Delacroix en 1840. - H. 4,06. - L. 4,92.

Baudouin, comte de Flandre, commandait les Français qui avaient donné l'assaut du côté de la terre, et le vieux doge Dandolo, à la tête des Vénitiens et sur ses vaisseaux, avait attaqué le port.

Les principaux chefs parcourent les divers quartiers de la ville, et les familles ẻplorées viennent sur leur passage invoquer leur clémence.

Ce tableau a été exposé aux Salons de 1841 et de 1855.

\section{Prise de Damiette. -1219.}

Par M. Henri Delaborde en 1839. - H. 0,70. - L. 0,79.

Les Croisés, commandés par Jean de Brienne, allèrent mettre le siége devant Damiette, vers la fin du mois de mai de l'année 1218. Ce siége ne dura pas moins de dix-huit mois; enfin dans les premiers jours de novembre de l'année suivante, un dernier assaut livra la ville aux assiégeants.

\section{Prise de Damiette. -1219.}

Par M. Henti Delaborde en 1839. - H. 0,70. - L. 0.79.

Les Croisés s'étant rendus maitres d'une tour, le cardinal Pélage, légat du pape, qui commandait l'attaque, entonne le cantique de la victoire.

456. Louis IX (saint Louis), roi de France. (Voir n ${ }^{693 .)}$

Par M. Émile Sicrou en 1844. - H. 2,98, - L. 2,32.

Il est représenté à cheval, au moment de son débarquement en Egypte.

\section{Robert de France, comte d'Artois.}

Par Decaisne. - H. 0,91. - L. 1,04.

Il suivit le roi saint Louis, son frère, à son premier voyage d'outre-mer, se trouva à la prise de Damiette, et fut tué à la ba- 
CINQUIĖME SALLE DES GROISADES, No 21.

taille de la Mansourah, le 9 février 1250, à l'âge de trente-quatre ans.

\section{Alphonse de France, comte de Poitiers et de Tou- louse.}

Par DeGaisne. - H. 0,91. - L. 1,04.

Son frère, saint Louis, lui donna en apanage le comté de Poi tou, et son mariage, en 1241, avec l'héritière du comté de Toulouse, assura la réunion de cet Etat à la couronne de France. Lorsque saint Louis partit pour l'Egypte, il nomma son frère régent avec la reine Blanche leur mère; mais Alphonse le rejoignit l'année suivante à Damiette, et fut prisonnier avec lui. Il voulut encore l'accompagner en 1270 dans son expédition contre Tunis, et mourut au château de Corneto dans le Siennois, le 21 août 1271, dans sa cinquante-unième année.

\section{Charles de France, comte d'Anjou, roi de Naples, de Sicile et de Jérusalem.}

Par Decaisne. H. 0,94. - L. 0,65.

Les comtés d'Anjou et du Maine lui furent donnés en apanage en 1246 par son frère saint Louis, et il devint comte de Provence par suite de son mariage avec Béatrix, héritière de Raymond Bérenger. Il accompagna saint Louis en Egypte, et à son retour reçut du pape Urbain IV le titre de patrice de Rome et la couronne des Deux-Siciles. Au moment de la mort de saint Louis devant Tunis, Charles d'Anjou lui amenait un renfort de troupes. Sacré et couronné roi de Jérusalem en 1283, après le massacre des Vêpres Siciliennes, qui lui avait enlevé la Sicile, il mourut à Foggia dans la Capitanate, le 7 janvier 1285̆, âgé de soixante-cinq ans.

460. Joinville (Jean, sire de), sénéchal de Champagne. Par BlondeL. - H. 2,57. - L. 0,70.

Sénéchal héréditaire de Champagne et conseiller de saint Louis, il suivit ce prince à la croisade de 1248. Revenu en France avec lui dans l'année 12ö̌, il assista en qualité de gouverneur dı comté de Champagne aux assises de cette province en 1296. L'année suivante le roi Louis IX fut mis au nombre des saints par le pape Boniface VIII, et Joinville rendit un culte pieux à sa mémoire en écrivant l'histoire du saint roi. Il mourut en 1319, âgé de quatre-vingt-quinze ans.

Il est représenté en pied. 


\section{Molay (Jacques), dernier grand-maître de l'ordre du Temple.}

Par M. Amadry-Duval. - H. 1,70. - L. 0,79.

Admis vers 1265 dans l'ordre du Temple, il fut élu grandmaître en 1298 et entra vainqueur dans Jérusalem en 1299. Il était retiré dans l'île de Chypre, lorsqu'il fut appelé en France par le pape Clément $\mathrm{V}$, et à la suite du procès intenté à son ordre il fut brûlé à Paris le 18 mars 1314.

\section{Villaret (Foulques de), 24. ${ }^{\mathrm{e}}$ grand-maître de l'ordre de Saint-Jean de Jérusalem.}

Par M. Eugène Goyer. - H. 1,70. - L. 1,11.

Il succéda en 1307 à son frère Guillaume dans la dignité de grand-maître, et après l'expulsion des Chrétiens de la TerreSainte, s'empara de l'île de Rhodes qui devint alors le chef-lieu de l'ordre et lui donna son nom. L'an 1315 il défendit cette conquête contre le sultan Osman, et abdiqua en 1319. Il mourut au château de Tiran, en Languedoc, le $1^{\text {er }}$ septembre 1327.

\section{Aubusson (Pierre d'), 38 e grand-maître de l'ordre de Saint-Jean de Jérusalem.}

Par M. E. OdIER. - H. 2,65. - L. 1,02.

Grand-prieur de la langue d'Auvergne, il fut élu grand-maître en 1476. Il présida en 1480 à la défense de Rhodes, et fut nommé cardinal par le pape Innocent VII. D'Aubusson mourut à Rhodes le 3 juillet 1503, âgé de quatre-vingts ans.

Il est représenté à cheval, en armure, avec le chapeau et le manteau de cardinal.

464. Aubusson (Pierre d'), grand-maître de l'ordre de Saint-Jean de Jérusalem. (Voir n $\left.{ }^{\circ} 463.\right)$

Statue couchée; plàtre. - Long. 2,04.

Le corps de cette figure a été moulé d'après la statue de Villiers de l'Isle-Adam rovenant de Malte $\left(n^{\circ} 321\right)$, et la tête a été faite par Simart.

465. Levée du siége de Rhodes. - 19 août 1480.

Par M. Edouard ODIER. - H. 4,06. - L. 6,55.

L'an 1480, ver's la fin du mois de mai, le grand-visir Misach Paléologue, renégat, de l'ancienne famille des empereurs grecs, parut devant Rhodes avec une flotte qui, au rapport des contemporains, ne portait pas moins de cent mille hommes. La ville fut

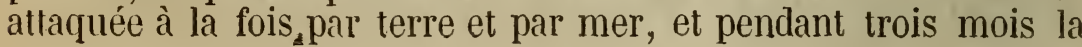


formidable artillerie de Mahomet II ne cessa pas de foudroyer ses murailles. Deux fois repoussés, les Turcs dirigèrent contre la basse ville et le quartier des Juifs, une troisième attaque. Le rempart est escaladé en silence, la garde endormie est égorgée, et le drapeau des Infidèles arboré en signe de triomphe. Pierre d'Aubusson, averti du péril fit déployer sur-le-champ le grand étendard de la religion. La lutte fut terrible: le sang des chevaliers y coula à grands flots, et le grand-maitre lui-même fut deux fois renversé. Mais ni cette double chute, ni les sept blessures qüil reccut ne ralentirent son ardeur, et, après une mêlée épouvantable, les Tures, subjugués par l'énergie surnaturelle de leurs ennemis, prirent la fuite. Paléologue découragé se retira sur ses vaisseaux, et pendant qu'il faisait voile vers le Bosphore, Pierre d'Aubusson allait dans l'église de Saint-Jean rendre grâces à Dieu de la victoire qu'il venait de remporter.

Ce tableau a été exposé au Salon de 1841.

466. Villiers de l'Isle-Adam (Philippe de), $42^{\mathrm{e}}$ grandmaître de l'ordre de Saint-Jean de Jérusalem ou de Malte.

Par M. SAINT-EvRE. - H. 1,70. -- L。 0,79.

Élu grand-maitre en 15ั21, il fut obligé de rendre l'île de Rhodes au sultan Soliman en 1522 , et se retira dans l'île de Candie. II transporta en 1530 le siége de l'ordre dans l'île de Malte qu'il avait obtenue de Charles-Quint, et y mourut le 22 août 1534, à soixante-dix ans.

\section{Villiers de l'Isle-Adam (Philippe de), grancl-} maître de l'ordre de Malte. (Voir n ${ }^{\circ} 466$. )

Statue à genoux; albâtre. - H. 1,25.

Cette figure, placée autrefois dans l'église du Temple, à Paris, a été entièrement restaurée sous la direction de Lenoir, et faisait partie du Nusée des Monuments français. - Lenoir, t. III, pl. 101.

\section{Entrée des chevaliers de l'ordre de Saint-Jean à Viterbe. -1527.}

par M. Auguste Debay. - H. 1,05. - L. 1,01.

Rhodes étant tombée aux mains de Soliman, Villiers de l'IsleAdam réunit ses chevaliers à Viterbe en un chapitre général. A ce chapitre fut remis le soin de décider si l'on courrait les chances d'une expédition pour reconquérir Rhodes, ou si l'on accepterait l'île de Malte, offerte par Charles-Quint. Ce dernier parti prévalut. 


\section{L'ordre de Saint-Jean prend possession de l'âle de Malte. - 26 octobre 1530.}

- Par M. Berthon. - H. 1,09. - L. 1,01.

" Le grand-maître Villiers de l'Isle-Adam, dit Vertot, le conseil et les principaux commandeurs entrèrent dans le grand port le 26 octobre, et après être débarqués, ils allèrent droit à l'église paroissiale de Saint-Laurent. Après y avoir rendu leurs premiers hommages à celui que l'ordre reconnoissoit pour son maître souverain, on se rendit au bourg situé au pied du château SaintAnge. »

470. Parisot de la Valette (Jean), 47 grand-maître de l'ordre de Malte.

Par M. LARIVIÉRE. - H. 2,65. - L. 1,01.

Il fut élevé à la dignité de grand-maître en 15\%ّ7, après avoir passé par toutes les dignités de l'ordre. Il défendit Malte en 15605 contre Soliman II, et après avoir fait relever le fort Saint-Elme, fit construire la ville nommée Cité Valette qui rend l'île imprenable. Il mourut à Malte le 21 août 1568, à soixante-quatorze ans.

Il est représenté à cheval et en armure.

471. Parisot de la Valette (Jean), grand-maître de l'ordre de Malte. (Voir no 470.)

Statue couchée; plâtre. - Long. 1,85.

La figure originale est dans l'église de Saint-Jean, à Malte.

\section{Levée du siége de Malte. - Septembre 1565.}

Par M. Larivière en 1842. - H. 4,06. - L. 6,55.

Le siége dura cinq mois. Mustapha, général des armées de Soliman, et Piali, amiral de sa flotte, rivalisèrent d'ardeur et d'opiniâtreté dans les attaques qu'ils livrèrent à l'île sur tous les points. Dragut, pacha de Tripoli, y laissa la vie. Toute l'audace et l'habileté des deux lieutenants de Soliman étaient épuisées : seize mille hommes formaient le reste unique de la puissante armée qu'ils avaient amenée des ports de Turquie, lorsque le vice-roi de Sicile, Don Garcie de Tolède, débarqua enfin des troupes qui firent lever le siége.

Ce tableau a étẻ exposé au Salon de 1843. 


\section{Pante centarie.}

\section{VESTIBULE № 22.}

473. Villeroy (Nicolas de Neufville, IV $V_{e} d u$ nom, seigneur de), secrétaire et ministre d'État.

Buste en plâtre. - H. 0,60 .

Trésorier des ordres du roi et gouverneur de Corbeil, il servit pendant cinquante-six ans les rois Charles IX, Henri III, Henri IV et Louis XIII. Il mourut à Rouen le 12 novembre 1617 et fut enterré dans la chapelle de l'église paroissiale de Magny.

\section{Personnage inconnu.}

Buste en marbre. - H. 0,55.

Ce buste représente un prélat commandeur de l'ordre du Saint Esprit, de l'époque de Henri IV.

\section{Personnage inconnu.}

Buste en marbre. - H. 0,50.

Ce buste représente un magistrat de l'époque de Henri IV. Il est chauve, porte une longue barbe, un col, et sous sa robe de magistrat un pourpoint attaché de distance en distance par quatre boutons.

\section{Personnage inconnu.}

Buste en marbre. - H. 0,50 .

Ce buste représente un magistrat de l'époque de Louis XIII. Il porte les moustaches relevées et la royale, un col d'où pendent deux glands, et une robe de magistrat.

477. Aubray (Antoine d'), comte d'Offemont, conseiller d'Etat, lieutenant civil au Châtelet de Paris.

Par DesjaRdins; bas-relief en plâtre. - H. 1,20. - L. 1,94.

Il était frère aîné de la marquise de Brinvilliers, et mourut à Paris, le 15 juillet 1670, empoisonné par sa sœur.

Ce bas relief qui représente la Justice tenant le médaillon d'Antoine d'Aubray, était placé autrêfois dans la chapelle de Saint-Antoine de l'église de l'Oratoire à Paris; il fut transporté ensuite au Musée des Monuments français. - Millin. n० XIIJ, pl. 4. 


\section{Perrault (Claude), architecte.}

Par M. ThÉrasse; buste en marbre. - H. 0,82.

Né à Paris en 1613, il fut d'abord docteur de la Faculté de Médecine de Paris, étudia successivement l'architecture, la peinture, la sculpture, la musique, la physique, lanatomie, et fit partie de l'Académie des sciences en 1666. Il donna les plans de l'Observatoire, de la colonnade du Louvre et de la porte SaintAntoine, fut chargé par Colbert de traduire le Vitruve, et rédigea des Mémoires sur l'Histoire naturelle. Il mourut à Paris le 9 octobre 1688.

Ce buste a été exposé au Salon de 1833.

\section{VESTIBULE N० 23.}

\section{Orléans (Louis d'Orléans, duc d').}

Par Cressent; buste en plâtre. - H. 0,58.

Né à Yersailles en 1703 , il porta d'abord le titre de duc de Chartres, entra au conseil de régence en 1718 et fit partie du comité de la guerre. Gouverneur du Dauphiné, grand-maître des ordres de Notre-Dame-du-Mont-Carmel et de Saint-Lazare, et colonel de linfanterie française, il représenta le duc de Normandie au sacre de Louis XV en 1722. Duc d'Orléans en 1723, après la mort du régent, il fut chargé, en $1720 \%$, des pouvoirs du roi pour épouser, en son nom, Marie Leczinska. Il se retira, en 1730, à l'abbave de Sainte-Genevière, et y mourut le 4 février 17002 . Il protégea les savants, se distingua dans l'étude des langues grecque, hébraiqque et syriaque, et fit plusieurs ouvrages de piẻté.

480. Conty (Louis-François de Bourbon, prince de). (Voir n 1200.)

Par Hoodos; buste en plâtre. - H. 0,60.

481. Louis de France, dauphin. (Voir n⿳ 192.)

Buste en marbre. - H. 0,51.

On lit sur le socle de ce buste:

BONUM VIRUN FACILE CREDERES MAGNEY LIBENTER.

482. Orléans (Louis-Philippe-d'Orléans, duc d').

Par Dexizot en 1789; buste en marbre. - H. 0,70.

Né à Versailles en 1720 , il porta d'abord le titre de duc de Chartres, fit ses premières armes comme colonel dans la guerre 
de 1742 et se distingua l'année suivante à la bataille de Deltingen. Maréchal de camp commandant la cavalerie et lieutenant-général en 1744, il accompagna la même année le roi à l'armée de Flandre, en Alsace, et se trouva au siége de Fribourg. Gouverneur du Dauphiné en 1747, il prit le titre de duc d'Orléans après la mort de son père en 1752, fit la campagne de 1757 sous les ordres du maréchal d'Estrées, se distingua à la bataille d'Hastembeck et représenta le duc d'Aquitaine au sacre de Louis XVI en 1775. Il mourut à Sainte-Assise le 18 novembre 1785. Ce prince avait épousé, en 1743, Louise-Henriette de Bourbon-Conty, morte en $\mathbf{1 7 5 9}$, et se remaria en 1773, à Charlotte-Jeanne-Beraud de La Haye de Riou, veuve du marquis de Montesson, lieutenantgénéral des armées du roi.

\section{Louis XVI, roi de France. (Voir n 718.)}

Buste en marbre. - H. 0,63 .

\section{Louis XVIII, roi de France. (Voir n 720.)}

Par Pradier; buste en marbre. - H. 0,51.

Ce buste a été exécuté à Rome en 1824.

485. Charles $\boldsymbol{X}$, roi de France. (Voir n ${ }^{\circ}$ 721.)

Par Bosio; buste en marbre. - H. 0,74.

\section{Condé (Louis-Henri-Joseph de Bourbon, duc de Bourbon, prince de).}

Par GoIs en 1830 ; buste en marbre. - H. 0,54.

Né à Chantilly en $\mathbf{1 7 5 0 6}$, il porta d'abord le titre de duc de Bourbon, fut nommé chevalier de l'ordre du Saint-Esprit en 1773, et épousa, en 1790, Louise-Thérèse-Bathilde d'Orléans, fille de Louis-Philippe, duc d'Orléans. Il quitta la France avec le prince de Condé et le duc d'Enghien, son fils, en 1789, commanda en plusieurs occasions l'armée royaliste, et se retira ensuite en Angleterre. De retour en France, en 1814, il fut nommé colonelgénéral de l'infanterie légère, et prit le titre de prince de Condé, en 1818, après la mort de son père. Le 27 aoùt 1830, il fut trouvé pendu dans sa chambre à coucher, au château de Saint-Leu.

\section{VESTIBULE No 24.}

\section{Jussieu (Bernard de), botaniste.}

Par Lucien Levieux; buste en plâtre. - H. 0,58.

Né à Lyon en 1699, après avoir fait plusieurs voyages avec son frère Antoine de Jussieu, il étudia la médecine à Montpellier, et 
y fut reçu docteur en 1720. Nommé en 1722, sous-démonstrateur de botanique au Jardin-du-Roi, et admis à l'Académie des Sciences en $\mathbf{1 7 2 0}$, il prit en $\mathbf{1 7 2 6}$ le grade de docteur à la Faculté de médecine de Paris. Bernard de Jussieu est un de ceux qui ont le plus contribué à l'agrandissement du Muséum d'Histoire naturelle. Il mourut à Paris, le 6 novembre 1777.

Le buste original est au Cabinet d'Histoire naturelle, à Paris.

\section{Linné ou Linnée (Charles), naturaliste.}

Par Bozillet; buste en plâtre. - H. 0,62.

Né en 1707, à Roeshult (Suède), il étudia à Upsal, puis à Leyde, visita l'Angleterre, la France, et fut nommé médecin du roi de Suède et professeur de botanique à l'université d'Upsal en 1741 . Il mourut le 10 janvier 1778, après avoir occupé cette chaire pendant trente-sept ans. - Linnée est auteur d'une classification pour la division des plantes en classes, en genres et en espèces.

Le buste original est ' au Cabinet d'Histoire naturelle, à Paris.

\section{Duhamol du Monceau (Henri-Louis), agronome.}

Par M. DoboIs; buste en marbre. - H. 0,58.

Né à Paris en 1700, il fut reçu à l'Académie des. Sciences dès 1728, et composa un grand nombre d'ouvrages sur l'agriculture, la marine et le commerce. Il mourut à Paris le 23 août 1782.

Le buste original est au Cabinet d'Histoire naturelle, à Paris.

\section{Adanson (Michel), naturaliste.}

Par Boulllet en 1798; buste en plâtre. - H. 0,54.

Né en 1727 à Aix (Bouches-du-Rhône), de parents d'origine écossaise, il fut destiné à l'état ecclésiastique et fit ses études aux colléges de Sainte-Barbe et du Plessis. En 1748, il visita le Sénégal, fut membre de l'Académie des Sciences en $\mathbf{1 7 5 9}$ et censeur royal la même année. Membre de l'Institut en 1794, il fut chevalier de la Légion d'Honneur en 1803, et mourut le 3 août 1806.

Le buste original est au Cabinet d'Histoire naturelle, à Paris.

\section{Lavoisier (Antoine-Laurent), chimiste.}

Par STouf; buste en marbre. - H. 0,63.

Né à Paris en 1743, il fit ses études au collége Mazarin et se livra ensuite à son goût pour les sciences. Astronome avec La 
Caille, chimiste avec Rouelle, botaniste avec Bernard de Jussieu, il fut admis à l'Académie des Sciences en 1768, étant à peine âgé de vingt-cing ans. De concert avec Guyton de Morveau, il créa en 1787 une nouvelle nomenclature qui changea la face de la chimie. Traduit comme fermier-général devant le tribunal révolutionnaire, il fut condamné à mort avec vingt-huit de ses collègues, et périt sur l'échafaud le 8 mai 1794, à l'âge de cinquante-un ans.

Ce buste, commandé pour la galerie des Consuls, aux Tuileries, a été exposé au Salon de 1801.

\section{Jussieu (Antoine-Laurent de), botaniste.}

Par David en 1838; buste elı plâtre. - H. 0,69.

Né à Lyon en 1748, il vint à Paris en 1763 pour terminer ses études sous la direction de son oncle Bernard, prit en 1770 le grade de docteur en médecine à la Faculté de Paris, et fut reçu à l'Académie des Sciences en 1773. Il professa la botanique au. Jardin-du-Roi, et fut nommé en 1777, démonstrateur de botanique à la place de son oncle. Membre de la municipalité de $\mathrm{Pa}-$ ris en 1790, il fut chargé de l'administration des hôpitaux jusqu'en 1793. Lors de la réorganisation du Jardin-des-Plantes, il fut placé sur la liste des professeurs, reprit à l'Institut la place que la suppression des Académies lui avait fait perdre, fut nommé membre de la Légion d'Honneur en 1803, et joignit à sa chaire de botanique celle de matière médicale à la Faculté de Paris. Conseiller de l'Université impériale en 1808, il mourut le 17 septembre 1836.

Le buste original est au Cabinet d'Histoire naturelle, à Paris.

\section{Fourcroy (Antoine-François de), chimiste.}

Par Chaudet; buste en plâtre. - H. 0,54.

Né à Paris le 15 juin 1755 , il étudia d'abord la médecine, fut professeur de chimie au Jardin-des-Plantes en 1784, et membre de l'Académie des Sciences l'année suivante. Député de Paris à la Convention en 1792, il entra ensuite au conseil des Cinq-Cents, fut appelé en 1799 au Conseil d'Etat, et devint en 1801 directeurgénéral de l'Instruction publique. Membre, puis commandant de l'ordre de la Légion d'Honneur en 1804, il mourut d'une attaque d'apoplexie le 16 décembre 1809. - Il publia en 1801 son principal ouvrage qui a pour titre : Système des connaissances chimiques.

Le buste original est au Cabinet d'Histoire naturelle, à Paris. 
494. Lacépède (Bernard-Germain-Étienne de Laville, comte de), naturaliste.

Par David en 1824; buste en plâte. - H. 0,53.

Né à Agen en 1756 d'une famille noble originaire de Lorraine, il fut destiné aux armes et recut un brevet de colonel au service de l'Empire. Il vint à Paris en 1776, fut nommé par la protection de Buffon, démonstrateur-garde-adjoint au Jardin-du-Roi, et fut choisi par ce savant pour continuer son Histoire naturelle. Député par les électeurs d'Agen à l'Assemblée constituante en 1789, professeur au Muséum d'Histoire naturelle et membre de l'Institut en 1794, il fut depuis membre du conseil des Cinq-Cents, sénateur, et devint en 1803 grand-chancelier de la Légion d'Honneur. Exclu de la Chambre des pairs en 1815 , il fut réintégré en 1819 , et mourut le 6 octobre 1825 .

Le buste original est au Cabinet d'Histoire naturelle, æà Paris.

\section{ARCADE DU NORD, No 25.}

Passage pour les voitures, communiquant directement de l'ancienne Cour royale dans les jardins.

495. Moncey (Bon-Adrien-Jeannot de), duc de Conegliano, maréchal de France. (Voir no 1115.)

Par M. Petitot; buste en marbre. - H. 0,72.

496. Soult (Jean-de-Dieu), duc de Dalmatie, maréchal de France. (Voir no 1131.)

Par Pradier; statue en marbre. - H. 1,98.

497. Brune (Guillaume-Marie-Anne, comte), maréchal de France. (Voir no 1132.)

Par M. Lanvo en 1845 ; statue en plâtre. - H. 2,03.

498. Mortier (Édouard-Adolphe-Casimir-Joseph), duc de Trévise, maréchal de France. (Voir no 1134.)

Par M. BRA; statue en marbre. - H. 2,10.

499. Macdonald (Étienne-Jacques-Joseph-Alexandre), duc de Tarente, maréchal de France. (Voir no 1156.)

par M. NaNTeUiL; statue en marbre. - H. 2,06. 
500. Oudinot (Charles-Marie), duc de Reggio, maréchal de France. (Voir no 1157.)

Par M. J. DebaY en 1853; statue en marbre. - II. 2,00.

Cette statue a été exposée au Salon de 1853.

501. Suchet (Louis-Gabriel), duc d'Albuféra, maré"chal de France. (Voir no 1159.)

Par M. Auguste DumonT; statue en marbre. - H. 2,00.

502. Duperré (Victor-Guy, baron), amiral. (Voir n 1168.

Par M. Pradier; statue en plâtre. - II. 2,03.

503. Gérard (Étienne-Maurice, comte), maréchal de France. (Voir no 1171.)

Par M. JALEY; statue en marbre. - H. 1,98.

Le modèle en plâtre a été exposé au Salon de 1841.

504. Lobau (Georges Mouton, comte), maréchal de France. (Voir no 1173.)

Par M. JALEY; statue en marbre. - H. 2,05.

Le modẻle en plâtre a été exposé au Salon de 1840.

505. Valée (Sylvain-Charles, comte), maréchal de France. (Voir no 1176.)

Par M. Manochetti; statue en plâtre. - H. 1,98.

506. Drouet (Jean-Baptiste), comte d'Erlon, maréchal de France. (Voir $\mathrm{n}^{\circ}$ 1179.)

Par M. Rochet; statue en marbre. - H. 2,00.

507. Dode de la Bruneris (Guillaume, vicomte), maréchal de France (Voir n $\left.{ }^{\circ} 1182.\right)$

Par M. JoUfFroY; statue en marbre. - H. 2,03.

508. Excelmans (Remy-Joseph-Isidore, comle), maréchal de France (Voir $\mathrm{n}^{\circ}{ }^{1184 .}$ )

Buste en marbre. - II. 0,72. 


\section{ESCALIER ET VESTIBULES, № 26.}

Cet escalier et les restibules qui y conduisent occupent l'emplacement du grand escalier, commu sous le nom d'Escalier du Roi ou d'Escalier des Ambassadeurs, qui fut détruit en 1750. Ce local servit alors de garde-meuble et de logement au premier valet de garde-robe du roi. L'escalier actuel a été construit à la place d'une petite cour, et les vestibules, entièrement réparés, ont été destinés à renfermer les bustes des officiers généraux tués sur le champ de bataille en combattant pour la France.

PREMIÈRE PARTIE.

509. Marbot (Jean-Antoine), général de division.

Par M. DeB.y père; buste en plâtre. - H. 0,70.

Il entra dans les gardes du corps en 1773 , et commanda les gardes nationales dans le département de la Corréze en 1789. Adjoint à l'état-major de l'armée des Pyrénées en 1792, général de brigade en 1793, général de division en 179', il fut employé aux armées d'Italie, des Pyrénées occidentales et de l'Ouest. Chargé du commandement de la $17^{\mathrm{e}}$ division en 1799 , il fut blessé à la jambe au siége de Gênes, et mourut dans cette ville le 19 avril 1800 .

\section{Roussel (Francois-Xavier), général de division}

Par Esperciecx; buste en plâtre. - H. 0,67.

Né à Charmes (Vosges) le 3 décembre 1770, il entra dans le régiment mestre-de-camp général-dragons en 1789, et fut nommé fourrier en 1791, époque où ce régiment devint le $10^{\mathrm{e}}$ dragons. Capitaine adjudant-major dans le 9 e bataillon de la Meurthe, en 1792, il passa, avec le même grade, à l'état-major de l'armée de la Moselle, et fit la campagne de Trèves. Lieutenant-colonel an 9e bataillon de la Meurthe en 1793, il servit à l'armée de la Moselle et fut fait prisonnier à l'affaire de Pirmassens. Chef de la $60^{\mathrm{e}}$ demi-brigade d’infanterie de ligne à l'armée du Nord, il se rendit ensuite à celle de Sambre-et-Meuse. Général de brigade en 1799, il fut employé à l'armée du Rhin, puis à celle dingleterre, et créé, en 1803, membre puis commandant de l'ordre de la Légion d'Honneur. Chef d'état-major de la division de la garde impériale en 180วั, nommé général de division en 1807, il fut tué par un boulet de canon au combat de Dieppen, près d'Heilsherg, en Prusse, le 10 juin 1807. 


\section{Colbert (Auguste-Francois-Marie), général de brigade.}

Par Revaud; buste en plâtre. - H. 0,60.

Né à Paris le 18 octobre 1777, il fut volontaire dans la garde nationale de Tarbes en 1792 et au 8 e bataillon de Paris en 1793. Chasseur au $7^{\mathrm{e}}$ régiment en $\mathbf{1 7 9 4}$, maréchal-des-logis au $15^{\mathrm{e}}$ régiment de chasseurs, puis lieutenant au $\mathbf{A}^{\mathrm{er}}$ bataillon de la LoireInférieure en 1795ٌ, il fut aide-de-camp de Grouchy et de Murat, et servit sans interruption aux armées de l'Ouest, de Hollande, d'Irlande et d'Italie. Nommé chef d'escadron par Bonaparte, sur le champ de bataille de Saléhieh en Egypte, il eut les deux cuisses percées d'un coup de feu au siége de Saint-Jean-d'Acre. Chef de brigade du $10^{\mathrm{e}}$ régiment de chasseurs en 1800 , il fut membre de la Légiơn d'Honneur en 1803 et général de brigade en 180 š. Employé au $6^{\mathrm{e}}$ corps de la grande armée en 1806, il se distingua à la bataille d'Iéna, fut envoyé en Espagne en 1808, et périt le 3 janvier 1809, près le village de Carcabelos, dans une attaque contre les Anglais.

Le buste original est dans la salle des Maréchaux, aux Tuileries.

\section{Montbrun (Louis-Pierre, comte de), général de division.}

Par Thérasse; buste en plâtre. - H. 0,60 .

Né à Florensac (Hérault) le $\mathbf{1}^{\mathrm{er}}$ mars $\mathbf{1 7 7 0}$, il entra dans le $1^{\text {er }}$ régiment de chasseurs en 1789. Il obtint sur les champs de bataille les grades de sous-lieutenant en 1796, de chef d'escadron en 1799 et de chef de brigade en 1800. Général de brigade en 1806, il servit dans les armées de Naples et d'Espagne jusqu'en 1808, et fut nommé général de division en 1809 à l'armée d'Allemagne. Il commandait la cavalerie de l'armée de Portugal en 1810 , le $2^{\mathrm{e}}$ corps de cavalerie de la réserve de la grande armée en 1812, et fut tué à la bataille de la Moskowa.

\section{Tharreau (Jean-Victor, baron), général de division.}

Par M. J. DebaY; buste en plâtre. - H. 0,66.

Né à Cholet (Mayenne-et-Loire) le 15 janvier 1767, il fut ajdudant-major au $2 \mathrm{e}$ bataillon de Mayenne-et-Loire en 1792, adjudantgénéral, chef de bataillon, puis général de brigade en 1794, et général de division en 1799. Il servit activement de 1794 à 1809 dans les armées des Ardennes, de Rhin-et-Moselle, d'Allemagne, d'Angleterre, de Mayence, Cisalpine, du Rhin et dans le cor'ps 
d'observation de l'Elbe. Il faisait partie, en 1812, dans la grandearmée, du contingent Westphalien, lorsqu'il fut blessé à la bataille de la Moskowa, et il mourut à Mojaïsk le 26 septembre 1812 , des suites de cette blessure.

\section{Candras (Jacques-Lazare Savettier de), baron de} la Tour de Pré, général de brigade.

Par M. Aug. Dumont; buste en plâtre. - H. 0,67.

Né à Epoisses (Côte-d"Or) le 24 août 1768, il fut soldat au $7^{\mathrm{e}}$ bataillon de Paris en 1792, chef de bataillon au 2e bataillon des Côtes-Maritimes en 1793, et servit de 1792 à 1799 aux armées du Nord, des Pyrénées, d'Italie et d'Angleterre. Colonel du $4^{\mathrm{e}}$ régiment d'infanterie en 1800, il fut employé en Hollande, à l'armée du Rhin et au camp de Saint-Omer, et fut nommé général de brigade en 1803. Attaché à la $2^{\mathrm{e}}$ division du $4^{\mathrm{e}}$ corps de la grandearmée en 180ðّ, il fit la campagne d'Allemagne en 1809 , et fut tué d'un coup de feu au passage de la Bérésina, le 28 novembre 1812.

515. Desvaux de Saint-Maurice (Jean-Jacques, baron), général de division.

Par M. DEBay père; buste en plâtre. - H. 0,70.

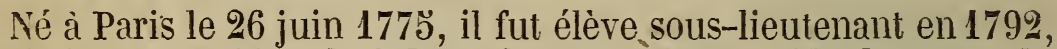
capitaine en 1793, chef d'escadron en 1799 , aide-de-camp du général Marmont en 1800, et servit aux armées des Alpes, des Pyrénées-Orientales et d'Angleterre de 1792 à 1800 . Colonel du $6^{\mathrm{e}}$ régiment d'artillerie à cheval en 1803 , puis du $1^{\mathrm{er}}$ d'artillerie à pied, il fut employé à l'armée d'Italie jusqu'en 180כٌ. Directeur' en Dalmatie en 1806, général de brigade en 1809, il fit partie de la grande-armée en 1812, fut nommé général de division en 1813, et mourut à la bataille de Waterloo, le 18 juin 1815 .

\section{La Chasse de Vérigny (Edme-Nicolas-Jean- Baptiste-Marie, marquis de), maréchal de camp.}

Par M. J. DebaY; buste en plâtre. - H. 0,65.

Né à Auxerre le 21 juin 1775, il entra, comme volontaire, au ว̈e bataillon de l'Yonne en 1792, puis passa dans le $4^{\mathrm{e}}$ régiment d'artillerie à pied en 1794. Lieutenant de pontonniers en 1797, capitaine adjoint à l'état-major en 1799, il fit les campagnes d'Italie depuis 1794 jusqu'en 1799. Aide-de-camp du général Moreau en 1800, il servit dans l'armée du Rhin en 1800 et 1801, sur les côtes de l'Océan en 1803 et 1804, et dans la grande-armée de 1803 à 
1807. Chef de bataillon en 1808, il commanda, comme chef d'étalmajor, les $5^{\mathrm{e}}$ et $3^{\mathrm{e}}$ division d'infanterie de l'armée de Portugal en 1812, et l'aile droite de l'armée d'Espagne en 1813. Employé au dépôt général de la guerre en 1818, puis à l'état-major général de l'armée des Pyrénées en 1823, il fut nommé maréchal-decamp la même année et commanda le corps d'expédition d'Andalousie . Directeur-général du dépôt de la guerre par intérim en 1824, commandant l'école d'application d'état-major en 1830, il fut tué à Paris le 28 juillet 1835 .

\section{Danrémont (Charles-Marie-Denys, comte de), lieutenant-général. (Voir $\left.\mathrm{n}^{\circ} 1900.\right)$}

Par Pradier; buste en plâtre. - H. 0,65.

\section{Perregaux (Alexandre-Charles, baron de), maréchal de camp.}

Par M. J. DebaY; buste en plâtre. - H. 0,68.

Né à Neufchâtel (Suisse) le 21 octobre 1791, il fut sous-lieutenant au bataillon de Neufchâtel en 1807 , lieutenant en 1808, aide-de-camp du maréchal de Raguse en 1809, capitaine provisoire au $4 \mathrm{e}$ régiment de chasseurs d'Illyrie en 1810 , et fit les campag'nes d'Autriche en 1809, d'Espagne et de Portugal en 1811, d'Allemagne en 1813. Prisonnier de guerre en 1813, il rentra en France l'année suivante et servit dans les gardes du corps comme capilaine et sous-aide-major. Lieutenant-colonel aux légions départementales de l'Isère et de la Haute-Loire en 1816 et 181.7, lieutenant-colonel au $3^{\mathrm{e}}$ régiment d'infanterie de la garde en 1819 et colonel au $15^{\mathrm{e}}$ régiment d'infanterie légère en 1823 , maréchal de camp en 1834, il servit en Afrique de 1832 à 1837, fut blessé au siége de Constantine, et mourut à bord du bateau à vapeur !la Chimère, le 6 novembre 1837, des suites de cette blessure.

\section{Bréa (Jean-Baptiste-Fidèle de), maréchal de camp.}

Par M. GrootaERs; buste en marbre. $-\mathrm{H} \cdot \mathbf{0 , 6 5}$.

Né à Menton, principauté de Monaco, le 23 avril 1790. Élève à l'Ecole spéciale militaire en 1806 , sous-lieutenant au ${ }_{22}{ }^{\mathrm{e}}$ régiment d’infanterie légère en 1807, lieutenant en 1809, capitaine en 1813 , il servit de 1807 à 1812 dans l'armée de Naples, dans la grandearmée en 1813, fut blessé de deux coups de feu et fait prisonnier de guerre à Leipsick. Rentré à la paix de 1814, il se trouva, en 1815, au combat des Quatre-Bras. Chef d'escadron en 1816, chef de bataillon au corps royal d'état-major, il fut employé à l'état- 
major de la $17^{\mathrm{e}}$ division militaire en 1818 , de la $12^{\mathrm{e}}$ division en 1820 , et de la $1^{\mathrm{re}}$ en 1827 . Colonel en 1831, chef d'état-major de la division de cavalerie de l'armée du Nord en 1832, il fit la campagne de Belgique. Colonel d'état-major en 1836, maréchal de camp en 184.0 , il commanda le département de la Loire-Inférieure de 184 à à 1848 , et fut tué à la barrière de Fontainebleau, à Paris, le 20 juin 1848.

Ce buste a été exposé au Salon de 1849.

\section{DEUXIÈME PARTIE.}

\section{Joubert (Barthélemy-Catherine), général en chef de l'armée d'Italie. (Voir no ${ }^{1213 .)}$}

Par Louis-Simon Borzot; buste en marbre. - H. 0,72.

Ce buste était placé dans la salle des Maréchaux, au palais des Tuileries.

\section{Espagne (Jean-Louis-Brigitte, comte), général de division.}

Par Callasard en 1810; buste en plâtre, - H. 0,69.

Né à Auch le 16 février 1769, il entra au 6e régiment de dragons en 1787. Il fut successivement sous-lieutenant au $6^{\mathrm{e}}$ de chasseurs à cheval, capitaine dans la légion de la Liberté et chef d'escadron au อ̆e régiment de hussards en 1792, adjudant-général chef de brigade en 1793 , fit les campagnes de 1792 et de 1793 et fut employé en 1794 aux armées des Alpes, de l'Ouest et de Sambre-et-MIeuse. Il servit les années suivantes aux armées du Nord et des Pyrénées-Occidentales, et fut nommé général de brigade en 1799 à l'armée du Danube. Général de division en 1805ั, commandant la cavalerie légère à l'armée d'Italie en 1806, il fut nommé commandant de la 3 e division de cuirassiers de la grandearmée par ordre de l'empereur en 1806. Atteint par un boulet à la bataille d'Essling, il mourut le 21 mai 1809 dans l'ìle de Lobau, des suites de sa blessure.

Le buste original est dans la salle des Maréchaux, aux Tuileries.

\section{Saint-Hilaire (Louis-Joseph Leblond, comte de), général de division.}

Par Pierre-Charles Bridaĩ; buste en plâtre. - H. 0,65.

Né à Ribemont (Aisne) le 4 septembre 1766, il fut sous-lieutenant au $3 \mathrm{~J}^{\mathrm{e}}$ régiment en 1783 , lieutenant en 1788 , capitaine en 1792. Adjudant-général chef de bataillon en 1794, général de 
brigade en 1796, il servit aux armées des Alpes et d'Italie. Général de division en 1799 , il recut le commandement de la $8^{\mathrm{e}}$ division militaire en 1800 et celui de la $\mathbf{1}^{\text {re }}$ division au camp de SaintOmer en 1803 ; membre et grand-officier de la Légion d'Honneur, il commanda la $4^{\text {re }}$ division du $4^{\mathrm{e}}$ corps de la grande-armée en 1805, et fut nommé successivement grand-aigle, comte de l'empire et commandeur de l'ordre de la Couronne de fer. Commandant de la $4^{\mathrm{e}}$ division du $2^{\mathrm{e}}$ corps de l'armée d'Allemagne en 1809, il eut le pied gauche emporté par un boulet à la bataille d'Esling, et mourut à Vienne, le 3 juin 1809, des suites de cette blessure.

Le bustc original est dans la salle des Maréchaux, aux Tuileries.

523. Lannes (Jean), duc de Montebello, maréchal de France. (Voir no ${ }^{1133 .)}$

Buste en plâtre. - H. 0,66 .

Le buste orıginal est dans a salle des Maréchaux, aux Tuileries.

TROISIEME PARTIE.

\section{Muiron (Jean-Baptiste), chef de bataillon d'artillerie.}

Par Taunay; buste en marbre. - H. 0,67.

Né à Paris le 11 janvier 1774, lieutenant en second au $4^{\mathrm{e}}$ régiment d'artillerie, le $\mathbf{1}^{\mathrm{er}}$ septembre 1792, premier lieutenant à la $15 \mathrm{e}$ compagnie à cheval le 15 avril 1793 , puis premier capitaine. Chef de bataillon provisoire le 17 janvier 1795 , confirmé dans ce grade le 3 juin suivant, il se signala dans la campagne d'Italie par son activité et son courage, commanda l'artillerie à la défense de Vérone, sous le général Kilmaine, et fut tué à lâage de vingt-trois ans à l'attaque du pont d'Arcole le 16 novembre 1796. - Le général Bonaparte écrivait à sa veuve : “Muiron est mort à mes côtés sur le champ de bataille d'Arcole. Vous avez perdu un mari qui vous était cher, j'ai perdu un ami auquel j'étais depuis longtemps attaché; mais la patrie perd plus que nous deux en perdant un officier distingué autant par ses talents que par son rare courage. " Bonaparte donna le nom de Muiron à la frégate qui le ramena d'Egypte.

Ce buste était placé dans la salle des Maréchaux, aux Tuileries.

\section{Elliot (Jacques), aide-de-camp du général Bonaparte.}

Par DARdel; buste en plâtre. - H. 0,67.

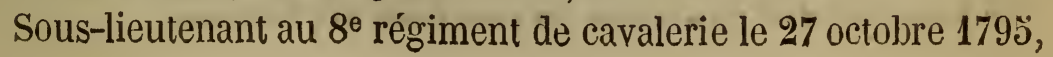


aide-de-camp du général Clarke, son oncle, le 5ั novembre suivant, il fut attaché à la personne du général Bonaparte, commandant en chef l'armée d'Italie, et fut tué à la bataille d'Arcole ( $3^{\mathrm{e}}$ journée) le 17 novembre 1796. "J'ai eu, dit Bonaparte, dans son rapport au Directoire, deux de mes aides-de-camp tués, les citoyens Elliot et Muiron, officiers de la plus grande distinction; jeunes encore, ils promettaient d'arriver un jour, avec gloire, aux premiers postes militaires. ”

Le buste original est dans la salle des Maréchaux, aux Tuileries.

\section{Marceau (Francois-Séverin), général en chef de l'armée de l'Ouest.}

. Par J. E. Dumont ; buste en plâtre. - H. 0,66.

Né à Chartres le $1^{\mathrm{er}}$ mars 1769 , il était fils de Francois-Séverin Marceau-Desgraviers, procureur au bailliage et siége présidial de Chartres. Volontaire au $1^{\text {er }}$ bataillon d'Eure-et-Loir en 1791, caporal en 1792, il devint successivement en 1793, chef de bataillon, adjudant-général, général de brigade et général de division, et servit aux armées des Côtes de La Rochelle et de l'Ouest. Il passa en 1794 à l'armée des Ardennes, et commanda l'aile droite à la bataille de Fleurus; employé à l'armée de Sambre-et-Meuse en 1795, il fut chargé en $1796 \mathrm{du}$ blocus de Mayence, et mourut le 20 septembre 1796, à la suite d'une blessure recue la veille à la bataille d'Altenkirchen, où il sauva l'armée de Sambre-et-Meuse. - L'armée autrichienne voulut se réunir à l'armée française pour lui rendre les honneurs funèbres.

Le buste original est dans la salle des Maréchaux, aux Tuileries.

\section{Julien (Thomas-Prosper), aide-de-camp du géné- ral Bonaparte.}

Par BoIzot; buste en marbre. - H. 0,69.

Né le 21 décembre 1773 à la Palud (Vaucluse), il entra au régiment d'Aquitaine (35๊e d'infanterie) comme sous-lieutenant, en 1792, et fut lieutenant la même année. Adjoint à l'adjudant-général Saint-Hilaire, le 23 décembre 1795, il eut le brevet de capitaine au titre de la $75^{\mathrm{e}}$ demi-brigade en 1796, et se distingua au passage des gorges de la Brenta. Aide-de-camp du général Bonaparte le 9 avril 1798, il fit la campagne d'Egypte et fut tué par les habitants d'Alkam en allant du Caireàla Rosette, le 2 août 1798.

Ce buste était placé dans_la salle des Maréchaux, aux Tuileries. 
528. Sulkowski (Joseph), aide-de-camp du général Bonaparte.

Par ESPERcieux; buste en plâtre. - H. 0,62.

Né en Pologne, il y servit pendant neuf ans en qualité de capitaine d'infanterie, d'aide-de-camp et de commandant d'un bataillon de chasseurs. Passé en France en 1792, il fut attaché à M. de Sémonville, ambassadeur de France en Turquie. Nommé capitaine à la suite le $\mathbf{1}^{\mathrm{er}}$ mai $\mathbf{1 7 9 6}$, il fit la campagne d'Italie et se distingua à la bataille de Saint-Georges. Chef de brigade et aidede-camp du général Bonaparte, le 13 avril 1798, il monta deux fois sur la brèche d'Alexandrie, fut nommé chef d'escadron sur le champ de bataille, et fut tué par les Arabes près du Caire en allant en reconnaissance le 21 octobre 1798. - Bonaparte donna son nom à un fort du Caire.

Le buste original est dans la salle des Maréchaux, aux Tuileries.

\section{Bon (Louis-André), général de division.}

Par ReNaud en 1805; buste en marbre. - H. 0,72.

Né à Romans (Drôme) le 26 novembre 1758. Soldat dans le régiment de Bourbon-Infanterie en 1776, chef du $1^{\text {er }}$ bataillon de la Drôme en 1792, il fut général de brigade en 1795 et servit aux armées des Pyrénées-Orientales, d'Italie, d'Angleterre et d'Orient. Nommé général de division par Bonaparte, alors général en chef de.l'armée d'Orient, il mourut le 12 juillet 1799 des blessures qu'il avait reçues au siége de Saint-Jean-d'Acre.

Ce buste était placé dans la salle des Maréchaux, au palais des Tuileries.

\section{Croizier, aide-de-camp du général Bonaparte.}

Par Petrot père; buste en plâtre. - H. 0,63.

Adjoint sous-lieutenant à l'état-major de l'armée de la Méditerranée, le 11 juin 1798, capitaine aide-de-camp du général en chef de l'armée d'Orient le 24 octobre de la même année, il fut blessé mortellement à l'assaut de Saint-Jean-d'Acre le 9 mai 1799, fut nommé chef d'escadron le 20 mai et mourut le 4 juin 1799 des suites de ses blessures.

Le buste original est dans la salle des Maréchaux, aux Tuileries.

\section{La Tour-d'A uvergne (Théophile-Malo de Corret de Kerbaufret de), premier grenadier de France.}

Par Corbet; buste en plàtre. - H. $\mathbf{0 , 6 7 .}$

Né le 23 décembre 1743 à Carhaix (Finistère), il était issu d'une branche bâtarde de la maison de Bouillon. Il entra au service 
comme simple grenadier, se trouva au siége de Mahon, en 175̌6, fut sous-lieutenant en 1767, lieutenant en 1771, capitaine en second en 1784, et chevalier de Saint-Louis en 1791. Il fit la campagne de 1792 à l'armée des Alpes où il commandait un corps de grenadiers appelé la Colonne infernale, et prit sa retraite en $\mathbf{1 7 9 5 .}$ Il partit de nouveau en 1799 pour l'armée d'Helvétie, recut en 1800, du premier Consul, un sabre d'honneur et le titre de premier grenadier de France, et fut tué en avant d'Oberhaussen, près de Neubourg, le 27 juin 1800. Un arrêté du premier Consul ordonna que son cœur serait porté par le fourrier de la compagnie dans laquelle il servait, que son nom serait maintenu sur les contrôles, qu'il serait nommé dans tous les appels, et que le caporal de son escouade devrait répondre : Mort au champ d'honneur. - La Tour d'Auvergne est auteur d'un ouvrage de linguistique sur les Origines gauloises.

Le buste original est dans la salle des Maréchaux, aux Tuileries.

\section{Kléber (Jean-Baptiste), général en chef de l'armée d'Orient}

Par Masson; buste en plâtre. - H. 0,66 .

Né à Strasbourg le 9 mars 1753, il fut officier au service del'Autriche de $\mathbf{1 7 7 6}$ à 1783 et professa l'architecture à Belfort de 1783 à 1789. Grenadier dans la garde nationalè de Belfort en 1789 , adjudant-major en 1792, lieutenant-colonel la même année, adjudant-général-chef de brigade et général de brigade en 1793, général de division en 1794, général en chef de l'armée de Sambreet-Meuse en 1796, il fit les campagnes de 1793 à 1796 aux armées de l'Ouest, du Nord, de Sambre-et-Meuse, Rhin-et-Moselle et d'Angleterre. Général en chef de l'armée d'Orient en 1799, il gagna la batailled'Héliopolis, et futassassinéau Caire le 14 juin 1800 .

Le buste original est dans la salle des Maréchaux, aux Tuileries.

QUATRIÈME PARTIE.

533. Gouvion (Jean-Baptiste), maréchal de camp.

Par M. Dastax aîné; buste en plâtre. - H. 0,68.

Né à Toul le 8 janvier 1747, il fut lieutenant en second à l'école de Mézières en 1769, et ingénieur en 1771. Il passa en 1777 au service des Etats-Unis d'Amérique, fut employé dans l'état-major de l'armée et reçut une pension pour sa conduite au siége d'YorckTown. De retour en France en 1783, il avait le rang de mestre de camp en 1787, fut adjudant-général et employé à la $17^{\mathrm{e}}$ division 
militaire en 1791, maréchal-de-camp à l'armée du-centre sous le général La Fayette en 1792, et fut tué à Hemptines, le 11 juin 1792.

\section{Richer-Drouet (Francois), maréchal de camp.}

Par M. ValoIs ; buste en plâtre. - H. 0,69.

Né à Rouen le 16 janvier 1733, il entra comme garde du corps dans la compagnie de Noailles en 17533, fut sous-lieutenant dans le régiment de La Fère en $175 \% 5$, aide-major en 1761 , major du régiment d'infanterie de Beauvais en 1777, et lieutenant-colonel du même régiment en 1783. Colonel du régiment de Picardie (depuis $2^{\mathrm{e}}$ régiment) en 1791 , puis maréchal de camp, il eut la jambe cassée d'un coup de feu à la bataille de Jemmapes, le 6 novembre 1792, et mourut de cette blessure.

\section{Guiscar de Bar (Georges), général de brigade.}

Par M. Dantan jeune; buste en plâtre. - H. 0,68.

Il commandait en qualité de lieutenant-colonel d'artillerie, lors du siége de Lille, en 1792, fut général de brigade en 1793, et périt à la bataille de Neerwinden, le 18 mars 1793, à l'âge de cinquantetrois ans.

536. Stengel (Henri-Christian-Michaël, baron de), général de division.

Par M. Thérasse; buste en plâtre. - H. 0,73.

Né le 10 mai 1744 à Neustadt, dans le Palatinat, il fut lieutenant dans les gardes palatines en $\mathbf{1 7 5 8}$, et entra au service de la France comme sous-lieutenant dans le régiment d'Alsace en 1760. Capitaine commandant dans le régiment de Chamborant-hussards en 1769, il fut major du même régiment en 1788. Colonel du 1 er régiment de hussards en 1792, il fut employé la même année comme maréchal de camp à l'armée du Nord, et se distingua à la bataille de Valmy. Général de division en 1795, il fut employé à l'armée des Alpes, puis à l'armée d'Italie; il commandait la cavalerie à la bataille de Mondovi le 21 avril 1796, et fut blessé mortellement dans une charge.

\section{Valhubert (Jean-Marie-Melon-Roger), général de brigade.}

Par M. DEBAX père; buste en plâtre. - H. 0,68 .

Né à Avranches (Manche) le 22 octobre 1764, il entra en 1784 dans le régiment d'infanterie de Rohan-Soubise. Chef du $1^{\text {er }}$ bataillon de la Manche en 1791, il fit les campagnes de 1792 et de 1793 à l'armée du Nord, et fut fait prisonnier au Quesnoy en 
1793. Chef de la 28e demi-brigade de bataille en 1797, il servit à l'armée de l'Intérieur jusqu'en 1799, fit les campagnes d'Italie et recut un sabre d'honneur en $\mathbf{1 8 0 3}$. Membre, puis commandant de l'ordre de la Légion d'Honneur, général de brigade en 1804, il fut attaché en 1805 à la $4^{\mathrm{e}}$ division du $4^{\mathrm{e}}$ corps de la grande armée et eut la cuisse fracassée par un éclat d'obus à la bataille d'Austerlitz, le 2 décembre 1805ّ; il mourut à la suite de cette blessure.

538. D'Hautpoul (Jean-Joseph, comte), général de division.

Par M. JALEY en 1837; buste en plâtre. - H. 0,72.

Né au château de Salette (Haute-Loire) le 13 mai 1754, il entra comme dragon dans la légion du Dauphiné en 1771, fut brigadier en 1774, maréchal-des-logis en 1776, sous-lieutenant à la suite du régiment de Languedoc-dragons en 1777, et lieutenant en 1783. Lieutenant dans le $6^{\mathrm{e}}$ régiment de chasseurs à cheval en 1791, capitaine et lieutenant-colonel en 1792 , chef de brigade en 1794, général de brigade en 1796, il servit à l'armée de Sambreet-Meuse. Général de division en 1796, inspecteur général de cavalerie dans les $2^{\mathrm{e}}, 4^{\mathrm{e}}, 6^{\mathrm{e}}$ et $18^{\mathrm{e}}$ divisions militaires en 1800 , il fut employé au camp de Compiègne en 1803 et chargé du commandement de la cavalerie du camp de Saint-Omer. Membre et grand-officier de la Légion d'Honneur, il commanda la $2^{\mathrm{e}}$ division de cavalerie de la grande-armée en 1805 et fut nommé en 1806 grand-aigle de la Légion d'Honneur et sénateur. Atteint par un biscaïen à la bataille d'Eylau, il mourut des suites de cette blessure le 14 février 1807, au château de Worin, entre Preussich-Eylau et Landsberg.

539. Colbert (Auguste-François-Marie), général de brigade. (Voir n $\left.{ }^{\circ} 511.\right)$

Par M. MAINDron; statue en marbre. - H. 2,35.

\section{Espagne (Jean-Louis-Brigitte, comte), général de division. (Voir $\mathrm{n}^{\circ} 521$.)}

Par M. Oudiné; statue en plâtre. - H. 2,35.

La figure en marbre a été exposée au Salon de 1842.

541. Duroc (Géraud-Christophe-Michel), duc de Frioul, général de division.

Par M. JACQvoT; buste en plâtre. - H. 0,72.

Né à Pont-à-Mousson (Meurthe) le 25̆ octobre 1772, il fut élève 
sous-lieutenant d'artillerie en 1792, lieutenant en 1793, capitaine en 1794, capitaine-commandant en 1797, et fit les campagnes d'Italie de 1793 à 1797. Chef de bataillon en 1798, il fit la campagne d'Egypte en qualité d'aide-de-camp du général Bonaparte, et fut chef de brigade en 1799. Général de brigade en 1800, général de division en 1803, membre de la Légion d'Honneur et grand-offlcier de l'ordre, il fut en 180' grand-maréchal du palais, grand-aigle de la Légion d'Honneur, et reçut du roi de Prusse la décoration de l'Aigle-Noir. Envoyé extraordinaire auprès des cours de Berlin, de Saint-Pétersbourg, de Stockholm et de Copenhague, il eut le grade de général-major de l'armée hollandaise, fut nommé en 1808 commandeur de la Couronne de fer et duc de Frioul, et recut en 1809, de l'empereur d'Autriche, la croix de l'ordre de Saint-Léopold. Nommé sénateur en 1813, il fut blessé d'un coup de boulet à la bataille de Wurschen, et mourut le 23 mai 1813, au village de Nidermaxertorff.

\section{Letort (Louis-Michel, baron), général de division.}

Par M. J. Debay; buste en plâtre. - H. 0,71.

Né à Saint-Germain-en-Laye (Seine-et-Oise) le 29 août 1773 , il entra en 1791 au $1^{\text {er }}$ bataillon de la $164^{\mathrm{e}}$ demi-brigade, et fut adjudant la même année; adjudant-major et capitaine en 1793, il fut aide-de-camp du général Huet et servit à l'armée de la Moselle. Sous-lieutenant de cavalerie légère, puis au $9^{\mathrm{e}}$ de dragons en 1796, il fit les campagnes d'Italie et fut nommé chef-d'escadron en 1801. Major au $14^{\mathrm{e}}$ régiment de dragons, membre de la Légion d'Honneur en 1804, il fit les campagnes de la grande-armée, fut créé baron de l'empire et officier de la Légion d'Honneur en 1808, combattit en Allemagne en 1809 et prit part à l'expédition de Russie en 1812. Général de brigade en 1813, il commanda la $1^{\text {re }}$ division de cuirassiers du $1^{\text {er }}$ corps de cavalerie de la grande-armée et fit la campagne de France. Général de division en 1814, il fut nommé par Louis XVIII chevalier de SaintLouis et commandeur de la Légion d'Honneur. Atteint d'une balle dans un combat près de Charleroi, le 15 juin 1815 , il mourut de cette blessure deux jours après.

\section{CINQUIÈME PARTIE.}

\section{Nérestang (Jean-Claude, marquis de), maréchal des camps et armées du roi.}

Par M. Garraud; buste en plâtre. - H. 0,69.

Il fut recu grand-maître de l'ordre de Saint-Lazare et de NotreDame-du-Mont-Carmel. Après s'être signalé en diverses occasions, 
particulièrement à Cazal et à Turin, il fut tué devant cette dernière place, le 2 août 1639.

544. Coislin (César du Cambout, marquis de), colonelgénéral des Suisses et Grisons.

Par M. Duseigneur en 1839; buste en plâtre. - H. 0,69.

Il fut lieutenant-général des armées du roi, se signala en plusieurs occasions, et principalement dans le passage du Rhin à Mayence, à la retraite de Vendres, à la prise de Hesdin et d'Arras. Il mourut en 1641, âgé de vingt-huit ans, des blessures qu'il avait reçues au siége d'Aire.

545. Praslin (Roger de Choiseul, marquis de), maréchal des camps et armées du roi.

Par M. MERCIER; buste en plâtre. - H. 0,66.

Il fut lieutenant-génêral au gouvernement deChampagne, mestre de camp de la cavalerie légère, et périt à la bataille de la Marfée, près de Sédan, le 6 juillet 1641 . - Une tradition le fait mourir longtemps après, ermite à Coiffy.

\section{Castelan (Olivier de), maréchal des camps et armées du roi.}

Par FEuchèRE; buste en plâtre. - H. 0,70.

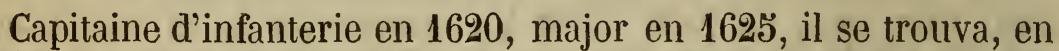
1627, au siége de la Rochelle, fit les campagnes de 1629 en Italie, de 1630 en Savoie, et de 1633 en Lorraine. Maréchal-de-camp en 1636, il servit en Italie jusqu'en 1643, se rendit, en 1644, à l'armée de Catalogne, et fut tué la même année au siége de Tarragone.

\section{Gesvres (Francois Potier, marquis de), maré- chal des camps et armées du roi.}

Par M. Duseigneur en 1844; buste en plâtre. - H. 0,66.

Connu d'abord sous le nom de marquis de Gamdelus, il servit comme volontaire en 1630 dans la campagne de Savoie, et fut nommé capitaine dans le régiment du cardinal de Richelieu. Après

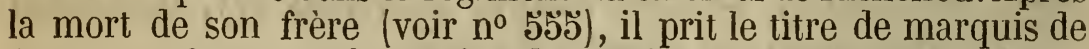
Gesvres et fut nommé capitaine des gardes du corps du roi. Maréchal de camp en 1643, il fit les campagnes de Flandre jusqu'en 1645, passa à l'armée de Catalogne en 1646, et fut tué le 27 mai devant Lérida, à l'âge de trente-quatre ans. 
548. Joyeuse (Louis de Lorraine, duc de), colonelgénéral de la cavalerie.

Par M. Bosio neveu en 1838; buste en plâtre. - H. 0,60.

Il était grand chambellan de France en 1644, fit les campagnes 'de Flandre en 1645 et 1646, fut nommé colonel-général de la cavalerie en 16533 , lieutenant-général des armées du roi en $163 \%$ et servit sous le maréchal de Turenne. Il mourut à Paris le 27 septembre 165ั4, à l'âge de trente-trois ans, des suites d'une blessure qu'il avait recue au siége d'Arras.

549. Castelan (Louis de), brigadier-général des armées du roi.

Par M. MERCIER; buste en plâtre. - H. 0,68.

Fils d'Olivier de Castelan, il servit d'abord en qualité de capitaine, puis de major des gardes-francaises, fut nommé brigadier en 1668 , et se rendit au siége de Candie, où il fut tué le 230 juin 1669 , à trente-sept ans.

550. Beringhen (Henri, marquis de), brigadier-général des armées du roi.

Par M. Fauginet en 1839; buste en plâtre. - H. 0,72.

Reçu en survivance de la charge de premier écuyer de la petite écurie du roi, il fut colonel d'infanterie du régiment du Dauphin et périt au siége de Besançon, le 18 mai 1674.

\section{SIXIÉME PARTIE.}

551. Senecey (Henri de Bauffremont, marquis de), maréchal des camps et armées du roi.

Par M. Rayus ; buste en plâtre. - H. 0,62.

Lieutenant pour le roi au comté de Mâcon, il fut président de la noblesse aux Etats-généraux de Paris en 1614. Ambassadeur extraordinaire en Espagne en 1617 et 1618, chevalier du SaintEsprit en 1619, il suivit deux ans après le roi Louis XIII dans la guerre contre les protestants, et reçut, en 1622, au siége de Royan, une blessure dont il mourut peu après à Lyon.

552. Rambures (Jean de), maréchal des camps et armées du roi.

Par M. Huguenin; buste en plâtre. - H. 0,65.

Mestre-du-camp du régiment des Gardes-du-Roi en 1632, et 
gouverneur de Doullens, il mourut en 1637 des blessures qu'il avait reçues pendant le siége de la Capelle.

553. Lorraine (Henri de), duc de Mayenne et d'Aiguillon.

Par M. ELShoect; buste en plâtre. - H. 0,67.

Né à Dijon en $15 \breve{7} 78$, il était fils du fameux duc de Mayenne, et fut créé duc d'Aiguillon en 15ั99. Ambassadeur extraordinaire en Espagne et chevalier de l'ordre du Saint-Esprit en 1619, il prit part à la guerre de l'année 1621, et fut tué d'un coup de mousquet, le 17 septembre de la même année, au siége de Montauban.

\section{Rohan (Henri, duc de), colonel-général des Suisses et des Grisons.}

Par M. L. PETrTor; buste en plâtre. - H. 0,66.

Il porta d'abord le nom de vicomte de Rohan, et fit sa première campagne en 1 9097 , au siége d'Amiens. Duc et pair de France en 1603, colonel-général des Suisses et des Grisons en 160弓, il se démit de cette charge en 1614, et fut le chef des protestants de France depuis 1621 jusqu'en 1628. Il commanda de nouveau pour le roi, en 1633, dans la Valteline et sur les frontières de Lorraine; en 1638 il se joignit à Bernard de Saxe-Weimar contre les Impériaux, recut deux coups de mousquet à la bataille de Rheinfeld, et mourut le 13 avril 1638 dans l'abbaye de Cunefeld (canton de Berne), à l'âge de cinquante-neuf ans, des suites de ses blessures. - Le duc de Rohan a laissé des écrits politiques et des Iémoires.

555. Gesvres (Louis Potier, marquis de), maréchal des camps et armées du roi.

Par M. Duseigneur en 18'48; buste en plàtre. - H. 0,65.

Gouverneur de Touraine, capitaine des gardes du corps en survivance de son père en 1627, Louis XIII lui donna en 1837 la capitainerie du château et des chasses de Montceaux. Après sêtre signalé dans diverses campagnes et avoir reçu plus de trente blessures, il fut tué au siége de Thionville, le 4 août 1643 .

556. Douglas (Jacques, comté de), maréchal des camps et armées du roi.

Buste en plâtre. - II. 0,53.

Il entra au service de France en 1633, fut capitaine, puis co- 
lonel dans le régiment d'Hébron, et fit les campagnes de Lorraine, d'Allemagne et de Franche-Comté, de 1634 à 1644. Maréchal de camp en 1645, il servit en Flandre sous Gassion, et fut tué dans un combat contre les Espagnols, près de Douai, le 21 octobre 1645 , à vingt-huit ans.

La statue originale est dans l'église de Saint-Germain-des-Prěs, à Paris.

\section{SEPTIÈME PARTIE.}

\section{Charles de Bourgogne, surnommé le Téméraire, duc de Bourgogne.}

Buste en plâtre. - H. 0,57.

Fils de Philippe-le-Bon, né à Dijon en 1433, il porta d'abord le titre de comte de Charolais, entra dans la Ligue du Bien Public, formée contre Louis XI, et livra contre lui, en 1465 , la bataille de Montlhéry. Duc de Bourgogne à la mort de son père, en 1467, il institua à Dijon le parlement de Bourgogne. Après une longue lutte contre Louis XI, il livra aux Suisses les deux batailles malheureuses de Granson et de Morat en 1476, et fut tué le 5 janvier 1477 , devant la ville de Nancy qu'il assiégeait.

La statue originale est placée sur le tombeau de Charles-le-Téméraire, à Bruges.

\section{Bayard (Pierre du Terrail, seigneur de), dit le Chevalier sans peur et sans reproche.}

Buste en plâtre. - H. 0,68.

Né en Dauphiné en 1476, il fut page du duc Charles de Savoie en 1489. Bayard entra ensuite dans la compagnie d'hommes d'armes du connétable de Saint-Pol, suivit en 1495 Charles VIII dans l'expédition du royaume de Naples, et se distingua à la bataille de Fornoue. Il accompagna Louis XII à Milan en 1499, se trouva au siége de Padoue en 1508, à la prise de Brescia, à la bataille de Ravenne en 1512, et l'année suivante au combat de Guinegate, appelé la Journée des Eperons. Lieutenant-général au gouvernement du Dauphiné en 1514, il était en 1515 à la bataille de Marignan, après laquelle il arma François I ${ }^{\mathrm{er}}$ chevalier. En 1521, Bayard se trouva au siége de Pampelune, défendit Mézières contre Charles-Quint, suivit en 1523 l'amiral de Bonnivet en Italie, reçut de lui le commandement de l'armée à la bataille de Rebec, et fut tué dans la retraite qui suivit cette bataille, entre Romagnano et Gattinara, le 30 avril 1524.

Le buste original est dans l'église des Minimes de la Plaine, près de Grenoble. 
559. La Trémoille (Louis II, sire de), vicomte de Thouars, prince de Talmont, etc.

Par M. Aug. BARre; buste en plâtre. - H. 0,64.

Il naquit en 1460 et fut page du roi Louis XI. En 1488 il commandait l'armée royale à la journée de Saint-Aubin-du-Cormier, fut en 149ö lieutenant-général du Poitou et de l'Angoumois, et en 1498 commandant en chef de l'armée d'Italie. Chevalier de l'ordre de Saint-Michel, gouverneur de Bourgogne, amiral de Guyenne et de Bretagne en 15002, il commandait le corps de bataille à Aignadel en 1509. Il fit la campagne d'Italie en 15้15, défendit la Picardie en 1522 et 15223 , et fut tué à la bataille de Pavie le 24 février 15ั25ั. - On l'avait surnommé le Chevalier sans reproche.

560. Strozzi (Léon), prieur de Capoue, général des galères.

Par M. Briax; buste en plâtre. - H. 0,67.

Frère du maréchal Pierre Strozzi, il parvint aux premiers grades dans l'ordre de Malte, fut chef d'escadre au service de la France et alla en Ecosse secourir, arec vingt galères, Marie Stuart contre Elisabeth. Il dirigea une expédition sur les côtes d'Espagne, investit le fort de Scarlino dans la principauté de Piombino, et y fut blessé mortellement en 1 כ̌ǒk.

561. Randan (Charles de La Rochefoucauld, comte de), colonel-général de l'infanterie française.

Par M. Brux; buste en piâtre. - H. 0,68.

Il commandait en $15 \%$ วั2 une compagnie de cent chevau-légers à la défense de Metz, et fut ensuite envoyé en mission en Angleterre. Nommé colonel-général de l'infanterie française, il se trouva aux siéges de Bourges et de Rouen, et mourut le 4 novembre 15062 , des suites d'une blessure qu'il avait reçue devant cette dernière ville.

562. Montmorency (Anne, duc de), connétable de France. (Voir no 954 .)

Par Pradier; buste en plâtre. - - Ir. 0,67.

563. Brissac (Timoléon de Cossé, comte de), colonelgénéral de l'infanterie française.

Par M. Lescorné; buste en plâtre. - H. 0,66.

Il était fils du maréchal de Brissac, et fut en 1503 , après la mort 
de son père, colonel-général de l'infanterie française, capitaine et gouverneur de la ville et du château d'Angers. Il se trouva à la bataille de Saint-Denis, au combat de Jarnac, et fut tué le 28 avril 1569, au siége de Mucidan en Périgord.

\section{Strozzi (Philippe), seigneur d'Épernay, colonel-} général de l'infanterie française.

Par M. JACQUOT; buste en plâtre. - H. 0,66.

Fils du maréchal Pierre Strozzi, il était né ả Venise en 15ّ4t, et fut placé en 15ّ42, comme enfant d'honneur auprès du dauphin, depuis Francois II. Nommé colonel des gardes-françaises en 1563 et colonel-général de l'infanterie en $\mathbf{1 5 6 9}$, il se trouva la même année aux batailles de Jarnac et de Moncontour. Chevalier du Saint-Esprit à la création de cet ordre, en 1579, il fut lieutenantgénéral de l'armée navale envoyée en Portugal, et fut tué le 26 juillet 1582, dans un combat naval contre la flotte espagnole, devant l'île Saint-Michel.

\section{Lanoue (François de), dit Bras-de-Fer.}

Par M. Desprez; buste en plâtre. - H. 0,67.

Il fit ses premières armes en Italie et prit part aux guerres de religion sous le prince de Condé. Etant au siége de Fontenay-leComte, en 1570, il eut le bras gauche brisé, et après l'amputation le fit remplacer par un bras de fer, d'où lui vint le súrnom sous lequel 3 ? est connu. Il commanda dans La Rochelle en 1573 et 1574, cl fut nommé par Henri IV, en 1589, lieutenant-général en Bretagne. Il assiégait le château de Lamballe en 15̆91, lorsqu'il y reçut un coup de feu, dont il mourut à l'âge de soixante ans. Lanoue a laissé des Mémoires qui ont pour titre : Discours politiques et militaires.

\section{Gondi (Charles de), marquis de Belle-Isle, gẹnéral des galères.}

Par M. Ocdine; buste en plâtre. - H. 0,69.

Nommé en 1579 général des galères, sous la surintendance du maréchal de Retz, son père, il prit une part active aux guerres de son temps, et fut tué en 1596 à l'attaque du Mont-Saint-Michel en Normandie, à l'âge de vingl-sept ans.

\section{Espinay (Francois d'), seigneur de Saint-Luc, grand-maître de l'artillerie.}

Par M. LemaIRE; buste en plâtre. - H. 0,68.

Il fut un des favoris de Henri III, alors duc d'Anjou, l'accompa- 
gna en Pologne et prit une part active à toutes les guerres de son temps. Nommé par Henri IV chevalier de l'ordre du Saint-Esprit en 1595, et grand-maître de l'artillerie en 1596, il fut tué le 8 septembre 1597 par un boulet de canon, au siég'e d'Amiens, à l'âge de quarante-trois ans.

568. Nérestang (Philibert, marquis de), maréchal des camps et armées du roi.

Par M. Joufrroy; buste en plàtre. - H. 0,72.

Henri IV lui conféra la grande-maitrise de l'ordre de Saint-Lazare et de Notre-Dame du Mont-Carmel, et le nomma capitaine de la première compagnie de ses gardes du corps, dite la Compagnie écossaise. Il mourut en 1620 des suites d'une blessure qu'il avait reçue à l'attaque du Pont-de-Cé, où il commandait une partie de l'armée sous les ordres du roi.

\section{SALLE No 27.}

Cette salle formait l'angle d'un des pavillons de l'ancien château de Louis XIII. Elle servit, jusqu'en $\mathbf{1 7 8 9}$, de salle des gardes pour l'appartement particulier du roi, auquel conduisait l'escalier $n^{\circ} 31$. Louis $X V$ venait de descendre cet escalier et de sortir de cette salle pour monter dans son carrosse, qui était rangé contre les marches de la cour de marbre, lorsqu'il fut frappé par Damiens, le 5 janvier 1757, à six heures du soir. Arrêté immédiatement et amené dans la salle des gardes, Damiens y fut aussitôt appliqué à la question par ordre du chancelier de Lamoignon. Cette salle est actuellement séparée en deux parties par quatre colonnes en marbre qui se trouvaient au milieu du vestibule de Louis XIII, $n^{\circ} 32$; la première partie fait suite aux vestibules contenant les bustes d'offciers-généraux tués sur les champs de bataille; la seconde partie termine la série des tableaux-plans contenus dans les salles nos 28 à 30 .

\section{PREMIÈRE PARTIE.}

569. Pierre de France, comte d'Alençon. (Voir no 262.) Buste en plâtre. - H. 0,56.

570. Charles d'Evreux, comte d'Étampes. (Voir n 274.) Buste en plâtre. - H. 0,52.

571. Charles de Valois, $\boldsymbol{I I}^{e}$ du nom, comte d'Alençon. Buste en plâtre. - H. 0,56.

Il assista au sacre de Philippe-de-Valois, son frère, en 1328, et se trouva à la bataille de Montcassel, où il fut dangeureusement blessé. En 1346, Charles de Valois commandait l'avant-garde à la bataille de Crécy où il fut tué.

La statue originale, provenant de l'église des Jacobins de Paris, est à SaintDenis. 


\section{Pierre de Bourbon, duc de Bourbon.}

Buste en platre. - H. 0,55.

Il assista, en 1342, Jean de France, duc de Normandie, dans les guerres de Bretagne et de Guyenne, se trouva à la bataille de Crécy, en 1346, au siége de Calais, en 1347, et fut tué à la bataille de Poitiers, le 19 septembre 1356 .

La statue originale, placée autrefois dans l'église des Jacobins de Paris, est à Saint-Denis.

573. Bayard (Pierre du Terrail, seigneur de). (Voir $\mathrm{n}^{\circ} 558$. )

Par Bridan; statue en plâtre. - H. 1,98.

574. Turenne (Henri de La Tour d'Auvergne, vicomte de), maréchal de France. (Voir no 999.)

Par PAJOU; statue en plâtre. - H. 1,98.

575. Berwick (Jacques de Fitz-James, duc de), maréchal de France. (Voir no ${ }^{\circ}$ 1062.)

Par M. DuRET; statue en plâtre. - H. 2,08.

\section{DEUXIÈME PARTIE.}

576. Plan du siége d'Anvers. - Du 21 novembre au 24 décembre 1832.

Par M. Siméon ForT en 1840, - H. 3,50, - L. 1,73.

La place d'Anvers, occupée par l'armée hollandaise sous les ordres du général Chassé, capitule après vingt-quatre jours de siége, dont dix-neuf de feu, et se rend aux Français, commandés par le maréchal Gérard. Le lieutenant-général Neigre commandait l'artillerie, et le lieutenant-général Haxo le gênie.

577. Marche de l'armée française sur Mascara. Du 28 novembre au 5 décembre 1835.

Par M. Justin Ouvrié, d'après M. Siméon Fort. - H. 3,50. - L. $1,79$.

Le maréchal Clausel, accompagné du duc d'Orléans, à la tête de quatre brigades, part d'oran le 26 novembre. Après les combats du Sig, de l'Habrah, de Sidi-Embarek et de Beni-Changaran, il parvient, le 5̆ décembre, jusqu'à Mascara, capitale de l'émir Abd-el-Kader, qu'il trouve pillée et en partie brûlée par les Arabes. 
578. Vue générale de Constantine et des environs, pour servir à l'intelligence des opérations du siége. - Du 6 au 13 octobre 1837.

Par M. Siméon ForT. - H. 3,50, - L. 1,44.

Une première expédition contre Constantine avait échoué en 1836 ; le soin de réparer cet échec fut confié au général Danrémont, gouverneur des possessions françaises en Afrique. On mit sous ses ordres un corps d'armée plus fort et mieux approvisionné que celui avec lequel le siége avait été tenté l'année précédente. La brigade d'avant-garde était commandée par le duc de Nemours, les deux autres par les généraux Trézel et Rulhière. Le général Perregaux remplissait les fonctions de chef d’étatmajor-général de l'armée. L'artillerie et le génie étaient sous les ordres des lieutenants-généraux Valée et Rohault de Fleury. Le $1^{\mathrm{er}}$ octobre 1837, l'armée quitta son campement de Medjz-Ammar, et le 6 au soir elle bivouaquait sous les murs de Constantine. Malgré une pluie battante, le feu de la place et les sorties continuelles de la garnison, les batteries furent armées et quelques pièces commencèrent à battre les murs dans la journée du 9 . Le 11, la batterie de brèche fut armée, et le 12, le général Danrémont ayant été tué d'un boulet de canon, le général Valée prit le commandement de l'armée. Le 13, à trois heures et demie du matin, la brèche fut reconnue praticable, et à sept heures le signal de l'assaut fut donné. A neuf heures, le drapeau français flottait sur Constantine.

579. Vue générale de l'itinéraire suivi par la colonne expéditionnaire depuis Constantine jusqu'à Alger. - Octobre et novembre 1839.

Par M. Siméon ForT en 1840. - H. 3,56. - L. 2,47.

La colonne expéditionnaire sous les ordres du maréchal Valée et du duc d'Orléans, part de Constantine le 1כّ octobre, et après avoir traversé Milah, Sétif, la plaine de Medjana, les Bibans ou Portes-de-Fer et la plaine d'Amza au pied du Jurjura, rentre à Alger par la porte Babazoun.

580. Vue générale de la smalah d'Abd-el-Kader, prise le 16 mai 1843.

Par M. Siméon Fort en 1847. - H. 3,50. - L. 1,63.

Le duc d'Aumale, à la tête de six cents cavaliers, aperçoit la smalah d'Abd-el-Kader, composée de milliers de tentes et bien défendue. Les Arabes ses alliẻs supplient le prince d'attendre les 
zouaves et l'arrivée de l'artillerie; mais celui-ci, apprenant que les tribus commençaient leur mouvement de retraite, se précipite au milieu du camp, a la tête d'un escadron et d'une trentaine de gendarmes, après avoir lancé sur la gauche le colonel Jusuf et ses spahis, et le lieutenant-colonel Norris sur la droite.

\section{Vue générale de la bataille d'Isly. - 14 août 1844.}

Par M. Siméon FoRT. - H. 3,50, - L. 1,77.

Le marẻchal Bugeaud, après avoir passé deux fois l'Jsly, découvre sur une hauteur le groupe du fils de l'empereur de Maroc, ses drapeaux et son parasol, signe de commandement. Il donne ce point au bataillon de direction de son ordre échelonné et l'affaire s'engage rapidement sur les deux flancs. Pendant ce temps, le colonel Morris, voyant une grosse masse de cavalerie qui se précipitait sur l'aile droite, passe l'Isly pour briser cette charge en attaquant lennemi par son flanc droit; il réussit, mais se trouve bientôt obligé de soutenir le combat le plus inégal. Il est heureusement secouru par trois bataillons que le général Bedeau, commandant l'aile droite, envoie à son secours. Après trois ou quatre heures de combat, l'armée marocaine, dans une complète déroute, se retire par la route de Thara et par les vallées qui conduisent aux Beni-Senassen, laissant huit cents morts sur le champ de bataille, tout son matériel, onze pièces d'artillerie, la tente avec le parasol de commandement et un butin immense.

\section{SALLE No 28.}

Salon du petit escalier du roi sous Louis XIV et appartement du capitaine des gardes de quartier sous Louis XV et sous Louis XVI.

\section{Plan du siége de Berg-op-Zoom. - Du 12 juillet au 16 septembre 1747.}

Par M. Siméon FORT en 1842. - H. 3,43. - L. 1,85.

Le comte de Lowendal arriva devant cette place le 12 juillet; il appuya sa droite à l'Escaut et sa gauche à la Zoom; dans la nuit du 14 au 150 on ouvrit la tranchée et les travaux continuèrent sans interruption pendant deux mois. Le 15 septembre Lowendal ordonna l'assaut et s'empara en même temps du fort d'Edem et des bastions la Pucelle et Cohorn. 


\section{Plan du siége d'York-Town. - Du 6 au 19 oc- tobre 1781.}

Par M. Siméon ForT. - H. 3,43. - L. 1,99.

York-Town fut investi le 6 octobre et la tranchée fut ouverte le 8. Après trois semaines de travaux, lord Cornwallis, commandant l'armée anglaisé forte de sept mille hommes, déposa les armes devant l'armée combinée Franco-Américaine, composée de seize mille hommes, dont sept mille de troupes françaises commandées par le marquis de La Fayette et le baron de Vioménil. Le général Lincoln commandait les Américains, et le comte de Grasse les forces navales françaises dans la baie de Chesapeack.

584. Plan du siége de Namur. - Du 19 novembre au 2 décembre 1792.

Par M. Siméon ForT. - H. 0,90. - L. 1,23.

Le général Valence mit le siége devant Namur, le 19 novembre, et la garnison autrichienne se retira dans la citadelle. Le 29 la tranchée était ouverte, et le 2 décembre le général Moitelle, qui commandait la garnison, demanda à capituler. Valence fut admirablement secondé par le général Leveneur qui, à la tête de douze cents hommes, s'introduisit par escalade dans le fort Villate et arracha lui-même les mèches qu'on voùlait allumer pour faire jouer les mines.

585. Plan du siége de Toulon. - Novembre el décembre 1793.

Par M. Siméon FoRT. - H. 2,12. - L. 1,17.

La ville et le port de Toulon étaient tombés au pouvoir des Anglais réunis aux Espagnols et aux Napolitains. Vers la fin de novembre, le général Dugommier fut investi du commandement en chef de l'armée de siége, et à son arrivée il convoqua un conseil où l'on décida qu'on commencerait par attaquer la redoute anglaise située sur la hauteur à l'ouest de l'Eguillette, la montagne de Faron et enfin le fort Malbousquet, tandis qu'on ferait vers la gauche une démonstration sur le cap Brun. Le chef de bataillon Bonaparte, commandant l'artillerie du siége, établit sur la colline des Arènes une batterie de six pièces de vingt-quatre qui commença à tirer contre le fort Malbousquet. Le 30 novembre les assiégés tentèrent une sortie; la redoute de l'Eguillette fut enlevée dans la nuit du $\mathbf{1 6}$ au $\mathbf{1 7}$ décembre, et les Anglais ayant évacué la ville après avoir incendié la flotte et l'arsenal, l'armée française entra à Toulon le 19 décembre. 
586. Vue générale des Alpes maritimes, de la chaîne des Apennins et de la côte, depuis Nice jusqu'à Gênes, pour servir à l'intelligence des opérations de l'armée française. - Du 5 avril au 15 mai 1796.

Par M. Siméon ForT. - H. 3,43. - L. 3,31.

Bonaparte prend le commandement de l'armée d'Italie le 27 mars, transfère son quartier-général à Albenga le $\mathbf{5}$ avril, puis à Savone le 9. Son plan était de tourner les Alpes et d'entrer en Italie par le col de Cadibone. A ce premier mouvement, Beaulieu divise son armée en trois corps. Colli forme la droite avec les Piémontais; il occupe le camp de Seva avec ordre de défendre le Tanaro et la Stura. Le général Argenteau est à Sassello avec le centre; il se dirige sur Montenotte pour tomber sur le flanc gauche des Français à Savone, et leur intercepter la route de la Corniche. Le général Beaulieu commande la gauche de sa personne ; voulant couvrir Gênes, il marche sur la Bocchetta pour tomber sur Voltri et arrêter les Français. Bonaparte, profitant de ces dispositions vicieuses qui morcelaient les forces des alliés, et ayant toutes ses troupes sous sa main, les attaque successivement. Il gagne les batailles de Montenotte le $\mathbf{1 1}$ avril, de Millesimo le 14, de Dego le 16, de Mondovi le 22; il signe le 28 avril l'armistice de Cherasco avec le roi de Sardaigne, se porte ensuite contre Beaulieu, et le bat à Lodi le 10 mai. Le 150 mai, Bonaparte faisait son entrée solennelle à Milan.

587. Vue générale d'une partie de l'Italie, pour servir à l'intelligence des opérations de l'armée francaise sous les ordres du général Bonaprate. Du 3 aoùt 1796 au 2 février 1797.

par M. Siméon Fort en 1843. - H. 3,43. - L. 3,25.

Cette campagne comprend les batailles de Lonato, Castiglione, Roveredo, Lavis, Primolano, Bassano, Saint-Georges, Arcole, Rivoli et la Favorite, jusqu'à la reddition de Mantoue. Le spectateur est supposé placé à l'ouest de la ville de Brescia, d'où il domine entièrement le lac de Garda, la chaîne des Alpes-Carniques et du Tyrol et toute la plaine du Pô, depuis Mantoue jusqu'aux lagunes de Venise. Le cours de l'Adige se déploie depuis sa source, au pied du Brenner, jusqu'à son embouchure dans l'Adriatique et dans la plaine. On distingue les villes de Mantoue, Peschiera, Vérone, Vicence, Rovigo, Ferrare, Padoue, Venise, Trévise, Udine et Trieste. 
588. Plan du siége de Mantoue. - Septembre 1796 à février 1797.

Par M. Siméon FoRT. - H. 0,90, - L. 1,23.

Après avoir perdu la bataille de Bassano, le feld-maréchal Wurmser avait été contraint de se renfermer dans Mantoue avec six mille hommes. Le blocus de Mantoue dura sept mois. Le général Serrurier le commandait ; le général Chasseloup-Laubat dirigea les travaux du génie, et le général Lespinasse l'artillerie. Pour se rendre maître de cette ville, Bonaparte dut détruire successivement trois armées autrichiennes; enfin le 2 février, ce dernier boulevard de l'Italie tomba après six mois d'une résistance qui fit honneur aux troupes autrichiennes.

\section{Plan de la bataille d'Aboukir. - 25 juillet 1799.}

par M. Siméon ForT. - H. 2,12. - L. 1,17.

Mustapha-Pacha, commandant l'armée turque, avait débarqué dans la rade d'Aboukir, et après s'être emparé du fort et de la ville, s'y trouvait à la tête de dix-huit mille hommes. Le général Bonaparte, après avoir lancé les corps des généraux Lannes, Destaing et Murat, pénètre dans le village. On pousse les Turcs la baïonnette dans les reins et on les précipite dans la mer, où plus de douze mille périrent. Dans cette bataille extraordinaire, l'armée ennemie fut détruite tout entière, fait jusqu'alors inouî dans l'histoire de la guerre.

590. Marche de l'armée française en Italie pendant la campagne de Marengo. - Du 15 mai au 14 juin 1800.

Par M. Justin OuvrIÉ, d'après Bagetti. - H. 3,43. - L. 6,72.

L'armée française, sous les ordres du premier consul Bonaparte, part de Genève le 15 mai, traverse le grand Saint-Bernard du 18 au 20, passe sous le fort de Bard le 21, entre à Milan le 2 juin, à Plaisance le 6 , remporte le 8 les batailles de Casteggio et de Montebello, et défait l'armée autrichienne à Marengo le 14 juin.

591. Plan du siége de Dantzick. - Du 12 mars au
21 mai 1807. Par M. Siméon ForT. - H. 3,43. - L. 2,05.

Cette place possédait une garnison de quinze mille Prussiens et de six mille Russes, commandée par le général Kalkreuth. Le 
14. mars le maréchal Lefebvre investit la place à la tête du $10^{\mathrm{e}}$ corps de la grande-armée, accompagné de Saxons et de Badois. Le général Savary servait sous ses ordres ; le général Lariboissière commandait l'artillerie, et le général Chasseloup-Laubat les travaux du génie. Dantzick se rendit le 21 mai suivant. Huit cents pièces de canon, des magasins immenses de munitions, de vivres et d'objets d'habillement et d'équipement tombèrent au pouvoir du vainqueur. Le maréchal Lefebvre reçut pour prix de son succès le titre de duc de Dantzick.

\section{Plan du siége de Tarragone. - Du 4 mai au 29 juin 1811.}

Par M. Siméon ForT. - H. 3,43. - L. 1,78.

Le général Suchet, commandant le $3^{\mathrm{e}}$ corps, assiége Tarragone défendue par une forte garnison commandée par les généraux Campoverde et Contreras, et soutenue et ravitaillée par la flotte anglaise sous les ordres du commandant Codrington. Après deux mois de travaux et de combats continuels, qui coûtèrent des pertes énormes aux deux partis, la ville est prise d'assaut le 29 juin. La prise de Tarragone fit évacuer la Catalogne à l'armée espagnole, et valut au général Suchet son brevet de maréchal.

\section{SALLE No 29.}

Dépendance de l'appartement du capitaine des gardes du rol.

\section{Secours de Cazal. - 26 octobre 1630.}

École française; $\mathrm{XVII}^{\mathrm{e}}$ siècle. - H. 3,23. - L. 2,14.

Les Espagnols tenaient Toiras étroitement assiégé dans Cazal depuis sept mois, lorsque l'armée française, commandée par les maréchaux de Schomberg, de La Force et de Marillac, vint à son secours. Mazarin, alors gentilhomme du pape, chargé d'interposer la médiation pontificale, parvint, en faisant reconnaître le traité de Ratisbonne par le général espagnol, à faire lever le siége de la place. Dès que le traité fut signé, Toiras demanda au marquis de Santa-Cruz la permission de passer au travers de son camp pour aller remercier ses libérateurs. Le marquis lui envoya des gardes pour traverser les lignes espagnoles rangées en bataille, et qui lui rendirent, disent les relations du temps, les mêmes honneurs qu'elles eussent rendus à un empereur.

Ce tabl zau provient de la galerie du château de Richelieu. (Voir salle $n^{\circ} 30$.) 


\section{Bataille d'Avein. - 20 mai 1635.}

École française; $\mathrm{XvII}^{\mathrm{e}}$ siècle. - H. 3,23. - L. 2,00.

La France ayant déclaré la guerre à l'Espagne, Richelieu ouvrit la campagne avec quatre armées qui devaient agir dans les Pays-Bas, en Alsace, dans les Grisons et en Piémont. L'armée du Nord, qui s'était rassemblée à Mézières sous les ordres des maréchaux de Châtillon et de Brézé, passait vingt-cinq mille hommes et devait se porter sur la Meuse pour se joindre au prince d'Orange, allié de la France. Le prince Thomas de Savoie, général des troupes espagnoles, s'avance avec douze mille hommes pour fermer aux Français le passage, et prend, près le village d'Avein, au pays de Liége, une forte position. Le combat était à peine commencé entre les Espagnols et le corps d'armée commandé par Brézé, lorsque le maréchal de Châtillon, qui marchait à quelque distance, arriva par une marche forcée. Le prince Thomas ne put résister à ces forces supérieures, et il fut contraint d'abandonner le champ de bataille, laissant quatre mille morts, quinze cents prisonniers, seize pièces d'artillerie et cinquante drapeaux.

Ce tableau provient de la galerie du château de Richelieu. (Voir salle nº 30. )

595. Siége d’Arras. - Du 13 mai au 9 août 1640.

(Voir $\mathrm{n}^{\circ} 597$. )

École française; xviıI ${ }^{\mathrm{e}}$ siècle. - H. 0,57. - L. 0,82.

Les maréchaux de La Meilleraye, de Châtillon et de Chaulnes, à la tête d'un corps d'armée qui montait à vingt-cinq mille hommes d'infanterie et neuf mille de cavalerie, investirent la ville d'Arras le 13 mai 1640. Le duc d'Enghien, qui n'avait que dix-neuf ans y fit ses premières armes comme volontaire. Les tranchées furent ouvertes le 4 juillet, mais les assiégés opposèrent une vigoureuse défense, et le cardinal-infant, gouverneur des Pays-Bas, vint à la tête d'une nombreuse armée, attaquer les lignes françaises. Enfin, l'arrivée d'un convoi considérable conduit par Du Hallier, décida la capitulation de la place, qui se rendit le 9 août.

\section{Siége d'Aire. - Du 19 mai au 26 juillet 1641.}

(Voir $\left.n^{\circ} 597.\right)$

École française; XviıI ${ }^{\text {e }}$ siècle. - H. 0,57. - L. 0,82.

Le maréchal de La Meilleraye se présenta, le 19 mai 1641, devant la ville d'Aire, en Artois, dont il entreprit le siége. 'La garnison, forte de deux mille hommes, se défendit bravement, sous la conduite de Bernovite. Le cardinal-infant chercha inutilement 
à faire lever le siége de la place, qui fut contrainte de se rendre après quarante-neuf jours de tranchée ouverte.

\section{Siége de Perpignan. - Du 25 avril au 5 sep- tembre 1642.}

École française; xviII siècle, - H, 0,57. - L, 0,82.

Après la prise de Collioure, Louis XIII alla investir Perpignan et présida lui-même aux premières opérations du siége. La santé du roi l'ayant obligé de se rendre à Narbonne, le maréchal de La Meilleraye continua le blocus établi autour de la ville, et le marquis de Florez d'Avila qui y commandait, après avoir consumé tous ses vivres et mangé jusqu'au dernier animal vivant, capitula et rendit la ville et la forteresse le $\boldsymbol{b}$ septembre.

Ce sujet et les deux précédents, peints sur la même toile, décoraient autrefo s l'Hôtel du grand-maître de la maison du roi, qui sert aujourd'hui de Mairie à la ville de Versailles. Des inscriptions anciennes, placées au-dessous de ces tableaux, rappellent que le duc d'Enghien avait servi comme volontaire à ces trois siéges. - La dimension du panneau entier est de : H. 3,23. - L. 1,44.

\section{Plan de la bataille des Dunes. - 14 juin 1658.}

Par M. Siméon Fort en 1842. - H. 3,23. - L. 2,03.

La ville de Dunkerque, prise par Condé en 1646 et reprise par les Espagnols en 1652, avait été investie par le vicomte de Turenne le 28 mai 1658. Une armée espagnole, commandée par Don Juan d'Autriche, auquel s'était joint le prince de Condé, qui combattait alors contre la France, vint occuper les Dunes; Turenne, décidé à prendre l'offensive, arrêta aussitôt toutes les dispositions qui devaient lui assurer la victoire.

599. Prise de Gravelines. - 30 août 1658.

École française; $\mathrm{XVII}^{\mathrm{e}}$ siècle. - H. 3,23. - L. 2,03 .

Aussitôt après la prise de Dunkerque, les troupes du vicomte de Turenne se portèrent devant la ville de Bergues. Le roi suivit l'armée, et peu de temps après il tomba malade à Mardick des fatigues de la campagne. On le transporta à Calais. Aussitôt que le roi fut rétabli, il partit de Calais avec la reine-mère et le cardinal de Mazarin, et alla rejoindre Turenne. On tint un conseil dans lequel le siége de Gravelines fut résolu : le maréchal de La Ferté fut chargé de cette entreprise. Gravelines est une ville forte et dont la garnison était de trois mille hommes; elle est située sur la mer près la rivière d'Aa, entre Calais et Dunkerque. Elle avait été fortifiée par Charles-Quint d'une citadelle, et depuis, ses fortifications avaient été augmentées, de manière que l'on regardait cette place comme l'une des plus fortes des Pays-Bas. La ville fut investie le 27 juillet; le 8 août, le maréchal de La Ferté 
fit ouvrir la tranchée, et le 27, le gouverneur Don Christophe Manrique demanda à capituler. Le cardinal Mazarin, qui s'était tenu à portée du siége pour donner tous les ordres nécessaires, prit lui-même possession de la place après qu'elle se fut rendue.

600. Siége de Maëstricht. - 29 juin 1673.

École française; xvire siècle. H. 3,23. - I. 2,99.

Louis XIV, pour assurer la communication avec ses conquêtes de Hollande, vient assiéger Maëstricht, et s'en rend maître après treize jours de tranchée ouverte.

601. Bataille de Seneff. - 11 aout 1674.

École française; xvıII siècle. - H. 1,44. - L. 1,15.

Ce tableau offre les dispositions prises par le prince de Condé au combat de Seneff, gagné contre les armées de l'empereur, du roi d'Espagne et des Hollandais.

602. Levée du siége d'Oudenarde. - 21 septembre
1674. École française; xviIre siècle. - H. 0,96. - L. 1,05.

Le prince d'Orange vint assiéger Oudenarde après avoir perdu la bataille de Seneff; mais dès qu'il eut appris que le prince de Condé marchait au secours de cette place, il se retira avec précipitation à la faveur d'un brouillard, et le prince entra sans obstacle dans Oudenarde.

Ce tableau et le précédent, peints sur la même toile, proviennent aussi de l'Hôtel du grand-maître (Voir $n^{\circ}$ 597). - La dimension du panneau est de : H. 3,23. - L. 1,42.

603. Siége de Valenciennes. - Du 28 février au 17 mars 1677.

Par Jean PAUL. - H. 3,23. - L. 3,93.

La ville de Valenciennes fut investie, le 28 février par le due de Luxembourg, et Louis XIV arriva le 4 mars devant la place, qui fut emportée d'assaut le 17.

Ce tableau était placé autrefois dans un vestibule du ch teau de Marly.

604. Siége de Saint-Omer. - Avril 1677.

Par M. Baptiste. - H. 0,57. - L. 0,42.

Pendant que Louis XIV s'emparait de Valenciennes et de Cambrai, le duc d'Orléans, son frère, faisait le siége de Saint-0mer. Il fit investir cette place, tracer les lignes de circonvallation et 
s'en rendit maître le 20 avril, après avoir battu le prince d'Orange à Cassel.

\section{Siége de Namur. - Mai 1692.}

Par M. Baptiste. - H. 0,57. - L. 0,42.

Louis XIV, à la tête de l'armée qui devait faire le siége de Namur, campa le 24 mai dans la plaine de Saint-Amand, entre Ligny et Fleurus. Le même jour, il partagea ses troupes en plusieurs quartiers pour investir la place et reconnut lui-même les environs depuis la basse Meuse jusqu'à la Sambre. Les opérations du siége, dirigées par Vauban, eurent pour résultat la reddition de la ville le $\breve{~ j u i n, ~ e t ~ c e l l e ~ d u ~ c h a ̂ t e a u ~ l e ~} 30$.

\section{Prise d'A th. - 5 juin 1697.}

Par M. Baptrste. - H. 0,57. - L. 0,42.

La ville d'Ath, en Belgicque, fut prise par le maréchal de Ca-

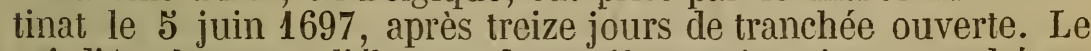
roi d'Angleterre et l'électeur de Bavière, qui avaient marché au secours de la place, ne voulurent pas cependant hasarder une bataille, et jugèrent plus à propos de faire choix d'un camp qui mit le pays à couvert le reste de la campagne.

\section{SALLE No 30 .}

Dépendance de l'appartement du capitaine des gardes du roi sous Louis XIV et Louis XV, cette salle était alors divisée en deux parties par le prolongement du mur de la façade latérale. La partie éclairée sur la cour cle marbre formait, sous Louis XVI, la chambre à coucher de l'appartement de bains de la reine Marie-Antoinette.

Les dix tableaux qui décorent cette salle, et deux autres, exposés dans la pièce précédente sous les nos 593 et 594 , étaient placés dans la galerie du château de Richelieu. Cette suite se composait de vingt sujets représentant des villes prises et des batailles gagnées sous le ministère du cardinal; ils ont dû être peints vers 1640 par un artiste de l'école de Callot. Huit sujets manquent à la collection, ce sont : le premier siége de Casal, la réduction d'Alez, le passage du pont d'Alpignan, le passage du Mont-Saint-Bernard, la prise de Chambéry, le combat de Veillane, la prise de Vic, Moyenvic et Marsal et la prise de Nancy.

\section{Levée du siége de l'île de Rhé. - 8 novembre 1627.}

École française; XVII e siècle. - H. 3,23. - L. 2,55.

Une flotte anglaise sous les ordres de Buckingham, forte de quatre-vingt-dix vaisseaux montés par seize mille hommes, avait paru le 20 juillet 1627 devant l'île de Rhé et s'en était ren¿due maîtresse malgré la résistance de Toiras, qui avait été obligé 
de se retirer dans le fort Saint-Martin. Ce fort, élevé l'année précédente, était à peine achevé; Toiras y soutint avec une faible garnison un siége de plus de trois mois. Enfin l'arrivée du maréchal de Schomberg avec des renforts considérables força Buckingham de lever le siége. " Il se retirait, dit Sismondi, vers l'île d'Oie où il comptait s'embarquer; lorsqu'il fut entré sur l'étroite chaussée qui y conduit, la cavalerie française s'élança sur lui et par une charge furieuse mit le désordre dans les rangs anglais. Ils furent rompus et poursuivis pendant le reste de la journée." La nuit seule mit un terme à leur défaite et ils se rembarquèrent le lendemain laissant sur le rivage dix-huit cents morts, quarante drapeaux et une grande quantité de prisonniers.

Sur le devant à gauche, Louis XIII, qui était arrivé devant La Rochelle le 12 oc. tobre, et qui avait présidé lui-même à l'embarquement des troupes destinées à délivrer l'île de Rhé, est représenté à cheval près du havre de La Rochelle; le cardinal de Richelieu, dont l'activité avait préparé le succès de cette expédition, l'accompagne en habit de voyage. Au delà de l'Océan couvert de bâtiments, s'étend l'île de Rhé; la rade qui se trouve à l'extrémité de gauche est celle où les Anglais avaient effectué leur débarquement; le fort Saint-Martin occupe le centre de l'ìle, et à l'extrẻmité de droite est la petite presqu'île de l'Oie où les Anglais furent défaits et contraints de se rembarquer.

\section{Siége de La Rochelle. - Du 10 août 1627 au 28 octobre 1628.}

École française; $\mathrm{XVII}^{\mathrm{e}}$ siècle. - H. 3,23. - L. 2,58.

Après la délivrance de Rhé, le cardinal de Richelieu résolut de s'emparer de La Rochelle et d'abattre ce dernier refuge du protestantisme. La ville fut investie du côté de la terre par le maréchal de Bassompierre qui occupait la gauche de la rade depuis le cap de Chef-de-Baie jusqu'au port, par le duc d'Angoulême du côté de la pointe de Coreille à droite de la rade, et par le maréchal de Schomberg qui eut son poste derrière la ville. Richelieu, nommé par le roi lieutenant-général de ses armées et de ses flottes, dirigeait tous les travaux du siége; par ses ordres l'architecte Metezeau construisit près de l'entrée de la rade qui précède le port et hors de la portée du canon de La Rochelle, une digue ou jetée de sept cent quarante toises de longueur, qui devait empêcher tout secours d'arriver par mer; cet ouvrage gigantesque fut exécuté par Jean Tiriot, maître-maçon de Paris. Le siége dura quatorze mois et seize jours; deux flottes anglaises essayèrent en vain de porter secours à La Rochelle; la première, commandée par le comte de Denbigh, beau-frère de Buckingham, fut repoussée le 11 mai 1628, par les batteries de la Pointe-deCoreille : la seconde, qui parut le 29 septembre du côté de Chefde-Baie, était dirigée par lord Lindsay. Après quelques jours d'attaques infructueuses, il prit le parti d'entamer des négociations, 
et le 17 octobre on vit arriver au quartier où était le roi, deux députés de la flotte anglaise et quatre députés de la ville, qui furent reçus par Richelieu. Les conditions accordées aux Rochelois furent moins rigoureuses que leur rébellion ne pouvait le faire craindre, et le 3 octobre le maréchal de Schomberg reçut les clefs de la ville au nom du roi.

Sur le devant du tableau la mer est couverte de vaisseaux anglais qui cherchent à forcer l'entrée de la rade défendue par la digue, par les batteries du cap de Chef-de-Baie à gauche, et par celles de la pointe de Coreille à droite. Le roi, suivi d'un nombreux cortêge longe le rivage de droite près duquel était son quartier.

\section{Combat du Pas-de-Suze. - 6 mars 1629.}

École française; Xviı siècle. - H. 3,23. - L. 2,57.

Pour rétablir le duc de Nevers dans la possession de l'héritage de Mantoue que lui disputaient l'empereur d'Autriche et le duc de Savoie, Louis XIII, malgré les rigueurs de l'hiver, résolut de passer en Piémont. Il arriva à Grenoble le 14 février avec le cardinal de Richelieu, passa le Mont-Genèvre le $\mathbf{1}^{\text {er }}$ mars et parvenu en face des barricades du Pas-de-Suze, en ordonna l'attaque dès la pointe du jour. Les retranchements gardés par les Piémontais et les Espagnols furent forcés à droite par le régiment des gardes et les mousquetaires, et à gauche par le régiment de Navarre, avec un tel ensemble et une telle impétuosité, que les ennemis n'eurent que le temps de prendre la fuite. De son côté le comte de Sault ayant défait un régiment milanais, et s'étant emparé du fort de Jaillon près de la rivière d'Oyre, l'armée française occupa en moins de deux heures tous les passages des montagnes jusqu'aux portes de Suze, première ville de Piémont. Ce brillant fait d'armes décida aussitôt le duc de Savoie à la soumission.

Sur le devant à gauche, Louis XIII et le cardinal de Richelieu à cheval dirigent l'attaque des retranchements.

\section{Prise de Privas. - 28 mai 1629.}

École française; xvıre siècle. - H. 3,23. - L. $2,57$.

Aussitôt après le traité de Suze, Louis XIII alla poursuivre contre les villes protestantes du Languedoc l'œuvre commencée à La Rochelle. Le 19 mai 1629, Richelieu vint le rejoindre avec Bassompierre et neuf mille hommes qu'il lui amenait d'Italie, et le 21 le roi somma Privas de se rendre. Le gouverneur, Saint-AndréMontbrun, ayant repoussé les ouvertures, la ville fut investie et le siége commença. La première attaque fut si vive qu'elle découragea les assiégés, et qu'ils abandonnèrent précipitamment leurs remparts pour se réfugier dans les montagnes. Le 28 mai, Montbrun consentit à se rendre à discrétion; mais au moment de l'ouverture des portes, l'explosion d'un magasin fit croire à une nou- 
velle résistance, la garnison fut taillée en pièces et la ville de Privas fut livrée au pillage et à l'incendie.

\section{Réduction de Nîmes. - 4 juillet 1629.}

École française; $x v I^{\mathrm{e}}$ siècle. - H. 3,23. - L. 2,58.

La prise de Privas entraîna la soumission de presque toutes les villes des Cévennes où les religionnaires étaient cantonnés. Louis XIII s'étant rendu maître d'Alais, la paix avec les protestants y fut conclue le 28 juin 1629. La ville de Nîmes, dont le maréchal d'Estrées ravageait les environs, envoya au roi une députation de ses principaux habitants pour le supplier de confirmer par sa présence la cessation des hostilités. Louis XIII fit son entrée dans cette ville le 4 juillet et y donna une nouvelle déclaration pour la publication de la paix.

Louis XIII et le carcinal de Richelieu reçoivent la soumission des habitants de Nîmes.

\section{Réduction de Montauban. - 21 août 1629.}

École française; $\mathbf{x}$ II $^{\mathrm{c}}$ siècle. - H. 3,23. - L. 1,47.

La ville de Montauban, jusqu'alors forteresse imprenable des protestants, fut la dernière à se soumettre aux conditions de la paix d'Alais; elle s'obstinait à garder ses fortifications comme garantie de sa sûreté. Louis XIII, désirant retourner à Paris, laissa le cardinal de Richelieu avec le maréchal de Bassompierre pour conduire l'armée devant Montauban; toutefois les hostilités ne se renouvelèrent pas; Bassompierre fut reçu le $\mathbf{1 8}$ août dans la ville et Richelieu y fit lui-même son entrée le 21.

Les consuls et le corps de la ville, avec leur suite, qui s'étaient avancés au-devant du cardinal à une lieue hors de la ville, font leur soumission. Richelieu, à cheval, est accompagné du duc de Montmorency, du marquis d'Effiat et du vicomte d'Arpajoux. Vingt-deux compagnies d'infanterie, quelques compagnies de cavalerie et cinq ou six cents gentilshommes entrèrent à sa suite dans IIontauban.

\section{Prise de Pignerol. - 31 mars 1630.}

École française; $x$ III $^{\mathrm{e}}$ siècle. - H. 3,23. - L. 2,56.

Richelieu, nommé premier ministre et généralissime des troupes françaises en Italie, arriva à Suze le 4 mars 1630, entra dans le Piémont et fut bientôt sous les murs de Pignerol. La ville se rendit à lui le 23 mars et le château le 31 . Cette forteresse était la clé d'un passage important des Alpes et de tout le pays des Vaudois.

\section{Combat du pont de Carignan. - 6 août 1630.}

École française; XvII ${ }^{\mathrm{e}}$ siècle. - H. 3,23. - L. 2,57.

Le duc de Montmorency et le marquis d'Effiat, à la tête d'un 
corps de l'armée de Piémont, forcent le passage du pont de Carignan, défendu par les Espagnols et les Allemands.

Ce tableau portait à tort le titre de Combat de Veillane.

\section{Bataille de Castelnaudary. - $1^{\mathrm{er}}$ septembre 1632.}

École française; XvII ${ }^{\mathrm{e}}$ siècle. - H. 3,23. - L. 2,34.

Le duc de Montmorency, gouverneur du Languedoc, s'était trouvé engagé dans la révolte du duc d'Orléans contre l'autorité du cardinal de Richelieu et lui avait amené à Lunel les troupes qu'il avait levées dans sa province. Une partie de l'armée des rebelles fut placée sous le commandement du duc d'Elbeuf pour combattre le maréchal de La Force, et l'autre partie, qui se composait d'environ treize mille hommes, s'avança sous les ordres de Gaston et de Montmorency contre Schomberg, qui, à la tête de sept mille hommes, se trouvait à une demi-lieue en avant de Castelnaudary. Dans cette rencontre le comte de Horet, qui commandait l'aile gauche des rebelles, perdit la vie, et Montmorency, qui dirigeait l'aile droite, fut atteint de dix blessures et fait prisonnier. Cette défaite mit fin à la révolte, et le duc de Montmorency eut la tête tranchée à Toulouse le 30 octobre suivant.

\section{Reprise de Corbie. - 14 novembre 1636.}

École française; $\mathrm{xvII}^{\mathrm{e}}$ siècle. - H. 3,23. - L. 2,57.

Les Espagnols s'étaient emparés de Corbie le 15 août 1636, et cet échec avait jeté l'effroi dans Paris. Le duc d'Orléans fut nommé lieutenant-g'énéral de l'armée de Picardie, qui était forte de cinquante mille hommes. Louis XIII et le cardinal de Richelieu vinrent rejoindre l'armée à Amiens, et le siége de Corbie fut entrepris avec un déploiement de travaux immenses. Le roi allait tous les jours visiter les lignes, qui formaient un circuit de sept lieues autour de la ville, et surveillait les opérations du siége. Enfin Corbie capitula le 14 novembre, et les Espagnols en sortirent aux termes d'une capitulation dont Richelieu avait régléles conditions.

Ce tableau portait à tort le titre de Prise de Casal.

\section{VESTIBULES No 31 .}

Dépendances et dégagements de l'appartement des bains (salles nos 52 à 54 ), et de celui du capitaine des gardes.

\section{PREMIĚRE PARTIE.}

Le petit escalier du roi, auquel conduit ce vestibule, avait autrefois son issue 
dans la salle $n^{\circ} 28$. C'est cet escalier, qui conduit aux petits appartements, que Louis XV venait de descendre lorsqu'il fut frappé par Damiens. (Voir salle $n^{\circ} 27$. .)

\section{Pie VII (Grégoire-Louis-Barnabé Chiaramonti), pape.}

Par Cavova; buste en marbre. - H. 0,56.

Né à Césène en 1740, il fut d'abord bénédictin, puis évêque de Tivoli en 1780. Elu pape à Venise en 1800, il signa, en 1801, un concordat avec le premier consul pour le rétablissement du culte catholique en France, et le sacra empereur à Notre-Dame en 1804 . Les états du pape ayant été réunis à l'empire français en 1809, Pie VII fut amené à Savone, puis à Fontainebleau, où il resta captif jusqu'en 1814. Il conclut, en 1817, un nouveau concordat avec la France, et mourut à Rome le 20 août 1823.

\section{Fox (Charles-Jacques), orateur.}

Par Anne SeYMour-Daser; buste en marbre. - H. 0,45.

Né à Londres le 13 janvier 1749, il était fils de Henri Fox (lord Holland), secrétaire d'Etat, et fut élu député en 1763, avant l'âge de vingt ans. Chargé en 1782 du portefeuille des affaires étrangères, il fit conclure la paix avec l'Amérique et la France en 1783. Il fut constamment opposé au parti de la guerre contre la France. Nommé de nouveau ministre des affaires êtrangères après la mort de son adversaire Pitt, il mourut le $\mathbf{1 3}$ septembre $\mathbf{1 8 0 6 .}$

On lit sur le socle de ce buste :

RESPEGTUEUSEMENT PRÉSENTE

A SA MAJESTE L'EMPEREUR ET ROI

PAR ANNE SEYMOUR-DAMER. 1812.

\section{Alexandre $\boldsymbol{I}^{\text {er }}$ (Paulowitch), empereur de Russie.}

Par Bartolini ; buste en marbre. - H. 0,66.

Fils de Paul I'r et petit-fils de Catherine II. Né en 1777, il succéda à son père en 1801. Dans les premières années de son rẻgne, il introduisit en Russie de grandes et utiles réformes, se ligua, en 1805 , avec l'Angleterre et l'Autriche contre la France, et signa, en 1807, le traité de Tilsitt. Après avoir fait la conquête de la Finlande sur la Suède en 1808, celle de plusieurs provinces sur la Perse et sur la Turquie (1809-1810), il rompit avec Napoléon en 1812, vit ses états envahis par la prise de Moscou, et réussit à former, en 1813, une nouvelle coalition qui amena, en 1814, les alliés à Paris. Il obtint la Pologne au congrès de Vienne, en 1815, signa à Paris le traité de la Sainte-Alliance avec l'Autriche et la Prusse, et assista aux congrès de Laybach en 1820 et de Vérone en 1822. Il mourut en décembre 1825 à Taganrock. 
620. Chlopicki (Joseph), général polonais.

Par M. StatTler en 1849; buste en bronze. - H. 0,64.

Il servit comme chef de bataillon dans la légion polonaise, fit les campagnes d'Italie en 1799 et 1800, enleva à la baïonnette le poste de Casa-Bianca, en avant de la ville de Peschiera, en 1801, et se signala à la prise de Saragosse en 1808. Nommé général de brigade, il prit une part glorieuse à la bataille de Sagonte, en 1811 . Il fut dictateur à Varsovie le 5 décembre 1830 , lors de la révolution polonaise, et mourut en 1854 .

Ce buste a été exposé au Salon de 1850.

\section{Ferdinand $I I$, roi de Naples.}

Par Fantoni; buste en plâtre. - H. 0,92.

Fils de Francois Ier et de Marie-Isabelle d'Espagne, sa seconde femme, né le 12 janvier 1810 , il porta d'abord le titre de duc do Calabre et succéda à son père le 8 novembre 1830 .

\section{Marie-Christine de Savoie, reine de Naples.}

Par Fantonı; buste en plâtre. - H. 0,79.

FilledeVictor-Emmanuel, roi de Sardaigne, née le 14 novembre 1812. Elle fut mariée à Gênes, en 1832, à Ferdinand II, roi de Naples, et mourut le 31 janvier 1836.

\section{DEUXIĖME PARTIE.}

Passage de la cour des Cerfs à la petite cour. Ces cours occupent en partie la place des anciens fossés du château de Louis XIII.

\section{Buonarotti (Michel-Ange), sculpteur, peintre et architecte.}

Par Вогснот; buste en marbre. - H. 0,73:

Né en 1474 au château de Chiusi ou de Caprèse, dans le pays d'Árezzo en Toscane, il étudia à Florence chez Dominique et David Ghirlandajo, et fut protégé dans sa jeunesse par Laurent de Médicis. Appelé à Rome par le pape Jules II, en 1503, il y sculpta le tombeau de ce pontife, peignit la voûte de la chapelle Sixtine, jouit également de la faveur des papes Léon X, Paul III et Jules III. Chargé de continuer dans la basilique de Saint-Pierre les travaux du Bramante, il en réforma les plans et en construisit la célèbre coupole. On doit encore à Michel-Ange, comme ingénieur, une partie des fortifications de Florence, et comme poète un recueil de sonnets. Il mourut à Rome en 1564, à l'âge de quatre-vingtdix ans. 


\section{Urbain VIII (Maffeo Barberini), pape.}

Par L'ALGARDE; buste en plâtre. - H. 0,76.

Né à Florence en 15้68, il fut archevêque de Nazareth, cardinal en 1606, et fut connu sous le nom de cardinal de Saint-Onufre. Elu pape en 1623, il réunit en 1625, au domaine du Saint-Siége, le duché d'Urbin avee les comtés de Montefeltro et de Gabio, la seigneurie de Pesaro et le vicariat de Sinigaglia par la donation que lui en fit le duc Franȩois Marie de La Rovère. Son différend avec Venise, en 1632, sa querelle avec Jean IV de Portugal, en 1641, et la guerre de Castro qui se termina par la paix de Venise en 1644, remplirent malheureusement les dernières années de son pontificat. Il mourut le 29 juillet 164 .

\section{Gustave-Adolphe II, dit le Grand, roi de Suède .}

par GoIs fils; buste en marbre. - H. 0,66.

Né le 9 décembre 1594, il était petit-fils de Gustave Wasa, et recut de Maurice de Nassau les premières lecons de l'art militaire. Parvenu à la couronne en 1611 , il soutint, dans les premières années de son règne, la guerre contre le Danemark, la Prusse et la Russie. C'est de l'année 1621, lors de la guerre dite de Pologne, que datent ses grandes réformes civiles et militaires. Tous les grands capitaines qui, plus tard, illustrèrent le règne de Louis XIV, se formèrent à l'école de Gustave-Adolphe. Il prit Riga en 1621, livra en $\$ 626$ contre les Polonais la bataille de Wallhof, en Sémigalle, et l'an $\mathbf{1 6 4 0}$ fit entrer la Suède comme partie belligérante dans la guerre de Trente-Ans. Il remporta la victoire de Leipsick en 1631, força en 1632 le passage du Lech, étendit en Piémont ses conquêtes et livra à l'armée impériale, le 16 novembre 1632 , la bataille de Lutzen, où il fut tué dans la trente-huitième année de son âge.

Ce buste, commandé pour la galerie des Consuls, aux Tuileries, a été exposé au Salon de 1801.

\section{Ruyter (Michel-Adrien), amiral hollandais.}

\section{Par RolaNd; buste en marbre. - H. 0,65.}

Né à Flessingue en 1607, il s'embarqua comme mousse à l'âge de onze ans, et après avoir passé par les premiers grades, il fut nommé capitaine de vaisseau en $\mathbf{1 6 3 0}$. Ruyter fit successivement plusieurs campagnes dans les Indes-Occidentales, commanda dans l'année 1645", en qualité de contre-amiral, l'escadre envoyée par la Hollande au secours des Portugais contre les Espagnols, et en 16522 l'armée navale de Hollande dirigée contre l'Angleterre. Il reçut en 16503 le commandement d'une des divisions de l'armée navale de Hollande, sous les ordres de l'amiral Tromp, fit en 16 วัว 
une campagne contre les corsaires de la Méditerranée, et commandait la flotte que les Etats-Généraux envoyèrent en $16599 \mathrm{au}$ secours du Danemark contre la Suède. Nommé lieutenant-amiralgénéral en 1666, il entra l'année suivante dans la Tamise avec son escadre, et porta l'effroi jusqu'à Londres. Il commanda la flotte hollandaise dans les mers d'Italie et de Sicile, de 1675 à 1676, et mourut le 29 avril 1676, des suites des blessures qu'il reçut au combat d'Aug'usta, en Sicile.

Ce buste, commandé pour la galerie des Consuls, aux Tuileries, a été exposé au Salon de 1801.

\section{Savoie (Eugène-François de), dit le Prince Eugène.}

Par Pierre Petitot; busie en marbre. - H. 0,69.

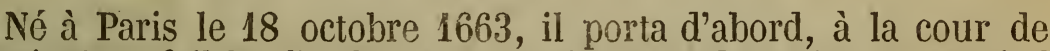
Louis XIV où il fut élevé, le nom de chevalier de Carignan; destiné à l'état ecclésiastique, il fut ensuite connu sous le nom d'abbé de Savoie. En 1683 il entra dans la carrière des armes et prit du service près de l'empereur, alors en guerre avec la Turquie. Après la campagne de 1683 sous les murs de Vienne, il fut nommé colonel de dragons, continua la guerre contre les Tures en 1688 et se trouva au siége de Belgrade. Il commanda en chef les troupes impériales en Italie dans l'année 1691, et fut nommé feld-maréchal vers 1692. Il livra contre les Tures, en 1697, la bataille de Zenta sur la Theiss, et fut à la tête des troupes de l'empereur pendant toute cette guerre, qui se termina, le 26 janvier 1699 , par le traité de Carlowitz. Général en chef des armées impériales pendant la guerre de la succession d'Espagne, il fut nommé président du conseil de guerre en 1702, fit la campagne de 1704 en Bavière avec le duc de Marlborough, celle de 1705 et 1706 en Italie, fut en 1707 gouverneur du Milanais, et en 1714, ministre plénipotentiaire de l'empire lors des conférences de Rastadt, où le maréchal de Villars était chargé des intérêts de la France. Le prince Eugène gagna sur les Turcs, en 1716, la bataille de Peterwaradin, celle de Belgrade en 1717, et fut nommé en 1724 vicaire-général desétatsd'Italie pour l'empereur Charles VI. Il mourut le $\mathbf{2 1}$ avril 1736.

Ce buste, commandé pour la galerie des Consuls, aux Tuileries, a été exposé au Salon cle 1801.

\section{Albani (Alexandre), cardinal.}

Buste en marbre. - H. 0,65 .

Né à Urbin en 1692, créé cardinal-diacre en 1721 par Innocent XIII, il se rendit célèbre par son goût pour les arts et par sa magnifique Villa où il avait rassemblé des chefs-d’œuvre de toute espèce. Il mourut en 1779. 


\section{Frédéric $I I$, dit le Grand, roi de Prusse.}

Buste en marbre. - H. 0,65.

Né à Berlin le 24 janvier 1712, il succéda à son père, FrédéricGuillaume II, le 31 mai 1740, et s'occupa au commencement de son règne de grandes réformes dans l'administration civile. Les ordonnances militaires de Frédéric II, qui introduisirent de grandes innovations dans l'art militaire, devinrent par la suite la règle de toutes les armées d'Europe. Aussitôt après la mort de l'empereur Charles VI, il s'empressa de se jeter sur la Silésie, sur laquelle il prétendait avoir des droits qu'il fit prévaloir par une suite de victoires; la paix de Dresde lui assura en 1747 la possession de cette province. La guerre de Sept-Ans, où il eut à lutter contre la France, la maison d'Autriche et la Russie, liguées pour détruire sa puissance, mit la monarchie prussienne en grand péril ; mais Frédéric, à force de courage et de génie, sortit victorieux de la lutte, et le traité d'Hutersbourg lui assura une paix glorieuse. ll mourut à Berlin le 17 août 1786 .

Ce buste avait étẻ exécuté pour la galerie des Çonsuls, aux Tuileries.

\section{Washington (Georges), président de la république des Etats-Unis.}

Par Houdon en 1801 ; buste en marbrè. - H. 0,67.

Né à Bridge-Creek, dans le comté de Westmoreland, en Virginie, le 22 février 1732, il fut à dix-neuf ans major des milices de la Virginie, et en $\mathbf{1 7 7 4}$ membre du congrès qui s'assembla à Philadelphie. La guerre s'étant engagée entre l'Amérique et l'Angleterre, le congrès nomma Washington général en chef des troupes américaines. Après huit ans de guerre, pendant lesquels il trouva, dans l'indiscipline de ses troupes et le manque de ressources, des obstacles sans cesse renaissants, dont une fermeté inébranlable le fit seule triompher, il parvint à affermir l'indépendance des Etats-Unis, qui fut reconnue par le traité du 20 janvier 1783. Député, malgré son refus, par la Virginie à la Convention assemblée à Philadelphie en mai 1787 pour organiser la forme du gouvernement, Washington fut élu à l'unanimité, en $\mathbf{1 7 8 9}$, président de l'Union et réélu en $\mathbf{1 7 9 3 . ~ I l ~ m o u r u t ~ l e ~} \mathbf{1 4}$ décembre 1799. Sa mort fut considérée comme une calamité publique, et son deuil porté jusque par la France : son nom a été donné à la ville qui est le siége du gouvernement des EtatsUnis.

Ce buste avait été exécutẻ pour la galerie des Consuls, aux Tuileries. 
TROISIÉME PARTIE.

\section{Charles-le-Téméraire, duc de Bourgogne} (Voir no 557.)

Statue en plâtre. - H. 1,56.

Cette statue a été moulée, ainsi que les quatre suivantes, d'après celles qui décorent la cheminée du palais de justice de Bruges, sculptée par Herman Glosen. camp, Rogier de Smet et Andrien Ras, sur les dessins et sous la direction de Guyot de Beaugrant de Malines et de Lancelot Blondeel de Bruges. (Lettre de AI. L. de Baecker dans les Annales archéologiques publiées par M. Didron aîné, 1858 , in $\left.-4^{\circ}\right)$.

\section{Marguerite d'York, duchesse de Bourgogne.}

Statue en plâtre. - H. 1,50.

Fille de Richard, duc d'York, elle épousa en 1468 Charlesle-Téméraire, dont elle fut la troisième femme, et mourut en 1 อั03.

\section{Maximilien $\boldsymbol{I}^{\text {er }}$ empereur d'Allemagne.}

Statue en plâtre. - H. 1,55.

Né le 22 mars 14509, Maximilien fut créé roi des Romains le 16 février 1486, et couronné à Aix-la-Chapelle le 9 avril suivant. Il succéda à 'son père, Frédéric IV, le 10 août 1493 , et prit le titre d'empereur, il soutint plusieurs guerres contre la France sous les règnes de Louis XI, Charles VIII, Louis XII et Francois I ${ }^{\mathrm{er}}$, et conclut, sous le règne de Louis XII, en 1508, le traité de Cambrai, qui fut ensuite renouvelé en 1509. Maximilien fit encore la guerre en Italie contre la France, dans l'année 15ั16, et il mourut à Wels le 12 janvier 1519.

\section{Marie, duchesse de Bourgogne, archiduchesse d'Autriche.}

Statue en plâtre. - H. 1,50.

Fille unique de Charles-le-Téméraire, Marie de Bourgogne, à la mort de son père, eut à défendre son héritage contre les attaques de Louis XI. Le duché de Bourgogne était déjà réuni à la couronne de France, l'Artois envahi et la Flandre menacée, lorsque les Gantois, entre les mains de qui elle était comme prisonnière, appelèrent l'archiduc Maximilien et lui donnèrent leur souveraine en mariage pour qu'il se fit le protecteur de leur indépendance (1477). Pendant sa courte union avec Maximilien, elle lui donna deux enfants, Philipp--le-Beau et Marguerite. Elle mourut à Bruges des suites d'une chute de cheval faite à la chasse le 27 mars 1481. 
635. Charles-Quint, empereur d'Allemagne et roi d'Espagne. (Voir no 631 .)

Statue en plâtre. - H. 1,56.

Né à Gand le 24 février 4000 , il succéda à la couronne d:Espagne en $\mathbf{1}$ Iั16, après la mort de son père, Philippe-le-Beau, fut élu empereur et roi des Romains le 28 juin $15 \% 19$, et couronnéle 23 octobre 15̌20, à Aix-la-Chapelle, par l'archevêque de Cologne. Roi de Lombardie en 1530, il fut couronné dans la même année à Bologne, comme empereur d'Occident par le pape Clément VII. Il présida le 13 juin 10330 , la ảiète d'Augsbourg, où les protestants présentèrent leur confession de foi. Charles-Quint abdiqua en 1 อัo 6 en faveur de son fils tous ses royaumes héréditaires, et le 27 février 1อัoั\%, il se retira en Estramadure, dans le monastère de Saint-Just, où il mourut le 21 septembre 1 อัอั8.

636. Ximenès (Francois de Cisneros), cardinal, archevêque de Tolède.

Buste en plàtre. - H. 0,50.

Né en 1437 à Torrelaguna, en Castille, il fit ses études à Alcala et à Salamanque, devint chanoine de la cathédrale de Siguenza et entra ensuite au couvent des Franciscains de Tolède. Archevêque de Tolède en 1493, cardinal en 1วّ07, Isabelle et Ferdinand lui confièrent le gouvernement de Castille, et il fit proclamer en 15̆14, Charles-Quint, alors âgé de seize ans, roi de Castille et d'Aragon. Il fonda l'Université d'Alcala et fit publier la Bible polyglotte qui a conservé son nom. Le cardinal Ximenès, après avoir gouverné l'Espagne pendant vingt-deux ans, mourut le 9 novembre 1517.

\section{Raphaël (Raffaello Sanzio), peintre, sculpteur et architecte.}

Par Rondovi; buste en plâtre. - H. 0,52.

Né à Urbin le jour du Vendredi-Saint 1483 (28 mars), il était fils d'un peintre nommé Giovani Santi ou Santo, qui lui enseigna les éléments du dessin. Après la mort de son père, en 1494 , Raphaël entra vers 149oั, dans l'atelier du Pérugin, quitta Pérouse en 1500 , peignit plusieurs tableaux à Citta di Castello, passa ensuite à Urbino, et arriva à Florence à la fin de 150 z. Il se lia avec Fra Bartolomeo et le Francia, partit pour Rome en 15008, fut présenté au pape Jules II, par le Bramante, son parent, et fut chargé de décorer la salle della Segnatura au Vatican 
puis celles connues sous le nom de delle Stanze. En 15ั14, Raphaël remplaça le Bramante comme directeur des constructions du Vatican et construisit les Loges; il eut en 15515 la conduite des constructions de l'église Saint-Pierre, et, en 15้16, il fut nommé surintendant des édifices de Rome. Outre ces immenses travaux, il fit bâtir sur ses dessins, à Rome et à Florence, plusieur's palais, et peignit un nombre considérable de tableaux. Il mourut à Rome le jour du Vendredi-Saint 1520 (6 avril), à l'âge de trente-sept ans. - Raphaël fut le fondateur de l'Ecole romaine.

\section{André del Sarte (Andrea Vanucchi, dit), peintre.}

Buste en plâtre. - H. 0,56 .

Né à Florence en 1488, Andrea Vanucchi fut surnommé del Surto, à cause de la profession de son père qui était tailleur. D'abord élève de Barile, peintre médiocre, et ensuite de Pietro di Cosimo, il se perfectionna par l'étude des ouvrages de Masaccio, de Ghirlandajo, de Michel-Ange et de Léonard de Vinci. Appelé en France par François I ${ }^{\text {er }}$ en 1518, il y exécuta un grand nombre de peintures, et repartit pour Florence l'année suivante, chargé par le roi d'acquérir en Italie des objets d'art pour la France. Ayant dissipé l'argent qui lui avait été confié, il traîna une pénible existence, et mourut de la peste à Florence, en 1530 .

\section{Carracci (Annibale) ou Annibal Carrache, pein- tre et graveur.}

Par Rondoni ; buste en plâtre. - H. 0,68.

Né à Bologne en 1560, il fut élève de Louis Carrache, son cousin. Il étudia les ouvrages de Corrège à Parme, ceux du Tintoret et de Paul Véronèse à Venise, et fonda à Bologne avec Louis, et Augustin son frère, une école d'où sortirent le Dominiquin, le Guide, l'Albane, le Guerchin, etc. Il mourut à Rome, le 16 juillet 1609.

\section{Bernini (Giovanni-Lorenzo), dit le cavalier Ber- nin, sculpteur, architecte et peintre.}

Buste en plâtre. - H. 0,58.

Né à Naples en 1508, il fut, dès l'âge de dix ans, présenté au pape Paul V, qui reconnut son talent précoce, et fit ses études à Rome, sous la direction de Pietro Bernini, son père, peintre et sculpteur. Créé chevalier par le pape Grégoire XV, il devint ar- 
chitecte du Vatican, exécutala statue de Charles Ier, roi d'Angleterre, et fut appelé en France en 1665 par Louis XIV. Il mourut à Rome, le 28 novembre 1680, âgé de quatre-vingt-deux ans.

\section{Lamoignon (Guillaume de), premier président au Parlement de Paris.}

Par Girardon; buste en terre cuite. - H. 0,66.

Né en 1617, il fut reçu avocat et conseiller au parlement de Paris en 1635, devint maître des requêtes en 1644 et premier président en 1658. Il mourut le 10 décembre 1677. Parmi les magistrats du règne de Louis XIV, Lamoignon fut un des plus célëbres par son savoir et ses vertus.

Ce buste était placé au Musée des Monuments français.

642. Harlay (Achille de), III ${ }^{e}$ du nom, premier président du Parlement de Paris.

Buste en plâtre. - H. 0,64.

Conseiller au parlement en 1657, procureur-général en 1667, premier président en 1689, il se démit en 1707 et mourut le 23 juillet 1712, âgé de soixante-treize ans. Il est connu par son esprit fin et mordant, et ses mots ont été recueillis sous le titre d'Hurlacana.

643. La Fontaine (Jean de), poète et fabuliste. (Voir $\mathrm{n}^{\circ}$ 230.)

Par Deserne; buste en terre cuite. - H. 0,61.

Ce buste était placé au Musée des Monuments français.

644. Coustou (Nicolas), sculpteur.

Par G. Coustou; buste en terre cuite. - H. 0,56 .

Né à Lyon en 1658, il fut élève d'Antoine Coyzevox, son oncle, remporta le grand prix de Rome en 1681 et fut reçu à l'Académie royale en 1683. Chargé par Louis XIV de divers travaux pour Versailles, Trianon, Marly, etc., il mourut le $1^{\text {er }}$ mai 1733.

Ce buste avait été donné au Musée des Monuments français par M. Coustou, petit-neveu de Guillaume et de Nicolas Coustou.

645. Rousseau (Jean-Baptiste), poète lyrique.

Par CAFrieri; buste en terre cuite. - H. 0,53.

Né à Paris en 1670, il accompagna le maréchal de Tallard à Londres en qualité de secrétaire, et fut banni de France par arret du parlement en 1712. Il se retira d'abord en Suisse, et se 
fixa enfin à Bruxelles, où il mourut le 17 mars 1741. - Ses poésies, et principalement ses odes, l'ont fait placer au premier rang parmi les lyriques français.

\section{Winckelmann (Jean-Joachim), antiquaire.}

Par Deseine; buste en terre cuite. - H. 0,58.

Né en 1717 à Steindall (Brandebourg), il fut directeur d'école à Sechausen, bibliothécaire du comte de Bunau, à Noetheniz près de Dresde, et se rendit en Italie en 1756. Winckelmann entra en 1758 chez le cardinal Albani, comme bibliothécaire et inspecteur de sa collection d'antiquités, fut nommé en 1763 président des antiquités à Rome et bibliothécaire du Vatican. Il fut assassiné sur la route de Trieste le 8 juin 1768.

\section{Montmorin-Saint-Hérem (Armand-Marc, comte de).}

Buste en terre cuite. - H. 0,54.

Menin du dauphin, depuis Louis XVI, il fut ambassadeur à Madrid et chevalier de la Toison-d'Or en 1783. Chevalier de l'ordre du Saint-Esprit en 1784, il fit partie de l'assemblée des notables et fut nommé ministre des affaires étrangères en 1787. Il recut par intérim le portefeuille de l'intérieur en 1791, fut décrété d'accusation en 1792, et périt sur l'échafaud le 21 août de la même année.

648. Desault (Pierre-Joseph), chirurgien.

Buste en plâtre. - H. 0,58.

Né en 1744, au Magny-Vernais en Franche-Comté, il vint en 1764 à Paris, suivit les lecons de Petit et des chirurgiens les plus célèbres, et commença en 1766 à faire des cours qui le rendirent célèbre. Professeur à l'école pratique, membre du collége de chirurgie en 1776, chirurgien en chef de la Charité en 1782 , puis de l'Hồtel-Dieu en 1788, Desault fut élu, en 1792, membre du comité de santé des armées, et devint professeur de clinique chirurgicale à la nouvelle école de santé. Il mourut à Paris en 1795.

649. Haydn (Joseph-François), compositeur.

Par Flatters; buste en terre cuite. - H. 0,57.

Né en 1732, au village de Rohrau, près de Vienne, il fut nommé en 1760 maître de chapelle du prince Nicolas à Vienne. Il s'est rendu célèbre par ses compositions instrumentales, et peu de musiciens furent plus féconds que lui. Il mourut à Vienne en 1809. 


\section{LaFayette (Marie-Joseph-Paul-Yves-Roch-Gilbert Mottier, marquis de), lieutenant-général.}

Buste en terre cuite. - H. 0,63.

Né à Chavagnac, près de Brioude (Haute-Loire), le 6 septembre 1757, il fut mousquetaire en 1771, devint sous-lieutenant au régiment de Noailles en 1773 et capitaine en 1774 . Il passa en Amérique en 1777, fut major-général dans l'armée de Washington et commanda un corps de troupes destiné à agir contre le Canada. Il passa la campagne de 1779 en France, et fut nommé aide-maréchal-général des logis de l'armée en Bretagne et en Normandie; il repartit en mars 1780 pour l'Amérique, commanda en Virginie au commencement de 1781, et apporta en France la nouvelle de la prise d'York-Town. Maréchal-de-camp et chevalier de Saint-Louis en 1781, membre de l'assemblée des notables en 1787, il commanda une brigade d'infanterie dans la division du Languedoc et du Roussillon en 1788, fut député d'Auvergne à l'Assemblée constituante et commandant-général de la garde de Paris en 1789. Lieutenant-général, commandant en chef l'armée du centre en 1791, il quitta le service en 1792. Membre de la chambre des députés en 1818, il fut en 1830 général en chef des gardes nationales de France, et mourut à Paris le 20 mai 1834.

\section{La Touche-Tréville (Louis̀-René-Madeleine Le Vassor de), vice-amiral.}

Par Renaud; buste en terre cuite. - H. 0,63.

Né à Rochefort le 3 juin 174.5 , il entra en 1758 dans les gardes de la marine. Chancelier de la maison du duc d'Orléans en 1787, il fut député de la noblesse du bailliage de Montargis aux EtatsGénéraux en 1789. Contre-amiral en 1792, commandant l'escadre de Brest en 1799, puis celle de la Méditerranée, vice-amiral en 1803, La Touche-Tréville fut un des inspecteurs-généraux des côtes et grand-officier de la Légion d'Honneur. Il mourut le 19 août 1804, à bord du vaisseau le Bucentaure, en rade de Toulon.

\section{VESTIBULE DE LOUIS XIII, No 32.}

Ancien péristyle du palais de Louis XIII, ce vestibule se trouve au milieu de la partie centrale et au-dessous de la chambre à coucher de Louis XIV. Il était orné de seize colonnes de marbre de Rance, d'ordre dorique, et servait, ainsi que la galerie parallèle, à passer de la cour de marbre dans les jardins. Les trois ouvertures par lesquelles, remarque Félibien, " on voit de loin l'entrée des jardins ", étaient fermées la nuit par des grilles en fer doré. Ce passage fut supprimé vers la fin du règne de Louis XV, et, sous Louis XVI, le vestibule fit partie de l'apparte- 
ment de bains de Marie-Antoinette. Quatre des colonnes qui se trouvaient au milieu de ce péristyle ont été supprimées et transportées dans la salle $\mathrm{n}^{\circ} 27$.

\section{L'Hôpital (Michel de), chancelier de France.}

Par GoIs ; statue en plâtre. - H. 1,85.

Né en 15003 à Aigueperse, en Auvergne, il étudia le droit à Milan et à Padoue, fut auditeur de rote à Rome et conseiller au parlement de Paris en 15̋37. Naître des requêtes et conseiller d'état, il fut ensuite premier président de la chambre des comptes en 15๊ว̌t, et fut élevé en 15̋60, par François II, à la dignité de chancelier de France. Il résigna les sceaux en 15268 et se retira à Vignay, près d'Etampes, où il mourut le 13 mars $10 ّ 73$.

La statue originale en marbre est aux Tuileries.

\section{Bossuet (Jacques-Bénigne), évêque de Meaux.}

Par PAJOU; statue en plâtre. - H. 1,89.

Né à Dijon le 27 septembre 1627, il fut élevé au collége de Navarre, prit les ordres et reçut en 16 ö2 le bonnet de docteur. Chanoine de Netz en 16อ̈2, il prêcha devant le roi et la reine-mère en 1661 et 1662, devint évêque de Condom en 1669, et fut nommé, en 1670, précepteur du dauphin. Nembre de l'Académie Francaise en 1671 et premier aumônier de la dauphine en 1680, il fut évêque de Meaux en 1681, fit partie de l'assemblée du clergé qui eut lieu en 1682 et rédigea les quatre propositions qui déterminent en France les rapports de l'Etat et de l'Eglise. Bossuet, un des plus savants prélats de l'Eglise de France, surnommé le dernier père de l'Église, mourut à Paris le 12 avril 1704 et fut enterré dans l'église de Meaux.

La statue originale en marbre est à l'Institut.

\section{Fénelon (Francois de Salignac de la Mothe-), ar- chevêque de Cambrai.}

Par LECoute; statue en plâtre. - H. 1,82.

Né le 6 août 16 ăl au château de Fénelon, en Querci, il étudia à Saint-Sulpice et entra dans les ordres en 167 ŏ. Nommé précepteur du duc de Bourgogne en 1689, il fut reçu del'Académie Française en 1694 et promu en $1695 ั$ à l'archevêché de Cambrai. Engagéavec Bossuet dans la controverse du quiétisme, il fut disgracié par Louis XIV, condamné par l'Eglise, et se soumit avec humilité à cette double affliction. Fénelon mourut à Cambrai le 7 janvier 1715 .

La statue originale en marbre est à l'Institut. 


\section{Daguesseau (Henri-François), chancelier de France.}

Par BERRoER; statue en plâtre. - H. 1,86.

Né à Limoges le 26 novembre 1668, il fut, dès l'âge de vingtdeux ans, avocat-général au parlement de Paris et devint procureur-général en 1700. Nommé par le régent chancelier de France et commandeur des ordres du roi en 1717, il fut destitué l'année suivante pour s'être opposé au système de Law, et rappelé en 1720. Le cardinal de Fleury lui rendit de nouveau, en 1737, les sceaux que Dubois lui avait retirés en 1722 , et Daguesseau mourut le 9 février $175 \%$, laissant la réputation d'un magistrat intègre et d'un orateur éloquent.

La statue originale en marbre est aux Tuileries.

\section{S.ALLE DES ROIS DE FRANCE, No 33.}

Cette salle était autrefois subdivisée par des murs et des cloisons, et, principalement par le prolongement du mur de la façade latérale de la cour de marbre. Elle formait, sous Louis XIII, l'appartement du comte de Soissons, grand-maittre de la garde-robe, qui se trouvait ainsi au-dessous du cabinet et de la chambre à coucher du roi, remplacés depuis par le salon de l'OEil-de-Bœuf. C'est dans la chambre du grand-maître que Richelieu passa la nuit du 11 au 12 novembre 1630, veille de la célèbre Journée des Dupes. "L'escalier dérobé par lequel Saint-Simon vint le chercher, dit M. Le Roi, existe encore dans un petit couloir placé à l'angle sud-ouest de cette salle, et aboutit, au premier étage, à l'angle correspondant du salon de l'OEil-de-Bœuf, et par conséquent à la partie du cabinet qui précédait la chambre à coucher du roi. " (Louis XIII et Versailles.1850.)

Sous Louis XIV, cette salle formait encore, avec une partie de la salle $n^{\circ} 34$, l'appartement du grand-maitre de la garde-robe; mais vers 1750 , ce local fut réuni à l'appartement du dauphin. La partie la plus rapprochée du vestibule ${ }^{\circ} 32$, servit de salle de bains à la reine Marie-Antoinette.

656. Clovis $I^{\text {er }}$. .......... - 0,90. - L. 0,72.

D'abord roi des Francs-Saliens, il soumit le royaume de Soissons; il épousa, en 493, Clotilde, fille de Chilpéric, roi de Bourgogne. Vainqueur des Allemands à Tolbiac, en 496, il se fit baptiser à Reims, le 25 décembre de la même année, par saint Remy. L'empereur Anastase rechercha son alliance et lui donna le titre d'Auguste. Ses conquêtes s'étendirent des bords de l'Escaut jusqu'aux Pyrénées, et de l'Océan jusqu'au Rhône. Clovis I ${ }^{\text {er }}$ mourut à Paris, au palais des Thermes, dans la quarante-sixième année de son âge, et fut enterré dans la basilique de Saint-Pierre et de Saint-Paul (depuis Sainte-Geneviève), fondée par Clotilde. 


\section{Childebert $\boldsymbol{I}^{\text {er }}$.}

Par M. BézaRd. - H. 0,90. - L. 0,72.

D'abord roi de Paris en 511, il réunit sous sa domination une partie du royaume d'Orléans en 523 , et celui de Bourgogne en 524. Il fonda, vers 5้43, l'abbaye de Saint-Germain-des-Prés. Childebert Ier mourut à Paris le 23 décembre 558 , et fut enterré dans la basilique de Saint-Vincent.

\section{Clotaire $\boldsymbol{I}^{\text {er. }}$.}

Par M. BÉzARD. - H. 0,90, - L. 0,72.

Il fut d'abord roi de Soissons, après la mort de son père Clovis Ier en $\breve{11}$, succéda à son frère Childebert Ier en 558 , et réunit ainsi toute la monarchie des Francs en héritant successivement des royaumes de ses frères. Il mourut à Compiègne, en 561, dans la soixante-quatrième année de son âge, et fut enterré à Soissons dans la basilique de Saint-Médard.

\section{Caribert.}

Par M. DASSY. - H. 0,90. - L. 0,72.

Il succéda à son père Clotaire $\mathrm{I}^{\mathrm{er}}$ en 561 et mourut le 7 mai כ̌67, après un règne de six ans. Il fut enterré à Paris, dans la basilique de Saint-Vincent, depuis Saint-Germain-des-Prés.

\section{Chilpéric I ${ }^{e r}$.}

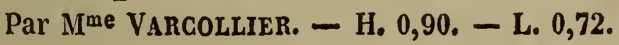

Roi de Soissons en 561 après la mort de son père Clotaire Ier, il succéda en 567 à son frère Caribert. Il mourut à Chelles en こั84, et fut enterré dans la basilique de Saint-Vincent.

\section{Clotaire II.}

Par M. Monvoisin. - H. 0,90. - L. 0,72.

D'abord roi de Soissons en 584, il réunit à la couronne les royaumes de Bourgogne, d'Austrasie et de Neustrie, et régna à dater de 613, sur toute la monarchie des Francs. Il mourut en 628 , et fut enterré dans l'abbaye de Saint-Vincent.

\section{Dagobert $\boldsymbol{I}^{e r}$.}

Par M. Signol. - H. 0,90. - L. 0,72.

D'abord associé en 622 au royaume d'Austrasie, il devint ensuite roi de Neustrie en 628 , succéda à son père la même année, et réunit, en 631 , le royaume d'Aquitaine à la couronne. Il 
mourut le 19 janvier 638, et fut enterré dans la basilique de SaintDenis, qu'il avait fondée en 630.

663. Clovis $I I$.

Par M. Signol. - H. 0,90. - L. 0,72.

Il succèda à son père Dagobert Ier en 638, et réunit à la couronne le royaume d'Austrasie après la mort de son frère Sigebert. Il mourut en 6อ̋6, et fut enterré dans la basilique de Saint-Denis.

664. Clotaire III.

Par M. Movvoisin. - H. 0,90. - L. 0,72.

Il succéda à son père Clovis II en 6ă6, et mourut sans postérité en 670 , âgé d'environ dix-huit ans. Il fut enterré dans la basilique de Saint-Denis.

665. Childéric II.

Par M. SignoL. - H. 0,90. - L. 0,72.

Roi d'Austrasie du vivant de son père Clovis II, il succéda à son frère Clotaire III en 670, et mourut en 674 âgé d'environ vingt-un ans. Il fut enterré dans la basilique de Saint-Vincent.

\section{Thierry $\mathbb{I}^{\text {er }}$.}

Par M. SignoL. - H. 0,90. - L. 0,72.

Troisième fils de Clovis II, il succéda à son frère Childéric II en 674, et mourut en 691 à l'âge de trente-sept ans environ. Il fut enterré dans l'abbaye de Saint-Waast d'Arras.

\section{Clovis III.}

Par M. Rodget. - H. 0,90. - L. 0,72.

Il régna sur l'Austrasie, la Neustrie et la Bourgogne, succéda à son père Thierry I ${ }^{\mathrm{er}}$ en 691 , et mourut en 695 . Il fut enterré dans l'église de Saint-Etienne, à Choisy-au-Bac, près de Compiègne.

668. Childebert II, surnommé le Juste.

Par M. Monvoisin. - H. 0,90. - L. 0,72.

Frère de Clovis III, il lui succéda en 695 , et mourut le 14 avril 711. Il fut enterré auprès de son frère dans l'église de SaintEtienne. 


\section{Dagobert II.}

Par M. Signol. - H. 0,90. - L. 0,72.

Il succéda à son père Childebert II en 711. Il mourut le 24 juin 715 , et fut enterré auprès de son père dans l'église de Saint-Etienne.

\section{Chilpéric II.}

Par M. IIonvoisin. - H. 0,90. - L. 0,72.

Il fut appelé à succéder à la couronne en 715, quarante-et-un ans après la mort de son père Childéric II, et mourut à Attigny en 720, après un règne de cinq ans. Il fut enterré à Noyon.

\section{Thierry II, dit de Chelles.}

Par M. SignoL。 - H. 0,90. - L. 0,72.

Fils unique de Dagobert II, il fut reconnu roi des Franes en 720. C'est sous le règne de ce prince que fut livrée, entre Tours et Poitiers, la bataille où Charles-Martel, maire du palais, défit Abdérame. Thierry II mourut en 737, à l'âge de vingi-quatre ans.

\section{Childéric IIII.}

Par M. SignoL. - H. 0,90. - L. 0,72 .

Fils de Chilpéric II, il régna de 742 à 752 , et mourut en 754 , dans le monastère de Sithieu (diocèse de Térouanne, abbaye de Saint-Bertin), à Saint-Omer.

\section{Pépin, dit le Bref.}

Par M. AMeL. - II. 0,90. - L. 0, 72 .

Fils de Charles-Martel, il fut proclamé roi par les grands du royaume dans l'assemblée générale de Soissons en 752 , et fut sacré el couronné dans cette ville par saint Boniface, archevêque de Mayence, légat du pape Zacharie. Pépin fut le premier souverain qui introduisit les cérémonies de l'église dans l'inauguration des rois; il recut en $75 \%$ la dignité de patrice de Rome; le pape Etienne II lui donna de nouveau l'onction sacrée dans l'église de Saint-Denis. Il mourut à Saint-Denis le 14 septembre 768, et fut enterré dảns la basilique.

\section{Charlemagne ou Charles $\mathbb{I}^{e r}$, surnommé le Grand.}

Par M. AMIEL. - H. 0,90. - L. 0,72.

Fils de Pépin-le-Bref et de la reine Berthe, il naquit au château 
d'Ingelheim, le 26 février 742. Après la mort de son père, il eut en partage les royaumes de Neustrie, de Bourgogne et de Provence, hérita ensuite, en $\mathbf{7 7 2}$, des états de son frère Carloman, et devint alors maître de toute la monarchie française. Nommé patrice de Rome en 774 par le pape Adrien I ${ }^{\mathrm{er}}$, il fut proclamé et couronné empereur d'Occident à Rome, par le pape Léon III, le 20 décembre 800 . Les bornes de son empire étaient : au nord, l'Océan et l'Eyder; à l'ouest, l'Océan et l'Ebre en Espagne ; au sud, la Méditerranée; à l'est, le Raab et les pays au-delà de l'Elbe ; et au nord-est les embouchures de l'Oder. Charlemagne mourut à Aix-la-Chapelle le 28 janvier 814, dans sa soixante-douzième année.

\section{Louis $\boldsymbol{I}^{e r}$, dit le Débonnaire.}

Par M. DAssy. - H. 0,90, - L. 0,72.

Il naquit à Casseneuil (Agenois) en 778, et porta immédiatement le titre de roi d'Aquitaine. Associé à l'empire, sacré du vivant de son père Charlemagne, et reconnu par les grands de l'état à l'assemblée générale d'Aix-la-Chapelle, en août 813, il fut courouné par le pape Etienne IV, dans l'église de Reims, en 816, avec la reine Hermengarde, sa première femme. Il mourut près de Mayence le 20 juin 840 , et fut enterré à Metz, dans l'église de Saint-Arnould.

\section{Charles II, surnommé le Chauve.}

Par Steuben. - H. 0,90. - L. 0,72.

Il naquit à Francfort-sur-le-Mein en 823 , reçut du vivant de son père, Louis-le-Débonnaire, les états de Neustrie en 836, ceux d'Aquitaine en 838, et devint roi de France en 840. Charles-leChauve, et ses frères Lothaire et Louis-le-Germanique, divisèrent entre eux les états de Charlemagne en 843 ; son neveu Louis II, fils de Lothaire, étant mort en 875 , Charles-le-Chauve fut sacré et couronné empereur par le pape Jean VIII. Il mourut à Brios en Piémont, le 6 octobre 877, et son corps, d'abord enterré à Nantua, fut ensuite transféré à Saint-Denis. - Charles-le-Chauve a laissé des Capitulaires qui furent joints à ceux de Charlemagne.

\section{Louis II, dit le Bègue.}

Par M. AMIEL. - H. 0,90. - L. 0,72.

Louis-le-Bègue, né en 8ł6, fut reconnu roi d'Aquitaine en 867, du vivant de son jère Charles-le-Chauve. Sacré et couronné à Compiègne le 3 décembre 877 par Hincmar, archevêque de Reims, il le fut de nouveau au concile de Troyes, le 7 décembre 878 
878 par le pape Jean VIII. Il mourut à Compiègne le 10 avril 879 , et fut enterré dans l'église de Notre-Dame de cette ville.

\section{Louis III et Carloman.}

Par Steuben, - H. 0,90. - L. 0,72.

Au mois de mars 880, Louis et Carloman, fils de Louis-leBègue, s'étant rendus à Amiens, partagèrent entre eux la monarchie; mais leur union fut si constante qu'ils semblent avoir régné par indivis, et tous les historiens les associent comme s'ils eussent occupé en commun le même trône. Louis III eut en partage tout ce qui dépendait de la Neustrie et de l'ancien royaume d'Austrasie, en deçâ de la Meuse, et Carloman les royaumes de Bourgogne, d'Aquitaine, le marquisat de Toulouse, etc. Louis III mourut le 3 ou le 5 août 882 , et Carloman le 6 décembre 884 . Ils ont été enterrés à Saint-Denis.

\section{Charles, dit le Gros.}

Par M. AMIEL. - H. 0,90. - L. 0,72.

Charles-le-Gros, fils de Louis-le-Germanique, eut en partage les états de Souabe et d'Alsace en 876 , fut associé à la royauté d'Italie par Carloman, son frère, en 879 , proclamé roi et couronné à Milan le 6 janvier 880. Empereur en 881, sacré et couronné par le pape Jean VIII, il succéda en janvier 882 aux états de Louis, son frère, roi de Saxe, et après la mort de Carloman, en 884, il fut reconnu roi de France par les grands de l'Etat; il réunit ainsi toute la succession de Charlemagne. Il mourut le 13 janvier 888, à l'abbaye de Reichnau, dans une île du lac de Constance.

\section{Eudes.}

Par STEUBen. - H. 0,90. - L. 0,72.

Eudes, fils aîné de Robert-le-Fort, duc de France, porta d'abord le titre de comte de Paris, et défendit courageusement Paris assiégé par les Normands en 885. Reconnu et proclamé roi par les grands de l'Etat, dans l'assemblée générale de Compiègne, il fut couronné en 888 , par Wautier, archevêque de Sens, et mou-

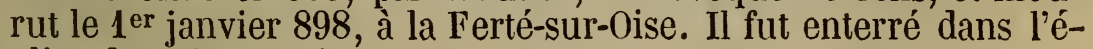
glise de Saint-Denis.

\section{Charles III, dit le Simple.}

Par M. Rouget. - H. 0,90. - L. 0,72.

Fils posthume de Louis-le-Bègue, né le 17 septembre 879 , il fut successivement dépossédé par Charles-le-Gros et par Eudes. 
Sacré et couronné à Reims en 893 , il fut reconnu en 898 seul el unique souverain de la monarchie française. Il mourut au château de Péronne le 7 octobre 929, et fut enterré dans l'abbaye de Saint-Foursi.

\section{Raoul ou Rodolphe.}

Far Dejuinine. - H. 0,90. - L. 0,72.

Raoul, duc de Bourgogne et gendre de Robert II, duc de France, fut, après la mort de Charles-le-Simple, élu roi de France par les grands de l'Etat et sacré dans l'église de Saint-Médard de Soissons en 923. Il mourut à Auxerre en janvier 936, et fut enterré à Sainte-Colombe de Sens.

\section{Louis IV, dit d'Outremer.}

Par Steubev. - H. 0,90. - L. 0,72.

Fils de Charles-le-Simple, il fut élevé en Angleterre par sa mère, ce qui lui fit donner le surnom d'Outremer, et fut reconnu roi après la mort de Raoul, en 936. Il mourut à Reims, le 10 septembre 9כ̌4, dans la trente-troisième année de son âge, et fut enterré dans l'église de Saint-Remy.

\section{Lothaire.}

Par M. Monvorsiv. - H. 0,90. - L. 0,72 .

Fils aîné de Lọuis d'Outremer, il fut associé à la couronne en 952 , du vivant de son père, lui succéda en 9ö4, et mourut à Compiègne le 2 mars 986 , à quarante-cinq ans. Il fut enterré dans l'église de Saint-Remy, à Reims.

\section{Louis $V$, surnommé le Fainéant.}

Par M. AMIEL. - H. 0,90. - L. 0,72.

Fils aîné de Lothaire, il fut associé à la couronne du vivant de son père, en 978 , lui succéda en 986 , et mourut le 21 mai 987 , à l'âge de vingt ans. Il fut enterré dans l'église de Notre-Dame, à Compiègne.

\section{Hugues Capet.}

Par Steuben. - H. 0,90. - L. 0,72.

Petit-fils de Robert-le-Fort, comte de Paris, et fils aîné de Hugues-le-Grand, Hugues Capel était duc de France, comte de Paris et d'Orléans, lorsqu'à la mort de Louis V, en 987, la couronne lui fut décernée par les grands du royaume dans une assemblée générale tenue à Noyon. Il se fit sacrer à Reims, choisit Paris pour sa résidence, et fut le chef de la troisième dynastie des rois 
SALLE DES hOIS DE FRANCE, NO 33.

de France, qui a pris de lui le nom de race Capétienne. Il mourit le 25 octobre 996 , à cinquante-quatre ans, el fut enterré à Saint-Denis.

\section{Robert, dit le Pieux.}

Par Blondel. - H. 0,90. - L, 0,72.

Filsaîné de Hugues Capet, il fut associé par son père à la couronne dès 988, et lui succéda en 996. Après la mort de Henri, duc de Bourgogne, son oncle, Robert étani devenu maître du duché de Bourgogne, en 1015, le donna à son second fils Henri, el réunil à la couronne le comté de Sens on 1017. Il mourut à Melun le 20 juillet 1031, à soixante-et-un ans, et fut enterré à Saint-Denis.

\section{Henri I ${ }^{e r}$.}

\section{Par Blondel. - H. 0,90. - L. 0,72.}

Second fils de Robert-le-Pieux, il était né en 1003, el avaitrer:u de son père, en 1015้, l'investiture du duché de Bourgogne. Ayait succédé à la couronne en 1031, il donna en 1032 le duché de Bourgogne à son frère Robert, qui fut le chef de la premicro branche royale des ducss de Bourgogne. Henri Ir fonda à Paris le prieuré de Saint-Martin-des-Champs, et mourul à Vitry, dans là forêt de Bierre (depuis Fontainebleau), le 29 aoûi 1060. Il fut enlerré à Saint-Denis.

\section{Philippe II ${ }^{e r}$.}

Par M. SaINT-EvRE. - H. 0,90. - L. 0,72.

Fils aîné de Henri Ier, il lui suecéda en 1060, à lậge de luuit ans, sous la tutelle de Baudouin, comte de Flandre. Le Gatinois, le Vexin francais et la vicomté de Bourges furent réunis à la couronne, et la première croisade fut entreprise sous le règne de ce prince. Il mourut à Melun le 29 juillet 1108, et fut enterré à Saint-Benoît-sur-Loire.

\section{Louis VI, surnommé le Gros.}

\section{Par BlondeL. - H. 0,90. - L. 0,72.}

Fils aîné de Philippe Ier, il naquit en 1078, fut d'abord créé comte du Vexin, en 1092, puis associé à la royauté, en 1098 ou 1099, et devint roi en 1108. Il combattit le système féodal et favorisa dans ce but l'institution des communes. Louis VI fonda l'albbaye de Saint-Victor à Paris, commença le Louvre, et mourulà Paris le $\mathbf{L}^{\mathrm{er}}$ aoùt 1137. Il fut enterré à Saint-Denis. 
691. Louis VII, dit le Jeune.

Par Decaisne. - H. 0,90. - L. 0,72.

Second fils de Louis-le-Gros, il naquit en 1120, fut appelé au tròne en 1137, par suite de la mort de son frère aîné, et entreprit la seconde croisade en 1147. Il répudia, en 1152, Eléonore de Guyenne, qui remariée à Henri II, roi d'Angleterre, fit passer sous sa domination le duché d'Aquitaine. Lotiis VII jeta, en 1160, les fondements de l'église cathédrale de Paris et ceux du palais de Fontainebleau. Il donna, en 1170 , à l'église de Reims, la prérogative du sacre des rois. Il mourut à Paris le 18 septembre $\mathbf{1 1 8 0}$ et fut enterré dans l'abbaye de Barbeaux, qu'il avait fondée en $114 \%$.

\section{Philippe II, dit Philippe-Auguste.}

Par M. AMiEL. - H. 0,90. - L. 0,72.

Fils de Louis-le-Jeune et d'Alix de Champagne, sa troisième femme, il naquit le 21 août 116 et fut roi en 1180, à l'âge de quinze ans. Il se croisa en 1190, fit rentrer sous son autorité immédiate, en 1202, les provinces d'Anjou, de Touraine, du Maine, de Normandie, et remporta, en 1214, la victoire de Bouvines sur la confédération du baronnage français, soutenue par l'empereur d'Allemagne et le roi d'Angleterre. On doit à ce prince l'établissement du trésor des chartes pour la conservation des archives de la couronne. Il mourut à Mantes le 14 juillet 1223, et fut ellterré à Saint-Denis.

\section{Louis VIII, surnommé le Lion.}

Par M. H. LehmaNx. - H. 0,90. - L. 0,72.

Fils et successeur de Philippe-Auguste ; né le 5̋ septembre 1187, roi en 1223, il prit aux Anglais le Poitou, le Limousin, le Périgord et l'Aunis, fit la guerre aux Albigeois et mourut au château de Montpensier, en Auvergne, le 8 novembre 1226 , après un règne de trois années. Il fut enterré à Saint-Denis. - Louis VIII est le premier roi de la troisième race dont le sacre n'ait pas devancé la mort de son père.

\section{Louis IX (saint Louis).}

Par De Creuse. - H. 0,90. - L. 0,72.

Fils de Louis VIII et de Blanche de Castille, il naquit au château de Poissy, le 25 avril 1215 , et succéda à son père en 1226 , à l'àge de onze ans. Sous la régence de sa mère, le traité de Paris, conclu en 1229, mit fin à la guerre des Albigeois et réunit à la couronne les sénéchaussées de Beaucaire et de Carcassonne. Déclaré majeur en 1236, il eut à combattre les révoltes de ses grands vassaux 
du Midi, unis au roi d'Anglerre, et fut vainqueur à Taillebourg et à Saintes. Il partit pour la cinquième croisade en 1248, fut fait prisonnier en Egypte et revint en France en 1254. Il fonda la Sorbonne en 1256, l'hôpital des Quinze-Vingts en 1260, partit en 1270 pour une nouvelle croisade, et mourut devant Tunis le 2. août 1270. - Philippe-le-Hardi, son fils, rapporta en 1171, dans l'église de Saint-Denis, les restes du pieux roi, qui fut canonisé en 1297.

\section{Philippe III, dit le Hardi.}

Par M. SAINT-EvRE. - H. 0,90. - L. 0,72.

Fils de saint Louis, il naquit en 1245 et suivit son père à la sixième croisade. Il lui succéda en 1270 , réunit à la couronne, en 1272, le marquisat de Provence et le comté de Toulouse, et fit la guerre au roi d'Aragon après le massacre des Vêpres Siciliennes, en 1282. Il mourut à Perpignan le 5ٌ octobre 1285, et fut enterré à Saint-Denis.

\section{Philippe IV, dit le Bel.}

Par M. BEzARd. - H. 0,90. - L. 0,72.

Fils de Philippe-le-Hardi, il naquit à Fontainebleau en 1268 , et succéda à son père en 1285. Philippe-le-Bel fonda l'Université de Montpellier en 1289. Ce fut sous son règne que les députés des villes et des communes, sous la dénomination de tiers-état, commencèrent à siéger à côté de ceux du clergé et de la noblesse, dans l'assemblée des états-généraux du royaume. Il rendit le parlement sédentaire à Paris et réunit á la couronne la ville et le comté de Lyon. Philippe-le-Bel mourut à Fontainebleau le 29 novembre 1314, et fut enterré à Saint-Denis.

\section{Louis $\boldsymbol{X}$, dit le Hutin,}

Par M. TAssaert. - H. 0,90. - L。 0,72.

Fils aîné de Philippe-le-Bel et de Jeanne, reine de Navarre, il naquit en 1289, hérita en 1305ّ, après la mort de sa mère, du royaume de Navarre, et succéda à son père en 1314. Après un règne de dix-huit mois, il mourut au château de Vincennes le ร้ juin 1316, et fut enterré à Saint-Denis.

\section{Philippe $V$, dit le Long.}

Par DebacQ. - H. 0,90. - I. 0,72.

Second fils de Philippe-le-Bel, il naquit à Lyon en 1294 et porta d'abord le titre de comte de Poitiers. Son frère aîné, Louis-leHutin, étant mort pendant la grossesse de la reine Clémence de 
Hongrie, Philippe-le-Long fut reconnu régent pendant l'interrègne qui s'écoula jusqu'à la naissance du roi Jean I ${ }^{\mathrm{er}}$. Ce prince, né le 15 novembre 1316 , étant mort quatre jours après, la succession fut dévolue à son oncle, qui mourut le 3 janvier 1322, après avoir régné cinq ans. Philippe-le-Long fut enterré à SaintDenis.

\section{Charles IV, dit le Bel.}

\section{par Mime Deht́rain. - H. 0,90. - L. 0,72.}

Troisième fils de Philippe-le-Bel, il naquit en 1295 et porta d'abord le titre de comte de la Marche. Philippe-le-Long étant mort sans enfants, Charles-le-Bel, son frère, lui succéda en 1322. Comme ses deux aînés, il šéteignit sans enfants mâles, et avec lui finit la ligne dite des Capétiens directs. Il mourut à Vincennes le $1^{\text {er }}$ février 1328, et fut enterré à Saint-Denis.

\section{Philippe VI, dit de Valois.}

\section{Par M. Robert-Fleury. - H. 0,9C. - L. 0,72.}

Fils de Charles de France, comte de Valois, et petit-fils de Philippe-le-Hardi, il naquit en 1293 et fut comte de Valois après la mort de son père. Charles-le-Bel étant mort en laissant, comme son frère Louis-le-Hutin, la reine enceinte, le comte de Valois fut proclamé régent du royaume jusqu'à l'accouchement de la reine, et la veuve de Charles-le-Bel ayanì donné naissance à une fille, le régent devint roi sans contestation en 1328. Philippe de Valois réunit à la couronne les provinces de Champagne ei de Brie, la ville et le comté de Montpellier; il reçut, en 1345, de Humbert, dauphin de Viennois, la cession du Dauphiné, stuus la condition que les fils ainés des rois de France porteraient le titre de dauphin. La longue guerre, qu'on a appelée de cent ans, entre la France et l'Angleterre, éclata sous le règne de ce prince, qui perdit, en 1346, la bataille de Crécy. Philippe de Valois mourut à Nogent-le-Roi, près de Chartres, le 22 août 1330 , et fut enterré à Saint-Denis.

\section{Jean II, dit le Bon.}

\section{Par M. LUGARDON. - H. 0,90. - L. 0,72.}

Fils aîné de Philipre de Valois, il naquit au château du Gué de Maulny, près du Ilans, le 26 avril 1319, et succéda à son père en 13ว00. La guerre de la France avec l'Angleterre continua sous ce règne; le roi Jean fut fait prisonnier à la bataille de Poitiers, en 13306 , et mourut captif à Londres le 8 avril 1364. Son corps, rapporté en France, fut enterré à Saint-Denis. 


\section{Charles $\boldsymbol{V}$, dit le Sage.}

Par Dejuinne. - H. 0,90. - L. 0,72.

Fils aîné de Jean-le-Bon, il naquit au château de Vincennes le 21 janvier $\mathbf{1 3 3 7}$, et fut le premier des fils aînés des rois de France qui ait porté le titre de dauphin. Il gouverna d'abord le royaume en qualité de régent pendant la captivité de son père, lui succéda en 1364, et réunit à la couronne les comtés d'Auxerre et de Poitiers, l'Aunis, la Saintonge, l'Angoumois et le Limousin. Il 'commença le château de la Bastille et fonda la Bibliothèque royale. Charles V mourut au chàteau de Beauté-sur-Marne, le 16 septembre 1380, et fut enterré à Saint-Denis.

\section{Charles VI.}

Par M. Saint-Evre. - H. 0,90. - L. 0,72.

Fils aîné de Charles V ; né à Paris en 1368, il n'avait que douze ans lorsqu'il succéda à son père en 1380. Les querelles des ducs d'Anjou, de Bourgogne, de Berry et de Bourbon, ses oncles, qui se disputèrent le pouvoir pendant sa minorité, commencèrent les malheurs de Charles VI, et la démence dont il fut frappé en $\mathbf{1 3 9 3}$ y mit le comble. Il avait épousé, en 1385ٌ, Isabeau de Bavière, qui fut mise à la tête d'un conseil de régence dont firent partie le duc d'Orléans, frère du roi, et Jean-sans-Peur, duc de Bourgogne. La rivalité de ces princes, qui produisit le double assassinat de la rue Barbette (1407) et du pont de Montereau (1419), les troubles excités par les factions des Armagnacs et des Bourguignons, la bataille d'Azincourt, gagnée par Henri V, roi d'Angleterre, en 1415 , et le traité de Troyes, qui lui livra en 1420 la couronne de France, tels sont les tristes souvenirs attachés au nom de Charles VI. Il mourut à l'hôtel Saint-Pol, à Paris, le 22 octobre 1422, et fut enterré dans l'église de Saint-Denis.

\section{Charles VII.}

Par M. H. Lehilann. - H. 0,90. - L. 0,72.

Né à Paris le 22 février 1403, ce prince n'était que le fils puîné de Charles VI, et porta d'abord le titre de comte de Ponthieu. A la mort de Jean, son frère aîné, il devint dauphin en 1416 et fut régent en 1418. Déshérité par le traité de Troyes, il se fit sacrer à Poitiers en 1422, et avec le secours de Jeanne d'Arc, força les Anglais à lever le siége d'Orléans et se fit sacrer de nouveau à Reims en 1429 . Il reconquit successivement toutes les provinces de son royaume sur les Anglais, réunit à la couronne le duché de Guyenne, et conclut le premier traité d'alliance de la France avec les cantons suisses. Il mourut au château de Mehun-sur- 
Yèvre, près de Bourges, le 27 juillet 1461, et fut enterré à SaintDenis.

\section{Louis $X I$.}

Par Claude Thévenin. - H. 0,90. - L. 0,72.

Fils aîné de Charles VII, il naquit à Bourges le 3 juillet 1423 et succéda à son père en 1461. Il créa le parlement de Bordeaux, établit les postes en 1464, institua l'ordre de Saint-Michel en 1469, attira à Paris des imprimeurs de Mayence, et établit des manufactures de soie et d'étoffe d'or et d'argent en 1470 . Il réunit à la couronne les duchés de Bourgogne et d'Anjou, les comtés du Maine et de Provence, et affranchit l'autorité royale de la domination des grands vassaux. Louis XI mourut au château du Plessislès-Tours, le 30 août 1483, et fut enterré dans l'église collégiale de Notre-Dame de Cléry.

\section{Charles VIII.}

\section{Par M. Gigoux. - H. 0,90。 - L. 0,72.}

Fils de Louis XI, né au château d'Amboise le 30 juin 1470, il n'avait que treize ans lorsqu'il succéda à son père en 1483. Anne de Beaujeu, sœur aînée de Charles VIII fut nommée régente pendant sa minorité ; déclaré majeur en 1484, par les états assemblés à Tours, il épousa, en 1491, Anne; duchesse de Bretagne, entreprit la conquête du royaume de Naples en 1495 , et recut du pape Alexandre VI le titre d'empereur de Constantinople. Il mourut sans postérité au château d'Amboise, le 7 avril 1498, et fut enterré à Saint-Denis.

\section{Louis XII, surnommé le Père du Peuple.}

Par M. Adolphe Bruse. - H. 0,90. - L. 0,72.

Né à Blois le 27 juin 1462 , il était arrière petit-fils du roi Charles V, succéda en 1498, à Charles VIII, mort sans postérité, et épousa, l'année suivante, la reine Anne de Bretagne. Il fit, en 1500, la conquête du Milanais et du royaume de Naples, et les états-généraux de 1506 lui décernèrent le titre de Père du Peuple. En 1514, Louis XII sacrifia toutes ses conquêtes pour assurer la paix à son royaume, et mourut au château des Tournelles, à Paris, le $1^{\mathrm{er}}$ janvier 15้5. Il fut enterré à Saint-Denis.

\section{Louis $X I I$. (Voir no 707.)}

Par Laurent DE MUGIANo; bronze. - H. 0,91.

Il est représenté la main droite relevée et la gauche appuyée sur une tablette oì sont figurées, par un de leurs monuments et indiquées par des in̂itiales, les 
villes principales de l'Italie: Mr. (Milano), Fr. (Firenza), n. (Roma), ve. (Y'erona), IT. (Italia). Le roi a la tête nue, porte le collier de l'ordre de Saint-Michel et il est revêtu d'une armure. On remarque sur la cuirasse un épisode d'un combat équestre et au-dessous une mêlée de fantassins; dans l'un et dans l'autre, un personnage dont le casque a pour cimier une fleur de lis, joue le rôle principal et les actions doivent être allusives à la valeur du prince. Plus bas et sur une bandelette qui contourne le bord, on lit : MEdIolanensis. LAVRENCIVS. DEMVGiano. OPVS. FECIT. 1508.

Ce buste a été moulé d'après un torse en albâtre, transporté en 1508 de Milan au château de Gaillon, puis placé au Musée des Monuments français. La tête qui avait ẻté brisée en 1793 a été refaite par Beauvallet, d'après la statue qui se trouve à Saint-Denis. La figure originale est au Musée du Louvre, no 16 de la Description des Sculptures modernes, par H. BARBET DE JOUY.

\section{François $\boldsymbol{I}^{e r}$.}

École française; xviıre siècle. - H. 0,90. - L. 0,72.

Fils de Charles d'Orléans, comte d'Angoulême, il naquit à Cognac le 12 septembre 1494, et porta d'abord le titre de comte d'Angoulême, puis celui de comte de Valois. Il épousa, en 15̆14, Claude, fille aînée de Louis XII, et ce prince étant mort sans enfants mâles, Francois qui, comme lui, descendait du roi Charles V, fut héritier de la couronne en 15̆15. Il remporta, la même année, la victoire de Marignan, et soutint contre l'empereur CharlesQuint une longue guerre qui se termina par le traité de Crespy en 1544. François I ${ }^{\text {er }}$ réunit à la France les provinces de Bourbonnais et d'Auvergne, le comté de Clermont, le Forez, le Beaujolais et le comté de la Marche. Il fonda, en 1523, le collége de France, et en 15̆31, l'imprimerie royale; la protection qu'il accorda aux arts lui mérita le titre de Restaurateur des Lettres. Sous son sègne, la Bretagne fut définitivement réunie à la France en 1532 , et le Canada fut découvert en 1534 par Jacques Cartier. François Ier mourut au château de Rambouillet le 31 mars 1547 , et fut enterré à Saint-Denis.

\section{Henri II.}

Par M. NAigeON. - H. 0,90. - L. 0,72.

Né à Saint-Germain-en-Laye le 31 mars $\mathbf{1 5 1 9}$, il était le second fils de François Ier, porta d'abord le titre de duc d'Orléans, et devint dauphin en 1536, après la mort de François de France, duc de Bretagne, son frère ainé. Il succéda à son père en 154.7, établit en 15533 le parlement de Bretagne, à la place des grandsjours créés par Charles VIII, et réunit à la couronne, en 15̌š8, par le traité de Cateau-Cambrésis, les trois évêchés de Toul, Metz et Verdun et le comté de Calais. Henri II mourut au palais des Tournelles à Paris, le 10 juillet 15559 , et fut enterré à SaintDenis. 


\section{François II.}

Par M. Racch. - H. 0,90. - L. 0,72.

Fils aîné de Henri II et de Catherine de Médicis. Né à Fontainebleau le 20 janvier 10ั44, il épousa en 100 วั8 Marie Stuart,

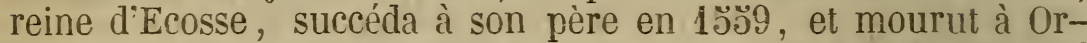
léans sans laisser de postérité, le ə̌ décembre 10ั60. Il fut enterré à Saint-Denis.

\section{Charles IX.}

Par M. Adolphe Brove. - H. 0,90. - L. 0,72.

Troisième fils de Henri II. Né à Saint-Germain-en-Laye le 27 juin 1 อัวั0, il porta d'abord le titre de duc d'Angoulême, ensuite celui de dúc d'Orléans, et succéda à son frère en 10060 . Il resta trois ans sous la tutelle de sa mère Catherine de Médicis, et fut déclaré majeur en 15้63. Sous son règne, le royaume fut déchiré par les guerres de religion, dont les événements les plus importants sont les batailles de Dreux en 10062 , de Saint-Denis en $15 \check{67}$, de Jarnac et de Montcontour en 15069 , et le massacre de la Saint-Barthélemy en 10ั72. Charles IX mourut sans posiérité an château de Vincennes, le 30 mai $15 \% 4$, et fut enterré à SaintDenis. C'est sous ce règne, en 4 6 6̆, que le commencement de l'année fut fixé au $1^{\text {er }}$ janvier ; jusqu'à cette époque, on avait coutume de la commencer à Pâques.

\section{Henri III.}

Par M. Rubio. - H. 0,90. - L. 0,72.

Quatrième fils de Henri II. Né à Fontainebleau le 19 septembre 1วัฒ1, il porta d'abord le titre de due d'Anjou et de Bourbonnais, et ensuite celui de duc d'Orléans. Nommé lieutenant-général du royaume en 15067 , il fut élu roi de Pologne en 15๊73. Il succéda à la couronne de France après la mort de son frère Charles IX, et institua l'ordre du Saint-Esprit en 1วั79. Les guerres de religion continuèrent sous son règne avec plus de violence. La Ligue ou Sainte-Union formée par les catholiques contre les protestants eut pour résultat, en 15888 , la journée des Barricades, qui chassa le roi de Paris, puis l'assemblée des états de Blois, où le duc de Guise fut assassiné. Henri III faisait le siége de Paris lorsqu'il tomba sous le couteau de Jacques Clément à Saint-Cloud, le 2 août 1 อั89. Il mourut, comme ses frères, sans postérité et fut enterré à SaintDenis.

\section{Henri IV.}

Par Me de Léomexr. - H. 0,90. - L. 0,72.

Né au château de Pau le 13 décembre 1วัวั3, fils d'Antoine de 
Bourbon, duc de Vendôme, et de Jeanne d'Albret, reine de Navarre, il porta d'abord le titre de prince de Béarn, fut gouverneur et amiral de Guyenne en 1562, et devint roi de Navarre en $15 \% 72$, après la mort de sa mère. La branche des Valois s'étant éteinte sans postérité, Henri, qui descendait de Robert, comte de Clermont, sixième fils te saint Louis, devint, en 1589, l'héritier légitime de la couronne de France. Vainqueur à Arques et à Ivry, il abjura, en 15993 le calvinisme, fut sacré à Chartres en 1594, publia en 1598 l'Edit de Nantes qui assurait aux protestants la liberté religieuse, et conclut avec le roi d'Espagne le traité de Vervins. Frappé d'un coup de couteau dans la rue de la Ferronnerie, il mourut à Paris le 14 mai 1610 et fut enterré à Saint-Denis. - Henri IV avait réuni à la couronne le royaumc de Navarre et la principauté de Béarn, le comté de Foix et annexé le Bugey et la Bresse.

\title{
715. Henri IV. (Voir n⿳ 714.)
}

Par Lenot en 1818; bronze. - H. 1,14.

Cette figure équestre est une réduction de celle érigée sur le Pont-Neuf à Paris le 25 août 1818.

On lit sur le devant du piédestal :

\author{
HENRICI. MAGNI \\ PATERNO. IN. POPVLVM. ANIMO \\ NOTISSIMI. PRINGIPIS \\ SACRAM. EFFIGIEM \\ GIVILES. INTER. TVMVLTVS \\ GALLIA. INDIGNANTE. DEJEGTAM \\ POST. OPTATVM. LVDOVICI. XVIII. REDITVM \\ EX. OMNIBVS. ORDINIBVS. GIVES \\ AERE. COLLATO. RESTITVERVNT \\ NEG. NON. ET. ELOGIVM \\ GVM. EFFIGIE. SIMVL. ABOLITVM \\ LAPIDI. RVRSVS. INSGRIBI \\ GVRAVERVNT \\ D D \\ DIE. $\overline{X X Y}$. MENS. $\Lambda$ TG. $\overline{\text { MDGGGXVIII }}$
}

Et sur la face postérieure :

\section{ERRICO. IV.}

GALLIARYM. IMPERATORI NAVAR. R.

LVDOVIGVS. XIII. FILIVS. EJVS

OPVS. INCHOATVM. ET. INTERMISSVM

PRO. DIGNITATE. PIETATIS. ET. IMPERII

PLENIVS. ET. AMPLIVS. ABSOLVIT

EMIN. D. C. RIGHELIVS

COMMTNE. VOTVM. POPVLI. PROMOVIT

SVPER. ILLVSTR. VIRI

DE. BVLLION. BOVTILliER. P. AERARII. F.

FAGIENDVM. GVRAVERVNT.

$$
\text { MDCXXX }
$$




\section{Louis XIII.}

Par M. de Lestaxg. - H. 0,90. - L. 0,72.

Fils de Henri IV et de Marie de Médicis, il naquit à Fontainebleau, le 27 septembre 1601 et devint roi en 1610 sous la régence de sa mère. Déclaré majeur au parlement de 1614 , il épousa l'année suivante Anne d'Autriche, fille de Philippe III, roi d'Espagne, et eut à lutter contre les partis politiques et religieux qui divisaient la France. L'entrée au ministère du cardinal de Richelieu, en 1624, vint raffermir le pouvoir royal; la Rochelle fut enlevée aux protestants en 1629, et les armées françaises triomphèrent dans les diverses guerres contre le Piémont, l'Autriche et l'Espagne. Louis XIII mourut au château de Saint-Germainen-Laye le 14 mai 1643, et fut enterré à Saint-Denis. - Il créa le parlement de Pau en 1620, celui de Metz en 1633, fonda l'hôpital des Incurables en 1634, et établit l'Académie française en 1635 .

\section{Louis $\mathbf{X I V}$, dit le Grand.}

D'après Hyacinthe Rigaud. - H. 0,90. - L. 0,72.

Fils de Louis XIII ; né au château de Saint-Germain-en-Laye, le כ̆ septembre 1638, Louis XIV n'avait que cinq ans à la mort de son père, et fut reconnu roi en 1643, sous la régence d'Anne d'Autriche, sa mère. La guerre de Trente-Ans, commencée sous le règne précédent, se termina en 1648 par la paix de Westphalie, qui donna à la France l'Alsace; les troubles de la Fronde prolongèrent jusqu'en 16599 la guerre avec l'Espagne, qui se termina par le traité des Pyrénées ; la cession du Roussillon, de la Cerdagne, de l'Artois, du Hainaut et du Luxembourg français et le mariage de Louis XIV avec l'infante Marie-Thérèse, fille de Philippe IV, furent les résultats de ce traité. Dans la guerre des droits de la Reine, l'Espagne perdit la Flandre en 1668 par le traité d'Aix-la-Chapelle. La guerre de Hollande terminée en 1678 par le traité de Nimègue, enleva encore à l'Espagne la FrancheComté. La ligue d'Augsbourg ayant forcé Louis XIV de résister à la coalition des puissances européennes, le traité de Ryswyck assura, en 1697, à la France, la possession de la ville de Strasbourg. En 1700, le roi d'Espagne, Charles II, étant mort sans postérité, le duc d'Anjou, petit-fils de Louis XIV, fut appelé à succéder à cette couronne, et après une longue guerre fut reconnu roi d'Espagne par le traité d'Utrecht en 1713. - Louis XIV établit l'Académie des Inscriptions et Belles-Lettres en 1663, celle de peinture et de Sculpture en 1664, celle des Sciences en 1666, celle des Elèves de Rome en 1667, celle de Musique en 1669, et celle 
d'Architecture en 1671; il commença les travaux de Versailles en 1661, fit bâtir la colonnade du Louvre en 1665̆, l'Observatoire en 1667 et l'hôtel des Invalidess en 1671; il fonda la maison de Saint-Cyr en 1686 pour l'éducation de deux cent-cinquante pauvres demoiselles nobles et institua l'ordre militaire de Saint-Louis en 1693. Louis XIV mourut à Versailles le $1^{\mathrm{er}}$ septembre 1715 après un règne de soixante-douze ans et dans la soixante-dixseptième année de son âge. Il fut enterré à Saint-Denis.

\section{Louis $X V$}

Par Amne-Baptiste Nivelon. - H. 0,90. - L. 0,72.

Né à Versailles le 15 février 1710 , Louis XV, arrière petit-fils de Louis XIV et fils du duc de Bourgogne, succéda au trône en 1715 , sous la régence de Philippe, duc d'Orléans, et fut déclaré majeur en 1723. Les principales guerres de Louis XV sont: pendant la régence, la guerre contre l'Espagne, terminée au traité de Cambrai en 1720, puis la guerre de la succession de Pologne, qui valut à la France, par le traité de Vienne en 1735̆, la réunion de la Lorraine; la guerre de la succession d'Autriche, terminée par le traité d'Aix-la-Chapelle, en 1748; et enfin la guerre de Sept-Ans, qui eut pour résultat le traité de Paris, qui enleva à la France, le Canada, la Louisiane, les Indes, le Sénégal, plusieurs Antilles, et détruisit sa puissance coloniale et maritime ; l'acquisition de la Corse en 1763, fut une bien faible compensation de cette grande perte. Louis XV'fonda l'École royale militaire en 17วั1. Il mourut à Versailles, le 10 mai 1775 , et fut enterré dans l'église de Saint-Denis.

\section{Louis XVI.}

Par Duplessis. - H. 0,90. - L. 0,72.

Né à Versailles, le 23 août 175\%, de Louis, dauphin, fils de Louis XV, Louis XVI monta sur le trône en 1774. Il donna des secours aux Américains insurgés contre l'Angleterre, assura leur indépendance par le traité conclu à Versailles en 1783 et releva la marine française; il rendit en 1787 l'état civil aux protestants et abolit les corvées, ainsi que la question préparatoire. Les étatsgénéraux convoqués en 1789 , s'étant transformés en assemblée nationale, Louis XVI accepta la constitution de 1791 et fut renversé du trône en 1792. Jugé et condamné par la Convention nationale, il périt sur l'échafaud le 21 janvier 1793. Ses restes furent transportés à Saint-Denis en 1815. 


\section{Napoléon I ${ }^{e r}$.}

Par Pobert Lefìvre. - H. 0,90. - L. 0,72.

Napoléon Bonaparte, né à Ajaccio (Corse), le 15 août 1769 , était fils de Charles-Marie Bonaparte, conseiller du roi et assesseur au tribunal d'Ajaccio, et de Marie-Letitia Ramolino. Il entra en 1779 à l'école militaire de Brienne, à celle de Paris en 1784 et en sortit en 1785. Lieutenant en second d'artillerie au régiment de La Fère le 1 er septembre 178ə̆, lieutenant en premier ati $4^{\mathrm{e}}$ d'artillerie le $1^{\mathrm{er}}$ avril 1791, il se rendit en Corse à la fin de 1791. Capitaine en second le 6 février 1792, il fut lieutenantcolonel du $1^{\text {er }}$ bataillon des volontaires nationaux de la Corse en avril 1792, capitaine en premier le 8 mars 1793; chef de batailIon au 2 régiment d'artillerie le 19 octobre de la même année, il commanda l'artillerie au siége de Toulon. Général de brigade d'artillerie le 12 janvier 179\%, il fut chargé de l'inspection des côtes de Provence et de les mettre en état de défense. Commandant en second de l'armée de l'intérieur le 5 octobre 1795, il fut général de division et geénéral en chef de l'armée de l'intérieur le 26 du même mois. Général en chef de l'armée d'italie le 2 mars 1796, il épousa le 9 mars suivant Marie-Francoise-Joséphine de Tascher de la Pagerie, veuve du général de Beauharnais. Le traité de Campo-Formio en 1797 fut le résultat de ses victoires. Général en chef de l'armée d'Egypte en 1798, il s'empara de Malle, soumit l'Egypte et fonda aù Caire un Institut. Premier consul en 1799, consul à vie en 1802, empereur des Français en 1804, roi d'Italie en 1803, protecteur de la Confédération du Rhin en 1806, sa carrière militaire fut illustrée jusqu'en 1812 sur les champs de bataille de Marengo, d'Austerlitz, de Wagram, d'Iéna, de Friedland et par l'occupation des villes de Vienne, de Berlin, de Wilna et de Moscou. Il s'unit le 1er avril 1810 à l'archiduchesse Marie-Louise, fille de Francois II, empereur d'Autriche. La retraite de Russie en 1812 et la campagne de $1813 \mathrm{fu-}$ rent suivies de l'invasion de la France dans laquelle Napoléon lutta contre l'Europe coalisée. Forcé d'abdiquer le 11 avril 1814, il recut la souveraincté de lîle d'Elbe, débarqua en France le 1 er mars 1815 et reprit la couronne impériale. Vaincu à Waterloo, le 18 juin 1815, il abdiqua de nouveau et fut déporté dans l'île de Saint-Hélène, où il mourut le 5 mai 1821 dans la cinquantedeuxième année de son âge. Ses restes ont été rapportés en France le 15 décembre 1840.

\section{Louis XVIII.}

Par P. Franque, d'après Gérari. - H. 0,90。 - L. 0,72.

Né à Versailles le 17 novembre 1755, de Louis, dauphin, fils de 
Louis XV, il porta d'abord le nom de comte de Provence, puis sous le règne de Louis XVI, celui de Monsieur, frère du roi, fut grand-maître des ordres de Notre-Dame-du-Nont-Carmel et de Saint-Lazare, et colonel du régiment royal des carabiniers. Le comte de Provence, qui était sorti de France en 1791, prit le titre de roi après la mort de son neveu en 1795 et monta sur le trône en 1814, après la chute de Napoléon. A son avènement, Louis XVIII donna une charte constitutionnelle et fit la guerre d'Espagne en 1823. Il mourut au palais des Tuileries, à Paris, le 16 septembre 1824, et fut enterré à Saint-Denis.

\section{Charles $\mathbf{X}$.}

Par P. Franque, d'après M. H. Vernet. - H. 0,90. - L. 0,72.

Né à Versailles le 9 novembre $175 \%$, frère de Louis XVI et de Louis XVIII, il porta d'abord le nom de comte d'Artois; il sortit de France en 1792, prit à l'avènement de Louis XVIII, le nom de Monsieur, frère du roi, et succéda à la couronne en 1824 . Charles X ordonna en 1827 l'expédition de Morée, et en 1830 celle d'Alger. Renversé du trône par la révolution de juillet 1830, il mourut à Goritz, en Bohême le 6 novembre 1836, et fut enterré dans l'église des Franciscains de cette ville.

\section{Louis-Philippe $\boldsymbol{I}^{e r}$.}

Par M. X. DupRe, d'après M. Winterhalter. - H. 0,90. - L. 0,72.

Né à Paris le 6 octobre 1773, fils de Louis-Philippe-Joseph, duc d'Orléans, il porta d'abord le nom de duc de Valois, puis celui de duc de Chartres. Colonel propriétaire du régiment de Chartres-infanterie et de Chartres-dragons en 1785, il fut nommé chevalier de l'ordre du Saint-Esprit en 1789. Gouverneur du Poitou, colonel commandant le $14^{\mathrm{e}}$ dragons en juin 1791, commandant de la place de Valenciennes en 1791 et 1792, maréchalde-camp commandant une brigade de dragons à l'armée du Nord le 7 mai 1792, lieutenant-général le 11 septembre, il commanda la seconde ligne de l'armée de Kellermann et l'aile droite de l'armée du Nord. Sorti de France en 1793, le duc d'Orléans épousa le 25 novembre 1809, à Palerme, Marie-Amélie, princesse des Deux-Siciles, fille de Ferdinand IV, roi de Naples. Après la rentrée des Bourbons, il fut nommé en 1814 grand-croix de l'ordre de Saint-Louis et de la Légion d'Honneur, colonel-général des hussards, et, en 1815 , commandant des départements du Nord. Lieutenant-général du royaume le 31 juillet 1830 , il fut proclamé roi des Français le 9 août. Les principaux évènements militaires de son règne sont l'expédition de Lisbonne en 1831, celle de Belgique en 1832, celle de Saint-Jean d'Ulloa en 1838 et les nom- 
breux combats livrés pour l'élablissement des possessions françaises en Algérie. Renversé en $\mathbf{1 8 4 8}$ par la révolution de février, il est mort à Claremont dans le comté de Surrey en Angleterre, le 26 août 18500 .

\section{Napoléon III.}

Par M. BoulARD, d'après M. Winterhalter. - H. 0,90. - L. 0,70.

Né à Paris le 20 avril 1808; fils de Louis-Napoléon, roi de Hollande, et de Hortense-Eugénie, reine de Hollande. Empereur des Français le 2 décembre 185ั2, marié le 29 janvier 1853, à Eugénie (Marie) de Guzman.

\section{SALLE No 34 .}

Dépendance de l'appartement du grand-maître de la garde-robe sous Louis XIV, et salle des gardes du corps du dauphin sous Louis XV et sous Louis XVI.

\section{Vue du château de Versailles, du côté de l'Oran- gerie.}

Par Vander Meulen. - H. 0,95. - L. 1,27.

Les bâtiments du château et de l'Orangerie sont ceux élevés par Louis XIII et que Louis XIV fit disparaître entièrement de ce côté. A droite on distingue l'étang qui devint plus tard la pièce des Suisses, et plus loin l'église de Saint-Julien sur l'emplacement de laquelle fut élevé le Grand-Commun. (Voir n 750 .)

Sur le devant, Louis XIV à cheval à l'entrée du bois de Satory, donne des ordres à l'officier des chasses; les gardes du corps et les mousquetaires viennent à la suite du roi. Dans la plaine, des valets avec des meutes de chiens. - Gravé par Baudouins. (Calc. imp.)

\section{Vue du château de Versailles, du côté de la place d'Armes.}

Par P. D. MARTIN. - H. 1,39. - L. 1,50.

Le tableau précédent offre l'aspect du château de Versailles, tel à peu près que Louis XIII l'avait laissé; celui-ci présente le résultat des travaux accomplis par Louis XIV. La grille d'entrée, la cour des ministres, la cour royale et ses deux pavillons ornés de statues, la cour de marbre, la chapelle avec sa lanterne dorée, les deux grandes ailes, le Grand-Commun et les jardins, formaient alors un magnifique ensemble qui n'existe plus aujourd'hui qu'en partie.

Des voitures sortent du château et se dirigent du côté de l'avenue de Paris. Ia 
première, attelée de six chevaux, à la livrée du prince de Conty, arrive sur la place d'Armes; elle est escortée par les officiers et les écuyers du prince. Une seconde voiture attelée de six chevaux arrive dans Ia cour du château. Vient ensuite une troisième voiture attelée de huit chevaux; c'est celle du roi; elle est suivie et escortée par les gardes-du-corps; enfin on en aperçoit une quatrième qui porte la livrée d'Orléans, et une cinquième qui est près de l'entrée principale du château. Les gardes-suisses et les gardes-françaises rangées en bataille sur deux rangs, à droite et à gauche dans la grande cour du château, sont sous les armes et rendent les honneurs.

Ce tableau est signé $P$. D. Martin, peintre ordinaire et pensionnaire du Roy. 1722.

\section{Vue du château de Versailles, du côté des jar- dins.}

École française; $\mathrm{XvII}^{\mathrm{e}}$ siècle. - H. 1,36. - L. 1,54.

Avant la construction de la galerie des glaces en 1679 , le milieu de la façade du château de Versailles, du côté des jardins était occupé par une terrasse. Le parterre d'eau était à la même époque orné d'un grand bassin dont la forme fut changée plusieurs fois.

Ce tableau provient de l'hôtel de la princesse de Conty, aujourd'hui l'Hôtel de ville de Versailles.

\section{Vue de l'Orangerie de Versailles, et de la pièce d'eau des Suisses.}

Par Cotelle. - H. 2,00. - L. 1,40 (1).

A l'extrémité de l'esplanade du midi, est une balustrade de pierre de laquelle on découvre le jardin de l'orangerie. Il faut descendre cent quatre marches, et l'on y arrive, par deux rampes d'une magnificence qu'on ne peut que difficilement exprimer : elles ont chacune dix toises de large, et sont interrompues par deux paliers. En face de l'Orangerie, et de l'autre côté de la route, est un grand canal nommé piéce d'eau des Suisses, parce que ce sont eux qui ont travaillé à sa construction. (Piganiolde la Force et Blondel).

Sur le devant, des Amours jouent et cueillent des fleurs; d'autres dans les airs tiennent une guirlande.

\section{Vue de l'Orangerie de Versailles, prise de la pièce d'eau des Suisses.}

Par Cotelle. - H. 2,00. - L. 1,39.

Le parterre de l'Orangerie, dit Piganiol, consiste en six grands

(1) Les vingt-un tableaux peints par Cotelle, qui représentent les bosquets de Versailles tels qu'ils existaient depuis 1685 jusque vers 1690 , formaient la décoration de la galerie du grand Trianon. 
compartiments de gazon avec enroulements, et un grand bassin au milieu, doù sélève une gerbe de quarante pieds de haut; il est fermé par une balustrade sur un mur en talus qui fait l'un des côtés d'un petit canal. Les deux entrées sont ornées de deux trumeaux, dont chacun est décoré de deux colonnes d'ordre toscan et porte un groupe de figures de pierre.

Sur le derant, le peintre a représenté l'enlèrement d'Hélène, et dans les airs Apollon sur son char.

\section{Bosquets de Versailles. - Entrée du Labyrinthe.} Par Cotelle. - H. 2,00. - L. 1,41.

Le bosquet du Labrrinthe fut supprimé en 177ö lorsque Louis XVI fit entièrement replanter le pare. On le nomme Labyrinthe, dit Félibien, parce que c'est un endroit composé d'une infinité de petites allées, tellement mêlées les unes aux autres qu'il est malaisé de les suivre et de ne pas s'égarer. A chaque détour on rencontre une fontaine ornée d'un bassin de rocaille fine, où l'on a représenté au naturel une fable d'Esope, dont le sujet est marqué par une inscription en lettres d'or sur une lame de bronze peinte en noir. Ces vers sont de Benserade, et servent à expliquer la fable. Il faut remarquer qu'en entrant dans ce bosquet, qui est du dessin de Le Nostre, on trouve deux statues (1) : l'une est celle du fameux Esope, connu par ses fables et dont un grand nombre sert à orner ce bosquet : elle est de Le Gros. L'autre est celle de l'Amour tenant entre ses mains un peloton de fil : cette statue est de Baptiste Tuby.

"Le Duc est ici au milieu d'un bassin de rocaille; et un grand nombre d'oiseaux, qui remplissent un demi-dòme de treillage orné d’architecture, jettent de l'eau en abondance sur le Duc, qui s'était attiré leur indignation par son chant lugubre et par son vilain plumage. » filets.

Sur le derant des Nymphes et des Amours prennent des oiseaux dans leurs

\section{Bosquets de Versailles. - Intérieur du Laby- rinthe.}

Par Cotelte. - H. 2,00. - L. 1,40.

A l'entrée de l'allée est représentée en deux groupes la fable intitulée le Renard tt la Grue. A gauche, "le renard a le museau sur une soucoupe de vermeil doré, posée sur un rocher de rocailles, et se régale lui seul, pendant que la pauvre grue fait un

(1) Ces deux figures et celles d'un grand nombre d'animaux existent encore dans les magasins de Versailles, mais presque toutes à l'état de fragments. 
jet en l'air. " A droite, "la grue a son bec dans un vase de cristal, et mange de la bouillie, pendant que le renard qui est auprès jette de l'eau. " Dañs le fond de l'allée on aperçoit la fable qui a pour sujet le Comuat des animaux.

Sur le devant, Diane, assise et entourée de ses Nymphes, se repose de la chasse. Près d'elle sont deux vases dont les socles en marbre de Languedoc se voient encore dans le bosquet de la Reine, qui a remplacé le Labyrinthe.

\section{Bosquets de Versailles. - La Salle de Bál.}

Par Cotelle. - H. 2,00. - L. 1,39.

Le bosquet, appelé la Salle du bal, a pris son nom de l'usage auquel on l'a quelquefois fait servir pendant la belle saison. Le Nostre, à son retour d'Italie, fit ce magnifique bosquet. Au milieu (1), il y a une espèce d'arène entourée de deux fossés revêtus de marbre de Languedoc et de marbre Campan, ornés de quatre cassolettes de métal sur lesquels on met des girandoles à plusieurs bougies. Le reste de la salle est occupé par une cascade et par l'amphithéâtre, qui consiste en plusieurs rangs de siéges de gazon. Huit torchères de métal servent à mettre des girandoles quand on y veut danser la nuit. (Piganiol de la Force, édition de 1701).

Sur le devant, Armide couronne Renaud de fleurs; des amours jouent avec ses armes.

\section{Bosquets de Versailles. - La Colonnade.}

Par CoTELLE. - H. 2,00. - L. 1, 30.

Le bosquet de la colonnade fut construit sur le dessin de Mansart. " Le roi, dit Dangeau, à la date du 19 juin 1684, ordonna une colonnade de marbre avec de grosses fontaines, dans l'endroit où étaient les sources. " C'est un péristyle de forme circulaire, qui est fermé par trente-deux colonnes d'ordre ionique, dont il y en a huit de brèche violette, douze de marbre de Languedoc, et douze de marbre bleu turquin. Chaque colonne répond à un pilastre de marbre de Languedoc qui est derrière. L'un et l'autre sont couronnés d'une corniche architravée, quỉ leur sert d'entablement. Les colonnes sont communiquées les unes aux autres par des arcades en plein-cintre, qui sont ornées de leurs archivoltes, avec des masques dans leurs chefs qui représentent ou des Nymphes, ou des Aaiades, ou des Sylvains. Cet ouvrage est couronné par une corniche corinthienne, au-dessus de laquelle il y a un socle ou finiment avec des postes en bas-relief, sur lequel sont des vases de marbre blanc, terminés par des pommes de pin. Les Jeux et les Amours, sous la forme de petits enfants, sont représentés en bas-reliefs sur les tympans triangulaires des

(1) Cette décoration du milieu fut supprimée vers 1705. 
arcades. Toute cette architecture est posée dans une rigole qui reçoit l'eau qui retombe en nappe de trente-un bassins de marbre blanc posés sur des pieds, dont chacun est orné de trois consoles, et du milieu desquels s'élèvent des jets ou lances d'eau à la hauteur de seize pieds. (Piganiol de la Force.)

Sur le devant, Apollon est servi par les Nymphes. Le groupe de Girardon, reprẻsentant l'enlèvement de Proserpine, n'était pas encore posé à l'époque où ce tableau a été exécuté.

\section{Bosquets de Versailles. - Les Dômes.}

\section{Par COTELLE. - H. 2,01. - L. 1,39.}

Le bosquet des Dômes fut nommé originairement bosquet de la Renommée, parce qu'au milieu du bassin qu'il renfermait était une Renommée de métal doré, posée sur un globe de même matière, et qui lançait un jet d'eau retombant d'une hauteur considérable. (1) Ce jet d'eau retombait dans un bassin à pans arrondis dans les angles et bordé de balustrades de marbre enrichies de piédestaux, de la tablette desquels sortaient des bouillons d'eau qui se répandaient ensuite en nappe. Cette balustrade était environnée d'une autre balustrade aussi en marbre, élevée sur plusieurs gradins et séparée par une terrasse sablée. En face l'un de l'autre, et dans l'un des diamètres de ce bosquet, qui était de forme circulaire, se trouvaient placés deux pavillons de marbre ornés de bronze et couverts en dôme, qui ont donné le nom à ce bosquet. Lorsqu'on détruisit la grotte pour bâtir l'aile du Nord, le groupe de Girardon représentant Apollon servi par les Nymphes, et ceux de Marsy et de Guérin qui le complètent, primitivement exécutés pour la grotte, furent d'abord placés dans le bosquet des Dômes.

Sur le devant, des Nymphes se lavent les pieds, d'autres ornent un char de guirlandes. Dans les airs sont plusieurs figures du Zodiaque.

\section{Bosquets de Versailles. - L'Encelade.}

\section{Par Cotelle. - H. 2,00. - L. 1,40.}

Le bosquet d'Encelade est enclavé dans celui des Dômes : l'on y voit au milieu d'un bassin, ce géant accablé sous le mont Ossa et le mont Olympe. Il sort de sa bouche un jet d'eau de soixantedix-huit pieds de haut, et qui est d'une grosseur extraordinaire.

Sur le devant, le repas de Lycaon renversé, et dans les airs Jupiter lançant la foudre.

(1) Dangeau mentionne, à la date du 7 juillet 1684 , un ordre du roi pour enlever la statue de la Renommée "voulant dans cet endroit-là faire encore quelque chose de plus magnifique, $n$ 


\title{
736. Bosquets de Versailles, - L'Étoile ou Mon- tagne d'eau.
}

Par COTELLE. - H. 2,00. - L. 1,39.

La Montagne d'eau se trouvait au milieu du bosquet de l'Étoile; ce bassin fut détruit vers 1705 . C'est, dit Félibien, une espèce de salon de figure ronde, palissadé et orné, comme les allées, d'une infinité de pots de porcelaine remplis de diverses fleurs qui font un effet admirable contre les grands arbres qui leur servent de fond. Au milieu du salon est un grand bassin de fontaine où retombe l'eau, qui en jaillissant forme comme une grosse montagne. Cette eau, qui se répand du bassin par cinq endroits vis-à-vis des allées forme cinq grandes nappes qui tombent au pied du bassin.

Le peintre a reprẻsentẻ au milieu du bassin Alphée poursuivant Aréthuse, sur le devant des Nymphes de Diane effrayées, et dans les airs Diane sur soll char.

\section{Bosquets de Versailles. - Le Théâtre d'eau; vue de la scène.}

\author{
Par Cotelle. - H. 2,00. - L. 1,40.
}

Sur le devant, la toilette de Vẻnus, et dans le fond des Amours dansant sur la scène.

\section{Bosquets de Versailles. - Le Théâtre d'eau. - Vue de l'amphithéâtre.}

Par Cotelle. - H. 2,00. - L. 1,40.

Le Théâtre d'eau était situé dans la partie qui conduit du bassin du Dragon à la fontaine de Cérès, et qui s'appelle aujourd'hui le rond-vert; il fut supprimé lorsque Louis XVI fit replanter les jardins en 1775. C'était, d'après Félibien et Piganiol, un grande place presque ronde et séparée en deux parties, dont l'une, environnée de marches de gazon, formait l'amphithéâtre ou parterre, et l'autre, de trois à quatre pieds plus élevée, composait le théâtre. Des bassins, des cascades, des groupes en métal doré décoraient ces lieux, où, dit Félibien, l'eau jaillit en si grande abondance et en tant de manières différentes, qu'il est impossible d'en pouvoir comprendre les divers effets qu'en les voyant. Le 12 septembre 1671 Louis XIV donna une fête au Théâtre d'eau " ajouté depuis peu, dit la Gazette, aux autres beautés du jardin ».

Sur le devant, Vẻnus est entourée de ses Nymphes qui lui présentent des objets précieux. 


\title{
739. Vue du grand Trianon, du côté de l'avenue.
}

\author{
Par P. D. Martin. - H. 1,37. - L. 1,55.
}

Trianon, dit Piganiol, est à l'autre bout du canal de traverse, vis-à-vis la Ménagerie. Ce - petit palais est également galant et magnifique, et la structure et les ornements sont d'un goût et d'un dessin exquis. La cour est ornée en face d'un beau péristyle, soutenu par des colonnes et des pilastres en marbre. Les deux ailes du bâtiment sont terminées par deux pavillons, et sur tout l'édifice règne une balustrade, le long de laquelle sont des statues, des corbeilles, des urnes et des cassolettes.

Le régent, dans l'avenue de Trianon, donne des ordres pour l'arrivée du roi Louis $X V$, dont on aperçoit la voiture attelée de huit chevaux dans la cour du château.

\section{Vue du chấteau de Clagny.}

Par J. B. Martin. - H. 1,40.- L. 1,90.

« Le château de Clagny est tout près de Versailles, dit Piganiol, et presque dans une position pareille à celle de cette maison royale. Le roi Louis XIV le fit bâtir pour $\mathbb{M}^{\text {me }}$ de Nontespan. Il ful commencé en 1676 , et achevé en 1679 et 1680 , sur les dessins de Jules Hardouin Mansart...... L'étang' qui servoit d'abreuvoir à Versailles servoit aussi de canal aux jardins de Clagny, et contribuoit à la beauté de la vue du château, pour lequel il sembloit avoir été fait exprès. " L'étang fut comblé vers 1756 , et le château détruit peu après.

Louis XIV conduit à grandes guides une calèche attelée de quatre chevaux; il est avec la reine, le grand dauphin, la grande dauphine et une des dames de la reine qui peut être $M^{\text {me }}$ de Montespan (1), alors surintendante de la maison de Marie-Thérèse. La voiture du roi vient de passer devant le château de Clagny ; elle est escortée par des officiers de la maison et des gardes du corps. Des valets de pied, à la livrée du roi et à celle de la reine, suivent à pied; d'autres valets des écuries et des chasses conduisent des chiens en laisse. Dans le fond, la ville de Versailles, la paroisse de Notre-Dame et le château.

\section{Vue du château et dè jardins de Marly.}

Par P. D. Martin. - H. 1,37. - L. 1,55.

"Ce palais, dit Piganiol, est composé d'un pavillon isolé et de douze petits, six d'un côté et six de l'autre. Le grand est décore en dehors de peintures à fresque. Les petits pavillons sont joints les uns aux autres par des berceaux qui se terminent à deux petits pavillons de feuillages qui sont derrière le château. Le còté

(1) Matiame dèc Sévigné, dans une lettre du 12 juin 1675 , disait à sa fllle : " La " reine alla faire hier collation à Trianon.... elle prit madame de Montespan " (à Clagny) dans son carrosse, et la mena à Triamon avec elle." 
du parterre, qui est en face du grand pavillon, offre une vue trèsbelle et très-étendue. On descend de là dans un second parterre qui est orné de statues de marbre, et au milieu duquel est un beau bassin que l'on nomme la fontaine des Quatre-Gerbes. La cascade rustique descend d'une montagne fort rapide, au haut de laquelle est un grand bassin, du milieu duquel s'en élève un petit de métal doré, porté par trois tritons de même. Aux extrémités de la balustrade qui termine ces magnifiques jardins, il y avoit deux chevaux ailés de marbre blane sur losquels étoient des renommées. Ces deux groupes qui sont de Coyzevox, ont été transportés à l'entrée du jardin des Tuileries en 1719. »

Louis XV dans une voiture à six chevaux, escorté par ses officiers, précédé et suivi de ses gardes du corps, sort du château de Marly et passe devant le grand bassin.

\section{Vue du château de Saint-Hubert.}

Par P. D. Martin. - H. 0,95. - L。 1,39.

Rendez-vous de chasse du roi Louis XV. On présume que c'est le pelit château de Saint-Hubert qui était, dit Piganiol, dans le diocèse de Chartres, à cinq lieues de Versailles, entre la forêl de Rambouillet et celle de Saint-Léger. " C'est aujourd'hui, ajoute le continuateur de Piganiol, dans la Description des environs de Paris, une maison royale depuis que Sa Majesté en a fait l'acquisition et à fait bâtir un château dont la bâtisse a été commencés en 175\%6. »

Louis XV, jeune, est à cheval : près de lui on recomnaît Philippe, duc d'Orléans, précédemment régent, et alors premier ministre depuis la majorité et le sacre du roi. Les officiers de la maison sont à la suite du roi, ainsi que les gardes-du-corps.

\section{Vue du château et des jardins de Saint-Cloud.}

Par Étienne Allegrain. - H. 3,09. - L. 3,83.

« Le château de Saint-Cloud, dit Piganiol, est du dessin de Lepautre : il est situé à mi-côte d'une montagne qui s'élève depuis la rivière de la Seine. Le terrain sur lequel est cette magnifique maison et ses jardins étoit auparavant occupé par trois maisons particulières, dont Monsieur, frère du roi Louis XIV, fil l'acquisition. L'avenue de cette maison royale est pratiquée sur le penchant de cette montagne; elle est fermée à droite par les maisons du bourg et à gauche par la muraille du parc. Dans l'origine, les jardins avoient été faits d'après les dessins de Le Nostre. Ses parterres étoient d'une grande beauté, avec des boulingrins, des pièces d'eau et quantité de bosquets.

Ce tableau représente le château de Saint-Gloud, ses jardins, le bourg et le pays 
environnant, vers 1700. On aperçoit autour de la rampe du bassin du fer-à-cheval une voiture attelée de six chevaux à la livrée de la maison d'Orléans; des jardiniers sont occupés dans le parc à diflérents travaux.

\section{Vue du château de Meudon du côté de l'avenue.}

Par P. D. Martin. - H. 1,37. - L. 1,50.

Ce château, qui appartenait anciennement à la maison de Guise, fut bâti pour le cardinal de Lorraine, par Philibert de Lorme, sous le règne de Henri II ; Servien et Louvois l'augmentèrent successivement. Le roi Louis XIV, l'ayant acquis de $\mathbf{I I}^{\mathrm{me}}$ de Louvois, le donna au grand dauphin, dont il fut la résidence habituelle, et qui y mourut en 1711 .

Le duc d'Orléans, régent, arrive à cheval au château de Meudon, accompagné de ses gentilshommes et de ses officiers. Il donne des ordres à l'un de ses écuyers, qui porte la livrée de sa maison. Le régent est précédé par les garles du corps du roi.

\section{Vue du château de Madrid.}

Par P. D. Martin. - H. 0,93 - L. 1,31.

Le château de Madrid, situé au milieu du bois de Boulogne, fut une résidence royale sous les règnes de Francois Ier, Henri II, Charles IX et Henri III, Henri IV le donna à la reine Marguerite; sous les règnes suivants ce château ne fut plus qu'un rendez-vous de chasse. La démolition en fut ordonnée par Louis XVI en 1787.

Le prince de Condé, premier ministre de Louis XV après la mort du régent, chasse dans le bois de Boulogne. Le cerf vient d'être forcé : les piqueurs qui accompagnent le prince portent la livrée de la maison de Condé.

\section{Vue du château et des jardins de Fontainebleau.}

Par P. D. Martin. - H. 1,36. - L. 1,54.

Les bâtiments du château, parmi lesquels on remarque la galerie de Henri II et la chapelle de Saint-Saturnin, se développent dans leur plus grande étendue depuis la cour du Cheval-Blanc jusqu'au petit château de Sully. A gauche, l'étang avec son pavillon octogone, et plus près le parterre du Tibre.

Sur le devant, la princesse de Conty habillée en amazone, chasse avec son frère le prince de Condé; la princesse porte l'habit de chasse de la maison du roi, de couleur bleue avec des galons d'or et d'argent; la chasse passe du côté des rochers d'Avon, devant le jardin; à gauche on aperçoit une calèche attelée le quatre chevaux, et dont les domestiques portent la livrée de la maison de Conty.

Ce tableau est signé $\boldsymbol{P} . \boldsymbol{D}$. Martin, peintre Ordinaire et pensionnaire $d u$ Roy et aussi de Sa Majesté Czarienne. 1722. 


\section{Vue du château de Chambord du côté du parc.}

Par P. D. Martin. - H. 1,37. - L. 1,50.

Chambord, résidence royale sur la rive gauche du Cosson, à une lieue de la Loire et à trois lieues de Blois. Ce château fut bâti sous Francois Ier et Henri IV, sur les dessins du Primatice ; il devint le séjour favori des derniers rois de la branche des Valois. Louis XIII y tint aussi quelquefois sa cour. Louis XIV habita plusieurs fois Chambord et y fit entreprendre des travaux considérables. Donné par Louis XV au roi Stanislas, il fut possédé ensuite par le maréchal de Saxe, par le maréchal Berthier, et fut offert en 1822 au duc de Bordeaux par souscription.

Le régent, en habit de sa maison, donne des ordres à un officier des chasses; il est suivi de ses gentilshommes et accompagné des gardes-du-corps du roi; des valets de pied, à la livrée du roi, conduisent les meutes.

\section{SALLE No 35 .}

Cette pièce et les suivantes étaient affectées au service des habits et de la garderobe du roi, et au logement des garçons de sa chambre.

\section{Vue du château de Versailles prise de la cour de marbre.}

Par J. B. Maftin. - H. 2,60. - L. 1,84.

Sur le devant, la cour Royale, séparée de l'avant-cour ou cour des ministres par une grille dont l'entrée se trouvait à la place où s'élève aujourd'hui la statue équestre de Louis XIV; les groupes de Tuby et de Coyzevox, placés de chaque côté de cette première grille, ont été transportés depuis aux deux angles de la seconde cour. L'espace compris entre les deux grilles est l'avant-cour; on aperçoit, à droite et à gauche, l'extrémité des deux ailes des ministres. Plus loin la place d'Armes, encore couverte de matériaux, la grande et la petite écurie, et, au milieu, l'avenue de Paris.

A gauche, les chevaux du roi, conduits par ses piqueurs, attendent dans la cour Royale. Les gardes-françaises et les gardes-suisses, dans la cour des ministres, soint en bataille sur trois rangs, les drapeaux sur le front du premier rang, et les tambours entre la première et la deuxième ligne. Une voiture à quatre chevaux et à la livrée de Condé, entre dans cette cour.

\section{Vue de la ville et du château de Versailles, prise de la butte de Montboron.}

Par J. B. MARTiN. - H. 2,60. - L. 1,84.

Les réservoirs de la butte de Montboron furent établis en 1684 
pour recevoir les eaux des étangs et faire jouer les bassins de Versailles, de Trianon et de la Ménagerie. Cette butte est renfermée, dit Félibien, d'une clôture de muraille et cing porles y donment entrée. Au milieu de l'esplanade, il y a cinq bassins profonds de dix-huit pieds; celui du milieu est rond, les autres sont carrés; leurs angles intérieur's sont arrondis en portion de cercle et les angles extérieurs forment des pans coupés. Le chenil n'est séparé de la butte Montboron que par une allée de traverse qui borne le bas de la butte et s'étend de l'avenue de Saint-Cloud à l'avenue de Paris. De l'autre côté de l'avenue de Paris est l'hôtel de Conty, dont l'extérieur faisait symétrie arec l'hôtel du GrandVeneur. Plus loin, les écuries, la place d'Armes, le château et ses cours, l'aile du nord dont l'extrémité contre les réservoirs est encore en construction, et de l'autre côté le Grand-Commun. On distingue, à droite, la paroisse de Notre-Dame et l'étang de Clagny, et à gauche dans le fond, la pièce d'eau des Suisses.

Louis XIV, suivi des officiers de sa maison, vient de traverser la chaussée qui sépare deux des réservoirs; il est à pied, tient son chapeau sous le bras et s'appuic sur une canne.

\section{Vue du château et d'une partie de la ville de Versailles, prise des hauteurs de Satory.}

Par J. B. Martin. - H. 2,60. - L. 1,84.

Ce tableau offre à peu près la même vue que celui no 7250 , mais prise environ vingt-cinc ans plus tard. Le château et l'Orangerie de Louis XIII ont entièrement disparu. Entre la pièce d'eau des Suisses et l'Orangerie, reconstruite par Mansart, passe la route de Saint-Cyr. On distingue au-dessus de l'Orangerie le parterre de broderie, la grande aile et lavant-corps du château. A droite le Grand-Commun, plus loin la place d'Ármes, les Ecuries, la Paroisse, et dans le fond le château de Clagny.

Sur le derant des chasseurs se préparent à partir ; l'un d'eux tient un faucon sur le poing et un valet à la livrée du roi sonne du cor. Une meute de chiens passe sur la route de Saint-GJr; dans le parterre de l'Orangerie des jardiniers transportent des orangers.

\section{Vue du château et des jardins de Versailles, prise du bassin de Neptune.}

Par J. B. MARTIN. - H. 2,60. - I. 1,82.

Cette vue est prise à l'opposé de la précédente et montre le chàteau du côté de l'aile neuve dont l'extrémité, ainsi que dans le $n^{0} 749$, n'est pas encore terminée ; la chapelle ne s'y trouve pas non plus. Au-delà du bassin de Neptune ou distingue la fontaine du Dragon, l'allée d'eau ; à gauche le bosquel de l'Arc-deTriomphe, à droite celui des Trois-Fontaines, le parterre du Nord, 
le parterre d'Eau, le bassin de Latone, et dans le fond la pièce d'eau des Suisses.

Sur le devant, des cavaliers passent sur la route circulaire qui conduit à la grille de Trianon; divers personnages sont debout ou assis près du bassin de Neptune, sur lequel se trouve une gondole.

\section{Vue des jardins de Versailles prise du côté du parterre du Nord.}

Par Gabriel Allegrain. - H. 2,60. - L. 2,89.

A gauche, l'extrémité de l'aile neuve, et au-devant le parterre du Nord avec les bassins de la Couronne et de la Pyramide. Plus loin l'allée d'eau et la fontaine du Dragon ; on distingue derrière le bassin de Neptune, la statue de Curtius, par le cavalier Bernin, qui, depuis, fut transportée à l'extrémité de la pièce d'eau des Suisses.

Sur le devant, Louis XIV à pied et s'appuyant sur une canne, est précédé de ses valets de pied et accompagné de plusieurs officiers de sa maison. Un carrosse escorté de gardes-du-corps à cheval descend la rampe de l'aile neuve.

\section{Bosquets de Versailles, - L'Ile Royale.}

\section{Par J. B. Martin. - H. 2,60. - L. 1,39.}

Cette grande pièce d'eau, qu'on appelait aussi l'Ile d'Amour, avait pris son nom d'une petite île qui se trouvait au milieu el qui fut promptement supprimée ; il en sortait cinq gerbes d'eau dont la plus grande s'élevait à quarante-sept pieds. Le bosquet nommé le Jardin du Roi remplace aujourd'hui l'Ile Royale. La partie inférieure de celte pièce d'eau, qui était séparée de la grande par une allée de traverse et était en forme de vertugadin, a seule été conservée.

Sur le devant, des dames de la cour donnent à manger à des cygnes; à diroite et un peu dans l'éloignement, Louis XIV conduit une dame masquée.

\section{Bosquets de Versailles. - La Salle des festins.}

Par J. B. Martin. - H. 2,60. - L. 1,37.

Ce bosquet appelé la Salle des Festins ou du Conseil se trouvait à la place occupée depuis par la fontaine de l'Obélisque. C'était, d'après Félibien, une place d'une fort grande étendue, revêtue tout autour de gazon, et plus longue que large. "Le milieu, dit-il, est comme une île fermée d'un fossé d'eau, avec des ponts qui avancent et reculent d'une manière toute particulière. Il y a, en quatre endroits de la place qui environne l'île, quatre bassins d'eau et quatre autres aux quatre coins de l'île. De ces bassins et de plusieurs endroits des fossés il sort soixante-treize jets d'eau. ")

Sur le devant, un seigneur salue une dame accompagnée d'un cavalier plus 
loin d'autres personnages se promènent ou sont assis sur les gazons. Dans le fond, Louis XIV portant le cordon bleu, donne la main à une dame masquée, et monte les degrés de l'île.

\section{Bosquets de Versailles. - L'Obélisque.}

Par P. D. Martin. - H. 2,60. - L. 1,84.

Ce bosquet a remplacé celui désigné sous le nom de Salle des Festins ou du Conseil représenté dans le tableau précédent. "On y voit au milieu, dit Piganiol, un grand bassin, duquel sort un obélisque d'eau qui s'élève à soixante-quinze pieds de hauteur, et aux rampes qui sont aux quatre faces de ce carré long, il y a quatre cascades dont l'eau tombe dans le fossé qui règne au pourtour. " Le 24 novembre 1706 " le roi, dit Dangeau, se promena l'après dinée dans ses jardins et alla voir une parfaitement belle fontaine qui est à l'endroit où étoit la petite île qu'on appeloit la Salle du Conseil. »

Louis XIV est dans un de ces fauteuils dont parle Saint-Simon lorsqu'il dit: "Que le roi se promenoit, dans les jardins de Versailles, dans un fauteuil à roues. "Il traverse le bosquet, précédé des officiers des gardes et suivi de ses valets de pied.

\section{Vue des jardins de Trianon, prise du parterre bas.}

Par Étienne AlLEgrain. - H. 2,60. - L. 1,79.

La partie qui s'élève en amphithéâtre et se termine par un bassin rond orné de quatre figures de nymphes, fait face à la croix du grand canal et se nommait autrefois le jardin des Marronniers.

Louis XIV debout, un pied sur sa chaise roulante, parle à un personnage qui paraît être l'architecte ou l'intendant des jardins. Plus loin, des jardiniers sont occupés à leurs travaux; dans l'éloignement on distingue un prince, encore enfant, accompagné de plusieurs dames.

\section{SALLE No 36 . (Voir salle no 35 .)}

\section{Vue du bassin d'Apollon et du grand canal de Versailles.}

Par P. D. Martin. - H. 2,96. - L. 1,85.

Tuby avait exécuté, d'après les dessins de Lebrun, le groupe en plomb doré représentant Apollon sur son char tiré par quatre chevaux et environné de Tritons. A la tête du grand canal se trouvaient deux autres groupes dus aux mêmes artistes; c'étaient des Tritons montés sur des chevaux marins.

Louis XIV, assis dans une chaise roulante qu'il dirige, passe devant le bassin 
d'Apollon; il est accompagné d'une cour nombreuse, au milieu de laquelle on distingue le duc d'Orléans, lepuis régent. Le cortége qui accompagne le roi est précédé des officiers des gardes du corps : des valets de pied à la livrée du roi marchent à la suite.

\section{Bosquets de Versailles. — La salle des Antiques.}

Par J. B. MARTIN, - H. 2,96. - L. 1,38.

La salle ou galerie des Antiques était ornée de vingt-quatre statues antiques restaurées par les frères Marsy. Les ailes de cette galerie étaient formées par deux rangs de jets d'eau, deux rangs de petits arbres et deux rangs de statues. Ce bosquet fut supprimé en 1704 et remplacé par celui qui porte encore aujourd'hui le nom de salle des Marronniers.

Des personnages du temps de Louis XIV se promènent dans le bosquet; on apercoit sur le devant plusieurs brouettes à bras qui servaient à la promenade dans les jardins.

Ce tableau était placé dans la galerie du grand Trianon.

\section{Bosquets de Versailles. - Les Bains d'Apollon.} Par P. D. Martin. - H. 2,96. - L. 1,84.

Ce bosquet s'appelait d'abord le Marais ou Chêne-Vert / Voir $n^{0} 767$ ). La disposition en fut changée lorsqu'en 1705 on y plaça sous des baldaquins en plomb doré les trois groupes de la grotte qui avaient d'abord été transportés dans le bosquet des Dômes (Voir $\left.n^{0} 734\right)$. Ce bosquet subit une dernière transformation lorsque Louis XVI fit replanter les jardins (Voir no 775). Les baldaquins furent détruits et les groupes servirent à la décoration du rocher.

Louis XIV se promène à pied dans les jardins de Versailles. On reconnait près de lui le duc d'Orléans. Le roi est accompagné d'une suite nombreuse.

\section{Vue du grand Trianon, prise du côté de l'a- venue.}

Par P. D. MARTin. - H. 2,96. - L. 2,23.

Ce tableau, exécuté à la même époque que celui $\mathrm{n}^{\circ} 739$, offre l'ensemble complet des bâtiments du grand Trianon, de ses jardins et du pays environnant, jusqu'à l'extrémité du grand canal.

Louis XV à cheval sort du château et se dirige du côté de Versailles. Le roi parait âgé de quatorze à quinze ans. Il est accompagné des principaux officiers cle sa maison, du capitaine des gardes et des gardes-du-corps.

\section{Vue de la Cascade ou Buffet dans les jardins de Trianon.}

Par Étienne Allegrain. - H. 2,96. - L. 1,42.

" L'allée de la Cascade est ainsi nommée, dit Piganiol, parce 
qu'à un de ses bouts on a bâti un buffet d'architecture incrusté de marbre de Languedoc et de marbre blanc, orné de plusieurs figures de métal doré qui jettent de l'eau, laquelle en tombant dans les bassins forme des nappes fort belles. "

Louis XIV est dans sa chaise roulante; il la dirige lui-même et adresse la parole à un personnage âgé, décoré de la croix de Saint-Michel, qui paraît être Jules Hardouin Mansart. On retrouve le même personnage dans le tableau représentant le petit parterre de Trianon. (Voir $\mathbf{n}^{\circ} 756^{6}$.) Deux officiers des gardes précèdent le roi.

\section{Vue du château et des jardins de Marly.}

Par P. D. Martin. - H. 2,96. - L. 2,24.

Ce tableau offre la même vue que le nº 740 , et il a été exécuté vers la même époque.

Sur le devant, le prince de Condé (Monsieur le Duc), conduit une calèche attelée de six chevaux. Il est suivi de ses gentilshommes et de ses écuyers, qui portent les armes et la livrée de sa maison; la voiture du prince passe devant l'étang, dit aussi l'abreuvoir de Marly, et paraît se diriger du côté cle la route de Paris.

\section{Vue du château neuf de Saint-Germain-en-Laye du côté de la terrasse.}

Par Gabriel Allegrain. - H. 3,96. - L، 2,23.

Le château neuf de Saint-Germain, bâti sous Henri IV par l'arl'architecte Marchand, était remarquable par la beauté et la disposition de son plan, par ses terrasses et par son admirable situation. Ce château, presque inhabité depuis Louis XIII et laissé sans réparations, fut abattu sous Louis XVI.

Sur le devant, le prince de Condé (Monsieur le Duc), chasse le cerf; il est suivi de ses écuyers et de ses piqueurs, qui portent la livrée de sa maison. Le cerf est pris par les chiens au moment où il veut traverser la rivière; un piqueur sonne du cor.

\section{Vue du château de Vincennes du côté du parc.}

Par Gabriel ALlEgrain. - H. 2,96. - L. 2,23.

L'origine du château de Vincennes est inconnue. On sait que Louis VII y fonda en 1461 un couvent de religieux. Après saint Louis, les rois jusqu'à Louis XI continuèrent à y habiter et à embellir Vincennes. Le donjon est l'ouvrage du roi Charles V, la chapelle fut fondée par Henri II ; on y tenait le chapitre des chevaliers de Saint-Michel. Louis XIII augmenta le châtean et fit construire la galerie qui existe encore aujourd'hui. Anne d'Autriche, régente de France, s'y retira avec ses enfants pendant 
quelque temps et y ordonna aussi des travaux. Louis XV habita Versailles en $\mathbf{1 7 1 5}$ par ordre de son aïeul.

Après la porte qui donne entrée sur le parc et les galeries qui s'unissent aux deux ailes, se trouve la cour Royale et dans le fond la chapelle fondée par Charles V. A gauche et sur un plan plus éloigné, la tour du donjon.

Le prince de Condé (Monsieur le Duc), chasse dans la forêt de Vincennes; il est en habit de chasse à la livrée de sa maison; on aperçoit'sa voiture près des fossés du château.

\section{SALLE No 37. (Voir salle $n^{\circ} 35$. )}

\section{Vue du château et des jardins de Versailles, prise de l'avenue de Paris.}

École française; xvII siècle. - H. 1,15. - L. 1,61.

Les premiers travaux ordonnés à Versailles par Louis XIV firent ensuite place à de plus vastes projets. Ce tableau offre l'aspect du château tel qu'il existait vers 1664. On voit à droite la grotte et les réservoirs remplacés depuis par la chapelle' et l'aile neuve; à gauche l'orangerie de Louis XIII et l'église de Saint-Julien. Dans les jardins on reconnaît l'allée d'eau, la fontaine de la Pyramide et celie de la Syrène.

I.ouis XIV, dans une voiture attelée de six chevaux se rend à Versailles; la voiture de la reine suit immédiatement celle du roi; elles sont escortées par les officiers de la maison, les gardes du corps et les mousquetaires. La musique marche en tête; elle est déjà arrivée dans la première cour du château.

\section{Jardins de Versailles. - Le Parterre d'Eau.} Par Cotelle. - H. 2,01. - L. 0,97 .

En face de l'avant-corps se trouve une grande terrasse ornće de deux grands bassins bordés d'une tablette de marbre blanc entourée de gazons. Les tablettes sont ornées chacune de huit groupes de bronze représentant des fleuves, des rivières el des fontaines.

Sur le devant, des prêtresses couronnées de fleurs oflrent un sacrifice; dans les airs, Jupiter et Junon, assis sur des nuages, sont environnés des dieux de !'Oly'mpe.

\section{Bosquets de Versailles. - Le Marais.}

\section{Par Cotelle. - H. 2,01. - L. ^, 39.}

Le Marais ou Chêne-Vert, était un grand bassin carré au milieu duquel se trouvait un chêne artificiel d'où sortaient de nombreux jets d'eau; quatre cygnes dorés en ornaient les quatre coins. Aux deux extrémités de ces bassins étaient placées deux grandes tables ovales en marbre, sur chacune desquelles étaient une corbeille de bronze doré remplie de fleurs, et d'où jaillissait un 
jet d'eau qui se perdait sans mouiller la table. Des buffets de marbre garnis de vases dorés décoraient les deux autres côtés. La disposition de ce bosquet fut changée lorsqu'on y transporta les trois groupes de la grotte (Voir n ${ }^{\circ} 759$.)

Sur le devant, des Nymphes et des Amours se reposent ou se livrent à divers jeux; dans les airs, des Amours suspendent des guirlandes aux arbres.

\section{Bosquets de Versailles. - Les Trois-Fontaines.} Par Cotelle. - H. 2,01. - L. 1,39.

Le bosquet des Trois-Fontaines, ainsi nommé parce que trois bassins de formes variées s'y trouvaient distribués dans sa longueur, était du dessin de Le Nôtre et sans ornement; il était seulement entouré de charmilles et de gradins de verdure; l'inégalité du sol était rachetée par des glacis en pierre. Il ne reste aujourd'hui que l'emplacement de ce bosquet, remarquable autrefois par la beauté et la variété de ses effets d'eaux.

Sur le devant, des Nymphes tressent des guirlandes; plus bin des Amours se livrent à divers jeux.

\section{Bosquets de Versailles. - Les Trois-Fontaines.}

Par Coteldz. - H. 2,01. - L. 1,39.

Cette vue, ainsi que la précédente, est prise du côté du bassin du Dragon. Au fond de celle-ci on aperçoit l'aile du nord ou aile neuve et l'avant-corps du château.

Des Amours se livrent aux travaux du jardinage.

\section{Jardins de Versailles. - Bassin du Dragon.}

Par Cotelle. - H. 2,01. - L. 1,39.

Le milieu de ce bassin était orné de diverses figures en plomb doré représentant un dragon qui lançait de l'eau, entouré de dauphins et de cygnes portant de petits amours. Ces figures n'existent plus. on aperçoit dans le fond le grand Trianon.

Sur le devant, Apollon sur son char perce un dragon de ses flèches; dans les airs, Jupiter au milieu de l'Olympe.

\section{Jardins de Versailles. - Bassin de Neptune.}

par Corelle. - H. 2,01. - L. 1,39.

La pièce d'eau de Neptune est bordée par une tablette ornée de vingt-deux vases en plomb doré, d'où s'élèvent des jets d'eau qui retombent dans un chéneau qui borde cette tablette; plus loin, se trouve le bassin du Dragon et l'allée d'eau. On distingue dans le fond l'allée d'eau, l'avant-corps dı château, et à gauche les réservoirs et l'aile neuve.

Le peintre a représenté sur le premier plan le Jugement de Pâris, et dans les airs Mercure apportant un message à Jupiter. 


\title{
772. Bosquets de Versailles. - L'Arc-de-Triomphe.
}

\author{
Par Cotelle. - II. 2,01. - L. 1,39.
}

Ce bosquet s'appelait d'abord la Fontaine du Pavillon ou le Pavillon d'eau; quatre jets d'eau sortant de la gueule de quatre dauphins de bronze et se joignant au milieu y formaient une sorte de pavillon. La disposition de ce bosquet fut ensuite changée par Le Nôtre. La vue est prise du côté du bassin du Dragon. Dans le fond se trouve le monument qui avait donné un nouveau nom à ce bosquet : c'était un frontispice composé de trois portiques en fer doré et orné d'une grande quantité de jets d'eau. De chaque côté étaient des buffets dorés composés de huit gradins, accompagnés d'obélisques triangulaires percés à jour et au travers desquels on apercevait des jets d'eau. Au devant étaient des goulottes ou petits canaux en marbre blane dont les gradins formaient de petites cascades.

Sur le premier plan, Apollon est sur un char précédé de nymphes et d'Amours qui portent les attributs de la chasse; dans les airs, Vénus, les Grâces et les Amours.

\section{Bosquets de Versailles. - L'Arc-de-Triomphe.}

Par Cotelle. - H. 1,40. - L. 1,75.

La vue est prise à l'opposé de la précédente, du côté du parterre du Nord. On distingue dans le fond un groupe de plomb doré, représentant la France assise sur un char et deux figures d'esclaves. Ce groupe, exécuté par Tuby et Coyzevox, subsiste seul dans l'emplacement de ce bosquet. Deux autres groupes en plomb doré décoraient les fontaines de la Victoire et de la Gloire.

Sur le devant, des guerriers sont environnẻs de Nymphes qui s'occupent à les désarmer; dans les airs Mars et Véuus sont sur des nuages.

\section{Jardins de Versailles. - Entrée du Tapis- Vert.}

Par Hubert RoberT. - H. 1,24. - L. 1,91.

Les jardins de Versailles, dont les parties les plus anciennes remontaient au temps de Louis XIII, furent entièrement rasés dans la première année du règne de Louis XVI, et replantés sous les ordres du comte d'Angiviller, par Lemoine, jardinier du parc et de l'Orangerie. La vente des bois de haute futaie, de ligne, de décoration et taillis en massif des jardins de Versailles et de Trianon eut lieu le 15 décembre 1774 à l'hôtel de la Surintendance. Les adjudicataires devaient commencer leur exploitation dans la huitaine et la suivre sans interruption, de manière qu'à 
la fin de mai 1775 les terrains exploités fussent entièrement vides et en état de recevoir les ouvriers chargés de la replantation. Des dispositions furent prises pour préserver les objets d'art et les conduites d'eau. La nouvelle plantation, en conservant les dispositions générales de Le Nôtre, fit disparaître les bosquets du Labyrinthe et du Théâtre d'Eau.

Sur le devant, à gauche, le groupe de Castor et Pollux, par Coyzerox, que l'artiste a placé sur un piédestal ruiné; et plus loin, le viilon du Puget transporté depuis au Musée du Louvre. On distingue, à droite du Tapis-Vert le bosquet des Dômes, à gauche, celui de la Colonnade, et dans le fond le grand canal.

Ce tableau a été exposé au Salon de 1777.

\section{Bosquets de Versailles. - Les Bains d'Apollon.}

Par Hubert RoberT. - H. 1,24. - L. 1,91.

Lors de la replantation du pare en $177 \%$, le bosquet des Bains d'Apollon, fut changé de forme. Les groupes de Girardon, de Guérin et de Marsy servirent à la décoration d'un rocher élevé sur les dessins d'Hubert Robert.

Le peintre a représenté ce bosquet au moment de l'abattage des arbres. Un des groupes de chevaux est déposé à droite; plus loin la rampe du parterre du Nord, et au fond l'avant corps dù château.

Ce tableau a été exposé au Salon de 1777.

\section{Vue du grand Trianon, prise du côté des jar- dins. (Voir $\mathrm{n}^{\circ}$ 728.)}

Par Cotelle. - H. 2,01. - L. 1,39.

Sur le devant, Flore endormie est entourée de Nymphes et d'Amours ; Zéphyre voltige dans les airs.

\section{Jardins de Trianon. - Le Plafond.}

Par Cotelle. $\rightarrow$ H. 2,01. - L. 1,40.

Ainsi que les bosquets de Versailles, ceux de Trianon ont dû changer plusieurs fois de forme; on croit reconnaître ici le bassin dit le Plafond, qui se trouve à l'extrémité de l'allée de la terrasse, et d'où l'on découvre la colonnade du château.

Sur le devant, Mars et Vénus sont assis sur un lit de repos; dans les airs Vrulcain et Apollon.

778. Vue de la Machine et de l'aqueduc de Marly. Par P. D. Martin. - H. 1,15. - L. 1,61.

La machine était composée de quatorze roues, sept sur le devant et autant sur le derrière. Ces quatorze roues, auxquelles l'eau de la rivière donnait le mouvement, faisaient agir soixante- 
quatre corps de pompes sur la rivière, soixante-dix-neuf à micôte, et quatre-vingt-deux au puisard supérieur. Ces deux centvingt-cing corps de pompes faisaient monter les eaux sur une tour d'où elles étaient conduites par un aqueduc jusqu'aux réservoirs de Marly.

\section{Vue de Paris, prise de l’île de la Cité. - Vers 1556.}

École française; XvI e siècle. - H. 0,89. - L. 1,3

Cette peinture offre la disposition d'un pont qui devait être bâti sur l'emplacement où se trouve aujourd'hui le Pont-Neuf et dont les habitants du faubourg Saint-Germain et de l'Université avaient demandé l'établissement en 15̋ว56. Au-delà de ce pont projeté se trouve le palais de la Cité, dont les jardins s'étendaient jusqu'à l'extrémité de l'île et étaient environnés de murailles crénelées. On distingue la Sainte-Chapelle avec sa flèche, les tours de NotreDame et le pont aux Meuniers.

M. Bonnardot a décrit ce tableau dans son Iconographie du vieux $\mathbb{P}^{2}$ aris tome III, page 204 et suiv. de la Revue universelle des Arts. - 1856, in-80.

\section{Vue de Paris, prise du Pont-Neuf, vers 1635.}

Ěcole française; XvII siècle. - H. 1,15. - L. 2,06.

Au milieu du pont la statue équestre de Henri IV dont la tigure était de Dupré et le cheval de Jean de Bologne. Dans l'angle à droite, le premier bâtiment de la Samaritaine, monumenl hydraulique construit en même temps que le Pont-Neuf. La facade du Louvre du côté de la rivière est celle qui faisait partie du projet de Pierre Lescot; plus loin la galerie d'Apollon, la grande Galerie, la porte Neuve et la tour qui lui servait de défense. A gauche, l'hôtel de Nevers, bâti sur une partie du terrain de l'hôtel de Nesle, et plus loin la porte et la tour de Nesle; au fond, le pont Barbier.

Des soldats et des personnages de l'époque traversent le Nont-Neuf, sur lequel on voit des échoppes de marchands. M. Bonnardot a décrit ce tableau dans son Iconographie du vieux Paris, tome III, page 301 et suiv. de la Revue universelle des Arts.

\section{Vue de la tour de Nesle, à Paris. - Vers 1650.} École française; XVII sičcle. - H. 0,58. - L. 0,80.

La tour et la porte de Nesle élaient situées sur la rive gauche de la Seine, vers le point où sélève le pavillon oriental du palais de l'Institut ou collége Mazarin. La tour et la porte de Nesle existaient encore dans les premières années du règne de Louis XIV. 
782. Vue de Paris, prise du Pont-Neuf.-Vers 1666. École française; xvII siècle. - H. 0,89. - L. 1,31.

La façade du Louvre du côté de la rivière est celle construite par Levau; plus loin la galerie d'Apollon et la grande galerie à l'extrémité de laquelle se trouvait encore la Porte-Neuve. A gauche l'hôtel Guénégaud et les deux pavillons du collége Mazarin. Dans le fond, le pont Barbier ou Pont-Rouge qui fut remplacé par le pont Royal en 168 ö.

Des personnages du temps traversent le Pont-Neuf, sur lequel sont établis des marchands ambulants dans leurs échoppes : au milieu est une voiture attelée de six chevaux blancs. M. Bonnardot a décrit ce tableau dans son Iconographie du vieux Paris, tome III, page 312 et suivantes, de la Revue universelle des Arts.

\section{Vue de la place Royale, à Paris. - Vers 1680.}

Par J. PARROCEL.-H. 1,98. - L. 2,65.

Cette place, régulièrement carrée, fut construite sous le règne de Henri IV; le pavillon qui fait face à la rue Royale se nommait le Pavillon du Roi, et celui en face de la chaussée des Minimes le Pavillon de la Reine. Au milieu d'un préau carré se trouvait la statue équestre de Louis XIII ; la figure du roi était de Biard le fils, et le cheval, de Daniel de Volterre.

Le cortége d'un ambassadeur fait le tour de la place et va sortir par le pavillon du Roi : les voitures, attelées de huit chevaux, sont eonduites par des laquais à la livrée du roi.

\section{Vue de Paris, prise du Pont-Royal. - Vers 1778.}

Par DE MAGHY. - H. 0,48, - L. 0,76.

Le port Saint-Nicolas est au bas de la grande galerie du Louvre; il règne depuis le Pont-Royal jusqu'au Pont-Neuf. Au-delà on aperçoit le Pont-au-Change, qui allait alors jusquà la tour de l'Horloge du Palais ; il est encore couvert de maisons. Au commencement du Pont-Neuf on reconnaît la Samaritaine, et plus loin la place Dauphine; à droite le dòme et l'une des ailes du collége Nazarin.

\section{Vue de Paris, prise du Pont-Neuf. - 1783.}

Par DE MACHY, - H. 0,89. L. 1,32.

A droite la colonnade du Louvre, le jardin de l'Infante, la galerie d'Apollon et la grande galerie. A gauche l'hôtel des Monnaies élevé sur l'emplacemant de l'hôtel de Conty. Dans le fond le Pont-Royal. 
786. Vue du pont Notre-Dame, à Paris. - Vers 1788. Par Hubert RoBert. - H. 1,15. - L. 1,61.

Avant la démolition des maisons du pont Notre-Dame, l'entrée de la Pompe était décorée d'une porte d'ordre ionique construite par Bullet.

On distingue sous le pont la pompe Notre-Dame; plus loin le Pont-au-change encore couvert de maisons, et dans le fond le Pont-Neuf.

787. Vue du Pont-au-Change et de la tour de l'Horloge, à Paris. - 1788.

Par Hubert Robert. - H. 1,15. - L. 1,61.

En 1788, Louis XVI, par son édit d'emprunt de trente millions. affecta la somme de $1,200,000$ livres à l'acquisition et démolition des maisons dont le Pont-au-Change était en grande partie couvert; elles furent démolies. Lorsqu'on renversa ces maisors, on débarrassa aussi le Palais, du côté du quai des Morfondus, de quelques-unes des maisons qui obstruaient sa façade.

Des ouvriers sont occupés à démolir les maisons du Pont-au-Change; dans le fond, à droite, la tour de l'Horloge du Palais et la flèche de la SainteChapelle.

788. Vue de Paris, prise du Pont-Royal. - 1834.

Par M. GaGNeRY. - H. 0,79. - L. 1,15.

A gauche, l'extrémité de la galerie du Louvre et la galerie d'Apollon ; à droite, le palais de l'Institut, et, au-delà du Pont-des-Arts, le terre-plein du Pont-Neuf avec la place Dauphine.

\section{VESTIBULES DE L'ESCALIER DE MARBRE, No 38.}

\section{FREMIÈRE PARTIE.}

Logement du premier valet de garde-robe sous Louis XIV.

\section{Louis $X I V$. (Voir $\mathrm{n}^{\circ}$ 717.)}

Par Coyzevox; buste en marbre. - H, 0,93.

Le roi est vêtu à la romaine; un manteau recouvre sa cuirasse, strr laquelle est une fleur de lis accompagnée de deux griffons.

790. Colbert (Jean-Baptiste), contrôleur général des finances. (Voir $\mathrm{n}^{\circ} 225$.)

Par Coyzevox; buste en plâtre. - H. 0,71. 
791. Bernini (Giovanni-Lorenzo), dit le Cavalier Bernin, sculpteur, peintre et architecte.

(Voir $\left.\mathrm{n}^{\circ} 640.\right)$

Buste en plâtre. - H. 0,57.

792. Cassini (Jean-Dominique), astronome.

Par M. Husson, d'après Caffieri; buste en marbre. - H. 0,58.

Né à Perinaldo, dans le comté de Nice, le 8 juin 1625 , il fit ses études au collége des jésuites à Gênes, fut nommé en 165\%, par le sénat de Bologne pour remplir la première chaire d'astronomie après la mort du P. Cavalieri, et devint ensuite, sous le pontificat d'Alexandre VII, surintendant des eaux de l'état ecclésiastique. Appelé en France en 1669, et reçu à l'Académie des Sciences, il prit en 1673 des lettres de naturalisation. Il mourut à l'Observatoire de Paris le 14 septembre 1712. - Cassini découvrit plusieurs des satellites de Jupiter et de Saturne, détermina la rotation de Jupiter, de Mars et de Vénus, publia, de 1668 à 1693, des $\boldsymbol{E}^{\prime} p h \dot{e}-$ mérides des satellites de Jupiter, et travailla à la mesure du méridien de Paris. Il avait perdu la vue dans ses dernières années.

Le buste original est à la Bibliothèque de Sainte-Geneviève.

\section{Le Nôtre (André), architecte:}

Par M. GourdeL, d'après Coyzevox; buste en marbre. - H. 0,67.

Né à Paris en 1613, il étudia la peinture à l'école de Simon Vouet. Devenu contrôleur des bâtiments et dessinateur des jardins du roi, il ordonna les travaux des jardins de Vaux, de Versailles, de Clagny, de Chantilly, de Saint-Cloud, de Meudon, de Sceaux, des Tuileries et de Fontainebleau. Louis XIV lui donna des lettres de noblesse en 1675 et le nomma chevalier de l'ordre de Saint-Michel. Le Nôtre fit un voyage à Rome en 1678, et mourut à Paris le 13 septembre 1700 .

Le buste original décore le tombeau de Le Nôtre, dans l'église de Saint-Roch, à Paris.

\section{La Quintinie (Jean de), directeur général des jardins fruitiers et potagers du roi.}

Par M. Woltreak; buste en plâtre. - H. 0,71.

Né en 1626 à Chabanais (Angoumois), il fut d'abord avocat et voyagea en Italie, où il étudia les diverses méthodes d'agriculture et de jardinage. De retour en France, il fut appelé par Louis XIV pour diriger les jardins de Versailles. Il mourut à Versailles le 11 novembre 1688, laissant un ouvrage ayant pour titre: Instruc- 
VESTIBULES DE L'ESCALIER DE MARBRE, N॰ 38.

tion pour les jardins fruitiers et potagers, qui le place au premier rang parmi les agronomes.

\section{Lebrun (Charles), premier peintre du roi.}

Par M. Bosio neveu, d'après Coyzevox; buste en marbre. - H. 0,66.

Né à Paris le 22 mars 1619, il entra à l'âge de onze ans dans l'atelier de Simon Vouet, et fit, par la protection du chancelier Séguier, le voyage d'Italie en 1642 . De retour en France, Lebrun contribua à la fondation de l'Académie de Peinture en 1648. Il reçut en 1662 des lettres de noblesse, fut nommé premier peintre du roi et chevalier de l'ordre de Saint-Michel ; directeur de la manufacture des Gobelins, Lebrun dirigea les travaux de peinture qui s'exécutèrent dans les maisons royales, et suivit Louis XIV dans les campagnes de 1667 et $\mathbf{1 6 7 2}$. Nommé recteur de l'Académie de France en 1683, il fut aussi prince de l'Académie de Saint-Luc à Rome, et mourut aux Gobelins le 12 février 1690.

Le buste original est au Musée du Louvre.

\section{Coyzevox (Antoine), sculpteur.}

Par M. Bosio neveu, d'après Coyzevox ; buste en marbre. - H. 0,68.

Né à Lyon en 1640, sa famille était d'origine espagnole. Il vint à Paris, fut élève de Lerambert et concourut à l'exécution des grands travaux de sculpture de Versailles, de Trianon et de Marly. Reçu de l'Académie royale en 1676, il fut professeur en 1677, recteur en 1694 et directeur et 1702. Coyzevox mourut le 10 octobre 1720, à l'âge de quatre-vingts ans.

Le buste original est au Musée du Louvre.

797. Félibien (André), historiographe des bâtiments du roi. (Voir no 227.)

Buste en plâtre. - H. 0,74.

\section{Mansart (Jules Hardouin), architecte.}

(Voir $\mathrm{n}^{\circ}$ 226.)

Par LEMOINE; buste en plâtre. - H. 0,78.

799. Cotte (Robert de), architecte.

Par Coyzevox; buste en plâtre. - H. 0,55.

Né à Paris le 14 janvier 165\%7, il fut èlève de J. H. Mansart. Nommé architecte ordinaire du roi et directeur de l'Académie royale d'Architecture en 1699, il fut peu après vice-protecteur de l'Académie de Peinture et de Sculpture, et devint, après la mort de Mansart en 1708, premier architecte du roi, intendant et or- 
donnateur général des bâtiments, jardins, arts et manufactures royales. Il mourut à Passy le 15 juillet 1735. - Il conduisit les travaux du péristyle de Trianon, de l'église des Invalides et de la chapelle de Versailles, et fit exécuter le portail de l'église de SaintRoch à Paris. C'est sur ses dessins et sous sa conduite qu'ont été bâtis le château de Popelsdorf pour l'électeur de Cologne, le palais de l'électeur de Bavière, le château de Wurtzbourg et le palais dı comte de Hanau.

On lit sur le socle de ce buste:

ROBERTUS DE COTTE EQU. ORD. S. M.

REG. A CONS : PRIM. ARGH. , ET PRAF.

REG. XED. HORT. ART. ET MANUF. OPER : REG.

ACAD. ARCHITEGT. MODERAT : PIGTOR ET SGULPT.

ACAD. VICPROT : D. D. GATH. BODIN. EJUS VID. 1738.

\section{DEUXIÈME PARTJE.}

800. Rotrou (Jean de), poète dramatique.

Par M. Maindron, d'après Caffieri; buste en marbre. - H. 0,72.

Né à Dreux le 21 août 1609 d'une famille noble de Normandie, il fut lieutenant civil et commissaire examinateur au comté et bailliage de Dreux et attaché au cabinet particulier du cardinal de Richelieu. Rotrou, qui avait commencé dès l'âge de dix-neuf ans à écrire pour la scène, a laissé plus de trente pièces de théâtre, parmi lesquelles on cite Venceslas et Cosroès. Appelé par les devoirs de sa charge dans sa ville natale où régnait une maladie épidémique, il s'empressa de quitter Paris, et mourut trois jours après son arrivée à Dreux, le 27 juin 1650.

Le buste original est dans le foyer de la Comédie-Française, à Paris.

\section{Corneille (Pierre), poète tragique.}

Par Matte, d'après Caffieri; buste en marbre.- H. 0,70.

Né à Rouen le 6 juin 1606, il fut destiné au barreau par son père, avocat général à la table de marbre de Normandie, et abandonna cette carrière pour suivre celle du théâtre. Il débuta en 1629 par la comédie de Mélite, donna le Cid en 1636, les Horaces et Cinna en 1639, Polyeucte en 1640 et Rodogune en 1646. Il mourut à Paris le $1^{\text {er }}$ octobre 1684 .

Le buste original est dans le foyer de la Comédie-Française, à Paris.

\section{Santeul (Jean-Baptiste de), poète latin mo- derne.}

Par M. Jouffroy; buste en marbre. - H. 0,63.

Né à Paris le 12 mai 1630, il étudia dans les colléges de Sainte- 
VESTIBULES DE L'ESCALIER DE MARBRe, No 38 .

Barbe et de Louis-le-Grand, et prit l'habit de chanoine récrulier à l'abbaye de Saint-Victor. Il composa des hymnes pour le nissel de Paris, fit plusieurs pièces de vers latins sur les événements du règne de Louis XIV, et rédigea les inscriptions des fontaines de Paris. Santeul mourut à Dijon le 5 août 1697 .

Le buste original est à la Bibliothèque de Sainte-Geneviève, à Paris.

\section{Molière (Jean-Baptiste Poquelin dit), poète comique. (Voir n ${ }^{\circ} 228$.)}

Par M. LEQUIEN, d'après Houdon; buste en marbre. - H. 0,68.

804. Racine (Jean), poète tragique. (Voir no 229.$)$

par M. MatTE, d'après Boizot ; buste en marbre. - H. 0,68.

805. La Fontaine (Jean de), poète et fabuliste.

(Voir no 230.)

Par M. Ramus, d'après Deseine; buste en marbre. - H. 0,61.

\section{Boileau Despréaux (Nicolas), poète satirique.}

Par M. Liotard de Lambesc, d'après Girardon; buste en marbre. II. 0,75 .

Né à Crosnes près de Villeneuve-Saint-Georges, le $1^{\mathrm{er}}$ novembre 1636 , il fut destiné au barreau, étudia le droit puis la théologie, et se consacra ensuite à la poésie. Il débuta par ses Satires en 1666, publia ensuite ses Epitres et enfin l'Art Poétique et le Lutrin. Nommé en 1677, avec Racine, historiographe du roi, il fut en 1684 membre de l'Académie Française, et mourut à Paris le 13 mars 1711.

Le buste original est au Nusée du Louvre.

\section{Corneille (Thomas), poète dramatique.}

Par M. Chenillion, d'après Caffieri; buste en marbre. - H. 0,71.

Frère puîné de Pierre Corneille. Né à Rouen le 20 août 162 , il fit ses études au collége des Jésuites de Rouen, et se rendit vers 164 auprès de son frère à Paris. Son premier ouvrage, les Engagements du Hasard, fut joué en 1647 à l'hôtel de Bourgogne; il donna ensuite un grand nombre de tragédies et de comédies, fit une traduction des Métamorphoses d'Ovide, et composa plusienrs livres d'érudition. Membre de l'Académie Française en 1684, il fut admis à l'Académie des Inscriptions et Belles-Lettres dans les dernières années de sa vie, et mourut aux Andelys le 8 décembre 1709, à quatre-vingt-quatre ans.

Le buste original est dans le foyer de la Comédlie-Française, à Paris. 


\section{TROISIÈME PARTIE.}

Ancien corps de garde des Cent-Suisses.

808. Quinault (Philippe), poète lyrique. (Voir n 231.)

Par M. GAILLOUET, d'après Caffieri; buste en marbre. - H. 0,66.

809. Regnard (Jean-François), poète comique.

Par M. MaIndron, d'après Foucou; buste en marbre. - H. 0,72.

Né à Paris le 8 février 165̋, il entreprit, à l'âge de vingt-trois ans, un voyage en Italie, à la suite duquel il fut fait prisonnier par les corsaires barbaresques et vendu à Constantinople, où il passa deux années. Sorti d'esclavage, il voyagea pendant quelque temps en Europe et acheta, vers 1684, une charge de trésorier de France au bureau des Finances, à Paris. Il commenca à travailler pour le théâtre Italien de 1688 jusqu'en 169' qu'il fit représenter ses ouvrages sur le théâtre de la Comédie-Française. Il mourut à Grillon, près Dourdan, le 5้ septembre 1709.

Le buste original est dans le foyer de la Comédie-Française, à Paris.

\section{Dufresny (Charles Rivière), auteur comique.}

Par A. PAJou; buste en plâtre. - H. 0,68.

Né à Paris en 1648, il fut d'abord valet-de-chambre du roi et contrôleur de ses jardins. Il travailla ensuite pour les théâtres Italien et Francais, d'abord en societé avec Regnard, puis seul,

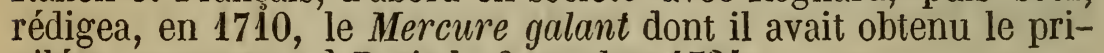
vilége, et mourut à Paris le 6 octobre 1724 .

Le buste original est dans le foyer de la Comédie-Française, à Paris.

\section{Dancourt (Florent Carton), poète comique.}

Par Foucou; buste en plâtre. - H. $\mathbf{0 , 7 5}$.

Né à Fontainebleau le $\mathbb{1}^{\mathrm{er}}$ novembre $\mathbf{1 6 6 1}$, il fit ses études au collége des Jésuites, à Paris, et fut reçu avocat vers 1678. Marié en 1680 à la fille du comédien La Thorillère, il se fit recevoir dans la troupe du roi où il fut à la fois acteur et auteur. Après avoir composé un grand nombre de comédies, il se retira, en 1718, à Courcelle-le-Roy en Berry, et y mourut le 6 octobre 1725.

Le buste original eśt dans le foyer de la Comédie-Française, à Paris.

812. Rousseau (Jean-Baptiste), poète lyrique. (Voir $\mathrm{n}^{\circ}$ 636.) Par M. FAROCHON, d'après Caffieri; buste en marbre. - H. 0,80. 


\section{Crébillon (Prosper Jolyot de), poète tragique.}

Par M. Pigalle, d'après d'Huez; buste en marbre. - H. 0,80.

Né à Dijon le 1 er février 1674, il fit ses études chez les Jésuites de cette ville et fut reçu avocat au parlement de Dijon. Placé à Paris chez un procureur, il quitta la carrière du barreau pour se livrer à l'art dramatique, et donna successivement : Idoménée (1705̆), Atrée (1707), Electre (1709), Rhadamiste (1711). Reç à l'Académie en 1731, il fit jouer Catilina en 1749 et mourut à Paris le 17 juin 1762, à quatre-vingt-huit ans.

- Le buste original est dans le foyer de la Comédie-Française, à Paris.

\section{Destouches (Philippe Néricault), poète comique.}

Par BERRUER; buste en plâtre. - H. 0,70.

Né à Tours en 1680, il s'engagea comme volontaire à l'àge de vingt ans et se trouva au siége de Landau et à la bataille de Friedlingen. Protégé par le comte de Puysieux, ambassadeur à Soleure, il suivit la carrière diplomatique tout en travaillant pour le théâtre. Son premier ouvrage, le Curieux impertinent, fut représenté en Suisse en 1709 et en France en 1710. Destouches, chargé en 1719 d'une mission en Angleterre, y resta jusqu'en 1723, fut reçu à son retour membre de l'Académie Francaise, et donna successivement : le Philosophe marié (1727), le Glorieux (1732), le Dissipateur (1736). Dans les dernières années de sa vie, il abandonna l'art dramatique pour l'étude de la théologie, et mourut à Paris le 4 juillet 1754 .

Le buste original est dans le foyer de la Comédie-Française, à Paris .

\section{Piron (Alexis), poète comique.}

Par M. Pigalle, d'après Caffieri; buste en marbre. - H. 0,71.

Fils d'Aimé Piron, apothicaire de Dijon, qui eut le rang d'éche. vin et composa des poésies bourguignonnes et latines, Alexis Piron, naquit à Dijon le 9 juillet 1689. Il fit son droit à Besancon, fut reçu avocat et vint à Paris vers 1719. Il fit représenter la tragédie de Gustave Wasa (1733) et la Métromanie (1738). Outre ses pièces de théâtre, Piron a laissé des odes, des poèmes, des contes, des épîtres, des satires et des épigrammes. Il mourut à Paris le 21 janvier 1773, dans la quatre-vingt-quatrième année de son âge.

Le buste original est dans le foyer de la Comédie-Française, à Paris. 


\section{Rameau (Jean-Jacques), musicien et composi- teur.}

Par M. Hugcesin, d'après Caffieri ; buste en marbre. - H. 0,63.

Né à Dijon le 20̈ octobre 1683, son père lui donna les premiers principes de son art. A l'âge de dix-huit ans il se rendit à Milan où il composa plusieurs ouvrages, fut ensuite organiste de l'église de Saint-Etienne à Lille, puis de celle de Notre-Dame à Clermont en Auvergne. Voltaire lui confia en $\mathbf{1 7 2 2}$ le poème de Samson et il obtint son premier succès à l'âge de cinquante ans avec l'opéra d'Hippolyte représenté en 1733 à l'Académie royale de musique. Nommé compositeur du cabinet du roi, il reçut le cordon de SaintNichel et des lettres de noblesse, et mourut à Paris le 12 septembre 1764 à quatre-vingt-un ans. - Rameau a fait faire de très-grands progrès à l'art musical et publia en 1722 un Traité d'karmonie qui créa la science de l'harmonie.

Le buste original est placé à la bibliothèque Sainte-Geneviève, à Paris.

\section{QUATRIÈME PARTIE..}

Le pilier vis-à-vis de l'escalier est orné d'un bas-relief en marbre par M. PEIITOT, représentant Louis $\mathbf{X I V}$ couronné par la Victoire et protégeant le Commerce, les Sciences et les Arts. Au-dessus est un bas-relief cintré, exécuté par le même artiste, dans lequel le Soleil, emblème de Louis $\mathbf{X I V}$, est entouré des Génies des Arts.

\section{Philippe de France (Monsieur), duc d'Orléans.}

Par M. DereT; statue en plâtre. - H. 2,01.

Second fils de Louis XIII et d'Anne d'Autriche, né à SaintGermain-en-Laye le 21 septembre 1640, il porta d'abord le nom de duc d'Anjou et fut chevalier de l'ordre du Saint-Esprit en 16ə̈4. Après la mort de Gaston de France, frère de Louis XIII, en 1660, il eut en apanage le duché d'Orléans et fut marié en 1661 à Henriette d'Angleterre, fille du roi Charles I ${ }^{\text {er }}$. Il accompagna Louis XIV dans la campagne de Flandre, en 1667, et dans la conquête de la Franche-Comté, en 1668, et fut nommé en 1668 général de l'armée de Flandre. Il se remaria en 1671 à ElisabethCharlotte de Bavière, fut généralissime de l'armée du roi en Hollande, en 1672, se trouva à la prise de plusieurs places et se rendit maître de Zutphen. Commandant en chef l'armée du roi en 1673, il accompagna Louis XIV au siége de Maëstricht, à la seconde conquête de la Franche-Comté en 1674, et le suivit dans l'année 167ว en Flandre, où il commandait un corps d'armée. Le duc d'Orlćans s'empara en 1676 de Condé el de Bouchain, fit en 1677 le siége de Saint-Omer, et remporta la victoire 
de Cassel sur le prince d'Orange. Il était avec le roi pendant la campagne de Flandre en 1678, au siége de Mons en 1691, et à celui de Namur en 1692. Il fut nommé ell 1693 commandant de toutes les troupes de Normandie, Bretagne, Poitou, Aunis, Saintonge, Touraine, au Maine et en Anjou, et mourut à Saint-Cloud le 9 juin 1701 .

\section{CINQUIÈME PARTIE.}

Passage de la Cour Royale à l'escalier de la Pieine.

\section{Louis $\mathrm{XIV}$. (Noir $\left.\mathrm{n}^{\circ} 716.\right)$}

Par Simon GuILI.AIx; statue en plâtre. - H. 1,55.

Cette statue a été moulée d'après une figure en bronze qui faisait partie d'un monument élevé sur le Pont-au-Change et placée aujourd'hui au sIusée du Louvre.

\section{Mignard (Pierre), premier peintre du roi.}

Par M. Grevenich, d'après Coyzevox; buste en marbre. - H. 0,68.

Né à Troyes en 1610, il reçut les premières leçons de Jean Boucher, peintre de Bourges, étudia pendant deux ans à Fontainebleau et entra ensuite dans l'atelier de Simon Vouet. Il se rendit en 1635 en Italie et y séjourna pendant vingt-deux ans. Rappelé en France par Louis XIV, il peignit en 1663 la coupole du Val-de-Grâce et, en 1677, la galerie du château de SaintCloud. Il recut des lettres de noblesse en 1687, fut nommé en 1690 , après la mort de Lebrun, premier peintre du roi, directeur de ses manufactures, et fut reçu le même jour à l'Académie royale, académicien, professeur, recteur, directeur et chancelier. Il mourut à Paris le 29 mai 1695,

Ls buste original est au Musée du Louvre, $n^{\circ} 240$ de la Description des Sculptures modernes par M. Barbet de Jouy.

820. Puget (Pierre), sculpteur, peintre et architecte. Par DeLaistre; buste en marbre. - H. 0,85.

Né à Marseille le 31 octobre 1622, il étudia les arts en Italie, et s'était déjà fait connaître par un grand nombre de travaux d'architecture, de sculpture et de peinture, lorsque Colbert le nomma vers 1668 directeur de la décoration des vaisseaux de la marine royale a Toulon. Il exécuta pour Versailles le Milon de Crotone, l'Andromède et le bas-relief d'Alexandre et Diogèné, placés depuis au Musée du Louvre, et fut présenté à Louis XIV ell 1688. Il mourut à Marseille le 2 décembre 1694.

Ce buste a été exposé au Salon de 1824. 
SIXIĖME PARTIE.

\section{Thou (Christophe de), premier président au par- lement de Paris).}

Par Prieur ; buste en plâtre. - H. 0,60 .

Né le 6 novembre 1508; conseiller et avocat du roi au siége de la table de marbre, contrôleur en la chancellerie et prévôt des marchands de la ville de Paris, il fut, en 15̌ว̆4, président au parlement, et devint premier président sous le règne de Charles IX. Il fut aussi chancelier des ducs d'Anjou et d'Alençon, et mourut le 11 novembre 1582.

Le buste original, placé autrefois dans l'église de Saint-André-des Arcs, est au Musée du Louvre, $\mathrm{n}^{\circ} 152$ de la Description des Sculptures modernes, par M. Barbet de Jouy.

\section{Goujon (Jean), sculpteur et architecte.}

Par G. Francis; buste en marbre. - $\mathrm{H} \cdot 0,62$.

L'année et lieu de sa naissance sont inconnus. Il travailla ell 1541 et 1542 à Rouen dans la cathédrale et l'église de Saint-Maclou, exécuta de 1544 à $15 \% 4$ les sculptures du jubéde Saint-Germain-l'Auxerrois à Paris, fut architecte du connétable de Montmorency puis du roi Henri II, sculpta en 1550 les cariatides de la salle des Suisses au Louvre et les bas-relifs de la fontaine des Innocents, et travailla au Louvre de 15๊ŏอ̆ à 15้62. " La tradition souvent répétée qui a désigné le plus illustre des sculpteurs français comme l'une des victimes de la Saint-Barthélemy (24 août 15\%72) est plutôt démentie que confirmée par les preuves qu'en recherche une critique éclairée. " (Description des sculptures modernes, par M. Barbet de Jouy).

\section{Lescot (Pierre), architecte.}

Par M. Dantan jeune en 1833 ; buste en marbre.- - H. 0,62.

Né à Paris en 15̆10, il était prieur et abbé commendataire de Clagny, et fut chargé par le roi François Ier de la conduite des travaux ordonnés au Louvre en 15̌41. La façade extérieure, appelée façade de l'Horloge, la salle des Cariatides et des CentSuisses et la fontaine des Innocents furent entreprises sur ses dessins. Il mourut à Paris en 1571, âgé de soixante-un ans.

\section{Montaigne (Michel de). philosophe.}

Par Deseine; buste en plâtre. - H. 0,66.

Né au château de Montaigne (Périgord) le 2 fevrier 1533, il 
VESTIBULES DE L'ESCALIER DE MARBRE, No 38.

fut conseiller au parlement de Bordeaux en 1554, chevalier de Saint-Michel, gentilhomme de la chambre du roi et député aux états de Blois en 15\%7. Il parcourut la France, l'Allemagne, la Suisse, l'Italie, fut recu citoyen romain, et publia en 1580 la première partie de ses Essais. Montaigne mourut le 13 septembre 1592.

\section{La Rochefoucauld (François de), cardinal, grand aumônier de France.}

Buste en plâtre. - H. 0,72 .

- Né à Paris le 8 décembre 15ॅั8, il fut évêque de Clermont en 1588\%, cardinal en 1607, sòus-doyen du sacre collége, évêque de Senlis en 1613, grand-aumônier de France et commandeur de l'ordre du Saint-Esprit en 1618, abbé de Sainte-Geneviève en 1619, chef des conseils du roi en 1622. Le cardinal de La Rochefoucauld se retira à l'abbaye de Sainte-Geneviève, où il mourut le 14 février $1645 \%$.

Le buste original est à la Bibliothèque de Sainte-Geneviève, à Paris.

\section{Bérulle (Pierre de), cardinal.}

Buste en plâtre. - H. 0,71.

Né au château de Serilly (Troyes), le \& février 1575, il fut diseiple de saint François de Sales et fonda la congrégation de l'Oratoire de France. Il fit un voyage en Espagne en 1603, et après avoir été médiateur entre Marie de Médicis et Louis XIII, il fut envoyé en mission à Rome près du pape Urbain VIII, qui le nomma cardinal en 1627. Il mourut à Paris le 2 octobre 1629 .

- Le buste original est à la Bibliothèque de Sainte-Geneviève, à Paris.

\section{Peyrese (Nicolas-Claude-Fabri, seigneur de), conseiller au parlement de Provence.}

Par Francin, d'après Caffieri; buste en plâtre. - H. 0,55.

Né au château de Beaugensie, en Provence, le $1^{\text {er }}$ décembre $15 ้ 80$, il fut conseiller au parlement d'Aix et siégea en 1617 à l'assemblée des notables de Rouen. Ses relations scientifiques, ses nombreuses collections de monuments, de manuscrits et de livres lui firent donner par Bayle le surnom de procureur général de la littérature. Il s'occupait d'astronomie. et travaillait avec Gassendi, lorsqu'il mourut à Aix le 24y juin 1637.

Le buste original en terre cuite est à la Bibliothèque Mazarine, et la copie en marbre par Francin est au Musée du Louvre. 
828. Descartes (René), philosophe et mathématicien. Buste en plâtre. - H. 0,70 .

Né à La Haye, en Touraine, le 31 mars 1弓̆96, il fit ses études au collége des Jésuites de La Flèche, s'enrôla comme volontaire dans les troupes de Hollande et du duc de Bavière, et se trouva au siége de Prague en 1620. Ayant renoncé au service militaire, il commença ses voyages et parcourut successivement la Hollande, la France, la Suisse, le Tyrol et une partie de l'Italie; il se retira en 1629 en Hollande où il se livra exclusivement à l'étude. Appelé en Suède par la reine Christine, il s'y rendit vers 1649 , et mourut à Stockholm le 10 février 16 อั0.

Le buste original est à la Bibliothèque de Sainte-Geneviève, à Paris.

\section{Poussin (Nicolas), peintre.}

Par B. BLAISE; buste en marbre. - H. 0,76.

Né en juin 1594 aux Andelys (Normandie), Il reçut les premières lecons de Quintin Varin, travailla ensuite chez Ferdinand Elle et chez Lallemand, et termina ses études en Italie, où il se fixa vers 1624. Appelé en France en 1639, il fut présenté au roi Louis XIII par le cardinal de Richelieu, et reçut, avec le titre de premier peintre du roi, une pension de trois mille livres, un logement aux Tuileries et la direction des ouvrages d'art des maisons royales. De retour à Rome en 1642, son titre et sa pension lui furent conservés sous Louis XIV, et il y mourut le 19 novemhre 166 , dans la soixante-onzième année de son âge. - Excellent dessinateur, grand historien, grand poète, sage compositeur, grand paysagiste, Le Poussin est au premier rang parmi les peintres les plus illustres de toutes les écoles.

\section{Arnauld (Antoine), théologien.}

Buste en plâtre. - H. 0,61 .

Né à Paris le 6 février 1612, il fut dirigé dans ses études par l'abbé de Saint-Cyran, étudia la théologie sous Lescot, et fut reçu docteur en Sorbonne en 1641. Antoine Arnauld, dit le Grand Arnauld, prit la part la plus active aux discussions religieuses sur la Grâce que firent éclater les écrits de Jansénius. Il se retira à Bruxelles en 1679 et y mourut le 8 août 1694 .

Le buste original est à la Bibliothèque de Sainte-Geneviève, à Paris.

\section{Claude Lorrain (Claude Gellée, dit), peintre et graveur.}

Par F. Masson; buste en marbre. - H. 0,73.

Né en 1690, au château de Chamagne, dans le diocèse de Toul, 
en Lorraine, il étudia à Naples sous Geoffroy Wals, et à Rome sous Augustin Tassi; il revint en Lorraine en 1623 et peignit plusieurs tableaux dans l'église des Carmélites de Nancy. De retour à Rome, il y ouvrit une école célèbre et y mourut le 21 novembre 1682.

Ce luste, exposé au Salon de 1806, était destiné à la galerie du Musée Napoléon au Louvre.

\section{Tournefort (Joseph Pitton de), botaniste.}

Buste en plâtre. - H. 0,67.

Né à Aix, en Provence, le 5 juin 16ö6, il fut destiné à l'état ecclésiastique et étudia ensuite la médecine à Montpellier. Aprês avoir parcouru les montagnes du Dauphiné, de la Savoie, du Roussillon, de la Catalogne, il vint à Paris, fut nommé en 1683 professeur de botanique au Jardin du Roi, se rendit par ordre de Louis XIV en Espagne, en Portugal, en Angleterre, en Hollande, et fut recu en $\mathbf{1 6 9 2}$ membre de l'Académie des Sciences et docteur en médecine de la faculté de Paris. Il publia en 1694 ses Eléments de Botanique, et fit en 1700 un voyage scientifique en Grèce, en Asie et en Afrique. De retour à Paris, en 1702, il fut professeur de médecine au Collége-Royal, et mourut le 8 décembre 1708.

Le buste original est au Cabinet d'histoire naturelle, à Paris. 833. Montesquieu (Charles de Secondat, baron de).
président à mortier au parlement de Bordeaux.

Par CLodiox; buste en marbre. - H. 0,63.

Né au chàteau de la Brède, près de Bordeaux, le 18 janvier 1689 , il fut reçu conseiller au parlement de Bordeaux en 1714, et devint en 1716 président à mortier. Il publia en 1721 les Lettres Persanes, fut admis à l'Académie francaise en 1727, visita ensuite l'Autriche, l'Italie, la Hollande et l'Angleterre, et fut membre de la Société royale de Londres. Il fit paraitre en 1734 les Considérutions sur les cuuses de la grandeur et de la décadence des Romains, en 1748, l'Esprit des Lois, et mourut à Paris le 10 février 17 อ๊อ.

Ce buste, exécuté en 1801, avait été commandé pour la galerie des Consul, aux Tuileries.

ARCADE DU MIDI, No 39.

Passage pour les voitures, communiquant de l'ancienne cour hoyale dans les |ardins. 
834. Montaigne (Michel de). (Voir no 824.)

Par M. Lavio; statue en plâtre. - H. 2,10.

Cette figure, exposée au Salon de 1855, est le modèle de la statue en bronze placée dans la ville de Périgueux.

835. Malherbe (François de), poète.

Par M. Daxtax aîné; statue en plâtre. - H. 2,05.

Né à Caen, vers 15ૅอ̆วั d'une famille noble de Normandie, il quitta sa ville natale à l'âge de dix-huit ou dix-neuf ans, s'attacha au grand prieur de France, Henri d'Angoulême, et suivit ce prince en Provence. Après la mort de Hènri d'Angoulême, il servit dans les troupes de la Ligue. L'ode qu'il composa en 1600 , sur l'arrivée en France de Marie de Médicis, fut le commencement de sa réputation et lui valut la protection de Henri IV. Il mourut en 1628, à l'âge de soixante-treize ans.

Cette figure, exposẻe au Salon de 1847, a été exe̊cutée en bronze pour la ville de Caen.

836. Descartes (René), philosophe et mathématicien. (Voir $\left.n^{\circ} 828.\right)$

Par PAJOU; statue en plâtre. - H. 1,88.

837. Poussin (Nicolas), peintre. (Voir no 829 .)

Par M. Auguste DoMoNT; statue en plâtre. - H. 1,74.

838. Bignon (Jérôme), avocat général au Parlement
de Paris.

Par Girardox; buste en plâtre. - H. 0,64.

Né à Paris en 1วั90, il fut choisi, en 1604, pour être enfant d'honneur du dauphin (depuis Louis XIII), voyagea en Italie en 1614, exerça ensuite, comme avocat au barreau de Paris, jusqu'en 1620, et fut alors nommé avocat général au grand conseil. Conseiller d'Elat vers 1621, avocat général au Parlement de Paris en 1626, et grand maître de la Bibliothèque du roi, il prit part au congrès de Munster en 1648 et au traité conclu avec la Hollande en 1649. Bignon mourut le 7 avril 16 อ̆6.

Le buste, exécute par Girardon, pour le tombeau de Bignon, est dans l'ẻglise de Saint-Nicolas-du-Chardonnet, à Paris.

839. Séguier (Pierre), chancelier de France.

Buste en plâtre. - H. 0,72.

Né à Paris le 28 mai 1588. Conseiller au parlement, maitre des 
requêtes, intendant de justice en Guyenne, président au parlement en 1624, garde des sceaux en 1633, chancelier de France et commandeur des ordres du roi en $\mathbf{1 6 3 5}$. Il fut protecteur de l'Académie royale de peinture et de sculpture en 16354 , et mourut à Saint-Germain-en-Laye le 28 janvier 1672.

Le buste original, attribué à Jacques Sarrazin, est au Musée du Louvre.

\section{Pascal (Blaise), géomètre et philosophe.}

Buste en plâtre. - H. 0,65 .

Né à Clermont en Auvergne, le 19 juin 1623, il fut élevé par son père, Etienne Pascal, premier président à la cour des aides de Clermont, puis intendant à Rouen. Le père de Pascal vint à Paris vers 1631, et son fils conçut dans la société des savants qu'il réunissait chez lui une grande jassion pour les sciences. Il trouva dès l'âge de douze ans, sans le secour's d'aucun livre, les trentedeux premières propositions d'Euclide, composa, à seize ans, un Traité des sections coniques, et trouva en $165 \%$ le triangle arithmétique. Il publia en 1656 et 1657 les Lettres provinciales, el mourut à Paris le 19 août 1662. - Ses Pensées furent publiées pour la première fois en 1670 .

\section{Lamoignon (Guillaume de), premier président au} Parlement de Paris. (Voir $\mathbf{n}^{\circ}$ 641.)

Par Girardon; buste en plâtre. - H. 0,66.

842. Corneille (Pierre), poète tragique. (Voir no 801. )

Par M. LaITIÉ ; statue en plâtre. - H. 1,78.

843. Molière (Jean-Baptiste Poquelin), poète comique. (Voir $n^{\circ}$ 228.)

Par M. DuRET; statue en plâtre. - H. 1,74.

844. Racine (Jean), poète tragique. (Voir no 229.)

Par M. Lemaine; statue en plâtre. - H. 1,75.

845. La Fontaine (Jean de), poète et fabuliste. (Voir $\mathrm{n}^{\circ}$ 230.)

Par M. SkurRe aîné; statue en plâtre. - H. 1,75.

\section{Régis (Pierre-Silvain de), philosophe.}

Buste en marbre. - H. 0,57.

Né à La Salvetat de Blanquefort, en Agenois, en 1632, il étudia la théologie à Cahors et à Paris, embrassa, sous Rohault, la phi- 
losophie de Descartes et la professa à Toulouse en 166ă, puis a Montpellier en 1671, et à Paris en 1680. Membre de l'Académie des sciences en 1699, il mourut à Paris le 11 janvier 1707.

Ce buste, placé autrefois dans une des chapelles de l'église de Saint-Paul, à paris, a fait partie du Musée des Monuments français.

\section{Le Nain de Tillemont (Louis-Sébastien), historien.}

Buste en plattre. - H. 0,66.

Né à Paris le 30 novembre 1637, il étudia à Port-Royal dès l'àge de neuf ans; il fut ordonné prêtre en 1676 et se retira, après la dispersion des solitaires de Port-Royal, à Tillemont, près de Vincennes. Il mourut le 10 janvier 1698. - Le Nain de Tillemont est auteur d'une Histoire des empereurs et de Mémoires pour servir ì l'histoire ecclésiastique.

Le buste original est à la Bibliothèque de Sainte-Geneviève.

\section{Dumolinet (Claude), antiquaire.}

Buste en plâtre. - H. $\mathbf{0 , 7 0 .}$

Né à Châlons-sur-Marne en 1620 , il prit l'habit de chanoine régulier à Sainte-Geneviève (ordre de Saint-Augustin); il fut procureur général de la congrégation des Génovéfains. Bibliothécaire de l'abbaye de Sainte-Geneviève, il y forma un cabinet de curiosités dont il a laissé une description, publiée en 1692. Il fut aussi chargé de l'arrangement des médailles du cabinet du roi, et donna en 1679 une Histoire numismatique des Papes. Molinet mourut à Paris le 2 septembre 1687 .

Le buste original est à la Bibliothèque de Sainte-Geneviève, à Paris.

\section{Daguesseau (Henri-Francois), chancelier de France. (Voir $\mathrm{n}^{\circ} 655$. \\ Buste en plâtre. - H. 0,71.}

\section{VESTIBULE $N^{\circ} 40$.}

L'emplacement de ce restibule et du passage qui conduit de l'ancienne cour des Princes dans les jardins, était occupé autrefois par une petite salle de spectacle, élevée seulement à la hauteur du rez-de-chaussée, et qui ne pouvait contenir qu'un petit nombre de spectateurs. Cette salle de spectacle a été détruite en 1810.

\section{Fontenelle (Bernard Le Bovier de), littérateur et} savant.

Buste en marbre. - II. 0,52.

Yé à Rouen le 11 février 1657, il était par sa mère neveu de 
Pierı'e Colmeille. Il fit ses études au collége des Jésuites à Rouen, et vint à Paris où il publia, en 1680, ses Dialogues des Morts, et en 1686 ses Entretiens sur la pluralité des Mondes. Membre de l'Académie française en 1691, secrétaire perpétuel de l'Académie des sciences en 1737, il rédigea l'histoire de cette Académie et mourut à Paris presque centenaire, le 9 janvier 1757 .

\section{Montesquieu (Charles de Secondat, baron de). (Voir no 833.)}

Par M. Nanteuil ; statue en plâtre. - H. 1,61.

Il est représentẻ assis, écrivant l'Esprit des lois.

\section{Voltaire (François-Marie Arouet de).}

Par Hoddon en 1782; buste en marbre. - H. 0,53.

Né à Châtenay, près de Sceaux, le 20 février 1694, il fit ses études à Paris au collége des Jésuites (depuis collége Louis-leGrand). Destiné à la magistrature, il entra chez un procureur et se livra de bonne heure à la culture des lettres. Il donna en 1718 sa première tragédie, OEdipe, et la Henriade en 1725. Gentilhomme de la chambre du roi et historiographe de France en 1745, membre de l'Académie francaise en 1746, il fut chambellan de Frédéric II en 1750 , et se fixa à Ferney en 1758. Il mourut à Paris le 30 mai 1778. - Philosophe, historien, critique, romancier, auteur dramatique, Voltaire est l'écrivain le plus universel des temps modernes.

Ce buste a fait partie du Musée des Monuments français.

853. Voltaire (François-Marie Arouet de). (Voir $\mathbf{n}^{\circ} 852$.

Par Houdon; statue en plàtre. - H. 1,26.

Il est assis dans un fauteuil; son corps est enveloppé d'un manteau.

La figure originale, exécutée par Houdon en 1781, est dans le vestibule de la Comédie-Française, à Paris.

\section{Rousseau (Jean-Jacques).}

Par BOYER ; buste en marbre. - H. 0,54.

Né à Genève le 28 juin 1712. Après avoir voyagé en Savoie, en France et à Venise, il obtint en 1748 une place de commis chez le fermier général Dupin, et remporta en 1749 le prix proposé par l'Académie de Dijon. Il donna successivement des ouvrages d'un genre très-divers : le Devin de village en 1752, la Nouvelle Héloïse en 1759, l'Émile en 1762. Décrété de prise de corps par le parlement de Paris, condamné également à Genève, il se ré- 
fugia d'abord à Motiers-Travers, dans la principauté de Neufchâtel, puis en Angleterre, revint en 1770 à Paris, et mourut à Ermenonville le 3juillet 1778. - Philosophe, compositeur, poète, botaniste, Rousseau laissa plusieurs ouvrages manuscrits, entre autres les Confessions. Il avait adopté pour devise: Vitam impendere vero.

Ce buste a fait partie du Musée des Monuments français.

\section{Diderot (Denis), philosophe.}

Par HodDon; buste en marbre. - H. 0,42.

Né à Langres en 1712, il fut destiné à l'état ecclésiastique, vint à Paris pour étudier la théologie, et entra ensuite chez un procureur. Entraîné par son goût pour l'étude, il embrassa tout à la fois la littérature, la métaphysique, la géométrie, la physique, fonda l'Encyclopédie avec Dalembert, et donna en 1757 et 17508 deux ouvrages dramatiques, le Fils naturel et le Père de famille. Il se rendit en 1773 à Saint-Pétersbourg, auprès de l'impératrice $\mathrm{Ca}-$ therine II, sa bienfaitrice, et mourut à Paris le 30 juillet 1784 .

Ce buste porte l'inscription suivante : A M. Robineau de Bougon Houdon sculpsit 1775.

\section{Raynal (Guillaume-Thomas-François), écrivain et philosophe.}

Par ESPERGIEUX; buste en marbre. - H. 0,66.

Né à Saint-Geniez (Aveyron) en 1713, il étudia chez les Jésuites, entra dans les ordres et obtint du succès dans l'enseignement et dans la prédication. Il vint à Paris en 1747, s'attacha pendant quelque temps à l'église Saint-Sulpice et quitta enfin l'état ecclésiastique pour s'enrôler parmi les encyclopédistes. Nommé rédacteur du Mercure, il publia successivement divers ouvrages historiques, Il rédigea avec Diderot et Pechméja son Histoire philosophique des deux Indes, ouvrage condamné par arrêt du parlement et qui força l'auteur de s'expatrier en 1781. De retour en France en 1788, il adressa une lettre à l'Assemblée nationale contre les principes révolutionnaires, et mourut à Chaillot en 1796.

Ce buste était placé au Musée des Monuments français.

\section{Dalembert (Jean Le Rond), géomètre et écrivain.}

Par Franciv; buste en marbre. - $\mathrm{H}_{2} \mathbf{0 , 4 3}$.

Né à Paris le 16 novembre 1717. Après avoir fait ses études au collége Mazarin, il prit le grade de maître ès arts et se fit recevoir avocat au barreau de Paris. Il s'occupa ensuite exclusivement de l'étude des mathématiques, fut reçu à l'Académie des sciences en 
1741 , et s'associa en 1750 à Diderot pour la publication de l'Ency ${ }^{2}$ clopédie. Admis en 1754 à l'Académie française, dont il devint secrétaire perpétuel en 1772 , membre de presque toutes les sociétés savantes de l'Europe, Dalembert mourut le 30 octobre 1783.

Ce buste faisait partie du Musée des Monuments français.

858. Helvétius (Claude-Adrien), philosophe.

Buste en plâtre. - H. 0,50.

Né à Paris en 1715, il était fils du premier médecin de la reine Marie Leczinska, et obtint dès l'âge de vingt-trois ans une charge de fermier général. Il quitta la finance pour se livrer aux lettres en $\mathbf{1 7 5 1}$, et publia en 17 כ̋8 son livre De l'Esprit. Helvétius mourut à Paris le 26 décembre 1771.

\section{Courtenvaux (Ćésar Le Tellier, marquis de).}

Buste en plâtre. - H. 0,88 .

Né à Paris en 1718, duc de Doudeauville, capitaine-colonel des Cent-Suisses de la garde du roi, grand d'Espagne de première classe, il entra aul service en $\mathbf{1 7 3 3}$ et servit sous le maréchal de Noailles. Il fit en 1742 les campagnes de Bohême et de Bavière, et en 1745 celle de Flandre. Membre de l'Académie des sciences en $\mathbf{1 7 6 5}$, il entreprit avec Pingré et Messier un voyage sur les côtes de France et de Hollande, pour le perfectionnement des montres marines. Il mourut à Paris le 7 juillet $\mathbf{1 7 8 1}$.

Le buste original est à la Bibliothèque de Sainte-Geneviève.

860. Buffon (Georges-Louis Leclerc, comte de), naturaliste et littérateur.

Buste en marbre. - II. 0,57.

Né à Montbard (Côte-d'Or) le 7 septembre 1707, il se livra dès sa jeunesse à l'étude des sciences, fut admis en 1739 à l'Académie des sciences, et nommé la même année intendant du Jardin du Roi. Il commença en $\mathbf{1 7 4 9}$ la publication de son Histoire naturelle, fut admis à l'Académie française en $\mathbf{1 7 5 3}$, et mourut à Paris le $\mathbf{1 6}$ avril 1788. 861. L'abbé de l'Épée (Charles-Michel de l'Épée), fon-
dateur de l'institution des sourds-muets.

Par M. A. Michaut; buste en plâtre.' - H. 0,67.

Né à Versailles le 25 novembre 1712 , il avait été reçu avocal au barreau de Paris avant d'entrer dans les ordres, et fut chanoine de l'église de Troyes. Il se consacra à l'éducation des sourds-muets, 
fonda, avec ses seules ressources, le premier établissement de ce genre qui ait existé en Europe, et mourut à Paris le 23 décembre 1789.

\section{Pingré (Alexandre-Gui), astronome.}

Par CAfrieri ; buste en plâtre. - H. 0,57.

Né à Paris le 4 septembre 1711. Après avoir fait ses études aux Génovéfains de Senlis, il entra dans les ordres en 1726, et commença en 1749 à s'occuper spécialement de l'étude de l'astronomie. Associé libre de l'Ácadémie des sciences en 1753, bibliothécaire de l'abbaye de Sainte-Geneviève et chancelier de l'Université, Pingré mourut à Paris le $1^{\mathrm{er}}$ mai 1796.

\section{Perronet (Jean-Rodolphe), ingénieur et archi- tecte.}

Par Masson ; buste en plâtre. - H. 0,61.

Né à Surênes en 1708, il fut en 1747 le premier directeur des ponts et chaussées. Il construisit treize ponts, parmi lesquels on cite le pont de Neuilly et le pont Louis XVI à Paris. Chevalier de l'ordre de Saint-Michel en 1763, il mourutà Parisle 27 février 1794.

Le buste original est à l'École des Ponts et Chaussées.

\section{Soufflot (Jacques-Germain), architecte.}

Par M. Dantax jeune en 1844; buste en marbre. - H. 0,69.

Né à Irancy (Yonne) en 1714, il se rendit de bonne heure en Italie, visita l'Asie-Mineure et fut admis au nombre des pensionnaires de l'école de Rome. De retour en France il construisit à Lyon l'hôtel du Change, le théâtre et l'Hôtel-Dieu. Membre de l'Académie d'architecture en 1749, et associé libre de l'Académie de peinture, il fut chevalier de l'ordre de Saint-Michel, contrôleur puis intendant général des bâtiments du roi. Chargé en 1730 'de la construction de l'église Sainte-Geneviève, il donna aussi les plans de l'Ecole de droit et mourut à Paris le 29 août 1781.

Ce buste a été exposé au Salon de 1845.

865. Wailly (Charles de), architecte.

Par PAJOU; buste en plàtre. - H. 0,55.

Né à Paris en 1729, il fut élève de Blondel et de Servandoni, et fit en 1752 le voyage de Rome commepensionnaire du roi. Membre de l'Académie d'architecture en $\mathbf{1 7 6 7}$, de l'Académie de peinture el de sculpture en 1771, il donna les pians de l'hôtel d'Argenson et du théâtre de l'Odéon à Paris, du château des Ornes en Tou- 
raine, et du palais Spinola à Gênes. Après la réunion de la Belgique à la France, et la conquête de la Hollande en 1796, de Wailly fut envoyé en qualité de commissaire pour recueillir les objets d'art destinés au Musée du Louvre, dont il était un des conservateurs. Il fut membre de l'Institut à sa création, et mourut à Paris le 2 novembre 1798.

Ce buste faisait partie du Musée des Monuments français.

\section{Chaptal (Jean-Antoine, comte), chimiste.}

Par RoLAND; buste en plâtre. - H. 0,67.

Né à Nogaret (Lozère) le 5 juin 1756, il fut reçu docteur en médecine à Montpellier en 1777. Nommé en 1781 professeur à la chaire de chimie créée par les états du Languedoc près la faculté de Montpellier, il reçut en 1787 l'ordre de Saint-Michel et des lettres de noblesse, et donna en 1790 ses Eléments de chimie. Il dirigea en 1793 les travaux de la poudrière de Grenelle, fut nommé ensuite professeur à l'Ecole polytechnique et devint membre de l'Institut à sa fondation. Ministre de l'intérieur en 1800, grand officier de la Légion d'honneur en 1804, sénaleur en 1805, comte de l'Empire en 1808, pair de France en 1819, Chaptal mourut le 29 juillet 1832. - Il est l'auteur de traités sur la Chimie appliquée aux arts et à l'agriculture.

\section{VESTIBULE No 41 .}

Cette pièce et la suivante (salle des Amiraux) n'en formaient autrefois qu'une seule, qui servait de salle des Gardes à l'appartement destiné aux dauphins de France. Cet appartement, qui comprenait toutes les salles à la suite jusqu’à la galerie Louis XIII, fut occupé successivement par le grand dauphin, fils de Louis XIV, et par tous les hẻritiers de la couronne jusqu'à Louis XVI. Le Régent l'habita en 1722 et 1723. Louis XVI, à son avénement au trône, le donna au comte de Provence qui y resta jusqu'en 1788, époque où les enfants de France y furent installés.

\section{Henri IV. Voir $\left.\mathrm{n}^{\circ} 714.\right)$}

Par Francheville; statue en plâtre. - H. 1,93.

Henri IV, revêtu d'une armure et du manteau royal, porte les colliers des ordres du Saint-Esprit et de Saint-Michel.

La statue originale, placée autrefors au Musée des Monuments français, a été depuis transportée au château de Pau.

\section{Ormesson (Olivier Le Fèvre, seigneur d'), prési- dent à la Chambre des comptes.}

Par Paul Ponce; buste en plâtre. - H. 0,54.

Né en 1525, il fut d'abord conseiller du roi Charles IX, puis 
contrôleur-général des finances vers 15072 , et ensuite président à la Chambre des comptes. Il mourut le 26 mai 1600 et fut enterré aux Minimes de Chaillot.

Le buste original en bronze, placé autrefois sur le tombeau de d'Ormesson, dans l'église des Minimes, est au Musée du Louvre.

\section{Vic (Dominique de), vice-amiral de France.}

Buste en plâtre. - H. 0,55.

Né en $15 ้ ว \mathrm{l}$, il fut d'abord enseigne, puis capitaine aux gardes, et se fit appeler le capitaine Sarred, du nom de sa mère. Il fut un des serviteurs les plus dévoués de Henri IV, et lui servit de sergent de bataille à la journée d'Ivry, en 1590. Gouverneur de SaintDenis en 1591, de Calais et d'Amiens en 1594, vice-amiral en 1602, ambassadeur en Suisse en 1604, Marie de Médicis le nomma conseiller d'Etat après la mort de Henri IV. En passant par la rue de la Féronnerie, où ce prince avait été assassiné, il fut saisi d'une telle douleur qu'il expira le lendemain (14 août 1610).

Le buste original en marbre était placé autrefois au Musée des Monuments français. On lit derrière cette inscription : MESS ${ }^{\text {re }}$ DOMINIQVE DE VIC CHEVALIER VISG TE DERENONVILLE GOV ${ }^{\text {T }}$ POUR LE ROY A CALAIS ET VISAMIRAL DE FRANCE 1610 .

\section{Fréminet (Martin), premier peintre du roi.}

Par Fraxcheville; buste en plâtre. - H. 0,50.

Né à Paris en 15067. Après avoir passé seize ans en Italie, il fut premier peintre du roi sous le règne de Henri IV, exécuta pour Fontainebleau un grand nombre de peintures, entre autres le plafond de la chapelle, et recut le cordon de l'ordre de Saint-Michel, Il mourut le 13 juin 1619 et fut enterré à l'abbaye de Barbeaux, diocèse de Sens.

Le buste original en bronze, exécuté par Francheville, pour le tombeau de Fréminet, est au Musée du Louvre.

\section{Elbenne (Thomas d'), secrétaire du roi.}

Buste en marbre. - H. 0,59.

Il mourut en 15993 et fut enterré dans la chapelle des Briçonnet, au couvent des Cordeliers à Paris.

Ce buste, qui ornait le tombeau de Thomas d'Elbenne, a fait partie du Musée des Monuments français.

\section{Briçonnet (Personnage de la famille de).}

Buste en marbre. - $\mathrm{H}, 0,48$.

Il porte un col rabattu et un pourpoint boutonné de distance en distance par trois petits boutons.

Ce buste et les deux suivants, provenant de la chapelle de la famille Briçonnet 
SALLE DES AMIRAUX, $\mathrm{N}^{\circ} 42$.

au couvent des Cordeliers de Paris, ont fait partie du Musée des Monuments français.

\section{Briçonnet (Personnage de la famille de).}

Buste en marbre. - H. 0,49.

Il porte une robe doublée de fourrure.

\section{Briçonnet (Personnage de la famille de). -}

Buste en marbre. - H. 0,49.

Il porte une petite collerette et un pourpoint boutonné. - Le nom de BRICONNET est gravé derrière le buste.

\section{SALLE DES AMIRAUX No 42.}

Partie de la salle des gardes de l'appartement du dauphin. (Voir salle $\mathbf{n}^{\circ}$ 41.)

875. Varennes (Florent de).

Peinture du xvirie siècle (1). - H. 0,76. — L. 0,61.

Il était amiral de France sous saint Louis, lors de la croisade de 1270, et reçut en 1271, au nom du roi Philippe-le-Hardi, l'hommage que lui rendit Aymar, comte de Valentinois.

876. Coucy (Enguerrand de).

Peinture du xviII siècle. - H. 0,76. - L. 0,61.

Il était, dit Guillaume de Nangis, amiral de la flotte du roi Philippe-le-Hardi en 128ə, et fut fait prisonnier dans un combat naval contre les Aragonnais.

\section{Montmorency (Mathieu IV, seigneur de).}

Peinture du xviri siècle. - H. 0,76. - L. 0,61.

Il accompagna le roi Philippe-le-Hardi au voyage d'Aragon en 128\%, et fut créé grand chambellan de France par Philippe-le-Bel. Il exerça la charge d'amiral de France en $1295 \%$, servit dans la guerre de Flandre en 1303, et mourut en 1304 ou 13030 .

878. Harcourt (Jean II, sire de).

Peinture du xviı ${ }^{\mathrm{e}}$ siècle. - H. 0,76. - L. 0,61.

Maréchal de France en 1283, il accompagna Philippe-le-Hardi

(1) La collection des portraits des amiraux, depuis Florent de Varennes jusqu'au duc de Penthièvre, était placée autrefois à l'hôtel de Toulouse, à Paris, dans la salle dite des Amiraux. Ces peintures ont été exécutées dans le XVIII ${ }^{\mathrm{e}}$ siècle et n'offrent d'authenticité, pour les traits des personnages, qu'à dater du xvI ${ }^{\mathrm{e}}$ siècle. 
darıs la guerre de 1285 contre le roi d'Aragon. Amiral en 1295, ll assiégea et prit la ville de Douvres en 1296. Il mourut le 21 décembre 1302.

879. Tocy (Othon de).

Peinture du xrııe siècle. - H. 0,76. - L. 0,64.

Il exerça la charge d'amiral en 1296, et mourut en 1297.

\section{Benoist Zacharie.}

Peinture du xvinle siècle. - H. 0,76. - L. 0,61.

Il était d'une ancienne famille de Gênes, commanda d'abord une partie de la flotte génoise, remporta plusieurs victoires sur les Pisans en 1284 et 1286 , et fut ensuite amiral de Sanche, roi de Castille. Il entra au service de la France, accompagna le roi Philippe-le-Bel au siége de Lille, et fut amiral de la mer en 1297. Benoist Zacharie vivait encore en 1314; mais il n'était plus amiral, ce qui démontre que cette charge n'avait alors ni la grandeur, ni la fixité qu'elle acquit plus tard.

\section{Grimaldi (Raynier de Grimaut ou).}

Peinture du xviII ${ }^{\mathrm{e}}$ siècle. - H. 0,76. - L. 0,61.

Il exerça l'office d'amiral de la mer, de 1302 à 1307, et se trouva à la bataille de Mons-en-Puelle, en 1304. Il mourut en 1314.

882. Chepoy (Thibaut, sire de), ou de Cepoy.

Peinture du xvirie siècle. - H. 0,76. - L. 0,61.

Grand maître des arbalétriers de France en 1304, il exerca la charge d'amiral de la mer, de 1335 à 1308, lors de l'expédition de Philippe-le-Bel en Romanie. Il mourut vers 1316.

\section{Bérenger Blanc.}

Peinture du xviII siècle. - H. 0,76. - L. 0,61.

Sergent d'armes du roi Philippe-le-Bel, il servit aux guerres de Gascogne en 1298, exerça la charge d'amiral de la mer dès l'année 1315, et fut envoyé en Flandre par le roi Louis-le-Hutin, en 1318, avec le comte d'Evreux. Il mourut vers 1326.

\section{Tristan (Gentian).}

Peinture du xvir ${ }^{\mathbf{e}}$ siècle. - H. 0,76. - L. 0,61.

Premier huissier d'armes de Philippe-le-Bel et échanson de ce 
prince, il fut nommé amiral de la mer pour la guerre de Gascogne et de Bayonne en 1324.

885. Miége (Pierre).

Peinture du xviri ${ }^{\mathrm{e}}$ siècle. - H. 0,76. - L. 0,61.

Il servit le roi Charles-le-Bel en $\mathbf{1 3 2 2}$ et $\mathbf{1 3 2 4}$, fut pourvu de la charge d'amiral de la mer, qu'il exerçait en 1326, et fut envoyé l'année suivante à Rouen, avec Jean Le Mire, huissier d'armes, pour visiter les navires qui devaient servir à la guerre de Gascogne.

886. Chepoy (Jean II, seigneur de).

Peinture du xviri ${ }^{e}$ siècle. - H. 0,76. - L. 0,61.

Il fut commis en 1334, avec Eustache de Monsigny, pour commander les galères que Philippe-de-Valois envoyait contre les Turcs, revint en France en 1335, et mourut la même année à Chatenoy.

\section{Quieret (Hugues).}

Peinture du xviII ${ }^{\mathrm{e}}$ siècle. - H. 0,76. - L. 0,61.

Il se trouva à la guerre de Gascogne en 1326, fut sénéchal de Beaucaire en 1329, et exerça dès l'année 1336 la charge d'amiral. Capitaine de Tournay en 1339, il mourut des blessures qu'il reçut dans un combat naval donné contre les Anglais, en 1340.

\section{Doria (Aithon).}

Peinture du xvine siècle. - H. 0,76. - L. 0,61.

Amiral de France en 1339, sous Philippe de Valois.

\section{Beuchet ou Behuchet (Nicolas).}

Peinture du xviII siècle. - H. 0,76. - L. 0,61.

Maître des eaux et forêts en 1328, puis trésorier de Philippe de Valois, qui le pourvut de la charge de maître des comptes en 1338, il commanda en 1339 l'armée de mer en qualité d'amiral, conjointement avec Hugues Quieret, passa en Angleterre, y brûla plusieurs places et s'empara de Portsmouth. Étant demeuré prisonnier dans un combat naval livré contre Édouard, roi d'Angleterre, ce prince le fit pendre au mât d'un navire, le 6 mai 1340 .

890. Espagne (Louis de la Cerda d').

Peinture du xviı́ siècle. - H. 0,76. - L. 0,61.

Il servit Philippe-de-Valois dans la guerre contre les Anglais, 
assista Charles de Blois, duc de Bretagne, contre le comte de Montfort, et prit sur lui Dinan et Guérande. Il exerça la charge d'amiral en 1341, et mourut vers 130 .

\section{Flotte (Pierre), dit Floton de Revel.}

Peinture du xvIrI siècle. - H. 0,76. - L. 0,61.

Il servit en 1337, sous le connétable d'Eu, dans les guerres de Gascogne et de Languedoc, et en 1338 dans les guerres de Flandre. Philippe de Valois le créa amiral de France en 1345; il

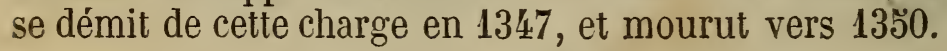

\section{Nanteuil (Frère Jean de).}

Peinture du xvine siècle. - H. 0,76. - L. 0,61.

Chevalier de l'ordre de Saint-Jean de Jérusalem, prieur d'Aquitaine, lieutenant au prieuré de France, amiral de la mer, conseiller du roi, capitaine de La Rochelle, de Saintonge, etc., Frère Jean de Nanteuil exerça en 1347 la charge d'amiral, après la démission de Pierre Flotte, et mourut en $130 ّ 6$.

\section{Quieret (Enguerrand).}

Peinture du xvire siècle. - H. 0,76. - L. 0,61.

Il fit les guerres de Guyenne, de Languedoc et de Flandre de 1337 à 1342, défendit la ville de Rue dont il était capitaine en 133̆4, et servit depuis en Picardie sous le maréchal de Nesle. Il portait en 13 əั7 le titre d'amiral, et mourut vers $\mathbf{1 3 5 9}$.

\section{Mentenay (Enguerrand de).}

Peinture du xvirre siècle. - H. 0,76. - L. 0,61.

Il exerça temporairement l'office d'amiral de France en 1320 .

\section{La Heuse (Jean de), dit le Baudran.}

Peinture du xviII siècle. - H. 0,76. - L. 0,61.

Il fit ses premières armes sous le connétable d'Eu en 1337, fut châtelain du château de Cherbourg en 1347, servit en Normandie sous le maréchal d'Audeneham en 135̆4, et fut commis en $\mathbf{1 3 5 6}$, pour garder Pontaudemer. Il se trouva en qualité de maréchal au siége de Honfleur en 1357, fut nommé amiral de la mer en 135ั9, et se démit de cette charge en 1368. Il mourut vers 1372.

\section{Périlleux (François de).}

Peinture du xviri ${ }^{\mathrm{e}}$ siècle. - H. 0,76. - L. 0,61.

Il fit ses premières armes au service de Pierre, roi d'Aragon, 
qui l'envoya en France comme ambassadeur en 1355 et 1361. Depuis, étant passé au service de la France, Charles V le pourvut de la charge d'amiral de la mer en 1368, et il mourut l'année suivante.

\section{Narbonne (Aimery ou Amaury X, vicomte de).}

Peinture du xviII siècle. - H. 0,76. - L. 0,61.

Blessé et fait prisonnier à la bataille de Poitiers en 1356, il fut encore fait prisonnier en 1366, dans un combat près de Montauban. Créé amiral de France en 1369, il fut destitué de cette charge en 1373 , et mourut en 1382.

\section{Vienne (Jean de).}

Peinture du xviri ${ }^{\mathrm{e}}$ siècle. - H. 0,76. - L. 0,61.

Il servit sous Charles $\mathrm{V}$ dans les guerres contre les Anglais, fut amiral en 1373, et suivit Charles VI en Flandre en 1382. Ambassadeur en Savoie et chevalier de l'Annonciade, il était en 1383 conseiller et chambellan du roi. Jean de Vienne marcha en 1396 au secours de Sigismond, roi de Hongrie, et périt à la bataille de Nicopolis, le 24 septembre 1396, en combattant à l'avant-garde de l'armée chrétienne.

\section{Trie (Renaud de).}

Peinture du xviı ${ }^{\mathrm{e}}$ siècle. - H. 0,76. - L. 0,61.

Chambellan de Charles VI et membre de son grand conseil en 1393, il exerça la charge de maître des arbalétriers en 1394 et 1395, fut amiral en 1397, se démit de cette charge en 1405, et mourut l'année suivante.

\section{Bréban (Pierre de), dit Clignet.}

Peinture du xviII ${ }^{\mathrm{e}}$ siècle. - H. 0,76. - L. 0,61.

Il fut l'un des sept chevaliers français qui, le 19 mars 1402 , combattirent à outrance, près de Bordeaux, contre sept chevaliers anglais qu'ils défirent. Conseiller et chambellan de Charles VI, lieutenant en Champagne, il s'attacha à Louis de France, duc d'Orléans, et fut pourvu de la charge d'amiral le $1^{\text {er }}$ avril 1405 ; il défendit en 1411 le château de Moymer, assiégé par les Bourguignons, et commença l'escarmouche à la bataille d'Azincourt, en 1415 . Il vivait encore en 1428.

\section{Dampierre (Jacques de Châtillon, sire de).}

Peinture du xviII siècle. - H. 0,76. - L. 0,61.

Conseiller et chambellan du roi, il fut pourvu de la charge 
d'amiral par la faveur du duc de Bourgogne, et à la place de Pierre de Bréban, par lettres du 23 avril 1408. Il accompagna ce prince, en 1408, à son expédition contre les Liégeois, et conclut, en 1410, une trève à Boulogne avec les députés du roi d'Angleterre; peu après, ayant été suspendu de la charge d'amiral, que Pierre de Bréban lui contestait, il se retira chez lui jusqu'en 1415 , qu'il leva des troupes pour le service du roi, et fut tue à la bataille d'Azincourt, le 250 octobre 1415.

\title{
902. Braquemont (Robert de), dit Robinet.
}

Peinture du xvini siècle. - H. 0,76. - L. 0,61.

Il était au service du roi de Sicile en 1384; deux ans après, il passa à celui du roi de Castille. De retour en France, le roi Charles VI le fit conseiller et chambellan, et en 1415, chef de l'armée de mer. Pourvu de la charge d'amiral de France, le 22 avril 1417, il en fut dépouillé l'année suivante par la faction de Bourgogne. Il se retira alors en Espagne, et mourut à Monsejon, près de Tolède.

\section{Poix (Jeannet de).}

\author{
Peinture du XvıII ${ }^{\mathrm{e}}$ siècle. - H. 0,76. - L. 0,61.
}

.Il suivit le parti du duc de Bourgogne, demeura prisonnier à la bataille d'Azincourt, en 1415 : l'année suivante, le duc de Bourgogne l'envoya en ambassade à Paris, et il suivit ce prince à Tours, en 1417; il servit la même année au ravitaillement de Senlis assiégé par le connétable d'Armagnac, et mourut de la peste, à Paris, en 1418. - Le roi, dit le P. Anselme, lui avait donné l'office d'amiral de France, qu'il n'exerça jamais.

\section{Recourt (Charles de), dit de Lens.}

Peinture du xviII siècle. - H. 0,76. - L. 0,61.

Il servit toute sa vie le parti de Jean-sans-Pcur, duc de Bourgogne, et fut banni de Paris par ordre de Charles VI, en 1413. La faction de Bourgogne ayant prévalu, il fut nommé amiral de France à la place de Robert de Braquemont, le 6 juin 1418, et lieutenant de la ville de Paris. Il était avec le duc de Bourgogne lorsque ce prince fut assassiné sur le pont de Montereau, le 10 septembre 1419.

905. Beauvoir (Georges de), ou de Chastellux.

Peinture du XviII siècle. - H. 0,76. - L. 0,65.

Frère du maréchal Claude de Beauvoir, il exerçait en 1420, l'office d'amiral de France. 
906. Culant (Louis, seigneur de).

Peinture du Xvırre siècle. - H. 0,76. - L. 0,65.

Il fut conseiller et chambellan de Charles VII, bailli de Melun en 14.17, et amiral de France avant 1422; il se trouva au combat de Rouvroy-Saint-Denis en 1428, à la prise de la bastille du pont d'Orléans en 1429, accompagna le roi à Reims, et assista à son sacre le 17 juillet de la même année. Il mourut en 1444 .

\section{Lohéac (André de Montfort de Laval, seigneur de).}

Peinture du Xville siècle. - H. 0,76. - L. 0,05.

Lohéac, fait chevalier à douze ans en 1423, au combat de la Gravelle, défendit Orléans, en 1429, et se trouva à la journée de Patay dans cette même année : il représenta un des pairs au sacre de Charles VII. Amiral de France en 1437, il remit cette charge, reçut celle de maréchal de France en 1439 : après s'être distingué à l'assaut de Pontoise en 1441, et avoir commandé l'avantgarde de l'armée française en 1442, dans l'expédition de Guyenne; il contribua à la prise de Tartas le 23 juin, se trouva à celle du Mans en 1447, de Coutances, de Saint-Lô, de Carentan, en 145ั0, au combat de Formigny, à la prise de Cherbourg, en 1450, et s'empara, en 1453, de Castillon et de Bordeaux. Suspendu de sa charge de maréchal en 1461, il fut créé lieutenant général au gouvernement de Paris, en 1465. Rétabli dans ses charges de maréchal et d'amiral de France, Louis XI le nomma, en 1469, chevalier de l'ordre de Saint-Michel. Il mourut en janvier 1486, à l'âge de soixante-quinze ans.

\section{Coëtivy (Prégent VII, seigneur de).}

Peinture du XvmIe siècle. - H. 0,76. - L. 0,65.

Lieutenant de Charles VII, alors dauphin, il soutint, en 142I, un siége dans le château de Montaguillon, fut capitaine en 1431, chambellan du roi en 1434, se trouva en 1437 à la reprise de Montereau, et reçut, la même année. le gouvernement de La Rochelle. Charles VII lui donna, en 1439, la charge d'amiral, en remplacement d'André de Laval, seigneur de Lohéac, nommé maréchal de France, Après avoir pris part à toutes les guerres de son temps, l'amiral de Coëtivy fut tué d'un coup de canon au siége de Cherbourg, en 14500, à l'ấge de cinquante ans. 
909. Bueil (Jean, sire de).

Peinture du XvıII ${ }^{\mathrm{e}}$ siècle. - H. 0,76. - L. 0,65.

Il défit les Anglais en 1431, près de Beaumont-le-Vicomte, et en 1435, vers Meulan et Gisors, surprit en 1439, par escalade, la ville de Sainte-Suzanne, servit en 1441 au siége de Pontoise, et suivit le dauphin en Allemagne, en 1444. Pendant la conquête de la Normandie, il servit sous le comte de Dunois, et se trouva aux prises de Rouen, Bayeux, Caen et Cherbourg, en 1450. Il fut pourvu de la charge d'amiral après la mort du sire de Coëtivy, en 1450, était à la prise de plusieurs places de Guyenne en $145 \mathrm{i} 1$ et 1453, et se signala à la bataille de Castillon en Périgord. Destitué de sa charge d'amiral en 1461, il continua à servir sous Louis XI, qui le fit chevalier de l'ordre de Saint-Michel en 1469; il était de plus conseiller et chambellan du roi, et commandait encore une compagnie de quatre-vingt-quinze lances en 1474. On ignore l'époque de sa mort.

\section{Montauban (Jean, sire de).}

Peinture du xviı ${ }^{\mathrm{e}}$ siècle. - H. 0,76. - L. 0,65。

Le sire de Montauban suivit le duc de Bretagne lors de la conquête de Normandie, et se trouva à la prise de Caen, de Cherbourg et de toutes les places de cette province, occupée par les Anglais. Nommé bailli de Costentin en $\mathbf{1 4 5 0} 0$, Louis XI le créa grand maître des eaux et forêts le 3 août 1461, et amiral le 8 octobre de la même année. Il mourut à Tours en mai 1466.

\section{Bourbon (Louis, bâtard de).}

Peinture du xviII siècle. - H. 0,76. - L. 0,65.

Fils naturel de Charles Ier, duc de Bourbon, il fut maréchal et sénéchal du Bourbonnais, gouverneur du Dauphiné et lieutenant général en Normandie. Légitimé en 1463, il épousa en 1465 Jeanne, fille naturelle de Louis XI, fut amiral de France en 1466, et chevalier de Saint-Michel en 1469. Il mourut le 19 janvier 1486.

\section{Graville (Louis Malet, sire de).}

Peinture du xviII ${ }^{\mathrm{e}}$ siècle. - H. 0,76. - L. 0,65.

Capitaine de cent gentilshommes de la chambre du roi, de 1475 à 1481, capitaine de Dieppe en 1480, chevalier de l'ordre de Saint-Michel, Graville fut nommé amiral en 1486, après la mort de Louis de Bourbon. Il se trouva à la journée de Saint-Aubindu-Cormier en 1488, fut capitaine des ville et châteaux de 
Saint-Malo et de Vincennes, et suivit le roi Charles VIII en Sicile et à Naples en 1494. Il se démit, en 1508' de la charge d'amiral en faveur de Charles d'Amboise, son gendre, après la mort duquel il y fut rétabli en 1511 , et mourut le 30 octobre 1516 , au château de Marcoussis, à l'âge de soixante-dix-huit ans.

\section{Amboise (Charles d'), seigneur de Chaumont.}

Peinture du xvirre siècle. - H. 0,76. - L. 0,65.

Connu d'abord sous le nom de seigneur de Chaumont, il fut capitaine de trente lances en 1494, conseiller et chambellan du roi, gouverneur et lieutenant général de la ville de Paris et de l'Ile-de-France, du 3 février 1495 au 2 juin 1496, et gouverneur. du duché de Milan en 1500. Maréchal de France en février 1506 , il remit Pérouse et Bologne sous l'obéissance du pape, et s'empara, le 27 avril 1507, de Gênes, révoltée contre Louis XII. Amiral de France en 1508, il commanda avec le maréchal Trivulce l'avant-garde à l'armée du roi, à la bataille d'Aignadel, en 1509, et s'empara en 15010 du Polésin, de Vicence et de Legnano. Etant tombé malade à Correggio (Lombardie), il y mourut le 11 février 1511, à l'âge de trente-huit ans.

Le portrait original, attribué à Léonard de Vinci, puis à Solario, est au Musée du Louvre. Il a été faussement désigné sous les noms de Charles VIII et de Louis XII, erreur qui n'existait pas encore au XVIII $^{\mathrm{e}}$ siècle, puisque ce portrait était alors copié comme celui de Charles d'Amboise.

\section{Bonnivet (Guillaume Gouffier, seigneur de).}

Peinture du xviı ${ }^{\mathrm{e}}$ siècle. - H. 0,76. - L. 0,61.

Il était en 1507 au siége de Gênes, et en 1513, à la Journée des Eperons. Nommé chevalier de l'ordre de Saint-Michel, amiral de France en 1517, ambassadeur en Allemagne en 1518, gouverneur du Dauphiné en 15\%19, de la Guyenne en 1521, il commanda en chef l'armée envoyée en Navarre et s'empara de Fontarabie. Lieutenant général de l'armée du roi en Italie, il fut tué à la bataille de Pavie, le 24 février 1525.

\section{Chabot (Philippe), comte de Charny et de Buzan- cois, seigneur de Brion, etc.}

Peinture du xviII ${ }^{\mathrm{e}}$ siècle. - H. 0,76. - L. 0,61.

Il défendit Marseille en 1522, combattit à Pavie en 1523, fut nommé chevalier de l'ordre de Saint-Michel et ensuite amiral de France en 1526. Ambassadeur en Angleterre dans l'année 1อ̆32, il recut l'ordre de la Jarretière. Philippe Chabot commanda en 1535 et 1536 l'armée de Piémont. Il tomba en 1536 dans la disgrâce de François I'er, qui l'accusait de n'avoir pas poussé ses 
conquètes comme il le pouvait, fut privé de sa charge en $10 \breve{41}$. et ensuite rétabli dans ses dignités par lettres patentes du 19 mars 10ั42. Il mourut à Paris le $1^{\text {er juin } 10 \% 43 . ~}$

\section{Annebaut (Claude d'), baron de Retz.}

Peinture du $\mathrm{xrrir}^{\mathrm{e}}$ siècle. - H. 0,76. - L. 0,61.

Il fit ses premières armes à la défense de Mézières assiégé en 1021 par le comte de Nassau, et fut fait prisonnier à la bataille de Pavie, en 15225. Conseiller, chambellan du roi, bailli et capitaine d'Evreux, chevalier de l'ordre de Saint-Michel en 153\%, commandant de l'armée française destinée à entrer dans le Piémont, il s'empara de Turin. Lieutenant général en Normandie avec l'amiral Chabot, le 7 mars 10336 , il s'empara de Carignan, de Montcallier, de Quiers et de Saluces. Nommé maréchal de France en 1538, et gouverneur général du Piémont en 1539, il se démit de sa lieutenance générale de Normandie. Ambassadeur à Venise en 1539, il revint en France en 1วั40, et fut associé au cardinal de Tournon, chargé de la conduite des affaires. De nouveau lieutenant général de la Normandie le 6 décembre 15ั42, il remit au roi le gouvernement du Piémont. Nommé amiral de France en 10ั44, après la mort de Chabot, il se démit alors de la charge de maréchal de France. Commandant l'armée de mer en $15 \% 450$, il remporta une victoire en vue de l'ìle de Wight sur l'armée anglaise. Conseiller de la reine Catherine de Médicis, régente du royaume, en 15 วั2, il mourut à La Fère en novembre 1 วัวั2.

\section{Coligny (Gaspard, comte de), seigneur de Châ- tillon.}

Peinture du xviri ${ }^{\mathrm{e}}$ siècle. - H. 0,76. - L. 0,61.

Né à Châtillon le 16 février 15̆16, il était fils du maréchal de Châtillon et fit les dernières campagnes du règne de François I ${ }^{\mathrm{er}}$. Chevalier de l'ordre de Saint-Michel et colonel général de l'infanterie française en $15 \mathbf{L}^{4} 7$, il fut envoyé en Angleterre pour traiter de la paix en 15̌20. Gouverneur général de Paris et de l'Ile de France en 1วัว̆1, amiral de France en 15ัวั2, il eut le commandement de l'infanterie francaise dans l'armée de Picardie en 15\%63, et combattit sous les ordres de Henri II, en 1ŏŏ4, à la bataille de Renty. Après la mort de ce prince, il résigna tous ses emplois, se retira dans ses terres et embrassa publiquement la réforme. En 1ว̌62, lorsque les guerres de religion éclatèrent, il partagea avec le prince de Condé le commandement des armées protestantes, et combattit sans succès à Dreux, à Saint-Denis, à Jarnac et à 
Montcontour. Après le traité de paix conclu avec les protestants en 1570, il avait été rétabli dans toutes ses charges; il fut assassiné à Paris le jour de la Saint-Barthélemy (24 août 1572).

\section{Villars (Honorat de Savoie, marquis de).}

Peinture du xvine siècle. - H. 0,76. - L. 0,61.

Connu sous le nom de comte de Villars jusqu'en 1563, Honorat de Savoie fut lieutenant général du Languedoc en 1547, et chevalier de l'ordre de Saint-Michel en 1549. Il pacifia le Languedoc en 1560 , combattit les calvinistes à la bataille de Saint-Denis, en 1567, à Jarnac et à Montcontour en 1569, obtint la même année la charge d'amiral de France, fut nommé lieutenant général de Guyenne en 1570, maréchal de France en 1571, et chevalier des ordres du roi en 1578. Il mourut à Paris en 1508.

\section{Mayenne (Charles de Lorraine, duc de).}

Peinture du xvine siècle. - H. 0,76. - L。 0,61.

Néà Alencon le 26 mars 15๊̌4, il était le deuxième fils de Francois de Lorraine, duc de Guise. Il fit les guerres contre les protestants, se distingua au siége de Poitiers, ainsi qu'à la bataille de Moncontour en 1569 , et fit une campagne contre les Turcs en 15770. Amiral de France en 1578, sur la démission du marquis de Villars, 'son beau-père, il exerça cette charge jusqu'en 1582, et fut dans cette même année nommé chevalier de l'ordre du Saint-Esprit. Après l'assassinat de son frère, le duc de Guise, aux états de Blois, en 1588, il fut reconnu comme chef de la Ligue, et prit en 1589 le titre de lieutenant général de l'Etat et Couronne de France. L'armée du roi d'Espagne ayant été défaite au combat de Fontaine-Française en 1595 , le duc de Mayenne rentra au service d'Henri IV, qu'il suivit, en 1597, au siege d'Amiens. Il mourut à Soissons le 4 octobre 1611 .

\section{Joyeuse (Anne, duc de).}

Peinture du xviII ${ }^{\mathrm{e}}$ siècle. - H. 0,76. - L. 0,61.

Né en 1561, fils du maréchal Guillaume de Joyeuse, il fut d'abord connu sous le nom de baron d'Arques, et se trouva au siége de La Fère en 1570. Elevé rapidement aux plus hautes dignités par la faveur de Henri III, il fut créé duc et pair de France en 1581, prit alors le titre de duc de Joyeuse, et fut marié la même année à Marguerite de Lorraine, soeur de la reine Louise de Vaudémont. Amiral de France et chevalier de l'ordre du Saint-Esprit 
en 1582, il fut gouverneur de Normandie et commandant gẻnéral de l'armée de Guyenne. Le duc de Joyeuse fut tué à la bataille de Coutras, le 20 octobre 1587.

\section{Epernon (Jean-Louis de Nogaret de La Valette, duc d').}

Peinture du xviII siècle. - H. 0,76. - L. 0,61.

Né en 15̌2̌, et connu d'abord sous le nom de Caumont, il fut quelque temps au service du roi de Navarre (depuis Henri IV) ; il s'attacha ensuite au roi Henri III, qui le créa duc et pair de France en 1581. Le duc d'Epernon fut successivement premier gentilhomme de la chambre du roi, colonel général de l'infanterie française, chevalier de l'ordre du Saint-Esprit, et enfin amiral de France en 1587. Henri IV le nomma gouverneur de Provence. Sous le règne de Louis XIII il secourut l'île de Ré, assiégée en 1627 par la flotte anglaise, et mourut à Loches le 13 janvier 1642.

\section{Nangis (Antoine de Brichanteau, marquis de).}

Peinture du xvirie siècle. - H. 0,76. - L. 0,61.

Gentilhomme ordinaire de la chambre du duc d'Anjou, et guidon de la compagnie du grand prieur de France, en 1569, il se trouva au siége de Mucidan et à la bataille de Montcontour, et suivit le duc de Mayenne dans la campagne contre les Tures en 1570. Mestre de camp commandant d'un régiment des gardes en 1575 , il servit dans le Poitou contre les protestants. Ambassadeur en Portugal et conseiller d'Etat en 1579, il fut pourvu de la charge d'amiral de France en 1589. Chevalier des ordres du roi en 15\%92, il se démit de sa charge d'amiral en $15{ }^{\circ} 9{ }^{\circ}$, et suivit Henri IV au siége de La Fère. Le marquis de Nangis était député aux Etatsgénéraux de 1614, et mourut à Nangis le 9 août 1617, à soixantecinq ans.

\section{La Valette (Bernard de Nogaret, seigneur de).} Peinture du xviII ${ }^{\mathrm{e}}$ siècle. - H. 0,76。 - I. 0,61.

Il se signala en diverses occasions dans les guerres d'Italie, fut chevalier des ordres du roi en 15̋3, gouverneur du Dauphiné et de Provence en 15587. Il devint amiral de France en 1589 sur la démission du duc d'Epernon, son frère, fit lever le siége de Barcelonnette au duc de Savoie, défit ses troupes et remporta sur lui la victoire d'Esparon en 15̆91. Il mourut le 11 février 1592, à l'âge de trente-neuf ans, d'une blessure qu'il reçut devant Roquebrune. 


\section{Biron (Charles de Gontaut, duc de).}

Peinture du XvıII ${ }^{\mathrm{e}}$ siècle. - H. 0,76. - L. 0,61.

Il fit ses premières armes en 1530 sous les ordres de son père Armand de Gontaut, maréchal de France, dans la campagne de Guyenne. En 1589 il commandait à Orléans, et se trouva en 1590 à Arques et à Ivry. Chevalier des ordres du roi en 1591, il fit la campagne de Normandie et fut pourvu en 1592 de la charge d'amiral de France, dont il se démit en 1594. Nommé la même année maréchal de France, commandant de l'armée de Bourgogne

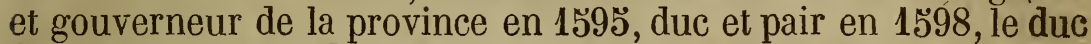
de Biron s'empara de la Bresse en 1600; ambassadeur extraordinaire en Suisse, il confirma le traité d'alliance avec les TreizeCantons. Ayant conspiré contre Henri IV, il fut décapité à la Bas* tille le 31 juillet 1602, à l'âge de quarante ans.

\section{Villars (André-Baptiste de Brancas, seigneur de).}

Peinture du xviII e siècle. - H. 0,76. - L. 0,61.

Capitaine de cent hommes d'armes et lieutenant général aux baillages de Rouen et de Caux, gouverneur du Havre-de-Grace, Villars fut nommé par Henri IV au gouvernement de Rouen et de Calais. Amiral de France, sur la démission du maréchal de Biron, le 23 août 1594, chevalier de l'ordre du Saint-Esprit en 1595 , il fut tué au combat de Dourlens le 24 juillet 1595.

\section{Damville (Charles de Montmorency, duc de).}

Peinture du xvirre siècle. - H. 0,76. - L. 0,61.

Troisième fils du connétable Anne de Montmorency, il fut connu d'abord sous le titre de seigneur de Méru, et combattit en $15 ૅ 5 \% 7$ à la bataille de Saint-Quentin, où il resta prisonnier. Il assista aux sacres des rois de France François II et Charles IX, fut gouverneur de Paris et de l'Ile de France en 1562, et se trouva aux batailles de Dreux, de Saint-Denis et de Montcontour. Nommé colonel général des Suisses, il prit le nom de Damville; amiral de France et de Bretagne en 1596, chevalier de l'ordre du SaintEsprit en 1597, duc et pair en 1610, il mourut en 1612, à l'âge de soixante-quinze ans.

\section{Montmorency (Henri II, duc de).}

Peinture du xvirie siècle. - H. 0,76. - L. 0,61.

Né à Chantilly le 30 avril 4595 , il était fils du connétable Henri Ier de Montmorency, et avait été tenu sur les fonts de baptême par Henri IV. Amiral de France et de Bretagne en 1612, et nommé 
dans la même année vice-roi de la Nouvelle-France (Canada), il fut chevalier des ordres du roi en 1619 et servit activement pendant les années 1621, 1622 et 1625. Commandant la flotte hollandaise contre les Rochellois, il détacha six vaisseaux pour sol1tenir La Rochefoucauld, Saint-Luc et Toiras, qui descendaient dans l'île de Ré, et il remporta une victoire complète, Le duc de Montmorency se démit de la charge d'amiral en 1626. Maréchal de France le 11 décembre 1630, il combattit contre les troupes du roi Louis XIII à Castelnaudary, où, ayant été fait prisonniel, il fut décapité à Toulouse le 30 octobre 1632.

\section{Richelieu (Armand-Jean du Plessis, cardinal, duc de).}

Peinture du XviII ${ }^{\mathrm{e}}$ siècle. - I. 0,76، - L. 0,61.

Né à Paris le ă septembre 1ö8ว̆, il fut d'abord destiné aux armes puis reçut les ordres. Evêque de Luçon en 1607, il fut successivement grand aumônier de la reine régente Marie de Médicis, premier secrétaire d'Etal au département de la guerre en 1616 , surintendant de la maison de la reine en 1621, cardinal en 1622, et ministre d'Etat en 1624. Grand maître, chef et surintendant général de la navigation et du commerce de France en octobre 1616, il commanda l'armée du roi en 1628, et fut premier ministre en 1729. Lieutenant général du roi, il commanda de noulveau ses armées en Italie et suivit Louis XIII dans la conquête de la Savoie. Chevalier des ordres du roi, lors de la promotion du 14 mai 1633, gouverneur général du Havre-de-Grâce en 1640, il était encore général des ordres de Cluny, de Prémontré et de Citeaux, et mourut à Paris, au Palais-Cardinal, le 4 décembre 1642 , à l'âge de cinquante-sept ans.

\section{Maillé (Armand de), duc de Brézé.}

Peinture du xvine siècle. - H. 0,76. - L. 0,61.

Connu d'abord sous le nom de marquis de Brézé, il combattit en 1635 à Avein contre les Espagnols. Grand maître et surintendant de la navigation, en survivance du cardinal de Richelieu, son oncle, le 22 juin 1636, il se trouva aux siéges de Corbie, de Landrecies, de Maubeuge en 1637, et de Saint-Ouen en 1638. Commandant de l'armée navale, il défit la flotte espagnole dans plusieurs rencontres. Grand maitre, chef et surintendant général de la navigation et du commerce de France, en 1642, Louis XIII lui donna le gouvernement général du pays d'Aunis, de La Rochelle et de Brouage. Reçu au parlement comme duc et pair de France, le 30 avril 1643, nommé chef de l'armée navale 
le 11 août suivant, il défit la flotte des Espagnols en vue de Carthagène le 3 septembre; leur ayant livré un nouveau combat sur les côtes de la Toscane le 14 juin 1646, il y fut tué à l'âge de vingt-sept ans.

\section{Anne d'Autriche, reine de France.}

Par Steuben. - H. 2,82. - L. 2,17.

Née le 22 septembre 1601, fille de Philippe III, roi d'Espagne,

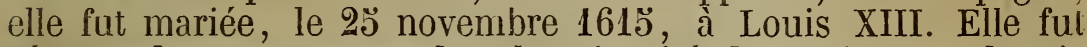
régente du royaume pendant la minorité de Louis XIV, depuis le 18 mai 1643 jusqu'au 7 octobre $163 \%$, et exerca, de 1646 à 16อั0, la charge de grand maître, chef et surintendant général de la navigation et du commerce de France. Elle mourut au Lourre le 20 janvier 1666 .

Elle est représentéc assise, et vêtue de noir ; au fond la mer courerte de vaisseaux.

\section{Vendôme (César, duc de) et de Beaufort.}

Peinture du xviII ${ }^{e}$ siècle. - H. 0,76. - L. 0,61.

Fils naturel de Henri IV et de Gabrielle d'Estrées, il naquit au château de Coucy, en Picardie, au mois de juin 1594, et fut légitimé en 1595ั. Gouverneur des provinces de Lyonnais, Forez et Beaujolais en 1595 , et de la province de Bretagne en 1508 , chevalier des ordres du roi en 1619, il commanda l'armée de Bretagne en 1626. Pourvu par Louis XIV de la charge de grand maître, chef et surintendant général de la navigation et du commerce de France le 12 mai 1650 , le duc de Vendôme prit part à la guerre contre l'Espagne, s'empara de Bourg (Guyenne) en 16033 , et livra, en septembre 16כ5, un combat naval en vue de Barcelone, où il dispersa la flotte espagnole. Il mourut à Paris le 22 octobre $166 \%$.

\section{Beaufort (François de Vendôme, duc de).}

Peinture du xvin ${ }^{\mathrm{e}}$ siècle. - H. 0,76. - L. 0,61.

Né à Paris en 1616 , fils de César de Vendôme el petit-fils d ${ }^{\circ}$ Henri IV, le duc de Beaufort était à la bataille d'Avein en 1635 , aux siéges de Corbie, de Hesdin et d'Arras en 1636, 1639 ei 1640. Nêlé aux troubles de la Fronde, dans lesquels il reçut du peuple le nom de Roi des Halles, il se réconcilia avec la cour et fut nommé grand maître, chef et surintendant général de la navigation et du commerce de France en 16コ0. Chevalier de l'ordre du Saint-Esprit en 1661, il fit, en 1664, une campagne 
sur la Méditerranée contre les Turcs, dispersa en 1669 leur flotte près de Tunis et d'Alger, et fut tué devant Candie le 25 juin 1669.

\section{Vermandois (Louis de Bourbon, comte de).}

Peinture du XvirI siècle. - H. 0,76. - L. 0,61.

Fils naturel de Louis XIV et de la duchesse de La Vallière, né au vieux château de Saint-Germain-en-Laye le 2 octobre 1667, il fut légitimé en 1669. La charge d'amiral de France fut rétablie pour lui, par édit du mois de novembre 1669. Le comte de Vermandois se rendit, en 1683 , devant Courtray, à l'armée commandée par le maréchal d'Humières; la place fut prise le 12 novembre, et le 18 le prince mourut d'une fièvre putride à l'âge de seize ans.

\section{Toulouse (Louis-Alexandre de Bourbon, comte de).}

Ėcole française. - H. 0,76. - L. 0,61.

Fils légitimé de Louis XIV et de la marquise de Montespan, il naquit le 6 juin 1678. Grand amiral de France en 1683, chevalier des ordres du Roi en 1692, le comte de Toulouse était au siége de Mons en 1691, à la prise de Namur en 1693, et servit comme maréchal de camp dans l'armée du maréchal Boufflers en 1696. Lors de la guerre de la succession, le comte de Toulonse commanda la flotte française dans la Méditerranée, et remporta, le 24 août 1704, la vicioire navale de Malaga. Chevalier de la Toison d'Or, grand veneur de France, il fut l'un des conseillers du conseil de régence, et chef du conseil de la marine en septembre $\mathbf{1 7 1 5}$. Il mourut le $\mathbb{1}^{\text {er }}$ décembre $\mathbf{1 7 3 7}$.

\section{Penthièvre (Louis-Jean-Marie de Bourbon, duc de).}

Par Jean Gharpentier. - H. 0,76. - L. 0,61.

Né à Rambouillet le 16 novembre 1725, il était fils du comte de Toulouse, et fut amiral de France en survivance de son père le $1^{\text {er }}$ janvier 1734. Grand veneur en 1738, chevalier de la Toison d'Or et des ordres du Roi en 1742, le duc de Penthièvre fit la campagne d'Allemagne en 1743 , et se trouva en 1744 aux siéges de Mrenin, d'Ypres, de Furnes et de Fribourg. Il était à la bataille de Fontenoy en $\mathbf{1 7 4 5}$, et mourut au château de Bissy, près de Vernon, le 4 mars 1793, à l'âge de soixante-huit ans. 


\section{Murat (Joachim).}

Par M. Ch. Lefebvre, d'après Gérard. - H. 0,76 - L. 0,61.

Né à la Bastide-Fortunière, près Cahors, le 200 mars 1767, il fut d'abord destiné à l'état ecclésiastique, puis entra dans le $12 \mathrm{e}$ régiment de chasseurs en 1787, et fut successivement, en 1792 , brigadier, maréchal des logis, sous-lieutenant et lieutenant. Capitaine et chef descadron au $21^{\mathrm{e}}$ de chasseurs à cheval en 1793 , chef de brigade, aide de camp du général Bonaparte et général de brigade en 1796, il fit les campagnes d'Italie en 1796 et 1797 , d'Egypte en 1798 et 1799 , et fut nommé général de division. Marié le 10 janvier 1800 à Marie-Annonciade-Caroline Bonaparte, sœur de Napoléon, il commanda le corps d'observation rassemblé à Dijon et fitla campagne de Marengo. Général en chef del'armée d'observation du Midi en 1801, il fut en 1802 gouverneur de la République Cisalpine. Chargé du commandement des troupes de la $1^{\text {re }}$ division militaire et de celui de la garnison et de la garde nationale de Paris en 1804, il fut, la même année, maréchal de l'empire. Prince de l'empire, grand amiral, grand-aigle de la Légion d'honneur, grand dignitaire de l'ordre de la Couronne de Fer, et lieutenant général de la grande armée en 1805̆, il commanda en chef la réserve de cavalerie et suivit l'empereur Napoléon dans sa campagne d'Austerlitz. Grand-duc de Clèves et de Berg en 1806, il fit la campagne de Prusse en 1806 et celle de Pologne en 1807. Général en chef de l'armée d'Espagne en 1808, il fut roi de Naples le $15 \%$ juillet de la même année et recut la grand'-croix de l'ordre de l'Aigle-Noir de Prusse, l'ordre de Saint-André de Russie, l'ordre de la Couronne de Saxe et l'ordre de Saint-Joseph de Wurtzbourg. Lieutenant général de la grande armée en 1812, il commanda toute la cavalerie dans la campagne de Russie, et après le départ de l'empereur, commanda en chef l'armée francaise pendant la retraite. Il commanda l'aile droite de l'armée française à la bataille de Dresde en 1813, combattit à Leipsick, et, de retour à Naples, se joignit aux armées de la coalation contre la France. Rallié à Napoléon après son retour de lîle d'Elbe, il perdit contre les Autrichiens la bataille de Tolentino, se réfugia dans le Midi de la France et en Corse, el tenta de reconquérir son royaume en débarquant dans le port du Pizzo. Il fut fait prisonnier, traduit devant une commission militaire, condamné à mort et fusillé le 13 octobre 1815 .

\section{Angoulême (Louis-Antoine d'Ariois, duc d').}

Par M. Ch. LeFebVRe, d'après Lawrence. - H. 0,76. - L. 0,61.

Fils aîné de Charles X, né à Versailles le 6 août 177.ั. Il épousa, 
en 1799, à Mittau, Marie-Thérèse-Charlotte de France, fille de Louis XVI, fit partie de l'armée de Condé et accompagna Louis XVIII à Varsovie et à Hartwell. Rentré en France en 1814, il commanda les troupes envoyées contre Napoléon à son retour de l'île d'Elbe, fut fait prisonnier et mis en liberté par ordre de l'empereur. Il commanda, en 1823, l'armée envoyée en Espagne au secours de Ferdinand VII, et après la révolution de 1830 , suivit Charles $\mathrm{X}$ en Angleterre, puis en Autriche. Il mourut à Goritz le 3 juin 1844 .

\section{SALLE DES CONNÉTABLES, No 43 . (Voir Salle n ${ }^{\circ} 41$. )}

Chambre à coucher du duc de Berry, petit-fils de Louis XIV.

La suite chronologique des trente-neuf connétables de France, depuis Albéric de Montmorency (1060) jusqu'au duc de Lesdiguières (1622), est représentée par une suite de portraits en buste ou d'écussons lorsque les portraits manquent ou que les personnages sont représentés en pied. Ces écussons contiennent les noms, titres, dates de promotion et de mort des connétables.

\section{Montmorency (Albéric de).}

Par M. Lavauden. - H. 2,15. - L. 1,40.

Albéric de Montmorency est désigné par les historiens comme ayant exercé le premier la charge de connétable. Il signa en 1060 la charte de fondation du prieuré de Saint-Martin-des-Champs faite par Henri I ${ }^{\text {er. }}$

Il est représenté en pied ; le portrait original fait partie de la galeric de la famille de Montmorency.

\section{Montmorency (Mathieu II de), dit le Grand,}

Par M. Lugardon. - H. 0,70. - L. 0,53.

Recu chevalier par Baudouin V, comte de Hainaut, il accompagna le roi Philippe-Auguste dans la conquête de la Normandie, et se trouva en 1214 à la bataille de Bouvines. Philippe-Auguste ajouta à son écusson douze alérions en mémoire des douze enseignes impériales qu'il avait prises à cette bataille. Connétable de France en 1219, il accompagna le roi Louis VIII en Poitou, lors de la guerre contre les Anglais en 1224. Pendant la minorité de saint Louis, il fut un des plus fidèles soutiens de la régente Blanche de Castille, et mourut le 24 novembre 1230.

\section{Montfort (Amaury VI, comte de).}

Par M. Henri Schefrer. - H. 2,15. - L. 1,40.

Il combattit en 1210 au siége dı château de Minerve, sous Simon de Montfort, son père, qui dirigeait la croisade contre les 
Albigeois, et reçut à Castelnaudary la ceinture militaire en 1213. Il se distingua au siége de Casseneuil, en 1214, et fit lever en 1223 le siége de Carcassonne aux comtes de Toulouse et de Foix. Nommé connétable par saint Louis en 1230, il passa en 1238 en terre sainte, fut fait prisonnier au siége de Gaza et conduit à Babylone. Il mourut à Otrante (Calabre) en 1241 pendant son retour en France.

Il est reprẻsenté en pied.

\section{Châtillon (Gaucher II, seigneur de).}

Par M. Monvorsin, en 1835. - H. 2,15. - L. 1,40.

Après avoir passé par tous les grades de la milice il fut créé connétable de Champasne en $\mathbf{1 2 8 6}$, et commanda depuis les troupes de cette province, combattit à la journée de Courtray et ful nommé connétable de France en 1302 . Créé comte de Porcéan (depuis Portien) en 1303, il se trouva à la bataille de Mons-enPuelle en 1304. Le connétable de Châtillon signa, comme commissaire, au nom du roi, les traités de paix faits avec l'Angleterre en 1325 et 1326 , commanda l'armée française à la bataille de Cassel en 1328, et mourut en 1329.

Il est représenté en piel.

\section{Espagne (Charles de Castille ou de la Cerda, dit d').}

Par M. Aug. COUdEr. - H. 0,70. - L. 0,53.

Il exerça en 1347 la charge de connétable pendant la captivité du comte d'Eu en Angleterre, et défendit Saint-Omer. Nommé connétable de France par le roi Jean, en 13ől, il fut son lieutenant en 135\%. Charles-le-Mauvais, roi de Navarre, le fit périr dans un guet-apens le 6 janvier $13 \check{4} 4$.

Le portrait original est au chàteau de Beauregard. (Voir $n^{\circ} 944$. )

\section{La Marche (Jacques de Bourbon, comte de).}

Par Blondel, en 1835. - H. 2,15. - L. 1,40.

Il se distingua à la bataille de Crécy, en 1346, défendit en 1349 et 1350 le Languedoc contre les Anglais, et fit la guerre en Picardie en 1351 et $135 \% 2$. Connétable en 1354, il commanda en Guyenne en 135̌5, se démit de la charge de connétable en 13306 , et se trouva la même année à la bataille de Poitiers. Blessé au combat de Brignais en 1361, il mourut des suites de ses blessures.

Il est représentẻ en pied. 


\section{Brienne (Gauthier de), duc d'Athènes.}

Par M. Rubio. - H. 0,71. - L. 0,53.

Il gouverna Florence comme lieutenant de Charles de Sicile, duc de Calabre, et en fut chassé par une conspiration populaire. Retiré en France, il servit Philippe VI dans les guerres contre les Anglais en 1339 et 1340 , fut nommé connétable par le roi Jean en $130 \% 6$, et fut tué à la bataille de Poitiers, le 19 septembre de la même année.

Le portrait original est au château de Beauregard (1).

\section{Du Guesclin (Bertrand).}

Par M. FéroN. - H. 2,15. - L. 1,37.

Né au château de la Motte-Broon (Bretagne) en 1314, il fit ses premières armes sous Charles de Blois, au siége de Rennes, en 1342, et prit part aux guerres de ce prince contre Jean de Montfort, pour l'héritage du duché de Bretagne. Il passa ensuite au service de la France, remporta en 136\% la victoire de Cocherel et fit couronner Henri de Transtamare, roi de Castille en 1366. Prisonnier des Anglais à la bataille de Navarette, en 1367, il fut rendu à la liberté en $\mathbf{1 3 6 8}$ et fut nommé connétable par Charles $^{\prime} \mathrm{V}$ en 1370. Il reconquit successivement sur les Anglais la Normandie, le Poitou, la Saintonge, le Limousin et la plus grande partie de la Guyenne, et mourut de maladie devant Châteauneuf de Randon le 13 juillet 1380 .

Il est représenté en pied. La tête est copiée d'après tin portrait qui se trourc au château de Beauregard.

\section{Clisson (Olivier, sire de).}

Par M. E. de LATSAC. - H. 2,73. - L. 2,03.

Issu d'une des plus anciennes familles de Bretagne, il fut élevé en Angleterre et combattit en 1364 pour Jean de Montfort, duc de Bretagne, à la bataille d'Auray où il perdit un œil. Il passa au service de la France en 1368, devint le frère d'armes de Du Guesclin, fut nommé lieutenant pour le roi en Poitou dans l'année 1371 et obligea les Anglais à lever le siége de Montcontour. Lieutenant général de Bretagne en 1377, il prit Auray et Dinan en 1380 et fut nommé connétable de France. Il se trouva à la bataille de Rosebecque en 1382, fit lever en 1383 le siége d'Ypres, investi par les Anglais, et se rendit maître de Bergues, de

(1) Le château de Beauregard, près de Blois, renferme une collection de portraits formée dans le Xvir ${ }^{\mathbf{e}}$ siècle par Gaspard de Fieubet, et qui remonte jusqu'à l'époque de Jean-le-Bon. Une grande partie de ces portraits a été copiée pour les galeries de Versailles. 
SALLE DES CONNÉTABLES, N゚ 43.

Gravelines et de Bourbourg. Destitué de la charge de connétable en 1392, pendant la démence de Charles VI, accusé de dilapidation et condamné à une amende de cent mille marcs d'argent, il se retira dans son château de Jousselin, en Brētagne, où il mourut le 23 avril 1407.

Il est reprẻsenté à cheval. Le portrait original est au château de Beauregard.

\section{Eu (Philippe d'Artois, comte d').}

Par Madzaisse. - H. 2,15. - L. 1,37.

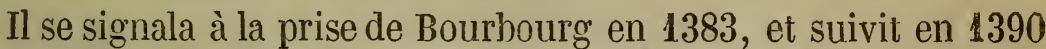
Louis II, duc de Bourbon, dans son expédition d'Afrique. Nommé connétable en 1392 après la disgrâce d'Olivier de Clisson, il suivit en Hongrie Jean-sans-Peur, qui portait alors le titre de comte de Nevers, et se trouva en 1396 à la bataille de Nicopolis où il fut fait prisonnier. Il mourut à Micalizo en Natolie, le 16 juin 1397.

Il est représenté en pied.

\section{Sancerre (Louis de Champagne, comte de).}

Par ZIÊGLER. - H. 2,73. - L. 2,03.

Il fut le frère d'armes de Du Guesclin et de Clisson, et fut nommé maréchal de France en 1368. Gouverneur général des provinces de Languedoc et de Guyenne, il recut en 1380 les clefs de Châteauneuf de Randon après la mort de Du Guesclin, se trouva à la bataille de Rosebecque en 1382, et soumit Marseille en 1384. Connétable de France en 1397, il fit rentrer le pays de Foix sous l'obéissance du roi en 1398, se démit en 1401 du gouvernement de Languedoc, et mourut le 6 février 1402 .

Il est représenté à cheval.

\section{Buchan (Jean Stuart, comte de).}

Par Blondel. - H. 0,71. - L. 0,55.

Fils de Robert Stuart, duc d'Albany et régent du royaume d'Écosse, il conduisit en France, dans l'année 1425, un corps d'armée écossais pour secourir le dauphin Charles (depuis Charles VII) contre les Anglais, et contribua au gain de la bataille de Beaugé en 1422. Connétable en 1424, il fut tué dans une bataille livrée sous les murs de la ville de Verneuil, le 17 août de la même année.

La peinture originale est au château de Beauregard. 


\section{Richemont (Artus de Bretagne, comte de), duc de Bretagne.}

Par M. Xavier DUPRE. - H. 0,71. - L. 0,55.

Recu chevalier en 1401 par Jean VI, duc de Bretagne, son frère aîné, ot gouverneur du duché de Nemours en 1414, il fut blessé et fait prisonnier à la bataille d'Azincourt en 1415ั. Connétable en 1430ั, il servit Charles VII dans les guerres contre les Anglais, fut nommé, en 1430ั, gouverneur et lieutenant général dans les pars de l'Ile de France, Normandie, Champagne et Brie, et fit rentrer Paris sous l'obéissance du roi en 1436. Il gagna en 1400 la bataille de Formigny, qui enleva la Normandie à la domination anglaise, devint duc de Bretagne en 14507 après la mort de son neveu, Pierre II, et mourut le 26 décembre 1458, à l’âge de soixante-cinq ans.

La peinture originale est au château de Beauregard.

\section{Saint-Pol (Louis de Luxembourg, comte de).}

Par Steubex. - H. 2,15. - L. 1,37.

Il servit d'abord sous Louis XI lorsqu'il n'était encore que dauphin, puis entra dans le parti du duc de Bourgogne et fut un des principaux chefs de la Ligue du Bien public. Après la bataille de Montlhéry, il reçut l'épée de connétable en $1460 ّ$ avec le gouvernement de la Champagne et de la Brie. Ambassadeur du roi en 1467 près le duc de Bourgogne, pour ménager la paix entre re prince et les Liégeois, et nommé chevalier de Saint-Michel, lors de l'institution de cet ordre en 1469 , il s'empara de SaintQuentin en 1470 et fit lever le siége de Beauvais à Charles-leTéméraire en 1472. Victime des dissentions du roi de France et du duc de Bourgogne, il fut jugé et condamné à mort par le parlement de Paris et eut la tête tranchée le 19 décembre $14.7 \%$.

Il est représenté en pied. La peinture originale est au château de Beauregard.

\section{Bourbon (Jean II, duc de).}

Par M. Legardor. - H. 0,71. - L. 0,55.

Fils aîné de Charles Ier, duc de Bourbon, il porta d'abord le nom de comte de Clermont, se trouva en $140 \mathrm{0} 0$ à la bataille de Formigny et en 14 3̈3 à celle de Castillon. Duc de Bourbon en 14อ̈6, grand chambellan de France en $140 ั 7$, il entra en 1463 dans la Ligue du Bien public. Après la paix de Conflans en 1460̈, il fut lieutenant général du roi au duché d'Orléans, gouverneur die Languedoc en 1466 et chevalier de Saint-Michel en $1^{\prime} 169$. 
Commétable de France en 1483, il se retira à Moulins, où il mourut le $1^{\text {er }}$ avril 1488, à l'âge de soixante-deux ans.

\section{Bourbon (Charles III, duc de), dit le Connétable de Bourbon.}

Par GaILLOT en 1835. - H. 2,15. - L. 1,40.

Il porta d'abord le titre de comte de Montpensier, et devint duc de Bourbon en 15ั0อ̆, par son mariage avec Suzanne de Bourbon, fille unique et héritière du duc Pierre II. Il fit ses premières armes en 15̌07, sous Louis XII, dans l'expédition contre les Génois, fut nommé pair de France en 1508 et se trouva à la bataille d'Aignadel en 1509. Gouverneur de Languedoc en 1512, il arrêta en 1513 l'irruption des Suisses en Bourgogne. Nommé connétable par Francois Ier en $15 \% 15$, il combattit à Marignan et fut vice-roi du Milanais. Persécuté par la reine mère, Louise de Savoie, le connétable de Bourbon passa au service de l'Espagne en 1523, combattit contre la France à Pavie, et fut tué au siége de Rome le 6 mai 15027, à l'âge de trente-sept ans.

Il est représenté en pied. La peinture originale faisait partie de la collection du château d'Eu.

\section{Montmorency (Anne, duc de).}

Par M. AyieL. - H. 2,15. - L. 1,40.

Né à Chantilly en 1492, il fut enfant d'honneur du duc d'Angoulême (depuis François I Ir), et fit ses premières armes à Marignan en 150 15. Admis au conseil du roi en 1520, premier gentilhomme de la chambre en 15221, il commanda en 1522 un corps de dix mille hommes Suisses en Italie. Maréchal de France et chevalier de Saint-Michel en 15222, il combattit à Pavie en 15025 , fut grand maitre de la maison du roi et gouverneur général du Languedoc en 1วั26. Il reçut en 15̌34 du roi d'Angleterre, Henri VIII, l'ordre de la Järetière, força en 1536 l'empereur Charles-Quint à lever le siége de Marseille et commanda en 15037 à Hesdin, Suze, Veillane, etc. Connétable de France en 1538, il fut en même temps chef de toutes les affaires de l'Etat, surintendant des finances et lieutenant général du roi. Disgracié en Iö4I, il fut rappelé de son exil par Henri II, qui le nomma duc et pair en 15ૅّ1. Il commanda en Lorraine en 15ัวั2, s'empara de Toul, de Hagueneau, de Wissembourg, et livra bataille aux Impériaux près de Dourlens en 15̆3̆3. Fait prisonnier à la bataille de Dreux en 1562, il chassa les Anglais du Havre en 1563, et mourut le 11 novembre 15067 d'une blessure qu'il avait reçue à la bataille de Saint-Denis.

II est représenté en pied. 


\section{Montmorency (Henri I, duc de).}

Par M. J. Étex. - H. 2,15. - L. 1,40.

Né à Chantilly en 15\%3, il était le second fils du connétable Anne de Montmorency, et fut d'abord connu sous le nom de seigneur de Damville. Gouverneur de la ville et du château de Caen en 15้วั1, il était en 15522 au siége de Metz, et commanda la cavalerie dans le Piémont en 1 อัǒs. Chevalier de l'ordre de Saint-Michel en 1 อ๊ŏ7, il fut nommé en $10 ّ 60$ colonel général de la cavalerie delà les monts; il accompagna en 15061 la reine Marie Stuart en Ecosse, et se trouva en 15262 à la bataille de Dreux. Gouverneur de Languedoc en 1อ̆63, maréchal de France en 10ั66, il garda depuis l'année 15369 jusqu'en 10 อั80 le commandement des troupes royales en Languedoc, Provence, Dauphiné et Guyemne, et s'empara de Fiac, de Lunel-Viel, de Teissargues, de Legues, de Monpezat, etc. La mort de son frère aîné lui donna le titre de duc de IIontmorency. Connétable de France en 1əั93, chevalier de l'ordre du Saint-Esprit en 1597, il commandait sous Henri IV au siége d'Amiens. Après la prise de Vervins en 1ૅ̆98, il se retira dans son gouvernement de Languedoc, où il mourut le 2 avril 1614, à lâge de quatre-vingts ans.

Il est représenté en pied. La peinture originale fait partie de la galerie de la famille de Montmorency.

\section{Luynes (Charles d'Albert, duc de).}

Par M. ROBERT-FLEURY.- H. 2,15. - L. 1,40。

Né à Pont-Saint-Esprit en 15̄78, il fut d'abord page de la chambre du roi Henri IV, qui le mit ensuite auprès de Louis XIII, encore dauphin. Gouverneur d'Amboise en 1610̈, il fut grand fauconnier de France en 1616 et premier gentilhomme de la chambre en 1617. Lieutenant général aux gouvernements de Normandie, de l'Ile de France et de Picardie, il fut créé en 1619 duc et pair de France et nommé chevalier de l'ordre du Saint-Esprit. Connétable de France en 1621, il s'empara de Namur et de Saint-Jean d'Angely, fut nommé garde des sceaux de France, et mourut le 15 décembre 1621 au camp de Longueville.

Il est représenté en pied. La peinture originale est au château de Dampierre.

\section{Lesdiguières (Francois de Bonne, duc de).}

Par M. Robert-FleUry. - H. 0,71 - - L. 0,55.

Né à Saint-Bonnet-de-Champsaur en 10̆43, il fut d'abord simple archer, et fit ses premières armes en $10 ّ 63$ dans l'armée des protestants. Lieutenant du roi de Navarre (Henri IV) en $15 \check{8} 8$, il reçut de ce prince, en 1589, le commandement des armées de Piémont, 
de Savoie et du Dauphiné, et s'empara de Montélimart, d'Embrun en 1590, et de Grenoble en 15\%91. Il commanda en Provence de l'année 15992 jusqu'en 15ั96. Lieutenant général commandant l'armée du roi en Piémont et en Savoie, il fit la campagne de 1597 et 1598 , et se rendit maître de Saint-Jean de Maurienne et du Mont-Cenis. Maréchal de France en 1609, conseiller d'honneur

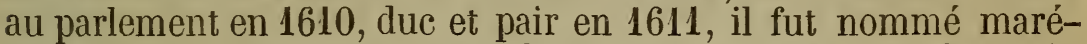
chal général des camps et armées du roi en 1621, connétable de France en 1622, chevalier de l'ordre du Saint-Esprit en 1523, et servit Louis XIII dans ses guerres jusqu'en 1626. Il mourut à Valence, le 28 septembre 1626.

Louis XIII supprima la dignité de connétable en 1627.

La peinture originale est au château de Beauregard.

\section{PREMIÈRE SALLE DES MARÉCHAUX, No 44.}

(Voir salle no 41 ).

Salle des gardes du clauphin en 1735 et grand cabinet de la dauphine en 1755.

La suite chronologique des maréchaux de France depuis Pierre (vers 1185) jusqu’à Arnoul, sire d'Audeneham (1351) est représentée par des écussons ou par des portraits en buste.

\section{Argentan (Henri Clément II, seigneur d') et du Mez.}

Par M. Couder. - H. 0,71. - L. 0,55.

Fils du maréchal de France Jean Clément, il succéda à son père dans cette dignité vers 1262, et mourut en 12603.

959. Montmorency (Charles, sire de).

Par Blondel. - H. 0,71. - L. 0,55.

Il servit en 1343 dans la guerre contre Édouard III, roi d'Anoleterre; maréchal de France en 1344, il commanda en 1345 l'armée de Guyenne, combattit à la bataille de Crécy en 1346, se démit de la charge de maréchal en 1347, et fut fait gouverneur de Picardie. Il fut parrain du roi Charles VI, et mourut le $\mathbf{1 1}$ septembre $\mathbf{1 3 8 1 .}$

960. Boucicault (Jean le Meingre II, dit).

Par M. Picot. - H. 2,15. - L. 1,40.

Fils de Jean le Meingre I, dit Boucicault, maréchal de France, il naquit à Tours en 136̆, et fut élevé à la cour du dauphin (depuis Charles VI), qui le fit chevalier en 1382. Il combattit à 
la bataille de Rosebecque, servit en Castille en 1386 et en Guyenne en 1387. Chambellan de France, en 1390, maréchal en 1391, il fut un des chefs de l'armée française qui alla secourir Sigismond, roi de Hongrie, contre les ottomans, et fut fait prisonnier à la bataille de Nicopolis. Rendu à la liberté, il retourna eu 1400 au secours de Constantinople qu'il sauva des mains des Turcs, et devint gouverneur de Gênes en 1401. Capitaine général en Languedoc en 1404, il fut fait prisonnier à la bataille d'Azincourt en 1415, et mourut captif en Angleterre au mois de mai 1421.

Il est représenté en pied. 'La peinture originale est au château de Beauregard.

\section{Beauvoir (Claude de), sire de Chastellux.}

Par M. Henri SchefFer. - H. 2,15. - L. $1,40$.

Conseiller et chambellan du duc de Bourgogne Jean-sans-Peur, en 1409, il fut nommé en 1418, pendant le triomphe de la faction Bourguignonne, maréchal de France, lieutenant et capitaine général du duché de Normandie et de la ville de Saint-Denis. Il mourut en 1453.

Il est représenté en pied. Ce tableau a été exécuté d'après un portrait de famille.

\section{Raiz (Gilles de Laval, sire de).}

Par M. FéRoN. - H. 2,15. - L. 1,40.

Il se signala dans les guerres du règne de Charles VII, défendit Orléans en 1428 et 14.29, et se trouva aux assauts de Jargeau, du pont de Meung et à la prise de Beaugency. Maréchal de France en 1429, il accompagna Dunois lorsqu'il battit le duc de Bedford à Lagny en 1432. Mis en jugement comme coupable contre l'autorité du duc de Bretagne, les crimes atroces dont il s'était souillé le firent cóndamner à mort. Il fut pendu et brûlé à Nantes le 2 ว้ octobre 1440.

Il est représenté en pied.

963. Lohéac (André de Montfort de Laval, seigneur de). (Voir n 907.)

Par M. FERON en 1835. - H. 2,74. - L. 2,02.

Il est représenté à cheval.

964. Xaintrailles (Jean, dit Poton, seigneur de),

Par M. Monvoisin en 1834. - H. 2,14. - L. 1,40.

Il servit en Picardie de 1419 à 1413 , se trouva en 1424. à la 
PREMIÉRE SALLE DES MARÉCHAUX, No 44.

bataille de Verneuil et suivit en 1427 le comte de Dunois au ravitaillement de Montargis. Xaintrailles était en 1429 au siége d'Orléans avec Jeanne d'Arce, et commanda l'avant-garde à la bataille de Patay, où il fit prisonnier le général anglais Talbot. Il continua de servir dans les guerres de Charles VII contre les Anglais, contribua en 1450 à la soumission de la Normandie, et en $145 \%$ à la conquête de la Guyenne. Sénéchal du Limousin en 1453, il fut nommé maréchal de France en 14อั4, et destitué par Louis XI à son avénement à la couronne en 1461. Il mourut à Bordeaux le 5 octobre 1461.

Il est représenté en pied. La peinture originale est au château de Beauregard.

965. Gyé (Pierre de Rohan, seigneur de).

Par M. Monvoisin en 1835. - H. 2,74. - L. 2,02.

Nommé par Louis XI chevalier de Saint-Michel, puis maréchal de France en 1476, il représenta le connétable au sacre de Charles VIII, en 1484, servit en 1486 et 1487 dans la Picardie, et en 1489 dans le Roussillon. Lieutenant général en 1491 au gouvernement de Bretagne, il passa les Alpes avec Charles VIII en 1494, et commanda l'avant-orarde à la bataille de Fornoue en 149.̈. Ił accompagna Louis XII dans la conquête du Milanais, el mourut le 22 avril 15014.

Ii est représenté à cheval. La peinture originale est au château de Beauregard.

966. Des Querdes (Philippe de Crèveccur, seigneur).

Par M. Eug. Devéria en 1835. - H. 2,14. - L. 1,40.

Écuyer de Charles-le-Téméraire, alors comte de Charolais, il se trouva au combat de Montlhéry en 14600 , et commanda les franes archers du prince contre les Liégeois en 1467. Gouverneur d'Artois et de Picardie, chevalier de la Toison d'Or en 1468, il passa après la mort de Charles-le-Téneéraire au service de Louis XI, qui le nomma chevalier de l'ordre de Saint-Michel. IIaréchal de France en 1483, il s'empara en 1487, de SaintOmer et de Térouanne, devint grand chambellan de France en 1493, et mourut à Bresse, près Lyon, le 22 avril 1494.

Il est représenté en pied. La peinture originale est au château de Beauregard.

\section{Trivulce (Jean-Jacques).}

Par M. Monvoisin en 1835. - H. 2,74. - L. $2,02$.

Il était d'une famille milanaise, et s'attacha au roi Charles VIII lorsque ce prince vint en Italie. Capitaine de cent lances en 1495 , 
il commanda l'avant-garde à la bataille de Fornoue et fut nommé conseiller, chambellan du roi, et chevalier de l'ordre de SaintMichel. Maréchal de France en 1499, il fit la conquête du duché de Milan sous le règne de Louis XII, s'empara de Concordia et de Bologne en 1511, et combattit à Marignan en $15 \% 15$. Il mourut à Châtre, près Montlhéry, le š décembre $15 ̋ 18$.

Il est représenté à cheval. La peinture originale est au château de Beauregard.

\section{Lautrec (Odet de Foix, seigneur de),} Par M. TrEzEL. - H. 2,14. - L. 1,40.

II suivit Louis XII au siége de Gênes en 1507, et fut nommé chevalier de l'ordre de Saint-Michel et maréchal de France en 15011. Il se trouva à la bataille de Ravenne en $15 \% 12$, et reç le gouvernement général de Guyenne. Au passage des Alpes, en $15 \% 15$, il commandait le corps de bataille que conduisait François ${ }^{\mathrm{er}}$, et il continua de faire la guerre en Italie jusqu'en 1522. Amiral de Guyenne en 15226, général de l'armée d'Italie en 15227, il s'empara de Gênes, de Pavie, et prit Melphes d'assaut en 15ّ28. Il assiégeait la ville de Naples lorsqu'il mourut de la peste sous ses murs, le 15 août 15228.

Il est représenté en pied. La peinture originale est au château de Beauregard.

969. La Palice (Jacques de Chabannes, seigneur de). Par M. Émile de Lansac. - H. 2,74. - L. 2,02.

Il fit ses premières armes en Bretagne en 1486 et 1487, se trouva à la bataille de Saint-Aubin-du-Cormier en 1488, suivit à Naples le roi Charles VIII en 1494, et combattit à Fornoue en 149气̆. En 1499, il accompagna Louis XII dans le Milanais; il était en 1506 à la prise de Bologne, en 1507 à celle de Gênes, et en 1 ő09 à la bataille d'Aignadel. Grand maître de la maison dı roi en 1511, il combattit à Ravenne en 1512, fut nommé maréchal de France en 15150 , et se trouva à la prise de Villefranche et à la bataille de Marignan. Le maréchal de La Palice était en 1522 à la journée de la Bicoque; il se rendit en 1523 sur les frontières d'Espagne, au secours de Fontarabie, s'empara d'Avignon en 1524 , et fut tué à la bataille de Pavie le 24 février 1525.

Il est représenté à cheval. La peinture originale est au château de Beauregard.

\section{Lescun (Thomas de Foix, seigneur de).}

Par ZIÉGLER. - H. 2,14. - L. 1,40.

Il était frère puîné du maréchal Lautrec, suivit Francois I ${ }^{\text {cr }}$ en Italie, et combattit en 1515 à Marignan. Chevalier de l'ordre 
de Saint-Michel et maréchal de France en 15\%18, il commanda dans le Milanais en 1521, prit Novarre en 1522, et se trouva à la journée de la Bicoque. Blessé à la bataille de Pavie, il mourut des suites de sa blessure le 3 mai 15้2ว.

Il est représenté en pied. La peinture originaie est au château de Beauregard.

\section{La Marck (Robert de), seigneur de Fleuranges.}

Par M. Picot, - H. 2,14. - L. 1,40.

Connu d'abord sous le nom de seigneur de Fleuranges, et désigné aussi par le surnom du Jeune adventureux, il se trouva aux batailles de Novarre en 1513 et de Marignan en 1515. Capitaine de la compagnie des Cent-Suisses de la garde du roi en 1516 , chevalier de l'ordre de Saint-Michel en 1518, il fut fait prisonnier à la bataille de Pavie en 1525. Maréchal de France en 1526, il défendit Saint-Quentin et Péronne en 1536, et mourut à Longjumeau en 1537. - Il a écrit pendant sa captivité des Mémoires qui s'étendent de 1499 à 1521.

Il est représenté en pied. La peinture originale est au château de Beauregard.

\section{Trivulce (Théodore).}

Par $\mathrm{M}_{2}$ Rouget. - H. 2,14. - L. 1,40.

Il combattit avec le maréchal Jean-Jacques Trivulce, son oncle, à la bataille d'Aignadel en 1509 , et fut nommé chevalier de l'ordre de Saint-Michel. Il était à la bataille de Ravenne en 1512 , commanda à Milan en 152こ, devint maréchal de France en 1526 ct gouverneur de Gênes en 1527. Il reçut en 1528 le gouvernement de Lyon, et mourut dans cette ville en 1531 .

Il est représenté en pied. La peinture originale est au château de Beauregard.

973. Annebaut (Claude d'). (Voir no 916.$)$

Par M. A. Brune. - H. 2,14. - L. 1,140.

Il est représenté en pied.

\section{Brissac (Charles de Cossé, comte de).}

Par M. Eug. Devénis, en 1835. - H. 2,14. - L. 1,40.

Enfant d'honneur, puis écuyer du dauphin, fils de François I ${ }^{\text {er }}$, il se distingua au siége de Naples en 15\%28. Grand fauconnier dé France en 1כ̋40, il fut blessé au siége de Perpignan en 15ّ42, commanda la cavalerie légère en Piémont, et suivit François I $^{\text {er }}$ en Flandre en 15ّ43. Ghevalier de l'ordre de Saint-Michel, grand maitre de l'artillerie et grand pannetier de France en 1547, il reçut, en 1550 , le gouvernement du Piémont et le bâton de ma- 
réchal de France, et se signala en Italie jusqu'en 15558 par ume suite d'exploits. Gouverneur de Picardie en 15วว9, lieutenant général commandant à Paris en 15ั62, et en Normandie en 15ั63, il mourut à Paris le 31 décembre 1503.

Il est représenté en pied. Le portrait original, attribué à Clouet, est au Musée du Louvre, $\mathrm{n}^{\circ} 116$ de la Notice des tableaux de l'École française, par ,I. F. Villot.

\section{DEUXIĖME SALLE DES MARÉCHAUX, No $40 ̈$. (Voir salle no 4.1.)}

Cette pièce faisait partie de l'appartement de la duclıesse de Berry en 1714, Sous Louis XV elle servit d'antichambre à l'appartement du dauphin en 1735, et devint ensuite la cbambre à coucher de la dauphine.

La suite chronologique des maréchaux de France depuis Rogues, seigneur de Hangest (1352), jusqu'à Jean de Baudricourt (1486), est représentéc par des écussons ou par des portraits en buste.

\section{Rieux (Jean, sire de).}

Par M. COUder. - H. 0,71. - L. 0,55.

Issu d'une ancienne famille bretonne, il servit d'abord en Espagne la cause de Pierre-le-Cruel, roi de Castille, et s'attacha ensuite à la France. Il se distingua à la bataille de Rosebecque en 1382, fut nommé maréchal de France en 1397, et fit la guerre en 1404 contre les Anglais, qui élaient descendus en BasseBretagne. Le maréchal de Rieux se démit de sa charge en 1417, et mourut en Bretagne la même année.

La peinture originale est au château de Beauregard.

\section{Rochefort (Pierre de Rieux, dit de).}

Pár Paulin Guéris. - H. 0,71. - L. 0,55.

Fils du maréchal de Rieux, il naquit à Ancenis en 1389, el succéda à son père en 1417. Il fut un des plus fidèles serviteurs de Charles VII, contribua à la levée du siége d'Orléans en 1429 , s'empara en 1430 de Dieppe, Fécamp, Moutiers, et de presque tout le pays de Caux, et fit lever aux Anglais le siége de Harfleur en en 1437. Le maréchal de Rochefort mourut en 1438.

La peinture originale est au château de Beauregard.

\section{Gamaches (Joachim Rouault, seigneur de).}

Par BLoNDEL. - H. 0,71. - L. 0,55.

ll était à la prise de Creil, de Saint-Denis, de Pontoise en 14\%1, se signala en 1442 au siége d'Acqs en Guyenne, et combattit à Bâle sous le dauphin (depuis Louis XI) contre les Suisses en 14'4'. 
De 14 Ł 6 à 1448 , il servit dans le Barrois, prit part à la conquête de la Normandie en 14k9, sc trouva à la bataille de Formigny en 14500, à celle de Castillon en 14.33, fit la campagne de 14.5\% dans le Rouergue et commanda en Ecosse en 14506. Maréchal de France en 1461, il défendit Paris en 1463 contre Charles-le-Téméraire, et força, en 1472 , ce prince de lever le siége de Beauvais. Il mourut le 7 aoùt 14.78 .

\section{Baudricourt (Jean, seigneur de).}

Par DEBACQ, - H. 2,15. - L. 0,55.

Il suivit d'abord le parti de Charles-le-Téméraire et se trouva à la bataille de Montlhéry en 146ə̋. Nommé par Louis XI chevalier de l'ordre de Saint-Michel et capitaine de cinquante hommes d'armes en 1469, Baudricourt fut ensuite bailli de Chaumont, capitaine de quatre mille francs archers, lieutenant général de lid ville d'Arras en 1479, gouverneur et lieutenant général du duché de Bourgogne en 1481, commandant de la ville de Besancon en 1482, et commandant en Provence en 1483. Maréchal de France en 1486, il prit part à la bataille de Saint-Aubin en 1488, et fit partie de l'expédition de Naples en 1494. Il mourut à Blois le 11 mai 14.99.

\section{Montmorency (François, duc de).}

Par Dejuinne. - II. 2,15. - L. 1,39.

Fils aîné du connétable Anne de Montmorency, il fit ses premières armes au siége de Lens en 15301 , et suivit Henri II à la défense de Metz en 1582. Chevalier de l'ordre de Saint-Michel, gouverneur de Paris et de l'Ile de France en 155\%6, il combattit à la journée de Saint-Quentin en 1อ๊ǒ7, suivit le duc de Guise au siége de Calais, et reçut la charge de grand maitre de France

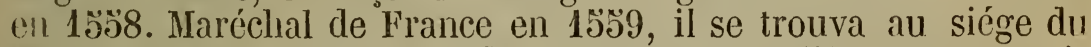
Havre en 15้63, à la bataille de Saint-Denis en 1567. Duc et pair de France en 1567, il fut nommé chevalier de l'ordre du SaintEsprit à la création de l'ordre en 1579 , et mourut au château d'Ecouen le 6 mai 1579.

11 est représenté en pied. La peinture originale est au château de Beauregard.

\section{Tavannes (Gaspard de Saulx, seigneur de).}

Par M. Tassaent, en 1835. - II. 2,15. - L. 1,40.

Né à Dijon en 15005 d'une ancienne maison de Bourgogne, il élait page de Francois $I^{\text {er }}$ et fut fait prisonnier avec ce prince à la bataille de Pavie en 1525. Il fit les guerres d'Italie en 1527 et 1วั28, servil dans l'armée de Pićmont en 1335 , prit part, en $13 \% 3$, 
à la concruête du Luxembourg, et se trouva à la bataille de Cerisoles en 15\%4. Chambellan du roi en 15\%5\%, maréchal de camp en 10ั32, il servit en Lorraine et en Flandre jusqu'en 15๊5ั4, et fut nommé chevalier de Saint-Michel sur le champ de bataille de Renty. Lieutenant général en Bourgogne en $15 \% 5 \%$, il suivit en $15 \mathrm{~s} 7$ le duc de Guise en Italie, revint en France avec ce prince et l'accompagna au siége de Calais en 15้ว๋8. Bailli de Dijon et chevalier d'honneur au parlement de Bourgogne en $1506 \ddot{6}$, il commanda, en 1569, l'armée sous le duc d'Anjou, depuis Henri III, et se trouva aux batailles de Jarnac et de Montcontour. Maréchal de France en 1570, gouverneur et lieutenant général en Provence, amiral des mers du Jevant en 15̆72, il mourut le 19 juin 1573.

Il est représenté en pied. La peinture originale est au château de Beauregard.

\section{Montluc (Blaise de Montesquiou-Lasseran- Massencôme, seigneur de).}

Par 1. II. SGHEFFÉR. - H. 2,15. - L. 1,40.

Pag'e d'Antoine, due de Lorraine, jusqu'à l'âge de seize ans, il entra au service comme simple soldat, fit la campagne de Navarre en 1521 , celle d'Italie en 1522 , et combattit à la bataille de la Bicoque. Enseigne d'une compagnie d'infanterie en 15223, il servil de nouveau à l'armée de Navarre, fit ensuite la campagne d'Italie en 15\%2ั, et se trouva à la bataille de Pavie. Capitaine d'une compagnie d'infanterie en 15\%37, il fit la guerre dans les Pays-Bas et fut envoyé au secours de Térouanne. Montluc se trouva au siége de Perpignan en 15ั42, servit en Piémont en 15̆43, i la bataille de Cérisoles en $15 \% 4$, et fit de nouveau une campagne dans le Piémont en 1548. Mestre de camp en 1551, cheralier de l'ordre de Saint-Michel en 15้อ̌s̆, il continua à servir en Italie, et accompagna le duc de Guise au siége de Calais en 15̋58. Colonel général de l’infanterie française en 15๊58, lieutenant général de la Guyenne en 1504, il servit au siége de la Rochelle en 1573 , et fut nommé maréchal de France en 1574. Il mourut à Estillac, près d'Agen, en 13̌77. - Montluc a laissé sous le titre de Commentaires des mémoires sur l'impitoyable guerre qu'il fit aux huguenots dans la Gascogne.

Il est représenté en pied. Ce tableau a été exécuté d'après un portrait de famille.

\section{Biron (Armand de Gontaut, baron de).}

Par M. Robert-Fleuri, en 1835.- - I. 2,15. - L. 1,40.

Page de la reine Marguerite de Valois, il commença à servir 
en 1542, fut cornette de chevau-légers en $10 \% 44$, guidon en $15 \% 45$, et fit en 1548 la campagne d'Ecosse. Capitaine de cent chevaulégers en 15้อ̌วั, il accompagna en 15537 le duc de Guise dans l'expédition de Naples, fut nommé gentilhomme ordinaire de la chambre du roi en 1559 , chevalier de l"ordre de Saint-Michel en 1562 et combattit à Dreux. Maréchal de camp en 1507 et maréchal de camp général en 1568, il se trouva aux batailles de SaintDenis, de Montcontour et de Jarnac, fut conseiller privé du roi et grand maître de l'artillerie en 1569 , et commanda en 1573 l'armée qui assiégait Ia Rochelle. Naréchal de France en 15้77, chevalier de l'ordre du Saint-Esprit en 1581, il était à la bataille d'Ivry en 1590 , et fut tué au siége d'Epernay le 26 juillet 1592.

Il est représenté en pied. Ia peinture originale est au château de Beauregart.

\section{Bouillon (Henri de LaTour d'Auvergne, duc de).} Par Blondel en 1835. - II. 2,15. - L. 1,40.

Il porta d'abord le nom de vicomte de Turenne, et se trouva en 1573 au siége de La Rochelle. Lieutenant général du roi de Navarre dans le Languedoc en 1580 , il se trouva à la bataille de Coutras en 1587. Premier gentilhomme de la chambre du roi en 1589, marćchal de France en 1592, il fit la campagne de 1594 en Champagne, et celle de 10095 en Picardie. Ambassadeur extraordinaire près de la cour d'Angleterre en 1612, il commanda en 1615 l'armée des princes révoltés contre l'autorité de la régente Marie de Médicis, et mourut à Sedan le 2 ă mars 1623, à soixantesept ans. Il avait épousé en 1591 Charlotte de la Marck, heritière du duché de Bouillon.

Il est représenté en pied. La peinture originale est au château de Beauregard.

\section{Biron (Charles de Gontaut, duc de). (Voir n 924.)}

Par M. Galiait en 1835. - H. 2,15. - L. 1,40.

Il est représenté en pied. La peinture originale est au château de Beautregard.

\section{Brissac (Charles de Cossé II, duc de).}

par M. J. Alaux. - II. 2,73. - L. 2,02.

Fils de Charles de Cossé Ier, maréchal de Brissac, il fut colonel général de l'infanterie française et grand fauconnier en 15069 , et servit en Piémont jusqu'en 15\%4. Grand pannetier en 1582, il présida en 15088 la chambre de la noblesse aux états de Blois. Maréchal de France et conseiller d'honneur en 15\%4, chevalier de l'ordre du Saint-Esprit en $159^{\circ}$, il commanda l'armée du roi en Bretagne en 1596 et fut nommé duc et pair de France en 1611. II mourut au château de Brissac en 1621.

Il est représenté à cheval. La peinture originale est au château de Beauregarıl. 


\section{Créquy (Charles de Blanchefort, duc de).}

Par M. TASSAERT en 1835. - H. 2,15. - L. 1,40.

Il fit sa première campagne au siége de Laon en 15\%94, et servit dans l'armée de Savoie en 15ั97. Colonel des gardes-françaises en 1603 , maréchal de camp et chevalier de l'ordre du Saint-Esprit en 1619, il se signala au combat du Pont-de-Cé en 1620, et fut nommé maréchal de France en 1621. Après avoir fait la campagne d'Italie en 1623 , il fut créé duc et pair en 1626 , et commanda en 1629 l'armée de Piémont. Premier gentilhomme de la chambre en 1632, ambassadeur à Rome en $\mathbf{1 6 3 3}$ et à Venise en 1634, lieutenant général commandant l'armée d'Italie en 163ö, le maréchal de Créquy fut tué d'un coup de canon devant le fort de Brême, le 17 mars 1638.

Il est représenté en pied. La peinture originale est au château de Beauregard.

\section{La Force (Jacques Nompar de Caumont, duc de).}

Par M. Рісот. - H. 2,15. - L. 1,40.

Né en $15 \%$ 9 d'une famille protestante, il servit dès sa première jeunesse sous les drapeaux du roi de Navarre. Conseiller et chanıhellan du roi en 1วั88, capitaine des gardes en 1วั92, gouverneur et lieutenant général de Béarn en $13 ั 93$, maréchal de France en 1622, il présida en 1626 l'assemblée des notables. Il commanda l'armée de Piémont en 1630, celles de Lorraine en 1631, de Picardie en 1636, de Flandre et d'Artois en 1638, et se retira à Bergerac où il mourut le 10 mai 1642.

Il est représenté en pied.

\section{Bassompierre (Francois, baron de).}

Par M. J. ALAUX en 1835. - H. 2,15. - L. 1,40.

Né alı château d'Harouel en Lorraine en 1วั79, Henri IV l'attacha à son service en 1วั99; et il fit en 1600 ses premières armes dans la campagne contre le duc de Savoie. En 1603 il se signnala en Hongrie dans un combat livré aux Turcs par les Impériaux, près l'île d'odon, sur le Danube. Conseiller d'Etat en 1610, colonel général des Suisses et Grisons en 1614, maréchal de camp en 161ว̆, chevalier de l'ordre du Saint-Esprit en 1619, il fut ambassadeur extraordinaire en Espagne en 1621. Maréchal de France en 1622, il suivit Louis XIII dans l'expédition de l'ile de Rhé, fut ambassadeur extraordinaire en Suisse en $1620 ̈$ et en Angleterre en 1626. Il se trouva, en 1628, au siége de La Rochelle, suivil Louis XIII dans ses campagnes de Piémont et de Languedoc en 
DEUXIÈME SALLE DES MARÉCHAUX, $\mathrm{N}^{0} / 5 \%$.

1629 et 1630. Enfermé à la Bastille en 1631, il en sortit en 1643 . après la mort du cardinal de Richelieu, et mourut le 12 octobre 1646. - On a de lui des Mémoires contenant l'histoire de sa vie.

Il est représenté en pied. La peinture originale est au château de Beauregara.

\section{Montmorency (Henri II, duc de). (Voir no 927.)}

Par M. Picot. - H. 2,15. - I. 1,40.

Il est représenté en pied.

\section{Toiras (Jean du Caylar de Saint-Bonnet, mar- quis de).}

Par M. H. SCHEFFER. - H. 2,15. - L. 1,40.

Gentilhomme de la maison du roi en 1617, maréchal de camp en $162 \%$, il fut nommé vice-amiral en 1626 , défendit en 1627 , dans l'île de Rhé, la citadelle de Saint-Martin, assiégée par Buckingham, et servit au siége de La Rochelle en 1628 . Il fit la campagne de Piémont en 1629, soutint dans Casal un siége contre les Espagnols, et fut nommé maréchal de France en 1630. Lieutenant général pour le roi en Italie en 1631, et chevalier de l'ordre du Saint-Esprit en 1633, il fut ensuite lieutenant général au service du duc de Savoie, et mourut le 14 juin 1636 des suites d'une blessure qu'il avait reçue au siége de Fontaneto, dans le Milanais.

Il est représenté en pied. Ce tableau a été exécuté d'après un portrait de famille.

\section{Sully (Maximilien de Béthune, duc de), marquis de Rosny.}

Par M. NoRblin. - H. 2,16. - L. 1,40.

Né au château de Rosny en 1วั0̈9, il porta jusqu'en 1606 le nom de baron, puis de marquis de Rosny, et fut de bonne heure engagé sous les drapeaux du roi de Navarre. Il combattit à Coulras en 15้87, à Arques en 1כ̌89, à Ivry en 1590, et au siége de Rouen en 1592. Surintendant des finances et principal ministre en 1508 , grand maître de l'artillerie en 15ั99, conseiller d'honneur en 1602, il signa comme ambassadeur du roi, en 1603, un projet de ligue défensive avec le roi d'Angleterre, et fut créé duc et pair de France en 1606. Après la mort de Henri IV, il s'éloigna de la cour, fut nommé maréchal de France par Louis XIII en 1634, et mourut au château de Villebon, au Pays-Chartrain, le 21 décembre 16 1. - Il a laissé des Mémoires qui ont pour titre : Economies royales.

Il est représenté en pied. Le portrait original faisait partie de la collection du château d'Eu. 


\section{Schomberg (Charles de).}

Par M. Roulllard en 1835. - H. 2,15. - L. 1,40.

Né en 1600, il était fils du maréchal Henri de Schomberg, et fut élevé comme enfant d'honneur auprès de Louis XIII. Créé duc ế pair de France en 1619, il fit la campague de Languedoc en 1622, celle de Savoie en 1630, et fut nommé en 1633 gouverneur du Languedoc el chevalier de l'ordre du Saint-Esprit. Maréchal de France en 1637, il fit dans le Roussillon les campagnes de 1638 à 1642, fut colonel général des Suisses et Grisons en 1647, et vice-roi de Catalogne en 1648. Il mourut à Paris le 6 juin 1636.

Il est représenté en pied.

\section{TROISIÈME SALLE DES MARÉCHAUX, No 46.}

(Voir Salle no 41. .)

Sous Louis XIV cette pièce et la suivante formaient la chambre à coucher du dauphin, puis du duc de Bourgogne. Après leur mort successive le duc de Berry ayant occupé l'appartement du dauphin, la même pièce devint la chambre à coucher de la duchesse de Berry, fille du régent. Elle y donna le jour, le 26 mars 1713, à un prince nommé le duc d'Alençon, qui mourut le 16 avril suivant. Après le retour de la cour à Versailles, cette pièce fut la chambre à coucher du régent, puis du dauphin, fils de Louis XV. Elle fut ensuite divisée en deux parties. La partie occupée par la a salle des Maréchaux, est indiquée par Blondel, en 1755, sous le nom de Cabinet en niche de l'appartement de la dlauphine.

La suite chronologique des maréchaux de France, depuis Jean-Jacques Trivulce (1499), juscju’à Antoine de Lettes (154/4), est représentée par cles écussons ou par des portraits en buste.

\section{Aubigny (Robert Stuart, seigneur d').}

Par BLGNDEL。 - H. 0,71. - L. 0,54.

Il passa les Alpes avec Charles VIII en 1494, resta dans le royaume de Naples aprèsla conquête qui en fut faite par ce prince, commanda en 1วّ01 l'armée française dans -le Milanais, et se trouva en $10 ّ 06$ au siége de Bologne et én 15007 à celui de Gênes. Maréchal de France en 15ั14, il était à Marignan en Lälö et à Pavie en 1รั2อั, commanda en Provence contre l'empereur Charles. Quint, et fut nommé chevalier de l'ordre de Saint-Michel en 1อั36. Il mourut en $10 ั 44$.

Le portrait original est au château de Beauregard.

\section{Montejan (René, seigneur de).}

Par M. Aug. Couder. - H. 0,71. - L. 0,55.

Il servit en 15023 dans le Milanais et se trouva en 15028 au siége de Pavie. Il présida en 1 อ̆33 les états de Bretagne au nom de 
Francois Ier, accompagna en 15335 l'amiral d'Annebaut dans søn expédition contre le Piémont et s'empara de Turin etde Chivasso. Lieutenant général pour le roi en Piémont, chevalier de l'ordre de Saint-Michel en 15337, il fut nommé maréchal de France en 1538 , et mourut au-delà des Alpes en 15339 .

995. La Meilleraye (Charles de La Porte, duc de).

Par Mauzaisse en 1834. - H. 2,15. - L. 1,37.

Né en 1602, il se trouva au siége de La Rochelle en 1628 ei fit la campagne de Piémont. Lieutenant général de Bretagne en 1632, chevalier de l'ordre du Saint-Esprit en 1633, grand maitre de l'artillerie en 1634, maréchal de camp en 1630̈, il combattit à Avein et servit de 1636 à 1638 en Flandre, en Franche-Comté et en Picardie. Maréchal de France en 1639, il commanda les armées de 1640 à 1646 , fut surintendant des finances en 1649 , et créé duc et pair en 1663 . Il mourut à Paris le 8 février $166 \%$.

Il est représenté en pied. Le portrait original est au château de Beauregard.

\section{Guébriant (Jean-Baptiste Budes, comte de).}

Par M. Rouget. - H 2,15. - L. 1,37 .

Né en 1602, au château du Plessis-Budes, en Bretagne, il fit ses premières armes en Hollande contre les Espagnols, servit ensuite au siége d'Alais et en Piémont en 1629 et 1630. Capitaine au régiment des gardes-francaises en 1631, maréchal de camp en 1638, il fut employé pendant les guerres de $163 \check{\text { à }}$ 1641 en Flandre, en Italie et en Allemagne. Lieutenant général des armées du roi et chevalier de l'ordre du Saint-Esprit en 16Æ1, il fit la campagne de 1642 en Allemagne. Maréchal de France en 1642, il commanda en 1643 l'armée d'observation pendant le siége de Thionville, et mourul le 24 novembre 1643 des suites d'une blessure qu'il avait reçue au siége de Rothweill.

Il est représenté en pied.

\section{La Mothe-Houdancourt (Philippe de), duc de Cardonne.}

Par BLoNdeL en 1835. - H. 2,15. - L. 1,40.

Il était au siége de Montpellier en 1622, se trouva au combat de l'île de Rhé en 1627, à l'attaque de Pignerol en 1630, à la bataille d'Avein en 1635̆, et marcha au secours de Saint-Jeande-Losne en 1636. Maréchal de camp en 1637, lieutenant général des armées du roi en 1641, il fit les campagnes de FrancheComté, de Piémont et de la Catalogne. Maréchal de France et vice-roi de la Catalogne en 1642, il fit lever le siége de Lórida, 
forca les lignes devant Barcelone en $\mathbf{1 6 5 2}$ et défendit cette place contre les Espagnols. Il mourut à Paris le 2\% mars 16.ั7, à l'àge de cinquante-deux ans.

Il est représenté en pied. Le portrait original cst au ciàteau ce Beauregarl.

\section{L'Hôpital (François de), seigneur Du Hallier.}

Par M. Rocget. - H. 2,15. - L. 1,40.

Destiné d'abord à l'état ecclésiastique, il fut abbé de SainteGeneviève de Paris, puis évêtque de Meaux, et prit le parti des armes en 1611 sous le nom de Du Hallier. Capitaine des gardes du corps du roi en 1617, chevaliel de l'ordre du Saint-Esprit en 1619, maréchal de camp en 1622, il servit activement de 1627 à 1636. Commandant de l'armée de Lorraine en 1641 , gouverneur de Champagne et maréchal de France en 1643, il commanda l'aile gauche à la bataille de Rocroy et reçut le gouvernement de Paris en 1649. Il mourut à Paris le 20 avril 1660 , à l'àge de soixante-dix-sept ans.

Il est représenté en pied.

\section{Turenne (Henri de La Tour d'Auvergne, vi- comte de).}

Par M.ıuzissse, en 1835. - H. 2,45. - L. 1,40.

Né à Sedan, le 11 septembre 1611, il était fils puîné du maréchal duc de Bouillon, et fit l'apprentissage de la guerre en Hollande, sous son oncle, le stathouder Maurice de Nassau, jusqu'en 1629. Entré au service de la France en 1630, il se troura au secours de Casal, et au siége de la Motte en 1634. Maréchal de camp en 1630̈, il fut employé en Allemagne et en Flandre sous le cardinal de La Valette, fit la campagne de 1638 sous Bernard de Saxe-ITeimar, et celles de 1639 à 16 h. en Italie. Lieutenant général des armées du roi en 1642, il fit la campagne de Roussillon en 1643 et commanda les armées comme maréchal de France jusqu'en 1649. Entrainé dans le parti des princes contre la cour pendant les troubles de la Fronde, il fit sa soumission en 16öl, fut nommé ministre d"Etat et gouverneur du Limousin en 16ə̈3, et fit les campagnes de Flandre de $160 ّ 4$ à 16วั9. Maréchal général des camps et armées du roi en 1660 , il commanda en 1667 l'armée de Flandre. En 1668 il ahjura la religion protestante et commanda l'armée des Pars-Bas. Il recut en 1672 et 1673 le commandement des troupes francaises en Allemagne, vainquit

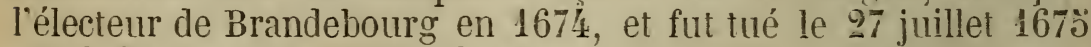
à Saltzbach par un boulet de canon.

Il est représenté en pied. Ce portrait a été exécuté d'après un pastẹl de Nanteuil qui se trouve au Musée du Louvre. 


\section{Gassion (Jean, comte de).}

Par M. J. Alaux. - H. 2,15. - L. 1,37.

Né à Pau en 1609, il servit d'abord en Piémont sous le duc de Rohan en 162\%, puis dans les armées de Gustave-Adolphe en Allemagne de 1631 à 1633. Mestre de camp au service de la France en 1633 , il fut employé à l'armée de Lorraine, se distingua au siége de Dôle en 1636 et à celui de Landrecies en 1637. Maréchal de camp en 1638, il fit toutes les campagnes de Flandre et d'Artois, commanda l'aile droite à la bataille de Rocroy, et fut nommé maréchal de France et conseiller d'Etat en 1643. Il fit partie de l'armée de Flandre en 1644, continua à servir activement dans les années suivantes, et mourut à Arras le 2 octobre 1647 des suites d'une blessure qu'il avait reçue au siége de Lens.

Il est représenté en pied.

\section{Choiseul (César, duc de), comte Du Plessis- Praslin.}

Par M. Saint-Èvre en 1835. - H. 2,15. - L. 1, 40.

Connu d'abord sous le nom de comte d'Hôtel, il fut enfant d'honneur de Louis XIII, fit ses premières armes dans les campagnes de 1621 et 1622 , et servit ensuite au siége de La Rochelle en 1625, au combat de l'ile de Rhé en 1627 et en Piémont en 1629 et 1630. Ambassadeur à Turin en 1631, maréchal de camp en 1635, lieutenant général en 1642, il fit les guerres d'Italie de 1633 à 1644 et fut nommé maréchal de France en 16450 . Après une nouvelle campagne en Italie, il fut attaché au duc d'Orléans en 1649 comme gouverneur, premier gentilhomme de sa chambre, chef de ses conseils et surintendant de ses finances, reçut en 16 ŏ0 le commandement de l'armée de Flandre et de Champagne, et fut ministre d'Etat en 16ว22. Créé chevalier de l'ordre du Saint-Esprit en 1661, duc de Choiseul et pair de France en 1664, il mourut à Paris le 23 décembre 1675.

Il est représenté en pied. Le portrait original est au château de Beauregard.

\section{QUATRIÈME SALLE DES MARÉCHAUX, No 47.}

(Voir Vestibule no 41 et Salle no 46. .)

Lorsque cette piêce fut séparée de la précédente, elle forma en 1755 le cahinetbibliothèque du dauphin, fils de Louis XV.

\section{Rantzau (Josias, comte de).}

Par M. Alaux en 1834. - H. 2,74. - L. 2,10.

Issu de la maison de Rantzau au duché de Holstein, il naquit 
en Danemark en 1609, servit d'abord en Hollande, en Suisse et en Allemagne, et vint en France en 163ว.. Maréchal de camp en 1636, il perdit un œil au siége de Dôle, défendit Saint-Jean-deLosne, eut une main estropiée et une jambe emportée au siége d'Arras en 16ł0. Il reçut encore sept blessures au siége d'Aire et à la bataille d'Honnecourt en 1640 et 1642, combattit à Rocroy en 1643 et fut nommé lieutenant général en 1644. Maréchal de France en 1640 , il commanda en Flandre jusqu'en 1648, et mourut à Paris le 4 septembre $160 ّ 0$.

Il est représenté à cheval. Le maréchal de Rantzau ayant perdu successivement sur les champs de bataille un oil, une oreille, un bras et une jambe, on lui fit cette épitaphe, qui se troure dans Les curres poétiques de Beys. Paris, 1652, in- $4^{\circ}$, page 175.

\section{Au tombeau de monseigneur le maréchal de Rantzau.}

Du corps du grand Rantzau tu n'as qu'une des parts;

L'autre moitié resta dans les plaines de Mars;

Il dispersa partout ses membres et sa gloire.

Tout abattu qu'il fut, il demeura vainqueur;

Son sang fut en cent lieux le prix de sa victoire,

Et Mars ne lui laissa rien d'entier que le cœur.

\section{CINQUIĖME SALLE DES MARECHAUX, No 48.}

\section{(Voir Vestibule no 41. )}

Grand cabinet du dauphin, fils de Louis XIV', cette salle était ornée alors d'un plafond peint à fresque par ilignard et gravé par Gérard Audran. Le grand dauphin y était représenté vêtu à la romaine et entouré des dieux et dies personnages de la fable. "Ce cabinet, dit Félibien, a de tous côtés et dans le plafond des glaces de miroir avec des compartiments de bordures dorées sur un fond de marqueterie d'ébène. Le parquet est aussi fait de bois de rapport et embelli de divers ornements, entr'autres de chiffres de Monseigneur et de Madame la Dauphine. „ Piganiol ajoute : "C'est le chef-d'œurre de Boulle et celui de son art. "

C'est lans cette salle qui, en 1722, servait de grand cabinet au régent, que le lundi 13 aont le maréchal de Villeroy fut arrêté par La Fare, capitaine des gardes du duc d'Orléans.

En 1728, des réparations considérables, faites à cette partie du chàteau, amenèrent la destruction du plafond de Mignard et des marqueteries de Boulle. La destination de la pièce resta la même, et on la troure encore indiquée dans les plans de Blondel sous le nom de grand cabinet de l'appartement du dauphin.

La suite chronologique des maréchaux de France, depuis Jean Caraccioli, prince de Melphes (1544) juscru'à Guillaume de Joyeuse (1582), est représentée par des écussons ou par des portraits en buste.

\section{Melphes (Jean Caraccioli, prince de).}

Par M. A. Couder. - H. 0,71. - L. 0,55.

Il était grand sénéchal du royaume de Naples lorsqu'il entra au service de la France en 1ว̈l2, et se trouva la même année à la bataille de Ravenne. Rentré sous les drapeaux de l'empereur Charles-Quint, il fut assiégé par Lautrec, en 1วّ28, dans la ville de Ielphes dont il était seigneur, et tomba prisonnier aux mains 
des Francais. Abandonné par Charles-Quint, il s'attacha définitivement à la France, et servit en 1536 dans la guerre de Provence contre l'empereur. Le prince de Melphes était en 1533 à la prise du château de Hesdin, et secourut Luxembourg en 15̆43. Maréchal de France en 1544, gouverneur et lieutenant général en Piémont en 15̆łร̆, il mourut à Suze le 29 juillet $1550 \% 0$.

Ce portrait a été exécuté d'après un dessin aux trois crayons qui fait partie du Cabinet des Estampes, à Paris.

\section{Saint-André (Jacques d'Albon, seigneur de).}

Par M. DeLORME. - H. 0,71. - L. 0,55 .

Il fit ses premières armes à la bataille de Cérisoles en 15̆44, et fut nommé lieutenant général en Dauphiné et Savoie. Maréchal de France en 1547, chevalier de l'ordre de Saint-Michel, gouverneur et lieutenant général en Lyonnais, il fut ambassadeur en Angleterre en 15วั0. Admis au conseil privé du roi en $15 \% 3$, il commanda en 15̋2, sous le connétable de Montmorency, l'armée qui s'empara des Trois-Evêchés. Il commanda successivement en Picardie et en Hainaut de 15503 à $15 \% 5 \%$, assista en qualité de plénipotentiaire aux conférences tenues pour la paix de Cateau-Cambrésis en 155ั8. Chargé de réduire les protestants dans le Poitou, en 1562, il s'empara de Poitiers et fut tué à la bataille de Dreux, le 15 décembre 1562.

Le portrait original est au Musée du Louvre.

\section{Strozzi (Pierre).}

Par M. RovgeT. - H. 0,71. - L. 0,55.

Exilé de Florence, sa ville natale, il entra en 1536 au service de la France comme colonel des bandes italiennes qui combattaient en Piémont avec l'armée française. Il fut ensuite naturalisé en 15̆43, reçut le titre de conseiller et de chambellan du roi, et fit partie d'une expédition maritime contre l'Angleterre en $155^{4} 5$. Colonel général de l'infanterie italienne au service de la France en 1547, chevalier de l'ordre de Saint-Michel en 1550, il secourut Parme en 15ّ̋1, et força, avec le duc de Guise, CharlesQuint à lever le siége de Mètz en 15๊̌̋3. Lieutenant général en Italie et en Siennois, maréchal de France en 15ૅ5้4, il combattit les Espagnols en 15056 et leur fit lever le siége de Rome en 1557. Il suivit encore le duc de Guise au siége de Calais et à celui de Thionville, où il fut tué le 20 juin $1550 \% 8$.

Le portrait original est au château de Beauregard. 
1006. Thermes (Paul de La Barthe, seigneur de).

Par M. A. BRUNE. - H. 0,71. - L. 0,55.

Il servit en 1522 dans la Navarre, en 1533 dans le Piémont ei la Savoie, se trouva au siége de Perpignan en $\mathbf{1 5 4 2}$ et à la bataille de Cerisoles en 1544. Lieutenant général au gouvernement de Piémont en 15̆46, il soumit en 1547 le marquisat de Saluces, et fut nommé en 15̌48, lieutenant général commandant l'armée en Ecosse. Ambassadeur vers le pape Jules III en 1วัว̆1, lieutenant général commandant en Italie et en Corse en 155̃2, il passa en 15 วัว à l'armée de Piémont, et s'empara, en 15ั5\%7, de Valfeniera et de Chierasso. Maréchal de France en 15̆58, il s'empara de Dunkerque, fut lieutenant général commandant l'armée de Guyenne en 1560 , et mourut à Paris le 6 mai 15562.

Le portrait original est dans la famille de La Barthe.

1007. Vieilleville (François de Scepeaux, seigneur de).

Par M. Sotra. - H. 0,71. - L. 0,55.

Il servit comme volontaire àl'armée d'Italie en 1528, se trouva en 1542 au siége de Perpignan et en 15544 à la bataille de Cerisoles. Ambassadeur près du roi d'Angleterre en $\mathbf{1 5 4 7}$, conseiller du roi en 15ૅ51, maréchal de camp en 15̆5̆2, chevalier de l'ordre de Saint-Michel en 15วั4, il était au siége de Thionville en 1558. Lieutenant général de la Normandie en 15559, il fut ambassadeur à Vienne et en Angleterre en 15\%62. Maréchal de France en 1562, commandant en Normandie et lieutenant général en Lyonnais, Dauphiné, etc., en 1563, il renouvela l'alliance avec les Suisses en 1504 et servit en 1569 au siége de Saint-Jeand'Angely. Il mourut au château de Duretal le 30 novembre 1571.

\section{Bourdillon (Imbert de La Plalière, seigneur de).}

Par M. Blondel. - H. 0,71. - L. 0,55.

Il combattit, en 15ั44, à Cerisoles, et fut successivement bailli d'Auxois en 15450 , premier écuyer de Henri II, alor's dauphin, capitaine de cinquante hommes d'armes et lieutenant général en Champagne et en Brie en 15\%47. Il fit partie de l'expédition d'Ecosse en 15\%48, fut nommé maréchal de camp en 1551 et se trouva en 1558 au siége de Thionville. Gouverneur et lieuterıant général du marquisat de Saluces en 15\%9, maréchal de France en 1564, il mourut à Fontainebleau le 4 avril 1567 . 
1009. Cossé (Arthus de).

Par M. Raverat. - H. 0,71. - L. 0,55.

Frère puiné du maréchal de Brissac, il fut connu d'abord sous le nom de Gonnor, se trouva au siége de Lens en 15551, puis à ceux d'Ulpiano et de Montcalvo en 155̌s. Nommé surintendant des finances en 1563, et maréchal de France en 1567, il prit alors le nom de Cossé. Lieutenant général commandant l'armée en Normandie, sous le duc d'Anjou, depuis Henri III, il était à la bataille de Montcontour et au siége de La Rochelle en 1573. Chevalier de l'ordre du Saint-Esprit en 15\%79, il mourut au château de Gonnor le 15 janvier $15 \% 82$.

\section{Retz (Albert de Gondi, duc de).}

Par M. Lécurieux. - H. 0,71. - L. 0,56.

Albert de Gondi, né à Florence en 1522, suivit en France Cidtherine de Médicis, obtint d'abord une compagnie de chevaulégers vers 15010 et servit, en 15̆5้, à la bataille de Renty. Gentilhomme de la chambre et maître de la garde-robe de Charles de France, depuis Charles IX, il combattit à Saint-Denis en 1567, à Jarnac et à Montcontour en 15̋69; il reçut, la même année, le collier de l'ordre de Saint-Michel et le titre de conseiller d'Etat. Ambassadeur à la cour de Vienne, en 1570, pour négocier le mariage de Charles IX avec Elisabeth d'Autriche, il épousa cette princesse au nom du roi. Gouverneur, lieutenant général au pays Messin en 1571, il fut nommé maréchal de France en 1573, accompagna Henri III en Pologne. et commanda en chef l'armée de Provence en 1575. Chevalier de l'ordre du Saint-Esprit en 1579, il représenta le comte de Toulouse au sacre de Henri IV en 15\%94, et mourut à Paris le 22 avril 1602. Il avait épousé en $1565 \mathrm{Ca}-$ therine de Clermont, qui lui apporta la baronnie de Retz, érigée en duché-pairie en 1581.

\section{Bellegarde (Roger de Saint-Lary), seigneur de).}

Par J. M. LangLoIS.- H. 0,71. - L. 0,56.

Il fit ses premières armes, en 1556, comme guidon de la compagnie d'hommes d'armes du maréchal de Thermes, son oncle, et servit en 1547 sous le maréchal de Brissac au siége de Valfeniera et de Chierasso; il fit en 15558 la campagne de Flandre et se trouva à la bataille de Gravelines. Colonel d'un régiment d'infanterie italienne en 1567, il servit en Piémont jusqu'en 1570, et suivit en 1573, au siége de La Rochelle, le duc d'Anjou (Henri III) dont il devint le favori et qu'il accompagna en Pologne. Maréchal 
de France en 10074 , il commanda en $15 \% 7$ l'armée du Languedoc avec le maréchal de Damville, recut en 15079 le gouvernement du marquisat de Saluces, et mourut le 20 décembre 1 ๖ั69.

\section{Matignon (Jacques de Goyon, sire de).}

Par J. II. LATgLoIS. - H. 0,71. - I. 0,56.

Enfant d'honneur du dauphin, depuis Henri II, il fit ses premières armes en 1 อัอั2 au siége de Metz, se trouva en 1 อัอั3 à celui de Hesdin, et en 1 อัŏ à la bataille de Saint-Quentin. Lieutenant général en Basse-Normandie en 1 วัวั9, chevalier de l'ordre de Saint-Michel en 10069 , il était en 10069 aux batailles de Jarnac et de Montcontour. Maréchal de camp en Iö69, maréchal de France et chevalier de l'ordre du Saint-Esprit en $1 \partial ั \mathrm{~J} 79$, lieutenant général de Guyenne en 10ั80, il commanda dans cette province jusqu'en 1อั87. Le maréchal de Matignon représenta le connétable au sacre de Henri IV en $1 \partial 9_{4}$, et mourut au chàteau de Lesparre le 27 juillet 10\%97, à l'àge de soixante-douze ans.

\section{Aumont (Jean d').}

Par M. Bilfeld。 - H. 0,71. - L. 0,56.

Capitaine de ćavalerie dans les guerres du Piémont, sous le maréchal de Brissac, il accompagna le duc de Guise à Naples en 15ั0ั6, et fut fait prisonnier à la bataille de Saint-Quentin en 1ว้วั7. Lieutenant de la compagnie de cent lances du duc de Montpensier, il était aux batailles de Dreux, de Saint-Denis, de Jarnac ef de Montcontour. Chevalier de l'ordre du Saint-Esprit en 10ั78, maréchal de France en 1ö79, il combattit à Ivry en $10 ั 90$ et reçut en 15092 le commandement de l'armée de Bretagne. Blessé au siége de Combourg, il mourut des suites de cette blessure le 19 aoùt 1 อั9อ̆.

Le portrait original est au château de Beauregard.

\section{Villeroy (Nicolas de Neufville, duc de). Par M. Robert-Fleeriy en 1835. - H. 2,15. - L. 1,40.}

Enfant d'honneur de Louis XIII, il servit en 1617, sous Lesdiguières, et commanda en Dauphiné en 1620. Maréchal de camp en 1624, il prit part à toutes les guerres de son temps jusquen 1640 et fut nommé lieutenant général en 1643. Grutverneur de Louis XIV et maréchal de France en 1646, conseiller d'honneur au parlement de Paris, duc et pair en 16öi, il représenta au sacre du roi, en 16ŏ4, le grand maître de France. Chef du conseil royal des finances et chevalier de l'ordre du Saint- 
CINQUIÈME SALLE DES MARÉCHAUX, No 48.

Esprit en 1661, il fit la campagne de Flandre en 1667, et mourut à Paris le 28 novembre 168วั, âgé de quatre-vingt-sept ans.

Il est représenté en pied.

\section{Estampes (Jacques d'), marquis de La Ferté- Imbault.}

Par M. LUGardon en 1835. - H. 2,15. - L. 1,40.

Connu d'abord sous le nom de marcuis de La Ferté-Imbault, il fut enseigne, puis capitaine-lieutenant dans la compagnie des g'endarmes de Gaston, duc d'Orléans, et fut employé dans les guerres de Louis XIII depuis 1610 jusqu'en 1639. Ambassadeur' en Angleterre en 1641, colonel général des Ecossais en 1643, il fit la campagne de Flandre en 1644, fut lieutenant général et conseiller d'Etat en 164气 et continua de servir en Flandre jusqu'en 1649. MIaréchal de France en 16ő1, chevalier de l'ordre du Saint-Esprit en 1669, il mourut au château de Mauny le 20 mai 1668, à l'âge de soixante-dix-huit-ans.

Il est représenté en pied.

\section{Hocquincourt (Charles de Monchy, marquis $\left.d^{\prime}\right)$.}

Par M. Galinnade. - H. 2,i5. - L. 1,40.

Lieutenant général au pays de Sancerre, gouverneur de Péronne et de Monididier en 1630̈, maréchal de camp en 1639, il servit en Lorraine et en Flandre dans les années 1640 et 164.1 . Grand prévôt de l'hôtel du roi en 1642, lieutenant général des armées du roi en 1640̆, il commandait l'aile gauche à la bataille de Réthel en 1650. Maréchai de France et chevalier de l'ordre du Saint-Esprit en 16ö1, vice-roi de Catalogne en 160̈3, il fut employé en 16ä́ à l'armée de Flandre. Il prit parti pour le prince de Condé en 16ä6, entra au service des Espagnols, et fut tué le 13 juin 16008 en allant reconnaître les lignes de l'armée française devant Dunkerque.

Il est représenté en pied.

\section{Clérembault (Philippe de), comte de Palluau.}

Par M. Aug. Couder. - H. 2,14. - L. 1,40.

Connu d'abord sous le nom de Palluau, il servit au combat du Tésin en 1636, se tronva en 1637 au siége de Landrecies, et en 1640 à l'attaque des lignes d'Arras. Marẻchal de camp en 1642 , il fit la campagne de Roussillon et combattit au siége de Perpignan. Il passa en 16ı3 à l'armée commandée par le jeune duc 
d'Enghien et fut à la prise de Thionville, puis à la bataille de Fribourg en 1644. Mestre de camp général de la cavalerie ell 1646, il servit en Flandre jusqu'en 1648, fut nommé lieutenant général des armées du roi et commanda l'armée du Berry en 16วั0. Naréchal de France en 16อ̃2, il prit le nom de maréchal de Clérembault, fut chevalier de l'ordre du Saint-Esprit en 1661, et mourut à Paris le 24 juillet $\mathbf{1 6 6 5 0}$.

Il est représenté en pied.

\section{Albret (César-Phébus d'), comte de Mios- sens.}

Par Madzaisse en 1835. - H. 2,14. - L. 1,40.

Il fit ses premières armes au service des Provinces-Unies contre les Espagnols, et commanda un régiment dinfanterie au siége de Corbie en 1636. Capitaine au régiment des gardes en 1639, maréchal de camp en 1645, il fit à l'armée de Flandre les campagnes de 16450 à 1649. Lieutenant général en 1650, maréchal de France en 1652, chevalier de l'ordre du Saint-Esprit ell 1662, il obtint le gouvernement de Guyenne en 1676 et mourut à Bordeaux le 3 septembre 1676, à soixante-deux ans.

ll est représenté en pied.

\section{Fabert (Abraham, marquis de).}

Par M. Schnetz. - H. 2,14. - L. 1,40.

Né à MIetz en 1592, il était fils d'un échevin de cette ville el fut élevé comme page auprès du duc d'Epernon. Admis comme cadet aux gardes françaises en 1613, capitaine d'infanterie en 1619 , il se trouva aux siéges de Saint-Jean-d'Angely en 1621 et de Royan en 1622. Major en 1627, il était au siége de La Rochelle, fit les campagnes de Piémont en 1629 et 1630 , et servit en Lorraine de 1631 à 1634. Il suivit le cardinal de La Valette sur les bords du Rhin et en Piémont, se trouva au siéges de Turin et d'Arras en 1640, combattit à la Marfée en 1641 et fit en 1642 la campagne de Roussillon. Gouverneur de Sedan et maréchal de camp en 1644, il servit en 1645 à l'armée de Catalogne, en 1646 en Italie, fut nommé lieutenant général en 16วั0, et s'empara de Stenay en 16ä4. Maréchal de France en 16ว̋, il se retira à Sedan, où il mourut le 17 mars 1662, dans sa soixantedixième année.

II est représenté eu pied. 


\section{SIXIÈYE SALLE DES MARÉCHAUX, No 49. \\ ( Voir Vestibule no 41. )}

Cabinet du grand dauphin, puis du duc de Berry, cette pièce servit ensuite de cabinet de travail au régent; il y fut frappé d'une attaque d'apoplexie et $\mathrm{y}$ mourut le 2 décembre 1723. Cabinet de l'appartement du dauphin en 1735 et chambre à coucher du dauphin en 1755.

La suite chronologique des maréchaux de France depuis Henri de La Tour d'Auvergne, duc de Bouillon (1592) jusqu'à Gaspard de Coligny, duc de Chấtillon (1622), est représentée par des écussons ou par des portraits en buste.

\section{Balagny (Jean de Montluc, seigneur de).}

Par M. Weber. - H.0,70. - L. 0,55.

Il accompagna en 1573 le duc d'Anjou élu roi de Pologne, commanda en 1574 . les gentilhommes volontaires au siége de Livron, suivit en 1578 le duc d'Alençon dans les Pays-Bays, et secourut en 1581 la ville de Cambrai dont il fut fait gouverneur et lieutenant général en 1584. Il combattit dans les rangs de la Ligue jusqu'en 1594, fut nommé maréchal de France par Henri IV, et mourut en 1603.

\section{Lavardin (Jean de Beaumanoir, marquis de).}

Par M. Monvoisin. - H. 0,71. - L. 0,55.

Élevé auprès du roi de Navarre (Henri IV) il fit ses premières armes au siége de Poitiers en 15569 , fut colonel de son infanterie et se trouva en 1580 à la prise de Cahors. Nommé maréchal de camp par Henri III, en 1586, il combattit les protestans à la bataille de Coutras en 1587. Après la mort de Henri III, il se rallia au roi de Navarre, se trouva au siége de Paris, fut nommé gouverneur du Maine en 1502, chevalier de l'ordre du Saint-Esprit et maréchal de France en 1595, et commandant en Bourgogne en 1602. Il représenta en 1610 le grand maître de France au sacre de Louis XIII, qui le nomma en 1611 ambassadeur extraordinaire en Angleterre. Il mourut à Paris, le 13 novembre 1614.

\section{Joyeuse (Henri, duc de).}

Par M. Eug. GoYeT. - H. 0,71. - L. 0,55.

Fils du maréchal Guillaume de Joyeuse et frère cadet de l'itmiral Anne de Joyeuse, il naquit à Toulouse en $\mathbf{1 5 6 7}$, et fit ses premières armes au siége de la Fère en 1380. Conseiller d'Etat et chevalier du Saint-Esprit en 1583, gouverneur des provinces 
de Touraine, du Maine et du Perche en 1584, il se retira en 1587 aux capucins de Toulouse, et y prit l'habit sous le nom de Père Ange. Il reprit l'épée en 1502 , se mit à la tête des catholiques du Languedoc et combattit contre Henri IV jusqu'en 1599. Maréchal de France et lieutenant général du Languedoc en 1596, il se retira de nouveau aux capucins en 1599 , et mourut à Rivoli, près de Turin, le 26 septembre 1608.

Le portrait original faisait partie de la collection du château d'Eu.

\section{Bois-Dauphin (Urbain de Montmorency-Laval, marquis de).}

Par Madzaisse. - H. 0,71. - L。 0,55.

Il était au siége de Livron en 1574, à celui de la Fère en 15080. et servit activement jusqu'en 1592. Henri IV le nomma en 1593 conseiller d'Etat, chevalier de l'ordre du Saint-Esprit et maréchal de France en 1507. Ambassadeur à la cour de Vienne en 1601, gouverneur et lieutenant général en Anjou en 1609, il se démit de cette charge en 1619, et se retira à Sablé où il mourut le 27 mars 1629.

\section{Ornano (Alphonse Corse, dit d').}

Par M. QUECQ. - H. 0,71. - L. 0,55.

Élevé à la cour de Henri II, il fut nommé colonel général des Corses et chevalier de l'ordre de Saint-Michel en 15̆70, et se trouva en 15073 au siége du château de Cauvisson, à la prise de Leques, etc. Colonel général des Italiens en 1584, maréchal de camp en 1588, et lieutenant général de la province du Dauphiné en 1589, Henri IV le créa chevalier de l'ordre du Saint-Esprit et maréchal de France en 1597 . Il mourut à Paris, le 21 janvier 1610.

Le portrait original est au château de Beauregard.

\section{Fervaques (Guillaume de Hautemer, sei- gneur de).}

Par M. DEDREUX-DoRaY. - H. 0,71. - L. 0,55.

Il fit ses premières armes dans les guerres du règne de Henri II, servit ensuite dans l'armée royale, et se trouva aux batailles de Dreux en 15̆62, et de Saint-Denis en 15067 . Maréchal de camp en 1573 , il fit la campagne de 1581 dans les Pays-Bas, se rallia à Henri IV et l'accompagna au siége de Paris, en 1590. Chevalier de l'ordre du Saint-Esprit en 1590ั, il était au siége d'Amiens en 15ั97, fut nommé maréchal de France et mourut en 1613. 
1026. Ancre (Concino Concini, marquis d').

Par M. LECOQ. - H. 0,71. - L. 0,55.

Né dans les états de Florence en 1506, il accompagna Marie de Médicis en France et fut son premier écuyer. Après la mort de Henri IV, le crédit de sa femme, Eleonora Galigai, dame d'atours de la reine, le fit élever aux charges de conseiller d'Etat et de premier ministre. Il obtint en $\mathbf{1 6 1 1}$ la lieutenance générale de Picardie et le gouvernement d'Amiens, fut nommé maréchal de France en 1613, commanda l'armée de Picardie, levée contre les

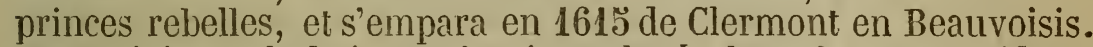
Poursuivis par la haine qu'avait soulevée leur fortune rapide et leur domination insolente, le maréchal d'Ancre fut tué par Vitry, en entrant au château du Louvre, le 24 avril 1617, et sa femme, condamnée à mort comme sorcière, fut brûlée le 8 juillet suivant.

Le portrait original est au château de Beauregard.

\section{Souvré (Gilles de), marquis de Courtenvaux.}

Par M. Chasselat-Saint-Ange. - H. 0,71. - L. 0,55.

Il accompagna en 1573 le duc d'Anjou en Pologne, fut nommé chevalier de l'ordre du Saint-Esprit en 1508̈, et se trouva à la bataille de Coutras en 15̋87. Gouverneur général de Touraine en 15\%92, gouverneur et premier gentilhomme de la chambre du dauphin en 160\%, maréchal de France en 1614, il mourut en 1626.

\section{Roquelaure (Antoine, scigneur de).}

Par Paulin Guériv. - H. 0,71. - L. 6,55

Lieutenant de la compagnie de gendarmes de Henri, roi de Navarre, il prit part à toutes les guerres de ce prince, et se trouva avec lui à la bataille d'Ivry et au siége de Paris en 1590. Chevalier de l'ordre du Saint-Esprit en 1595, capitaine et gouverneur du château de Dreux, il continua à servir jusqu'en 1597 , fut nommé maréchal de France en 1614, et mourut le 9 juin 162.5, dans le gouvernement de Lectoure qu'il avait reçu en 1622 .

\section{Thémines (Pons de Lauzières, marquis de).}

Par MAUZZASSE. - H. 0,71. - L. 0,55.

Il fit ses premières armes en Languedoc sous le règne de Henri III, et fit rentrer le Quercy sous l'obéissance de Henri IV en 1591. Gouverneur de Montauban en 1592, chevalier de l'ordre 
du Saint-Esprit en 1597, et maréchal de France en 1616, il commanda l'armée de Champagne sous le duc de Guise, en 1617, fut lieutenant général de la province de Guyenne en 1622, commanda l'armée du Languedoc en 1625, et celle du Poitou en 1626. Gouverneur de Bretagne en 1626, il mourut à Auray, le $1^{\text {er no- }}$ vembre 1627.

\section{Vitry (Nicolas de l'Hôpital, duc de ).}

École française, xvir ${ }^{e}$ siècle. - H. 0,71. - L. 0,55.

Guidon de la compagnie des gendarmes du dauphin en 1602 , enseigne de la même compagnie en 1605ٌ, capitaine des gardes du corps du roi en 1611, il fut chargé en 1617 d'arrêter le maréchal d'Ancre, et fut nommé la même année maréchal de France et chevalier de l'ordre du Saint-Esprit et commanda en 1622 l'aile droite de l'armée du roi dans l'île de Rhé. Gouverneur et lieutenant général de Provence en 1632, il défendit la ville de Beaucaire contre la rébellion du duc de Montmorency, et fut rappelé de son gouvernement en 1637 pour être enfermé à la Bastille. Il en sortit en 1643, après la mort du cardinal de Richelieu, fut créé duc et pair de France, et mourut le 28 septembre 1644 .

\section{Praslin (Charles de Choiseul, marquis de).}

Par M. Féron. - I. 0,71. - L. 0,55.

Il servit comme volontaire au siége de La Fère en 1580, et fit les guerres de Henri III contre les protestants et la Ligue. Rallié au roi Henri IV, il combattit à Ivry en $\mathbf{1 5 9 0}$, et suivit ce prince aux siéges de Chartres et de Rouen en 1592. Capitaine des gardes du corps et gouverneur de Troyes, il fit lever en 1593, au duc de Lorraine, le siége de Beaumont. Chevalier de l'ordre du SaintEsprit en 1596, maréchal de camp en 1597, maréchal de France en 1619, gouverneur et lieutenant général en Saintonge et pays d'Aunis, en 1622, il se trouva pendant sa carrière militaire à cinquante-trois siéges, à quarante-sept combats et batailles, et reçut vingt-deux blessures. Il mourut le $1^{\text {er }}$ février 1626 , à l'âge de soixante-trois ans.

I.c portrait original est dans la famille de Choiseul.

1032. Saint-Géran (Jean-Francois de La Guıche, seigneur de).

Par DebacQ. - H. 0,71. - L. 0,55.

Il fit sa première campagne au siége de la citadelle d'Orléans, en 15้88, s'attacha à Henri IV, et combattit à la bataille d'Ivry et 
au siége de Paris en 13390 , aux siéges de Chartres et de Rouen en 1591 et 1592, au combat de Fontaine-Française en 1595̆, au siége de La Fère en 15̆96, et à la prise d'Amiens en 1597. Maréchal de camp en 1597, il servit dans l'armée du Poitou en 161:; fut nommé, en 1619, gouverneur du Bourbonnais, maréchal de France et chevalier du Saint-Esprit, et commanda l'armée royale en 1621 et 1622. Il mourut au château de La Palice, en Bourbonnais, le 2 décembre 1632.

\section{Chaulnes (Honoré d'Albert, duc de).}

Par M. LECOCQ. - H. 0,71. - L. 0,55.

Frère puîné du connétable de Luynes, il fut connu d'abord sous le nom de Cadenet. Mestre de camp au régiment de Normandie en 1617, lieutenant général au gouvernement de Picardie en 1619, maréchal de France, chevalier de l'ordre du SaintEsprit, et créé duc et pair en 1621, il commanda avec le maréchal de La Force l'armée de Picardie en 1620 et 1626. Gouverneur de Picardie en 1633, il fit la campagne de $\mathbf{1 6 3 5}$ dans l'Artois, et concourut à la prise d'Arras en 1640. Gouverneur d'Auvergne en 164t, il mourut à Paris le 30 octobre 1649 .

Le portrait original est au château de Dampierre.

1034. Aubeterre (Francois d'Esparbès de Lussan, vicomte d').

Par M Mle Clotilde GÉrard. - H. 0,71. - L. 0,55.

Il fit ses premières armes dans les guerres de Henri IV contre la Ligue, et obtint en $\mathbf{1 5 9 0}$ le gouvernement de Blaye. Conseiller d'Etat en 1611, gouverneur et sénéchal de l'Agénois, chevalier de l'ordre du Saint-Esprit en 1612, maréchal de France en 1620 il prit part à la guerre contre les protestants en 1621 et 1622 , s'empara de Caumont et de Nérac et se retira ensuite au château d'Aubeterre, où il mourut en 1628.

\section{Châtillon (Gaspard de Coligny III, duc de).}

Par Paulin Guérin. - H. 0,71. - L. 0,55.

Né en 1584, il fit ses premières armes en Hollande contre les Espagnols et eut, en 1614, la charge de colonel général des Français qui servaient en Hollande. Maréchal de camp en 1616, maréchal de France en 1622, il commanda en 1629 au siége de Boisle-Duc, sous le prince d'Orange, et accompagna en 1630 Louis XIII dans son expédition de Savoie. Il servit dans le Languedoc en 1632, se trouva à la bataille d Avein en 16330 , commanda les ar- 
mées de Hollande en 1636, de Champagne en 1637, de Picardie et d'Artois en 1640, et fut créé duc et pair en 1643. Il mourut au château de Châtillon le 4 janvier 1646 .

Le portrait original est au château de Beauregard.

\section{Castelnau (Jacques, marquis de).}

Par Degaisne en 1835. - H. 2,15. - L. 1,40.

Il fit ses premières armes en Hollande en 1634, et, de retour en France, il fut colonel en 1636, se trouva au siége de Corbie et fit, dans les armées de Flandre, les campagnes de 1637 à 1641 . Il combattit sous le due d'Enghien, à la bataille de Fribourg en 1644 , à la bataille de Nordlingen en 1645 , et fut nommé maréchal de camp. Lieutenant général en 1650 , chevalier de l'ordre du Saint-Esprit en 16351 , il fit les campagnes de Flandre de 1631 à 1657 et commanda l'aile gauche à la bataille des Dunes en 16508 . Maréchal de France en 16508, il mourut à Calais le 15 juillet de la même année, par suite des blessures qu'il avait reçuesau siége de Dunkerque.

Il est représenté en pied.

\section{Créquy (François de Blanchefort, marquis de).} Par DeGaisne en 1835. - H. 2,15. - L. 1,40.

Il servit comme volontaire au siége d'Arras en 1640, fut nommé capitaine d'une compagnie de chevau-légers en 1641, et fit la guerre en Flandre jusqu'en 1647. Commandant d'un régiment de cavalerie, il fut employé dans l'armée de Catalogne en 1649, obtint le grade de maréchal de camp en 16อ̈1, celui de lieutenant général en $165 \%$, et fit toutes les campagnes de Flandre et des Pays-Bas de 1630 à 163̊8. Général des galères en 1661, il commanda l'armée du Rhin en 1667, fut maréchal de France en 1668 et commanda successivement les armées de Lorraine, d'Allemagne, du Rhin et de la frontière de Champagne. Il mourut à Paris le 4 février 1687, et fut enterré dans l'église des Jacoljins.

Il est représenté eu pied.

1038. Humières (Louis de Crevant, duc d').

Par MaUzaisse en 1835. - II. 2,15. - L. 1,40.

Maréchal de camp en 1650 , il fit les campagnes de Flandre de 1633 à 16อ๊ŏ, fut lieutenant général en 16506 et continua de servir en Flandre et dans les Pays-Bas jusqu'en 163̈8. Maréchal de France en 1668, il commanda l'armée de Flandre de 1673 à 1678, fut ambassadeur en Angleterre et grand maître de l'artillerie en 
1685, et chevalier de l'ordre du Saint-Esprit en 1688. Il commanda de nouveau l'armée de Flandre de 1689 à 1693, fut créé duc d'Humières en 1690, et mourut à Versailles le 31 août 1694.

Il est représenté en pied.

\section{Schomberg (Frédéric-Armand, comte de).}

École française; $\mathrm{xvII}^{\mathrm{e}}$ siècle. - H. 2,15. - L. 1,40.

Après avoir fait la guerre en Hollande sous les stathouders Frédéric-Henri et Guillaume II, il entra comme volontaire au service de France en 165\%1, fut maréchal de camp en 16322 et fit les campagnes de Flandre de 1651 à $165 \%$. Lieutenant général en 16อ̉š, il continua de servir en Flandre jusqu'en 1638 et passa en 16009 dans le royaume de Portugal où il fut employé jusqu'en 1668. De retour en France, il commanda en 1674 l'armée de Catalogne, fut nommé maréchal de France en $1675^{\circ}$ et commanda les armées de Flandre en 1676,1677 et 1684 . Lors de la révocation de l'édit de Nantes, en 168ว, le maréchal de Schomberg, qui appartenait à la religion protestante, quitta la France, entra au service de l'électeur de Brandebourg, puis à celui du prince d'Orange (Guillaume III, roi d'Angleterre), et fut tué le 11 juillet 1690 , à la bataille de la Boyne, en Irlande.

Ce portrait, peint en buste, a étẻ agrandi pour en faire un portrait en piel.

\section{La Feuillade (François d'Aubusson, duc de).}

Par M. DEDREEX-DorcY. - H. 2,15. - L. 1,40.

Capitaine de cavalerie en 1647, mestre de camp d'infanterie en 1652, il servit en Flandre jusqu'en 16506 et commanda la cavalerie au siége d'Ypres en 16ä8. Naréchal de camp en 1663, il fil partie de l'expédition de Hongrie en 1664, et fut, la même année, lieutenant général. Créé duc de Rouannois et pair de France en 1667, il servit aux armées de Flandre, de FrancheComité et de Flandre, et fut nommé maréchal de France en $167 \%$. Vice-roi de Sicile en 1677, il commanda l'armée navale en 1678 , fut chevalier du Saint-Esprit en 1688 et fit sa dernière campagne au siége de Mons en 1691. Il mourutà Paris le 19 septembre 1691. - Le maréchal de La Feuillade avait fait ériger à ses frais, en 1686 , sur la place des Victoires, une statue de Louis XIV, au-
jourd'hui détruite. famille.

Il est représenté en pied. Ce tableau a été exécuté d'après un portrait de 


\section{Luxembourg (François-Henri de Montmorency, duc de).}

Par M. Wachsmet. - H. 2,75. - L. 2,04.

Né en 1628, il fut connu sous le nom de comte de Bouterille jusquen 1661, et devint alors, par son mariage avec l'héritière de la maison de Luxembourg, duc de Luxembourg, prince de Tingry et pair de France. Attaché dès sa jeunesse au grand Condé, il arait fait toutes ses campagnes. Capitaine des gardes du corps du roi en 1673, il suivit Louis XIV en Franche-Comté en 1674, fut maréchal de France en $167 \%$, commanda l'armée d'Allemagne en 1676 et celle de Flandre en 1677 et 1678. Chevalier de l'ordre du Saint-Esprit en 1688, il recut le commandement de l'armée de Flandre en 1690 et remporta successivement les batailles de Fleurus, de Leuze, de Steinkerqu!e et de Nerwinde.

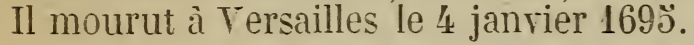

Il est représenté à cheval. Ce tableau a été exécuté d'après un portrait de famille.

\section{Lorges (Guy-Aldonce de Durfort, duc de).}

Par Bloxdel. - H. 2,15. - L. 1,40.

Né à Duras en 1630, il était frère cadet du maréchal de Duras, et fit ses premières armes en Allemagne comme capitaine de cavalerie jusqu'en 16'19. Maréchal de camp en 166ö, il servit en Flandre en 1667 et 1668 , fut lieutenant général en 1672 et fit les campagnes de Hollande et d'Allemagne jusqu en 1673̈. Maréchal de France en 1676, ambassadeur extraordinaire en Angleterre en 168ə̆, chevalier de l’ordre du Saint-Esprit en 1688, créé duc en 1691, il commanda les armées jusqu'en 169̋̈, et mourut à Paris le 22 octobre 1702.

Il est représenté en pieł.

\section{Villeroy (François de Neufville, duc de).}

Par M. Caminade. - H. 2,15. - L. 1,40.

Né en 164y. Colonel du régiment d’infanterie de Lyonnais en 166', il fit sa première campagne en Hongrie, servit en Flandre en 1667 et 1668 , fut brigadier d'infanterie en 1672 et fit la campagne d'Allemagne. Maréchal de camp en 1674, lieutenant général en 167\%, il servit en Flandre à plusieurs reprises et fut chevalier de l'ordre du Saint-Esprit en 1688. Maréchal de France on 1693, il commanda les armées de Flandre de 1693 à 1607, celles d'Allemagne et d'Italie en 1701 et 1702 , et de nouveau celle de Flandre de 1703 à 1706 . Ministre d'Etat et chef du conseil roval 
des finances en 1714, gouverneur du roi Louis XV pendant sa minorité, il fut arrêté en 1722 par ordre du régent (voir cidessus, page 278), et mourut à Paris le 18 juillet 1730 .

Il est représenté en pied.

\section{Bouflers (Louis-François, duc de).}

Par M. Aug. Couder. - H. 2,15. - L. 1,40.

Né en 1644. Cadet au régiment des Gardes en 1662, mestre de camp en 1669, il servit activement jusqu'en 1676, fut maréchal de camp en 1677 et devint en 1678, après avoir fait la campagıe d'Allemagne, colonel général de dragons. Lieutenant général en 1681, il servit en Allemagne en 1688 et fut nommé chevalier de l'ordre du Saint-Esprit. Colonel du régiment des gardes-francaises en 1692, maréchal de France en 1693, créé duc en 1693., il commanda les armées jusqu'en 1703. Chevalier de la Toison d'Or en 1703, pair de France en 1708 après la défense de Lille; il fit sa dernière campagne en Flandre, et mourut à Fontainebleau le 22 août 1711.

II est représenté en pied.

1045. Tourville (Anne-Hilarion de Costentin, comle
de).

Par M. Eug. DelaGRoIx. - H. 2,25. - L. 1,40.

Né en 1642 au chàteau de Tourville (Manche), il entra dans l'ordre de Malte à quatorze ans, devint capitaine de vaisseau en 1667, servit sur mer jusqu'en 1676 , et fut nommé chef d'escadre en 1677. Lieutenant général des armées navales en 1682, il se trouva, la même année, au bombardement d'Alger et à celui de Gênes en 1684. Nommé vice-amiral du Levant en 1689, il remporta la victoire de Béveziers, fut fait maréchal de France en 1693 et commanda sur mer jusqu'en 1694. Il mourut à Paris le 28 mars 1701 .

Il est représenté en pied.

1046. Estrées (Victor-Marie, duc d').

Par Degaisne. - H. 2,15. - L. 1,40.

Né en 1660, fils du maréchal Jean d'Estrées, il fut connu jusqu'en 1707 sous le nom de comte de Couvres. Il fit ses premières armes en Allemagne en 1678, fut nommé capitaine de vaisseau

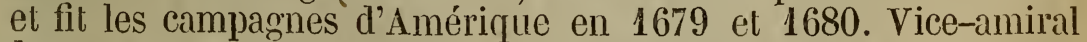
de France en 1684, il servit contre les corsaires d'Alger', se trouva en 168 ä au bombardement de Tripoli, et en 1688 à celui d'Alger. Il passa ensuite à l'armée d'Allemagne, fut lieutenant général des 
armées navales en 1689, prit part, en 1690, à la bataille de Bévezier's, commanda l'armée navale en Catalogne en 1693, défendit les côtes de Provence en 169ä et servit à Cadix en $\mathbf{1 6 9 8 .}$ Naréchal de France et grand d'Espagne de première classe en 1703, chevalier de l'ordre du Saint-Esprit en $1700 ั$, il fut en $1710 ّ$ membre du conseil de régence et président du conseil de la marine. Duc et pair en 1723, ministre d'Etat en 1733 , il mourut à Paris le 27 décembre 1737. - Le maréchal d'Estrées avait été reçu membre de l'Académie française en $4 \overline{7} 150$.

Il est représenté en pied.

\section{SEPTIĖNE SALLE DES MARÉCHAUX, No 50.}

\section{[Voir Vestibule no 41.)}

Dépendance de l'appartement du grand dauphin, puis du duc de Berry sous Louis XIV, cette pièce servait en 1735 d'antichambre à l'appartement du cluc de Châtillon, gouverneur du dauphin, fils de Louis $\mathrm{XV}$, et formait en 1755 la seconde antichambre de l'appartement du dauphin.

La suite chronologique des maréchaux de France depuis Jacques Nompar de Caumont, duc de La Force (1622) jusqu'à Antoine, duc d'Aumont (1651) est représentée par des écussons ou par des portraits en buste.

\section{Schomberg (Henri de), comtede Nanteuil.}

Par M. Rotget. - H. 0,71. - L. 0,55.

Né en $15 \% \%$, il fit ses premières armes au siége d'Amiens en 1วั97. Gouverneur de la Marche en $10 ّ 99$, conseiller d'État en $160 \overline{7}$, ambassadeur extraordinaire en Angleterre en 161ว̆, et en Allemagne en $161 \overline{7}$, il fut surintendant des finances et chevalier de l'ordre du Saint-Esprit en 1619. Gouverneur général du Limousin et de l'Angoumois en 1622, maréchal de France en 1620̈, il commanda au siége de La Rochelle en 1627, et dans la campagne du Piémont en 1629. Il venait de vaincre à Castelnaudary l'armée rebelle du duc de Montmorency et d'être nommé gouverneur général du Languedoc, lorsqu'il mourut à Bordeaux le 17 novembre 1632.

Le portrait original est au château de Beauregard.

\section{Estrées (François-Annibal, duc d').}

Par J.-M. LANGLOIS. - H. 0,71. - L. 0,55.

Né en 10ั81, il fut d'abord destiné à l'état ecclésiastique, et nommé en 15094 à l'évêché de Noyon. Il embrassa la profession des armes après la mort de son frère aîné, se trouva au siége d'Amiens en 1597 et fit la campagne de Savoie en 1600. Ambassadeur à Rome en 1621, maréchal de camp en 1622, il réunit en 1624 les fonctions d'ambassadeur extraordinaire en Suisse "et 
de général des troupes auxiliaires de France, de Venise et de Savoie dans la Valteline. Maréchal de France en 1626, il commanda l'armée du roi en Languedoc en 1629, fut ambassadeur à Venise en 1630, et commanda l'armée d'Allemagne en 1632. Chevalier de l'ordre du Saint-Esprit en 1633, ambassadeur à Rome de 1636 à 1642, il fut créé duc et pair en 1648, et représenta le connétable au sacre de Louis XIV en 165\%4. Il mourut le 5 mai 1670.

\section{Saint-Luc (Timoléon d'Espinay, seigneur de).}

Par M. Rouget. - H. 0,71. - L. 0,55.

Après avoir servi au siége de La Fère en 1596 et à celui d'Amiens en 1597, il reçut le gouvernement général de Brouage et des îles de Saintonge. Maréchal de camp en 1617, chevalier de de l'ordre du Saint-Esprit en 1619, colonel d'infanterie en 1620, il se trouva en 1621 au siége de Saint-Jean-d'Angely. Vice-amiral de France en 1622, il servit la même annće dans lîlle de Riez, fut lieutenant général au gouvernement de Guyenne et maréchal de France en 1627, et mourut à Bordeaux le 12 septembre 1644.

\section{Marillac (Louis de).}

Par Mile Cogniet. - H. 0,71. - L. 0,51.

Né en Auvergne en 15:72, il fit ses premières armes au siége de Laon en 1594. Gentilhomme ordinaire de la chambre du roi en 1598, il fut, après la mort de Henri IV, envoyé successivement comme ambassadeur en Italie, en Lorraine et en Allemagne. Maréchal de camp en 1617, il fit les campagnes de 1621 et 1622 contre les protestants, recut le gouvernement de Verdun, et se trouva en 1627 au siége de La Rochelle. Maréchal de France et chevalier de l'ordre du Saint-Esprit en 1629, il fut envoyé l'année suivante comme un des lieutenants du roi en Piémont. Arrêté au milieu de son armée comme complice des intrigues de Marie de Médicis contre Richelieu, il fut jugé et décapité le $\mathbf{1 0}$ mai 1632.

\section{Effiat (Antoine Coiffer, dit Ruzé, marquis d').}

Par M. Grgoux. - H. 0,71. - L. 0,55.

Gentilhomme de la chambre du roi en 1599, conseiller d'état en 1616, ambassadeur en Angleterre en 1624, chevalier de l'ordre du Saint-Esprit en 1625, il fut surintendant des finances en 1626, et suivit Louis XIII dans les campagnes de Savoie et du Languedoc. Gouverneur d'Anjou en 1630, maréchal de France et gouverneur général d'Auvergne en 1631, il fut envoyé en 
1632 en Alsace au secour's de l'électeur de Trèves, et mourut dans le cours de cette expédition, le 27 juillet de la même année.

\section{Brézé (Urbain de Maillé, marquis de).}

Par J.-M. LanguloIs. - H. 0,71. - L. 0,55.

Capitaine des gardes du corps de la reine Marie Médicis, puis du roi Louis XIII, il fit la campagne de Piémont en 1629 , et fut nommé conseiller d'Etat. Maréchal de camp en 1630, ambassadeur en Suède et maréchal de France en 1632, chevalier de l'ordre du Saint-Esprit en 1633, il commanda en 1634 l'armée d'Allemagne. Ambassadeur en Hollande en 1635, gouverneur général d'Anjou en 1636, il fut vice-roi de Catalogne, commanda Tarmée francaise dans cette province, et mourut en Anjou, le 13 février 1650 , à l'âge de cinquante-trois ans.

\section{Gramont (Antoine III, duc de).}

Par Mme Rochard. - H. 0,71. - L. 0,55.

Né à Hagettmau (Landes) en 1604, il fit ses premières armes sous le nom de comte de Guiche aux siéges de Saint-Antonin et de Montpellier en 1621 et 1622. Maréchal de camp en 1635, il fit les campagnes de 1635 et 1636 en Allemagne, de 1637 en Flandre et de 1638 en Italie. Mestre de camp du régiment des gardesfrançaises en 1639, il se signala au siége d'Arras en 1640 , et fut nommé maréchal de France en 1641. Il défendit Arras contre les Espagnols en 1643, et servit sous le duc d'Enghien aux batailles de Fribourg, de Nordlingen et de Lens. Créé duc et pair de France en 1648, il fut ambassadeur extraordinaire près de la diète de Francfort en 1657 , colonel général des gardes-françaises et chevalier de l'ordre du Saint-Esprit en 1661. Il se trouva encore aux siéges de Douai et de Courtray en 1667, et se retira à Bayomne où il mourut le 12 juillet 1678, à l'âge de soixantequatorze ans. - Il a laissé des Mémoires sur ses négociations.

Le portrait original est dans la famille de Gramont.

1054. Aumont (Antoine, duc d').

Par MaUzaisse. - H. 0,71. - L. 0,55.

Né en 1601. Connu d'abord sous le nom de marquis de Villequier, il fut enfant d'honneur de Louis XIII, flt ses premières armes dans les guerres contre les protestants jusqu'en 1628, et se trouva au Pas-de-Suze en 1629. Capitaine des gardes du corps du roi en 1632, chevalier de l'ordre du Saint-Esprit en 1633, maréchal de camp en 1638, il fit les campagnes de Flandre et de Roussillon, et fut.nommé conseiller d'Etat. Lieutenant général 
des armées du roi en 1645, il servit en Flandre; maréchal de France en 165ٌ1, gouverneur général de la ville de Paris en 1662, il fut créé duc et pair en 166วั. Il commanda un corps -l'armée dans la campagne de 1667 en Flandre, et mourut à Paris e 11 janvier 1669.

Le portrait original est au château de Beauregard.

1055. Noailles (Anne-Jules, duc de).

Par M. Mosvorsin. - H. 2,14. - L. 1,40.

Né en 1650 , il porta d'abord le nom de comte d'Ayen, et fit sa première campagne au siége de Marsal en 1663, à l'âge de treize ans. Brigadier des gardes du corps en 1665̆, aide de camp du roi en 1672, maréchal de camp en 1677, il fit toutes les campagnes de Flandre et devint duc et pair en 1678. Lieutenant général en 1682, chevalier des ordres du roi en 1688, il commanda en chef l'armée du Roussillon dès 1689, fut maréchal de France en 1693, vice-roi de Catalogne en 1691, et mourut à Versailles le 2 octobre 1708.

II est représenté en pied. Ce tableau a été exécuté d'après un portrait de famille.

\section{Catinat (Nicolas de), seigneur de St-Gratien.}

Par M. Jollivet. - H. 2,14. L. 1,40.

Né à Paris en 1637, il fut lieutenant au régiment de cavalerie de Fourille et fit les campagnes de Flandre en 1667 et 1668. Capitaine au régiment des gardes en 1670 , il servit de nouveau à l'armée de Flandre en 1672, en Lorraine et en Alsace en 1673, en Franche-Comté et en Flandre en 1674, et en Allemagne en 167. Major général de l'infanterie à l'armée de Flandre en $\mathbf{1 6 7 6 ,}$ et brigadier en 1677, il eut en 1678, le commandement de Dunkerque. Maréchal de camp en 1681, il eut en 1682 le gouvernemient de Casal et commanda les armées du roi en Savoie en 1686, la province de Luxembourg en 1687 et le camp de la Meuse en 1688. Lieutenant général en 1688, il fut employé à l'armée d'Allemagne, commanda l'armée de Piémont en 1690, et celle d'Italie en 1692. Maréchal de France en 1693, il commanda l'armée d'Italie jusqu'en 1696; appelé en Flandre en 1697, il commanda dans le Milanais en 1701, en Allemagne en 1702, et fut nommé chevalier de l'ordre du Saint-Esprit en 170כ. Il mourut à Saint-Gratien, le 23 février 1712.

Il est représenté en pied.

\section{Villars (Louis-Claude-Hector, duc de).}

Par Pierre Franque. - II. 2,14. - L. 1,40.

Né à Moulins en 165̃2, il fut d'abord page de la grande écurie 
en 1670, entra dans les mousquetaires en 1671 , et en 1672 fut attaché comme aide de camp à son cousin, le maréchal de Bellefonds. Colonel de cavalerie et mestre de camp en 1674, il servil en Flandre et en Allemagne jusqu'en 1679, se trouva au siége de Luxembourg en 1684, et passa en Hongrie en 1687. Maréchal de camp en 1690, il fut employé jusqu'en 1693 dans les armées de Flandre, de la Moselle et d'Allemagne. Lieutenant général en 1693, il fit les campagnes d'Allemagne et d'Italie, commanda la cavalerie de l'armée du Rhin en 1697 et fut ambassadeur à Vienme de 1698 à 1701. Maréchal de France en 1702, il commanda en chef l'armée d'Allemagrie en 1703, et dans la province du Lang'uedoc en 1704. Nommé chevalier de l'ordre du Saint-Esprit et duc de Villars en 1700̆, il commanda successivement les armées de la Moselle, du Rhin, du Dauphiné, de Flandre, et fut créé pair de France en 1709. Appelé de nouveau au commandement de l'armée de Flandre en 1710 , il remporta en 1712 , la victoire de Denain, fut gouverneur général de la Provence, et commanda les armées du Rhin et de la Moselle. Ministre plénipotentiaire au congrès de Rastadt en 1712, chevalier de la Toison d'Or en 1714, président du conseil de la guerre en 1715 , membre du conseil de régence en 1718, grand d'Espagne de première classe et ministre

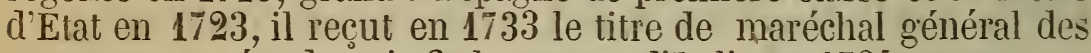
camps et armées du roi, fit la guerre ditalie en 1734, et mourut à Turin, le 17 juin de la même année.

Il est représenté en pied.

\section{Chamilly (Noël Bouton, marquis de).}

Par M. HeIM. - H. 2,14. - L. 1,40.

Né à Chamilly en Bourgogne en 1636, il fit ses premières armes comme volontaire au siége de Valenciennes en 16วั6; capitaine au régiment de cavalerie du cardinal Mazarin en 16.̋, il fit la campagne de Flandre et passa en 1663 dans le royaume de Portugal où il prit du service. De retour en France, il fit partie de l'expédition de Candie en 1669, fut brigadier d'infanterie en 1673, maréchal de camp en 1674, et fut employé en Flandre en 1676 et 1678. Lieutenant général en 1678, gouverneur de Fribourg en 1679 et de Strasbourg en 1681, il commanda en chef dans la Basse-Alsace et fit les campagnes d'Allemagne de 1691 à 1697. Maréchal de France en 1703, chevalier de l'ordre du SaintEsprit en 1705, il commanda en chef les provinces de Poitou, Aunis et Saintonge, et mourut à.Paris le 8 janvier 1715 .

Il est représentẻ en pied. 


\section{Vauban (Sébastien Le Prestre, seigneur de).}

Par M. Larivière. - H. 2,14. - L. 1,40.

Né à Saint-Léger (Yonne) le 15 mai 1633, il entra comme cadet au régiment de Condé en 16ă1, et fit ses premières campagnes dans les armées d'Espagne. Il passa en $160 ̈ 3$ au service de la France, fut lieutenant au régiment de Bourgogne, et se trouva en $16 \breve{4}$ comme ingénieur en second aux siéges de Sainte-Menehould et de Stenay. Ingénieur en 16\%ั, il servit la même année aux siéges de Landrecies, de Condé et de Saint-Guillain. Capitaine d'infanterie en 16006 , il était au siége de Valenciennes, à celui de Montmédy en 16ö7, et dirigea en chef les siéges de Gravelines, d'Oudenarde et d'Ýpres en 16ว8. Lieutenant colonel du régiment de La Ferté en 1662, il fortifia Charleroi en 1667, construisit en 1668 la citadelle de Lille, dont il eut le gouvernement, et accompagna Louis XIV dans les campagnes de 1672, 1673 et 1676. Brigadier et maréchal de camp en 1676, commissaire général des fortifications de France en 1678, gouverneur de Douai en 1680, il construisit le fort de Dunkerque, fortifia en 1681 Casal et Strasbourg, et dirigea en 1684 les opérations du siége de Luxembourg. Lieutenant général des armées du roi en 1688, il fut chargé de faire les siéges de Philipsbourg, de Manheim en 1689, de Mons en 1691, de la ville et des châteaux de Namur en 1692. Grand'croix de l'ordre de Saint-Louis en 1693, il dirigea les travaux du siége de Charleroi, fut employé en 169' en Bretagne à la défense des côtes, commanda à Brest et sur les côtes en 169 s̆, et dirigea en 1697 le siége d'Ath. Maréchal de France en 1703, il commanda l'armée d'Allemagne avec le maréchal de Tallard, sous les ordres du duc de Bourgogne. Chevalier de l'ordre du Saint-Esprit en 1705 et commandant à Dunkerque en 1706, il mourut à Paris le 30 mars 1717. Vauban avait été reçu membre honoraire de l'Académie des sciences en 1699; il a laissé un grand nombre d'écrits stratégiques et des mémoires.

Il est représenté en pied.

\section{Montrevel (Nicolas-Auguste de La Baume, marquis de).}

Par M. SAINT-Èvre, en 1835. - H. 2,14. - L. 1,40.

Né à Paris en 1640ั, il était capitaine au régiment de la Reinecavalerie en 1667, et servit en Flandre et en Hollande de 1667 à 1674. Lieutenant général des provinces de Bresse, Bugey, etc., en 1673 , commissaire général de la cavalerie en 1677 , il continua à servir en Flandre et en Allemagne, fut maréchal de camp en 
1688, lieutenant général en 1693, commanda en 169't un corps de larmée de Flandre, et servit dans différentes armées jusçu' en 1702. Maréchal de France en 1703, il commanda successivement en Guyenne, en Alsace et en Franehe-Comté, fut chevalier de l'ordre du Saint-Esprit en $1700 ّ$, et mourut à Paris le 11 octobre 1716.

Il est représentẻ en pied.

\section{Harcourt (Henri, duc d').}

Par M. SGHNETZ. - H, 2,14. - L. 1,40.

Né en 16ăł. Cornette de cavalerie en 1673 , aide de camp de Turenne en 1674, colonel d"un régiment dinfanterie en $167 \%$, il fit les campagnes de Flandre et d'Allemagne jusqu'en 1618. Lieutenant général au gouvernement de Normandie en 1678, inspecteur général de l'infanterie en 1682, il était au siége de Luxembourg en 168', fut maréchal de camp en 1688, et servit actirement jusqu'en 1692. Lieutenant général en 1693, il commanda l'armée de la Moselle en 1694, et fut ambassadeur en Espagne en 1697 et 1700. Créé duc en 1701, maréchal de France en 1703, chevalier de l'ordre du Saint-Esprit en 1700ّ, il commanda les armées d'Allemagne et du Rhin, fit partie du conseil de régence en $1710 \%$, et mourut à Paris le 19 octobre 1718.

Il est représenté en pied.

\section{Berwick (Jacques de Fitz-James, duc de).}

Par II. Champuartix. - H. 2,14. - L. 1,40.

Fils naturel du duc d'York (Jacques II), il naquit à Moulins en 1671 , et à l'âge de quinze ans, il alla servir comme volontaire en Hongrie. Jacques II le créa en 1687, duc de Berwick, et lui donna l'ordre de la Jarretière en 1688. Entré au service de France en 1691, il fut lieutenant général en 1693, et employé à l'armée de Flandre en 1694 et 1695े. Nommé par Philippe $\dot{V}$, pour prix de ses services, grand dEspagne et chevalier de la Toison d'Or. Maréchal de France en 1706 , il fut créé duc et pair en 1710 , et eut successivement le commandement des armées du Rhin, du Piémont, etc. Conseiller au conseil de régence, chevalier de l'ordre du Saint-Esprit en 1724, il commanda l'armée du Rhin en 1733, et fut tué d'un coup de canon au siége de Philipsbourg, le 12 juin 1734 .

Il est représenté en pied.

1063. Matignon (Charles-A uguste de Goyon, comte de).

Par M. SchNeTZ. - H. 2,14. - L. 1,40.

Né en 1647. Connu d'abord sous le nom de chevalier de Tho- 
rigny, il entra au service comme cornette de cavalerie en $\mathbf{1 6 6 7}$ fit partie de l'expédition de Candie en 1669, et servit en Flandre et en Allemagne jusqu'en 1684. Maréchal de camp en 1689, lieutenant général en 1694, il servit activement jusqu'en 1707, fut nommé maréchal de France en 1708, commanda l'armée de Flandre sous le duc de Bourgogne, et mourut à Paris, le 6 décembre 1729.

Il est représenté en pied.

\section{GALERIE LOUIS XIII, No $5 \%$.}

Ce vestibule, situé au-dessous de la galerie des glaces, servait à passer directement de la cour de marbre dans les jardins et communiquait à droite à l'appartement des bains, et à gauche à l'appartement du dauphin. Il avait été rétréci sous Louis XV pour ajouter des dépendances à ces deux appartements.

Les trumeaux sont décorés par MM. ALACx, LAFAYE et H. LEcoute, de portraits et de sujets appartenant aux règnes de Louis XIII et de Louis XIV; ce sont :

Louis XIII. - Mariage de Louis XIII et d'Anne d'Autriche (25 novembre 1615).

Anne d'Aulriche. - Combat du Pas de Suze (6 mars 1629).

Gaston de France, duc d'Orléans. - Traité de Ratisbonne (13 octobre 1630).

Christine de France, duchesse de Savoie. - Prise de Perpignan (5 septembre 1642).

Henrictte de France, reine d'Angleterre. - Richelieu fait don du PalaisRoyal à Louis XIII (2 décembre 1642).

Le cardinal de Richelieu. - Le Poussin présenté à Louis XIII (1640).

Elisabeth de France, reine d'Espagne. - Fondation de l'Académie Fransaise (1634).

Le cardinal Mazarin. - Réception des chevaliers du Saint-Esprit à Fontainebleau (5 mai 1633).

Le grand Condé. - Bataille de Nordlingen (3 aout 1645).

Turenne. - Levée dus siége d'Arras (25 aoùt 1654).

Louis XIV. - Masarin présente Colbert à Louis XIV (mai 1661).

Philippe de France, duc d'Orléans. - Bataille de Cassel (11 avril 1677).

\section{Louis XIII. (Voir $\left.\mathrm{n}^{\circ} 716.\right)$}

Par Simon Gulllain, statue en plâtre. - H. 2,03.

Cette statuc et la suivante ont été moulées, ainsi que le $n^{\circ} 818$, d'après les statues en bronze qui décoraient autrefois le monument du Pont-au-Change et qui sont au Musée du Louvre. (N $N^{\text {os }} 168,169$ et 170 de la Description des sculpleurs modernes, par M. Barbet de Jouy.)

1065. Anne d'Autriche. (Voir no 930 .

Par Simon Guillain, statue en plâtre. - H. 2,00.

\section{Bataille de Rocroy. - 19 mai 1643. (Voir no 82. )}

Par M. Schnetz. - H. 3,48. - L. 5,01.

Ce tableau a été exposé au Salon de 1822, comme représentant le grand Condé à la bataille de Senef. 


\section{Entrée de Louis XIV à Dunkerque. -26 mai 1653.}

Far Mathied, d'après Lebrun et Vander Meulen - H. 3,48. - L. 5,97.

La reddition de cette place fut une suite de la bataille des Dunes gagnées par Turenne. Cette ville, bloquée par les Anglais, se rendit le 20 juin, et le roi y entra le 26.

Louis XIV, à cheval, est accompagné de Turenne et du duc de Saint-Aignan. $\mathrm{Au}$ fond, à gauche, la ville de Dunkerque.

Cette peinture, exécutée d'après les compositions de Lebrun et de Vander Meulen, a servi de modèle pour les tapisseries des Gobelins.

\section{Entrevue de Louis XIV et de Philippe IV dans l'île des Faisans. - 7 juin 1660.}

Par Matileu, d'après Lebrun et Vander Meulen. - H. 3,48. - L. 5,97.

Les premières cérémonies du mariage de Louis XIV avec Marie-Thérèse d'Autriche, fille de Philippe IV, roi d'Espagne, se firent à Fontarabie, dans l'église cathédrale, le 3 juin 1660 . Trois jours après, les deux rois retournèrent à l'île de la Conférence, pour y promettre et jurer solennellement l'exécution du traité de paix. Louis XIV était accompagné de la reine-mère, de Monsieur, duc d'Orléans, son frère, du prince de Conty et du cardinal Mazarin, premier ministre; madame de Navailles, dame d'honneur, était à la suite de la reine-mère. Parmi les grands officiers de la couronne on remarquait le vicomte de Turenne, qui venait d'être nommé maréchal général des camps et armées du roi, et le maréchal duc de Gramont, ambassadeur extraordinaire, qui avait fait à Madrid, au nom du roi, la demande du mariage. Philippe IV était suivi de don Louis de Haro, premier ministre d'Espagne ; de don Pedro d'Aragon, capitaine de la garde bourguignonne; du marquis d'Aytone, du marquis de Malepique, grand maître des cérémonies; du marquis de Lecce et du comte de Monterey, tous deux fils de don Louis de Haro ; de don Fernando Vouès de Canto-Carrero, secrétaire d'État; de Pimentel et du peintre Velasquez. L'infante arriva avec le roi d'Espagne. Elle portait, selon le récit de Mlle de Montpensier, avec le guarda-infante, une robe de satin blane en broderies de jais. Coiffée en cheveux, elle avait un bouquet d'émeraudes en poire, avec des diamants qui étaient un présent du roi.

Cette peinture a servi de modèle pour les tapisseries des Gobelins. - Gravé par Jeaurat (Calc. imp., $n^{\circ}$ 733). 


\section{Louis XIV recoit au Louvre la réparation faite au nom de Philippe IV par le comte de Fuentes. - 24 mars 1662.}

D’après Lebruv. - II. 3,49. - L. 5,01.

Le 10 octobre 1661, lors de l'entrée à Londres de l'ambassadeur extraordinaire de Suède, le baron de Watteville, ambassadeur d'Espagne, avait pris le pas sur le comte d'Estrades, ambassadeur de France. La réparation suivit l'offense de près. Philippe IV désapprouva la conduite de son ambassadeur; ;e baron Watteville fut rappelé, et le comte de Fuentes, envoyé extraordinairement près de la cour de France, fit de la part de son maître, et en présence de tous les ministres étrangers, une déclaration authentique, en vertu de laquelle les ministres espagnols ne concourraient plus désormais avec ceux de France. Louis XIV reçut cette réparation dans son grand cabinet au Louvre.

Louis XIV, debout, la tête couverte, écoute le discours de l'ambassalleur d'Espagne; près du roi est son frère, Monsieur, duc d'Orléans, et à sa droite le nonce du pape (Piccolomini, archevêque de Césarée). Derrière l'ambassadeur d'Espagne sont les ministres et agents des puissances étrangères. Parmi les objets d'arts qui décorent le grand cabinet du roi ou salle du Trône, on remarque la Diane antique, les deux tableaux de Carrache, représentant la chasse et la pêche, qui font aujourd'hui partie de la galerie du Músée premier plan, à gauche un des vases d'argale du Musée du Louvre, et, sur lo lans lequel ilans lequel est planté un oranger chargé de fleurs et de fruits.

Cette peinture a servi de modèle pour les tapisseries des Gobelins.

1070. Louis XIV reçoit à Fontainebleau la réparation faite au nom du pape Alexandre VII par le cardinal Chigi. — 28 juillet 1664.

Par Ziégler. - H. 3,49. - L. 5,97.

Le duc de Créquy, ambassadeur du roi à Rome, avait été insulté par les Corses de la garde du pape Alexandre VII. Pour obtenir réparation de l'insulte faite à son ambassadeur, le roi arma et donna ordre à ses troupes d'entrer en Italie. Le cardinal Chigi, neveu du pape, fut alors envoyé en France en qualité de légat a latere. Il fut reçu à Fontainebleau, dans la chambre du roi, où il présenta ses titres de créance, et fit ses excuses en présence des princes et des grands officiers de la couronne.

Ce tableau a été exécuté d'après une tapisserie des Gobelins. 


\section{Reddition de la citadelle de Cambrai. - 18 avril 1677. (Voir no 155 .)}

Par MaUzaISSE, d'après Vander Meulen. -- H. 3,49. - L. 5,97.

A gauche Louis XIV à cheval; plus loin, à droite, don Pedro Zavala, gouverneur de Cambrai, est à la portière de son carrosse. Il avait été blessé à la jambe et se fit conduire ainsi au devant du roi.

\section{HUITIÈMIE SALLE DES MARÉCHAUX, No 52.}

Cette salle portait autrefois le nom de Cabinet des Bains, et formait avec les suivantes l'Appartement des Bains, pavé et revêtu, dit Félibien, de différentes sortes de marbre. Au milieu du cabinet des bains était une grande cuve en marbre, de forme octogone, et faite d'un seul bloc; dans une partie en renfoncement qui formait une sorte d'alcôve, et à laquelle on montait par plusieurs marches, se trouvaient de petites baignoires de marbre, et derrière, le réservoir pour les eaux. Ces dispositions furent 'changées lorsqu'en 1684 Louis XIV donna à $\mathrm{MI}^{\mathrm{me}}$ de Montespan l'appartement des bains. On'en ôta les marbres, dit Dangeau, et on le parqueta pour le rendre logeable en hiver. $M^{\text {me }}$ de Montespan s'étant retirée de la cour en mars 1691, cet appartement fut alors donné au duc du Maine, puis au comte de Toulouse. Cette pièce était, en 1735, le cabinet de la comtesse de Toulouse. En 1750, dit Piganiol de La Force (édit. de 1764, tome I, page 320 ), des ouvriers qui travaillaient dans cet appartement découvrirent sous le parquet de la chambre la grande baignoire octogone qui fut transportée au pavillon de l'Ermitage (1). En 1755, cette pièce était la chambre à coucher de $M^{\text {me }}$ Sophie, fille de Louis $X V$, et fit partie, sous Louis XVI, de l'appartement de $\mathrm{M}^{\text {we }}$ Victoire.

La suite chronologique des maréchaux de France, depuis Jacques d'Estampes (1651) jusqu'à François-Henri de Montmorency, duc de Luxembourg (1675), est représenté par des écussons ou par des portraits en buste.

\section{La Ferté (Henri de Senneterre, duc de).}

Par M. HeIM. - H. 0,71. - L. 0,55.

Capitaine au régiment du comte de Soissons en 1627, il servit activement jusqu'en 1629, fut nommé maréchal de camp sur la brèche de Hesdin, et commanda l'aile gauche à la bataille de Rocroy en 16ł3. Lieutenant général en 1646, il fut employé dans les guerres contre les Espagnols jusqu'en 16ว̋0. Maréchal de France en 16ö1, chevalier de l'ordre du Saint-Esprit en 1661, créé duc et pair en 166 ö, il mourut à La Ferté le 27 septembre 1681, âgé de quatre-vingt-deux ans.

\section{Schulemberg (Jean de), comte de Montdejeu.}

Par M. Herм. - H. 0,71. - L, 0,55.

Il entra au service de France en 1621, se trouva aux siéges de Saint-Jean-d'Angely et de Montauban, fut mestre de camp

(1) Cette baignoire se trouve encore dans l'ancien emplacement de l'Ermitage, rue de Maurepas, à Versailles. Elle sert de bassin dans le jardin. 
HUITIÈME SALLE DES MARÉCHAUX, $\mathrm{N}^{0} 52$.

d'infanterie en 1630 , et fit les campagnes de 1632 et de 1637 en Allemagne. Nommé maréchal de camp au siége de Hesdin en 1639 , lieutenant général en 1650 , il fut gouverneur d'Arras en 1632 , et défendit cette place contre les Espagnols en 1654. Maréchal de France en 1658, chevalier de l'ordre du Saint-Esprit en 1661, il mourut à Montdejeu en 1671 .

\section{Bellefonds (Bernardin Gigault, marquis de).}

Par M. RouilLard. - II. 0,71. - L. 0,55.

Capitaine au régiment de Piémont en 1645̆, il servit en Flandre depuis 1645 jusqu'en 1648, en Normandie en 1649, et fit en Catalogne les campagnes de 1649 à 16031 . Maréchal de camp en $160 ̋ 1$, il fut employé de nouveau à l'armée de Catalogne en 16533. Lieutenant général des armées du roi en $165 ̋$, il continua à faire la guterre en Catalogne jusqu'en 165̋7, se rendit en Flandre en 16.8 , et se trouva à la bataille des Dunes. Il commanda en Flandre en 16509 et en Italie en 1663, fit à l'armée de Flandre la campagne de 1667, et servit à l'armée des Pays-Bas en 1668. Maréchal de France en 1668, ambassadeur extraordinaire ell Angleterre en 1670, il eut différents commandements en Flandre et en Hollande de 1672 à 1674. Le maréchal de Bellefonds commanda en chef l'armée du Roussillon en 1684, fut créé chevalier de l'ordre du Saint-Esprit en 1688, et mourut au château de Vincennes le \& décembre 1694.

\section{Estrades (Godefroy, comte d'),}

Par M. IIEIM. - H. 0,71. - L. 0,55.

Il fit ses premières armes en Hollande en 1637; conseiller d'Etat en 1639, ambassadeur extraordinaire en Hollande en 1646, maréchal de camp en 1647, lieutenant général en 1650, il servit en Italie et en Flandre. Lieutenant général dans le pays d'Aunis et maire perpétuel de Bordeaux en 1653 , chevalier de l'ordre du Saint-Esprit en 165\%", il commanda l'armée de Catalogne en 165̋, fut ambassadeur extraordinaire en Angleterre en 1661, en Hollande en 1666, et recut le titre de vice-roi de l'Amérique. Maréchal de France en 1675 , ministre plénipotentiaire pour la paix signée à Nimègue en 1678, il mourut à Paris le 26 février 1686.

\section{Navailles (Philippe de Montault, duc de).}

par M. Murat. - H. 0,71. - L. 0,55.

Page du cardinal de Richelieu en 1635 , il fut successivement enseigne, capilaine et colonel du régiment de la marine, de 1638 à 1641, et fit ses premières armes en Flandre. Après avoir 
servi en Italie de 1641 à 1644 , et en Catalogne en 1645 et 1646 , il fut maréchal de camp en 1647, et commanda en 1648 l'armée d'Italie. Lieutenant général en $163 \% 0$, il fut employé à l'armée de Flandre jusqu'en 16oั\%. Ambassadeur extraordinaire en Italie en 16ə̋8, chevalier de l'ordre du Saint-Esprit en 1661, il commanda les troupes de l'expédition de Candie en 1669, servit en Bourgogne et en Franche-Comté en 1673 et 1674, et fut nommé maréchal de France en 1675 . Il fit la guerre de Catalogne de 1676 à 1678, fut en 1683 gouverneur du duc de Chartres (depuis régent du royaume), et mourut à Paris le כ̌ février 168ł.

\section{Duras (Jacques-Henri de Durfort, duc de).}

Par Mime Julllerat. - H. 0,71. - L. 0,55.

Né en 162气, il fut capitaine au régiment de son oncle, le maréchal de Turenne, en 1643, servit en Italie en 1643 et $\mathbf{1 6 4 4 ,}$ et en Allemagne de 1645 à 1648. Lieutenant général en 16ä7, il fit les campagnes de Flandre en 16057 et 1667, celle de FrancheComté en 1674, et commanda l'armée d'Allemagne en 1673̈. Maréchal de France en 1675, chevalier de l'ordre du Saint-Esprit en 1688, il reçut de nouveau le commandement de l'armée d'Allemagne en 1689, et mourut à Paris le 12 octobre 1704, à soixante-dix-neuf ans.

Ce portrait à été exécuté d'après un pastel de la collection du Louvre.

\section{Vivonne-Mortemart (Louis-Victor de Roche- chouart, duc de).}

Par Grancourt. - H. 0,71. - L. 0,55.

Né en 1636, il fut élevé comme enfant d'honneur auprès de Louis XIV; capitaine de cavalerie en 16ว̆4, il servit en Flandre jusqu'en 16.37 , fut mestre de camp en $163 \% 9$, el fit la campagne d"Italie en 1663. Naréchal de camp en 1664, il fit partie de l'expédition de Gigeri sous le duc de Beaufort, et fut nommé, en 166ə̃, lieutenant général des mers du Levant. Après aroir fait les campagnes de Flandre de 1667 et de 1668, il fut général des galères en 1669 , porta des secours à Candie en 1671 , et fut blessé au passage du Rhin en 1672. Vice-roi de Sicile et commandant la flotte du roi en 1674, il s'empara de Messine en 167ö, fut nommé maréchal de France et commanda en 1676 l'armée navale devant Palerme. Il fit encore la campagne de Flandre en 1678 et mourut à Chaillot le 1 septembre 1688 .

Cette peinture décorait autrefois l'hôtel de la Marine, à Versailles. 


\section{Médavy (Jacques-Léonor Rouxel, comte de).}

Par Mauzaisse. - H. 2,15. - L. 1,40.

Né en 1655 à Chalençay, en Bourgogne, il entra comme cadet dans les gardes du corps en 1673, suivit Louis XIV au siége de Maëstricht, et fit la campagne de 1674. Colonel d'infanterie en 1675, il servit activement jusqu'en 1683, fut brigadier en 1688, maréchal de camp en 1693 , et fit les campagnes d'Italie, de Flandre et d'Allemagne. Lieutenant général en 1702, il commanda en chef un corps de l'armée d'Italie de 1703 à 1707, fut chevalier du Saint-Esprit en 1711, et servit en Dauphiné jusqu'en 1713. Commandant en chef de la Provence en 1719, maréchal de France en 1724, il mourut à Paris le 6 novembre $1720 \%$.

Il est représenté en pied.

\section{Puységur (Jean-François de Chastenet, mar- quis de).}

Par M. Latil en 1835. - H. 2,15. - L. 1,40.

Né à Paris en 1669, il fut lieutenant au régiment du Roi en 1677, maréchal de camp en 1702, et fit les campagnes de Flandre el d'Allemagne. Lieutenant général en 1704, il servit en Espagne, puis aux armées de Flandre et du Rhin jusqu'en 1713. Conseiller au conseil de guerre en 1715 , il fut employé en 1733 à l'armée du Rhin. Maréchal de France en 1734, chevalier de l'ordre du Saint-Esprit en 1739, il mourut le 15 août 1743.

Il est représenté en pied.

1081. Asfeldt (Claude-François Bidal, marquis d').

Par M. SGHOPIN. - H. 2,15. - L. 1,40.

Lieutenant de dragons au service de France en 1683 , il se trouva au siége de Luxembourg et fit les campagnes d'Allemagne et de Flandre de 1689 à 1697. Maréchal de camp en 1702, lieutenant général en 1704, il fut employé en Espagne et continua de servir activement jusqu'en 1715 . Chevalier de la Toison d'Or en 1715 , admis au conseil de guerre et nommé directeur-général des fortifications, il fit partie de l'armée d'Espagne en 1719, et commanda celles d'Italie et du Rhin en 1733 et 1734. Maréchal de France en 1734, il mourut à Paris le 7 mars 1743, à l'àge de soixante-seize ans.

Il estreprésenté en pied. 


\section{Noailles (Adrien-Maurice, duc de).}

Par M. FéRoN. - H. 2,15. - L. 1,40.

Né à Paris en 1678, il était fils du maréchal Anne-Jules de Noailles, et porta d'abord le titre de comte d'Ayen. Il entra aux mousquetaires en 1692, fit sa première campagne dans l'armée de Catalogne en 1693, et servit en Flandre en 1696 et 1697. Chevalier de la Toison d'Or et brigadier de cavalerie en 1702, il fut employé à l'armée d'Allemagne, fit la campagne sur le Rhin, et fut nommé maréchal de camp en 1704. Lieutenant général en 1706, capitaine des gardes du corps en 1707, il commanda en chef l'armée de Catalogne, et fut créé grand d'Espagne de première classe en 1711. Président du conseil des finances en 1715 ,

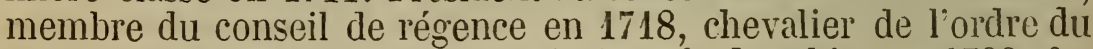
Saint-Esprit en 1724, il servit à l'armée du Rhin en 1733, fut nommé maréchal de France en 1734, et commanda les armées jusqu'à la paix de 1748. Il mourut à Paris le 24 juin 1766 , à l'âge de quatre-vingt-huit ans. - Il avait épousé, en 1698, Françoise-Charlotte-Amable d'Aubigné, nièce de $\mathbb{M}^{\mathrm{me}}$ de Maintenon.

Il est représentẻ en pied. Le portıait original est dans la famille de Noailles.

\section{Coigny (François de Franquetot, duc de).}

Par Paulin Guérin. - H. 2,15. - L. 1,40.

Né en 1670, il entra dans les mousquetaires en 1687, fut capitaine en 1690, et fit les campagnes d'Allemagne, de Flandre et d'Italie. Naréchal de camp et colonel général des dragons en 170', il fut employé aux armées de la Moselle, du Rhin et de Flandre. Lieutenant général en 1709, il continua à servir activement, fut conseiller au conseil de guerre en 1719, chevalier de l'ordre du Saint-Esprit en 1724, et commanda en chef l'armée d'Italie en 1734. Maréchal de France et chevalier de la Toison d'Or en 1734, il fut créé duc en 1747, et mourut à Paris le 18 décembre 1759.

ll est représenté en pied.

\section{Maillebois (Jean-Baptiste-François Desmaretz, marquis de).}

Par M. Caninade. - H. 2,15. - L. 1,40.

Né en 1682, il entra aux mousquetaires en 1698 , fut souslieutenant en 1699, colonel en 1703, et servit en Flandre, en Allemagne, en Savoie et en Dauphiné, de 1701 à 1708. Brigadier en 1708, il fit les campagnes de Flandro et d'Allemagne, fut maréchal de camp en 1718, chevalier de l'ordre du Saint-Esprit en 
1724, lieutenant général en 1731, el fut employé à l'armée d’Italie jusqu'en 1736. Maréchal de France en 1741, il commanda les armées de la Meuse, du Bas-Rhin et d'Italie jusqu'en 1746, et fut créé grand d'Espagne de première classe. Gouverneur général de l'Alsace en 1759, il mourut le 7 février 1762.

Il est représenté en pied.

\section{Belle-Isle (Louis-Charles-Auguste Fouquet, duc de).}

Par NivelON. - H. 2,15. - L. 1,40.

Né en 1684 à Villefranche-de-Rouergue, il était petit-fils du surintendant Fouquet. Il entra aux mousquetaires en 1701, fut capitaine dans le régiment Royal-cavalerie en $\mathbf{1 7 0 2}$, et servit aux armées d'Allemagne, du Rhin, d'Italie et de Flandre. Mestre de camp général des dragons en 1707, maréchal de camp en 1718, il commanda le camp de la Moselle en 1727, et celui de la HauteMeuse en 1730. Lieutenant général en 1731, chevalier de l'ordre du Saint-Esprit en 1734, il fut, en 174.1, ambassadeur extraordinaire et plénipotentiaire en Allemagne pour l'élection de l'empereur Charles VII. Maréchal de France en $\mathbf{1 7 4 1}$, il commanda l'armée de France sous l'électeur de Bavière, fut nommé chevalier de la Toison d'Or en 1742, et reçut le commandement de l'armée de Bohême. Général de l'armée du Rhin en 1744, de celle du Piémont en 1746 , et de celle d'Italie en 1748, il fut créé pair de France en 174:9, et ministre d'État en 1756. Il mourut à Versailles le 26 janvier 1761. - Le maréchal de Belle-Isle avait été reçu à l'Académie française en 1749.

Il est représenté en pied, mais le buste seul est peint par Nivelon; le bas du ableau a été ajouté par une main moderne.

\section{Saxe (Arminius-Maurice, comte de).}

Par M. Aug. Couder en 1834. - H. 2,15. - L. 1,40.

Né en 1696 à Goslar (Hanovre), il était fils naturel de FrédéricAuguste Ier, électeur de Saxe et roi de Pologne. Dès l'âge de douze ans, il se trouva comme fantassin au siége de Lille en 1708. Après avoir servi dans les armées du roi de Pologne, il reçut la décoration de l'Aigle-Blanc en 1718 et le grade de général-major. Il entra au service de France en 1720 et fut nommé maréchal de camp. Lieutenant général en $\mathbf{1 7 3 4}$, il servit dans les armées du

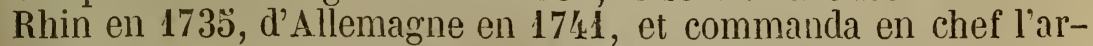
mée française en Bavière en 1743. Maréchal de France en 1744, il commanda l'armée de Flandre, remporta les victoires de Fontenoy, de Rocoux et de Lawfeldt, et fut, en 1747, maréchal- 
général des camps et armées du roi. Il reçut du roi Louis XV le domaine de Chambord, et mourut dans cette résidence le 30 novembre 1750 .

Il est représenté en pied.

\section{Lowendal (Ulric-Frédéric-Woldemar, comte de).}

Par M. Aug. Couder. - H. 2,15. - L. 1,40.

Né à Hambourg en 1700, il fit en Pologne sa première campagne comme simple soldat, en 1713 , servit successivement en Danemark, en Hongrie, en Saxe et en Russie, où il fut lieutenant général, gouverneur général du duché d'Esthonie et de Revel en 1739, et comte de l'Empire en 1741. Lieutenant général au service de la France en 1744, il fit les campagnes de Flandre en 1744 et $174 \%$, fut chevalier de l'ordre du Saint-Esprit en 1746, et maréchal de France après la prise de Berg-opZoom en 1747. Il commanda l'armée de Flandre conjointement avec le maréchal de Saxe, en 1748, et mourut le 27 mai $175 \%$.

Il est représenté en pied.

\section{NEUVIÈME SALLE DES MARÉCHAUX No 53.}

Ancienne Chambre des Bains (voir Salle no 52 ); elle était décorée de six colonnes en marbre avec des bases et des chapitaux de bronze doré; au milieu se trouvait un buffet en marbre sur lequel on plaçait les vases et ustensiles nécessaires pour les bains. Cette salle servit ensuite de chambre à coucher à la comtesse de Toulouse et à Madame Victoire. Les ornements des volets rappellent encore sa première destination.

La suite ehronologique des maréchaux de France, depuis Henri-Louis d'Aloigny, marquis de Rochefort (1675), jusqu'à Pierre de Montesquiou (1709) est représentée par des écussons ou par des portraits en buste.

1088. Choiseul (Claude, comte de).

Par Mme HaUdebourT. - H. 0,71. - L. 0,55.

Il servit comme volontaire en $\mathbf{1 6 4 9}$, fut mestre de camp de cavalerie en 1653 , et fit les campagnes de Flandre de 1653 à 16509 . Il suivit le comte de Coligny dans l'expédition de Hongrie en 1664, fut brigadier de cavalerie en 1667, maréchal de camp en 1669, et fit partie de l'expédition de Candie. Employé depuis 1672 à l'armée d'Allemagne, lieutenant général en 1676 , chevalier de l'ordre du Saint-Esprit en 1688, il fit partie de l'armée de Normandie en 1692. Naréchal de france en 1693, il commanda l'armée du Rhin en 1696 et 1697, et mourut à Paris le 15 mars 1711, âgé de soixante-dix-neuf ans. 
NEUVIÈME SALLE DES MARÉGHAUX, No 53.

\section{Tourville (Anne-Hilarion de Costentin, comte de). (Voir no 1045.)}

Par Graingourt. - H. 0,71. - L. 0,55.

Cette peinture et la suivante décoraient autrefois l'hôtel de la Marine, à Versailles.

\section{Châteauregnaud (François-Louis Rousselet, marquis de).}

Par Graingourt. - H. 0,71. - L. 0,55.

Né en 1637, il commença par servir dans les armées de terre et fit les campagnes de Flandre en 16508 et 16599 . Il se trouva à la prise de Gigeri en 166\%, fut nommé chef d'escadre en 1673 et fit sur l'Océan les campagnes de 1673 et de 1678. Il prit part au bombardement d'Alger en 1688, fit la campagne de 1689 sur les côtes d'Irlande, celle de $\mathbf{1 6 9 0}$ dans la Manche, et commanda l'avantgarde à la bataille navale de Béveziers. Grand'croix de SaintLouis lors de la création de cet ordre, en 1693, il fut nommé en 1701, par Philippe V, roi d'Espagne, capitaine général de la mer océane, et par Louis XIV vice-amiral du Levant. Maréchal de France en 1703, lieutenant général commandant en Bretagne en 170/, chevalier de l'ordre du Saint-Esprit en 1705, il mourut à Paris le 15 novembre 1716.

\section{Tallard (Camille d'Hostun, comte de), duc d'Hostun.}

Par Mme Cordellier-Delanoue. - H. 0,71. - L. 0,55.

Né en 1652, il était à quinze ans guidon des gendarmes anglais, et il fit en 1658 la campagne de la Franche-Comté. Mestre de camp lieutenant du régiment royal des Cravates en 1669, il servit en Hollande et en Flandre, de 1672 à $1675^{\circ}$. Lieutenant général au gouvernement de Dauphiné en 1675 , brigadier de cavalerie en 1677, il fut employé activement jusqu'en 1685. Maréchal de camp en 1688, lieutenant général en 1693, il fit la campagne d'Allemagne et servit jusqu'en 1697. Ambassadeur en Angleterre en 1698, chevalier de l'ordre du Saint-Esprit en 1701, maréchal de France en 1703, il commanda l'armée d'Allemagne sous le duc de Bourgogne en 1704, et fut fait prisonnier à la bataille d'Hochstett. Créé duc d'Hostun en 1712, et pair de France en 1714, il fit partie du conseil de régence et fut ministre d'Etat en 1726. Il mourut à Paris le 30 mars 1728. - Le maréchal de Tallard était membre honoraire de l'Académie des sciences. 


\section{Bezons (Jacques Bazin, comte de).}

Par M. Lutieread, d'après Detroy. - H. 0,71. - L. 0,55.

Il servit d'abord en Portugal sous le comte Schomberg en 1667 , fit la campagne de Catalogne en 1668 et celle de Hollande en 1672. Mestre de camp en 1675, inspecteur général de la cavalerie en 1688, maréchal de camp et commandant de l'ordre de SaintLouis en 1693, il fit toutes les campagnes de 1675 à 1708 et commanda l'armée d'Espagne en 1709. Naréchal de France en 1709, il commanda les armées de la Moselle et du Rhin, fit partie du conseil de régence en $1710 \%$, fut chevalier de lordre du SaintEsprit en 1724, et mourut le 22 mai 1733, à l'âge de quatrevingt-sept ans.

\section{Montesquiou (Pierre de), comte d'Artagnan}

Par $\mathbf{I}^{\text {me }}$ Rochatid. - H. 0,71. - L. 0,55.

Page du roi en 1660 , mousquetaire en 1666 , lieutenant en 1673, capitaine en 1678, il servit activement en Flandre, en Franche-Comté et en Hollande. Major du régiment des gardes en 1681, major général de l'infanterie en 1683, inspecteur général de l'infanterie en 1689, il se trouva à la bataille de Fleurus en 1690 et au siége de Mons en 1691. Naréchal de camp en 1691, il fut major-général de l'armée de Flandre, lieutenant général en 1696, et commanda en Flandre jusqu'en 1712. Maréchal de France en 1709, conseiller au conseil de régence en 1720, chevalier de l'ordre du Saint-Esprit en 1724. il mourut au Plessis-Piquet près Paris, le 12 mai $1720 \%$, â l'âge de quatre-vingts ans.

\section{Richelieu (Louis-Francois-:mand de Vignerot Du Plessis, duc de).}

Par M. Aug. Couder. - H. 2,15. - L. 1,40.

Né à Paris en 1696, il fut connu d'abord sous le nom de duc de Fronsac, entra aux mousquetaires en $\mathbf{1 7 1 2}$ et fit la campagne de Flandre. Il prit le nom de duc de Richelieu à la mort de son père, en 1715 , fut duc et pair de France en 1721, remplit les fonctions d'ambassadeur à Vienne en 1724, et fut fait chevalier de l'ordre du Saint-Esprit en 1728. Brigadier en 1734, maréchal de camp en 1738 , il servit aux armées de Flandre et du Rhin, fut créé en 174 4 preinier gentilhomme de la chambre et lieutenant général, et prit part aux victoires de Fontenoy et de Rocoux. Ambassadeur en Saxe en 1746, il se trouva en 1747 à la hataille de Lawfeld et passa ensuite à l'armée d'Italie. Naréchal de France en 1748, gouverneur général de Guyenne en $173 \%$, il s'empara en 
1750 de Port-Mahon, et commanda en 1757 l'armée de Hanovre. Il mourut à Paris le 9 août 1788, à l'âge de quatre-vingt-dix ans. - Le maréchal de Richelieu avait été recu de l'Académie française en 1721, el membre de l'Académie des sciences en 1731.

Il est représenté en pierl.

1095. Biron (Louis-Antoine de Gontaut, duc de).

Par I. COURT. - H. 2,15. - L. 1,40.

Il fut garde-marine en 1716 , capitaine de cavalerie en 1727 , colonel en 1729, et servit en Italie de 1733 à 1735ั. Maréchal de camp en 1734, il fit la campagne de Bohême, fut lieutenant général en 1743, chevalier de l'ordre du Saint-Esprit en 1744, et servit en Flandre jusqu'en 1747. Pair de France en 1749, maréchal de France en 175\%7, gouverneur général du Langucdoc en 1775 , il mourut le 29 octobre 1788, à l'âge de quatre-vingthuit ans.

Il est représenté assis sur un tertre.

1096. Estrées (Louis-Charles-César Le Tellier, comte d'), marquis de Louvois et de Courtenvaux.

Par II. Caninade. - H. 2,15. - L. 1,40.

Il entra dans l'ordre de Malte en 1697 sous le nom du chevalier de Louvois, fut mestre de camp de cavalerie en 1716 , et fit sa première campagne en Espagne en 1719. Capitaine des CentSuisses en 1722, il prit alors le nom de marquis de Courtenvaux, fut brigadier en 1734. et servit sur les bords du Rhin. Naréchal de camp en 1738, il fut substitué au nom et anx armes dEstrées en 1739, et fit les campagnes de Bohême et de Bavière. Lieutenant genéral en 1744, chevalier de l'ordre du Saint-Esprit en 1746 , il commanda à l'armée de Flandre, puis sur les côtes de la Normandie. Maréchal de France en 1757, il commanda l'armée d'Allemagne, fut ministre d'Etat en 1758, et mourut le 2 janvier 1771 , à soixante-seize ans.

Il est représentẻ en pied.

1097. Contades (Louis-Georges-Erasme, marquis de).

Par M. Gosse en 1835. - H. 2,15. - L. 1,40.

Enseigne au régiment des gardes-françaises en 1720, il y ful successivement lieutenant et capitaine; brigadier en 173/4, il servit en Italie et en Corse jusquien 1739. Maréchal de camp en 1740, il fit les campagnes d'Allemagne et de Flandre, fut lieuienant géméral en 1745 , et commanda en chef l'armée d'Alle- 
magne en 1758. Maréchal de France en 1758, chevalier de l'ordre du Saint-Esprit en 1759 , il commanda' de nouveau l'armée d'Allemagne en 1762, et mourut à Livry, le 19 janvier 1775, âgé de soixante-onze ans.

Il est représenté en pied.

\section{Soubise, (Charles de Rohan, prince de).}

École française, xvırie siècle. - H. 2,15. - L. 1,40.

Il entra aux mousquetaires en 1732, fut brigadier de cavalerie en 1740, maréchal de camp en 1743, et servit aux armées du Rhin et de Flandre. Lieutenant général en 1748, il fut gouverneur général de la Flandre et fit les campagnes d'Allemagne. Maréchal de France en 1758, ministre d'état en 1759, il fut grand'croix de l'ordre de Saint-Louis en 1779, et mourut le 4 . juillet 1787, à l'âge de soixante-douze ans.

Ce tableau a été agrandi pour former un portrait en pied.

\section{Broglie (Victor-François, duc de).}

Par M. Caminade. - H. 2,15. - L. 1,40.

Né en 1718, il était fils du maréchal François-Marie de Broglie. Il entra comme capitaine dans le régiment Dauphin-cavalerie en 1734 et servit en Italie, en Bavière et en Bohême. Brigadier en 1742, maréchal de camp en 1745\%, il prit alors le titre de duc après la mort de son père, fut lieutenant général en 17 148, et fit les campagnes du Rhin, de Flandre, d'Allemagne et de Hanovre. Chevalier de l'ordre du Saint-Esprit et maréchal de France en 1759, il fut général en chef de l'armée d'Allemagne et créé prince de l'Empire. En 1788 le maréchal de Broglie reçut le commandement du camp rassemblé sous les murs de Metz, et fut ministre de la guerre en 1789. Il se trouva en 1792 à la tête d'un corps d'émigrés qui envahit la Champagne avec l'armée prussienne, et mourut à Munster en Westphalie, le 30 mars 1804.

Il est représenté en pied.

\section{Du Muy (Louis-Nicolas-Victor de Félix d'O- lières, comte).}

École française, xvırre siècle. - H. 2,15. - L. 1,40.

Né à Marseille en 1711, il entra dans l'ordre de Malte, et fut ensuite guidon d'une compagnie de gendarmes en 1726. Mestre de camp de cavalerie en 1731, il fit les campagnes d'Allemagne, de Westphalie et de Bohême, fut brigadier en 1743 , et servit aux armées du Rhin et de Flandre. Menin du dauphin et ma- 
réchal de camp en 1745̆, lieutenant général en 1748, il fit les campagnes d'Állemagne de 1757 à 1761. Chevalier de l'ordre du Saint-Esprit en 1764, ministre de la guerre en 1774, maréchal de France en 1775, il mourut le 10 octobre de la même année.

Ce tableau a été agrandi pour former un portrait en pied.

\section{Castries (Charles-Eugène-Gabriel de La Croix, marquis de).}

Par Joseph Boze. - H. 2,15. - L. 1,40.

Lieutenant dans le régiment du Roi en 1742 , il fit les campagnes de Flandre, fut maréchal de camp en 1748, et commanda la cavalerie au camp de Sarrelouis en 1753. Lieutenant général en 1758, mestre de camp général de la cavalerie en 1759 , il fit les campagnes d'Allemagne, fut chevalier de l'ordre du SaintEsprit en 1762, ministre de la marine en 1780 , maréchal de France en 1783, et gouverneur général en Flandre en 1787. Il commanda en 1792 un corps de l'armée des émigrés qui envahil la Champagne, et mourut à Wolfenbuttel, le 11 janvier 1801 , à l'âge de soixante-quatorze ans.

Il est représenté en pied. Ce tableau est signẻ : Boze ft.

\section{Ségur (Philippe-Henri, marquis de).}

Par M. François Dubois. - H. 2,15。 - L. 1,40.

Cornette de cavalerie en 1739, capitaine en 1740, il servit à l'armée de Bohême, fut colonel en 1743, et fit les campagnes d'Italie et de Flandre. Brigadier en 1747, maréchal de camp en 1749 , il fut employé à l'armée d'Allemagne de 1757 à 1759 , Lieutenant général en 1760, chevalier de l'ordre du Saint-Esprit en 1767, il fut ministre de la guerre en 1781 et maréchal de France en 1783. Il mourut à Paris, le 3 octobre 1801, à l'âge de soixante-dix-huit ans.

Il est représenté en pied.

\section{Vaux (Noël de Jourda, comte de).}

Par M. Caminade. - H. 2,15. - L. 1,40.

Né en 1710 au château de Vaux (Haute-Loire), il entra comme enseigne au régiment d'Auvergne en 1723, fut successivement lieutenant en 1724, capitaine en 1734, colonel en 1743, brigadier en 1746, et fit en Flandre les campagnes de 1744 à 1747. Maréchal de camp en 1748, il commanda la Franche-Comté, et fut nommé en 174.7 au commandement en chef de l'île de Corse, Lieutenant général en 1759, il fit les campagnes d'Allemagne. fut grand'croix de l'ordre de Saint-Louis en 1768, et commanda 
sur les còtes de Normandic et de Bretagne en 1779. Haréchal de France en 1783, il mourut à Grenoble, le 12 septembre 1788.

Il est réprésenté en pied.

\section{DIXIĖIIE SALLE DES MARÉCHAUX, No วั4.}

Ancien Salon de l'appartement des Bains (voir Salle $n^{\circ} 52$ ). Ce salon était orné de douze figures en plomb doré servant de torclières et représentant les douze mois de l'année; elles furent détruites en 1772. Salon de l'appartement de la comtesse de Toulouse, puis grand cabinet de l'appartement de Mesdames en 1755.

Lid suite chronologique des maréchaux de France depuis Victor-Maurice, comte de Broglie (1724) jusqu’à Jean-Baptiste c?e Durfort, duc de Duras (1741), est représentée par des écussons ou par des portraits en buste.

\section{Eroglie (Victor-Maurice, comte de).}

Par M. Radch. - H. 0,71. - L. 0,55.

Guidon dans la compagnie des gendarmes de la garde en 1666 , capitaine en 1670, maréchal de camp en 1676, il servit activement en Flandre, dans la Franche-Comté et en Hollande. Employé à l'armée d'Allemagne, en 1678, il se trouva au siége de Luxembourg en 1684. Lieutenant général en 1688, il commanda d'abord en Flandre, puis en Languedoc. Maréchal de France en 1724, il mourut le 4 août 1717, à l'âge de quatre-vingts ans.

\section{Aubusson (Louis d'), duc de La Feuillade.}

Par M. Bilfeldt. -- H. 0,71. - L. 0,55.

Fils puiné du maréchal de La Feuillade, il fut connu d'abord sous le nom de vicomte d'Aubusson et fit, comme volontaire, à l'âge de quinze ans, la campagne d'Allemagne en 1688 et 1689. Colonel de cavalerie en 1689, il se trouva à la bataille de Fleurus en 1690 et au siége de Mons en 1691. Devenu due de La Feuillade à la mort de son père, il fut gouverneur général du Dauphiné et fit les campagnes de Flandre et d'Allemagne jusqu'en 1697. Brigadier et maréchal de camp en 1702, lieutenant général en 170', il commanda en Dauphiné et en Savoie jusqu'en 1706. Maréchal de France en 1724, il mourut à Narly le 29 janvier 1720, à l'âge de cinquante-deux ans.

\section{Gramont (Antoine IV, duc de).}

Par Mime Bruyère. - H. 0,71. - L. 0,54.

Connu d'abord sous le nom de comte de Guiche, il entra aux mousquetaires en 168气̃, fut colonel en 1687 et aide de camp du grand-dauphin en 1688. Il servit activement en Allemagne et en 
DIXIÈNE SALLE DES MARÉGHAUX, No

Flandre, fut brigadier en 169\%, pair de France en 1700, colonel général des dragons en 1703 et lieutenant général en 1704. Membre des conseils de régence et de la guerre en 1715, il prit en 1720 le nom de duc de Gramont et fut nommé maréchal de France en 1724. Il mourut le 6 septembre 1725, àgé de cinquantetrois ans.

\section{Coёtlogon (Alain-Emmanuel, marquis de).}

Par Graincourt. - H. 0,71. - L. 0,54.

Enseigne au régiment Dauphin en 1668, il passa dans l'armée de mer en 1670, comme enseigne de vaisseau, fut lieutenant en 1672, capitaine en $167 \mathrm{~s}$ et fit sur mer les campagnes de la Méditerranée et de la Manche. Chef d'escadre en 1689, lieutenant général des armées navales en 1701, il commanda le corps de bataille dans le combat naval de Malaga en 1704. Commandant de l'ordre de Saint-Louis en 1705, membre du conseil de marine en 1715, vice-amiral du Levant en 1716, il fut chevalier de l'ordre du Saint-Esprit en 1722. Maréchal de France en 1730, il mourut le 7 juin 1730, à quatre-vingt-quatre ans.

Cette peinture déeorait autrefois l'hôtel de la Marine, à Versailles.

1108. Broglie (François-Marie, duc de).

Par $\mathrm{M}^{\mathrm{me}}$ Haudebourt. - H. 0,71. - L. 0,55.

Né en 1671, il était fils du maréchal Victor-Maurice de Broglie et entra en 1685 dans la compagnie des cadets de Besançon. Cornette de cuirassiers en 1689, il fit les campagnes d'Allemagne, d'Italie, de Flandre et de Hollande, fut brigadier en 1702, maréchal de camp en 170\% et fut employé aux armées d'Italie et du Rhin. Lieutenant-général en 1710, il commanda dans les armées de Flandre et du Rhin, fut directeur général de la cavalerie en 1719, ambassadeur en Angleterre en 1724 et chevalier de l'ordre du Saint-Esprit en 1731. Maréchal de France en 1734, il eut, conjointement avec le maréchal de Coigny, le commandement de l'armée d'Italie, fut créé duc en 1742, commanda l'armée de Bavière, et mourut le 22 mai 1745.

\section{Brancas (Louis de Brancas de Forcalquier, dit le marquis de).}

Par M. Gallait. - H. 0,71. - L. 0,55.

Il entra aux mousquetaires en 1689 et fit ses premières armes en Allemagne. Enseigne de vaisseau en 1692, lieutenant en 1693, il servit sur mer jusqu'en 1699. Mestre de camp et lieutenant du régiment d'infanterie d'Orléans en 1699, il fut employé à l'armée de Flandre en 1703, fut maréchal de camp en 1704 et 
servit en Espagne juscu'en 1709. Lieutenant général en 1710, chevalier de la Toison d"Or et ambassadeur en Espagne en 1714, il fit partie du conseil de régence en 1710\%. Lieutenant général au gouvernement de Provence en 1718, chevalier de l'ordre du Saint-Esprit en 1724, il fut créé grand d'Espagne de première classe en 1730, maréchal de France en 1741 et mourut le 9 août 17 ôn, à l'âge de soixante-dix-neuf ans.

\section{Choiseul-Stainville (Jacques-Philippe, duc de).}

Par M. Vatchelet, en 1835. - H. 2,15. - L. 1,40.

Né à Lunéville en 1727, il servit dès sa jeunesse dans les troupes de l'impératrice Marie-Thérèse, puis entra au service de France comme lieutenant général à l'armée d'Allemagne en 1760 . Inspecteur général de l'infanterie et chevalier de l'ordre de SaintLouis en 1761, il servit à l'armée du Haut-Rhin et fut gouverneur de Lorraine. Maréchal de France en 1783, gouverneur général de l'Alsace en 1788, il mourut en 1789, à l'âge de soixante-deux ans. Il est représenté en pied.

\section{Luckner (Nicolas, baron de).}

Par M. Aug. COLdER. - H. 2,15. - L. 1,40.

Né en 1722 à Camb en Bavière, il servit d'abord dans les armées du roi de Prusse, où il devint colonel de hussards, puis entra au service de France en 1763 , et fut employé, avec le grade de lieutenant général, en Normandie et en Bretagne en 1778. Il recut en $\mathbf{1 7 9 1}$ le commandement des $7^{\mathrm{e}}$ et $8^{\mathrm{e}}$ divisions militaires, fut nommé la même année maréchal de France, et commanda en 1792 l'armée du Rhin. Condamné à mort par le tribunal révolutionnaire, il périt sur l'échafaud à Paris, le 4 janvier 1794.

Il est représenté ell pied.

\section{Rochambeau (Jean-Baptiste-Donatien de Vi- meur, comte de).}

Par M. LARIVIÈRE. - - H. 2,15. - L. 1,40.

Né à Rochambeau en $1720 \%$, il entra au service en 1742 comme cornette de cavalerie, fut successivement capitaine en 1743 , colonel en 1747, et fit les campagnes de Bohême et du Bas-Rhin. Brigadier d'infanterie en 1756 , il servit en Allemagne, fut maréchal de camp en 1766, et grand'croix de l'ordre de Saint-Louis en 1771. Lieutenant général en 1780, il reçut le commandement de l'armée envoyée en Amérique pour la guerre de l'indépendance, et fut nommé chevalier de l'ordre du Saint-Esprit en 1783. Commandant des $1^{\text {re }}$ et $16^{\mathrm{e}}$ division militaires et maréchal de 
France en 1791, il fut mis, en 1792, à la tête de l'armée du Nord. Grand-officier de la Légion d'honneur en 1804, il mourut à Rochambeau le 10 mai 1807.

Il est représentẻ en piẹd.

\section{Berthier (Louis-Alexandre), prince de Neuf- châtel et de Wagram.}

Par PAJOU. - H. 2,15. - L。 1,33.

Né à Versailles le 20 novembre 1753 . Ingénieur-géographe des camps et armées du roi en 1766, lieutenant dans le corps royal d'état-major en 1770, capitaine de dragons en 1777, il fit les campagnes d'Amérique de 1780 à 1783 . Aide-major des logis en 1787, major en 1788, lieutenant-colonel en 1789, il fut la même année major général de la garde nationale de Versailles. Colonel adjudant général en 1790, maréchal de camp en 1792, il servit comme chef d'état-major de l'armée du Nord, commandée par le maréchal Luckner, et fut employé en 1793 à l'armée des côtes de la Rochelle. Général de division en $\mathbf{1 7 9 5}$, chef d'étatmajor des armées d'Italie et des Alpes en 1796, il fit les campagnes d'Italie de 1795,1796 et 1797 , et commanda en chef l'armée d'Italie en 1797. Chef de l'état-major de l'armée d'Angleterre en 1798, il fit partie de l'armée expéditionnaire d'Egypte en 1798 et 1799. Ministre de la guerre en 1799, il commandait en chef l'armée de réserve en 1800, et fit la campagne de Marengo. Il fut nommé maréchal de l'Empire, grand-officier de la Légion d'honneur et grand veneur en 1804. Grand-cordon de la Légion d'honneur et major général de la grande armée en 1805ั, grand dignitaire de l'ordre de la Couronne de Fer, prince et duc de de Neufchâtel en 1806, membre du sénat et vice-connétable en 1807, il fit la campagne de 1805 en Allemagne, de 1806 et 1807 en Prusse et en Pologne, de 1808 en Espagne, et de 1809 en Autriche. Créé prince de Wagram en 1809, il fit, comme major général de la grande armée, les campagnes de Russie en 1812, de Saxe en 1813, et de France en 1814. Le maréchal Berthier fut nommé en 1814 pair de France, capitaine des gardes du corps du roi et commandeur de l'ordre de Saint-Louis. Il mourut à Bamberg en Bavière, le $1^{\mathrm{er}}$ juin $\mathbf{1 8 1 5}$.

Il est reprẻsenté en pied. Ce tableau est signé : Pajou fls, 1808.

\section{Murat (Joachim), grand-duc de Clèves et de Berg. (Voir no 936.)}

Par Gerard. - H. 2,15. - L. 1,33.

Il est reprẻsenté en pied. 


\section{Moncey (Bon-Adrien Jannot de), duc de Coné- gliano.}

Par M. Barbier-Walbonye. - H. 2,15. - L. 1, 33.

Né à Palisse (Doubs) le 31 juillet 187\%. Volontaire au régiment de Champagne-infanterie en 1768, il fut successivement souslieutenant de dragons en $\mathbf{1 7 7 9}$, lieutenant en premier en $\mathbf{1 7 8 5}$ et capitaine en 1791. Chef de bataillon en 1793, il servit dans l'armée des Pyrénées-Orientales, fut successivement nommé dans l'année 1794 général de brigade, général de division et commandant en chef de l'armée des Pyrénées-Orientales. Commanmandant la $11^{\mathrm{e}}$ division militaire en $179 \mathrm{~s}^{\circ}$, et les $12^{\mathrm{e}}$ et $19^{\mathrm{e}}$ en 1799 , il fit les campagnes de 1799 et de 1800 , en Italie, comme lieutenant du général en chef, fut employé en Suisse dans l'année 1800 , et passa ensuite à l'armée de réserve. Lieutenant général commandant le corps des troupes françaises dans la république Cisalpine en 1801, il servit à l'armée du Midi comme général de division, et fut nommé premier inspecteur général de gendarmerie. Maréchal de I'Empire en 1804, grand-cordon de la Légion d'honneur en 180 š, et duc de Conégliano en 1808, il eut le commandement du 3 e corps de l'armée française en Espagne, où il fit les campagnes de 1808 et de $\mathbf{1 8 0 9}$. Il reçut en 1809 le commandement de l'armée de la Tête-de-Flandre, et fut nommé grand-dignitaire de l'ordre de la Couronne de Fer. Commandant en chef de l'armée de réserve des Pyrénées en 1813, il fut en 1814 major général de la garde nationale de Paris. Cheralier de Saint-Louis et pair de France en 1815̆, gouverneur de la 9e division militaire, chevalier de l'ordre du Saint-Esprit et commandeur de l'ordre de Saint-Louis en 1820, le maréchal Moncey commanda en chef le 4e corps de l'armée des Pyrénées en 1823 , et fut la même année grand'croix de l'ordre de Saint-Louis. Il lfut nommé gouverneur de l'Hôtel Royal des Invalides en 1833, et mourut le 20 avril 1842.

Il est représenté en pied.

\section{ONZIÈME SALLE DES MARÉCHAUX, № ว๊ŏ.}

Cette salle portait autrefois le nom de Salle de Diane; elle était alors ornée de douze colonnes d'ordre ionique en marbre, qui furent supprimées lorsque l'appartement des bains fut habité par Mesdames, filles de Louis XV.

La suite chronologique des maréchaux de France depuis Jean-Francois Desmaretz, marquis de Maillebois (1741) jusqu'à Louis, duc de Noailles (1775), est représentée par des écussons ou par des portraits en buste. 
ONZIĖME SALLE DES MARÉCHAUX, No ว้ว้.

\section{Balincourt (Claude-Guillaume T'estu, mar- quis de).}

Par M. GaMinade. - H. 0,71. - L. 0,55.

Il entra aux mousquetaires en 1697, et servit en Flandre en 1701 et 1702 . Colonel d'infanterie en 1703, il fit les campagnes d'Allemagne et d'Espagne juscu'en 1714, fut maréchal de camp en 1719, lieutenant géréral en 1734, et servit activement jusqu'en 1745. Maréchal de France en 1746, il continua de commander en Alsace jusqu'à la paix de 1748, fut nommé en 1767 chevalier de l'ordre du Saint-Esprit, et mourut en 1770, à l'âg'e de quatrevingt-dix ans.

\section{La Fare (Philippe-Charles, marquis de).}

Par M. SERrur. - I. 0,71. - L. 0.55 .

Il entra aux mousquetaires en 1701, fit la campagne de Flandre en 1702, et se rendit en 1704 à l'armée d'Italie, en qualité de colonel du régiment d'infanterie du Gatinais. Capitaine des gardes du duc d'Orléans en 1712, brigadier d'infanterie en 1716, il était au siége de Fontarabie en 1719. Maréchal de camp en 1720, chevalier de la Toison d'Or en 1722, il commanda en chef dans le Languedoc en 1724. Chevalier de l'ordre du Saint-Esprit en 1731, lieutenant général en 1734, il servit successivement dans les armées du Rhin, de Bavière, de Bohême, de la HauteAlsace et du Bas-Rhin, de 173כ̃ à 1746. Naréchal de France en 1746, il mourut le 4 septembre 17322 , à l'âge de soixante-cinq ans.

1118. Clermont-Tonnerre (Gaspard, duc de).

Par M. AMIEL. - H. 0,71. - L. 0,55.

Né en 1688, il entra comme cornette au régiment de cavalerie du Châtelet en 1703, fut successivement capitaine et mestre de camp, et fit les campagnes de 1703 à 1713 en Allemagne et en

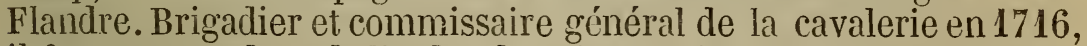
il fut commandeur de l'ordre de Saint-Louis en 1720, et chevalier de l'ordre du Saint-Esprit en 1724. Maréchal de camp en 1730, lieutenant-général en 1734, il servit à l'armée du Rhin jusqu'en 1733 , fut mestre de camp général de la cavalerie en 1736 , et fit les campagnes de Bohême, d'Allemagne et de Flandre. Maréchal de France en 1747, il était en 1774 le doyen des maréchaux et représenta le connétable au sacre de Louis XVI. Il mourut le 16 mars 1781, à l'âge de quatre-vingt-douze ans. 


\section{La Tour-Maubourg (Jean-Hertor de Fay, marquis de).}

Par Paulin GUERIn. - H. 0,71. - L. 0,55.

Né en 1684 au château de Maubourg, en Velay, il entra aux mousquetaires en 1698, fut lieutenant en 1701, et fit en Flandre les campagnes de 1703 à 170ั. Colonel en 1707, il fut employé dans les armées de Savoie et de Catalogne jusqu'en 1715. Inspecteur-général d'infanterie en 1718, brigadier en 1719, maréchal de camp en 1734, il fit la campagne d'Allemagne en 1735 . Lieu. tenant général en 1738, il commanda dans les armées de Flandre et du Rhin, fut chevalier de l'ordre du saint-Esprit en 1748 et maréchal de France en $\mathbf{1 7}$ วั7. Il mourut à Paris le 150 mai 1764.

\section{Mirepoix (Gaston-Charles-Pierre de Lévis, duc de).}

Par Mime HaUdebourt. - H. 0,71. - L. 0,55.

Né en 1699, il entra aux mousquetaires en 1718, se trouva en 1733 au siége de Kehl et servit à l'armée du Rhin. Ambassadeur à Vienne en 1735, maréchal de camp en 1738 , chevalier du Saint-Esprit en 1739, il servit en Bavière, en Bohême et en Italie. Ambassadeur en Angleterre en 1749, créé duc de Mirepoix en 17500, il fut capitaine des gardes du corps en 17506 . Maréchal de France en 17.̌̉, il commanda en chef l'armée des côtes de la Méditerranée, et mourut à Montpellier le 2气̆ septembre 1757.

\section{Berchény (Ladislas-Ignace, comte de).}

Par M. LatiL. - H. 0,71. - L. 0,55.

Né à Eperies (Hongrie) en 1689, il entra en 1712 au service de la France et fit la campagne de 1713 à l'armée du Rhin. Colonel en 1720, il se trouva en 1733 àu siége de Kehl, et servit à l'armée du Rhin en 1734 et 1735. Grand écuyer de Lorraine en 1738, il fit les campagnes de Bohême, d'Allemagne et de Flandre, fut lieutenant général en 1744, et grand'croix de l'ordre de Saint-Louis en 1753. Maréchal de France en 1758, il mourut en 1778.

\section{Lorges (Guy-Michel de Durfort, duc de).}

Par Mme Haddeвourt. - H. 0,71. - L. 0,55.

Il entra aux mousquetaires en 1719 et fut colonel en 1723 . Lieutenant général au gouvernement de Franche-Comté en 1730, il fit la campagne d'Italie, fut maréchal de camp en $\mathbf{1 7 4 0}$ 
et servit aux armées de la Meuse et du Rhin. Chevalier de l'ordre du Saint-Esprit en 1745, lieutenant général à l'armée de Flandre en 1746, il fit à l'armée d'Allemagne la campagne de 1757 . Nommé maréchal de France en 1768, il mourut le 6 juin $\mathbf{1 7 7 3 ,}$ à l'âge de soixante-neuf ans.

\section{Armentières (Louis de Brienne de Conflans, marquis d').}

Par II. ROdGet. - H. 0,71. - L. 0,53.

Il entra aux mousquetaires en 1726, fut nommé colonel en 1727, servit en Italie en 1733, et se trouva à la bataille de Parme en 1734. Maréchal de camp en 1743, lieutenant général en 1746 , il fit les campagnes de Bohême et de Flandre, fut chevalier de l'ordre du Saint-Fsprit en 1733 et servit à l'armée d'Allemagne. Maréchal de France en 1768, il mourut à Paris, le 20 janvier 1774, à l'âge de soixante-trois ans.

\section{Brissac (Jean-Paul-Timoléon de Cossé, duc de).}

Par M. Gallatt. - H. 0,71. - L. 0,53.

Il entra d'abord dans l'ordre de Malte, puis fut capitaine de cavalerie en 1718, et se trouva en 1719 aux siéges de Fontarabie et de Saint-Sébastien. Duc et pair de France en 1732, il obtint la charge de grand pannetier et fit les campagnes d'Italie et de Bohême. Chevalier de l'ordre du Saint-Esprit et maréchal de camp en 1743, il servit aux armées de Bavière, de Flandre, du Bas-Rhin, et fut nommé lieutenant général en 1748. Employé à l'armée d'Allemagne en 15ว7, il fut maréchal de France en 1768, gouverneur de Paris en 1771, et mourut à Paris, le 17 décembre 1780, à l'àge de quatre-vingt-deux ans.

1125. Harcourt (Anne-Pierre, duc d').

Par M. SCHNETZ。 - H. 0,71 - - L. 0,52.

Connu d'abord sous le nom de comte de Beuvron, il entra comme cadet dans les gardes du corps en 1716, fut capitaine en 1719 et fit la campagne d'Espagne. Brigadier de cavalerie en 1734, il servit aux armées d'Italie et de Bavière, fut maréchal de camp en 1743, et servit jusqu'en 1747 aux armées du Rhin, de la Moselle et d'Italie. Lieutenant général en 1748, créé duc d'Harcourt et pair de France en 1750 , chevalier de l'ordre dı SaintEsprit en 1756, gouverneur général de Normandie en 1764. et maréchal de France en 1775 , il mourut vers 1784. 


\section{Noailles (Louis, duc de) et d'Ayen.}

Par IIme BruYère. - H. 0,71 - L. 0,52.

Né en 1713, il était fils aîné du maréchal Adrien-Maırice de Noailles, et porta d'abord le titre de comte d'Ayen. Il entra aux mousquetaires en 1729, commanda ensuite une compagnie des gardes du corps, et servit en Allemagne et en Italie. Créé duc d'Ayen en 1737, il fut brigadier en 1740, et employé à l'armée de Bavière en 1742; maréchal de camp en 1743, lieutenant général en 1748, il servit aux armées du Rhin et de Flandre, fut chevalier de l'ordre du Saint-Esprit en 1749, et fit la campagne de Hanovre. Duc de Noailles en 1766, il fut gouverneur général du Roussillon et maréchal de France en 177 ơ. Il mourut à̀ SaintGermain-en-Laye, le $2 \mathbf{2}$ août 1793.

\section{Jourdan (Jean-Baptiste, comte).}

Par M. Eug. Carpentien, d'après Vien. - H. 2,15. - L. 1,40.

Né à Limoges le 29 avril 1762. Soldat au dépôt de lî̀le de Rhé en 1778, il passa dans le régiment d'Auxerrois, et servit en Amérique jusqu'en 1782. Chef du 2 e bataillon de la Haute-Vienne en 1791, il fut envoyé à l'armée du Nord, et fut successivement nommé dans l'année 1793 général de brigade, général de division et général en chef des armées des Ardennes et du Nord. Appelé en 1794, d’abord au commandement en chef de l'armée de la Nioselle, il livra la bataille de Fleurus, et fut ensuite commandant en chef de larmée de Sambre-et-Meuse; il acheva la campagne de 1794 en Flandre, fit celle de 1793 sur le Rhin, et do 1796 en Allemagne. Député au conseil des Cinq-Cents en 1797, il fut deux fois président de cotte assemblée. Général en chef de l'armée du Danube en 1798, il fit la campagne de 1799 en Auiriche, et fut nommé en 1800 inspecteur général d'infanterie et de cavalerie, et administrateur général du Piémont. Conseiller d'Etat en 1802, général en chef de l'armée d'Italie, maréchal de I'Empire en 1804, grand-cordon de la Légion d'honneur, il passa en 1806 au service du roi de Naples (Joseph Napoléon), et fut gouverneur de la ville de Naples. Niajor général du roi d'Espagnne (Joseph Napoléon) en 1806, il fit en cette qualité les campagnes de 1808 et 1809. Gouverneur de Madrid en 1811, il servit en Espaģue jusqu'à la fin de 1813. Chevalier de l'ordre de Saint-Louis, commandant supérieur et gouverneur de la $15^{\circ} \mathrm{e}$ division militaire en 1814, il fut créé comte la même année. Gouverneur de Besancon en 1810ั, il fut commandant supérieur de la $6^{\mathrm{e}}$ division militaire, et reçut dans la même année le commandement de l'armée du Rhin. Pair de France en 1816, il fut gouverneur de la 
OXZIE்ME SALLE DES MARÉCHAUX, N゚ כૅכ̈.

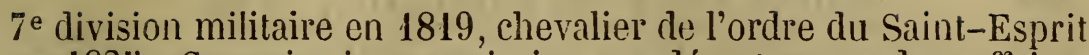
en 1825. Commissaire provisoire au département des affaires étrangères et gouverneur des Invalides en 1830 , le maréchal Jourdan mourut à Paris le 23 novembre 1833.

Il est représent jen pied. Le portrait original est dans la salle des Maréchaux, au palais des Tuileries.

\section{Masséna (André), duc de Rivoli, prince d'Essling.}

Par M. Fontaine, d'après Gros. - H. 2,15. - L. 1,40.

Né à Nice le 6 mai 17506 . Soldat au $\mathcal{A}^{\text {er }}$ bataillon d'infanterie légère, ci-devant régiment Royal-italien, en $\mathbf{1 7 7 5}$, et successivement caporal en 1776, sergent en 1777, fourrier en 1784, il fut ${ }^{\circ}$ congédié par ancienneté de service en 1789 , fut adjudant-major au $2^{\mathrm{e}}$ bataillon du Var en 1791 et chef de bataillon en 1792. Général de brigade et général de division en 1793, il servit à l'armée d'Italie en 1793, à l'armée des Álpes et d'Italie en 1790 , et à l'armée de Mayence en 1798. Il commanda en chef l'armée française en Helvétie à la fin de 1798 et en $\mathbf{1 7 9 9}$, puis celle du Danube, et enfin celle d'Italie. Maréchal de l'Empire et grand-croix de la Légion d'honneur en 180', général en chef de l'armée d'Italie en 180כ̆, il fut la même année grand dignitaire de l'ordre de la Couronne de Fer, et commanda le $\mathbf{A r}^{\mathrm{er}}$ corps de l'armée de Naples en 1806. Appelé en 1807 à la grande armée d'Allemagne, il eut le commandement en chef du 5ैe corps, et fut créé duc de Rivoli en 1808. Chargé du commandement du corps d'observation de l'armée du Rhin en 1809, il fit la campagne d'Autriche et recut le titre de prince d'Essling en 1810. Il commanda en chef l'armée française en Portugal depuis 1810 jusqu'en 1812, et fut nommé en 1813 gouverneur de Toulon et commandant supérieur de la $8^{\mathrm{e}}$ division militaire. Le maréchal Masséna reçut en 1814 le gouvernement de la $8^{\mathrm{e}}$ division militaire et fut créé commandeur de l'ordre de Saint-Louis. Commandant en chef de la garde nationale et gouverneur de Paris en 1815, il mourut à Paris le 4 avril 1817.

Il est représenté en pied. Le portrait original est dans la salle des Maréchaıx, au palais des Tuileries.

\section{Augereau (Charles-Pierre-François), duc de Castiglione.}

Par Robert Lefebvre. - H. 2,15. - L. 1,40.

Né à Paris, le 21 octobre 1757. Soldat dans le régiment de Clarck-Irlandais au service de France en 1774, il passa en 1776 dans le régiment d'Artois-dragons. Adjudant-major dans la lé- 
gion germanique en 1791, capitaine au $11^{\mathrm{e}}$ régiment de hussards, vaguemestre général de l'armée des côtes de La Rochelle, adjudant général chef de brigade et général de division en 1793, il servit en cette qualité à l'armée des Pyrénées-Orientales jusqu'en $\mathbf{1 7 9 5}$, passa ensuite à l'armée d'Italie où il fit la campagne de 1796, et se trouva à la bataille d'Arcole. Il reçut en 1797 le commandement de la $17^{\mathrm{e}}$ division militaire, commanda en chef la même année les armées de Sambre-et-Meuse, de Rhin-et-Moselle et du Rhin. Commandant la $10^{\mathrm{e}}$ division militaire en 1798 , il fut nommé en 1800 général en chef de l'armée française en Hollande, où il fit la campagne de 1800 et 1801. Il commanda en chef le camp de Bayonne en 1803, fut maréchal de l'Empire et grand officier de la Légion d'honneur en 1804, grand-croix en $180 \mathrm{z}$ et grand dignitaire de la Couronne de Fer. Le maréchal Augereau commanda en chef le $7^{\mathrm{e}}$ corps de la grande armée dans la campagne d'Allemagne en 1805 , et dans celles de Prusse et de Pologne en 1806 et 1807. Créé duc de Castiglione en 1808, il fut chargé en 1809 du commandement en chef des troupes de Catalogne, où il fit les campagnes de 1809 et 1810. Commandant en chef du $11^{\mathrm{e}}$ corps de la grande armée en 1812 , il fit la campagne de Russie en 1812, celle de Saxe en 1813 et commanda, au commencement de 1814, l'armée de Lyon. Gouverneur de la $14^{\mathrm{e}}$ division militaire, pair de France et chevalier de Saint-Louis en 1814, le maréchal Augereau mourut le 12 juin 1816.

Il est représenté en pied.

\section{Bernadotte (Jean-Baptiste-Jules), prince de Ponte-Corvo, roi de Suède.}

Par Kinson. - H. 2,15. - L. 1,40.

Né à Pau le 26 juin 1763 . Soldat au $60^{\mathrm{e}}$ régiment d'infanterie en 1780, grenadier en 1782, caporal en 1785̌, fourrier en 1787,

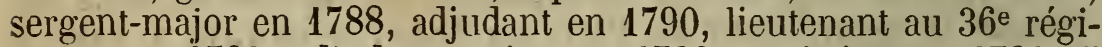
ment en 1791, adjudant-major en 1792, capitaine en 1793, il servit en 1792 à l'armée du Rhin, et en 1793 à celle du Nord. Successivement chef de bataillon, chef de brigade, général de brigade et général de division en 1794, il fit la campagne de 1794 à 1796 à l'armée de Sambre-et-Meuse. Nommé en 1798 ambassadeur à Vienne, il fut employé la même année à l'armée d'Italie, et à celle dı Danube en 1799. Ministre de la guerre et conseiller d'Etat en 1799, général en chef de l'armée de l'Ouest en 1800 , nommé à l'ambassade des Etats-Unis en 1803, il recut le commandement en chef de l'armée de Hanovre en 1804. Maréchal de l'Empire, grand officier de la Légion d'honneur, grandaigle de la Légion d'honneur, grand dignitaire de l'ordre de la 
Couronne de Fer, et prince de Ponte-Corvo en 180弓ٌ, il commanda en chef le 1 er corps de la grande armée en 180כ̆, fit la même année la campagne d'Allemagne et celle de Prusse et de Pologne en 1806 et 1807. Il eut en 1808 le commandement d'un corps de Francais, d'Espagnols et de Hollandais qui se rassembla à Hambourg, commanda le 9e corps de la grande armée dans la campagne d'Autriche en $\mathbf{1 8 0 9}$, et fut envoyé la même année en Hollande pour y commander en chef. Le maréchal Bernadotte proclamé prince royal de Suède par les Etats assemblés en 1810,

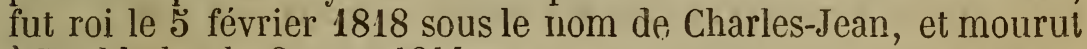
à Stockholm le 8 mars 1844 .

\section{Soult (Jean-de-Dieu), duc de Dalmatie.}

Par N. DE RuddeR, d'après Broc. - H. 2,15. -- L. 1,40.

Né à Saint-Amans-la-Bastide (Tarn), Je 29 mars 1769. Soldat dans le régiment du Roi-infanterie (depuis $23^{\mathrm{e}}$ régiment d'infanterie) en 1785, il fut successivement caporal en 1787, caporalfourrier et sergent en 1791. Adjudant-major en 1792, il servit la même année à l'armée du Nord. Capitaine en 1793 et adjoint provisoire à l'état-major de la Moselle, il fit la campagne de 1793 à l'armée de la Moselle. Chef de bataillon, adjudant général chef de brigade et général de brigade en 1794, il fut employé à l'armée de Sambre-et-Meuse, fit la campagne d'Allemagne en 1796 et 1797, et passa en 1798 à l'armée de Mayence. Général de division en 1799, il servit d'abord à l'armée du Danube et ensuite à celle d'Italie, où il fut en 1800 nommé lieutenant du général en chef. Il passa en 1801 à l'armée du Midi avec le même grade. Nommé en 1802 l'un des quatre généraux commandant la garde des consuls, il commanda en chef le camp de Saint-Omer en 1803. Maréchal de l'Empire en 1804, grand-croix de la Légion d'honneur en 1805 , il eut le commandement en chef du $4^{\mathrm{e}}$ corps de la grande armée, fit la campagne d'Allemagne en 180ă , celles de Prusse et de Pologne en 1806 et 1807. Créé duc de Dalmatie en 1808 , il eut le commandement en chef du $2^{\mathrm{e}}$ corps de l'armée d'Espagne, devint major général de cette armée en 1809, commanda en chef l'armée du Midi en 1810, fut en 1813 lieutenant général commandant en chef des armées d'Espagne et des Pyrénées, et fit en Espagne les campagines de 1808 à 1813, et celle de France en 1814. Le duc de Dalmatie fut nommé en 1814 gouverneur de la $13^{\mathrm{e}}$ division militaire, commandeur de l'ordre de Saint-Louis, et eut le portefeuille de la guerre depuis le 3 décembre 1814 jusqu'au 2 mars 1815. Pair de France et majorgénéral de l'armée du Nord le 9 mai 1815 , il fit la campagne des Pays-Bas. Le maréchal Soult fut créé chevalier de l'ordre du Saint- 
Esprit en 1823. Ministre de la guerre en 1830 et président du conseil en 1832, le maréchal Soult fut ministre des affaires étran. gères en 1839, et de nouveau ministre de la guerre et président dı conseil en 1846. Il mourut au château de Soult-Berğ le 26 novembre $185 \%$.

Il est représenté en pied. Le portrait original est dans la salle des Maréchaux au palais des Tuileries.

\section{Brune (Guillaume-Marie-Anne, comte de),}

Par M. BatTaille, d'après $\mathrm{I}^{\text {me }}$ Benoist. - H. 2,15. - L. 1,40.

Né à Brive-la-Gaillarde le 13 mars 1763. Adjudant-major au $2^{2}$ bataillon de Seine-et-0ise en 1791 , adjoint aux adjudants généraux de l'intérieur, adjudant général et chef de brigade en 1792, il servit en 1793 à l'armée du Nord et fut nommé général de brigade. Employé à l'armée d'Italie en 1796, général de division en 1797, il commanda en chef l'armée d'Italie en 1798 ; il eut ensuite la même année le commandement de l'armée de Hollande, où il fit les campagnes de 1798 et 1799. D'abord général en chef de l'armée de l'Ouest en 1800, il eut ensuite dans la même année le commandement en chef de l'armée de réserve formée à Dijon, et enfin celui de l'armée d'Italie. Conseiller d'état en 1801, il fut ambassadeur à Constantinople en 1802. Maréchal de l'Empire, grand-cordon de la Légion d"honneur et général en chef de l'armée des Còtes en 1804, il eut le gouvernement général des villes hanséatiques en 1806, et recut la même année la croix de commandeur de l'ordre de la Couronne de Fer. Le maréchal Brune fut chevalier de Saint-Louis en 1814. Gouverneur de la $8^{\mathrm{e}}$ division militaire et commandant du 9e corps d'armée en 1815 , il fut nommé pair de France et fut assassiné à Avignon le $\mathbf{2}$ août 1815 .

Il est représenté en pied. Le portrait original est dans la salle des Maréchaux, au palais des Tuileries.

\section{Lannes (Jean), duc de Montebello.}

Par Perrin. - H. 2,15, - L. 1,40.

Né à Lectoure le 11 avril 1769 . Sous-lieutenant au $2^{\mathrm{e}}$ bataillon du Gers en 1792, il fut successivement lieutenant, capitaine et chef de brigade en 1793, et servit à l'armée des Pyrénées-Orientales de 1792 à 1795 . Employé à l'armée d'Italie en 1795, il fut nommé général de brigade en 1797 et fit la campagne d'Italie en 1796 et 1797. Il fit partie de l'armée expéditionnaire d'Egypte en 1798, et fit les campagnes d'Orient de 1798 et 1799 . Général de division en 1799, il eut la même anné le commandement de Toulouse. Commandant et inspecteur de la garde des consuls en 
1800, il fit la campagne de Marengo. Ambassadeur à Lisbontue en 1801, maréchal de l'Empire, grand officier de la Légion d'honneur en 1804, il fut grand cordon de la Légion d'honneur et commandeur de lordre de la Couronne de Fer en 1805. Commandant en chef du $4^{\mathrm{e}}$ corps de l'armée des côtes de l'Océan et du 5้ corps de la grande armée, il fit la campagne d'Allemagne en 1803 et celle de Prusse en 1806. Commandant du corps d'armée de réserve en 1807, il fit la campagne de Pologne et fut nommé colonel général des Suisses en 1807. Créé duc de Montebello en 1808, il fut chargé du commandement supérieur des $13^{\mathrm{e}}$ et $15^{\mathrm{e}}$ corps de l'armée d'Espagne, où il fit les campagnes de 1808 et 1809. Chargé du commandement du 2 e corps de l'armée d'Allemagne en 1809, il fut blessé mortellement à la bataille d'Essling, et mourut à Vienne le 31 mai 1809.

Il est reprẻsenté en pied.

\section{Mortier (Édouard-Adolphe-Casimir-Joseph), duc de Trévise.}

Par Ponce-Gamus. - H. 2,15. - L. 1,40.

Né à Catean-Cambresis (Nord) le 13 février 1768. Sous-lieutenant au régiment de carabiniers et capitaine au $\mathbb{1}^{\text {er }}$ bataillon du Nord en 1791, chef de bataillon et adjudant général en 1793, il servit à l'armée du Nord en 1793, 1794 et 1795. Chef de brigade en 1795, il fit à l'armée de Sambre-et-Meuse les campagnes de 1795 et 1796. Général de brigade et général de division en 1799 , il fut employé à l'armée du Danube et passa la même année à l'armée d'Helvétie. Il commanda la $17 \mathrm{e}$ division militaire en 1800 et 1801. Lieutenant général commandant le camp de Nimègue et commandant l'arméede Hanovre en 1803, il fut nommé en 1804 un des quatre commandants de la garde des consuls. Maréchal del'Empire et grand officier de l'ordre de la Légion d'honneur en 1804, il fit la même année la campagne de Hanovre. Il commanda le je et le $8^{\mathrm{e}}$ corps de la grande armée en 1806, le $3^{\mathrm{e}}$ corps en 1807, et fit les campagnes de 1806 et 1807 en Prusse et en Pologne, Crééduc de Trévise, il fut employé à l'armée d'Espagne, y commanda le

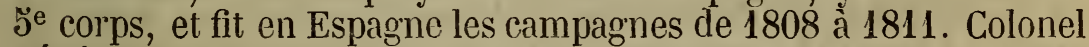
général de l'artillerie, des sapeurs et marins de la garde en 1811, commandandant la jeune garde en 1812, il fit la campagne de 1812 en Russie, celles de 1813 en Saxe, et de 1814 en France. D'abord commissaire extraordinaire du roi dans la $16^{\mathrm{e}}$ division militaire en 1814, et ensuite gouverneur de la même division, il fut chevalier de l'ordre de Saint-Louis, pair de France, et contmanda le 16 mars 1815 les troupes stationnées dans le département du Nord. Chargé, le 30 avril 1815 , d'inspecter toute la troupe 
de ligne des places fortes depuis Calais jusqu'à Landau, il fut nommé le 8 juin 1815 commandant de toute la cavalerie de la garde. Gouverneur de la 15้e division militaire en 1816, commandeur de l'ordre de Saint-Louis en 1820, chevalier de l'ordre du Saint-Esprit en 182.ั, il fut gouverneur de la $14^{\mathrm{e}}$ division militaire en 1829. Ambassadeur en Russie en 1830, grand chancelier de la Légion d'honneur en 1831, le maréchal Mortier fut président du conseil et ministre de la guerre en 1834, et fut tué à Paris le. 28 juillet 183 .

Il est représenté en pied.

\section{Ney (Michel), duc d'Elchingen, prince de La Moskowa.}

Par M. Battaille, d'après Langlois. - H. 2,15. - L. 1,40.

Né à Sarre-Louis le 10 janvier 1769 . Hussard au $4^{\mathrm{e}}$ régiment en 1788, il fut successivement brigadier en 1791, maréchal des logis, adjudant-sous-officier, sous-lieutenant et lieutenant en $\mathbf{1 7 9 2 ,}$ capitaine, aide de camp du genéral Lamarche et adjudant général chef de brigade près l'armée de Rhin-et-Moselle en 1794; il commanda la cavalerie de la division du général Collaud à l'armée de Sambre-et-1Ieuse en 1794 et 1795. Employé à l'armée d'Allemagne en 1796, général de brigade, il fit la campagne de Mayence en 1798, fut nommé en 1799 général de division et employé à l'armée du Danube en 1799, et en 1800 à celle du Rhin. Inspecteur de cavalerie dans les $3 \mathrm{e}$, $3^{\mathrm{e}}$ et $26^{\mathrm{e}}$ divisions militaires en 1801 , il commanda la même année la cavalerie de l'armée de Saint-Domingue. Ministre plénipotentiaire en Suisse en 1802, il commanda en chef l'armée francaise en Suisse, le camp de Compiègne en 1803, et fut nommé en 1804 maréchal de l'Empire et grand officier de la Légion dhonneur. Grand cordon de la Légion d'honneur en 180 ö, il fut l'un des commandants de l'armée réunie au camp de Boulogne, commanda en chef le $6^{\mathrm{e}}$ corps de la grande armée à l'armée d'Allemagne en 180ð̃, fit la campagne de Prusse en 1806, celle de Pologne en $180 \overline{7}$, et fut créé duc d'Elchingen en 1808. Général en chef de l'un des corps de l'armée d'Espagne en 1808, il fit les campagnes de 1809 et 1810 dans la Péninsule. Nommé au commandement du $3^{\text {e }}$ corps de la grande armée en 1812, le maréchal Ney fitla campagne de Russie et reçut le titre de prince de La Moskowa en 1813. Il commanda les $4^{\mathrm{e}}$ et $7^{\mathrm{e}}$ corps et le $3^{\mathrm{e}}$ corps de cavalerie, fit la campagne de Saxe en 1813 et celle de France en 1814. Commandant en chef du corps royal des cuirassiers, des dragons, des chasseurs et des chevau-légers-lanciers de Frarice, et gouverneur de la $7^{\mathrm{e}}$ division militaire en 1814, il fut nommé chevalier de l'ordre de Saint-Louis et pair de France en 1815 . Il commanda l'aile gauche de la grande armée en 1815 
et fit la campagne des Pays-Bas. Traduit devant la cour des pairs, il fut condamné à mort, puis fusillé à Paris le 7 décembre 1815 .

Il est représenté en pied. Le portrait original est dans la salle des Maréchaux, au palais des Tuileries.

\section{Davoust (Louis-Nicolas), duc d'Auerstaëdt, prince d'Eckmühl.}

Par M. MARzocchi, d'après Gautherot. - H. 2,15. - L. 1,10.

Né à Annoux, près Noyers en Bourgogne, le 10 mai 1770. Cadet gentilhomme à l'Ecole militaire en 1785, il fut sous-lieutenant au régiment Royal-Champagne-cavalerie en 1789. Chef de bataillon au $3^{\text {e }}$ bataillon de l'Yonne en 1791, il servit à l'armée de Belgique en 1791 et 1792. Successivement chef de brigade, adjudant général et général de brigade en 1793, il fut employé dans l'armée de Rhin-et-Moselle en 1794 et 1795, et dans celle du Rhin en 1796 et 1797. Employé à l'armée expéditionnaire d'Egypte en 1798, il fit en Orient les campagnes de $\mathbf{1 7 9 8}$ et de 1799. Général de division en 1800 , il commanda la cavalerie à l'armée d'Italie, fit la campagne de Marengo, et fut inspecteur général de la cavalerie en 1801. Commandant l'infanterie de la garde des consuls en 1801, il eut en 1803 le commandement en chef du camp de Bruges. Maréchal de l'Empire et grand officier de la Légion d'honneur en 1804, grand cordon du même ordre en 1805 , il commanda en chef le 3 e corps de la grande armée, fit la campagne d'Allemagne en $\mathbf{1 8 0 5}$, celle de Prusse en 1806 et 1807, et fut nommé gouverneur général du grandduché de Varsovie. Duc d'Auerstaëdt en 1808, il commanda en chef l'armée du Rhin, le $3^{\mathrm{e}}$ corps de l'armée d'Allemagne en 1809, fut créé prince d'Eckmühl et fit la campagne d'Autriche. Il commanda en chef l'armée d'Allemagne en 1810, le corps d'observation de l'Elbe et le $\mathbf{1}^{\mathrm{er}}$ corps de la grande armée en 1812, et fit la campagne de Russie. Commandant en chef le $13^{\circ}$ corps de la grande armée en 1813, il fit la campagne de Saxe. Ministre secrétaire d'Etat au département de la guerre et général en chef de l'armée de la Loire en 1815, pair de France en 1819, il mourut à Paris le $1^{\text {er juin } 1823 .}$

Il est représenté en pied. Le portrait original est dans la salle des Maréchaux, au palais des Tuileries.

\section{Bessières (Jean-Baptiste), duc d'Istrie.}

Par M. Hédouin, d'après Riesener. - H. 2,15. - L. 1,40.

Né à Proissac (Lot) le 6 août 1768. Il servit d'abord dans la garde à cheval du roi en 1792, et fut ensuite la même année 
chasseur à cheval dans la légion des Pyrénées et adjudant sousofficier ; successivement sous-lieutenant, lieutenant en 1793 et capitaine en 1794, il fit les campagnes de 1792 à 1794 à l'arméc des Pyrénées-Orientales. Capitaine commandant les guides à cheval en 1794, il fut employé à l'armée d'Italie où il termina la campagne de 1794, et y fit celle de 1795 et 1796. Nommé chef d'escadron en 1796, chef de brigade dans l'armée expéditionnaire d'Egypte, il fit les campagnes d'Orient en 1798 et 1799. Général de brigade et commandant la garde des consuls en 1800, il se trouva à la bataille de Marengo et servit activement dans les années 1801 et 1802. Général de division en 1802, maréchal de l'Empire, grand officier de la Légion d'honneur en 1804, il fut orand cordon de la Légion d'honneur en 180כ̃ et commandeur de l'ordre de la Couronne de Fer en 1806. Il commanda ladivision de lagarde impériale à la grande armée et fit la campagne d'Allemagne en 1805 et celle de Prusse et de Pologne en 1806 et $\mathbf{1 8 0 7}$. Employé dans l'année 1808 en Espagne, il eut le commandement du $2^{\mathrm{e}}$ corps de l'armée, et recut en 1809 celui du corps de réserve de cavalerie. Duc d'Istrie en 1809, il commanda la 6 e division militaire, fut nommé général en chef de l'armée du Nord et fit la campagne d'Autriche en 1809. Gouverneur de Strasbourg en $\mathbf{1 8 1 0}$, il eut en $\mathbf{1 8 1 1}$ le commandement de l'armée du Nord en Espagne, où il fit la campagne de cette année. Il commanda en 1812 la cavalerie de la garde impériale, fit la campagne de 1812 en Russie, celle de 1813 en Saxe, et fut tué la veille de la bataille de Lutzen, le $1{ }^{\text {er }}$ mai 1813.

Il est représenté en pied. Le portrait original est dans la salle des Maréchaux, au palais des Tuileries.

\section{Kellermann (François-Christophe), duc de Valmy.}

D'après ANSIAUX. - H. 2,15. - L. 1,40.

Né à Strasbourg le 28 mai 1735̃. Cadet dans le régiment de Lowendal en 1752 , enseigne au régiment Royal-Bavière en 1753 , lieutenant dans les volontaires d'Alsace en 1756 , et capitaine en second de dragons dans le même corps en 175\%8, il fit en Allemagne les campagnes de 1758 et 1759 . Capitaine dans les volontaires du Dauphiné en 1761, il continua de servir à l'armée d'Al-

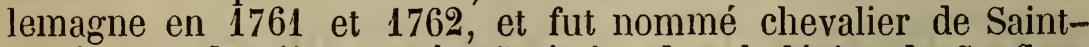
Louis cette dernière année. Capitaine dans la légion de Conflans en 1763, envoyé en mission en Pologne et en Tartarie dans les années 176כ et 1766, il fit en Pologne les campagnes de 1771 et 1772. Lieutenant colonel en 1772, major des hussards de Conflans en 1779, lieutenant colonel du régiment Colonel-hussard 
en 1780, brigadier des armées du roi et mestre de camp en second dans l'année 1784, maréchal de camp en 1788, commandeur de l'ordre de Saint-Louis en 1790, il servit dans le Haut et le Bas-Rhin en 1790 et 1791 . Lieutenant général des armées du roi en 1792, il commanda dans la même année d'abord l'armée du Centre, ensuite celle des Alpes, et livra la bataille de Valmy. Il eut en 1793 le commandement de l'armée des Alpes et d'Italie, commença la campagne de 1793 en Piémont, la continua en France et la termina dans le Piémont. Commandant de la $7^{\mathrm{e}}$ division militaire en 1797 , président du comité militaire pour la classification des places de guerre en 1798, il fut la même année inspecteur général de la cavalerie de l'armée d'Angleterre. Dans l'année 1799, il fut d'abord inspecteur général de la cavalerie de l'intérieur, et ensuite des troupes françaises en Batavie. Sénateur en 1799, maréchal de l'Empire en 1804, il fut nommé grand cordon de la Légion d'honneur en 1805. Il commanda successivement le $3^{\mathrm{e}}$ corps de réserve en 1805 , l'armée de réserve en 1806, les armées de réserve sur le Rhin et en Espagne en 1808, et fut créé duc de Valmy la même année. Le maréchal Kellermann commanda de nouveau l'armée de réserve du Rhin en 1809, ainsi que l'armée d'observation de l'Elbe. Il reçut la même année le commandement supérieur des $5^{\mathrm{e}}, 25^{\mathrm{e}}$ et $26^{\circ}$ divisions militaires, et le commandement en chef de l'armée de réserve du Nord. Il fut chargé en $\mathbf{1 8 1 2}$ de l'organisation des cohortes de la garde nationale dans la $1^{\text {re }}$ division militaire, et reçut de nouveau dans la même année le commandement des $2 \mathrm{~J}^{\mathrm{e}}$ et $26^{\mathrm{e}}$ divisions militaires. D'abord commandant provisoire des corps d'observation du Rhin en 1813, il fut ensuite dans la même année commandant supérieur des $2 \mathrm{e}, 3^{\mathrm{e}}$ et $4^{\mathrm{e}}$ divisions militaires. Commandant extraordinaire du roi dans la $3^{\text {e }}$ division militaire et gouverneur de la 5̆e division militaire en 1814, il fut la même année pair de France el grand-croix de l'ordre de Saint-Louis. Il mourut à Paris le 13 septembre 1820.

Le portrait original est dans la salle des Maréchaux, au palais des Tuileries.

\section{Lefebvre (Francois-Joseph), duc de Dantzick.}

Par Mme Davin-MirvaulT. - H. 2,15. - L. 1,40.

Né à Ruffach (Haut-Rhin) le 20 octobre 175̆. Soldal au régiment des gardes françaises en 1773, il fut successivement caporal en 1777, sergent en 1782 et premier sergent en 1788. Lieutenant dans la garde nationale en 1789 , capitaine au $13^{\mathrm{e}}$ bataillon d'infanterie légère en 1792, il servit à l'armée de la Moselle. Chef de bataillon, adjudant général en 1793, il fut employé à larmée de liayence et nommé général de brigade en 
1793. Général de division en 179', il reçut d'abord le commandement de la $17^{\mathrm{e}}$ division militaire, et fut ensuite appelé au commandement supérieur des $14^{\mathrm{e}}, 1 \mathrm{~g}^{\mathrm{e}}$ et 17 divisions militaires. Il fit à l'armée de Sambre-et-Meuse les campagnes de 1794 à 1798, et celle de 1799 à l'armée du Danube. Lieutenant du général en chef Bonaparte en 1799 , il commanda la $1^{\text {re }}$ division de réserve en 1800 , et fut nommé sénateur la même année. Maréchal de l'Empire, grand officier de la Légion d'honneur en 1804, grand cordon de la Légion d'honneur en 180ðั, il fut appelé la mème année au commandement du $2^{\mathrm{e}}$ corps de réserve de la grande armée. Le maréchal Lefebvre commanda le วe corps de la grande armée en 1806, le $10^{\mathrm{e}}$ en 1807, fit la campagne de Prusse et de Pologne en 1806 et $\mathbf{1 8 0 \pi}$, et fut créé duc de Dantzick celte dernière année. Il reçut en 1808 le commandement du $4^{\mathrm{e}}$ corps envoyé en Espagne, où il fit la campagne de cette année; il eut en 1809 d'abord le commandement du $4^{\mathrm{e}}$ corps de l'armée bavaroise, ensuite celui du $7^{\text {e }}$ corps de l'armée d'Allemagne, et fit la campagne d'Autriche en 1809. Commandant la vieille garde en 1812, il fit la campagne de Russie en 1812 et celle de France en 1814. Nommé chevalier de Saint-Louis et pair de France en 1814, il mourut le 4 septembre 1820.

Il est représenté en pied. Ce tableau est signé : C. Davin, née Mirvault, 1807.

\section{Pérignon (Dominique-Catherine, marquis).}

Par HeNrequis. - H. 2,15. - L. 1,28.

Né à Grenade-sur-Garonne le 31 mai 17วั4. Il fut d'abord souslieutenant dans le bataillon de garnison du Lyonnais en 1782 , et ensuite dans les grenadiers royaux de Guienne en 1783. Lieutenant colonel dans la légion des Pyrénées en 1792, il fut sucessirement chef de brigade et général de division en 1793, et servit à l'armée des Prrénées-Orientales en 1793 et 1794. Commandant en chef de l'armée des còtes de Brest en $179 \mathrm{o}$, ambassadeur en Espagne dans les années 1795̆, 1796 et 1797, général en chef de l'armée d'Italie en 1798, il fit la campagne d'Italie en 1799. Commandant de la $10^{\mathrm{e}}$ division militaire et sénateur en 1801, il fut en 1802 commissaire extraordinaire pour régler les limites entre la France et l'Espagne. Maréchal de l'Empire en 180', grand cordon de la Légion d'honneur en 180ă, il fut nommé en 1806 gouverneur général des états de Parme et de Plaisance; il fut appelé au gouvernement de la ville de Naples en 1808, eut sous les ordres du roi (Joseph Napoléon) le commandement de l'armée dans ce rovaume, fut nommé rand dignitaire de l'ordre des Deux-Siciles en 1808, et créé comte en 1811. Le maréchal Pérignon fut nommé pair de France et chevalier do 
DOUZIÈME SALLE des MARÉCHAUX, № 56 .

Saint-Louis en 1814, et fut gouverneur de la $10^{\mathrm{e}}$ division militaire en 1815. Appelé au gouvernement de la $1^{\text {re }}$ division mimilitaire en 1816, il fut nommé commandeur de l'ordre de SaintLouis la même année, grand-croix du même ordre et marquis en 1817. Il mourut à Paris le 25 décembre 1818.

Il est représenté en pied.

\section{Sérurier (Jean-Mathieu-Philibert, comte).}

Par LANEUVILle. - H. 2,15. - L. 1,28.

Né à Laon le 8 décembre 1742. Lieutenant au bataillon de milice de Laon en 175วั, il servit à l'armée de Hanovre en 1758, passa enseigne au régiment d'infanterie de Mazarin en 1759 , et fit la campagne de Hanovre en 1759 et 1760 . Lieutenant au régiment de La Tour du Pin en 1762, il fut successivement lieutenant au régiment de Beauce en 1767, premier lieutenant en 1776, capitaine en second en 1778, capitaine commandant et chevalier de Saint-Louis en 1782. Major du $70^{\mathrm{e}}$ régiment en 1789, chef de bataillon el général de brigade en 1793, il servit à l'armée des Pyrénées-Orientales en 1794. Général de division en 179ðั, il fit la campagne d'Italie en 1795 , celle des Alpes en 1796 et celle d'Italie en 1797, 1798 et 1799. Sénateur en 1799, il fut viceprésident du Sénat en 1802 et préteur en 1803. Gouverneur de l'Hôtel des Invalides, maréchal de l'Empire en 1804, il fut en 180 ว grand cordon de la Légion d'honneur et grand dignilaire de l'ordre de la Couronne de Fer. Créé comte en 1808, il recout en 1809 le commiandement général de la garde nationale de Paris. Pair de France et commandeur de l'ordre de Saint-Louis en 1814, grand-croix de l'ordre de Saint-Louis en 1818, il mourut à Paris le 21 décembre 1819.

Il est representé en pied.

\section{DOUZIÈME SALLE DES MARÉCHAUX, № 56.}

Vestibule de l'appartement des Bains (voir Salle ${ }^{\circ} 52$ ), décoré de huit colonnes d'ordre dorique, en marbre de Rance. Sous Louis XV, ce salon était divisé en trois parties : celle du côté de la salle no 55 était la première antichambre de Mesdames; la partie du milieu était réservée pour la comtesse de Toulouse, et celle du côté de la salle $\mathrm{n}^{\circ} 57$ formait le petit cabinet de l'appartement de $\mathbf{M}^{\text {me }}$ de Pompadour.

La suite chronologique des maréchaux de France, depuis Antoine-Chrétien, chevalier de Nicolaï (1775), jusqu'à Laurent, marquis de Gouvion Saint-Cyr (1812), est représentée par des écussons ou par des portraits en buste.

1142. Nicolaï (Antoine-Chrétien, chevalier de).

$\mathrm{Pa}$ II. François Dubors. - H. 0,71. - L. 0,55.

Cornette au régiment de dragons de Nicolaï en 1729 , il servit à 
l'armée d'Italie, fut brigadier en 1740, maréchal de camp en 1744, et fut employé successivement aux armées du Bas-Rhin, de Flandre et des Pays-Bas. Lieutenant général en 1748 , il servit à larmée d'Allemagne, commanda la province du Hainaut en 1760 , et fut nommé maréchal de France en 177\%̈. Il mourut en 1777 à l'âge de soixante-quinze ans.

\section{Fitz-James (Charles, duc de).}

Par Me Haudebourt. - H. 0,71. - L. 0,55.

Né à Saint-Germain en 1712, il était fils du maréchal de Berwick, et entra aux mousquetaires en 1730. Créé duc et pair de France en 1736, il servit en $\mathbf{1 7 4 1}$ à l'armée de la Meuse, fut maréchal de camp en 1744 et fit les campagnes de Flandre et des Pays-Bas. Lieutenant général en 1748, chevalier de l'ordre du Saint-Esprit en 17ö6, il servit à l'armée d'Allemagne de 17507 à 1759, et fut nommé maréchal de France en 1775 . Il mourut en 1787.

\section{Mouchy (Philippe de Noailles, duc de).}

Par M. CaMinade. - H. 0,71. - L. 0,55.

Né en 1715 ; il était fils puîné du maréchal Adrien-Maurice de Noailles, et il entra aux mousquetaires en 1729. Colonel en 1734, il servit en Allemagne et en Italie, fut grand d'Espagne en $\mathbf{1 7 4 1}$ et entra dans l'ordre de Malte. Brigadier en 1743, maréchal de camp en 174.1, il servit aux armées du Rhin et de Flandre, fut chevalier de la Toison d'Or en 1746 et lieutenant général en 1748. Ambassadeur extraordinaire en Sardaigne en 175̌, il fit ensuite les campagnes d'Allemagne, fut chevalier de l'ordre du Saint-Esprit en 1767 et maréchal de France en $177 \%$. Condamné à mort par le tribunal révolutionnaire, il mourut à Paris le 27 juin 1794.

\section{Duras (Emmanuel-Félicité de Durfort, duc de).}

Par M. Albrier. - H. 0, 71. - L. 0,55.

Connu d'abord sous le nom de comte de Durfort, il entra aux mousquetaires en 1731 et servit ensuite à l'armée d'Italie. Duc de Duras en 1741, il fit les campagnes de Bavière et de Flandre, et fut successivement maréchal de camp en 17450 , lieutenant général en 1748, ambassadeur extraordinaire en Espagne et pair de France en 1752. Premier gentilhomme de la chambre du roi en 173\%7, il servit à l'armée d'Allemagne, fut chevalier de l'ordre du Saint-Esprit en 1767 et maréchal de France en 1775̃. Il mourut à Versailles le 6 septembre 1789, à l'âge de soixante quatorze ans. 
1146. Montmorency-Laval (Guy-A ndré-Pierre, duc de).

Par Axsiadx. - H. 0,71. - L. 0,55.

Connu d'abord sous le nom de marquis de Laval, il entra aux mousquetaires en 1741 et fit la campagne de Flandre en 1742. Colonel de cavalerie en 1743, il servit aux armées du Bas-Rhin et de Flandre, fut maréchal de camp en 1748 et fit les campagnes d'Allemagne. Duc de Laval en 1758, lieutenant général en 1759, grand-croix de l'ordre de Saint-Louis en 1779, maréchal de France en 1783, il mourut le 28 septembre 1798, à l'âge de soixante-quinze ans.

1147. Beauvau-Craon (Charles-Just, prince de).

Par Mne BruY̌̀re. - H. 0,71. - L. 0,55.

Créé prince de l'Empire en 1722, il était lieutenant en 1738, colonel en 1740 et chevalier de Saint-Louis en 1743. Brigadier en 1746 et maréchal de camp en 1748, il fit les campagnes d'Allemagne et de Flandre, fut créé grand d'Espagne en $175 \%$ et se trouva à la conquête de lî̀le de Minorque en 1756. Grand maître de la maison de Stanislas, duc de Lorraine, chevalier de l'ordre du Saint-Esprit et capitaine d'une compagnie des gardes du corps en 175ั7, lieutenant général en 1758, il fit les campagnes d'Allemagne et du Haut-Rhin de $170 \hat{9} 9$ à 1761. Gouverneur de Provence en 1782, maréchal de France en 1783, il mourut le 21 mai 1793, à l'âge de soixante-treize ans.

\section{Mailly (Joseph-Augustin, comte de).}

Par M. SchNetz. - H. 0,71. - L. 0,55.

Il entra aux mousquetaires en 1726 et servit au siége de Kehl en 1733. Capitaine en 1738, il passa en 1741 à l'ar'mée de Westphalie, fut brigadier de cavalerie en 1743, maréchal de camp en 1745 et servit aux armées du Rhin, de Flandre et d'Italie. Lieutenant général en 1748, il servit aux armées d'Allemagne et du Bas-Rhin de 17507 à 1761. Chevalier de l'ordre du Saint-Esprit en 1776, maréchal de France en 1783, il commanda en chef les $1 \mathbf{t}^{\mathrm{e}}$ et $1 \tilde{5}^{\mathrm{e}}$ divisions militaires en 1791 , et mourut à Arras le 20 mars 1794, à l'âge de quatre-vingt-six ans.

\section{A ubeterre (Joseph-Henri Bouchard d'Esparbès de Lussan, marquis d').}

Par M. Joux. - H. 0,71. - L. 0,55.

Mousquetaire en 1730, capitaine de cavalerie en 1\%33, il servit 
sur le Rhin jusqu'en 173ä, fut colonel d'infanterie en 1738 , et fit les campagnes de Westphalie, de Bohême et d'Italie. Maréchal de camp en 1748, ambassadeur à Vienne en 1752, en Espagne en 17ว6, chevalier de l'ordre du Saint-Esprit en 1757, lieutenant général en 1758, il était au congrès d'Augsbourg en qualité de ministre plénipotentiaire. Lieutenant général en Bretagne en 1775, il fut nommé maréchal de France en 1783, et mourut en 1790, à l'âge de soixante-quatorze ans.

\section{Croy (Emmanuel de Croy-Solre, duc de).}

Par M. Vauchelet. - H. 0,71. - L. 0,55.

Il entra aux mousquetaires en 1736, fit la campagne de Westphalie en 1741 et celle de Flandre en 1744. Brigadier en 1740ั, maréchal de camp en 1748, il continua à servir en Flandre et commanda en Picardie en 17วั7. Chevalier de l'ordre du SaintEsprit et lieutenant général en 17วั9, il fit les campagnes d'Allemagne et fut nommé maréchal de France en 1783. Il mourut à Paris le 30 mars 178', à l'âge de soixante-six ans.

\section{Lévis (François-Gaston, duc de).}

Par Me Haddebocrt. - H. 0,71. - L. 0,51.

Lieutenant dans le régiment de la Marine en 173วّ, capitaine en 1737, il fit la campagone du Rhin et celle de Bohême. Brigadier en 17วั6, maréchal de camp en 17ว̀8, il servit en Canada sous Montcalm jusqu'en 1761. De retour en France, il fut nommé lieutenant général, gouverneur de l'Artois en 1764, capitaine des gardes du comte de Provence en 1771, et chevalier de lordre du Saint-Esprit en 1776. Maréchal de France en 1783, il mourut à Arras le 26 novembre 1787, à l'âge de soixante-huit ans.

\section{Estaing (Charles-Henri-Théodat, comte d').}

Par Pierre Franque. - H. 0,71. - L. 0,51.

Né en 1729 au château de Ruvel (Auvergne), il entra aux mousquetaires en 1743 , et fut successivement lieutenant dans le régiment de Rouergue en 1746, capitaine en 1747, colonel en 1748 et brigadier en 17306 . Il s'embarqua en $170 \% 7$ sur l'escadre du comte d'Aché, commandant en chef les établissements français dans les Indes-Orientales, s'empara de Gondelour en 1758, et se trouva la même année à la prise du fort Saint-David, surnommé le Berg-op-Zoom de l'Inde. IIaréchal de camp en 1761, lieutenant général des armées navales en 1762, il fut chevalier de l'ordre du Saint-Esprit en 1767. Vice-amiral des mers d'Asie et d'Amérique en 1777, il reçut le commandant diune escadre destinée pour l'Amérique septentrionale, et s'empara en 1779 des 
îles de Saint-Vincent et de la Grenade. Il commanda en 1783 les flottes combinées de France et d'Espagne, et fut nommé grand d'Espagne de $1^{\text {re }}$ classe. En 1787, il fit partie de l'assemblée des notables, reçut en 1789 le commandement de la garde nationale de Versailles, et fut nommé amiral en 1791. Condamné à mort par le tribunal révolutionnaire, il mourut à Paris le 28 avril 1794.

\section{Orléans (Louis-Philippe-Joseph, duc d').}

Par M. LaRivière. - H. 0,71.- L. 0,51.

Né à Saint-Cloud en 1747, il porta d'abord le nom de duc de Chartres, fit deux campagnes sur l'Océan et la Méditerranée en 1777, fut nommé lieutenant géneral des armées navales, et montait le vaisseau le Suint-Esprit au combat d'Ouessant en 1778 . Duc d'Orléans en 1780 , il fit partie de l'assemblée des notables en 1787, fut député de la noblesse aux états généraux en 1789 , et fut créé amiral en 1791. Membre de la Convention nationale en 1792, il fut condamné à mort par le tribunal révolutionnaire, et mourut à Paris le 6 novembre 1793.

1154. Du Chaffault (Louis-Charles de Rezay, comte). Par M. MaRLET. - H. 0,71. - L. 0,51.

Lieutenant général des armées navales en 1777, il commanda l'aile gauche au combat d'Ouessant en 1778, et fut nommé amiral en 1791. Il mourut à Nantes en 1793, à l'âge de quatre-vingtdeux arıs.

\section{Bellune (Claude-Victor Perrin, duc de).}

Par Gros. - H. 2,14. - L. 1,40.

Né à La Narche (Vosges) le 7 décembre 1764. Soldat au $4^{\mathrm{e}}$ régiment d'artillerie en 1781, volontaire au $3^{\mathrm{e}}$ bataillon de la Drôme en 1791, il fut successivement adjudant sous-officier, adjudantmajor au כّe bataillon des Bouches-du-Rhône et chef de bataillon en 1792. Chef de brigade, adjudant général en 1793, il se trouva au siége de Toulon et fut nommé la même année général de brigade; il servit à l'armée des Pyrénées en 179', et à celle d'Italie en 179د et 1796. Général de division en 1797 et commandant la $12^{\mathrm{e}}$ division militaire en 1798 , il fut employé à l'armée d'Italie en 1798 et 1799, et fit la campagne de Marengo en 1800. Lieutenant du général en chef de l'armée batave en 1800 , capitaine général de la Louisiane en 1802, il fut ministre plénipotentiaire en Danemarck depuis 180כّ jusqu'en 1806. Commandant en chef le $1^{\text {er }}$ corps de la grande armée en 1807, il fit la campagne de la même année en Pologne. Grand cordon de la Légion d'honneur, maréchal de l'Empire en 1807, commandant en chef le 1 er corps 
de l'armée d'Espagne et créé duc de Bellune en 1808, il fit dans la Péninsule les campagnes de 1808 à 1812. Commandant en chef le $9^{\text {e }}$ corps de la grande armée en 1812, il fit la campagne de 1812 en Russie, commanda en chef le $2^{\mathrm{e}}$ corps en 1813 , fit lit même année la campagne de Saxe et celle de 1814 en France. Gouverneur de la $2^{\mathrm{e}}$ division militaire et chevalier de Saint-Louis en 1814, pair de France et l'un des quatre majors généraux de la garde royale en $181 \%$, gouverneur de la $16^{\mathrm{e}}$ division militaire et commandeur de l'ordre de Saint-Louis en 1816, grand-croix du même ordre et chevalier de l'ordre du Saint-Esprit en 1820, il fut en $182 \mathrm{~A}$ commandant extraordinaire des $6^{\mathrm{e}}, 7^{\mathrm{e}}$ et $19^{\mathrm{e}}$ divisions militaires, et ministre de la guerre de 1821 à 1823. D'abord major général de l'armée des Pyrénées en 1823, il fut ensuite dans la même année ministre d'Etat, membre du conseil privé, et en 1828 membre du conseil supérieur de la guerre. Il mourut le $\mathcal{L}^{\text {er }}$ mars 1841.

Il est représenté en pied.

\section{Macdonald (Etienne-Jacques-Joseph-Alexandre), duc de Tarente.}

Par Rocillakd. - H. 2,14. - L. 1,40.

Né à Sancerre, en Berry, le 17 novembre 176วั. Il servit d'abord dans la légion de Maillebois en 1784 et fut sous-lieutenant au régiment de Dillon en 1787. Lieutenant en 1791 , capitaine et aide de camp des généraux Beurnonville et Dumouriez en 1792, lieutenant-colonel au $94^{\mathrm{e}}$ régiment la même année, il servit à l'armée du Nord en 1792 et fut chef de brigade du $2^{\mathrm{e}}$ régiment d'infanterie en 1793. Général de brigade en 1793, il fit la campagne de 1793 et de 179' à l'armée du Nord. Général de division en 1794, il servit à l'armée de Sambre-et-IIeuse en 1795 , et fit en Allemagne les campagnes de cette année; détaché à l'armée d'Italie en 1796, il y fit les campagnes de $\mathbf{1 7 9 6}$ et 1797. Employé près les troupes stationnées en Hollande en 1797 et à l'armée d'Italie en 1798 , il commanda les troupes françaises à Rome en 1798 et l'armée de Naples en 1799. Inspecteur général d'infanterie et attaché à l'armée de réserve en 1800 , il fit la campagne de 1801 à l'armée des Grisolis, et fut nommé en 1801 ministre plénipotentiaire en Danemarck, et en 1804 grand officier de la Légion d'honneur. Employé d'abord à l'armée d'Italie en 1809, il fit ensuite la même année la campagne d'Autriche à la grande armée. Maréchal de l'Empire, duc de Tarente et grand aigle de la Légion d'honneur en 1809, il commanda en chef l'arméc de Catalogine en 1810 avec le titre de gonverneur de cette province, et servit dans la Péninsule en 
1810 et 1811 . Commandant le $10^{\mathrm{e}}$ corps de la grande armée ell 1812, il fit la campagne de 1812 en Russie, commanda le $11^{\mathrm{e}}$ corps en 1813 et fit la campagne de Saxe en 1813 et celle de France en 1814. Pair de France, chevalier de Saint-Louis et gouverneur de la $21^{\mathrm{e}}$ division militaire en 1814 , il commanda en chef l'armée de la Loire en 1810ั. Grand chancelier de l'orddre royal de la Légion d'honneur, major général de la garde royale et ministre d'Etat, nembre du conseil privé en 1815, il fut commandeur de l'ordre de Saint-Louis en 1816, grand-croix du même ordre et chevalier de l'ordre du Saint-Esprit en 1820. Le maréchal Macdonal mourut au château de Courcelles, près Gien (Loiret), le 7 septembre 1840 .

Il est représenté en pied.

\section{Oudinot (Nicolas-Charles), duc de Reggio.}

Par Robert Lefebvre. - H. 2,14. - L. 1,40.

Né à Bar-sur-Ornain le $2 כ$ avril 1767 . Soldat au régiment d'infanterie de Médoc en 1784, second lieutenant colonel au $3^{\mathrm{e}}$ bataillon de la Meuse en 1791, il servit en 1792 et 1793 à l'armée de la Moselle. Chef de la $4^{\mathrm{e}}$ demi-brigade en 1793, général de briçade en 1794, il fut employé à l'armée du Rhin et de la Moselle depuis 1794 jusqu'en 1798. Général de division en 1799, il se trouva à la bataille de Zurich. Chef de l'état-major de l'armée commandée par le général Masséna, il acheva la campagne de 1799 en Italie, y fit ensuite celle de 1800, après laquelle il reçut un sabre d'honneur au commencement de 1801. Inspecteur général d'infanterie et de cavalerie en 1801, il fut employé au camp de Bruges en 1803. Chevalier de la Légion d'honneur en 1803, grand-officier du même ordre en 1804, il commanda les grenadiers de la réserve au camp d'Arras en 18050, et fut nommé la même année grand-cordon de la Légion d'honneur et chevalier de l'ordre de la Couronne de Fer. Commandant en chef les grenadiers et voltigeurs réunis, et gouverneur général de la principauté de Neufchâtel ế de Vallengin en 1806, il fit les campagnes de Prusse et de Pologne en 1806 et 1807, et fut chargé du commandement particulier de Dantzick. Gouverneur d'Erfurth et créé comte en 1808 , commandant en chef le $2^{\mathrm{e}}$ corps de l'armée d'Allemagne en 1809, il fit la campagne d'Autriche et fut nommé la même année maréchal de l'Empire. Duc de Reggio en 1810, il reçut le commandement de l'armée du Nord en Hollande en $\mathbf{1 8 1 0}$, et prit possession du royaume de Hollande au nom de l'Empereur. Le maréchal Oudinot commanda le $12^{\mathrm{e}}$ corps de la grande armée en 1812, le 2 e corps en 1813 , le 7 e corps en 1814 , et fit les campagnes de 1812 en Russie, de 1813 en Saxe et de 1814 en 
France. Ministre d'état, membre du conseil privé et pair de France en 1814, il fut commandant des corps royaux des grenadiers et chasseurs de France, et gouverneur de la $3^{\mathrm{e}}$ division militaire. Un des quatre majors généraux de la garde royale et commandant en chef de la garde nationale de Paris en 1815, grand-croix de l'ordre de Saint-Louis en 1817, chevalier de l'ordre du SaintEsprit en 1820, il commanda en chef la même année le $1^{\text {er }}$ corps de l'armée des Pyrénées. Il fut nommé grand chancelier de l'ordre royal de la Légion d'honneur en 1839, et mourut en 1847.

Il est représenté en pied. Ce tableau est signé : Robert Lefevre ft 1811.

\section{Marmont (Auguste-Frédéric-Louis Viesse de), duc de Raguse.}

Par Paulin Guérin. - H. 0,71. - L. 0,55.

Né à Châtillon-sur-Seine le 20 juillet 1774. Il fut d'abord souslieutenant en 1790 , ensuite élève sous-lieutenant d'artillerie à l'école de La Fère et lieutenant en 1792, et fit la campagne de 1792 à l'armée de la Moselle. Capitaine en 1793, il servit la même année aux armées des Alpes et des Pyrénées, et fut employé en 1794 et 1793 dans les armées d'Italie et de Mavence. Aide de camp du général Bonaparte en 1796 , chef de bataillon et de brigade la même année, il commanda en 1797 le $2^{\mathrm{e}}$ régiment d'artillerie à cheval, et servit en Italie dans les années 1796 et 1797 : il avait recu en 1796 un sabre d'honneur. Général de brigade en 1798, il fit la campagne d'Orient en 1798 et 1799 . Commandant en chef l'artillerie de l'armée d'Italie et général de division en 1800, il fit la campagne de Marengo. Premier inspecteur général de l'artillerie en 1802, il commanda en chef le camp d'Utrecht en 1804, et nommé colonel général des chasseurs à cheval en $180 \%$, il fit en Allemagne la campagne de cette année. Comandeur de l'ordre de la Couronne de Fer, il commanda en chef en 1806 l'armée en Dalmatie, où il resta jusqu'en 1809 : il avait été nommé duc de Raguse en 1808. Appelé à la grande armée en 1809, il fut nommé maréchal de l'Empire, commandant le $11^{\mathrm{e}}$ corps, et fit la même année la campagne d'Autriche. Commandant en chef l'armée de Portugal en 1811, il fit en Portugal et en Espagne les campagnes de 1811 et 1812. Le duc de Raguse commanda en 1813 le 2 corps d'observation sur le Rhin et le $6^{\mathrm{e}}$ corps de la grande armée, fit en Saxe la campagne de 1813 et en France celle de 1814. Pair de France, capitaine des gardes du corps du roi en 1814, il fut major général de la garde royale en 1815 , commandeur de l'ordre de Saint-Louis en 1816, lieutenant du roi, commissaire extraordinaire dans les $7^{\mathrm{e}}$ et $19^{\mathrm{e}}$ divisions militaires, et ministre d'état, membre du conseil privé en 1817. 
Grand-croix de l'ordre de Saint-Louis et chevalier de l'ordre du Saint-Esprit en 1820 , il reçut le gouvernement de la $\mathbf{1}^{\mathrm{re}}$ division militaire en 1821, fut envoyé à Moscou en 1826 comme ambassadeus extraordinaire pour assister au couronnement de l'empereur Nicolas, et fut nommé en 1828 membre du conseil supérieur de la guerre. Il mourut à Venise le 2 mars 1852. - Il a laissé une relation de ses voyages et des Mémoires publiés après sa mort.

\section{Suchet (Louis-Gabriel), duc d'Albuféra.}

Par Paulin Gotrin. - H. 2,15. - L. 1,40.

Né à Lyon le 2 mars 1770. Soldat dans une compagnie franche en 1792, chef de bataillon à la $18^{\circ}$ demi-brigade en 1793 , il se trouva la même année au siége de Toulon, fit la campagne de 1795 en Piémont, celles de 1796 et 1797 à l'armée d'Itatie, et fut nommé cette dernière année chef de brigade. Employé à l'armée d'Helvétie en 1798, il fut nommé la même année général de brigade, et servit à l'armée de Nayence en 1799. Général de division et chef d'état-major de l'armée d'Italie en 1799, il y fit les cam-

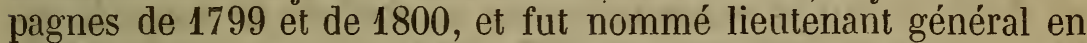
chef de cette armée en 1800 . Inspecteur général d'infanterie en 1801, il commanda la $4^{\mathrm{e}}$ division du camp de Saint-Omer en 1803. Grand officier de la Légion d'honneur en 1804, il fut appelé au commandement de la $4^{\mathrm{e}}$ division du $4^{\mathrm{e}}$ corps de la grande armée en 180今̈, et fit la même année la campagne d'Allemagne. Grand cordon de la Légion d'honneur en 1806, il fit la campagne de Prusse en 1806, commanda le $5^{\mathrm{e}}$ corps de la grande armée en 1807, et fit la même année la campagne de Pologne. Créé comte en 1808, il recut le commandement de la $1^{\text {re }}$ division du $5^{\mathrm{e}}$ corps de l'armée d'Éspagne en 1808, du $3^{\mathrm{e}}$ corps en 1809, et fit les campagnes de 1808 à 1810 en Espagne. Maréchal de l'Empire en 1811, il continua à servir en Espagne dans les années 1811 et 1812, fut nommé en 1813 colonel général de la garde et commandant de l'armée d'Aragon et de Catalogne et créé la même année duc d'Albuféra. Il fit en Espagne la campagne de 1813 et celle de 1814 dans le midi de la France. Pair de France en 1814, il fut la même année gouverneur des $10^{\mathrm{e}}$ et $5^{\mathrm{e}}$ divisions militaires et commandeur de l'ordre de Saint-Louis. Le maréchal Suchet fut chargé en 1815 d'une mission dans les $9^{\mathrm{e}}$ et $10^{\mathrm{e}}$ divisions militaires, et commanda en chef le $7^{\mathrm{e}}$ corps d'observation (armée des Alpes). Chevalier de l'ordre du Saint-Esprit en 1820, il mourut au château de Saint-Joseph, près Marseille, le 3 janvier 1826.

Il est représenté en pied. 


\section{Gouvion-Saint-Cyr (Laurent, marquis de).}

Par M. Horace Vernet. - H. 2,14. - L. 1,40.

Né à Toul (Meurthe) le 13 avril 1764. Volontaire au $1^{\mathrm{er}}$ Jaa. taillon de chasseurs de Paris, capitaine au même bataillon ell 1792, chef de bataillon adjudant général en 1793, successivement chef de brigade, général de brigade et ensuite de division en 1794, il servit à l'armée du Rhin en 1792, 1793 et 1794, et à celle de Rhin-et-Moselle en 1795, 1796 et 1797. Nommé commandant de Rome en 1798, il commença la campagne de cette année en Italie et la termina à l'armée de Mayence. Employé de nouveau à l'armée d'Italie en 1799, il fut ensuite appelé à l'armée du Rhin et nommé en 1800 lieutenant général en chef de cette armée. Conseiller d'état en 1800, il commanda l'année suivante les armées française et espagnole dans la guerre contre le Portugal. Ambassadeur près la cour d'Espagne en 1801, il reçut en 1802 un sabre d'honneur du premier consul, et fut nommé en 1803 lieutenant général commandant en chef le corps d'observation du royaume de Naples. Grand officier de l'empire et colonel général des cuirassiers en 1804, grand cordon de la Légion d'honneur en 1805, il eut le commandement en chef du $4^{\mathrm{e}}$ corps de réserve (camp de Boulogne) en 1806, fut appelé à la grande armée d'Allemagne en 1807, fit la campagne de Pologne et reçut le gouvernement général de Varsovie. Général en chef du $7^{\mathrm{e}}$ corps de l'armée d'Espagne (armée de Catalogne) en 1808, il fut créé comte la même année et fit en Espagne les campagnes de 1808 et 1809. Commandant en 1812 d'abord le corps bavarois $\left(6^{\mathrm{e}}\right.$ corps de la grande armée), il eut ensuite sous ses ordres les $2^{\mathrm{e}}$ et $6^{\mathrm{e}}$ corps réunis, fit en Russie la campagne de 1812, et fut nommé la mème année maréchal de l'Empire; il commanda le $14^{\mathrm{e}}$ corps d'armée en 1813 et fit la campagne de Saxe. Le maréchal Gouvion-Saint-Cyr fut pair de France en 1814; il commanda en chef le corps d'armée sur la Loire en 1815 , fut appelé au ministère de la guerre la même année, devint ministre d'état, membre du conseil privé, et eut le gouvernement de la $12^{\mathrm{e}}$ division militaire. Gouverneur de la 5̆e division militaire et grand-croix de l'ordre de Saint-Louis en 1816, il fut en 1817 d'abord ministre de la marine et des colonies, et ensuite ministre de la guerre. Nommé marquis en 1819, il quitta le ministère la même année. Il mourut à Hyères (Var) le $\mathbf{1 7}$ mars 1830.

Il est représenté en pied.

\section{Poniatowski (Joseph-Antoine, prince).}

Par M. Vauchelet. - H. 2,14. - L. 1,40.

Né à Varsovie le 7 mai 1762. Sous lieutenant au service d'Au- 
triche en 1779 , colonel de dragons et aide de camp de l'empereur' Joseph II en 1787, il servit dans la guerre de l'Autriche contre la Turquie. Volontaire de l'armée polonaise en 1792, il eut le cominandement en chef de l'armée polonaise. Le prince Joseph Poniatowski commandait en 1806 et 1807 un corps d'armée polonais ati service de la France; il fit la campagne de 1809 en Galicie. En 1811 , il fut envoyé à Paris ambassadeur extraordinaire du roi de Saxe, grand-duc de Varsovie. Il prit part en 1812 à la guerre contre la Russie, et eut le commandement du $5^{\mathrm{e}}$ corps de la grande armée. Général en chef de l'arrière-ban de la Pologne, il fit en 1813 la campagne de Saxe et de Silésie, et fut nommé maréchal de l'Empire en 1813. Il périt au passage de l'Elster le 19 octobre 1813.

II est représenté en pied.

\section{Coigny (Marie-Henri-François de Franquetot, duc de).}

Par M. Rouget. - H. 2,14. - L. 1,28.

Né à Paris le 28 mars 1737. Gouverneur de Choisy en 1748, mousquetaire en 1752 , mestre de camp général des dragons en $173 ั 4$, gouverneur des ville et chàteau de Caen l'année suivante, brigadier en 1756 , il servit en 17507 à l'armée d'Allemagne, et fit partie en 1758 de l'armée sıus les ordres du comte de Clermont. Maréchal de camp en 1761, il servit à l'armée du Bas-Rhin la même année. Colonel général des dragons en 1771, il fut gouverneur de Cambrai en 1773. Chevalier de l'ordre du Saint-Esprit en 1777, il fut employé dans les provinces de Bretagne et de Normandie en 1778. Lieutenant général des armées du roi en 1780, il était chef de division en Normandie en 1788. Le duc de Coigny, nommé pair de France en 1814, fut gouverneur de l'Hồtel royal des Invalides et maréchal de France en 1816. Il mourut à Paris le $\mathbf{1 9}$ mai 1821.

Il est ręrésenté en pied.

\section{Bournonville (Pierre de Riel, marquis de).}

Par Rathier. - H. 2,14. - L. 1,28.

Né à Champignolle le 10 mai 1752. Volontaire au régiment de l'Tle de France en 1774, porte-drapeau en 1775 , lieutenant sous aide-major des milices de l'île Bourbon en 1780, capitaine aidemajor en 1781, il fit les campagnes de 1779 à 1781 dans les colonies orientales. Colonel en 1789, il fut lieutenant de la compagnie des Suisses du comte d'Artois. Aide de camp du maréchal Luckner, maréchal de camp en 1792, il servit à l'armée du Nord, 
fut nommé lieutenant général et général en chef de l'armée de la Moselle la même année. Ministre de la guerre dans l'année 1793, il fut envoyé la même année comme commissaire extraordinaire à l'armée du Nord. En 1796, il fut d'abord attaché à l'armée de l'intérieur et adjoint au ministre de la guerre, et ensuite général en chef des troupes stationnées en Batavie. Inspecteur général d'infanterie à l'armée d'Angleterre en 1798, il fut appelé au conseil supérieur de la guerre en 1799. Ambassadeur à Berlin en 1800 , en Espagne en 1802 , sénateur en $1803 \%$, il fut créé comte en 1808, et organisa en 1812 les cohortes des gardes nationales de la $21^{\mathrm{e}}$ division militaire. Ministre d'Etat et pair de France en 1814, grand-croix de la Légion d'honneur la même année, il fut commandeur de l'ordre de Saint-Louis en 1816. Nommé maréchal de France la même année, marquis en 1817, chevalier de l'ordre du Saint-Esprit en 1820, il mourut le 23 avril 1821.

Jl est représenté en pied.

\section{Clarke (Henri-Jacques-Guillaume), comte d'Hunebourg, duc de Feltre.}

Par Descamps. - H. 2,14. - L. 1,40.

Né à Landrecies le 17 octobre 176 ö. Cadet à l'Ecole militaire de Paris en 1781, sous-lieutenant au régiment de Berwick en 1782, il fut capitaine en 178'́t. Il servit à l'armée dı Rhin en 1792, et fut nommé la même année lieuienant colonel. Général de brigade en $\mathbf{1 7} 93$, il continua le service à l'armée du Rhin. Général de division et envoyé extraordinaire à Vienne en 1797, il prit part la même année aux conférences de Montebello et d'Udine. Commandant extraordinaire de Lunéville et du département de la Meurthe en 1800, il fut ambassadeur en Toscane en 1801, conseiller d'Etat et secrétaire intime de l'Empereur en 180כ̆; il fit la campagne de 180כ̃ en Allemagne et fut nommé gouverneur de la haute et basse Autriche. D'abord gouverneur d'Erfurt en 1806 et ensuite gouverneur de Berlin la même année, il fit à la grande armée les campagnes de 1806 et 1807 en Prusse et en Pologne. Nommé ministre de la guerre en 1807, comte d'Hunebourg en 1808, il fut eréé grand cordon de la Légion d'honneur et duc de Feltre en 1809. Pair de France et chevalier de l'ordre de SaintLouis en 1814, il fut ministre secrétaire d'Etat au département de la guerre en 1815. Le duc de Feltre eut le gouvernement des $9^{\mathrm{e}}$ et $14^{\mathrm{e}}$ divisions militaires en 1815 et 1816 ; maréchal de France en 1816, il mourut le 28 octobre 1818.

Il est représenté en pied. Ce tableau est signé : G. DEsc.amps 1817. 


\section{Vioménil (Joseph-Hyacinthe Du Houx, marquis de).}

Par M. Delaval en 1817. - H. 2,14. - L. 1,40.

Né à Ruppes le 22 août 1734 . Lieutenant au régiment de Limousin en 1747, capitaine réformé en 1759 , chevalier de l'ordre de Saint-Louis en 1760, colonel en 1761, il fit les campagnes d'Allemagne en 1761 et 1762. Brigadier en 1763, colonel de la légion de Lorraine en 1770 , mestre de camp du $3^{\mathrm{e}}$ régiment de chasseurs à cheval en 1779, maréchal de camp en 1780, il servit en Amérique sous les ordres du comte de Rochambeau dans les années 1780,1781 et, 1782. Gouverneur de la Martinique il fut commandeur de l'ordre de Saint-Louis en 1789. Il entra en 1798 au service de Russie en qualité de lieutenant général jusqu'en 1800, et fut nommé en 1802 maréchal général des armées portugaises. Pair de France en 1814, il commanda dans l'année 1815 les $11^{\mathrm{e}}, 12^{\mathrm{e}}$ et $13^{\mathrm{e}}$ divisions militaires. Maréchal de France en 1816, il fut nommé marquis en 1818, chevalier de l'ordre du Saint-Esprit en 1820, et grand officier de la Légion d'honneur en 1823. Il mourut à Paris le 5 mars 1827.

Il est représenté en pied.

\section{Lauriston (Jacques-Alexandre-Bernard Law, marquis de).}

Par Mlle GodefroId, d'après Gérard. - H. 2,14. - L. 1,40.

Né à Pondichéry le $1^{\text {er }}$ février 1768 . Elève d'artillerie en $\mathbf{1 7 8 4 ,}$ lieutenant en 1789, capitaine en 1791, aide de camp du général Beauvoir à l'armée du Nord en 1792, il servit aux armées du Nord et de la Moselle en 1792 et 1 93, à l'armée de Sambre-etMeuse en 1794 et 1795, et fut chef de brigade du $4^{\mathrm{e}}$ régiment d'artillerie à cheval en 1796. Aide de camp du premier consul en 1800, il fit la campagne de Marengo. Général de brigade en 1802, il fut chargé d'inspecter les côtes de l'océan et de porter à Londres les préliminaires de la paix d'Amiens. Envoyé en mission extraordinaire à Copenhague dans l'année 1801, nommé commandant de la Légion d'honneur en 1803, il fut chargé en 1804 de l'inspection gẻnérale des côtes de France. Général de division en $180 \tilde{s}$, il recut le commandement en chef des troupes destinées pour l'expédition de Batavia et embarquées sur l'escadre de l'amiral Villeneuve ; il fit une campagne à la Martinique. De retour en France dans la même année, il fut employé à la grande armée d'Allemagne et nommé gouverneur général de l'Inn wiertel. Commandant et gouverneur de Raguse et des bouches du Cattaro en 1806, il défendit la même année Raguse et fut gouverneur de 
Venise en 1807. Il fit en Espagne la campagne de 1808 et fut créé comte la mème année. En 1809, il commanda le corps de troupes chargé d'opérer la jonction de l'armée d'Italie avec la grande armée; il se trouva à la bataille de Raab sous les ordres du vice-roi d'Italie (Eugène Napoléon), et commanda le siége de Raab. L'artillerie de la garde impériale ayant été mise sous les ordres du comte de Lauriston, il commandait à la bataille de Wagram la batterie de cent pièces de canon. Grand dignitaire de l'ordre de la Couronne de Fer en 1809, il fut chargé en 1810 de l'inspection et de l'armement des côtes de l'Adriatique. Ambassadeur. en Russie dans l'année 1811, il rejoignit en 1812 la grande armée à Moscou et fut envoyé au quartier général de l'armée russe pour y proposer un armistice. Général en chef du .̌ corps de la grande armée en 1813, il fit la campagne de Saxe. Chevalier de l'ordre de Saint-Louis et grand cordon de la Légion d'honneur en 1814, il fut en $181 \%$ capitaine-lieutenant de la $4^{\text {re }}$ compagnie des mousquetaires de la maison du roi. Pair de France et commandant la $1^{\text {re }}$ division d'infanterie de la garde royale en 1815, commandeur de l'ordre de Saint-Iouis en 1816, marquis en 1817, ministre secrétaire d'Etat de la maison du roi en 1820, il fut grand-croix de l'ordre de Saint-Louis en 1821. Maréchal de France en 1823 , il commanda le $2^{\mathrm{e}}$ corps de réserve de l'armée d'Espagne, fut créé la même année chevalier del'ordre dı Saint-Esprit, et nommé grand veneur et ministre d'Etat. Membre dı conseil privé en 1824, il mourut à Paris le 11 juin 1828.

Il est représenté en pied.

\section{Molitor (Gabriel-Jean-Joseph, comte).}

Par M. Horace Vernet. - H. 2,14. - L. 1,40.

Né à Hayange (Lorraine) le 7 mars 1770. Volontaire en 1791, il fut la même année capitaine au $4^{\mathrm{e}}$ bataillon de la Moselle et se -it à l'armée du Nord en 1792. Il était au camp de Forbarh en 1793, et il fut nommé adjudant général chef de bataillon. Il fut d'abord employé à l'armée des Årdennes la même année, et fit ensuite à l'armée de la Moselle les campagnes de 1793 et 1794 . Il continua à servir comme adjudant général chef de bataillon et fut ensuite chef de brigade aux armées de la Moselle, du Rhin et du Danube, où il fit les campagnes de 179 à à 1798. Général de brigade en 1799, il passa à l'armée d'Helvétie sous les ordres du général Masséna, et fit la campagne de cette année. Employé en 1800 à l'armée du Rhin sous les ordres du général Moreau, il fit la campagne d'Allemagne et fut nommé la même année général de division. Il commanda en 1801 la $7^{\mathrm{e}}$ division militaire, fut envové en 1805 à l'armée d'Italie sous les ordres du maréchal Masséna et il servit jusqu'en 1807. Grand officier de la I.é- 
gion d'honneur et de la Couronme de Fer en 1806, il recut en 1807 à la grande armée le commandement de l'armée d'observation et fut investi des fonctions de gouverneur général civil et militaire de la Poméranie suédoise. Créé comte en 1808, il fit en Allemagne la campagne de 1809 sous les ordres du maréchal Masséna. Le général Molitor prit en 1810 possession des villes hanséatiques, fut nommé en 1811 gouverneur de la $17^{\text {e }}$ division militaire en Hollande, où il fit la campagne de 1813. Il se réunit en 1814 au corps du maréchal Macdonald et commanda ensuite le $11^{\mathrm{e}}$ corps de la grande armée. Inspecteur général d'infanterie en 1814, il fut nommé chevalier de Saint-Louis la même année. Grand-croix de la Légion d'honneur en 1815, il fut chargé d'organiser les gardes nationales

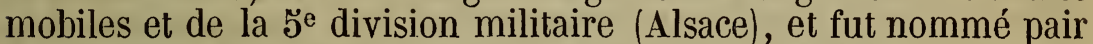
de France. Inspecteur général d'infanterie en 1818, il recut en 1823 le commandement en chef du 2 e corps de' l'armée des Pyrénées, fut nommé commandeur de l'ordre de Saint-Louis, pair et maréchal de France la même année, chevalier de l'ordre du Saint-Esprit en 1827, et membre du conseil supérieur de la guerre en 1828. Le maréchal Molitor fut envoyé en 1831 à Marseille, où il eut le commandement supérieur des $8^{\mathrm{e}}$ et $9^{\mathrm{e}}$ divisions militaires. Il mourut en 1849.

Il est représenté en pied.

\section{Maison (Nicolas-Joseph, marquis).}

Par M. Léon Cogniet. - H. 2,14. - L. 1,40.

Né à Épinay suus Saint-Denis le 19 décembre 1771. Capitaine au 9e bataillon des fédérés nationaux en 1792, il fit les campagnes de 1792 à 1796 aux armées du Nord et de Sambre-et-Meuse. Chef de bataillon en 1796, il servit en Italie en 1797 ; employé à la divison du général Bernadotte en 1798 et 1799, il servit à l'armée du Rhin. Employé en 1800 et 1801 aux armées de Hollande et de l'Ouest, il fit les campagnes de 1804 et 1805 dans le Hanovre et en Allemagne. Général de brigade en 1806 il commanda la même année une brigade au $1^{\mathrm{er}}$ corps de la grande armée, et fut chef d'état-major de ce corps en 1807. Commandant une brigade d'infanterie au $1^{\text {er }}$ corps de l'armée d'Espagne en 1808, il fit à la fin de cette année la campagne de la Péninsule. Il servit en 1809 à l'armée de réserve en Allemagne, et à l'armée d'Anvers devenue armée du Nord, passa dans l'année 1810 au corps d'observation en Hollande, fut employé en 1811 à la $6^{\mathrm{e}}$ division du corps d'observation de l'Elbe, et en 1812 à la division du $2^{\text {e }}$ corps de la grande armée, et fit en Russie la campagne de 1812. Général de division en 1812, il fut chargé en 1813 du commandement de la $l^{\text {re }}$ division du corps d'observation de l'Elbe $/ 5^{\mathrm{e}}$ corps de la grande 
armée), fut créé comte au mois d'août de la même année, et fit la campagne de Saxe. Il recut ensuite le commandement en chef du 1 er corps d'armée (armée du Nord) et fit la campagrie de 1814 en France. Chevalier de Saint-Louis, pair de France, grand-croix de la Légion d'honneur, gouverneur et commandant de la $1^{\text {re }}$ division militaire en 1814, il eut en 1815 le commandement en chef $d u 1^{\text {er }}$ corps d'armée. Il fut en 1816 gouverneur de la $8^{\mathrm{e}}$ division militaire, marquis en 1817, grand-croix de l'ordre de Saint-Louis, ministre d'Etat en 1818, et appelé de nouveau en 1819 au commandement de la $1^{\text {re }}$ division militaire. Il reçut en 1828 le commandement en chef de la division d'expédition en Morée, fit la campagne de Grèce et fut nommé maréchal de France en 1829. Le marquis Maison, ministre secrétaire d'Etat au département des affaires étrangères en 1830, fut-ambassadeur en Russie en 1833, et ministre secrétaire d'Etat au département de la guerre en 183ă. Il mourut à Paris le 13 février 1840 .

ll est représenté en pied.

\section{Duperré (Victor-Guy, baron).}

Par M. CourT. - H. 2,14. - L. 1,40.

Né à La Rochelle le 20 février 1775. Pilotin à bord du Henri IV, (navire du commerce) en 1791, il fit un voyage dans linde. Second chef de timonnerie sur la corvette le Marie-Guiton en 1793, il passa la même année sur la frégate le Turtu. Enseigne de vaisseau en 1795, il montait la frégate la Virginie en 1796. Commandant la corvette la Pélagie en 1800, il fut chargé de diverses missions sur les côtes d'Afriçue et aux Antilles. Lieutenant de vaisseau en 1802 et attaché comme adjudant à létat-major de la flottille de Boulogne, il fit partie de l'état-major du vaisseau le Vétéran et fit une campagne dans les mers du cap de BonneEspérance, au Brésil et aux Antilles. Capitaine de frégate en 1806, il eut le commandement de la Sirène et fut chargé d'une nouvelle mission aux Antilles. Capitaine de vaisseau en 1808, il prit le commandement de la frégate la Bellone, et fit une campagne à l'Ile-de-France en 1809 et 1810. Chevalier de la Légion d'honneur en 1810, il fut créé la même année baron de l'Empire et commandant de l'ordre de la Légion dhonneur. Contre-amiral en 1811, il fut chargé du commandement de l'escadre légère de l'armée navale de la Méditerranée, sous les ordres du vice-amiral Emeriau, et recut ensuite le commandement des forces navales françaises et italiennes réunies dans l'Adriatique, où il servit jusqu'en 1814. Chevalier de Saint-Louis en 1814, préfet maritime à Toulon en 181.̌, il commanda en 1818 la station navale des Antilles. Grand officier de la Légion dhonneur en 1820, il reçut 
TREIZIÈME SALLE DES MARÉCHAUX, No 57.

en 1823 le commandement de l'armée navale et fit la campagne de 1823 en Espagne. Nommé vice-amiral en 1823, il fut en 1824 commandeur de l'ordre de Saint-Louis. Appelé en 1826 au commandement en chef des forces navales réunies dans les Antilles, il fit dans cette année une campagne au Mexique, et fut préfet maritime à Brest de 1827 à 1830 . Il commanda en chef la flottille dans l'expédition d'Alger. Pair et amiral de France en 1830, il fut président du conseil d'amirauté et ministre secrétaire d'Etat de la marine et des colonies depuis 1834 jusqu'en 1836 , et de nouveau en 1840. Il mourut en 1846 .

Il est représenté en pied.

\section{TREIZIÈME SALLE DES MARÉCHAUX, № 57.}

Cette salle et les suivantes formaient un appartement habité, sous Louis XIV, par le marquis d'O, sous Louis XV par le duc de Penthièvre, puis par $\mathrm{IIme}^{\mathrm{e}}$ de Pompadour, et sous I ouis XVI par Madame Aclelaïde. Cette salle était la chambre à coucher de $M^{\text {me }}$ de Pompadour.

La suite chronologique des maréchaux de France depuis Josepl-Antoine, prince Poniatowski (1813), jusqu'à Guillaume, vicomie Dode de la Brunerie (1847), est représtntée par des écussons ou par des portraits en buste.

\section{Hohenlohe (Louis-Aloys-Joseph-Joachim-Fran- cois-Xaxier-Antoine de), prince de Hohen- lohe-Waldenbourg-Bartenstein.}

Par M. Rouget. - H. 0,71. - L. 0,55.

Né le 18 août 1763 . Il succéda en 1798 à son père, qui lui avait résigné la régence de la principauté de Hohenlohe. En 1816, il entra au service de France avec le grade de lieutenant général des armées du roi, fut colonel supérieur de la légion de Hohenlohe, inspecteur général d'infanterie et chevalier de l'ordre du Saint-Esprit. Chevalier de la Légion d'honneur en 1820, officier du même ordre et grand-croix de Saint-Louis en 1823, il commanda en chef la même année le $3^{\text {e }}$ corps' de l'armée des Pyrénées et fit la campagne d'Espagne. Commandant supérieur du camp de Lunéville en 1824, il fut nommé maréchal de France en 1827 et pair de France en 1828. Il mourut à Paris le 31 mai 1829.

\section{Gérard (Maurice Étienne, comte).}

Par M. LARIVIÈRe. - H. 2,15. - L. 1,40.

Né à Damvilliers (Meuse), le 4 avril 1773. Volontaire au $2 \mathrm{e}$ bataillon de la Meuse en 1791, sergent-major en 1792, il servit à l'armée d'Allemagne en 1792 et 1793, et fut employé à l'armée de Sambre-et-Meuse en 1794, 1795 et 1796. Capitaine en 1797 et 
aide de camp du général Bernadotte, il fit à l'armée ditalie les campagnes de 1797, de 1798, fut nommé chef d'escadron en 1799, et incorporé au $9 \mathrm{e}$ de hussards. Chef de brigade en 1800, adjudantcommandant et premier aide de camp du général Bernardotte en $1800 ّ$, il fit en cette qualité la campagne d'Allemagne de cette année. Général de brigade en 1806, il fit les campagnes de 1809 en Autriche. Baron en 1810, il fut employé la même année à l'armée d'Espagne, où il fit les campagnes de 1810 et 1811. Appelé au $1^{\mathrm{er}}$ corps de la grande armée en 1812 , il fit la campagne de Russie, fut nommé général de division en 1812 et servit en 1813 dans la campagne de Saxe. Il commanda le $11^{\mathrm{e}}$ corps de la grande armée, fut créé comte en 1813, commanda d'abord en 1814 le corps des réserves de Paris et ensuite le $2^{\mathrm{e}}$ corps de la grande armée, et fit la campagne de France. Chevalier de Saint-Louis en 1814, il fut la même année grand-croix de la Légion d'honneur. Général en chef de l'armée de la Moselle en 1815, il reçut la même année le commandement supérieur des $3^{\mathrm{e}}$ et $4^{\mathrm{e}}$ divisions militaires et fit la campagne des Pays-Bas. Ministre de la guerre en 1830, il fut nommé maréchal de France la même année, commanda en chef, dans l'année 1830, l'armée du Nord qui fit ell 1831 le siége d'Anvers, et fut pair de France cette dernière année. Appelé de nouveau en 1834 au ministère de la guerre, avec la présidence du conseil, le maréchal Gérard fut grand chancelier de la Légion d'honneur en 1835 et commandant supérieur des gardes nationales du département de la Seine en 1838. Il mourut le 17 avril 1852 .

Il est représenté en pied.

\section{Clausel (Bertrand, comte).}

Par M. Champuartin. - H. 2,15. - L. 1,40.

Né à Mirepoix (Arriège) le 12 décembre 1772. Sous-lieutenant au régiment royal des vaisseaux $\left(43^{\mathrm{e}}\right)$ en 1791, capitaine dans la légion nationale des Pyrénées en 1792, il servit en 1792, 1793 et 1794 à l'armée des Pyrénées-Orientales. Chef de bataillon adjudant général en 1794, chef de brigade adjudant général en 1795ั, il fut attaché à l'ambassade de France en Espagne. Employé à l'armée d'Angleterre en 1798, il servit la même année à l'armée d'Italie où il fit la campagne de 1798 et de 1799, et fut nommé général de brigade cette dernière année. Employé à l'armée de Saint-Domingue, il y servit en 1801 et 1802. Général de division en 1802, il fit partie de l'armée du Nord en 180弓̆, et dans l'annèe 1806 il servit d'abord en Hollande et ensuite dans l'armée d'Italie. Employé dans l'armée de Dalmatie en 1808, il passa en 1809 au $11^{\mathrm{e}}$ corps de l'armée d'Allemagne et commença à la 
grande armée la campagne de 1809. Commandant en chef du corps d'armée qui prit possession des provinces illyriennes, il rejoignit en Espagne, encore dans la même année, le $8^{\mathrm{e}}$ corps de l'armée et fit ensuite partie de l'armée du Portugal. Il fit en Portugal les campagnes de 1810 à 1812. Général en chef de l'armée de Portugal en 1812, il fut créé comte en 1813. Il commanda en 1813 d'abord l'armée du Nord et ensuite l'aile gauche de la grande armée en Espagne, et fit les campagnes de 1813 et 1814 en Espagne. Chevalier de Saint-Louis en 1814, il fut inspecteur de la $12^{\text {e }}$ division militaire en 1814. Gouverneur provisoire de la $11^{\mathrm{e}}$ division militaire (Basses-Pyrénées, Landes et Gironde), commandant en chef le corps des Pyrénées-Orientales, et commandant supérieur des $11^{\mathrm{e}}$ et $20^{\mathrm{e}}$ divisions militaires en 1815 , il fit en France la campagne de 1815. Appelé au commandement en chef de l'armée d'Afrique en 1830, il fut nommé maréchal de France en 1831 et gouverneur général des possessions françaises dans le nord de l'Afrique de 1835̆à 1837. Il mourutle 21 avril 1842.

Il est représenté en pied.

\section{Lobau (Georges Mouton, comte de).}

Par Ary SCHEFFER. - H. 2,15. - L. 1,40.

Né à Phalsbourg (Meurthe) le 21 février 1770. Soldat au 9 e bataillon de la Meurthe en 1792, lieutenant et capitaine la même année, il fit la campagne de $\mathbf{1 7 9 2}$ aux armées du Centre et de la Moselle. Aide de camp du général Meynier en 1793, il fit la campagne de 1793 aux armées de la Moselle et des Vosges, celle de 1794 et de 1795 à celle du Rhin, et fut employé à l'armée d'Italie en 1796. Chef de bataillon en 1797, il continua à servir en Italie en 1797 et 1798, et fut employé en 1804 et 1805 sur les côtes de la Méditerranée. Général de brigade et aide de camp de l'empereur Napoléon en 1805, il fit à la grande armée la campagne d'Allemagne de 1805 , celles de 1806 et 1807 en Prusse et en Pologne. Général de division en 1807, il commanda la division d'observation des Pyrénées, fit en 1808 la campagne d'Espagne, celle d'Autriche en 1809, recut le titre de comte cette dernière année et celui de comte de Lobau en 1810. Grand officier de la Légion d'honneur en 1811, aide de camp de l'Empereur et aide-major général de l'infanterie en 1812 , aide-major de la garde impériale en 1813 , il commandait en chef le $1^{\text {er }}$ corps de la grande armée en 1813 , et fut employé pendant les années 1812,1813 et $1815^{\circ}$ à la grande armée et à l'armée du Nord. Il commanda en $1815^{\circ}$ la $1^{\text {re }}$ division militaire et le $6^{\mathrm{e}}$ corps d'observation. Grand-croix de|la Légion d'honneur en 1830, il fut nommé en 1831 maréchal de France puis commandant supérieur des gardes nationales de la 
354 TREIZIÈME SALLE DES MARÉCHAUX, No 57 .

Seine et pair de France en 1833. Il mourut à Paris le 27 novembre 1838.

Il est représenté en pied.

\section{Truguet (Laurent-Jean-Francois, comte).}

Par Paulin Guerin. - H. 2,15. - L. 1,39.

Né à Toulon le 10 janvier 1752 . Garde-marine en 1765 , gardepavillon en 1769 et enseigne de vaisseau en 1773, il fit la campagne d'Amérique en 1778 et 1779 , et fut nommé lieutenant de vaisseau. Chevalier de Saint-Louis en 1780, il continua de servir en Amérique sous le comte d'Estaing jusqu'en 1783. Commandant de la corvette le Tarleton en 1784, il fit partie de l'ambassade du comte de Chóiseul-Gouffier à Constantinople comme chargé de diverses opérations scientifiques. Capitaine de vaisseau et contre-amiral en 1792, il commanda les forces navales dans la Méditerranée. Vice-amiral en 1794, il fut ministre de là marine de $179 \partial$ à 1797 , et ambassadeur en Espagne cette dernière année. Conseiller d'Etat en 1799, il reçut en 1802 le commandement des forces navales de France et d'Espagne réunies à Cadix, et fut grand officier de la Légion d'honneur en 1803. Appelé en 1809 au commandement de l'escadre de Rochefort, et en 1810 à l'administration maritime de la Hollánde, il remplit ces dernières fonctions depuis 1810 jusqu'en 1813. Grand-croix de la Légion d'honneur et comte en 1814, il fut préfet du $3^{\mathrm{e}}$ arrondissement maritime en 1815, commandeur de l'ordre de Saint-Louis en 1816, grand-croix du même ordre en 1818 et pair de France en 1819. Amiral en 1831, il mourut à Paris le 26 décembre 1839.

II est représenté en pied.

\section{Grouchy (Emmanuel, marquis de).}

Par RoumLaRd. - H. 2,15. - L. 1,39.

Nó à Paris le 23 octobre 1766. Elève d'artillerie à l'école de Strasbourg en 1782, lieutenant d'artillerie en 1783 , capitaine en 1784, il fut lieutenant-colonel et sous-lieutenant des gardes du corps du roi en 1786. Colonel en 1792, maréchal de camp la même année, il fit la campagne de 1792 et 1793 à l'armée du midi, et celle de 1793 sur les côtes de Cherbourg et de Brest. Général de division, chef d'état-major général de l'armée de l'Ouest en 1795 et de celle du Nord en 1796 , il commanda cette dernière année dans l'île de Rhé, fut employé en 1798 aux armées d'Angleterre et de Mayence, servit en 1799 el 1800 en Italie, et en 1801 à l'armée du Rhin. Inspecteur général de cavalerie en 1801, il fut employé en 1803 au camp de Bayonne, puis de Brest en 1804, et à celui d'Utrecht. Attaché au $2^{\mathrm{e}}$ corps de la 
TREIZIĖME SALLE DES MARÉCHAUX, No 57.

grande armée en 1805, il y fit en 1806 et 1807 les campagnes de Prusse et de Pologne. Inspecteur général de cavalerie de la $1^{\mathrm{re}}$ division militaire, il fut grand-croix de la Légion d'honneur en 1807, et servit la même année dans le corps d'observation des côtes de l'Océan. D'abord gouverneur de Madrid en 1808, et ensuite commandant de l'armée d'Espagne, il fut employé la même année en Italie. Nommé comte et colonel général des chasseurs en 1809, commandeur de l'ordre de la Couronne de Fer en 1811, il recul le commandement du $3^{\mathrm{e}}$ corps de cavalerie de la réserve en 1812 et fit la campagne de Russie. Il commanda en chef la cavalerie de la grande armée en 1813, fit la campagne de Saxe en 1813, et celle de France en 1814. Inspecteur général des chasseurs et chevau-légers lanciers en 1814, il fut nommé commandeur de l'ordre de Saint-Louis en 1810ั. Commandant supérieur des $7^{\mathrm{e}}$ et $19^{\mathrm{e}}$ divisions militaires en 1815 , il fut la même année général en chef du $7^{\mathrm{e}}$ corps d'observation (grande armée); nommé maréchal de l'Empire (nomination annulée par l'ordonnance du $1^{\text {er }}$ août 181 ) $)$, il commanda en chef la cavalerie et eut ensuite le commandement de l'armée du Nord; il fit la campagne des Pays-Bas en 1810ّ. Maréchal de France en 1831, le marquis de Grouchy fut pair de France en 1832, et mourut en 1847.

Il est représenté en pied.

\section{Valée (Sylvain-Charles, comte).}

Par M. Court en 1838. - H. 2,15. - L. 1,30.

Né à Briennie-le-Château le 17 décembre 1773. Elève souslieutenant à l'école d'artillerie de Châlons en 1792, il fit la campagne de 1793 à l'armée de la Moselle, fut lieutenant d'artillerie en 1793, capitaine en 1795 , et fit les campagnes de 1794 à 1802 , aux armées de Sambre-et-Mleuse, du Danube et du Rhin. Chef d'escadron en 1802, major au Ler régiment d'artillerie à pied et inspecteur général du train d'artillerie à l'armée des côtes de l'Océan en 1804, il servit à cette armée en 1803 et 1804. Lieutenant-colonel cette dernière année, il passa à la grande armée en 1805, fut sous-chef d'état-major général d'artillerie en 1806 , colonel en 1807, et continua de servir à la grande armée en 1806 et 1807. Officier de la Légion d'honneur en 1808, il fut employé en Espagne la même année, devint général de brigade en 1809, et continua de servir en Espagne de 1809 à 1811, Créé baron et général de division d'artillerie en 1811, il servit à l'armée d'Aragon en 1812 et 1813, à l'armée de Lyon en 1814, et fut créé comte la même année. Inspecteur général d'artillerie à Strasbourg, chevalier de l'ordre de Saint-Louis et commandeur de la Légion d'honneur en 1814, grand-officier en 1815, il 
commanda l'artillerie dans la 5̆e division militaire (Bas-Rhin) et recut le commandement en second de l'artillerie de Vincennes en 1815̆. Directeur du dépôt central de l'artillerie en 1820, inspecteur général du service central de l'artillerie et grand-croix de la Légion d'honneur en 1822, commandeur de l'ordre royal et militaire de Saint-Louis en 1827, membre du conseil supérieur de la guerre en 1823, il fut nommé pair de France en janvier 1830. Directeur du service des poudres et salpêtres en 1830̆, commandant en chef de l'artillerie dans la province de Bone et celle du siége de Constantine, il fut nommé le 11 novembre 1837, maréchal de France et gouverneur général des possessions françaises en Afrique, et mourut en 1846.

Il est représenté en pied.

\section{Sébastiani (François-Horace, comte).}

Par M. F. WinterhaLter en 1841. - H. 2,15. - L. 1,39.

Né à la Porta (Corse), le 10 novembre 1772. Lieutenant au $1 \mathrm{e}^{\mathrm{e}}$ d'infanterie légère en 1793 , capitaine au 9 e régiment de dragons en $179 \ddot{3}$, chef d'escadron en 1797 , chef de brigade en 1799 , il servit activement et fit toutes les campagnes de l'armée d'Italie depuis 1793 jusqu'à 1801. Général de brigade en 1803, il fut chargé de l'inspection des côtes de la Manche. Employé à la $1^{\text {re }}$ division de dragons en 1804, il fit la campagne de 180 à à la grande armée en Allemagne, à la $2^{\mathrm{e}}$ division de dragons, et fut nommé général de division à la fin de 180 ö. Il commanda le camp d'Utrecht en 1806, fut ambassadeur de Turquie dans les années 1806 et $180 \overline{7}$, et nommé grand officier et grand cordon de la Légion d'honneur cette dernière année. Il organisa en 1808 la division qui se forma à Paris pour faire partie du $4^{\mathrm{e}}$ corps de l'armée d'Espagne; ayant été appelé au commandement en chef du $4^{\mathrm{e}}$ corps d'infanterie légère, il fit en Espagne les campagnes de 1809,1810 et 1811 , et fut créé comte cette dernière année. Commandant en chef du camp de Boulogne au commencement de 1812, il fut nommé cette année commandant en chef du $2^{\mathrm{e}}$ corps de cavalerie, et il fit à la grande armée la campagne de 1812 en Russie. Commandant en chef le כ̌ corps d'armée d'infanterie en 1813, et commandant en chef de la garde impériale en 1814, il fit en Saxe la campagne de 1813 et en France celle de 1814. Membre de la chambre des représentants en 1815, le général Sébastiani fut ensuite membre de la chambre des députés depuis 1819 jusqu'en 1824 , et de 1826 à 1830. Il fut successivement en 1830 ministre des affaires étrangères, et en 1831, ministre de la guerre par intérim, et ministre sans portefeuille ayant voix au conseil en 1833, puis fut de nouveau la mème an- 
TREIZIẺME SALLE DES MARÉCHAUX, No 57.

née chargé de l'intérim du ministère de la guerre. Ambassadeur de France en Angleterre depuis 1835 jusqu'en 1839, il fut nommé maréchal de France le 21 octobre 1840 . Il mourut à Paris le 20 juillet $185 \% 1$.

Il est représenté en pied.

\section{Roussin (Albin-Reine, baron).}

Par M. LARIVIÈre. - H. 2,15. - L. 1,39.

Né à Dijon le 21 avril 1781. Mousse en 1793, matelot-timonier en 1794, il fit une campagne en Norwège, une à SaintDomingue et diverses croisières dans les mers d'Europe. Aspirant de $1^{\text {re }}$ classe en 1800 , il fut employé en 1801 dans l'escadre sous les ordres du contre-amiral La Touche-Tréville, d'abord comme second sur le bateau-canonnier le Mars, et ensuite en qualité de commandant du bateau-canonnier le Mentor, dans la même division. Il fit la campagne de 1802 à la Martinique sur la frégate la Torche, d'où il passa à la fin de la même année sur la frégate la Sémillante, pour faire la campagne dans l'Inde. Enseigne de vaisseau en 1803 , il se trouva à tous les combats soutenus par la frégate la Surveillante dans les mers de l'Inde dans les années 1804, 1805 et 1808. Lieutenant de vaisseau en 1808, il servit comme second sur l'Iéna, chargé d'établir une croisière dans le golfe Persique et celui du Bengale. Embarqué en 1810 comme second capitaine sur la frégate la Minerve, il était aux combats du Grand-Port et de l'Ile de France et fut nommé capitaine de vaisseau et chevalier de la Légion d'honneur à la fin de cette campagne. Appelé au commandement de la frégate la Gloire en 1811, il fit à la fin de 1812 et au commencement de 1813 une croisière de soixante-treize jours dans l'Océan et dans la Méditerranée. Capitaine de vaisseau et chevalier de l'ordre de Saint-Louis en 1814, il fut chargé en 1816 de l'exploration hydrographique des côtes occidentales d'Afrique, reçut en 1819 la mission d'explorer les côtes du Brésil, et fut nommé baron et officier de la Légion d'honneur en 1820; il recut en 1821 le commandement de la frégate l'Amazone et de la station navale sur les côtes de l'Amérique méridionale. Contre-amiral en 1822, il recut au mois de juin 1824 le commandement d'une division de l'escadre d'évolution sous les ordres du vice-amiral Duperré. Appelé à Paris au conseil d'amirauté en 1824, il fut commandeur' de l'ordre de la Légion d'honneur en 1825, et reçut en 1828 le commandement d'une escadre de neuf bâtiments de guerre chargée de protéger les intérêts du commerce francais au Brésil. Gentihomme honoraire de la chambre du roi en 1828 , il fit de nouveau partie du conseil d'amirauté en 1829, et fut nommé 
commandeur de l'ordre de Saint-Louis. En 1830, d'abord menbre du conseil d'amirauté et directeur du personnel de la marine, il fut ensuite préfet maritime à Brest. Grand-officier de la Légion d'honneur en 1831, il commanda en chef l'expédition dirigée contre Lisbonne. Pair de France en 1832, il fut nommé la même année ambassadeur à Constantinople, et en 1836 grand-croix de la Légion d'honneur. Ministre secrétaire d'Etat de la marine et des colonies en 1840, il fut créé amiral le 30 octobre de la même annnée.

Il est représenté en pied.

\section{Drouet (Jean-Baptiste), comte d'Erlon.}

Par M. LARIVIERE. - H. 2,15. - L. 1,40.

Né à Reims le 29 juillet 1765 . Soldat au régiment de Beaujolais en 1782, il quitta le service en 1787. Caporal au bataillon des chasseurs de Reims en 1792, capitaine en 1793, aide de camp du général Lefebvre, puis capitaine dans la $13^{\mathrm{e}}$ demi brigade en 1794, et fut chef de bataillon en 1795 , et fit les campagnes de 1792 à 1795. Employé comme adjudant général à l'armée de Sambre-et-Meuse en 1798, puis la même année à celle d'Angleterre ; il passa ensuite à celle de Nayence. Général de brigade en 1799, il fut mis en activité et employé dans la $1^{\text {re }}$ division en 1801, et servit au camp de Nimègue et à l'armée de Hanovre en 1802. Général de division en 1803, il fut employé à la $1^{\text {re }}$ division du $1^{\text {er }}$ corps de la grande armée en 1805ั. Chef d'état-major du $10^{\mathrm{e}}$ corps de la grande armée, puis du corps de réserve en 1807 , il reçut le commandement de la $1^{\text {re }}$ division en 1808, fut chef de l'état-major de l'armée bavaroise en 1809, et commanda successivement la division d'arrière-garde (armée d'Espagne) et les autres corps de la même armée de 1810 à 1813 . Commandant la $16^{\mathrm{e}}$ division militaire en 1814 , chevalier de l'ordre de Saint-Louis et grand-croix de la Légion d'honneur la même année, il fut à la tête du 1 er corps d'observation en 1815 . Admis au traitement de réforme en 1825, il était en 1836 doyen des lieutenants généraux. Le comte d'Erlon, nommé maréchal de France le 9 avril 1843, mourut à Paris le 20 janvier 1844.

Il est représenté en pied.

\section{Bugeaud de la Piconnerie (Thomas-Robert), duc d'Isly.}

Par M. LARIVIÈE - H. 2,15. - L. 1,40.

Né à Limoges le 15 octobre 1784. Vélite aux grenadiers à pied de la garde impériale en 1804 et caporal en 1805 , il servit dans 
l'armée des côtes. Sous-lieutenant, puis lieutenant au $64^{\mathrm{e}}$ régiment de ligne en 1806, il servit dans la grande armée en $\mathbf{1 8 0 6}$ et 1807 . Lieutenant au $116^{\mathrm{e}}$ régiment de ligne en 1808 , capitaine en 1809, chef de bataillon et chevalier de la Légion d'honneur en 1811, major au $14^{\mathrm{e}}$ régiment de ligne en 1814, il servit en Espagne de 1808 à 1814. Colonel ąu $14^{\mathrm{e}}$ régiment de ligne en 1814, il fut chevalier de l'ordre de Saint-Louis la même année, officier, puis commandeur de la Légion d'honneur et employé à l'armée des Alpes en 1815. Colonel du 56 e régiment de ligne en 1830, il fut nommé maréchal de camp en 1831 et commanda une des brigades d'infanterie de la garnison de Paris de 1832. Il recut en 1833 le commandement supérieur de la ville et du château de Blaye et commanda une des brigades d'infanterie de la garnison de Paris de 1833 à 1836. Appelé en 1836 au commandement des troupes dẻ l'expédition d'Oran, il fut la même année nommé lieutenant général, commandant de la division active d'Oran, inspecteur général des troupes d'infanterie sous son commandement, et grand officier de la Légion d'honneur en 1837. Commandant la $4^{\mathrm{e}}$ division d'infanterie du corps de rassemblement sur la frontière du Nord en 1839, il était en 1840 membre du comité de l'infanterie et de la cavalerie. Gouverneur gėnéral de l'Algérie en 1840, il servit en Afrique en 1841 et 1842 , et fut nommé maréchal de France le 31 juillet 1843. Nommé duc d'Isly après sa victoire sur les troupes marocaines en 1844, il mourut à Paris en 1849.

Il est représenté en pied.

\section{Reille (Honoré-Charles-Michel-Joseph, comte).}

Par M. LARIVIERE. - H. 2,15. - L. 1,40.

Né à Antibes (Var) le $1^{\text {er }}$ septembre 1775 , il entra comme grenadier au $2^{\mathrm{e}}$ bataillon du Var en 1791 , et fut sous-lieutenant au $94^{\text {e }}$ régiment d'infanterie en 1792 ; lieutenant en 1793 , capitaine et aide de camp du général Masséna en 1796, chef d'escadron au $15^{e}$ régiment de dragons en 1797, adjudant général en 1799, il fut employé aux armées d'Italie, d'Helvétie et du Midi. Employé près des troupes stationnées dans la république italienne en 1802, il fut général de brigade en 1803, servit au camp de Bruges, à l'état-major de l'armée des côtes de l'Océan, et fut membre de la Légion d'honneur. Général de division en 1806, chef du $5^{\mathrm{e}}$ corps d'état-major de la grande armée et aide de camp de l'Empereur ell 1807 , il reçut la décoration de la Couronne de Fer. Créé comte de l'Empire en 1808, il commanda deux divisions de l'armée du Nord en 1809, fut gouverneur de la Navarre en 1810 , 
et commanda en chef les corps de l'Ebre en Espagne et en Portugal en 1812. Grand-croix de l'ordre de la Réunion en 1813, il commanda l'aile droite de l'armée d'Espagne sous le maréchal Soult. Chevalier de Saint-Louis, inspecteur général des $14^{\mathrm{e}}$ et $1 \mathrm{\jmath}^{\mathrm{e}}$ divisions militaires et grand officier de la Légion d'honneur en 1814, il commanda le $2^{\text {e }}$ corps de l'armée du Nord en 1815 . Pair de France en 1819, membre du conseil supérieur de ia guerre en 1836, le comte Reille a été promu à la dignité de maréchal de France le 17 septembre 1847.

Il est représenté en pied.

\section{Dode de la Brunerie (Guillaume, vicomte).}

Par M. Larivière. - H. 2,15. - L. 1,40.

Né le 30 avril 1775 à Saint-Geoire (Isère), il entra au service en 1794 comme élève sous-lieutenant à l'école du génie à Metz.

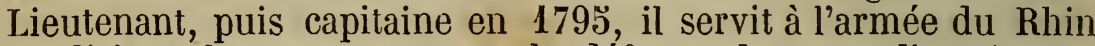
et dirigea les travaux pour la défense du pont d'Huningue. Nommé chef de bataillon par le général en chef de l'armée d 0 rient en 1800, il fut employé au camp de Boulogne et fut membre de la Légion d'honneur en 1804. Colonel en 1805, il se trouva au combat d'Hollabrünn, fit les campagnes de Prusse et de Pologne, assista au combat de Saarfeld, à la bataille d'Iéna, au combat d'Ostrolenka, et fut nommé officier de la Légion d'honneur en 1807. Général de brigade en 1809, il servit en Espagne et fit la campagne de Russie en 1812. Chevalier de Saint-Louis, commandeur de la Légion d'honneur et lieutenant général en 1814, il fut un des quatre inspecteurs généraux du génie en 1816. Commandant en chef du génie à l'armée des Pyrénées en 1823, il fut grand officier de la Légion d'honneur, pair de France, et reçut le titre de vicomte en 1825. Membre du conseil supérieur de la guerre en 1828, président du comité des fortifications et grand croix de la Légion d'honneur en 1840, il fut promu à la dignité de maréchal de France le 17 septembre 1847, et mourut en 1851 .

Il est représenté en pied.

\section{Mackau (Ange-René-Armand, baron de).}

Par M. Lariviére. - H. 2,15. - L. 1,40.

Né à Paris le 19 février 1788, il entra au service en $180 \mathrm{~s}$ en qualité de novice matelot. A la suite de deux campagnes, l'une sur le Vétéran, commandé par le prince Jérôme, l'autre sur la frégate l'Hortense, il fut nommé en 1808 aspirant de $1^{\text {re }}$ classe et servit comme sous-adjudant sous le contre-amiral Baudin. Embarqué en 1810 sur le brick l'Abeille, il commandait provi- 
soirement ce bâtiment, lorsqu'il rencontra le 26 mai 1811 le brick anglais l'Alacrity, dont il s'empara, et fut nommé lieutenant de vaisseau et membre de la Légion d'honneur. Capitaine de frégate en 1812, il fut appelé au commandement supérieur de la flottille chargée de la protection de la navigation sur les côtes de Toscane. En 1816, il s'embarqua comme second sur la frégate l'Eurydice, avec laquelle, dans une campagne de vingt-six mois, il visita les mers du Nord, les Antilles, le port de New-York et Terre-Neuve. Nommé en 1818 au commandement de la corvette le Golo, il fut chargé de travaux hydrographiques et de recueillir des renseignements sur les nouveaux états de l'Amérique méridionale et sur Saint-Domingue. Capitaine de vaisseau en 1819 , il fut chargé pour le Sénégal d'une mission relative à la colonisation de ce pays; en 1821, il fut appelé au commandement de la Clorinde, destinée à tenir station dans l'Océan pacifique, et recut l'ordre en 1823 de se rendre avec une division navale devant Saint-Domingue, à l'effet de faire accepter au gouvernement haïtien l'ordonnance d'affranchissement. Promu à son retour au grade de contre-amiral, le baron de Mackau prit de 1820 à 1830 ine part considérable aux travaux du département de la marine, soit comme président de commission, soit comme inspecteur général, soit comme directeur du personnel. En 1833, il fut appelé au commandement de la division navale chargée d'établir le blocus des ports de la Hollande, fut ensuite nommé au commandement de la station des Antilles, et força le gouvernement de la Nouvelle-Grenade à réparer une insulte faite au consul de France. Commandant en chef des forces navales aux Antilles et gouverneur de la Martinique en 1836, vice-amiral en 1837, il fut appelé en 1840 au commandement en chef d'une force navale de quarante-trois bâtiments de guerre, et, comme agent plénipotentiaire dans le Rio de la Plata, il conclut un traité avec le gouvernement de la Confédération argentine. Ministre de la marine de 1843 à 1847, il fut nommé amiral de France le 23 décembre 1847, et mourut à Paris le 13 mai 18505.

Il est représenté en pied. Ce portrait a été exposé au Salon de 1853.

\section{QUATORZIÈME SALLE DES MARÉCHAUX, No 58.}

Dépendance de l'appartement du marquis d'O, sous Louis XIV, cabinet du duc de Penthièvre, puis de $M^{\text {me }}$ de Pompadour sous Lonis $X V$, et dépendance de l'appartement de $\mathrm{M}^{\text {me }}$ Adélaïde sous Louis XVI.

1184. Exelmans (Remy-Joseph-Isidore, comte).

Par M. Lariviêre. - H. 2,15. - L. 1,40.

Né à Bar-sur-Ornain (Meuse) le 13 novembre 1775. Il entra 
au service comme volontaire dans le $3^{\text {e }}$ bataillon de la Meuse en 1791, fut sergent dans la compagnie de canonniers en 1792 et servit à l'armée de la Moselle en 1792 et 1793, et à l'armée de Sambre-et-Meuse de 1794 à 1796. Sous-lieutenant en 1796 , lieutenant en 1798, il fut nommé aide de camp du général Eblé et l'accompagna en Italie. Capitaine provisoire au $16^{\mathrm{e}}$ régiment de dragons en 1799, il fut nommé par le général en chef de l'armée d'Italie aide de camp du général Broussier, fut confirmé dans son grade de capitaine en 1800, et devint en 1801 aide de camp de Murat, qui commandait en chef le corps d'observation du Midi. Chef d'escadron en 1803, membre de la Légion d'honneur en 1804, il fit les campagnes d'Autriche, de Prusse et de Pologne, et fut en 180כّ officier de la Légion d'honneur et colonel du 1er régiment de chasseurs à cheval. Général de brigade en 1807 , il passa en Espagne en 1808, fut fait prisonnier de guerre, puis se rendit à la cour du roi de Naples, qui le nomma grand maréchal du palais. De retour en France en 1811, il fut major des chasseurs à cheval, puis des grenadiers de la garde; général de division et baron de l'Empire en 1812, il fit la campagne de Russie. Appelé au commandement d'une division de cavalerie légère au $2^{\mathrm{e}}$ corps de cavalerie en 1813, il fut grand officier de la Légion d'honneur la même année et fit la campagne de France. Il fut en 1814 inspecteur général de cavalerie dans la $1^{\text {re }}$ division militaire et chevalier de Saint-Louis. Pair de France en 1815, il commanda une division de cavalerie dans le $2^{\mathrm{e}}$ corps à l'armée du nord et détruisit une avant-garde prussienne près de Versailles. Admis comme disponible dans le corps de l'état-major général en 1819, il fut en 1828 inspecteur général de cavalerie. Grand-croix de la Légion d'honneur en 1830, pair de France en 1831, grand chancelier de la Légion d'honneur en 1849, maréchal de France le 10 mars $180 \% 1$, le comte Exelmans mourut à Saint-Cloud en 1852.

\section{Harispe (Jean-Isidore, comte).}

Par M. RICARD. - H. 2,15. - L. 1,40.

Né le 7 décembre 1768 à Saint-Étienne-de-Baygorry (BassesPyrénées). Capitaine commandant une compagnie franche du département des Basses-Pyrénées en 1792, il défendit la vallée de Baygorry contre les espagnols et fut blessé à la prise du camp d'Espéguy en 1793. Chef de brigade en 1794, il servit dans les armées des Pyrénées-Orientales, dans la $11^{\mathrm{e}}$ division militaire, à l'armée de réserve et à l'armée d'Italie, commanda la $16^{\mathrm{e}}$ demibrigade d'infanterie légère en 1802, fut blessé à la bataille d'Iéna en 1806 et devint général de brigade en 1807. Chef d'état-major 
du corps d'observation des côtes de l'Océan en 1807, puis du $3^{\mathrm{e}}$ corps de l'armée d'Espagne en 1808, il fut blessé à la bataille de Saragosse en 1809 et fut nommé général de division en 1810. Grand officier de la Légion d'honneur en 1811, créé comte de l'Empire en 1813, il continua à servir en Espagne et fut blessé à la bataille de Toulouse en 1814. Chevalier de Saint-Louis en 1814, il reçut le commandement de la $11^{\mathrm{e}}$ division militaire. En 1815 il commanda la $26^{\text {e }}$ division d'infanterie du corps d'observation des Pyrénées et fut admis à la retraite en 1824. Commandant supérieur des Hautes et Basses-Pyrénées en 1830, grandcroix de la Légion d'honneur en 1833, il fut membre de la chambre des députés de 1831 à 1834. Maréchal de France le 11 décembre 185\% , il mourut au château de la Carre, près Bayonne, le 26 mai 185 ว.

\section{Vaillant (Jean-Baptiste-Philibert).}

Par M. Émile Bin en 1853. - H. 2,11. - L. 1,40.

Né à Dijon, le 6 décembre 1790, il entra à l'École polytechnique et futélève sous-lieutenant du génie en 1809. Lieutenant en premier au bataillon de sapeurs détaché à Dantzick en 1811, il passa à l'étatmajor la même année et fut capitaine en second au bataillon de sapeurs à l'armée de Russie en 1812. Aide de camp du général Haxo en 1813, il fut fait prisonnier à l'affaire de Kulm. Rentré à la paix en 1814, il fut employé en 1815 aux travaux de défense de Paris, se trouva au combat de Gilly, à la bataille de Ligny et à Waterloo. Capitaine de $1^{\text {re }}$ classe en 1816 , chevalier de SaintLouis en 1825, il fut chef de bataillon en 1826, prit part à l'expédition d'Alger en 1830 et eut une jambe cassée au siége du fort l'Empereur. Lieutenant-colonel en 1831, il se trouva au siége de la citadelle d'Anvers, fut nommé colonel puis chef d'état-major du génie à l'armée du Nord en 1833 . Colonel commandant le 2 e régiment du génie en 1834, directeur des fortifications à Alger en en 1837, maréchal de camp en 1838, il fut directeur supérieur des fortifications et commandant des troupes du génie en Afrique. Commandant de l'École polytechnique en 1839, directeur des travaux des fortifications en 1840 , membre adjoint du comité des fortifications en 1841, il fut lieutenant général en 1845 et inspecteur des $4^{\mathrm{e}}$ et $5^{\mathrm{e}}$ arrondissements du génie en 1846 et 1847. Président du comité des fortifications et inspecteur général du 1 er $\mathrm{ar}-$ rondissement en 1848, il fut en 1850 commandant de l'arme du génie au corps expéditionnaire de la Méditerranée. Maréchal de France le 11 décembre 1851, grand maréchal du Palais en 1852, le maréchal Vaillant a été nommé ministre de la guerre en 1854.

Ce tableau a été exposé au Salon de 1853. 


\section{Magnan (Bernard-Pierre).}

Par M. Larivière en 1853. - H. 2,15. - L. 1,50.

Né à Paris le 7 décembre 1791, il abandonna en 1809 la carrière du notariat pour celle des armes, entra comme enrôlé volontairc au $66^{\circ}$ de ligne, fut sergent en 1810 , sous-lieutenant en 1811, lieutenant en 1813, fit les campagnes d'Espagne et de Portugal de 1810 à 1813 , et fut nommé membre de la Légion d'honneur. Passé dans les tirailleurs de la garde impériale (1 ${ }^{\text {er }}$ régiment) en 1814, il fit les campagnes de France et de Belgique et fut blessé d'un coup de biscaïen à Craonne. Capitaine adjudant-major au $6^{\mathrm{e}}$ régiment d'infanterie de la garde royale en 1815 , il passa en 1817 au $34^{\mathrm{e}}$ de ligne comme chef de bataillon. Offlcier de la Légion d'honneur en 1820 , lieutenant-colonel au $60^{\circ}$ de ligne en 1822, il fit la campagne d'Espagne, fut nommé chevalier de SaintLouis en 182כั, colonel dụ 49e de ligne en 1827 et prit part à l'expédition d'Alger. Envoyéen mission en Belgique en 1832, il y recut le grade de général belge et le commandement d'une brigade, puis d'un corps d'avant-garde de l'armée de Flandre. De retour en France il fut nomme en 1835 maréchal de camp et commandeur de la Légion dhonneur, commanda une brigade du corps d'observation des Pyrénées, puis le département du Nord et devint lieutenant général en 1845ั. En 1846 le général Magnan inspecta les troupes de la division d'Alger et eut en 1847 un arrondissement d'inspection en France. Appelé en 1848 au commandement de la Corse, puis à celui de la $3^{\mathrm{e}}$ division dinfanterie de l'armée des Alpes, il commanda en 1849 la $4^{\mathrm{e}}$ division militaire (Strasbourg), et réunit à ce commandement celui des troupes stationnées dans la $\mathbf{A}^{\text {re }}$ subdivision (Bas-Rhin), et fut nommé grand officier de la Légion d'honneur. Commandant de la $1^{\text {re }}$ division militaire en 1850, maréchal de France, sénateur et grand veneur en 18522, le maréchal Magnan est commandant en chef de l'armée de Paris.

\section{Castellane (Esprit-Victor-Elisabeth-Boniface, comte de).}

Par M. Émile BIN. - H. 2,15. - L. 1,40.

Né à Paris, le 21 mars 1788. Soldat au ร̌e régiment d'infanterie légère en 1804, caporal et sergent en 1805ั, sous-lieutenant au $7 \mathrm{e}$ puis au $24^{\mathrm{e}}$ régiment de dragons en 1806 , lieutenant en 1808 , il fut aide de camp du général Mouton, servit en 1806 et 1807 aux armées de Naples et d'Italie, fit la campagne d'Espagne en 1808 et celle d'Allemagne en 1809 et fut nommé chevalier de l'ordre de la Légion d'honneur en 1809. Capitaine en 1810, il fit 
comme aide de camp du général comte de Narbonne la campagne de Russie et fut nommé chef d'escadron en 1812. Colonel du ${ }^{\text {er }}$ régiment des gardes d'honneur, colonel à la suite du $1^{\text {er }}$ régiment de hussards en 1814, il fit les campagnes de la grande armée en 1813 et 1814. Chevalier de Saint-Louis en 1814, colonel du régiment des hussards du Bas-Rhin en 1810ั, puis du régiment des hussards de la garde royale en 1822, il fut nommé maréchal de camp en 1824. Employé au corps d'armée d'occupation en Espagne, division de Barcelone, il passa à la division de Cadix et servit en Espagne jusqu'en 1827. Commandant la $2 \mathrm{e}$ subdivision de la $21^{\mathrm{e}}$ division militaire (Allier et Nièvre), en 1827, il fut en 1829, inspecteur genéral de cavalerie dans les $9^{\mathrm{e}}, 10^{\mathrm{e}}$, $18^{\mathrm{e}}$ et $21^{\mathrm{e}}$ divisions militaires. Chargé d'une inspection générale extraordinaire en 1830, il commanda en 1831 le département de la Haute-Saône et une brigade de cavalerie à Vesoul. Commandant la $1^{\text {re }}$ brigade de la $2^{\text {e }}$ division d'infanterie de l'armée du Nord en 1832, lieutenant général en 1833, il commanda la division des Pyrénées-Orientales. Inspecteur général d'irıfanterie eı 1834, commandant la $21^{\mathrm{e}}$ division militaire en 1830ั, grand officier de la Légion d'honneur en 1836, il fut mis à la disposition du gouvermeur général des possessions françaises dans le Nord de $l^{\prime}$ Afrique en 1837. Commandant la $21^{\text {e }}$ division militaire et la division active des Pyrénées-Orientales en 1838, il fut inspecteur général des troupes d'infanterie et de cavalerie de 1838 à 1847, commanda la $14^{\mathrm{e}}$ division militaire et fut nommé grand-croix de la Légion d'honneur en 1847. En 1850 il fut appelé au commandement de la $12^{\mathrm{e}}$ division militaire et à exercer en outre le commandement supérieur des $14^{\mathrm{e}}$ et $1 \mathrm{ŏ}^{\mathrm{e}}$ divisions militaires, puis fut nommé commandant de la $6^{\mathrm{e}}$ division militaire et fut chargé en outre du commandement supérieur de la ら̌e division. Commandant en chef de l'armée de Lyon en 18วั1, sénateur et maréchal de France en 18ว22, le maréchal de Castellane a été nommé en 185ั8, commandant de l'armée de Lyon et commandant supérieur des divisions du Sud-Est à Lyon.

\section{Baraguey-d'Hilliers (Achille).}

Par M. LARIVIÈRE, en 185\% - H. 2,15. - L. 1,40.

Né à Paris le 6 septembre 179ă. Il entra au ge régiment de dragons en 1806 et fut élève du Prytanée militaire en 1807. Sous-lieutenant au $2^{\mathrm{e}}$ régiment de chasseurs à cheval en 1812 , il fit la campagne de Russie. Lieutenant en 1813, il fit la campagne d'Allemagne comme aide de camp du duc de Raguse, eut le pois'net gauche emporté par un boulet de canon à la bataille de Leipsick, et fut nommé chevalier de l'ordre de la Légion d'hon- 
neur. En 1814, il obtint le grade de capitaine à la suite du $6^{\mathrm{e}}$ régiment de chasseurs à cheval. Capitaine en second du 2 e régiment de grenadiers à cheral de la garde en 1815 , chef d'escadron de la ligne en 1818, chef de bataillon à la légion du Cher, puis au 9 e régiment d'infanterie de ligne en 1820 , chevalier de Saint-Louis en 1823, major du $2^{\mathrm{e}}$ régiment d'infanterie de la garde en 1825, il servit en Espagne de 1823 à 1820. Chef de bataillon en 1826, il fut lieutenant-colonel du 2 e régiment d'infanterie de ligne en 1827, puis du $1^{\mathrm{er}}$ régiment d'infanterie légère en 1830 , et servit en Afrique. Colonel en 1830, colonel commandant en second l'École militaire de Saint-Cyr en 1833, maréchal de camp en 1836, il fut mis en 1841 à la disposition du gouverneur général de l'Algérie et nommé commandeur de la Légion d'honneur. Commandant la province de Constantine et lieutenant général en 1843, il fut inspecteur général du $21^{\mathrm{e}}$ arrondissement d'infanterie en 1847. En 1848, il commanda la $6^{\text {e }}$ division à Besançon et la 2 division d'infanterie de l'armée des Alpes. Commandant en chef le corps expéditionnaire de la Méditerrannée en 1849, il fut envoyé extraordinaire et ministre plénipotentiaire près du pape. Commandant en chef les troupes de la $1^{\text {re }}$ division militaire et grand-croix de la Légion d'honneur en 18วั1, sénateur en 18วั2, ambassadeur extraordinaire à Constantinople en 180ั3, il commanda le corps expéditionnaire dans la Baltique en 18ă4 et fut nommé maréchal de France. Commandant l'armée du Nord en 185̆5̆, le maréchal Baraguey-d'Hilliers a été nommé en 1850 commandant supérieur des divisions de l'Ouest.

\section{Baudin (Charles).}

Par M. LANDELLE, en 1857。 - H. 2,15. - L. 1,40.

Né à Paris le 21 juillet 1784, il commença à naviguer comme novice sur les bâtiments de l'Etat en 1799, fut aspirant de $1^{\text {re }}$ classe en 1802, enseigne de vaisseau en 1804, lieutenant de vaisseau et chevalier de l'ordre de la Légion d'honneur en 1809, et capitaine de frégate en 1812. Admis à la retraite en 1816, il fut rappelé à l'activité en 1830, et fut nommé capitaine de vaisseau en 1834 . Contre-amiral en 1838, il recut le commandement d'une division navale destinée à bloquer les côtes du Mexique. Vice-amiral en 1839, il eut en 1840 le commandement en chef des forces navales dans les mer's de l'Amérique du Sud. Préfet maritime à Toulon en 1841 , il fut en 1847 président de la commission supérieure chargée d'examiner les travaux des différentes commissions relatifs à l'ordonnance de 1827 sur le service de la mer, puis membre de la commission mixte des travaux et membre du conseil d'amirauté. Commandant en chef des forces navales de la Méditerranée 
QUATORZIẺME SALLE DES MARÉCHAUX, No $\mathrm{N}^{\circ} 5$.

en 1848, inspecteur général des équipages de ligne, de l'artillerie et de la gendarmerie maritime dans les ports de Eherbourg et de Brest en 1850, il fut en $\mathbf{1 8 5 2}$ inspecteur général dans les arrondissements de Rochefort et de Toulon, puis président du conseil des travaux. Grand-croix de la Légion d’honneur en 1853, amiral le 27 mai 185̌4, il mourut à Paris le 7 juin suivant.

\section{Parceval-Deschesnes (Alexandre-Ferdinand).}

Par M. LARIVIÈRE, en 1855. - H. 2,15. - L. 1,40.

Né à Paris le 27 novembre 1790, il servit comme marin de 1804. à 1805, fut aspirant de $2^{\circ}$ classe de 1807 à 1811 , et enseigne de vaisseau en 1811. Lieutenant de vaisseau en 1819, chevalier de l'ordre de la Légion d'honneur en 1822, il fut capitaine de frégate en 1827 et chevalier de Saint-Louis en 1828. Capitaine de vaisseau de $2^{\mathrm{e}}$ classe en 1833 , contre-amiral et major général de la marine à Toulon en 1840 , préfet maritime à Cherbourg en 1841, il recut en 1843 le commandement de l'escadre de la Méditerranée. Vice-amiral en 1846, il fut en 1847 président d'une commission chargée d'examiner diverses propositions relatives à une nouvelle organisation du corps royal de la marine, puis membre de la commission mixte des travaux publics et préfet maritime à Toulon. Commandant de l'escadre de la Méditerranée en 1849, il fut membre du conseil d'amirauté et président du conseil des travaux en 1851 . Membre du sénat en $185 \% 1$, il recut en $185{ }^{4}$ le commandement en chef de la $3^{\mathrm{e}}$ escadre, se trouva au bombardement de Bomarsund et fut nommé amiral le 2 décembre $185 \%$. L'amiral Perseval-Deschesnes a été nommé en 18555 président de la commission de constitution de la flotte à vapeur.

\section{Hamelin (Ferdinand-Alphonse).}

Par M. Eug. Giraud, en 1856. - H. 2,15. - L. 1,40.

Né le 2 septembre 1796 à Pont-l'Evêque (Calvados), il servit comme marin dans les mers de l'Inde de 1806 à 1808, fut aspirant et enseigne provisoire de 1808 à 1812, enseigne de vaisseau en 1812, et fit partie de l'escadre de l'Escaut. Lieutenant de vaisseau et chevalier de l'ordre de la Légion d'honneur en 1821, il fit en 1823, comme sous-adjudant du contre-amiral Hamelin, une croisière sur les côtes d'Espagne, et fut nommé chevalier de Saint-Louis en 182ว et capitaine de frégate en 1828. Capitaine de vaisseau de $2^{\mathrm{e}}$ classe en 1836 , et de $1^{\text {re }}$ classe en 1841 , contreamiral et major général de la marine à Toulon en 1842 , il fut nommé en 1844 commandant de la station de l'Océan pacifique. Vice-amiral,imembre du conseil de perfectionnement de l'École 
polytechnique et inspecteur général à Toulon et à Rochefort en 1848, il fut en 1849 membre de la commission des phares, de la commission mixte des travaux publies, du conseil d'amirauté, el préfet maritime à Toulon. Nommé en 1853 commandant en chef de l'escadre d'évolution, il reçut ie commandement de l'escadre à Besika, se trouva au bombädement de Sébastopol le 17 octobre $180 ั 4$, et fut nommé amiral le 2 décembre suivant. Membre du sénat et ministre de la marine en $185 \%$, l'amiral Hamelin a été nommé grand-croix de la Légion d'homneur en 1856 .

\section{Bruat (Armand-Joseph).}

Par M. Eug. Ginaud, en 1856. - H. 2,15. - L. 1,40.

Né à Colmar le 26 mai 1796, il fut élève à l'École spéciale de Brest de 1811 à 1815 . Aspirant de $1^{\text {re }}$ classe en 1815 , élève de $1^{\text {re }}$ classe en 1816, enseigne de vaisseau en 1819, lieutenant de vaisseau et chevalier de la Légion d'honneur en 1827, il commanda le brick|le Silène à Alger en 1830, fit naufrag'e sur les côtes d'Alger et fut fait prisonnier de guerre. Capitaine de corvette en 1831, capitaine de vaisseau de 2 e classe en 1838 et de $1^{\text {re }}$ classe en 1845, il fut gouverneur des îles Marquises, puis des établissements français de l'Océanie, contre-amiral en 1846, et grand officier de la Légion d'honneur en 1847. Préfet maritime à Toulon, gouverneur de la Martinique et commandant de la station navale des Antilles et du golfe de Mexique en 1848, gouverneur général des Antilles en 1849, il fut vice-amiral et membre du conseil d'amirauté en 1852. Hembre de la commission mixte des travaux publics en 1853, il recut le commandement en chef de l'escadre d'évolution de l'Océan, fut en $185 \%$ commandant en second, sous les ordres du vice-amiral Hamelin, des forces maritimes dans la Mer Noire, prit part au bombardement de Sébastopol et recut le commandement en chef de l'escadre de la Méditerranée. Ảmiral le 15 septembre 1855 , il mourut à la mer le 19 novembre suivant.

\section{SALLE DES GUERRIERS CÉLÈBRES, No 59.}

Salon de l'escalier du roi ou des ambassadeurs sous Louis XIV, et salle des gardes de la prévôté de l'hôtel sous Louis XV. Cette pièce fut ensuite çoupée en deux pour servir de première et de deuxième antichambre à l'appartement de $\mathrm{M}^{\text {me }}$ de Pompadour, puis à celui de $\mathrm{M}^{\text {me }}$ Adelaïde sous Louis XVI.

\section{Philippe de France (Monsieur), duc d'Orléans.} (Voir $\left.\mathrm{n}^{\circ} 817.\right)$

par II. NAIGEON, - H. 0,71. - L. 0,53. 


\section{Du Quesne (Abraham, marquis), lieutenant général des armées navales.}

Par Graincourt, - H. 0,71. - L. 0,53.

Né à Dieppe en 1610 , Du Quesne commandait un vaisseau dans la flotte qui, après avoir battu celle des Espagnols, le 15 mai 1637, les chassa des îles de Lérins. Lors de la guerre contre les Espagnols, il fit partie de l'expédition de la Corogne en 1639, se trouva au combat de Tarragone en 1641 età celui du cap de Gates en 1643 . Il prit ensuite du service en Suède dans l'année 1644, et devint vice-amiral de la flotte suédoise. En 16500, Du Quesne arma à ses frais une escadre pour faire des courses contre les Espagnols, et fut alors nommé chef d'escadre par la reine régente Anne d'Autriche. Il fut le chef le plus redoutable de la marine française dans la guerre de 1671 à 1678 , combattit le 30 mai 1673 les flottes hollandaises sous les ordres des amiraux Ruyter et Tromp, et gagna la bataille navale de Messine en 1675 . Il commandait la flotte qui combattit le 8 janvier 1676 celle des Hollandais près de. l'île de Stromboli, et ravitailla Messine. Il livra le 22 avril de la même année le combat naval d'Auğusta en Sicile, où l'amiral Ruyter fut blessé à mort. Du Quesne commanda deux fois le bonbardement d'Alger, et forca les Barbaresques à demander la paix, ce fut aussi lui qui fit bombarder Gênes en 1684. Il mourut à Paris le 2 février 1688.

Cette peinture et la suivante décoraient autrefois l'Hôtel de la Marine, à Versailles.

\section{Bart (Jean), chef d'escadre.}

Par Graincourt. - H. 0,71. - L. 0,53.

Né à Dunkerque le 20 octobre 1650 , il servit d'abord comıne mousse dans la marine militaire de la Hollande, et fut embarqué sur le bâtiment que commandait Ruyter, sous lequel il fit plúsieurs campagnes. La guerre ayant éclaté en 1670 entre la France et la Hollande, Jean Bart revint à Dunkerque, fit alors plusieurs courses en mer et enleva en $\mathbf{1 6 7 5}$, à la hauteur du Texel, une corvette de guerre de dix-huit canons et de soixante-cing hommes d'équipage. Il commandait en 1676 le corsaire la Royale, et s'empara d'un grand nombre de bâtiments hollandais et espagnols. Ayant été appelé vers 1678 au service de la marine royale, il fut nommé capitaine de vaisseau, commanda les frégates la Vipère el la Serpente, fit la campagne de 1692, se trouva en 1693 sous les ordres de Tourville, et détruisit six bâtiments à la hauteur du cap Faro. Nommé chef d'escadre en 1697, et chargé de conduire le prince de Conty en Pologne, ce fut dans cette dernière campagne qu'il mourut le 27 avril 1702. 


\section{Vendôme (Louis-Joseph, duc de).}

Par M. MURaT. - H. 2,75. - L. 2,01.

Fils aîné de Louis, duc de Vendôme, petit-fils de Henri IV, né å Paris le 1 er juillet 16ö4. Il porta d'abord le nom de due de Penthièvre, et prit ensuite le titre de duc de Vendôme à la mort de son père, en 1669. Colonel du régiment d'infanterie de Vendôme cette même année, il servit comme volontaire du roi en Hollande en 1672, et fit toutes les campagnes jusqu'en 1676. Brigadier d'infanterie en 1677, il était la même année à la prise de Cambrai. Maréchal de camp en 1678, il se trouva à la prise d'Ypres, fut gouverneur de Provence en 1681 et combattit au siége de Luxembourg en 1684. Lieutenant général des armées du roi et chevalier des Ordres en 1688, il fut employé à l'armée de Flandre en 1691 et 1692, à celle d'Italie en 1693 et 1694. Général des galères en 1694, il commanda en chef l'armée de Catalogne dans les années 169y̆, 1696 et 1697, et prit la ville de Barcelone après avoir battu une nombreuse armée espagnole, succès qui amenèrent la paix de Riswyck. Général de l'armée d'Italie en 1702, il la commanda jusqu'en 1706, et inspira la plus grande confiance à Philippe V, qui, après la bataille de Luzzara, lui donna l'ordre de la Toison d'or. Le duc de Vendôme fut ensuite envoyé en Flandre en 1708 pour remplacer Villeroy. Appelé par Philippe V en Espagne en 1710, il rétablit ce monarque dans sa capitale et gagna sur Stahremberg la bataille de Villaviciosa : cette victoire lui valut le titre d'infant d'Espagne. Il mourut à Vignaroz, dans le royaume de Valence, le 11 juin 1712.

Il est représenté à cheval.

\section{Duguay-Trouin (René), lieutenant général des armées navales.}

Par Graincourt. - H. 0,71. - L. 0,53.

Né à Saint-Malo le 10 juin 1673 , il entra de bonne heure dans la marine et fit sa première campagne en 1689 comme volontaire, sur le vaisseau la Trinité. Son père, qui était armateur à SaintMalo, lui donna en 1691 le commandement d'une frégate de quatorze canons qu'il avait armée à ses frais, et en 1692 celui d'une frégate de dix-huit canons, avec lesquelles lejeune Duguay-Trouin fit plusieurs prises sur les Anglais et les Hollandais. S'étant emparé en 169 du vaisseau de guerre le Sans-Pareil, de cinquante canons, Louis XIV lui fit présent d'une épée, et après plusieurs campagnes sur mer dans les années 169วั et 1696, Duguay-Trouin entra dans la marine royale en 1701, et fut nommé capitaine de frégate. Capitaine en second dans l'année 1702, sur un vaisseau 
SALLE DES GUERRIERS CÉLĖBREs, N 59.

commande par le comte de Hautefort, il fit sur mer les campagnes de 1702 à 1703 . Nommé capitaine de vaisseau en 1706, chevalier de Saint-Louis en 1707, il recut des lettres de noblesse en 1709, et s'empara de Rio-Janeiro en 1711. Chef d'escadre en 1715, membre du conseil des Indes en 1723, commandeur de l'ordre de SaintLouis et lieutenant général des armées navales en 1728, il reçut en 1731 le commandement d'une escadre dans le Levant. DuguayTrouin mourut à Paris le 27 septembre 1736.

Cette peinture décorait autrefois l'Hôtel de la Marine à Versailles.

\section{Chevert (Francois de), lieutenant général des armées du Roi.}

Par M. LARIVIÊRE. - H. 2,07. - L. 1,25.

Né à Verdun, le 21 février $\mathbf{1 6 9 5}$, il servit d'abord dans le régiment d'infanterie de Carné en 1706. Sous-lieutenant en 1710, il se trouva en $\mathbf{1 7 1 1}$ à l'attaque d'Arleux, fut nommé lieutenant et fit en 1712 la campagne de Flandre. Aide-major en 1719, capitaine en 1721, major en 1728, il était aux siéges de Trèves et de Philipsbourg en 1734, et à l'affaire de Clausen en 1735. Lieutenantcolonel en 1739, il fit la campagne de 1741 en Bohême, se trouva à la prise de Prague et commanda cette place en 1742. Brigadier dans le Dauphiné en 1743, employé à l'armée d'Italie sous les ordres du prince de Conty en 1744, nommé, la même année, maréchal de camp, il servit de nouveau à l'armée d'Italie en $\mathbf{1 7 4 5}$, 1746 et 1747. Lieutenant général des armées du roi en 1748, commandeur de l'ordre de Saint-Louis en 1754 , il commanda le camp de Sarrelouis jusqu'en 1756, fit la campagne de 1757 dans le Hanovre, et se trouva à la bataille d'Hastembeck. Grand-croix de l'ordre de Saint-Louis en 1758 , il fut employé, la même année, à l'armée d'Allemagne, à celles de Flandre en 1760 et du Bas-Rhin en 1761. Gouverneur de Charlemont et de Givet cette dernière année, il mourut à Paris le 24 janvier 1769.

Il est représenté en pied.

\section{Conty (Louis-Francois de Bourbon, prince de).}

Par P. Franque. - H. 0,71. - L. 0,53.

Fils de Louis-Armand de Bourbon, prince de Conty, né à Paris le 13 août 1717. Il porta d'abord le nom de comte de la Marche jusqu'à la mort de son père, en 1727, et fut marié en 1732 à Louise-Diane d'Orléans (Mademoiselle de Chartres), fille du régent. Chevalier des Ordres du roi en 1733 , il fut la même année colonel d'un régiment de cavalerie, et fit sa première campagne au siége de Kehl. Lieutenant général des armées du roi en $\mathbf{1 7 3 5}$, 
il fit la campagne de 1742 et 1743 en Bavière, celle de 1744 en Italie, et se trouva à la bataille de Coni. Nommé général de l'armée du Bas-Rhin en 1745, il commanda en chef celle sur les froniières de l'Allemagne en $\mathbf{1 7 4 6}$ et s'empara de Mons, de SaintGuilhain et de Charleroi. Grand prieur de France en 1749, gouverneur du château d'Alais et du pays des Cévennes en 1751, le prince de Conty se retira au Temple et y mourut le 2 juillet 1776.

\section{Suffren (Pierre-André de Suffren-Saint- Tropez, dit le bailli de), bailli de l'ordre de Malte, vice-amiral.}

Par M. LATiL. - H. 0.74. - L. 0,52.

Né le 13 juillet 1726, garde-marine en 1743 , enseigne en 1748 , il fit plusieurs campagnes sur mer. Après le traité de paix de 1748 , il se rendit à Malte, où il entra dans l'Ordre, et servit activement jusqu en $175 \%$. Nommé lieutenant de vaisseau en 1750 , il se trouva à la prise de Nahon en 1757; capitaine de frégate en 1767, il se rendit de nouveau à Malte en 1768 et continua ses caravanes contre les Bar'baresques. Commandeur de l'ordre de Malte et capitaine de vaisseau en 1772, il fit successivement plusieurs campagnes sur mer, et se trouva en $\mathbf{1 7 7 9}$, pendant la guerre de lindépendance d'Amérique, au combat de l'île de la Grenade. Chef d'escadre en 1781, il livra le combat de Praya, fit ensuite les campagnes de l'Inde, et se couvrit de gloire dans les combats de Negapatnam en 1782, de Gondelour en 1783. Nommé chevalier des Ordres du Roi et vice-amiral en 1784, il fut commandant en chef en 1787. Le bailli de Suffren mourut à Paris le 8 décembre 1788.

\section{Du Teil (Jean-Pierre, baron), lieutenant général des armées du roi.}

M. A. de JAUBert. - H. 2,07. - L. 1,25.

Fẻ en 1722 à La Côte-Saint-André (Dauphiné), il entra en 1731 en qualité de cadet dans le corps royal d'artillerie, fut lieutenant en 1735, servit successivement en Ttalie, en Flandre et en Allemagne, et devint capitaine et chevalier de Saint-Louis. Colonel du régiment d’artillerie de La Fère en 1776, maréchal de camp en 1784, il commanda l'école d'artillerie et la ville d'Auxonne. Lieutenant général des armées du roi et inspecteur général d'artillerie en 1791, il fut arrèté à Grenoble en 1793, conduit à Lyon, condamné à mort par une commission révolutionnaire, et fusillé le 22 février 1794. - L'empereur Napoléon, qui avait servi sous ses ordres, l'a constaté en ces termes dans un article de son testament 
SALLE DES GUERRIERS CÉLĖBRES, No 59.

du 24 février 1821: "Nous léguons aux fils ou petits-fils du baron Du Teil, lieutenant général d'artillerie, ancien seigneur de Saint-André, qui a commandé l'école d'Auxonne avant la révolulion, la somme de cent mille francs, comme souvenir de reconnaissance pour les soins que ce brave général a pris de nous lorsque nous servions comme lieutenant et capilaine sous ses ordres. »

\section{La Fayette (Marie-Joseph-Paul-Yves-Roch- Gilbert Mottier, marquis de). (Voir no 650.)}

Par M. H. ScheFFer. - H. 2,27. - L. 1,27.

\section{Dumouriez (Charles-François), général en chef de l'armée du Nord.}

Par Rodillarid. - H. 2,07. - L. 1,27.

Né à Cambrai le 6 janvier 1739. Cornette au régiment de Pentthièvre-cavalerie, il fit les campagnes d'Allemagne de 1758 à 1761, fut nommé capitaine en $\mathbf{1 7 6 1}$ et réformé en $\mathbf{1 7 6 3}$. Il reprit du ser-' vice en 1768, servit en Corse et obtint successivement les grades d'aide-major général, d'aide-maréchal général des logis et de mestre de camp de cavalerie. Après avoir fait la campagne de Pologne ell 1770 et 1771, il fut attaché comme colonel à la légion de Lorraine en 1772, fut commandant de Cherbourg en 1778, aide-major général des logis de l'armée en Bretagne et en Normandie en 1779, brigadier en 1781, maréchal de camp en 1788. Lieutenant général en 1792, il commanda en chef les armées du Nord et de la Belgique, fut ministre des afiaires étrangères et de la guerre, et remporta les victoires de Jemmapes et de Valmy. Il sortit de France en 1793, se retira en Russie, puis en Angleterre, et mourut à Henley le 14 mars 1823.

\section{Biron (Armand-Louis de Gontaut, duc de), général en chef de l'armée du Rhin.}

Par Mile Revest, d'après M. Rouget. - H. 0,71. - L. 0,52.

Né le 15 avril 1747 , il fut d'abord connu sous le nom de due de Lauzun. Deuxième enseigne aux gardes françaises, puis enseigne et sous-lieutenant en 1761, il fut successivement lieutenant ell 1764, aide-major en 1766, capitaine en 1767, colonel de la légion royale en 1774, mestre de camp du régiment Royal-dragons en 1776, colonel et inspecteur du corps des volontaires étrangers de la marine en 1778. Brigadier en 1783, il passa la même année en Amérique, où il fit l'avant-garde de Rochambeau et forma l'investissement de Glocester en Virginie. Maréchal de camp en 1783, 
commandant d'une brigade de cavalerie dans les Evêchés en 1788, lieutenant général en 1792, il commanda en chef l'armée du Rhin la même année, puis l'armée des côtes de La Rochelle l'année suivante. Il avait été député à l'assemblée nationale constituante en 1789, et périt sur l'échafaud le 31 décembre 1793.

\section{Custine (Adam-Philippe, comte de), général en chef des armées du Rhin et du Nord.}

Par Mile PriLippaln. - H. 0,71. - L. 0,52.

Né à Metz le 4 février 1742. Lieutenant au régiment de SaintChamand, il fit, à peine âgé de sept ans, la campagne de Maëstricht en Flandre. Il reprit du service en 1758 en qualité de lieutenant en second au régiment du roi, et fut lieutenant en 1759. Capitaine au régiment de Schomberg en 1761, il fit les campagnes de la guerre d'Allemagne de 1757 à 1762 , et fut mestre de camp d'un régiment de son nom en 1763. Brigadier, puis mestre de camp commandant du régiment de Saintonge en 1780, il passa en Amérique, se trouva au siége d'York-Town, et obtint en 1782, à son retour en France, le gouvernement de Toulon. Inspecteur divisionnaire des troupes à cheval en Flandre en 1788, il fut lieutenant général en 1791, commanda en 1792 la force armée dans le département du Haut-Rhin, puis la 5e division et l'armée de la Moselle. En 1793, il eut successivement le commandement en chef des armées du Rhin, de Rhin-et-Moselle, du Nord et des Ardennes. Condamné à mort par le tribunal révolutionnaire, il mourut sur l'échafaud le 28 aoùt 1793.

\section{Dampierre (Auguste-Marie-Henri Picot, comte de), général en chef des armées du Nord.}

Par M. Philippoteadx. - H. 2,07. - L. 1,27.

Né à Paris le 19 août 1756. Enseigne dans les gardes françaises

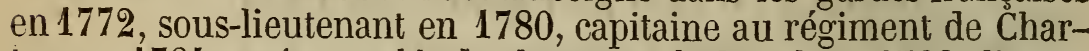
tres en 1784, major au $11^{\mathrm{e}}$ de chasseurs à cheval en 1788, lieutenant colonel au 5e de dragons en 1791, colonel au même régiment, puis maréchal de camp en 1792 et lieutenant général en 1793. Il commanda le centre de l'armée à la bataille de Neerwinde, remplaça Dumouriez dans le commandement en chef de l'armée du Nord, et fut tué le 8 mai 1793 en combattant à la tête d'une de ses colonnes contre les Autrichiens retranchés dans le bois de Vigogne sous Valenciennes.

Il est représenté en pied. Ce tableau à étẻ exécuté d'après un portrait de famille. 
SALLE DES GUERRIERS CÉLÈBRES, № 59 .

1208. Houchard (Jean-Nicolas), général en chef des armées du Rhin et de la Moselle.

Par M. Rouget. - H. 0,71. - L. 0,52.

Né à Forbach (Moselle) en 1739, il entra au service comme volontaire dans le régiment Royal-Allemand-cavalerie en 1755, passa ensuite sous-lieutenant de grenadiers aux volontaires de Hainaut en 1760, devint cornette en 1761, sous-lieutenant de dragons en 1763, lieutenant en 1773, premier lieutenant de chasseurs en 1776, et capitaine en 1779. Capitaine, puis aide de camp du général Custine en 1791, général de brigade en 1792 et général de division en 1793, il remplaça Custine dans le commandement des armées de la Moselle et du Rhin, et remporta la victoire de Hondschootte. Condamné à mort par le tribunal révolutionnaire, il périt sur l'échafaud le 27 octobre 1793.

\section{Dugommier (Jacques-Christophe Coquille), général en chef de l'armée des Pyrénées-Orien- tales.}

Par M. Rouget. - H. 0,71. - L. 0,52.

Né en 1736 à la Basse-Terre (Guadeloupe), il fut cadet à Rochefort en 1753, garçon-major en 1757 , et officier sur les batteries de la marine la même année. Enseigne d'une compagnie d'infanterie à la Martinique en 1758, il fut major des milices du quartier de la Basse-Terre en 1765 . Député à l'assemblée coloniale et maréchal de camp en 1792, il fut employé à l'armée d'Italie en 1793, et commanda en chef l'armée au siége de Toulon. Général en chef commandant l'armée des Pyrénées-Orientales en 1794, il fut tué aux avant - postes de la redoute, sur la Montagne-Noire, près de Saint-Sébastien, le 18 novembre 1794.

\section{Dagobert-Fontenelle (Luc-Simon-Auguste), gé- néral de division.}

Par M. Maurin aîné. - H. 0,71. - L. 0,52.

Né à La Chapelle (Manche) le 8 mars 1736, il fut lieutenant au régiment de Tournaisis-infanterie en 1756, et fit la campagne aux volontaires de Vire en $\mathbf{1 7 5 9}$. Lieutenant-colonel en 1768, incorporé au régiment Royal-Italien en 1775ั, major au même régiment en 1787, il passa avec le même grade au bataillon de sapeurs-royaux du Dauphiné en 1788. Lieutenant-colonel en 1791, colonel du $5 \mathrm{I}^{\mathrm{e}}$ régiment d'infanterie en 1792 , général de brigade, puis de division en 1793, il fut employé aux armées du Rhin et 
des Pyrénées, et eut le commandement de la place de MontLouis. Il mourut à Puycerda en Espagne au mois de mai 1794 .

1211. Aubert Du Bayet (Jean-Baptiste-Annibal), général en chef de l'armée des côtes de Cherbourg.

Par Paulin GUÉRIN. - H. 0,71. - L. 0,52.

Né à la Louisiane le 19 aoùt $175 \overline{7}$, il entra au service avec rang de sous-lieutenant au 13 e régiment d'infanterie ci-devant Bourbonnais en 177 ŏ, fut successivement lieutenant en second en 1780, premier lieutenant en 1783 , capitaine en 178כ̈ et fit la campagne d'Amérique. Député à l'assemblée législative en 1790 , il fut chef de bataillon en 1792, général de brigade en $1793 \mathrm{et}$ employé à l'armée des côtes de La Rochelle. Général de division en 179 s̆, il commanda en chef les troupes destinées pour les IndesOrientales, ainsi que l'armée des côtes de Cherbourg, et fut ministre de la guerre la même année. Nommé ambassadeur près la Porte ottomane en 1796, Aubert du Bayet mourut à Péra le 17 décembre 1797.

1212. Marceau (Francois-Séverin), général cn chef de l'armée de l'Ouest. (Voir no ${ }^{526 .)}$

Par Вочснот. - H. 0,71. - L. 0,52.

\section{Joubert (Barthélemy-Catherine), général en chef de l'armée d'Italie.}

Par Bouchот. - H. 2,07. - L. 1,27.

Né à Pont-de-Vaux (Aisne) le 4 août $\mathbf{1 7 6 9}$, il servit dans le

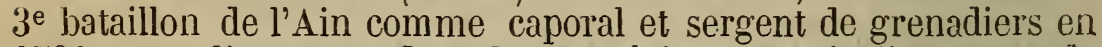
1791. Sous-lieutenant dans le 5ै $1^{\mathrm{e}}$ régiment, puis lieutenant de grenadiers en 1792, il fut chef de bataillon, adjudant général en 1794, chef de brigade de l'armée des Alpes et d'Italie, général de brigade en 1795 et général de division en 1796. Chargé en 1797 du commandement des troupes stationnées en Hollande, du commandement en chef de l'armée de Mayence et de celui de l'armée d'Italie en $\mathbf{1 7 9 8}$, il commanda en chef la $7^{\mathrm{e}}$ division militaire, et les armées d'Italie et des Alpes en 1799. Il fut tué à la bataille de Novi, le 15 août 1799.

11 est réprésenté en pied. 
1214. Hoche (Louis-Lazare), général en chef des armées de l'Ouest et de Sambre-et-Meuse.

Par Ary Schefrer. - H. 2,07. - L. 1,27.

Né à Versailles le 24 juin 1768. Il entra en 1784 dans le régiment des gardes françaises, et fut ensuite caporal, puis sergent dans la garde soldée de Paris en 1789, adjudant au 10\% régiment, puis lieutenant au 58 régiment, et capitaine en 1792. Chef de bataillon, adjudant général à l'armée du Nord, général de brigade, employé à l'armée des Ardennes, général de division et commandant en chef de l'armée de la Moselle en 1793, il commanda l'armée des côtes de Cherbourg en 1794, celles de Brest et de l'Ouest en 1795, celle de l'Océan et les $12^{\mathrm{e}}, 13^{\mathrm{e}}, 14^{\mathrm{e}}$ et $22^{\mathrm{e}}$ divisions militaires en 1796. Général en chef de l'armée de Sambreet-Meuse en 1797, il mourut à Wetzlar le 19 septembre 1797, à l'âge de vingt-neuf ans.

\section{Kléber (Jean-Baptiste), général en chef de l'ar-} mée d'Orient. (Voir $\mathrm{n}^{\circ} 532$. )

Par Ansiaux. - H. 2,49. - L. 1,66.

II est représenté en piecl. Ce tableau est signé : Ansiaux f. 1804.

\section{Desaix (Louis-Charles-Antoine), général de di- vision.}

Par Steuben. - H. 0,71. - L. 0,52.

Né à Ayat (Puy-de-Dôme) le 17 "août 1768, il fut troisième sous-lieutenant dans le $46^{\mathrm{e}}$ régiment d'infanterie (ci-devant Bretagne) en 1783, et sous-lieutenant en 1784. Lieutenant en 1791, capitaine en 1792, il servit à l'armée de Rhin-et-Moselle en 1793 et 1794, et fut nommé par les représentants du peuple près cette armée, général de brigade, puis de division en 1794. Chargé provisoirement par le général Bonaparte du commandement de l'armée d'Angleterre en 1797, il fuî employé aux armées d'Orient et d'Italie, et fut tué à la bataille de Marengo, le 14 juin 1800 .

\section{Leclerc (Charles-Emmanuel), général en chef de l'armée de Saint-Domingue.}

Par KINSON. - H. 2,07. - L. 1,27.

Né à Pontoise le 17 mars 1772 . Lieutenant au $2^{\mathrm{e}}$ bataillon de Seine-et-Oise en 1791, sous-lieutenant au $12^{\mathrm{e}}$ régiment de cavalerie en 1792, il servit au siége de Toulon en 1793, et fut nommé après la prise de cette ville adjudant général chef de bataillon. 
Employé aux armées des Ardennes et des Alpes en 1794, et à l'armée d'Italie en 1796, il fut général de brigade en 1797 et épousa Marie-Pauline Bonaparte (depuis princesse Borghèse). Employé à l'armée d'Angleterre en 1798, général de division en 1799, il commanda la 9 e division militaire et fut employé à l'armée du Rhin. Lieutenant du général en chef de l'armée du Rhin en 1801, il commanda le corps d'observation de la Gironde, et fut nommé commandant en chef de l'armée de Saint-Domingue. Il mourut dans l'île de la Tortue, dans la nuit du $1^{\text {er }}$ au 2 novembre 1802.

\section{Hatry (Jacques-Maurice), général en chef de l'armée de Hollande.}

Par M. de Schwiter. - H. 0,71, - L. 0,54.

Né à Strasbourg le 13 février 1742. Sous-lieutenant dans le régiment de la Marck (infanterie allemande) en 1758, lieutenant en 1767, il fit les campagnes d'Allemagne de 1759 à 1762, et celle de Corse en 1768 et 1769. Capitaine en 1782, il fit la campagne de l'Inde de 1781 à 1785 . Chef de bataillon en 1791, général de division en 1793, il servit aux armées du Rhin et de Sambre-etMeuse, fut général en chef de l'armée de l'intérieur et commanda en chef la $17^{\mathrm{e}}$ division militaire en 1796. Inspecteur à l'armée de Sambre-et-Meuse, puis général en chef de l'armée de Mayence en 1797, il commanda les troupes francaises en Hollande en 1798. Employé à l'armée d'Italie en 1798, il commanda la $15^{\circ}$ division militaire en 1799, fut nommé sénateur en 1800, et mourut le 30 novembre 1802.

\section{Pichegru (Jean-Charles'), général en chef des armées du Nord et de Rhin-et-Moselle,}

Par Steuben. - H. 2,07. - L. 1,91.

Né à Arbois (Jura) en 1761, il entra au 2 e régiment d'artillerie en 1780, fut caporal en 1783, sergent en 1785 , sergent-major en 1789 et adjudant en 1792. Chef du $3^{\mathrm{e}}$ bataillon du Gard en 1792, capitaine au 2e régiment d’artillerie, général de brigade, puis de division en 1793, il commanda en chef la même annẻe les armées du Rhin et du Nord. Il commanda en chef les armées réunies du Rhin et de la Moselle en 1795, se retira du service l'année suivante, et fut élu membre, puis président du Conseil des Anciens en 1797. Déporté à la suite de la journée du 18 fructidor, il fut arrêté le 28 février 1804, comme prévenu de conspiration contre les jours du premier consul, et s'étrangla dans sa prison le 6 avril suivant. 
SALLE DES GUERRIERS CÉLĖBRES, No 59.

\section{Moreau (Jean-Victor), général en chef de l'ar- mée du Rhin.}

Par M. BARbier-WALbONNE.- H. 2,07. - L. 1,91.

Né à Morlaix (Finistère) en 1764, il suivit d'abord la carrière judiciaire et était prévôt de droit à Rennes en 1787. Chef du $\mathbf{1}^{\mathrm{er}}$ bataillon des volontaires d'Ille-et-Vilaine en 1791, il servit d'abord sous Dumouriez. Général de brigade en 1794, il fut employé à l'armée du Nord, et fut nommé la même année général de division et commandant en chef de l'armée du Nord. Général en chef de l'armée de Rhin-et-Moselle en 1796, il remporta en Allemagne plusieurs victoires sur l'archiduc Charles, et fit une savante retraite sur le Rhin. Général des armées d'Italie et de Naples en 1798, général en chef de l'armée du Rhin en 1799, il fit une nouvelle campagne en Allemagne et battit les Autrichiens à Hohenlinden en 1800. Mis en non-activité en 1801, il fut arrêté en 1804 comme impliqué dans une conspiration contre les jours du premier consul et fut condamné à deux années d'emprisonnement, peine qui fut convertie en celle de l'exportation. Conduit à Cadix, il s'embarqua de là pour les Etats-Unis, où il resta jusqu'en 1813. Moreau entra alors au service de la Russie; il fut blessé mortellement à peu de distance de l'empereur Alexandre, au commencement de la bataille de Dresde, et mourut à Lahn, en Bohême, dans la nuit du $\mathbf{1}^{\text {er }}$ au 2 septembre 1813.

\section{Du Teil (Jean, chevalier), lieutenant général.}

Par M. MASSY. - H. 0,71. - L. 0,55.

Né au château de Pommier-lès-Saint-Andrẻ le 7 juillet 1738, il entra comme surnuméraire dans le corps royal de l'artillerie en 1747, parvint au grade de lieutenant-colonel en 1785, après avoir fait les campagnes de 1747 en Flandre, de 1758 à 1762 à l'armée du Bas-Rhin, et de 1779 sur mer, et reçut la croix de Saint-Louis. Colonel en 1791, maréchal de camp en 1792, général de division en 1793, il servit au siége de Toulon et à l'armée des Alpes. Commandant de la place de Metz en 1800, membre de la Légion d'honneur, puis commandant de l'ordre en 1804, il obtint sa retraite en 1813, et mourut à Ancy-sur-Moselle, le 25 avril 1820.

\section{Beauharnais (Eugène de), vice-roi d'Italie.}

Par M. H. SGHEFFER. - H. 2,55. - L. $2,00$.

Né à Paris le 4 septembre 1781, il était fils d'Alexandre, vicomte de Beauharnais, général en chef de l'armée du Rhin, et 
fut connu, après le second mariage de sa mère avec Napoléon Bonaparte, sous les noms d'Éugène Napoléon et de Prince Eugène. Il entra au service comme sous-lieutenant au $1^{\text {er }}$ régiment de hussards en 1797, fut aide de camp du général Bonaparte, et l'accompagna en Italie et en Egypte. Capitaine des chasseurs à cheval de la garde consulaire en 1799, il se trouva à la bataille de Marengo. Colonel en 1802, membre de la Légion d'honneur en 1803, l'empereur le nomma en 1804 général de brigade, colonel général des chasseurs, commandant de la Légion d'honueur, et l'éleva à la dignité de prince français. Archichancelier d'Etat de

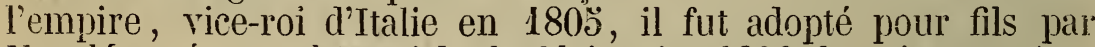
Napoléon, épousa à Munich, le 14 janvier 1806, la princesse Auguste-Amélie, fille de Maximilien-Joseph, roi de Bavière, eut le titre de prince de Venise, et fut désigné par Napoléon pour lui succéder à la couronne d'Italie. Le prince Eugène commanda le centre de la grande armée à la bataille de Wagram en 1809, et fui déclaré en 1810 successeur du prince-primat, comme grand-due de Francfort. Il commanda le 4 e corps de l'armée en 1812 , lors de la campagne de Russie, et prit le commandement génélal à Posen

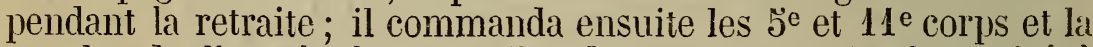
gauche de l'armée à la bataille de Lutzen en 1813. Retiré à Munich en 1814, il reçut du roi de Bavière le duché de Leuchtemberg et le titre de prince d'Eichstadt. Il mourut à Leuchtemberg le 21 février 1824.

Il est représenté à cheval.

\section{Lasalle (Antoine-Louis-Charles, comte de), gé- néral de division.}

Par M. BOYER, d'après Gros. - H. 2,48. - L. 1,72.

Né à Metz le 10 mai 1775 , il entra à l'âge de onze ans dans le régiment d'Alsace comme sous-lieutenant de remplacement. Souslieutenant dans le 24.e régiment de cavalerie en 1791, maréchal des logis au 23e régiment de chasseurs à cheval en 1794, lieutenant en 1795, il fit les campagnes de 1792 à 1795 à l'armée du Nord. Aide de camp du général Kellermann en 1795 , il le suivit en Italie, fut capitaine en 1796, chef d'escadron au $\mathbf{7}^{\mathrm{e}}$ de hussards en 1797, passa à l'armée d'Orient, et fut nommé chef de brigade au 22e de chasseurs après la bataille des Pyramides. Chef de brigade au $10^{\mathrm{e}}$ de hussards en 1800 , il fit la campagne d'Italie et fut nommé commandant de l'ordre de la Légion d'honneur en 1804. Général de brigade en 1805, général de division en 1806, chargé du commandement des régiments de cavalerie légère de la réserve en 1807, il fut attaché à la grande armée et fit les campagnes de Prusse et d'Espagne. Grand officier de la Légion d'honneur et 
comte de l'Empire en 1808 , il fut tué par un boulet à la lyataille de Wagram le 6 juillet 1809 .

\section{Junot (Jean-Andoche), duc d'Abrantès, général en chef de l'armée de Portugal.}

Par M. Raverat. - H. 2,07. - L. 1,31.

Né à Bussy-le-Grand (Côte-d'Or), le 2à septembre 1771. Grenadier au $2^{\mathrm{e}}$ bataillon de la Côte-d'Or en 1791, sergent en 1792, il servit la même année à l'armée du Nord. Sous-lieutenant adjudant à l'état-major de l'artillerie en 1793, il fut après le siége de 'Toulon aide de camp du général Bonaparte en 1794, capitaine au $1^{\text {er }}$ régiment de hussards en 1795 , chef de brigade en 1796, et fit les campagnes de 1795 à 1798 à l'armée d'Italie. Général de brigade à l'armée d'Orient en 1799, il fut chargé du commandement de la place de Paris en 1800 ; général de division en 1801, grand aigle et grand officier de l'Empire en 1804, il commanda le corps des grenadiers de la réserve et fut colonel général des hussards. Ambassadeur en Portugal en $\mathbf{1 8 0 5}$, il eut le gouvernement général des états de Parme et de Plaisance, fut en 1806 gouverneur général de Paris, et commanda la $1^{\text {re }}$ division militaire. Général en chef commandant le corps d'observation de la Gironde en 1807, il fut successivement chargé du commandement de l'armée de réserve en Allemagne, de celui du $8^{\mathrm{e}}$ corps de l'armée d'Espagne et fut nommé duc d'Abrantès, gouverneur général de Portugal en 1808. Après avoir fait la campagne de Pussie, il fut nommé gouverneur de Venise, puis commandant des Provinces Illyriennes, et mourut le 29 juillet 1813.

\section{La Touche-Tréville (Louis-Réné-Madeleine Levassor de), vice-amiral. (Voir $\mathrm{n}^{\circ} 651$.)}

Par Paulin GUérin. - H. 0,71. - L. 0,54.

\section{Villaret de Joyeuse (Louis-Thomas), vice- amiral.}

Par Paulin Guérin. - H. 0,71. - L. 0,54.

Né à Auch en 1750, il fit ses premières armes dans les gendarmes de la maison du roi, s'embarqua en 1773 comme volontaire, et fit plusieurs campagnes dans les mers des Indes. Capitaine de vaisseau en 1791, il prit le commandement de la frégate la Prudente, destinée pour Saint-Domingue, et se trouva dans cette colonie lors des premiers troubles qui y éclatèrent. Nommé contre-amiral en 1794, il prit le commandement de la flotte de Brest. En 1796, il fut nommé par le département du Morbihan député au conseil, 
des Cinq-Cents, et fut chargé en 1801 du commandement des forces navales destinées à agir contre Saint-Domingue. A son retour, en 1802, il fut nommé capitaine général de la Martinique et de Sainte-Lucie, qu'il gouverna pendant sept ans, et fut successivement membre de la Légion d'honneur en 1803, officier en 1804 et grand aigle en 180ə̈. Gouverneur général de Venise et commandant de la $12^{\mathrm{e}}$ division militaire en 1811 , il mourut à Venise en 1812.

\section{Bruix (Eustache), vice-amiral.}

Par Paulin Guérin. - H. 0,71. - L. 0,54.

Né à Saint-Domingue en 1759, il obtint en 1778 le brevet de garde de la marine et parvint au grade de capitaine de vaisseau. De 1794 à 1796, Bruix fut employé en qualité de major général de la marine, puis de directeur du port de Brest. Il passa ensuite à l'armée d'Irlande, devint contre-amiral, puis ministre de la marine en 1798. Il commanda en $\mathbf{1 7 9 9}$ une armée navale avec laquelle il ravitailla Gênes, puis l'escadre rassemblée sur la rade de l'île d'Aix. Nommé amiral en 1802, il prit le commandement de la flottille de Boulogne, fut grand officier de la Légion d'honneur et mourut à Paris le 18 mars 180 ŏ.

\section{Lecourbe (Claude-Jacques), général de division.}

Par M. Vadchelet. - H. 2,07. - L. 1,31.

Né à Ruffey-sur-Seille (Jura), le 22 février 1759 , il entra comme soldat dans le régiment Aquitaine-infanterie en 1777 et fut caporal en 1780. Chef du $7^{\mathrm{e}}$ bataillon des volontaires du Jura en 1791, il servit aux armées du Rhin et du Nord et fut général de brigade en 1794. Employé aux armées de Sambre-et-Meuse et du Rhin en 1795̆, à celles du Haut-Rhin, d'Angleterre, de Mayence et d'Helvétie en 1799, il commanda la même annee l'armée du Rhin en qualité de général de division. Inspecteur général d'infanterie en 1801 et membre de la Légion d'honneur en 1804 , il fut admis à la retraite la même année. Réintégré dans son grade de général de division en 1814, il fut inspecteur général d'infanterie dans les $6^{\mathrm{e}}$ et $18^{\mathrm{e}}$ divisions militaires, chevalier de Saint-Louis et grand cordon de la Légion d'honneur. Commandant supérieur des divisions d'infanterie et de cavalerie réunies à Béfort en 1815 , et nommé pair de France par Napoléon, Lecourbe mourut à Béfort le 23 octobre 1815 .

\section{Rapp (Jean, comte), général de division.}

par M. Сівот. - H. 0,71. - L. 0,54.

Né à Colmar le 26 avril 1772, il entra en 1788, dans le $10^{\circ}$ ró- 
giment de chasseurs à cheval, fut brigadier-fourrier en 1791, maréchal des logis, en 1793, sous-lieutenant puis lieutenant en 1794, et servit aux armées du Rhin, de la Moselle et des Alpes. Capitaine en 1797, il fit la campagne d'Egypte, fut nommé chef d'escadron sur le champ de bataille de Sedinam, et colonel à l'affaire de Samanhout. Aide de camp du premier consul en 1800, il commanda l'escadron des Mameloucks en 1801, et fut colonel du $7^{\text {e }}$ régiment de hussards, puis général de brigade en 1803 . Commandeur de la Légion d'honneur en 1804, général de divi-

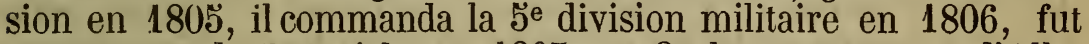
gouverneur de Dantzick en 1807, et fit les campagnes d'Allemagne. Comte de l'Empire en 1809, commandant en chef le $10^{\mathrm{e}}$ corps de la grande armée en 1813, il fut prisonnier de guerre, revint en France en 1814, et fut nommé grand cordon de la Légion d'honneur. Pair de France en 1815 , il reçut de Napoléon le commandement en chef de l'armée du Rhin, et aprèsle licenciement de l'armée, se retira en Argovie. Rentré en France en 1819, il fut premier chambellan de la garde-robe du roi en 1820 , et mourut au château de Rheinviller le 8 novembre 1821.

\section{Reynier (Jean-Louis-Ebenezer, comte), général de division.}

Par M. Philippoteaux. - H. 0,71. - L. 0,54.

Né à Lausanne (Suisse) le-14 juillet 1771, il entra comme aspirant à l'École des ponts et chaussées à Paris en 1790. Canonnier volontaire dans le bataillon du Théâtre-Français en 1792, il fut rappelé à Paris la même année pour être employé comme ingénieur aux retranchements commencés lans la plaine de Saint-Denis, puis adjoint à l'état-major de l'armée du Nord et fit la campagne de Belgique. Adjudant général chef de bataillon en 1793, adjudant général chef de brigade en 1794, général de brigade en 1795, il passa à l'armée de Rhin et Moselle et servit sous Moreau comme chef d'état-major. Général de division en 1796, il fut appelé à l'armée d'Orient en 1798. Nembre de la Légion d'honneur en 1803, il fut chargé du commandement des troupes cantonnées à Toulon, et fut commandant de la Légion d'honneur en 1804. Employé dans le royaume de Naples, il y commanda la

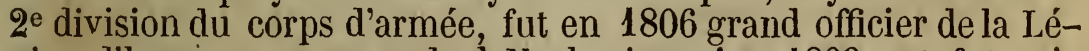
gion d'honneur, commanda à̀ Naples jusqu'en 1809, et fut ministre de la guerre et de la marine de ce royaume. Créé comte de l'Empire, et appelé au commandement de la $2^{\text {e }}$ division de l'armée d'Espagne en 1809, il fit les campagnes de Portugal en 1810 et 1811 , et celles de 1812 et 1813 á la grande armée dont il commanda le $7^{\text {e }}$ corps; fait prisonnier à la bataille de Leip- 
sick, il reçut, après sa mise en liberté, la grand' croix de l'ordre de la Réunion, et mourut à Paris, le 27 février 1814.

\section{Vandamme (Dominique-Joseph-René,) comte d'Unebourg, lieutenant général.}

Par N. Roulllard. - H. 0,71. - L. 0,54.

Né à Cassel (Nord) le כ̌ novembre 1770, il entra en 1788 dans le bataillon auxiliaire du régiment des colonies, fut incorporé en 1789 au régiment de la Martinique, et de retour en France, entra en 1791 comme soldat au régiment de Brie, depuis $24^{\mathrm{e}}$ de ligne. Capitaine d'une compagnie franche incorporée aux chasseurs du Mont-Cassel en 1792, chef de ce bataillon, puis général de brigade en 1793, il servit aux armées du Nord, de Rhin-et-Moselle, du Rhin, d'Allemagne et d'Angleterre. Général de division en 1799 , il fut employé à l'armée des Grisons en 1800, au camp de SaintOmer en 1803, et devint grand officier de la Légion d'honneur en 1804. Employé au $4^{\mathrm{e}}$ corps de la grande armée en 180อ̆, puis aux $6^{\mathrm{e}}$ et $9^{\mathrm{e}}$ corps, il commanda la $16^{\mathrm{e}}$ division militaire en 1807 , lecamp de Boulogne en 1808, la division des troupes de Wurtemberg en 1809 , la $14^{\mathrm{e}}$ division militaire en 1811 , les troupes Westphaliennes au $8^{\text {e }}$ corps en 1812. Créé comte d'Unebourg, il commanda en 1813 les $2^{\mathrm{e}}$ et $\mathrm{5}^{\mathrm{e}}$ divisions d'infanterie, la division de réserve, puis le $1^{\text {er }}$ corps de la grande armée, et fut fait prisonnier derant Kulm en Bohême. Pair de France ct commandant

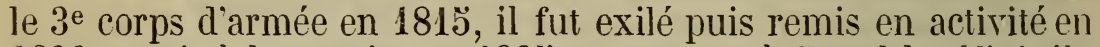
1820 , remis à la retraite en 1820ّ, et mourut à Cassel le 150 juillet 1830 .

\section{Hédouville (Gabriel-Marie-Théodore-Joseph, comte d'), lieutenant général.}

Par Paulin Gúris. - H. 0,7i. - L. 0,54.

Né à Laon le 27 juillet 17 วั, il fut élève de l'École royale militaire en 1769 , sous-lieutenant au 6 e régiment dë chasseurs à cheval en 1773 , et lieutenant en 1788. Adjoint aux adjudants généraux en 1791, capitaine dans le $6^{\mathrm{e}}$ régiment de chasseurs à cheval en 1792, général de brigade en 1793, il servit aux armées du Nord et de la Moselle. Général de division en $1795^{\circ}$, il fut chargé du commandement en chef des côtes de Brest. Commandant en chef de l'armée d'Angleterre en 1799, commandant supérieur des $1^{\mathrm{re}}, 15^{\mathrm{e}}$ et $16^{\mathrm{e}}$ divisions militaires la même année, et de la $13^{\mathrm{e}}$ en 1800 , inspecteur général d'infanterie en 1801 , il fut ambassadeur en Russie. Grand officier de la Légion d'honneur en 1804, sénateur, chambellan de l'Empereur, comte de l'Empire, il fut ambassadeur extraordinaire près du prince de 
Lucques et de Piombino en 1805,, gouverneur de la ville de Jintz, commandant de Bayonne en 1808 et ministre plénipotentiaire près le duc de Francfort en 1809. Pair de France et chevalier de Saint-Louis en 1814, il fut chargé en 1818 de régler les prétentions de la France avec le grand-duché de Varsovie, et mourut le 31 mars 1825.

\title{
1233. Klein (Louis-Antoine-Dominique, comte), lieu- tenant général.
}

\author{
Par $\mathrm{N}^{\text {me }}$ VARCollier. - H. 0,71. - L. 0,54.
}

Né à Blamont (Meurthe) le 24 janvier 1761, il servit dans les gardes de la porte de 1777 à 1787 . Rentré au service en 1792 comme premier lieutenant au $83^{\text {e }}$ régiment, il passa ensuite au $11^{\mathrm{e}}$ de chasseurs à cheval et fit la campagne de Belgique. Général de brigade en 1794, il servit à l'armée de Sambre-et-Meuse el devint général de division en 1799. Inspecteur général de cavalerie en 1802, grand officier de la Légion d'honneur en 1804, il commanda la $1^{\text {re }}$ division de dragons dans le département de la Somme. Envoyé à la grande armée en 1805̆, il fit la campagne d'Allemagne, fut en 1807 sénateur, comte de l'Empire et gouverneur du palais impérial en 1808. Pair de France et chevalier de Saint-Louis en 1814, il fut nommé grand-croix de la Légion d'honneur en $\mathbf{1 8 3 4}$, et mourut le 2 novembre $\mathbf{1 8 4 5}$.

\section{$\infty \infty$ \\ Aile ater Hidi.}

(PARTIE BASSE.)

GALERIE No 60 .

Cette galerie servait autrefois de dégagement et de couloir de service pour les offices, cuisines et fourrières de l'aile du midi ou aile des Princes.

\section{Aymon, comte de Corbeil.}

Statue couchée ; plâtre. - Long. 1,90.

" Aymon fut le premier comte Corbeil. Il était fils d'Osmond le Danois, gouverneur de la jeunesse de Richard Ier, duc de Normandie, qu'il tira si adroitement des mains du roi Louis d'Outremer qui le retenait comme prisonnier à Laon. On lui donna pour femme Elisabeth, proche parente d'Hedwige, épouse 
de Hugues-le-Grand, duc de France, et par conséquent de l'empereur Othon ${ }^{\mathrm{I}}{ }^{\text {r }}$, frère d'Hedwige. Ce fut en considération de ce mariage que Hugues-le-Grand lui donna le comté de Corbeil, qui faisait partie de son duché de France. L'an 946, il se déclara pour Hugues et Richard dans la guerre qu'Othon et Louis d'Outremer leur firent, et contribua à repousser les Allemands qui étaient venus faire le siége de Rouen. Aymon se rendit maître en 9500 du château de Pallıau, près de Corbeil.

" Le comte Aymon, ajoute Millin, est ordinairement représenté perçant de sa lance un dragon ailé à deux têtes. Il y a dans Corbeil une rue dite le Trou-Patris: là est un égout couvert, aboutissant à la rivière d'Etampes. Une tradition populaire veut que ç'ait été jadis le repaire d'un animal extraordinaire et redouté dans le pays, que le comte Aymon l'ait combattu et en ait été le vainqueur. »

La figure originale est dans l'église de Corbeil. "Cette église fut rebâtie vers 1440, ainsi le tombeau peut y avoir été fait vers 1450. „ (MILLIN. - Antiquités rationales, tome $1 I$, no 22.)

\section{Estouteville (Nicolas, sire d').}

Statue couchée ; plâtre. - Long. 1,25.

La figure originale, dont le masque est en albâtre et le corps en pierre, se trouve dans l'abbaye de Valmont. On lit sur le tombeau cette inscription : Cy gist hault et puissant seigneur Nicolas, sire d'Estouteville, chevalier, lequel en son vivant fonda cette potente abbaye en l'an de grâce mil cent seize, et trépassa le 22e jour d'avril mil cent et quarante.

\section{Saint Laurent, archevêque de Dublin,}

Statue couchée; plâtre. - 'Long. 1,89.

Issu d'une famille de sang royal, Laurent eut pour père Maurice, qui possédait la Lagénie, province d'Irlande. Maurice envoya son fils à Donat, comte de Kildare, pour le faire baptiser. Abbé de Glindale, il fut élu archevêque de Dublin, et reçut le titre de légat apostolique en Irlande. Retenu prisonnier par Henri II, Laurent se retira dans le monastère d'Abbendon. Il mourut à Eu le 14 novembre 1181. Le pape Honorius III canonisa ce saint évêque en 1223 ,

La figure originale est dans la cathédrale de Bouen.

\section{Richard $\boldsymbol{I}^{e r}$, dit Cour-de-Lion, roi d'Angle- terre. (Voir no ${ }^{447 .)}$}

Statue couchée; plâtre. - Long. 2,25.

La figure originale est dans l'église de Fontevrault. 


\section{Richard $I^{e r}$, dit Cour-de-Lion, roi d'Angle- terre. (Voir $\mathrm{n}^{\circ}$ 447.)}

Statue couchée; plâtre. - Long. 2,36.

La figure originale est dans la cathédrale de Rouen.

\section{Berengère de Navarre, reine d'Angleterre.}

Statue couchée ; plâtre. - Long. 2,20.

Fille de Sanche VI, roi de Navarre, elle fut mariée à Limisso en Sicile, le 12 mai 1191, à Richard Cour-de-Lion. " La reine Berengère, dit l'Art de vérifier les dates, survécut à son époux et vivait encore l'an 1229, résidant au Mans qui lui avait été donné pour son douaire, comme on le voit par le soin qu'elle prit cette année de rétablir l'abbaye de Lespau, près de cette ville. »

La figure originale placée autrefois au milieu du chœur de l'abbaye de Lespau, est dans la cathédrale du Mans.

\section{Maurille, archevêque de Rouen.}

Statue couchée; piâtre. - Long. 2,12.

Il était archidiacre de l'église de Troyes lorsqu'il fut nommé évêque du Mans en 1215 et devint archevêque de Rouen en 1231. Il mourut à Sanceuse le 10 janvier 1233 .

La figure originale est dans la cathédrale de Rouen.

\section{Blanche de Castille, reine France.}

Statue à genoux; plâtre. - H. 1,05.

La figure originale sculptée au pignon du tombeau de Nantilde à Saint-Denis est désignée, sans aucune preuve, comme représentant la mère de saint-Louis. La reine porte de longs chevenx qui flottent sur ses épaules; une escarcelle est suspendue à son côté gauche. (Gurluermy. - Monographie de SaintDenis.

\section{Châtillon (Hugues de), comte de Saint-Pol.}

Statue couchée; marbre. - Long. 2,00.

Fils de Gaucher III, seigneur de Châtillon, il succéda à son père dans la charge de bouteillier de Champagne et accompagna le roi saint Louis lorsqu'il marcha contre Pierre de Dreux, comte de Bretagne. Il se trouva dans l'assemblée tenue à Saint-Denis en 1235 , pour le règlement de la juridiction des prélats, et mourut le 9 avril 1243. Il fut enterré dans l'abbaye de Pont-auxDames, en Brie, qu'il avait fondée.

Cette figure et la suivante étaient placées autrefois dans l'abbaye de Pont-auxDames. 
1243. Avesnes (Marie d'), comtesse de Saint-Pol.

Statue couchée; marbre. - Long. 1,85.

Elle fut mariée en 122: à Hugues de Châtillon, comte de Saint-Pol, et mourut en 1241. Elle fut enterrée avec son époux dans l'abbaye de Pont-aux-Dames.

\section{Jean II, duc de Bretagne.}

Statue couchée; plâtre. - Long. 1,98.

Il suivit en 1260 le roi saint Louis à Tunis, se rendit ensuite en Palestine et revint en 1273. Il succéda en 1286 à son père Jean Ier, et fut créé duc et pair de France en 1297. Il prit part à la victoire de Mons-en-Puelle en 1304. S'étant rendu l'année suivante à Lyon, pour assister au sacre du pape Clément V, il y fut écrasé par la chute d'une muraille et mourut quelques jours après, le 18 novembre 1305, à l'âge de soixante-sept ans. Son corps fut transporté dans l'église des Carmes de Ploërmel, qu'il avait fondée.

La figure originale est à Ploërmel.

\section{Béatrix de Bourgogne, còmtesse de Clermont.}

Statue couchée; plâtre. - Long. 1,90.

Elle épousa en. 1272, Robert de France, comte de Clermont, fils de saint Louis, et mourut au château du Murat en Bourbonnais, le $1^{\text {er }}$ octobre 1310. - Elle fut enterrée dans l'église des Cordeliers de Champagne, proche du prieuré de Souvigny.

La figure originale est dans l'église de l'ancien prieuré des Bénédictins à Souvigny.

1246. Philippe IV, dit le Bel, roi de France. (Voir $\mathrm{n}^{\circ}$ 696.)

Statue couchée ; plâtre. - Long. 1,98.

La figure originale est à Saint-Denis.

1247. Philippe $V$, surnommé le Long, roi de France, (Voir n 698.)

Statue couchée; plâtre. Long. 1,93.

La figure originale est à Saint-Denis.

1248. Blanche de Bretagne, dame de Conches.

Buste en plâtre. - H. 0,55.

Fille aìnée de Jean II, duc de Bretagne, et mariée, en 1280, à 
Philippe d'Artois, sire de Conches; elle mourut en 1327 et fut enterrée près de son époux dans l'église des Jacobins à Paris.

La statue originale est à Saint-Denis.

\section{Montmorency (Jean $I^{e r}$, seigneur de).}

Statue couchée; plâtre. - Long. 1,96.

Il accompagna en 1303 avec son père Mathieu IV, dit le Grand, le roi Philippe-le-Bel en Flandre, et fut seigneur de Montmorency en 1313. Appelé à Paris en 1318 par le roi Philippe-le-Long pour servir dans la guerre de Flandre, Jean de Montmorency mourut en juin 1325 et fut enterré dans l'église de Conflans-Sainte-Honorine.

La figure originale est dans l'église de Conflans-Sainte-Honorine.

\section{Catherine de Courtenay, impératrice titulaire de Constantinople. (Voir $\mathrm{n}^{\circ} 266$.)}

Statue couchẻe; plâtre. - Long. 1,94.

La figure originale est à Saint-Denis. "La statue et tous les accessoires, lit funéraire et coussin, sont en marbre noir. Les cheveux flottent sur le cou, le voile lescend de chaque côtẻ du visage, sans l'envelopper; la couronne est fleuronnée. Les mains jointes portent des gants longs; un anneau se voit par dessus le gant à un des doigts de la main droite. Le manteau qui recourre presque complétement la robe est taillé en façon de dalmatique; il a des manches pendantes et s'ouvre sur les côtés. Sa bordure d'hermine n'existe plus que du côté gauche. Le sculpteur nous semble avoir été préoccupé de l'intention de donner a l'impératrice d'Orient un costume singulier. Le bord inférieur de la robe cache toutà fait les pieds. Deux dragons, d'une allure très-vivante, se jouent sur les derniers pans de cette robe; l'un mord l'étoffe, l'autre regarde en l'air. L'épitaphe, tracée suivant l'usage ancien, sur la bordure du tombeau, est moderne; mais les termes en ont été extraits d'un acte de transaction passé par le comte de Valois, Cinarles, avec le chapitre de Notre-Dame de Chartres :

Cy gist dame de noble memoire madame liatherine emperiere de Costatinoble dame de Cortenay fille a monsr Charles fil le roy de Frace cote de Valois de Alancon de Chartres de Anjou qui trespassa en l'an mil aGa viI le huictiesme jour d'aoust pries pour l'ame d'elle amen.

Le graveur a commis une erreur dans le nom du mois; il fallait écrire octobre et non pas août." - GuilHermy. - Monographie de Saint-Denis.

\section{Lorraine (Henri III de), comte de Vaudémont.}

Statue couchée; plàtre. - H. 1,86.

Il épousa en 1306, Isabelle de Lorraine, fille de Ferry III, et entra en possession du comté de Vaudémont. Il fonda de concert avec sa femme en 1325, le chapitre de Vaudémont, et mourut ell 1332.

La figure originale est dans l'église des Cordeliers de Nancy. 
1252. Lorraine (Isabelle de), comtesse de Vaudémont.

Statue couchée; plâtre. - Long. 1,90.

Elle mourut le 11 mai 1333 et fut enterrée avec son mari dans le chapitre de Vaudémont qu'ils avaient fondé.

La figure originale est dans l'église des Cordeliers de Nancy.

\section{Jean III, dit le Bou, duc de Bretagne.}

Statue couchée ; plâtre. - Long. 1,95.

Il succéda en 1312 à son père Arthur II, assista les rois Louisle-Hutin et Philipje de Valois dans les guerres de Flandre, et fut blessé à la bataille de Mont-Cassel. Il mourut à Caen, le 30 avril 1341, à l'âge de cinquante-cinq ans, et fut enterré dans l'église des Carmes de Ploërmel. C'est lui qui le premier prit l'écusson herminé.

La figure originale est à Ploërmel.

\section{Marigny (Jean de), archevêque de Rouen, chancelier de France,}

Statue couchée; plâtre. - Long. 1,95.

Évêque et comte de Beauvais, pair de France en 1312, il tint les sceaux deux fois dans l'année 1329. Il passa en Terre Sainte en 1332 et n'en revint qu'en 1335 . Er 1342 le roi Philippe de Valois l'établit son lieutenant général en Languedoc pour résister aux invasions des Anglais. Il fut nommé à l'archevêché de Rouen par le pape Clément VI, et mourut le 26 décembre $130 \% 1$. Son corps fut transporté dans l'église collégiale d'Ecouis auprès d'Enguerrand de Marigny, son frère.

La figure originale est dans l'église d'Ecouis.

1255. Marguerite de France, comtesse de Flandre. (Voir n०278.)

Statue couchée; plâtre. - Long. 1,76.

La statue originale est à Saint-Denis.

1256. Bonne de Luxembourg, reine de France.

Buste en plâtre. - H. 0,60.

Fille de Jean de Luxembourg, roi de Bohême, elle fut mariée en 1332 à Jean II, roi de France, et mourut à l'abbaye de Maubuisson, le 11 septembre 1349.

La figure originale est à Saint-Denis. 


\section{Blanche de France, duchesse d'Orléans.}

Buste en plâtre. - H. $\mathbf{0 , 6 0 .}$

Fille de Charles-le-Bel et de Jeanne d'Évreux, elle naquit à Châteauneuf près d'Orléans, en 1327, fut mariée en 1344 à Philippe de France, duc d'Orléans, fils de Philippe de Valois, et mourut le 8 février 1392.

La statue originale est à Saint-Denis.

1258. Charles $V$, roi de France. (Voir n 702.$)$

Par M, Duseigneur; buste en marbre. - H. 0,62.

1259. Jeanne de Bourbon, reine de France.

(Voir $\mathrm{n}^{\circ} 285$. )

Par N. Husson; buste en marbre. - H. 0,59.

1260. Philippe de France, surnommé le Hardi, duc de Bourgogne.

Statue à genoux; plâtre. - H. 1,37.

Né à Pontoise en 1342, il était fils puîné de Jean-le-Bon, roî de France, et combattit en $135 ّ 6$ à la bataille de Poitiers où il mérita le surnom de Hardi. Son père lui donna ponr lui et ses héritiers le duché de Bourgogne, et son mariage avec Marguerite de Flandre le fit, en 1369, comte de Flandre et d'Artois. Il fut régent du royaume sous le règne de Charles VI et mourut à Hall en Brabant le 27 avril 1404. Il fut enterré dans l'église des Chartreux de Dijon.

La figure originale est placée au portail de l'ancienne Chartreuse de Dijon.

\section{Marguerite de Flandre, duchesse de Bour- gogne.}

Statue ’̀ genoux; plâtre. - H. 1,27.

Fille unique de Louis III, comte de Flandre, elle était veuve de Philippe de Rouvre, dernier de la branche des anciens ducs de Bourgogne, lorsqu'elle épousa, en 1369, Philippe-le-Hardi. Elle mourut à Arras, le 16 mars 1405 .

La figure originale est placée au portail de l'ancienne Chartreuse de Dijon.

1262. Dormans (Yde de), dame de Saint-Venant.

Statue couchée; pierre (1). - Long. 1,73.

Soeur de Jean et de Renaud de Dormans (Voir nos 298 et 299),

(1) Le masque et les mains de cette figure étaient en albảtre ; les inains ont été reiaites, et le masque est proîondément altéré. 
elle fut mariée à Robert de Nesle, seigneur de Saint-Venant, mourut le 8 octobre 1379, et fut enterrée dans la chapelle du collége de Beauvais à Paris.

\section{Louis de France, duc d'Orléans. (Voir n 295.)}

Par M. Laxro; buste en marbre. - H. 0,60.

\section{Valentine de Milan, duchesse d'Orléans.}

(Voir $\left.n^{\circ} 296.\right)$

Par M. MERCIER ; buste en marbre. - H. 0,66.

\section{Berry (Jean de France, duc de).}

Statue couchée; plâtre. - Long. 2,05.

Troisième fils de Jean-le-Bon, né au château de Vincennes en 1340, il porta d:abord le titre de comte de Poitier's. Il se trouva, en 13כ̈6, à la bataille de Poitiers, et fut domné en otage aux Anglais lorsque le roi Jean revint en France en 1369. A l'avénement de son frère Charles V en 1364, il reçut le duché de Berry en apanage et servit dans les guerres contre les Anglais. Pendant la minorité de Charles VI, il eut, avec les ducs d'Anjou et de Bourgogne, sa part dans l'administration du royaume et dans les désordres qui signalèrent ce malheureux règne. Gouverneur et lieutenant général de Guienne et de Languedoc, gouverneur de Paris, il combattit à Rosebecque en 1382, et mourut à l'hôtel de Nesle, à Paris, le 15 juin 1416.

La figure originale est dans la cathédrale de Bourges.

\section{Bourbon (Louis II, duc de), pair et cham- brier de France.}

Statue couchẻe; plâtre. - Long. 2,10.

Fils aîné de Pierre Jer, duc de Bourbon, né en 1337. Il fut un des princes envoyés comme otages en Angleterre pour y remplacer le roi Jean, et servit Charles V dans ses guerres contre Charlesle-Mauvais, Jean de Montfort et Édouard III. A l'avénement de Charles VI, il partagea le gouvernement du royaume avec les dues d'Anjou, de Berry et de Bourg'ogne, et commanda l'arrièregarde à la bataille de Rosebecque en 1382. Il marcha au secour's des Génois en 1390, et fit une expédition contre le souverain de Tunis. Louis de Bourbon, surnommé le Bon, mourut à Montlucon, le 19 août 1410 , et fut enterré dans la chapelle du prieuré de Souvigny, qu'il avait fait bâtir.

La figure originale est dans l'ancien prieuré des Bẻnédictins, à Souvigny. 
1267. Bourbon (Anne, dauphine d'Auvergne, duchesse de).

Statue couchẻe; plâtre. - Long. 2,02.

Fille unique et héritière de Béraud II, comle de Clermont, elle fut fiancée à Louis II, duc de Bourbon, par contrat passé à Montbrison, le 4 juillet 1368 , et le mariage accompli le 19 août 1371. Elle vivait encore le 250 octobre $\mathbf{1 4 1 6}$, et fut enterrée près de son mari dans la chapelle de Bourbon.

La figure originale est dans l'ancien prieuré des Bénédictins à Souvigny.

1268. Jean Sans-Peur, duc de Bourgogne. (Voir no 412.) Buste en plâtre. - H. 0,61.

La statue originale est à Dijon.

1269. Marguerite de Bavière, duchesse de Bourgogne. Buste en plâtre. - If. 0,60.

Fille d'Albert de Bavière, comte de Hainaut, de Hollande et de Zélande, elle fut mariée à Cambrai, le 9 avril 1385, à Jean-Sans-Peur, alors comte de Nevers. Elle fut enterrée dans l'église des Chartreux de Dijon, auprès de son mari. - L'épitaphe gravée sur son tombeau place sa mort à la date du 13 janvier 1423 ; mais l'historien de la maison de Bourgogne, Monstrelet, ne la fait mourir que deux ans après, à son retour du mariage de sa fille Agnès avec Charles, duc de Bourbon.

La statue originale est à Dijon.

1270. Philippe d'Artois, comte d'Eu, connétable de France. (Voir nos 288 et 947.)

Buste en plâtre. - H. 0,54.

La figure originale est dans l'église d'Eu.

1271. Clisson (Olivier de), connétable de France. (Voir $\mathrm{n}^{\circ} 946$. )

Statue couchée; plâtre. - Long. 2,02.

La figure originale est dans l'église de Notre-Dame, à Josselin (Morbihan).

1272. Laval (Catherine de), dame de Clisson.

Statue couchée; plâtre. - Long. 1,80.

Première femme du connétable de Clisson. On ignore les dates de sa naissance, de son mariage et de sa mort.

La figure originale est dans l'église de Notre-Dame, à Josselin. 
1273. Vienne (Jean de), seigneur de Pagny.

Statue couchée; plâtre. - Long. 2,10.

Jean de Vienne, surnommé à la grande Barbe, prit part aux guerres du règne de Charles VI, et mourut en $1430 ̈$.

La figure originale est au château de Pagny; elle porte l'inscription suivante en caractères gothiques :

Ci gist : noble. baron : mess ${ }^{e}$ iehan : de riane

chlr : seig : de Pagny : et : de : Vignau : qui trespassa

audit : Vignau : la veille : des bordes :

l'an : mil : cccG : xxxy :

1274. Neufchâtel ( Thibaut VII, seigneur de).

Statue couchée; plâtre. - Long. 2,14.

Il était fils de Thibaut VI, seigneur de Neufchâtel, gardien du comté de Bourgogne, accompagna en Hongrie le comte de Nevers (Jean-Sans-Peur), et fut tué à la bataille de Nicopolis le 28 septembre 1396.

La figure originale est dans l'église des Cordelięrs de Nancy.

\section{Charles d'Orléans, duc d'Orléans. (Voir n 304.)}

Par M. Desboedfs; buste en marbre. - H. 0,56 .

\section{Bourbon (Charles $I^{e r}$, duc de), pair et cham- brier de France.}

Statue couchée; plâtre. - Long. 2,16.

Fils aîné de Jean Ier, duc de Bourbon. Né en 1401, il porta d'abordle nom de comte de Clermont, et eut la charge degrand chambrier de France. Attaché au parti du dauphin, depuis Charles VII, il fut, en 1420, capitaine genéral en Languedoc et en Guyenne, et s'empara de la ville de Béziers. Après la levée du siége d'Orléans, le comte de Clermont accompagna Charles VII à Reims et assista à son sacre, où il représenta le duc de Normandie. Devenu duc de Bourbon en 1434, après la mort de son père, il conclut, en 1430̈, avec le duc de Bourgogne, le traité d'Arras. En 1440 il prit part à la révolte du dauphin (Louis XI) et après être rentré en grâce en 1442, il vécut paisible dans ses domaines. Il mourut au château de Moulins, le 4 décembre 14 ǒ6, et fut enterré dans une chapelle du prieuré de Souvigny quiil avait fait bâtir.

La figure originale est dans l'église de l'ancien prieuré des Bénédictins à Souvigny. 
1277. Bourbon (Agnès de Bourgogne, duchesse de).

Statue couchée; plâtre. - Long. 2,01.

Fille de Jean-Sans-Peur, duc de Bourgogne, elle fut fiancée, en 1418, au comte de Clermont, mais ce mariage, rompu par les guerres civiles, ne fut célébré qu'en 1425 . Elle mourut vingt ans après le duc de Bourbon, le $1^{\text {er }}$ décembre 1476 ,

f La figure originale est dans l'église de l'ancien prieuré des Bénédictins de Souvigny.

\section{Charles d'Anjou, I Ir du nom, comte du Maine.}

Statuc couchée; plâtre. - Long. 1,77.

Fils de Louis II d'Anjou, roi de Naples, né le 14 octobre 1414. Gouverneur et capitaine de la ville de Paris en 1430ั, ce prince assista en 1440, avec le roi Charles VII, à l'assemblée tenue à Bourges pour la Pragmatique-Sanction, et il prit part à toutes les guerres de ce monarque contre les Anglais. En 1443, le roi lui donna le gouvernement du Languedoc. Dunois ayant délivré, en 1448, la ville du Mans, assiégée par les Anglais, Charles d’Anjou fut mis en pleine possession de son comté. Sous le règne de Louis XI, il tint le parti du roi à la bataille de Montlhéry. Il mourut à Aix le 10 avril 1472, et son corps fut transporté dans la cathédrale du Mans.

La figure originale est dans l'église cathédrale du Mans.

\section{Chabannes (Antoine de), comte de Dammartin, grand maître de France.}

Statue couchée; plâtre. - Long. 2,19.

Né en 1411, il fut page du comte de Ventadour et du seigneur de Lahire, et fit ses premières armes à la bataille de Verneuil, où il demeura prisonnier des Anglais en 1424. Il se trouva ensuite au siége de Jargeau, au combat de Patay en 1429, et au secours de Compiègne en 1430. S'étant mis à la tête de sa compagnie qu'on surnommait les Ecorcheurs, il parcourut avec eux le Cambrésis et le Hainaut qu'il ravagea ainsi que plusieurs autres provinces au pouvoir des ennemis de l'autorité royale. Il quitta cette compagnie en 1439, et s'attacha au parti de Charles VII, qui lui donna la charge de grand pannetier en 1449. A l'avénement de Louis XI, en 1461, il fut enfermé à la Bastille, mais il s'échappa en 1464, et se retira en Bretagne, où il embrassa le parti des princes ligués. Rentré en grâce auprès du roi , il fut rétabli dans tous ses emplois, et recut en 1467 la charge de grand maître de France et le collier de l'ordre de Saint-Michel en 1469. Il fut mis ensuite à la tête des troupes opposées à l'armée du duc de Bourgogne, et fut 
député à Senlis en 1473 auprès de ce prince pour la négociation de la paix. Quelques années après il eut le gouvernement de Paris, où il mourut le 25 décembre 1488. Il fut enterré au milieu du chœur de l'église du prieuré de Dammartin qu'il avait fondé en 1480.

Ja figure originale est dans l'église de Dammartin (Seine-et-Marne).

\section{Agnès Sorel ou Soreau.}

Statue couchẻe; plâtre. - Long. 1,71.

Née au village de Fromenteau, près de Loches, vers 1409, elle était fille d'honneur d'Isabelle de Lorraine, duchesse d'Anjou, et accompagna cette princesse à la cour de France en 1431. Attachée à la maison de la reine, elle devint la maîtresse de Charles VII, et contribua, par son ascendant sur le roi, à délivrer la France des Anglais. Charles VII lui donna des terres considérables en Bretagne, dans le Berry, et le château de Beauté-sur-Marne, près de Vincennes. Poursuivie par la haine du dauphin (depuis Louis XI), elle se retira, en 1445̋, au château de Loches que le roi lui avait fait bâtir. Après l'entrée de Charles VII à Rouen, Agnès se rendit près de lui à l'abbaye de Jumièges, et mourut le 9 février 14500 , au château du Ménil.

La figure originale est à Loches.

\section{Vaudémont (Antoine de Lorraine, comte de ).}

Statue couchée; plâtre. - Long. 2,00.

Fils de Ferry Ier, comte de Vaudémont, il lui succéda en 1416, et disputa en 1421, à René d'Anjou, l'héritage du duché de Lorraine. Il mourut en 1447, et fut enterré dans l'église collégiale de Saint-Jean de Vaudémont.

La figure originale est dans l'église des Cordeliers de Nancy.

1282. Vaudémont (Marie d'Harcourt, comtesse de).

Statue couchée; plâtre. - Long. 2,00.

Fille de Jean VII, comte d'Harcourt, elle épousa en 1417 le comte de Vaudémont, et mourut le 19 avril 1476.

La figure originale est dans l'église des Cordeliers de Nancy.

1283. Charles de Bourgogne, surnommé le Téméraire, duc de Bourgogne. (Voir n ${ }^{557 .)}$

Statue couchée; plâtre. - Long. 2,19.

La figure originale est dans l'église de Notre-Dame, à Bruges. 
1284. Marie, duchesse de Bourgogne, archiduchesse d'Autriche. (Voir no 634.)

Statue couchée; plâtre. - Long. 1,98.

La figure originale est dans l'église de Notre-Dame, à Bruges.

\section{Ferdinand $V$, dit le Catholique, roi d'Aragon et de Sicile. (Voir no ${ }^{311 .}$.)}

Statue couchée; plâtre. - Long. 2,52.

La figure originale fait partie du mausolée placé dans la galerie $\mathbf{n}^{0} \mathbf{1 6}$.

1286. Isabelle de Castille, reine de Castille et d'Aragon.

(Voir no 311.)

Statue couchée; plâtre. - Long. 2,48.

La figure originale fait partie du monument placé dans la galerie $n^{\circ} 16$.

\section{Estouteville (Jacques, sire d').}

Statue couchée; plâtre. - Long. 1,76.

Conseiller et chambellan du roi, capitaine de Falaise, il assista aux Etats tenus à Tours en $\mathbf{1 4 7 5}$, et aux échiquiers de Normandie des années 1484 et $148 \%$. Il mourut le 22 mars 1489.

Ia figure originale, en albâtre, est à l'abbaye de Valmont.

\section{Albret (Louise d'), dame d'Estouteville.}

Statue couchée; plàtre. - Long. 1,76.

Elle épousa en 1480 Jacques, sire d'Estouteville, et mourut le 8 septembre 1494 .

La figure originale, en albâtre, est à l'abbaye de Valmont.

\section{François II, duc de Bretagne.}

Par Michel CoLоmве; statue couchée; plâtre. - Long. 2,48.

Petit-fils de Jean V, duc de Bretagne, né en 1435 , il succéda au duc Arthur II, son oncle, en 1459. Après la mort de Charles VII, François entra dans la Ligue du Bien public, s'allia ensuite avec le roi d'Angleterre Édouard IV, et perdit contre Charles VIII la bataille de Saint-Aubin-du-Cormier, en 1488. Il mourut à Coiron le 9 septembre 1488, et fut enterré dans l'église des Carmes de Nantes, où sa fille Anne lui fit ériger, en 1507, une magnifique sépulture de marbre blanc.

La figure originale fait partie du tombeau de François II, placé dans la cathédrale de Nantes. 


\section{Marguerite de Foix, duchesse de Bretagne.}

Par Michel Colombe; plâtre. - H. 2,25.

Elle fut mariée à Clisson, en 1471, à François II, duc de Bretagne, dont elle fut la seconde femme, et mourut à Nantes le 15 mai 1486. Enterré d'abord dans la cathédrale de Nantes, son corps fut transporté, en 1507, auprès de celui du duc François, dans le tombeau qu'Anne de Bretagne, leur fille, avait fait élever dans l'église des Carmes.

La figure originale est dans l'église cathédrale de Nantes.

\section{Guibé (Jacques de).}

Statue couchée; plâtre. - Long. 2,20.

La figure originale, qui se troure dans la cour du Musée de Rennes, provient de l'ancienne cathédrale de cette ville. Elle est mentionnée dans l'inventaire qui fut fait avant la démolition de cette cathédrale en 1755, comme existant dans la chapelle Saint-Armel, derrière le maître-autel, chapelle dite des Guibé, et dont toutes les clefs de voûtes, vitraux, etc., portaient l'écusson de Guibé : d'argent à trois jumelles de gueules, accompagné de six coquilles d'azur au chef cousu d'or. " Du côté de l'Epître est la figure, en marbre blanc, d'un homme vêtu de sa cotte d'armes, chargée du même écusson. Aux pieds de cette figure est celle d'un lion tenant entre ses griffes un pareil écusson. Dês deux côtés des genoux de la statue sont deux figures d'anges tenant chacun en main un écusson." On présume que cette figure représente Jacques de Guibé, gouverneur et capitaine de Rennes, dont le père, Adenet de Guibé, avait épousé la fille du fameux trésorier de Bretagne, Pierre Landais.

\section{La Palu (Olivier de).}

Statue couchée; plâtre. - Long. 2,48.

La figure originale est au château de La Palu.

\section{Tombeau des fils de Charles VIII.}

Plâtre. - H. 1,31. - L. 0,91. - Long. 1,91.

Charles Orland, dauphin de Viennois, né au château de Montilslès-Tours, le 10 octobre 1492, mort à Amboise le 6 décembre 1490 วั.

Charles, dauphin de Viennois, né à Montils-lès-Tours, le 8 septembre 1496, mort le 2 octobre suivant.

Les deux jeunes princes sont couchés et revêtus de robes armoriées. Deux anges sont à leur tête et deux autres à leurs pieds. La frise, dont les angles sont décorés de quatre dauphins, offre d'un côté les travaux de Samson et de l'autre ceux d'Hercule. Au inilieu des faces latérales de la base, deux anges soutiennent un écusson. Dans une des faces est un cartouche rond qui contient l'inscription suivante en caractères gothiques :

Par Atropos qui les cueurs humas fend

Dun dard mortel de cruelle souffrace

Cy dessoubz gist Charles second enfant

Du roy Charles et de Anne royne en France. 
Le quel vesquit daulphin de Viennoys

Conte dyois et de Valentinoys.

Vingt et cinq iours puis lez Tours au Plessis

En octobre morut a deux du moys

Mil quatre cens auec nonate et six.

Sur la face opposée est un cartouche de même forme avec cette inscription :

Charles huitiesme roy preux et excellet

Eut de Anne royne et duchesse de Btaigne

Son premier filz nome Charles Orlend

Le ql regna sans mort que rien nepgne

Trois ans trois moys daulphi. de Viennoys

Conte dyois et de Valentinoys

Mais lan $\mathrm{V} \operatorname{cen}^{\mathrm{s}} \mathrm{mai}^{\mathrm{s}} \mathrm{V}$ et rendit lame

A Amboise le ceziesme du moy

De decebre puis fut mis soubz la lame.

Enfin, au bas du monument, on lit sur un des côtés :

Restitutui Fidelibus curis A. E. H. Destouches Prefecti DIE XXV AUGUSTI MDCCCXV.

Et sur un autre :

$$
\begin{aligned}
& \text { EXORNATUM } \\
& \text { ANNO MDCGCXXX. }
\end{aligned}
$$

Ce monument a été moulé dans l'église cathédrale de Tours.

\section{Montauban (Philippe de), baron de Grenonville, chancelier de Bretagne.}

Statue couchée; plâtre. - Long. 2,28.

Lieutenant général de François II, duc de Bretagne en la ville de Rennes pendant la guerre avec la France, il fut chancelier de Bretagne en 1487, et contribua à la conclusion du mariage d'Anne de Bretagne avec Charles VIII. Sa charge de chancelier ayant été supprimée en 1494, il eut le titre de gouverneur et garde de la chancellerie de Bretagne. Il mourut le $1^{\text {er juillet } 10 ั 16 .}$

La figure originale est dans l'église de Ploërmel.

\section{Du Chastellier (Anne).}

Statue couchée; plâtre. - Long. 2,28.

Elle était veuve de Gilles de Rieux, seigneur de Châteauneuf, lorsqu'elle épousa Philippe de Montauban. On ignore l'époque de son mariage et celle de sa mort.

La figure originale est dnns l'église de Ploërmel.

\section{Orléans (Renée d'), comtesse de Dunois.}

Statue couchée; plâtre. - Long. 1,40.

Renée d'Orléans était petite fille de Dunois et fille de François d'Orléans, duc de Longueville; elle n'avait encore que sept ans, 
quand elle mourut le 23 mai 1öıวั, à Paris, dans l'hôtel abbatial de Sainte-Geneviève.

"Le sculpteur a répandu à profusion les pierreries sur la couronne, sur la coiffe et le réseau qui enveloppent les cheveux, sur la double attache du manteau, sur la ceinture de la robe et sur le corsage garni d'hermine. Une espice de chapelet formé de dix globes assez gros, d'un gland de soie et d'un crucifix, pend à la ceinture. La chaussure est à bouts carrés et à semelles épaisses. Une licorne accroupie sous ses pieds, armée d'une corne au front, portant barbe au menton et décorée d'un collier, tient entre ses pattes un écusson de forme losangée, écartelé au $1^{\text {er }}$ et 4 d'Órléans-Longueville, aux 2 et 3 d'Alençon. La licorne était au moyen âge un symbole de virginité." - (GullHenMY. - Monographie de Saint-Denis.)

La figure originale, provenant des Célestins de Paris, est à Saint-Denis.

\section{Marguerite de Bourbon, duchesse de Savoie.}

Par Conrard MEYT; statue couchée; plâtre. - Long. 1,98.

Fille de Charles I ${ }^{\text {er }}$, duc de Bourbon, elle fut mariée à Moulins le 6 avril 1472, à Philippe II, duc de Savoie, et mourut au château du Pont-d'Ain le 24 avril 1483.

La figure originale se trouve dans l'église du séminaire de Brou, à Bourg-enBresse.

\section{Philibert II, dit le Beau, duc de Savoie.}

Par Conrard MEYT; statue couchée; plâtre. - Long. 2,17.

Fils de Philippe II, duc de Savoie, et de Marguerite de Bourbon, né au chàteau du Pont-d'Ain en 1480. Il succéda à son père en 1497, accompagna Louis XII dans la conquête du Milanais en 1วั03, et mourut le 10 septembre 15004 , au château du Pont-d'Ain, dans la même chambre où il était né.

La figure originale se trouve dans l'église du séminaire de Brou, à Bourg-enBresse.

\section{Marguerite d'Autriche, duchesse de Savoie, gouvernante des Pays-Bas.}

Par Conrard MEYT : statue couchée ; plâtre. — Long. 1,99.

Fille de Maximilien I ${ }^{\mathrm{er}}$, empereur d'Allemagne, née à Gand en 1480. Elle fut fiancée en 1483 à Charles VIII, alors dauphin, épousa en 1497 l'infant Jean de Castille, qui mourut la même année, et fut mariée en 1501, à Philibert le Beau, duc de Savoie. De nouveau veuve en 1504 , son père lui donna en 15006 le gouvernement des Pays-Bas ; elle conclut en 15\%08, avec le cardinal d'Amboise, le traité de la Ligue de Cambrai, et en 15\%29, avec Louise de Savoie, mère de François Ier, le traité de Cambrai, dit Paix des Dames. Elle mourut à Malines, le $1^{\text {er }}$ décembre 1530.

Ia statue originale se trouve, ainsi que les deux précédentes, dans l'église ılı 
sẻminaire de Brou, que Marguerite d'Autriche fit commencer en 1505, pour y être inhumée auprès de son époux et de Marguerite de Bourbon, mère de Philibert II.

\section{Phlilippe de Gueldres, duchesse de Lorraine.}

Par Léger Richier; statue couchée; plâtre. - Long. 2,36.

Elle épousa en 1485, Réné II, duc de Lorraine, et après la mort de son mari elle se fit religieuse de Sainte-Claire, à Pont-àMousson, où elle fit profession, le 8 décembre 1520. Elle y mourut le 26 février 1547, âgée de quatre-vingt-cinq ans.

La figure originale a été transportée en 1822 aux Cordeliers de Nancy.

\section{Marie de Bourbon.}

Statue à genoux; plâtre. - H. 1,08.

Fille ânée de Charles de Bourbon, duc de Vendòme, elle naquit au château de $\mathrm{I}_{\mathrm{i} a}$ Fère en $\mathbf{1 5 1 5}$, et fut fiancée à Jacques $\mathrm{V}$, roi d'Ecosse. Elle mourut à La Fère le 28 septembre 1538, et fut enterrée dans l'abbaye de Notre-Dame de Soissons, dont sa soeur Catherine était abbesse.

La figure originale, qui se trouvait dans l'église de Notre-Dame de Soissons fut transportée au Musée des Petits-Augustins, puis à Saint-Denis. "Marie de Bourbon est à genoux sur un coussin; elle porte une couronne, une coiffe et un collier enrichis de pierreries, une double robe, et un surcot garni d'orfèvrerie et de pierres précieuses, une fraise élégamment plissée, un manteau à col et doublure d'hermine. " (Gullmermy. - Monographie de Saint-Denis.)

\section{Chabot (Philippe de), amiral de France.} (Voir no 915.)

Par Jean Cousin; statue demi-couchée; plâtre. - Long. 1,60.

La figure originale est au Musée du Louvre. No 103 de la Description des Sculptures modernes, par M. Barbet de Jouy.

\section{Du Bellay (Guillaume), seigneur de Langey.}

Statue demi-couchée; plâtre. - Long. 1,80.

Né en 1491, près de Montargis, Guillaume Du Bellay fut un des capitaines les plus braves de son temps, un habile négociateur, et se distingua aussi dans les lettres. Il fit les guerres d'Italie sous Louis XH et sous François Ier, et fut chevalier de l'ordre de Saint-Michel. Il se rendit auprès de François Ier, prisonnier à Madrid, remplit plusieurs ambassades en Italie, elı Angleterre et en Allemagne, fut gouverneur de Turin en 1537 et vice-roi de Piémont en 1542. Il mourut à Saint-Symphorien, près de I Lyon, le 9 janvier 1543. - Guillaume Du Bellay est au- 
teur d'un Epitome de l'antiquité des Gaules et 'de la France, et de Mémoires sur les affaires de son temps.

La figure originale est dans l'église cathédrale du Mans.

\section{Guise (Henri de Lorraine, duc de).}

Statue demi-couchée; plâtre. - Long. 1,63.

Né en 15ั50, il fut élevé à la cour de Henri II et porta d'abord le titre de prince de Joinville. Il fit ses premières armes en 1563 au siége d'Orléans, où son père fut assassiné, devint alors duc de Guise, et se rendit en 1566 en Hongrie pour prendre part à la guerre contre les Turcs. De retour en France, il combattit à Jarnac en 1こ69, défendit Poitiers contre l'amiral Coligny, et se distingua à la bataille de Montcontour. En 15̆72, il fut le principal moteur du massacre de la Saint-Barthélemy en ordonnant le meurtre de Coligny. Lieutenant général dans les provinces de Champagne et de Bourgogne en $15 \% 7$, il défit à Dormans un corps d'Allemands alliés des huguenots, et y reçut au visage une blessure qui lui fit donner le surnom de Balafré. L'année suivante se forma la Sainte-Ligue, dirigée contre le triomphe de l'hérésie en France, et le duc de Guise fut reconnu comme chef de ce parti. Allié avec le pape Grégoire XIII et le roi d'Espagne Philippe II, il fut vainqueur des Allemands à Vimory, près de Montargis en 15้87, et fut lieutenant général de toutes les armées du roi en 1588. Henri III, qui avait été contraint de quitter Paris après la Journée des Barricades, fit assassiner le duc de Guise au château de Blois, le 23 décembre 1588.

La figure originale est dans la chapelle du collége $\mathrm{d}^{\prime} \mathrm{Eu}$.

\section{Guise (Catherine de Clèves, duchesse de).}

Statue demi-couchée; plâtre. - Long. 1,66.

Elle fut mariée en premières noces à Antoine de Croy, prince de Porcien, qui mourut en 1564 et après six années de veuvage, elle épousa, en 1570, Henri le Balafré. Lorsqu'en 1588 le duc de Guise fut assassiné aux Etats de Blois, sa veuve porta plainte au parlement contre Henri III. Catherine de Clèves mourut le 11 mai 1633 , à l'âge de quatre-vingt-quatre ans, et fut inhumée à Eu, dans la chapelle du collége qu'elle avait fondée.

La figure originale est dans la chapelle du collége d'Eu.

\section{Lorraine (Charles de), cardinal de Vaude- mont.}

Par Nicolas Drourn ; statue à genoux; plâtre. - H. 1,32.

Fils de Nicolas de Lorraine, duc de Mercour, né en 1561, il fut 
créé cardinal en 1578 par le pape Grégoire XIII. Évêque de Toul en 1580, puis de Verdun en 1584, il fut commandeur de l'ordre du Saint-Esprit en 1583. Il mourut le 30 octobre 1587, et fut enterré dans l'église des Cordeliers de Nancy.

La figure originale est dans l'église des Cordeliers de Nancy.

\section{Villeroy (Nicolas de Neufville, III du nom, seigneur de).}

Statue à genoux; plâtre. - H. 1,36.

Secrétaire du roi en 15339, et trésorier de l'ordre de Saint-Michel en 1547, il fut élu prévôt des marchands de la ville de $\mathrm{Pa}$ ris en 1506, et le roi Charles IX le fit chevalier de l'ordre de Saint-Michel en 15ั72. Il fut depuis gouverneur de Melun, Mantes et Meulan, et lieutenant du roi en l'Ile-de-France. Il mourut en 1598, et fut enterré dans l'église de Notre-Dame-de-Magny.

La figure originale est à Magny.

\section{Le Bouteiller de Senlis (Philippe)}

Statue à genoux; plâtre. - H. 1,37.

Il servit d'abord le roi Henri III, en qualité de gentilhomme ordinaire de sa chambre, fut enseigne, puis lieutenant et capitaine d'une compagnie de cent hommes d'armes, gouverneur de Paris et de l'Ile-de-France. Il mourut en 1627, âgé de soixanteseize ans. - Le chœur de l'église de Moussy-le-Vieux, près de Dammartin, a été bâti par Philippe Le Bouteiller de Senlis et Anne Dauvet, sa seconde femme, et un mausolée leur a été élevé en 1629, dans cette église, par Jean Le Bouteiller, leur fils.

La figure originale est dans l'église de Moussy-le-Vieux (Seine-et-Marne).

\section{Jeannin (Pierre), premier président au parle-} ment de Bourgogne.

Par Nicolas Goillain ; statue à genoux; plâtre. - H. 1,29.

Né à Autun en 15\%40, il étudia le droit sous Cujas et fut reçu avocat en 1569. Choisi pour être conseil des Etats de Bourgogne en 1571, il préserva la ville de Dijon des fureurs de la SaintBarthélemy, et fut envoyé comme député aux premiers Etats généraux de Blois en 1576. Il entra ensuite dans le parti de la Ligue et fut pendant six ans un des conseillers du duc de Mayenne. Après l'avénement de Henri IV, il se rallia à ce prince, fut nommé premier président au parlement de Bourgogne, partagea avec Sully toute la confiance du roi qui le chargea des négociations les plus importantes et signa en 1609, le traité qui assurait l'indépendance des Provinces-Unies. Nommé surintendant des 
finances par la reine régente Marie de Médicis, le président Jeannin mourut à Paris le 31 octobre 1622. - Ses Négociations ont été publiées par son petit-fils en $160 ّ 6$.

Cette statue et la suivante ont été moulées d'après des figures qui se trouvaient avant 1793 sous la chapelle Jeannin dans l'église cathédrale d'Autur. Mutilées durant les temps révolutionnaires, ces statues furent replacées ensuite dans une chapelle de la même église, à droite du maître-autel, dans une niche faite avec les débris du mausolée primitif. Sur la plaque de pierre qui supporte les statues originales, on lit cette inscription : N. G. dit de Cambray. F. Cet artiste fut le pere du sculpteur Simon Guillain.

\section{Gueniot (Anne).}

Par Nicolas Guillain; statue à genoux; plâtre. - 1,29.

Elle épousa, le 18 mars $10 ั 70$ Pierre Jeannin. On ignore l'époque de sa mort.

La figure originale est dans l'église cathédrale d'Autun. (Voir $\mathrm{n}^{\circ}{ }^{1309 .)}$

\section{L'Aubespine (Guillaumède), baron de Château- neuf.}

Par Ph. Buyster; statue à genoux ; plâtre. - H. 1,35.

Conseiller au parlement de Paris en 15̆68, et maître des requêtes en 10̆72, il fut ambassadeur en Angleterre, conseiller d'Etat et chevalier de la reine Louise de Lorrainè. Nommé en 1606 chevalier des ordres du roi, il mourut en 1629.

La figure originale est ,dans la cathédrale de Bourges.

\section{L'Aubespine (Marie de La Châtre, dame de).}

Par Ph. Boyster; statue à genoux; plâtre. - H. 1,34.

Femme de Guillaume de L'Aubespine. On ignore les dates de sa naissance, de son mariage et de sa mort.

La figure originale est dans la cathédrale de Bourges.

1313. Villeroy. (Nicolas de Neufville, IV $V^{e}$ du nom, seigneur de), secrétaire et ministre d'Etat. (Voir no 473.)

Statue à genoux; plâtre. - H. 1,36.

La figure originale est à Magny.

\section{L'Aubespine (Madeleine de).}

Statue à genoux ; plâtre. - H. 1.36 .

Fille de Claude de L'Aubespine, secrétaire d'État, née en $\mathbf{1 5 4 6}$, elle fut mariée en 15562 à Nicolas de Neufville, IVe du nom, seigneur de Villeroy. Elle fit l'ornement des cours de Charles IX, 
Henri III et Henri IV, et fut célébrée par Ronsard et les autres poètes de l'époque. On lui attribue une traduction des Epitres d'Ovide. Elle mourut à Villeroy, le 17 mai 1596, et fut enterrée avec son mari dans la chapelle de l'église paroissiale de Magny.

La figure originale est à Magny.

\section{Groulard (Claude), président au parlement de Rouen.}

Statue à genoux; plâtre. - H. 1,33.

Conseiller au grand conseil en 15ั78, premier président au parlement de Rouen en 1585 , il travailla par ordre du roi à la réforme de la Coutume de Normandie. Il mourut le $\perp^{\mathrm{er}}$ décembre 1607, âgé de cinquante-six ans, et fut inhumé aux Célestins de Rouen.

La figure originale est à Rouen.

\section{Guiffard (Barbe).}

Statue couchée; plâtre. - Long. 1,88.

Elle avait épousé en premières noces Robert Le Roux de Tilly, conseiller au parlement de Rouen, et se remaria en 1584 à Claude Groulard, dont elle fut la seconde femme.

La figure originale est à Rouen.

\section{Bec de Lièvre (Charles de), seigneur d'Hoc- queville.}

Statue à genoux; plâtre. - H. 1,40.

Né en 1579, il suivit le duc de Mercœur aux guerres de Hongrie et se distingua a siége de Canise. Maître d'hôtel du roi Henri IV, puis gentilhomme ordinaire de la chambre de Louis XIII, il fut conseiller d'Etat d'épée en 1619 et mestre de camp d'infanterie en 1620. Il mourut le 15 novembre 1622.

La figure originale est à Rouen.

1318. Le Goux (Jean-Baptiste), seigneur de La Berchère, premier président au parlement de Bourgogne.

Statue à genoux; plâtre. - H. 1,26.

Pourvu en 1595 d'un office de président aux requêtes, il fut nommé, en 1604, second président au parlement de Bourgogne, et peu après député par le parlement auprès de Henri IV, pour l'assurer de la fidélité de ce corps. Le 15 février 1612, il fut député de sa compagnie, par ordre du roi, pour traiter avec les députés 
du roi d'Espagne sur les limites du duché de Bourgogne, du comté d'Auxonne et de Franche-Comté,traité ratifié par Louis XIII en avril 1612. Il fut pourvu, en 1627, de la charge de premier président dans le même parlement, et mourut le 18 juin 1631, à l'âge de soixante-trois ans. Il fut enterré dans l'église des Cordeliers de Dijon.

La figure originale est dans l'église cathédrale de Dijon.

1319. Bérulle (Pierre de), cardinal. (Voir n ${ }^{\circ 26 .)}$

Par Pigalle; statue à genoux ; plâtre.- H. 1,35.

La figure originale est au collége de Juilly.

1320. L'Aubespine (Charles de), marquis de Châteauneuf, chancelier de France.

Statue à genoux; plâtre.-H. 1,32.

Né en 1580, il fut conseiller au parlement de Paris en 1603, ambassadeur extraordinaire en Hollande en 1609, puis à Bruxelles, à Venise et en Angleterre. Garde des sceaux en 1630, après la Journée des Dupes, il présida en 1632 au procès des maréchaux de Marillac et de Montmorency, et l'année suivante il fut luimême arrêté et enfermé au shâteau d'Angoulême, où il resta jusqu'en 1643. La reine Anne d'Autriche lui rendit les sceaux en 1650, et il mourut à Leuville le 17 septembre 1653.

La figure originale est dans l'église cathédrale de Bourges.

\section{Bourgoin (Jacques de), gouverneur de Cor- beil.}

Statue à genoux; plàtre. - H. 1,35.

Il fonda, en 1657 le collége de Corbeil, mourut elı 1661, et fut enterré dans l'église de Notre-Dame de Corbeil, sa paroisse natale.

La figure originale est dans l'église de Corbeil.

\section{Bec de Lièvre (Pierre de), marquis de Que- villy.}

Statue à genoux; plâtre. - H. 1,39.

Premier président de la cour des aides de Normandie, conseiller d'Etat ei au conseil privé en 16506 , il mourut le 13 juillet 1685 , et fut inhumé dans l'église des Carmes déchaussés de Rouen, qu'il avait fait bâtir.

La figure originale est à Rouen. 
1323. Cotoner (Nicolas), $59^{\mathrm{e}}$ grand maître de l'ordre de Malte.

Buste en plâtre. - H. 0,71.

Frère de Raphaël Cotoner, il était bailli de Négrepont et fut élu grand maître en 1663. Le 16 septembre 1669, les Tures s'emparèrent de Candie après vingt ans de blocus et vingt-neuf mois de siége, malgré les secours envoyés par Cotoner et ceux que le duc de Beaufort avait amenés de France. Nicolas Cotoner, qui mourut le 20 avril 1680, à l'âge de soixante-treize ans, avait beaucoup contribué à fortifier l'île de Malte.

Le buste original est dans l'ẻglise de Saint-Jean, à Malte.

\section{Caraffa (Grégoire), $60^{\mathrm{e}}$ grand maître de l'ordre de Malte.}

Buste en plâtre. - H. 0,76.

Grégoire Caraffa, napolitain, prieur de la Roccella au royaume de Naples, fut élu grand maître le 2 mai 1680. Sous son magistère, les chevaliers se distinguèrent dans les expéditions des Vénitiens en Dalmatie et dans la Morée. Caraffa mourut le 21 juillet 1690, âgé de soixante-seize ans.

Le buste original est dans l'église de Saint-Jean, à Malte.

\section{Pérellos (Raymond), $62^{\mathrm{e}}$ grand maître de l'ordre de Malte.}

Buste en plâtre. - H. 0,68 .

Raymond Pérellos de Roccaful, aragonais, bailli de Négrepont, fut élu grand maître au mois de février 1697 . Il augmenta la marine de la religion et fit construire des vaisseaux de guerre. Il mourut en 1720 , dans un âge fort avancé.

Le buste original est dans l'église de Saint-Jean, à Malte.

\section{Stanislas I (Stanislas Leczinski), roi de $\boldsymbol{P}_{0-}$ logne, duc de Lorraine et de Bar.}

Par VASSE; ; statue demi-couchée; plâtre. - Long. 1,86.

Staroste ou juge de la noblesse du palatinat d'Odalonow en 1696, il était palatin de Posnanie en 1700, lorsque la coalition des rois de Pologne et de Danemarck avec le czar de Russie attira les armées de Charles XII en Pologne; Stanislas fut alors élu roi le 12 juillet 1704. Le traité d'Altranstadt l'affermit d'abord sur le trône de Pologne, mais il le perdit à la suite de la bataille de Pultawa en 1709. Il prit álors possession de la princi- 
pauté des Deux-Ponts, qui lui avait été donnée par le roi de Suède, et y resta jusqu'en 1720. Il vint alors chercher un asile en France, habita d'abord Weissembourg, puis le château de Chambord. En 1733, Stanislas fut de nouveau appelé au trône de Pologne, et en 1738, le traité de Vienne lui accorda la souveraineté de la Lorraine et du duché de Bar. Il mourut au château de Lunéville, le 23 février 1766, à l'âge de quatre-vingt-neuf ans

La figure originale est dans l'église de Bon-Secours, à Nancy.

\section{Catherine Bnin-Opalinska, reine de Pologne.}

Par N.-S. ADAM; statue à genoux; plâtre. - H. 1,63.

Elle épousa en 1698 Stanislas I ${ }^{\mathrm{er}}$, roi de Pologne, et mourut $\dot{\mathrm{d}}$ Lunéville, le 19 mars 1747, à l'âge de soixante-sept ans.

La flgure originale est dans l'église de Bon-Secours, à Nancy.

1328. Vilhena (Antoine-Manucl de), $64^{\mathrm{e}}$ grand maître de l'ordre de Malte.

Buste en plâtre. - H. 0,62.

Vilhena était Portugais, et il devint grand maître le 19 juillet 1722, après avoir passé par toutes les charges de la religion. Il mourut le 12 décembre 1736, à l'âge de soixante-quatorze ans.

Le buste original est dans l'église de Saint-Jean, à Malte.

\section{Rohan (Emmanuel de), 68 e grand maître de} l'ordre de Malte.

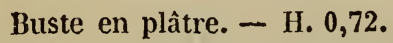

Emmanuel-Marie des Neiges de Rohan de Polduc, de la langue de France, bailli de l'ordre, général des galères en 1757, parvint au magistère le 12 novembre 1775 . Il convoqua en 1776 un chapitre général auquel il présida; il acheva de réunir l'ordre de Saint-Antoine à celui de Malte; en 1782, il fut créé une nouvelle langue sous le nom de Bavière. Il mourut en 1797.

Le buste original est dans l'église de Saint-Jean, à Malte.

\section{Du Couedic de Kergoualer (Charles-Louis, vicomte), capitaine de vaisseau.}

Par M. Bovgron en 1830; buste en plâtre. - H. 0,70.

Né au château de Kerguelenen le 17 juillet 1740, il fut gardemarine en 4756 et servit sur mer jusqu'en 1759 . Sous-brigadier en 1763, et ensuite enseigne de vaisseau, il croisa dans les mers de l'Inde depuis 1767 jusqu'en 1771. Enseigne des gardes de la 
marine en 1773 , lieutenant de vaisseau et chevalier de SaintLouis en 1777, il se trouva à la bataille d'Ouessant en 1778. Du Couedic fut blessé dans un combat livré par la Surveillante à la frégate anglaise le Québec le 7 octobre 1779; il fut nommé capitaine de vaisseau, et mourut à Brest des suites de ses blessures le 7 janvier 1780.

Le buste original est au Musée de Marine, au Louvre.

\section{Lamotte-Picquet (Toussaint-Guillaume), comte de), lieutenant général des armées navales.}

Par M. Brion; buste en plàtre. - H. 0,72.

Né à Rennes en 1720 , il entra dans la marine en 1735 , et fit plusieurs campagnes dans la Méditerranée. Lieutenant de vaisseau et chevalier de Saint-Louis en 1745 , capitaine de vaisseau en 1763, il fit une campagne au Canada. Chef d'escadre en 1778, Lamotte-Picquet se trouva au combat d'Ouessant et à la prise de la Grenade en 1779. Dans la campagne d'Amérique, il se signala all combat de Fort-Royal, captura vingt-six vaisseaux de l'escadre de l'amiral Rodney en $\mathbf{1 7 8 2}$, et fut nommé lieutenant général en 1782. Il mourut à Brest le 11 juin 1791.

Le buste original est au Musée de Marine, au Louvre.

\section{Lapérouse (Jean-François Galaup, comle de), chef d'escadre.}

Par M. Rude ; buste en plâtre. - H. 0;70.

Né à Alby en 1741, il fut garde-marine en 1756, enseigne de vaisseau en 1764, et fit de 1765 à 1777 plusieurs campagnes au Bengale, en Chine et dans l'Inde. Lieutenant de vaisseau en 1777, il se trouva à la prise des îles de Saint-Vincent et de la Grenade. Capitaine de vaisseau en 1780, il fit en 1782 une campagne en Amérique, et reçut en $\mathbf{1 7 8 5}$ le commandement d'une expédition autour du monde. Lapérouse partit le $\mathbf{L}^{\mathrm{er}}$ août $\mathbf{1 7 8 5}$ de Brest, ayant sous ses ordres les frégates la Boussole et l'Astrolabe. Il était à Botany-Bay au mois de février 1788, et depuis on cessa entièrement d'avoir de ses nouvelles. En 1816, le hasard fit découvrir au capitaine anglais Dillon les débris des vaisseaux de Lapérouse dans une des îles Vanikoro, et ces débris, recueillis en 1828 par le capitaine Dumont d'Urville, ont servi à composer le monument en forme d'obélisque qui se trouve au Musée de Marine.

Le buste original est au Musée de Marine, au Louvre. 


\section{VESTIBULE $N^{\circ} 61$.}

\section{Condé (Louis de Bourbon I ${ }^{e r}$, prince de).}

Par Aug. Dumont; statue en plâtre. - H. 2,10.

Né à Vendôme en 15ั30, il était fils de Charles de Bourbon, duc de Vendôme, et fit ses premières armes sous le maréchal de Brissac en Piémont. Reconnu à Orléans en 1502 comme chef du parti calviniste, il commanda les armées protestantes aux batailles de Dreux et de Saint-Denis, et fut assassiné à la suite de la bataille de Jarnac, le 13 mars 15069.

\section{Condé (Henri de Bourbon II, prince de), grand maître et grand veneur de France.}

Par G. GuÉnin; statue demi-couchée; plâtre. - Long. 1.90.

Fils unique et posthume de Henri de Bourbon, Ier du nom, prince de Condé. Né à Saint-Jean-d'Angely le ${ }^{\text {er }}$ septembre 1508; chevalier de lordre du Saint-Esprit en 1610, il fit la campagne de 1621 sous le roi Louis XIII, et commanda en 1622 l'avantgarde de l'armée au combat de Rié, fut genéral des armées du roi en Guyenne et en Languedoc dans l'année 1627, gouverneur de la Lorraine en 1630̈, et commanda en Franche-Comté dans l'année 1636. Le prince de Condé fut nommé en 1643 chef des conseils de régence sous l'autorité d'Anne d'Autriche pendant la minorité de Louis XIV. Il mourut à Paris le 26 décembre 1646.

" Henri de Bourbon, prince de Condé, étant mort en l'année 1646, on lui fit deux magnifiques mausolées : un dans l'église des Jésuites de la rue Saint-Antoine, où son cœur est en dépôt, et l'autre élevé sur le lieu où repose son corps dans la chapelle du château de Valery, qui est dans le Gatinais, entre Sens et Fontainebleau. Celui de Valery fut fait par M. Guérin. Dans celui-ci on roit la figure de $M$. le Prince, couchée sur le côté, au-dessus d'une espèce d'ordre d'architecture, soutenu par quatre grands termes. Tout est de marbre. Les armes de M. le Prince sont portées par de jeunes enfants qui représentent les Génies de la Douleur, et au-dessus il $\mathrm{y}$ a quatre figures chacune de six pieds de haut, qui représentent la Force, la Justice, la Prudence et la Tempérance." (Guillet de Saint-Georges. - Mémoire des ouvrages de M. Guérin.)

La figure originale est dans l'église de Valery en Gatinais.

\section{Condé (Louis de Bourbon II, prince de), sur- nommé le Grand Condé.}

Par Corzevox; statue en plàtre. - H. 2,12.

Fils de Henri de Bourbon, II ${ }^{e}$ du nom, prince de Condé, né à Paris le 8 septembre 1621. Connu d'abord sous le nom de duc 
d'Enghien, il fit ses premières campagnes comme volontaire au siége d'Arras en 1640, et au siége d'Aire en 1641. Il commanda la noblesse de Languedoc au siége de Perpignan en $\mathbf{1 6 4 2}$, recut le commandement en chef des armées de Flandre et de $\mathrm{Pi}$ cardie dans l'année 1643 et gagna la bataille de Rocroy. Gouverneur de Champagne et de Brie en 1644, il commanda l'armée d'Allemagne, se joignit au vicomte de Turenne, combattit à Fribourg le général Merci, et s'empara ensuite des villes de Spire, Philipsbourg, Worms, Oppenheim. En 164.ّ, il prit Rottembourg et remporta la victoire de Nordlingen ; il commença en 1646 la campagne de Flandre sous les ordres de Monsieur, duc d'Orléans, et reçut le commandement en chef de l'armée après le départ de ce prince. Prince de Condé en 1646, après la mort de son père, gouverneur de Berry, grand maître de la maison du roi, gouverneur de Bourgogne et de Bresse en 1647, il fit la même année la campagne de Catalogne après avoir été nommé vice-roi de cette province et commandant en chef de l'armée. Dans l'année 1648, il passa en Flandre, s'empara des villes d'Ypres et de Furnes, et gagna la bataille de Lens : son rôle fut moins glorieux pendant les troubles de la Fronde. Rentré en France en 1659 , après le traité des Pyrénées, il recouvra les bonnes grâces du roi, le précéda en Franche-Comté dans l'année 1668, et après la conquête de cette province il prit le commandement de l'armée sur la Sambre. Il fit en 1672 la campagne de Hollande et se trouva au passage du Rhin. Dans les années 1673 et 1674 , il continua à commander les armées de Flandre et de Franche-Comté, et gagna la bataille de Seneff. Général des armées de Flandre et d'Allemagne en 1675 , il forca Montécuculli à repasser le Rhin, et se retira ensuite à Chantilly. Il mourut le $\mathbf{1 1}$ décembre $\mathbf{1 6 8 6}$.

La figure originale est à Chantilly.

\section{Condé ( Louis-Joseph de Bourbon, prince de).}

Par M. Dantan aîné; statue en plâtre. - H. 2,12.

Fils de Louis-Henri de Bourbon, prince de Condé, né à Chantilly en 1736, il fit ses premières armes en Allemagne dans la guerre de Sept-Ans. Il émigra le 17 juillet 1789 avec sa famille, ainsi qu'un grand nombre de gentilshommes qui plus tard formèrent sous ses ordres l'armée dite de Condé. Après la dispersion'de cette armée en 1800, il se retira en Angleterre, rentra en France lors de la Restauration, et reçut de Louis XVIII le titre de grand maître de la maison du roi et de colonel général de l'infanterie. Il mourut à Chantilly le 13 mai 1818. 
1337. Condé (Louis-Henri-Joseph de Bourbon, prince de). (Voir n ${ }^{\circ} 486$.)

Par M. LeMaIRe en 1846 ; statue ell plâtre. - H. $2,12$.

1338. Condé (Louise-Marie-Thérèse-Bathilde d'Orléans, princesse de).

Par M. Duret; buste en plàtre. - H. 0,70.

Fille de Louis-Philippe, duc d'Orléans, née en 17000 , elle fuน mariée en 1770 à Louis-Henri-Joseph de Bourbon-Condé, et mourut à Paris le 10 janvier 1822.

1339. Enghien (Louis-Antoine-Henri de Bourbon),
duc d').

Par Bosio; statue en marbre. - H. 2,08.

Fils de Louis-Henri-Joseph de Bourbon-Condé, né à Chantilly en 1772. Il suivit le prince de Condé, son grand-père, dans l'émigration, et fut chargé d'un commandement de cavalerie dans l'armée dite de Condé. Après le licenciement de cette armée, le duc d'Enghien se retira, en 1801, à Ettenheim, dans le grandduché de Bade. Soupconné de conspirer contre le gouvernement français, il fut arrêté dans cette retraite, conduit au château de Vincennes, condamné par une commission militaire, et fusillé le 21 mars 1804.

VESTIBULES DE L'ORANGERIE, № 62. PREMIĖRE PARTIE.

1340. Louis XVIII, roi de France. (Voir $n^{\circ} 721$. )

Par RoMagnesi en 1817; buste en marbre. - H. 0,80.

1341. Louis XVIII, roi de France. (Voir $\mathrm{n}^{\circ} 721$.)

Buste en marbre. - H. 0,74.

1342. Louis XVIII, roi de France. (Voir $\left.n^{\circ} 721.\right)$

Buste en marbre. - H. 0,72.

1343. Louis XVIII, roi de France. (Voir no 721.)

Buste en marbre. - H. 0,62. 


\section{DEUXIÈME PARTIE.}

1344. Ferdinand $I^{\text {er }}$ ou $I V$, roi des Deux-Siciles.

Par M. Ristori; buste en marbre. - H. 0,62.

Troisième fils de Charles III, roi d'Espagne, né à Naples en 175\%1. Il n'avait que huit ans lorsqu'il prit possession du trône de Naples en 1759 , sous la régence d'un conseil présidé par le marquis de Tanucci. En 1799, les Français s'emparèrent de ses états de terre ferme, mais il y rentra l'année suivante. Il les perdit de nouveau en 1806; Napoléon donna ce royaume à Joseph, son frère, puis à Murat, et Ferdinand continua de régner en Sicile. En 1814, il remonta sur le trône de Naples, et mourut le 4 janvier 182.

1345. Louis-Philippe $I^{e r}$, roi des Français. (Voir $\left.1^{\circ} 723.\right)$

Par M. Aug. Dumont; statue en plâtre. - H. 2,19.

1346. Marie-Amélie-Thérèse, princesse des DeuxSiciles, reine des Français.

Par Bosio; statue en marbre. - H. 2,08.

Fille de Ferdinand Ier, roi des Deux-Siciles, née à Caserte, en 1782, elle fut mariée à Palerme, en 1809, à Louis-Philippe, duc d'Orléans, depuis roi des Français.

\section{Orléans (Ferdinand-Philippe-Louis, duc d').}

Par M. JALEY; statue en plâtre. - H. 2,21.

Fils ainé de Louis-Philippe, duc d'Orléans, né à Palerme en 1810, il fut colonel du $1^{\text {er }}$ régiment de hussards en 1820. Devenu prince royal après la révolution de 1830 , il commanda en 1832 l'avant-garde au siége d'Anvers, fut blessé en 1835 au combat de l'Habrah, en Algérie, et franchit en 1839, avec le maréchal Valée, le passage des Portes de Fer. Il périt, le 13 juillet 1842 , d'une chute de voiture sur la route du château de Neuilly.

\section{Louis (Louis-Dominique, baron), ministre.}

Buste en plâtre. - H. 0,65.

Né à Toul, en $175 \%$, il recut les ordres et assista l'évêque d Autun en qualité de diacre à la fête de la Fédération en 1790. Pendant l'émigration, il étudia le système financier de l'Angleterre, fut chargé du portefeuille des finances en 1816, 1818 et 1831, et 
414 Vestibule de L'escalier de PROVence, No 63.

siégea comme député dans presque toutes les assemblées législatives depuis 1815. Il mourut à Bry-sur-Marne le 26 août 1837.

\section{Rigny (Henri Gauthier, comte de), vice-amiral.} Buste en plâtre. - H. 0,70 .

Né à Toul (Meurthe), en 1783, il entra de bonne heure dans la marine, fut incorporé en 1806 dans la grande armée avec les marins de la garde, et combattit en Allemagne et en Espagne. Capitaine de vaisseau en 1816, il fut plus tard chargé de croiser dans les mers du Levant, et fut élevé en 1824 au grade de contreamiral. Il commanda en $\mathbf{1 8 2 6}$ l'escadre française à Navarin, et fut nommé vice-amiral. Depuis 1830 , le comte de Rigny fut successivement ministre de la marine, ministre des affaires étrangères et ambassadeur à Naples. Il mourut à Paris le 7 novembre $1830 ّ$.

\section{Magnay (Charles), lord maire de la ville de Londres.}

Par M. J.-E. JoNes en 1844 ; buste en marbre. - H. 0,71.

VESTIBULE DE L'ESCALIER DE PROVENCE, No 63.

Cet escalier, qui conduisait, sous Louis XVI, dans la partie occupée par Monsieur, comte de Provence, a conservé le nom d'Escalier de.Provence.

1351. Marie Leczinska, reine de France.

Par M. Joufrroy; buste en plâtre. - H. 0,69.

Fille de Stanislas Leczinski, roi de Pologne. Née à-Posen en 1703, elle fut mariée à Fontainebleau, le š septembre 1725, à Louis XV, et mourut à Versailles le 24 juin 1768.

\section{Louis de France, dauphin (Voir no ${ }^{192 .)}$}

Par M. Dantan aîné; statue en plâtre. - H. 2,20.

1353. Marie-Thérèse-Antoinette-Raphaelle, infante d'Espagne, dauphine de France.

Par M. MERGier; buste en plâtre. - H. 0,67.

Fille de Philippe V, roi d'Espagne, née en 1726. Le mariage de cette princesse avec Louis, dauphin, fils de Louis XV, fut célébré en 1744 à Madrid, et en $1745^{\circ}$ à Versailles. Elle mourut à Versailles le 22 juillet 1746 . 


\section{Marie-Josèphe de Saxe, dauphine de France.}

Par M. Dantan aîné; buste en plâtre. - H. 0,71.

Fille de Frédéric-Auguste II, roi de Pologne et électeur de Saxe, née à Dresde en 1731. Louis de France, dauphin, l'épousa en secondes noces en 1747. Cette princesse fut mère de Louis XVI, de Louis XVIII et de Charles X. Elle mourut à Versailles le 13 mars 1767.

\section{Louis XVI, roi de France. (Voir n ${ }^{\circ}$ 719.)}

Par Согтот; statue en plâtre. - H. 2,37.

Cette statue était destinée à décorer le monument à la mémoire de Louis XVI, qui devait être élevé au centre de la place de la Concorde, à Paris. Aux angles du piédestal sont placées quatre figures de 1,05 de proportion, représentant $l a$ Justice, la Piété, la Bienfaisance et la Modération, qui faisaient partie du monument projeté,

\section{Louis $X V I$, roi de France. (Voir n $\left.{ }^{\circ} 719.\right)$}

Par CoRтот; statue en plâtre. - H. 2,23.

\section{Marie-Antoinette d'Autriche, reine de France.}

Par Leconte; buste en plâtre. - H. 0,74.

Fille de François Ier, empereur d'Allemagne, et de Marie-Thérèse d'Autriche. Née à Vienne le 2 novembre 1755 , elle fut mariée à Versailles, le 16 mai 1770, à Louis-Auguste de France, dauphin, depuis Louis XVI. Elle mourut à Paris sur l'échafaud révolutionnaire le 16 octobre 1793. Sa dépouille mortelle, d'abord déposée dans le cimetière de l'église de la Madeleine, fut transférée dans la basilique de Saint-Denis en 1815 .

\section{Marie-Adélaïde-Clotilde-Xavière de France} (Madame Clotilde), reine de Sardaigne.

Par FEUGHÈre; buste en plâtre. - H. 0,80.

Fille de Louis, dauphin, et de Marie-Josèphe de Saxe, nēe en 17509. Elle fut mariée en 1775 à Charles-Emmanuel Ferdinand IV, roi de Sardaigne, et mourut en 1802.

\section{Elisabeth-Philippine-Marie-Hélène de France (Madame Elisabeth).}

Par M. Aug. Dumont; buste en plâtre. - H. 0,65 .

Fille de Louis, dauphin, née en 1764. Elle fut enfermée au Temple avec la famille de son frère Louis XVI, et périt sur l'échafaud révolutionnaire le 10 mai $\mathbf{1 7 9 4 .}$ 
1360. Louis XVIII, roi de France. (Voir n' ${ }^{\circ 21 .)}$

Par M. Bosio neveu; statue en plâtre. - H. 1,90.

Le roi est représenté assis sur son trône et tenant la Charte. Cette figure derait ètre exécutée pour la place du Palais-Bourbon, à Paris.

1361. Charles $\mathrm{X}$, roi de France. (Voir no ${ }^{\circ 22 .)}$

Par M. GaIllouet; statue en plâtre. - H. 2,20.

1362. Angoulême (Louis-Antoine d'Artois, duc d'). (Voir nº 937.)

Par M. BrA; statue en marbre. - H. 2,12.

Le prince est représenté au siége de Cadix, disant aux envoyés des Cortès : "Si la famille royale n'est pas délivrée ce soir, demain à la pointe du jour les hostilités commenceront; le roi ou l'assaut. n

Cette figure a été exposée au Salon de 1824.

1363. Angoulême (Marie-Thérèse-Charlotte de France, duchesse d').

Par M. ValoIs; buste en plâtre. - H. 0,68 .

Fille de Louis XVI, née à Versailles en 1778. Elle fut enfermée au Temple avec la famille royale et en sortit en 179ò. Le 10 juin 1799, elle épousa à Mittau son cousin, le duc d'Angoulême, et revint en France en 1814. Lors de la révolution de 1830, elle suivit le roi Charles $\mathrm{X}$ dans l'exil, et mourut à Frohsdorff le 19 octobre 18 šl.

\section{Berry (Charles-Ferdinand d'Artois, duc de).}

Par Rutahies; buste en plâtre. - H. 0,39.

Second fils du comte d'Artois (depuis Charles $\mathbf{X}$ ), né à Versailles en 1778. Il suivit sa famille dans l'émigration, servit dans l'armée de Condé et revint en France en 1814. Il épousa en 1816 Marie-Caroline, princesse des Deux-Siciles, et fut assassiné à Paris le 13 février 1820, en sortant de l'Opéra.

VESTIBULES No 64 .

PREMIĖRE PARTIE.

1365. Mausolée de Philippe-le-Beau et de Jeanne-la. Folle.

Plàtre. - II. 2,76. - L. 3,06. - Long. 3,57.

Philippe-le-Beau, archiduc d'Autriche, second fils de Maximi- 
lien Ier, empereur d'Allemagne, épousa en 1496 l'infante Jeanne, fille de Ferdinand-le-Catholique et d'Isabelle de Castille. Cette princesse lui apporta en dot le royaume de Castille et ceux qui en dépendaient, et après la mort d'Isabelle, il fut reconnu et couronné roi sous le nom de Philippe Ier. Il mourut à Burgos le 20 décembre 1506, à l'âge de vingt-huit ans, et Jeanne lui survécut jusqu'en 1555ว ; mais sa raison s'était égarée, ce qui l'a fait appeler Jeanne-la-Folle.

Les angles de la base sont ornés de quatre figures ailées à pieds de griffons, accompagnées d'enfants et portant divers attributs; au centre de chacune des faces se trouve un bas-relief circulaire représentant : la Nativité de J.-C., l'Adoration des Mages, J.-C. au Jardin des Oliviers et la Mise au tombeau. Ces bas-reliefs sont accompagnés de douze figures de Vertus. Aux angles de la frise sont, du côté du roi, saint Michel terrassant le démon et saint Philippe, et du côté de la reine, saint Jean l'Evangéliste et saint Jean le Précurseur. Au centre de la face principale, deux anges soutiennent un cartouche sur lequel est tracée une inscription; sur les trois autres côtés, des anges portent l'écusson l'Espagne. Sur la plate-forme supérieure sont les statues couchées de Philippe et de Jeanne, dont un moulage séparé est placé dans la même salle.

Ce monument, élevé par Charles-Quint à la mémoire de son père et de sa mère, a été moulé d'après le tombeau placé dans la chapelle royale de l'église de l'Ange-Gardien, à Grenade. (Voir $\mathbf{n}^{\circ} 311$.)

On lit sur le cartouche de la fice principale :

Vita defunctos : Fama superstites tegit hoc sepulchrum.

Philippum, et nomine et Austriaco genere Hispan. Reg. I : quem, cum falcata mors invenisset virtutib. maturu ampu tavit Juvenem, dû putavit senem. Obijt an Dni. 1506 etat S. 28 et Joannam eius conjugem, quâ oia Castelle, Legion. et Aragon. Regia stémata collustrarunt. Ob. an. 1555 etat. S. 76 Quid plura

exeorû. Consortio mundo illuxit Seren. Imp. Carolus V. qui Parentibus suis hoc erexit Monumentum.

\section{DEUXIÈME PARTIE.}

\section{Tombeau de Diane de Poitiers.}

Marbre. - H. 3,19. - L. 1,08. - Long. 2,10.

Ce monument, élevé à la mémoire de Diane de Poitiers par sa fille, Louise de Brézé, était placé autrefois dans une chapelle extérieure du château d'Anet, dite chapelle de Diane. Il est décrit de la manière suivante dans la Description du chateau d'Anet. - Chartres, 1777 : "Le bâtiment est voûté en pierres et briques, et au milieu est le mausolée de Diane en marbre noir, soutenu par quatre sphinx de marbre blanc. Au-dessus du tombeau est Diane à genoux devant un prieDieu et les mains jointes. Derrière elle deux génies soutiennent l'écusson de ses armes; le tout en marbre blanc. Au côté droit de ce monument est cette inscription :

D. 0 . M.

ETERNA Q. MEMORIE

DIANCE PICTONEN. DVCIS VALETINA LODOICI BRESEI SVHI APUD NORMANOS

SENESGALLI VXORIS PIETAT. AG RELIGIONIS

INTEGRITATE LAVDABILIS HVIVSQ. SACRE EDIS CONDITRICIS CHARISS. MATRIS PIETISS.

FIL. LODOICA PRINCIP. ILLVSTRISS CLAVD. LOTHARAX

DVC. AVMALIVI FRANGISCO ROBERTI MARKIANI

STRENVISS. DVG. BVLLIONEN COIVG. MESTISS. P. P. 
SALLES DES MARINES, No 6 ă.

Au côté gauche du même mausolée est cette autre inscription :

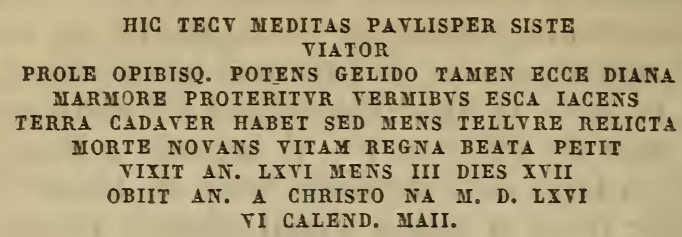

Acheté sous la Rérolution par Alexandre Lenoir, le tombeau de Diane de Poitiers avait été transporté au Musée des Monuments français, et lors de la suppression de ce Musée, le duc d'Orléans l'avait fait placer dans un pavillon clu parc de Neuilly. (Voir $n^{\circ} 328$. )

\section{SALLES DES MARINES, N0 6วั.}

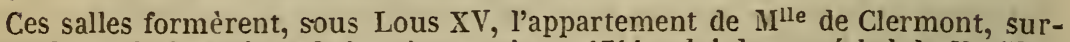
intendante de la maison de la reine, puis en 1741 celui du maréchal de Noailles. Sous Louis XVI, le comte de Provence (depuis Louis XVIII) eut la jouissance de toute cette partie du palais, qui a conservé les noms de Pavillon de Monsieur et de Pavillon de Provence.

\section{PREMIÉRE SALLE.}

La frise est ornée de sept médaillons peints par P. Frar̃us, et représentant Hugues Quieret, Jean de Vienne, Charles d'Amboise, André Doria, le duc de Richelieu, Henri d'Estampes-Valençay, César et François, ducs de Beaufort, le duc de Brézé, et Sourdis, archevêque de Bordeaux.

\section{La flotte de Philippe de Valois pille et brûle Southampton. - 1339 .}

Par M. Th. Gudix. - H. 0,58. - L. 0,80.

Philippe de Valois, menacé à la fois sur terre et sur mer par Édouard III, roi d Angleterre, avait engagée à śa solde des vaissaux espagnols, que leurs capitaines lonaient alors au plus offrant, et appelé aussi des mers d'Italie vingt galères de Gênes, et vingt de Monaco, sous les ordres d'Aitone Doria et de Barbavara, corsaire de Porto-Venere. A cette flotte étrangère il joignit tout ce quil put rassembler de navires français des côtes de Bretagne, de Normandie et de Picardie, et il mit le tout sous les ordres de Hugues Quieret, amiral de France, et de Pierre Behuchet, son trésorier.

" Il vinrent, dit Froissart, un dimanche matin au havre de Hantonne (Southampton), entrementes (pendant) que les gens étoient à messe ; et entrèrent lesdits Normands et Gênois en la ville et la prirent, et la pillèrent, et robèrent tout entièrement, et y tuèrent moult de gens, etchargèrent leurs nefs et leurs vaisseaux de grand pillage qu'ils trouvèrent en la ville, qui étoit pleine, drue et bien garnie, et puis rentrèrent en leurs nefs. Et quand le flux 
de la mer fut revenu, ils désancrèrent et cinglèrent à l'exploit du vent devers Normandie, et s'envinrent rafraîchir à Dieppe, et là départirent leur butin et leur pillage. »

\section{Expédition de Jean de Vienne sur les côtes d'Angleterre. - 1377.}

Par M. Th. Gudin. - H. 0,58. - L. 1,04.

Sous le règne de Charles $\mathrm{V}$, les flottes combinées de France et de Castille, commandées par les amiraux Jean de Vienne et Fernand Sanche de Tomar, opérèrent une descente à Rye, un des cinq ports privilégiés d'Angleterre, et réduisirent cette ville en cendres. Durant plus de deux mois, la flotte franco-espagnole promena la terreur et la dévastation tout le long de la côte méridionale d'Angleterre; elle ravagea l'île de Wight, brùla Yarmouth, Darmouth, Plymouth, Winchelsea et Douvres, sans les attaquer sérieusement parce que ces villes étaient trop bien gardées.

\section{Défaite d'une flotte anglaise devant Saint- Mahé. - 1403 .}

Par M. Th. Gudiv. - H. 0,58. - L. 1,04.

Au commencement de l'an 1403, rapporte Monstrelet, "l'amiral de Bretagne, le sire de Penhoet, le seigneur du Châtel, le seigneur du Bois, et plusieurs autres chevaliers et écuyers de Bretagne, jusqu'au nombre de douze cents hommes d'armes, s'assemblèrent à Morlans, puis entrèrent en trente nefs, à un port nommé Châtel-Pol, contre les Anglois qui étoient sur mer en grande multitude, épiant les marchands comme pillards et écumeurs de mer. Les Bretons leur allèrent après, et les poursuivirent jusqu'au lendemain soleil levant, qu'ils s'arrêtèrent ensemble en bataille, qui dura jusqu'à trois heures. Finalement les Bretons obtinrent victoire, et prirent des Anglois deux mille combattants, avec quarante nefs à voiles, et une grosse carraque, dorit la plus grande partie furent jetés à bord et noyés en la mer. »

\section{Victoire des Français sur la flotte anglaise devant Brest. - 25 avril 1513.}

Par M. Th. GUdiN. - Forme ronde; diam. 0,58.

Henri VIII, entré dans la Ligue contre la France, préparait une descente sur les côtes du royaume. Louis XII, pour écarter ce danger, fit, selon le récit de Du Bellay, passer par le détroit de Gibraltar quatre galères sous la charge du capitaine Prégent pour résister aux incursions que faisaient les Anglais le long des côtes 
de Normandie et de Bretagne. "L'amiral d'Angleterre, lequel avoit donné la chasse aux galères dudit Prégent, jusque près de Brest, fut combattu par lesdites galères, et fut blessé ledit amiral, rui mourut quelques jours après. „ (Mémoires de Martin Du Bellay.)

\section{Combat de la Cordelière et de la Régente devant Saint-Mathieu. - 10 août 1513.}

Par M. Th. Gudin. - H. 0,58. - L. 0,79.

" Devant Saint-Mathieu en Bretaigne, le jour de saint Laurent, fut combattu par quatre-vingts navires angloises contre vingt bretonnes et normandes, et estant le vent pour nous et contraire aux Anglois, fut combattu en pareille force : et entre autres le capitaine Primauguet, Breton, capitaine de la Cordelière, navire surpassant les autres en grandeur, que la royne Anne avoit fait construire et équipper, se voyant investy de dix ou douze navires d'Angleterre, et ne voyant moyen de se développer, voulut vendre sa mort ; car ayant attaché la Régente d'Angleterre, qui estoit la principale nef des Anglois, jeta feu, de sorte que la Cordelière et la Régente furent bruslées, et tous les hommes perdus, tant d'une part que d'autre. "(Mémoires de Martin Du Bellay.)

1372. André Doria disperse une flotte espagnole devant l'embouchure du Var. - 7 juillet 1524. Par M. Th. GUdiv. - H. 1,42, - L. 2, 27.

La flotte commandée par André Doria, amiral génois alors au service de François Ier, attaque, devant l'embouchure du Var, la flotte espagnole de Hugues de Moncade; elle lui coule à fond trois galères, et force le reste à abandonner les côtes de Provence.

Ce tableau a été exposé au Salon dè 1847.

1373. Une flotte équipée par Ango bloque Lisbonne. -1533 .

Par M. Th. GudrN. - H. 0,58. - L. 1,00.

Ango, riche armateur de Dieppe, avait reçu de François I ${ }^{\text {er }}$ la nomination de gouverneur des ville et chẳeau de Dieppe. Les Portugais ayant, en pleine paix, attaqué et pris un des vaisseaux de l'armateur dieppois, Ango résolut de tirer vengeance de cet acte déloyal, équipa dix-sept bâtiments, tant grands que petits, et fit bloquer le port de Lisbonne pendant que les flottes portugaises étaient occupées dans les Indes. Parvenue à l'embouchure 
lu Tage, la flotte dieppoise s'empara d'une foule de petits bâtiments, fit une descente et ravagea la côte. Ango ne cessa ses hostilités que lorsque le roi de Portugal eut adressé un ambassadeur au roi de France, qui le renvoya à Dieppe pour qu'il entrât en négociation avec l'auteur de l'expédition.

Ce tableau a étẻ exposé au Salon de 1848.

\section{Jacques Cartier découvre le fleuve Saint-Lau- rent. - 1535.}

Par M. Th. GudrN. - H. 1,42. - L. 2,27.

Jacques Cartier, navigateur de Saint-Malo, s'était proposé à Philippe de Chabot, grand amiral de France, pour aller visiter les terres de l'Amérique septentrionale désignées sous le nom de Terres-Neuves. Cette demande ayant été présentée au roi par le grand amiral, Francois Ier avait chargé Cartier lui-même d'exécuter ses projets, et dans un premier voyage, en 1534, il avait découvert le golfe Saint-Laurent et l'embouchure de ce fleuve; mais l'approche de la mauvaise saison l'avait rappelé avant quil cût eu le temps de pousser plus loin ses découvertes. Sur le récit de son voyage, le roi ordonna un armement plus considérable que le premier : on équipa trois hâtiments, dont un propre à entrer dans les rivières où il n'y aurait pas assez d'eau pour les deux autres; ils mirent à la voile le 19 mai 1530. Cartier, dans cette nouvelle campagne, pénétra dans l'intérieur du fleuve SaintLaurent; il le visita avec soin, et s'avança à sept ou huit lieues au delà de l'endroit où depuis la ville de Québec fut bâtie. La rivière près de laquelle la flotte mouilla recut le nom de SainteCroix; mais la postérité lui a donné celui de Jacques Cartier. Cartier remonta avec ses canots jusqu'à un village que les habitants appelaient Hochelaga, et sur les ruines duquel s`éleva plus tard la ville de Montréal, située à plus de cent cinquante lieues marines de l'embouchure du fleuve. Après un hiver rigoureux passé à Sainte-Croix, Cartier se rembarqua le 6 mai 1536 , et sortit du fleuve par le canal qui est au sud de l'ìle d'Anticosti, et qu'il avait pris, en 1534, pour un golfe. Il vint ensuite chercher le passage qu'il avait supposé, à la même époque, devoir exister au sud de Terre-Neuve ; il le trouva, et compléta, par cette dernière découverte, celle du fleuve et du golfe Saint-Laurent. Les bâtiments revinrent à Saint-Malo le 16 juillet 1536. Jacques Cartier nıontra ainsi aux Français la route du Canada.

Ce tableau a été expos: au Salon de 1847. 


\section{Défaite d'une flotte hollandaise sur les côtes d'Angleterre. - août 1555.}

Par M. Th. Gudin. - H. 0,58. - L. 1,00.

Marie d'Autriche, gouvernante des Pays-Bas, venait de saisir et de confisquer tous les navires français trafiquant dans les ports de Flandre. Pour tirer vengeance de cet affront, les bourgeois et marchands de Dieppe équipèrent une flotte composée de dix-neuf bateaux pêcheurs armés en guerre, dont le commandement fut donné à d'Espineville, de Harfleur. Le $\breve{~ a o u ̂ t ~ 15 ๊ o ̆ ~ l a ~ f l o-~}$ tille sortit du port et rencontra le 11 une flotte flamande composée de vingt-quatre hourques. Après un combat acharné dans lequel d'Espineville fut blessé mortellement, douze bâtiments flamands furent engloutis à demi consumés, le reste prit la fuite ou devint la proie des Dieppois. Le lendemain, 12 août, la flotille, veuve de son capitaine, et réduite à quatorze ou quinze voiles, mais victorieuse, et traînant à la remorque six de ces grandes hourques flamandes chargées de poivre, d'alun, de riches denrées, rentra dans le port de Dieppe, en présence de toute la population répandue sur le rivage, au bruit des cloches et de toute l'artillerie des remparts.

Ce tableau a été exposé au Salın de 1847.

\section{Le chevalier de La Villegagnon entre dans le Rio-Janeiro. - 10 novembre 1555.}

Par M. Th. Gudin. - Forme ronde, diam. 0,58.

Le chevalier de La Villegagnon, nommé vice-amiral de Bretagne par Henri II, sollicita la permission d'aller former un établissement en Amérique. Il obtint, par la protection de l'amiral de Coligny, une somme de dix mille livres pour les premiers besoins de la colonie, avec deux vaisseaux de deux cents tonneaux, abondamment pourvus, bien armés, et sur lesquels on embarqua une compagnie d'artillerie, de soldats et de nobles aventuriers. Le 12 juillet $15 \%$ ŏ il partit du Havre, qui portait à cette époque le nom de Franciscopole, et après une navigation pénible, il arriva, le 10 novembre, à l'embouchure du fleure Ganabara (le Rio-Janeiro). Il avait songé d'abord à former son établissement en terre ferme; mais diverses raisons l'ayant fait changer d'avis, il se décida à bâtir un fort en bois sur un rocher de cent pieds de long et soixante de large, situé au milieu du détroit que forme l'entrée du fleuve. Il comptait se rendre ainsi maître de la passe; mais il ne tarda pas à reconnaître que les eaux, à marée haute, couvraient ses constructions, et il se réfugia alors dans une île d'un mille de circonférence, placée une 
SALLES DES MARINES, No 65 .

lieue plus haut et entourée de rochers. Cette île n'avait qu'un seul port, commandé par une éminence qu'il fortifia. Il fixa sa résidence au centre de l'île, sur un rocher de cinquante pieds de haut, sous lequel il creusa des magasins, et qu'il nomma fort Coligny, en l'honneur de son protecteur.

\section{Fondation de la colonie de la Martinique.- 1635.}

Par M. Th. Gudiv. - H. 1,42. - L. 2,27.

Vandrosques Diel d'Énambuc, gouverneur de l'île Saint-Christophe pour les Français, conduisit en 1635, dans l'île de la Martinique, une colonie de cent hommes, qui s'établit tout près de l'emplacement de Saint-Pierre, et forma le premier noyau de la colonie aujourd'hui existante.

Ce tableaụ a été exposé au Salon de 1844 .

\section{Combat naval de Saint-Vincent. - 22 juillet 1640.}

Par M. Th. GudiN. - H. 0,58. - L. 1,00.

Le marquis de Brézé ayant rencontré entre le cap de SaintVincent et Cadix la flotte des Indes, commandée par le marquis de Castignosa, l'attaqua et le contraignit à se retirer dans la baie de Cadix, après avoir perdu six galions brûlés ou coulés à fond, avec un grand nombre de marchandises et d'hommes tués ou noyés, entre lesquels se trouvait Castignosa.

\section{Sourdis chasse les espagnols du port de Rozes. - 26 mars 1641.}

Par M. Th. Gudin. - H. 1,42. - L. $2,26$.

Le cardinal de Richelieu avait mis à la tête de l'armée navale Sourdis, archevêque de Bordeaux, qualifié général des armées navales du Levant, avec ordre de se préparer à faire voile vers les côtes de Catalogne avec les vaisseaux et les galères de la Méditerranée. " Le prélat, dit Levassor, qui étudioit plus assidument le cérémonial de la mer que les rubriques de son bréviaire et de son missel, et auquel le bruit du canon plaisoit beaucoup plus que la musique et le son des orgues de son église, exécuta promptement l'ordre qu'on lui avoit donné de se mettre en mer avec les vaisseaux et les galères, et de se rendre maître du cap de Quiers. Le 15 février il y envoie trois vaisseaux avec quatre cents hommes, qui s'emparent de la ville et de trois tours sur les éminences; fait partir ensuite dix vaisseaux de guerre avec 
des munitions et huit cents hommes de pied, qui arrivent le 19 mars. Le prélat-général d'armée vient enfin lui-mème le 26 avec douze galères, chasse celles des Espagnols et leurs vaisseaux du port de Rozes et des autres qu'ils avoient encore, et leur prend quelques vaisseaux et quelques galères.» [Hist. de Lonis XIII.]

Ce tableau a étẻ esposé au Salon de 1846.

\section{Combat naval devant Tarragone. -20 août 1641.}

Par M. Th. Gedis. - H. 0,58. - L. $0,79$.

Le duc d'Olivarès avait envoyé pour secourir la ville de Tarragone, assiégée par le comte de La Mothe-Houdancourt, une flotte nombreuse et puissante, où l'on comptait soixante-dix gros bâtiments. Sourdis, quoique bien inférieur à ces forces, réussit à repousser l'attaque des Espagnols, après un combat de quatre heures et que la nuit termina.

\section{Prise d'un galion espagnol. -1643 .}

Par M. Th. Gedis, - Forme ronde; diam. 0,58.

Parmi les flibustiers dieppois, Pierre Legrand est un des plus célèbres. Voici comment il débuta dans la carrière. Il croisait depuis quinze jours au débouquement de Bahama, lorsqu il vit venir à lui un grand galion espagnol avec un parillon de viceamiral. Legrand montait un bateau de quatre canons, et n'avait avec lui que ringt-huit hommes, mais tous braves et décidés comme lui. Forçant aussitôt de voiles et de rames, il court au-derant du galion, le joint, s'élance sur son bord et en mème temps coule à fond son propre navire. Cette audace désespérée étourdit le capitaine espagnol ; son équipage stupéfait ne songe pas même à se défendre. Legrand, maître du galion, dépose une partie de ses prisonniers sur le rivage, et n'emmenant avec lui que le capitaine et ses officiers, s'en retourne fièrement à Dieppe, sa patrie, faire admirer sa prise, et en recueillir les immenses profits.

\section{Combat naval de Carthagène.-3 septembre 1643.}

Par M. Th. GcDrs. - H. 0,58. - L. $0,79$.

L'amiral de Brézé, après un combat livré sur les côtes de Barcelone, avait pris ou coulé à fond six des vaisseaux de l'armée espagnole. Le 3 septembre il eut avec elle un nourel engagement à la hauteur de Carthagène. Les Espagnols se défendirent fort longtemps; mais ils furent enfin obligés de céder aux efforts des Francais, qui leur enlerèrent le raisseau amiral de Naples, deux autres gros navires et un galion, sur lesquels étaient cent 
soixante pièces de canon. On leur tua ou fit prisonniers quinze cents hommes.

\section{Bataille navale de Castel-à-Mare. - 1648.}

Par M. Th. Gudis en 1847. - H. 0,50. - L. 0,79.

Naples, fatiguée de la tyrannie espagnole, avait chassé son' vice-roi et mis à sa tête le duc de Guise. Le prince sollicita le secours de la France, et le duc de Richelieu fut envoyé à Naples avec l'armée navale, composée de trente vaisseaux français et trois portuguais sortis du jort de Marseille. Les Espagnols, mâ̂tres du château de l'Euf, qui commande à l'entrée, fermaient le port de Naples; tellement, que le duc de Richelieu ne pouvait les attaquer; mais il se tourna contre cinq vaisseaux qui étaient à l'abri de la forteresse de Castel-à-Mare, et leś aborda malgré les canonnades du château. Ceux qui étaient dedans voyant qu'ils ne pouvaient les sauver, se jetèrent à terre avec ce qu'ils avaient de meilleur, et brûlèrent leurs vaisseaux. Durant ce combat, la flotte d'Espagne sortit du port de Naples et se mit en mer, ce qui obligea le duc de Richelieu d'aller droit à elle et de l'attaquer. Le bruit des coups de canon fut si grand, que toute la ville de Naples en fut ébranlée, et les vitres cassées: mais enfin, l'amiral et le vice-roi d'Espagne furent contraints de se retirer dans le golfe de Naples, sous le château de l'(Euf, et le reste de leur armée les suivit, après avoir eu quatre vaisseaux coulés à fond.

Ce tableau a été exposé au Salon de 1818.

\section{Combat naval de Barcelone. - 29 sept. 1655.}

Par M. Th. Gudin. - H. 0,58. - L. 0,86.

Le duc de Vendôme, qui commandait la flotte du roi dans la Méditerranée, ayant rencontré à la hauteur de Barcelone l'armée navale d'Espagne, l'attaqua, quoiqu'elle fût supérieure à la sienne, et la battit après un combat très-vif de quelques heures.

\section{Combat d'un vaisseau francais contre quatre vaisseaux anglais. - 1655 .}

Par M. Th. Gudin. - H. 0,58. - L. 1,23.

" Le chevalier de Valbelle, commandant un vaisseau du roi de trente pièces de canon, fut attaqué par quatre vaisseaux anglois qui, après un combat de plusieurs heures, le criblèrent de coups de canon, et le désemparèrent de manière qu'à peine il lui restoit une voile pour manœuvrer; il refusa cependant de se 
rendre, et, voyant qu'il alloit périr, il alla s'échouer sur un banc. Le commandant anglais fut si touché de la valeur et de la fermeté qu'il avoit fait paroître dans cette action, qu'il lui envoya une barque pour le sauver avec ce qui lui restoit de monde, et lui permit ensuite de se retirer en France.") (Quincy. - Hist. milit. de Louis $X I V$.)

Ce tableau a été exposé au Salon de 1846.

\section{Combat naval de la Goulette. - 24 juin 1665.}

Par Th. Gudin. - H. 1,43. - L. 2,26.

"Quoique la paix régnât dans le royaume, le duc de Beaufort, qui commandoit une escadre dans la Méditerranée, s'attachoit à nettoyer cette mer des corsaires d'Alger; il les alla chercher et les rencontra, le 24 juin, sous le fort de la Goulette, proche de Tunis ; il les attaqua, et après un combat des plus opiniâtres, il les battit, leur coula à fond et brûla trois vaisseaux, à savoir : l'amiral, le vice-amiral et le contre-amiral. Cette perte pour les Algériens fut d'autant plus considérable, que le vaisseau amiral étoit neuf, monté de six cents hommes et de cinquante pièces de canon.» (Quincy. - Hist. milit. de Louis XIV.)

Ce tableau a été exposẻ au Salon de 1846.

\section{Combat naval entre Nevis et Redonde. -1667 .}

Par M. Th. Gudin. - H. 0,58. - L. 0,86.

Le Fèvre de la Barre, lieutenant général pour le roi en Amérique, ayant appris que le chevalier de Saint-Laurent, gouverneur de l'île de Saint-Christophe était réduit à l'extrémité, parce que les Anglais le tenaient bloqué dans cette île depuis six semaines, y fit voile avec une escadre de dix-sept navires et de deux brülots. Il rencontra la flotte anglaise, qu'il attaqua entre Nevis et Redonde, et la battit après un combat de quelques heures fort opiniâtre de part et d'autre. Il tua aux ennemis quatre ou cinq cents hommes, outre deux cents qui furent noyés, et leur fit quatre cents prisonniers. Cette action sauva l'île de SaintChristophe.

Ce tableau a été exposé au Salon de 1846.

\section{Combat naval de Sole-Bay. - 7 juin 1672.}

\section{Par M. Th. Gudin. - H. 0,58. - L. 0,86.}

Par suite de la déclaration de guerre faite par la France et l'Angleterre à la Hollande, le roi d'Angleterre avait mis en mer une flotte commandée par le duc d'Yorck, son frère. Le comte d'Estrées, vice-amiral de France, fit sa jonction avec la flotte anglaise, 
à l'île de Wight, et les deux flottes combinées ne tardèrent pas à rencontrer celle des Etats-Généraux; Ruyter la commandait. Les armées restèrent quelque temps en présence sans combattre. Les flottes française et anglaise se rendaient à Sole-Bay, sur la côte d'Angleterre pour faire de l'eau, lorsque Ruyter, qui avait l'avantage du vent, les attaqua. Il était environ cinq heures du matin lorsque les deux flottes étaient en présence, et les Hollandais soutinrent jusqu'à la nuit les grands efforts des flottes de France et d'Angleterre, qui avaient pris si fort le dessus, qu'elles les contraignirent de se retirer à la faveur de la nuit. Les Anglais et les Français se retirèrent vers la Tamise, où le sieur de La Robinière, chef d'escadre de France, mourut d'une grande blessure qu'il avait recue. Les Hollandais perdirent deux vaisseaux de soixante-dix pièces de canon chacun, outre le vice-amiral Sandwick, qui fut submergé avec le vaisseau qu’il commandait pendant le combat.

\section{Combat naval du Texel. - 21 aoút 1673.}

Par M. Th. GUdiN. - H. 1,42. - L. 1,77.

Les flottes de France et d'Angleterre cherchaient celle de Hollande pour la forcer à combattre, et l'amiral Ruyter, après avoir quelque temps évité l'ennemi, d'après la recommandation des Etats, reçut tout-à-coup l'ordre d'accepter la bataille, afin de protéger le retour de la flotte que les Hollandais avait envoyée aux Indes. Il apprit que la flotte d'Angleterre, commandée par le prince Rupert, après avoir tenté une descente en plusieurs endroits était devant le Texel; il y fit voile, et se prépara à l'attaque. Jamais combat ne fut plus rude ni plus long : il dura depuis le matin jusqu'au soir sans se ralentir de part et d'autre. Le comte d'Estrées soutint dans cette occasion l'honneur de la nation française, aussi bien que le marquis de Martel, à qui les Anglais et les Hollandais ne purent refuser des louanges, pour s'être démêlé, avec quatre vaisseaux, d'une grande partie de la flotte ennemie, qui avait entrepris de le faire périr.

Ce tableau a été exposé au Salon de 1846.

\section{Bataille de la Marlinique. - 21 août 1674.}

Par M. Th. Gudin. - H. 1,04. - L. 1,34.

Les États-Généraux avaient mis en mer une flotte qui, après avoir croisé quelques jours unie dans la Manche, se sépara en deux; la moins nombreuse partie, sous le commandement de l'amiral Ruyter, fit voile pour les Indes-Occidentales. Ruyter' alla tenter une descente au cul-de-sac de la Martinique, qu'il avait 
espéré surprendre; mais les troupes françaises qui le gardaient, les habitants et les vaisseaux de guerre et marchands qui s'y trouvèrent, firent une telle défense et tuèrent un si grand nombre de Hollandais qui avaient mis pied à terre pour attaquer le fort, que Ruyter, voyant le mauvais succès de cette tentative, et qu'il consumerait inutilement son temps et ses troupes s'il s'obstinait à vouloir l'emporter, les fit rembarquer le jour même de la descente, et reprit la route de la Hollande sans faire aucune autre entreprise.

Ce tableau a été exposé au Salon de 1846.

\section{Prise de Messine. - 11 février 1675.}

Par M. Th. Gudis en 1845. - H. 0,58. - L。 0,78.

Les Messinois, fatigués de la dureté du gouvernement espagnol, s'étaient soulevés et avaient réclamé la protection de la France. Louis XIV leur envoya en 1674 un premier secours commandé par le marquis de Valavoire et le chevalier de Valbelle, puis il nomma le duc de Vivonne vice-roi de la Sicile. Le 11 février 167らั, Vivonne et Duquesne défirent la flotte espagnole qui fermait l'entrée de la ville et la contraignirent de se retirer à toutes voiles à Naples. Le duc de Vivonne entra le lendemain dans Messine, où il fut reçu et reconnu en qualité de vice-roi.

\section{Prise d'Augusta. - 23 août 1675.}

Par M. Th. Gudin. - Forme ronde; diam. 0,58.

La ville d'Augusta, entre Syracuse et Catane, pouvait protéger la navigation et la communication des troupes du duc de Vivonne, vice-roi de la Sicile. Il l'attaqua avec sa flotte et la prit après six jours de siége. Il s'empara ensuite de la petite ville de Lentini, et se rendit maître d'une partie du pays des environs.

\section{Combat en vue de l'âle de Stromboli. - 8 jan- vier 1676.}

Par M. Th. GUdin. - H. 0,58. - L. 0,80.

Duquesne venait de quitter les côtes de Provence, et, au commencement de janvier 1676, il conduisait une flotte composée de vingt vaisseaux et d'un grand nombre de brûlots et de bâtiments de transport. Ruyter commandait la flotte combinée des Hollandais et des Espagnols, composée de vingt-six vaisseaux de guerre et de neuf galères, et le 7 janvier 1676, les deux escadres étaient en présence près de l'île de Stromboli. Le 8, Duquesne fit commencer le combat sur les neuf heures du matin : il fut si opiniâtre 
SALLES DES MARINES, No 63.

et si long (qu'il dura jusqu'à deux heures après midi. Il survint alors un calme qui empêcha l'armée de France de profiter de ses avantages, et qui permit aux galères d'Espagne de venir remorquer les vaisseaux hollandais qui étaient endommagés; elle ne purent pourtant pas empêcher qu'un vaisseau de l'avant-garde ennemie ne coulât bas du grand nombre de coups de canon dont il avait été percé.

\section{Combat d'Augusta. - 21 avril 1676.}

Par M. Louis Garneray en 1836. - H. 1,42. - L. 2,27.

Duquesne partit des environs de Messine le 19 avril, et dès que l'amiral Ruyter en eut avis, il s'avança avec toute sa flotte et celle d'Espagne. Les flottes se rencontrèrent le 21, sur le midi, environ à trois lieues d'Augusta, par le travers du golfe de Catane; celle de France était composée de trente vaisseaux et de sept brûlots; celle des ennemis était de vingt-neuf vaisseaux, tant espagnols que hollandais, de neuf galères et de quelques brûlots. Les deux avant-gardes commencèrent le combat sur les quatre heures après midi, et s'attaquèrent avec tanl de valeur et d'opiniâtreté que presque tous les vaisseaux de part et d'autre furent endommagés. Le marquis d'Alméras fut tué dans le fort du combat, étant sur le tillac, et le chevalier de Tambonneau, qui commandait un des vaisseaux de cette avant-garde, fut emporté d'un coup de canon. L'amiral Ruyter eut le devant du pied gauche emporté d'un éclat, et les deux os de la jambe droite brisés, en sorte qu'il tomba du coup, et se fit une légère blessure à la tête; ce qui ne l'empêcha pas de continuer à donner ses ordres. Le combat dura jusqu'à la nuit, qui sépara les deux armées. Le lendemain, l'armée hollandaise se retirait; elle fut poursuivie par la flotte française jusque dans le port de Syracuse, où l'amiral Ruyter mourut le 29 avril.

\section{Bataille navale devant Palerme.-2 juin 1676.}

Par M. Th. Gudin. - H. 0,58. - L. 0,80.

Le maréchal de Vivonne était sorti du port de Messine avec une flotte composée de vingt-huit vaisseaux, de vingt-cinq galères et de neuf brûlots; il rencontra, le 31 , la flotte combinée de Hollande et d'Espagne, composée de vingt-sept vaisseaux de guerre, de dix-neuf galères et de quatre brûlots, qui était en bataille sur une ligne, ayant le môle de Palerme à sa gauche, le fort de Castel-à-Nare derrière la ligne et une grossetour avec les bastions de la ville à sa droite. Le combat s'engagea le 2 juin, et dès le commencement de l'action les brûlots français réussirent à embraser 
plusieurs vaisseaux ennemis. L'incendie de ces vaisseaux et des brûlots, et les efforts de la poudre qui y était enfermée, poussant en l'air des pièces de fer et des parties entières de navires, abîmèrent six galères, sans compter un grand nombre d'officiers, de soldats et de matelots tués et estropiés. Le port fut ravagé; plusieurs édifices de Palerme furent ruinés. Les ennemis perdirent en ce combat sept gros vaisseaux de guerre, six galères, sept brûlots et quelques autres petits bâtiments, sept cents pièces de canon et près de cinq mille hommes.

Ce tableau a été exposé au Salon de 1848.

\section{DEUXIÈME SALLE.}

La frise et les panneaux de cette salle sont ornés de portraits peints par P. Franque, représentant : le comte de Valbelle, le maréchal de Châteaurenaud, le comte de Vermandois, Duquesne, Jean Bart, Tourville, le maréchal de Vivonne, Duguay-Trouin, le comte de Toulouse, le comte de Forbin, le maréchal d'Estrées et le maréchal de Coëtlogon.

\section{Combat de Chio. - 1681.}

\section{Par M. Th. Gudin. - H. 0,58. - L. 0,86.}

Les pirates de Tripoli continuant à infester les côtes de Provence, Duquesne, qui commandait une escadre du roi dans la Méditerranée, les poursuivit dans le port de Chio, canonna le château et coula à fond un grand nombre de ces corsaires.

Ce tableau a été exposé au Salon de 1842.

\section{Bombardement d'Alger. - 27 juin 1683.}

Par M. Th. Gudin. - H. 0,58. - L. 0,86.

Les pirates d'Alger avaient plusieurs fois violé leur's traités avec la France. Louis XIV, résolu de les châtier, chargea Duquesne de cette mission. En peu de jours, l'amiral français balaya devant lui la faible flottille de ces forbans, et les contraignit de se réfugier dans leur port; puis, arrivé devant Alger, le 27 juin 1683 , il en commença aussitôt le bombardement. La ville fut incendiée et en partie détruite; et les habitants, réduits à l'extrémité, eurent recours à la clémence du vainqueur.

\section{Bombardement de Gênes. - 26 mai 1684.}

Par M. Th. Gudin. - H. 1,41.- L. 2,26.

Les Génois, au mépris de leur alliance avec la France, entretenaient des intelligences avec l'Espagne et même avec les Algériens dont ils favorisaient les pirateries. Louis XIV envoya sur 
leurs côtes une flotte commandée par Duquesne et sur laquelle se trouvait le marquis de Seignelay. Toute réparation ayant été refusée, les bâtiments français lancèrent dans la ville une quantité de bombes qui réduisit en cendres une partie de ses édifices. On fit une descente au faubourg de Saint-Pierre-d'Arène, et les Gênois furent contraints d'avoir recours au pape pour fléchir la colère du roi.

Ce tableau a été exposé au Salon de $\mathbf{1 8 4 0 .}$

\section{Combat d'un vaisseau français contre trente- cinq galères d'Espagne. - $\mathbf{1 6 8 4 .}$}

Par M. Th. Gudin en 1840. - H. 1,67. - L. 2,26. '

Le comte de Relingue, commandant un vaisseau du roi dans la Méditerranée, fut rencontré et attaqué pendant un calme par trente-cinq galères d'Espagne : il se défendit avec tant de valeur, qu'après en avoir désemparé plusieurs, il leur donna la chasse et poursuivit ensuite sa route.

Ce tableau a été exposé au salon de 1841.

\section{Expédition de La Salle à la Louisiane.-1684.}

Par M. Th. Gudin. - H. 1,41. - L. 2,25.

Robert de La Salle, voyageur né à Rouen, s'était rendu vers 1670 au Canada, et de retour en France, avait proposé à Seignelay de reconnaître l'embouchure du Mississipi. Il descendit le fleuve jusqu'à la mer et prit possession au nom de la France de tout le pays auquel il donna le nom de Louisiane. En 1684 il obtint quelques navires pour y retourner par mer et y former un établissement : il entra dans la baie de Saint-Bernard, remonta le Rio-Colorado, y construisit deux forts et fut assassiné en 1687 par trois de ses compagnons de voyage.

Ce tableau a été exposé au Salon de 1844.

\section{Bombardement de Tripoli. - 22 juin 1685.}

Par M. Th. Gudin. - H. 0,56. - L. 0,78.

Les corsaires de Tripoli, malgre la paix que Louis XIV leur avait accordée en 1683, avaient fait des courses sur les vaisseaux marchands du roi. La flotte destinée à les châtier, commandée par le maréchal d'Estrées, partit le 17 juin de l'île de Lampedouse, et arriva le 19 devant Tripoli. Après quelques jours passés en préparatifs, Tourville, qui commandait l'attaque, fit poster les bâtiments à̀ l'entrée du port, et les galiotes à bombes commencèrent à tirer sur la ville le 22 juin, vers dix heures du soir. Les Tripolitains envoyèrent demander la paix de la part du divan de 
Tripuli. Les principales conditions furent le payement de deux cent mille écus pour le dédommagement des prises qu'ils avaient faites sur les marchands français, et la délivrance de tous les esclaves chrétiens pris sous la bannière de France.

Ce tableau a été exposé au Salon de $\mathbf{1 8 4 2 .}$

\section{Combat de la baie de Bantry. - 12 mai 1689.}

Par M. Th. Gudin. - H. 0,58. - L. 0,79.

Louis XIV n'avait pas reconnu la révolution qui s’était accomplie en Angleterre; Guillaume III n'était toujours pour lui que le stathouder de la Hollande, tandis qu'il prodiguait à Jacques II les bienfaits d'une hospitalité toute royale, et l'aidait de ses armées et de ses flottes. le comte de Châteaurenaud partit de Brest le 6 mai avec vingt-quatre vaisseaux, pour porter des secours au monarque détrôné. L'escadre française arriva en vue des côtes d'Irlande, entre le cap de Glare et de Kinsale. La flotte anglaise l'y attendait depuis quinze jours. Il fut arrêté que l'on ferait roile vers la baie de Bantry pour y tenter un débarquement, et le 19 mai on mouilla à cinq lieues de ce bourg. On commença à dẹbarquer les troupes et les munitions lorsqu'on eut avis que la flotte ennemie, commandée par le vice-amiral Herbert approchail. Châteaurenaud alla l'attaquer avec sa division et mit l'amiral anglais en fuite. Il rentra à Brest le 28 mai après avoir pris en revenant sept vaisseaux hollandais richement chargés.

\section{Bataille de Béveziers. - 10 juillet 1690.}

Par M. Th. Gudin. - H. 1,67. - L. 2,26.

Le 10 juillet 1690 la flotte française, composée de soixantedouze vaisseaux de haut bord, rencontra les deux flottes combinées d'Angleterre et de Hollande, un peu inférieures en nombre, à la hauteur du cap de Béveziers. Les Français étaient commandés par l'amiral de Tourville et par les chef́s d'escadre de Châteaurenaud, d'Estrées, de Nesmond et d'Amfreville. Les ennemis avaient à leur tête lamiral anglais Herbert et les vice-amiraux hollandais Evertzen et Van Calemburg. Après une action rivement disputée, la flotte des alliés fut battue, dispersée et perdit dixsept bâtiments brùlés ou échoués à la côte. Le reste alla se réfugier dans la Tamise ou parmi les bancs de la Hollande, abandondonnant la mer aux Français.

Ce tableau a été exposé au Salon de 1839.

1404. Combat de Lagos ou de Cadix.-27 juin 1693.

Par M. Th. Gedin. - H. 1,05. - L. 1,42.

Le 27 juin Tourville ayant attaqué entre Lagos et Cadix, sur 
les côtes de Portugal, le vice-amiral Rook qui escortait la flotte de Smyrne, lui brûla quatre vaisseaux de guerre et prit, brûla ou coula à fond plus de quatre-vingis vaisseaux richement chargés. Jean Bart en prit ou brûla six; on évalua la perte des ennemis à trente-six millions au moins.

Ce tableau a été exposé au Salon de 1841.

\section{Expédition de Coëtlogon à Gibraltar. - 1693.}

Par Th. GUdin. - H. 0,57. - L. 0,78.

Le chevalier de Coëtlogon brûle el coule à fond dans le vieux Gibraltar cinq navires anglais qui faisaient partie de la flotte de Smyrne.

\section{Expédition de Malaga. - 19 juillet 1693.}

Par M. Th. Gudrv. - H. 0,57. - L. 0,78.

Le 19 juillet la flotte française arriva en vue de Malaga, et le maréchal de Tourville, qui la commandait, ayant résolu d'attaquer les vaisseaux ennemis jusque dans le môle, fit avancer pendant la nuit du 20 des chaloupes qui pénétrèrent jusqu'au fond du môle maloré le feu des bâtiments et des batteries de la ville. Elles se saisirent de tous les vaisseaux que les ennemis s'étaient vus forcés d'abandonner et que Tourville fit brûler ne pouvant les emmener à la remorque. Après cette expédition la flotte française rentra à Toulon pour se ravitailler.

Ce tableau a été exposé au Salon de $\mathbf{1 8} 41$.

\section{Combat du Texel. - 29 juin 169/.}

Par M. Eugène Isabex. - II. 2,48. L. 3,57.

Jean Bart, avec six frégates, livre combat à l'amiral de Frise, contre huit vaisseaux hollandais, en prend trois, met les autres en fuite et ramène à Dunkerque la flotte chargée de blé envoyée en France par la reine de Pologne. Deux bâtimens danois et un suédois, qui escortaient cette flotte, restèrent neutres dans celte affaire qui ne dura qu'une demi-heure.

Ce tableau a été exposé au Salon de 1839.

\section{Combat dans la mer du Nord.-18 juin 1696.}

Par M. Th. Gudin. - H. 0,57. - L. 0,78.

Vingt vaisseaux anglais et hollandais tenaient Jean Bart bloqué dans le port de Dunkerque. Il résolut de sortir et rencontra, le 18 juin, la flotte hollandaise, qui venait de la mer Ballique, composée de plus de cent voiles, sous l'escorte de cinc frégates. 
Après un assez rude combat, les vaisseaux de Jean Bart abordèrent les frégates ennemies et s'en rendirent maîtres, pendant que les autres navires et les armateurs coupèrent les vaisseaux marchands, et en prirent trente, les autres, qui étaient au-dessus du vent, s'étant échappés.

Ce tableau a été exposé au Salon de 1841.

\section{Bombardement de Carthagène. - Mai 1697.}

Par M. Th. GcDIr. - Forme ronde; diam. 0,57.

"Pointis étoit parti des côtes de France au commencement de l'année, avec une escadre de sept vaisseaux de guerre et plusieurs autres bâtiments. Il arriva devant Carthagène, ville du nouveau royaume de Grenade dans l'Amérique méridionale, où les Espagnols tenoient la plus grande partie des richesses qu'ils tiroient du Pérou. Il attaqua cette place avec tant de vigueur, assisté des troupes que lui amena le gouverneur de SaintDomingue, qu'il la prit de force en peu de jours el la pilla. Les immenses richesses qu il en tira redressèrent un peu les firınces épuisées de la France, et mirent le roi en état de continuer la guerre aux dépens de ses ennemis. (Quixcy. - Histoire militaire de Louis XIV.)

Ce tableau a été exposé au Salon de 1841.

\section{Combat de cinq vaisseaux français contre sept vaisseaux anglais. - 24 aout 1697.}

Par M. Th. Gudis. - H. 0,58. - L. 0,79.

Au retour de l'expédition de Carthagène, Pointis eut à combattre une escadre de sept hâtiments anglais. Il n'avait sous ses ordres que cinq vaisseaux. Le 24 aoùt, à la pointe du jour, il découvrit l'ennemi qui faisait force de voiles pour l'atteindre. Pointis lui épargna la moitié du chemin. L'engagement dura jusqu’à la nuit; les bâtiments français reçurent courageusement les bordées d'un ennemi qui leur était de tout point supérieur, et eurent l'honneur de poursuivre, en face de lui, leur route sans dommage.

Ce tableau a été exposé au Salon de 1841.

\section{Prise de trois vaisseaux anglais. - 28 août 1697.}

Par M. Th. Gudin. - Forme ronde; diam. 0,57.

"Le marquis de Nesmond, lieutenant général des armées navales dı roi, avoit armé une escadre de six vaisseaux pour aller 
en course. Il rencontra trois vaisseaux anglois qui revenoient des Indes. Il les attaqua avec tant de vigueur, qu'après une médiocre résistance, la partie n'étant pas égale, ils ne purent éviter de tomber entre ses mains. Ils étoient tous trois chargés de marchandises pour plus de six millions. "(Quincy. - Histoire militaire de Louis XIV.)

Ce tableau a été exposé au Salon de 1841.

1412. Combat d'un vaisseau français contre trois vaisseaux anglais. - 5 septembre 1697.

Par M. Th. Gudin. - H. 0,58. - L. 0,78.

D'Iberville, chargé de reprendre le fort de Nelson, dit Bourbon, dans la baie d'Hudson, était parti avec quatre vaisseaux de guerre. Trois de ses bâtiments ayant été retenus dans les glaces du détroit d'Hudson, le Pélican, monté par d'Iberville, arriva seul devant le fort Bourbon le 5 septembre, et se trouva en présence de trois vaisseaux anglais. Après trois heures et demie de combat, un des bâtiments anglais fut coulé bas, un autre amena pavillon et le troisième prit la fuite.

Ce tableau a été exposé au Salon de 1841.

\section{Prise du fort de Bourbon. - 13 septembre 1697.}

Par M. Th. Gudin. - H. 0,58. - L. 0,78.

Quelques jours après le combat du 5 septembre, d'Iberville bombarda le fort Bourbon. Ce fort était composé de trois bastions et demi-bastions; un des bastions sauta en l'air, et le 13, le gouverneur rendit la place.

Ce tableau a été exposé au Salon de 1841.

1414. Prise d'un vaissean hollandais par les galères de France à la hauteur d'Ostende. - 1702.

Par M. Th. Gudin. - H. 0,57. - L. 0,79.

Ce tableau a été exposé au Salon de 1839.

1415. Prise de quinze vaisseaux hollandais par neuf vaisseaux français. - 21 avril 1703.

Par M. Th. Gudin. - H. 1,05. - L. 1,42.

"La flotte des vaisseaux marchands de Hollande sortit de la Meuse le 19 avril, pour aller à la rivière de Londres avec quelques yacths d'Angleterre, où étoit milord Paget et le baron de Baisan, ministre du roi de Pologne. Cette flotte fut attacuée le 
21 par trois vaisseaux de guerre du roi, et par six capres de Dunkerque, d'Ostende et du Havre. Après un rude combat, deux vaisseaux de guerre, qui servoient de convoi à la flotte, furent pris, et les armateur's, pendant le combat, prirent treize vaisseaux marchands.» (QunNcY.-Histoire militaire de Louis XIV.)

Ce tableau a été exposé au Salon de 1841.

\section{Combat à la hauteur de Lisbonne._Mai 1703.}

par M. Th. Gudin. - H. 0,99. - L. 1,42.

Le marquis de Coëtlogon étant parti de Brest le $\mathbf{1 3}$ mai, avec cinq gros vaisseaux, rencontra, à la hauteur de Lisbonne, une flotte anglaise et hollandaise de près de cent voiles, escortée par cinq vaisseaux de guerre, et, après quelques heures d'un combat fort opiniâtre, il en prit quatre et coula à fond le cinquième. Pendant le combat tous les vaisseaux marchands se sauvèrent et retournèrent dans les ports de Portugal, d'où ils étaient partis. Le marquis de Coëtlogon rentra dans le port de Toulon avec les quatre vaisseaux de guerre qu'il avait pris.

Ce tableau a été exposé au Salon de $\mathbf{1 8 4 1 .}$

\section{Combat à la hauteur d'Albardin. - 10 août 1703.}

Par M. Th. GUdin. - H. 0,58. - L. 0,93.

Le comte de La Luzerne, embarqué sur le vaisseau l'Amphrtrite, avait ordre d'aller croiser dans le nord de l'Ecosse avec les navires le Jersey et les Jeux. Il joignit une escadre que commandait le chevalier de Saint-Pol, et découvrit le 10 la flotte de la pêche du hareng de la Meuse, composée de deux cents voiles, et escortée de quatre vaisseaux de guerre hollandais, de quarante ou cinquante canons chacun. Des quatre vaisseaux hollandais, trois furent pris; le quatrième échappa ; trente et un vaisseaux de la flotte furent capturés et bon nombre rançonnés.

Le tableau représente la fin de l'action au moment où on brûle les bâtiments de la pêche du hareng; dans le lointain un des vaisseaux hollandais se sauv à la faveur de la nuit.

Ce tableau a été exposé au Salon de 1839.

\section{TROISIÈME SALLE.}

La frise et les panneaux de cette Salle sont ornés de portraits peints par Pierre Franque, représentant : le marquis de La Galissonnière, le bailli de Suffren, le comte de Vautreuil, le duc de Penthièvre, le duc d'Orléans, le comte de Guichen, le v.comte Du Couëdic, le comte de Iamotte-Picquet, l'amiral Duchafault et le conte d'Estaing. 


\section{Bataille navale de Malaga. - 25 août 1704.}

Par Th. Gudin. - II. 1,41. - L. 2,26.

Le comte de Toulouse, ayant sous ses ordres le maréchal de Coeuvres, était parti de Brest le 16 mai. Les vaisseaux de Toulon et les galères ayant rejoint l'armée, le comte de Toulouse se trouva à la tête de trente-deux vaisseaux, dix-neuf galères, huit galiotes à bombes, six brûlots et plusieurs bâtiments de transport, et le 24 août il rencontra l'ennemi à onze heures, au nord et au sud de Malaga. La flotte anglo-hollandaise ne comptait pas moins de soixante-quatorze voiles. L'amiral Showel commandait l'avant-garde, le corps de bataille était sous les ordres de l'amiral Rook, et l'amiral Van Calemburg, avec les vaisseaux hollandais, était à l'arrière-garde. On se battit sur toute la ligne avec un acharnement sans égal, et le combat ne fut pas moins vif à l'avant qu'à l'arrière-garde. Il ne cessa qu'à la fin de la journée. Les armées restèrent en présence pendant toute la nuit qui suivit la bataille, et échangèrent encore des coups de canon. Enfin, le lendemain matin la flotte anglo-hollandaise se retira.

Ce tableau a été exposé au Salon de 1841.

\section{Combat dans la mer du Nord. - 2 octobre 1706.}

Par M. Th. GudiN. - H. 1,67. - L. 2,26.

A l'époque de la guerre de la succession, en 1706, le chevatlier de Forbin ayant reçu le commandement d'une escadre de sept navires pour s'opposer aux opérations des flottes de l'Angleterre et de la Hollande, se dirigea dans la mer du Nord. Il avait déjà fait quelques prises lorsqu'il rencontra, le 2 octobre, une flotte hollandaise qui venait de la mer Baltique, et qui était composée de soixante voiles escortées par six vaisseaux de guerre. Le chevalier de Forbin donna aussitôt le signal du combat, qui commença à neuf heures du matin, par un gros temps. Trois bâtiments hollandais furent pris ou détruits, les trois autres se sauvèrent et toute la flotte marchande échappa pendant le combat.

Le chevalier de Forbin vient de mettre le feu au vaisseau de l'amiral loollandais, et pendant qu'il s'efforce de s'eloigner de l'incendie, il coule d'une bordie un autre vaisseau ennemi qui venait l'attaquer.

Ce tableau a été exposé au Salon de 1839.

\section{Combat du cap Lézard. - 21 octobre 1707.}

Par M. Th. Gudin. - H. 1,97. - L. 2,20.

Duguay-Trouin, après avoir armé à Brest une escadre de six vaisseaux, mit à la voile le 19 octobre 1707, et fut rejoint le 21 
par le chevalier de Forbin, qui commandait également une escadre de six vaisseaux. Ayant eu connaissance d'une flotte de cent vingt voiles escortée par cinq vaisseaux de guerre anglais, ils résolurent de l'attaquer. Le vaisseau anglais le Ruby fut capturé par Forbin, et le Royal-Oak fut brùlé.

Pendant l'abordage des vaisseaux anglais et français, un contre-maître francais s'empare d'un pavillon anglais, le jette à la mer, vient à la nage prendre une embarcation sur l'arrière du vaisseau anglais, et regagne son vaisseau sous une grêle de balles.

Ce tableau a été exposé au Salon de 1839.

\section{Prise de Rio-Janeiro. - 23 septembre 1711.}

Par II. Th. Gudin en 1840. - H. 1,41. - L. 2,20.

En 1711, une escadre sous les ordres du commandant Duclerc avait été chargée d'aller attaquer Rio-Janeiro. Cette expédition n'avait pas réussi, et Duclerc, prisonnier avec les officiers qui l'accompagnaient, avait été ensuite massacré avec eux. Louis XIV résolut de tirer une vengeance éclatante de cette violation du droit des gens. Il confia à Dugay-Trouin le commandement d'une flotte qui partit de La Rochelle le 9 juin. Elle était composée de dix-sept vaisseaux et portait environ trois mille cinq cents hommes de débarquement. Arrivé au Brésil dans les premiers jours de septembre, Dugay-Trouin demanda satisfaction au gouverneur, don Francisco de Castro Marias. N'ayant pu l'obtenir, il força l'entrée de la baie de Riø-Janeiro et passa dans le goulet défendu par près de trois cents pièces de canon, dont il essuya le feu avec une intrépidité extraordinaire. Il s'empara 'de l'île et entra dans le port où, malgré un violent orage, et après un combat opiniâtre, il mit à terre environ trois mille cinq cents hommes de débarquement. Ils attaquèrent des forts bien fortifiés et obligèrent les Portugais à les abandonner aussi bien que la ville.

Ce tableau a été exposé au Salon de 1841.

\section{Prise de trois vaisseaux hollandais par la Fi- dèle, la Mutine et le Jupiter. - 1711.}

Par M. Th. GLdiN, - H. 0,68. - L. 0,71.

Trois vaisseaux hollandais venant de Curaçao furent pris, après un combat de peu de résistance, par la Fidéle et la Mutine, qui avaient été armées à Dunkerque, accompagnées du Jupiter, armé à Bayonne. Ces vaisseaux furent menés à Paimbœuf. Ils étaient chargés de riches marchandises et de trois cent mille piastres.

Ce tableau a étẻ exposé au Salon de 1848. 


\section{Combat du vaisseau l'Intrépide, contre plusieurs vaisseaux anglais. - 17 octobre 1747.}

Par Gilbert. - H. 0,88. - L. 1,43.

Une escadre de huit bâtiments de l'État, sortie de l'île d'Aix, escortait deux cent cinquante vaisseaux marchands. Le 17 octobre 1747, à la hauteur du cap Finistère, elle rencontra une flotte anglaise composée de vingt-trois vaisseaux et commandée par l'amiral Hawke. Pendant le combat, le Tonnant, que montait le marquis de L'Etanduère, commandant de l'escadre, avait successivement essuyé le feu de toute la ligne anglaise; plusieurs fois il s'était vu au milieu de trois ou quatre vaisseaux qu'il avait repoussés; mais après la réduction des quatre vaisseaux français, tous les efforts de l'amiral Hawke se réunirent contre lui. Il allait se rendre ou périr lorsque le comte de Vaudreuil, qui commandait l'Intrépide, traversa la flotte anglaise et vint le secourir. $L$ 'Intrépide et le Tonnant restèrent donc exposés seuls à tout le feu de l'artillerie d'une flotte entière. Déjà cinq vaisseaux anglais désemparés sont contraints de se retirer; d'autres reviennent à la charge, puis s'éloignent aussi pour réparer leur dommage. Tandis qu'ils se préparent à un nouveau combat, L'Etanduère fait fausse route, leur échappe à la faveur des ténèbres, et le Tonnant rentre dans Brest, remorqué par l'Intrépide.

\section{Prise de Port-Mahon. - Juin 1756.}

École française; $\mathrm{xvIII}^{\mathrm{e}}$ siècle. - H. 1,16. - L. 1,43.

Ie maréchal de Richelieu, nommé généralissime des côtes de la Méditerranée, partit des îles diHières le 12 avril $175 \%$, avec une flotte composée de douze vaisseaux de ligne, de cinq frégates et d'un grand nombre de bâtiments de transport. Cette flotte fit voile vers I île de Minorque, où elle occupa sans coup férir la ville de Mahon. A cette nouvelle quatorze vaisseaux anglais, commandés par l'amiral Byng, se dirigèrent vers Minorque pour la secourir. L'action s'engagea, et le succès en fut très-vivement disputé. L'escadre anglaise fut enfin dispersée et contrainte de se réfugier à Gibraltar.

\section{Combat naval d'Ouessant. - 27 juillet 1778.}

Par M. Th. Gudin. - H. 2,48. - L. 3,49.

Le comte d'Orvilliers, sorti de Brest à la tête d'une flotte de trente-deux vaisseaux de ligne, avait sous ses ordres le duc de Chartres et Duchaffault, lieutenants généraux de marine. La flotte était divisée en trois escaures : la Blanche au corps de bataille, la 
Blanche et la Bleue à l'avant-garde, et la Bleue à l'arrière-garde. Le comte d'Orvilliers était au corps de bataille, Duchafiault dirigeait l'avant-garde, et le duc de Chartres, monté sur le SaintEsprit, conduisait l'arrière-garde. Les armées navales de France et d'Angleterre se rencontrèrent le 23 juillet, et le 27 juillet, à neuf heures du matin, le temps paraissant favorable, la flotte française offrit le combat à l'ennemi. Le Saint-Esprit fut exposé, à demi-portée de canon, au premier feu des Anglais. Sept vaisseaux le combattirent successivement. Après une journée entière de combat, la flotte française rentra à Brest sans avoir perdu un seul vaisseau, résultat qui fut considéré comme une victoire par un ennemi qui, durant la guerre de Sept-Ans, avait exercé une incontestable supériorité sur les mers.

Ce tableau a été exposé au Salon de 1839.

\section{Combat de la Minerve contre quatre bâtiments anglais. - 7 février 1779.}

Par GILBERT. - H. 0,59. - L. 1,15.

Le chevalier de Grimoard, commandant la frégate la Minerve, aperçut au point du jour, en sortant de la baie des Baradaires, le 7 février, deux bâtiments anglais, le vaisseau le Ruby et la frégate la Lowestone, qu'il attaqua aussitôt, et eut ensuite à se défendre contre le vaisseau le Brislol et la frégate l'Eolus, qui cherchaient à l'envelopper. Il attaqua la frégate l' Eolus, et après trois-quarts d'heure de combat, elle fut forcée de l'abandonner. Le calme vint quelque temps après el dura jusqu'à une heure. Lorsque la brise s'éleva du nord-nord-ouest, les vaisseaux qui l'entouraient commencèrent à le chasser ; mais il força de voiles, et la nuit tomba sans qu'ils pussent l'atteindre : il en profita pour faire fausse route et se soustraire a leur poursuite.

Le tableau original est dans la galerie du Ministère de la Marine.

\section{Prise de l'âle de la Grenade. - 4 juillet 1779.}

Par J.-F. HuE en 1787. - H. 2,28. - L. 2,12.

Le comte d'Estaing, après avoir réuni à son armée navale l'escadre du chevalier de Lamotte-Piquet, appareilla du Fort-Royal de la Martinique, et parut, le 2 juillet au matin, à la vue de la Grenade. Il mouilla le soir devant l'anse Molenier, et mit à terre treize cents hommes qui occupèrent les hauteurs voisines. La journée du 3 fut employée à examiner les positions de l'ennemi et à concerter le plan d'attaque. Après cette reconnaissance, le comte d'Estaing commence l'attaque dans la nuit du 3 au 4 , saute un des premiers dins les retranchements anglais, se porte avec 
SALLES DES MARINES, No 63 .

rapidité au sommet du Morne et s'en empare de vive force. Il y trouva quatre pièces de vingt-quatre, et en fit tourner une, au point du jour, contre le fort dans lequel s'était retiré le gouverneur. Ainsi menacé d'être foudroyé à chaque instant par une artillerie quidominait le lieu de sa retraite, lord Macartney futobligé, deux heures après, de se rendre à discrétion. On fit sept cents prisonniers, et l'on prit sur les ennemis trois drapeaux, centdeux pièces de canon et seize mortiers.

\section{Combat naval de l'île de la Grenade. - 6 juil- let 1779.}

Par J.-F. HUE. - H. 1,28. - L. 2,17.

Le lendemain de la prise de la Grenade, le comte d'Estaing reçut l'avis de l'approche de l'armée navale anglaise. Elle avait l'avantage du vent et s'approchait, toutes voiles dehors, dans l'ordre de bataille suivant : à l'avant-garde, le vice-amiral Barrington, sur le Prince-de-Galles; au corps de bataille, l'amiral Byron, sur la Princesse-Royale; et à l'arrière-garde, le contreamiral Hyde-Parker, sur le Conquérant. L'arriée francaise, qui courait à bord opposé, était ainsi formée : à l'avant-garde, le comte de Breugnon, commandant, sur le Tonnant; le comte d'Estaing, général, au corps de bataille, sur le Languedoc; et à l'arrière-garde, M. de Broves, sur le César. Le combat, commencé à la pointe du jour, continua avec la plus grande vivacité jusqu'à midi un quart; il cessa alors, parce que l'armée anglaise forçait toujours de voiles et serrait le vent pour rejoindre son convoi, tandis que l'amiral français arrivait insensiblement pour' rallier ses vaisseaux sous le vent.

Ce tableau, commandé par Louis XVI, lui fut présenté à Versailles e 5 ocobre 1788.

\section{Combat des frégates francaises la Junon et la Gentille contre le vaisseau anglais l'Ardent. - 17 août 1779.}

Par Gilbert. - H. 0,98. - L. 1,43.

La frégate la Junon, commandée par le chevalier de Marigny, découvrit le 17 août à huit heures du matin, sur la pointe de Good-Start, deux bâtimentts dont l'un donnait chasse à l'autre, et le visitait après l'avoir atteint. Le chevalier de Marigny reconnut que le bàtiment visité était danois et que l'autre était un vaisseau de ligne anglais. Lorsqu'il fut à petite portée de canon, il arbora la flamme et le pavillon français, et envoya deux volées à ce vaisseau qui lui présentait la hanche. En ce moment, 
la frégate la Gentille, commandée par le lieutenant Mengaud de La Haye, arriva à portée de combattre, et fit le feu le plus vif. Le vaisseau anglais commença alors à tirer sur les deux frégates. Il ne leur fit aucun mal, et après cette courte défense, le capitaine amena son pavillon et nous laissa maîtres du vaisseau l'Ardent, de soixante-quatre canons.

Le tableau original est dans la galerie du Ministère de la Marine.

\section{Combat de la Surveillante contre le Québec. - 7 octobre 1779.}

Par Gilbert, d'après le marquis de Rossel. - H. 0,59. - L. 1,15.

La frégate la Surveillante de vingt-six canons, commandée par Du Couëdic, lieutenant de vaisseau, croisait à la hauteur de l'île d'Ouessant avec le cutter l'Expédition; on découvrit le 7 octobre, à la pointe du jour, une frégate et un cutter anglais, et l'action s'engagea bord ả bord à six heures et demie; elle fut soutenue, de part et d'autre, avec la même vivacité et le même courage. A une heure après midi, la Surveillante fut démâtée de tous ses mâts, et peu de minutes après, la mâture de la frégate anglaise éprouva le même sort. Ces deux, bâtiments, privés de tous leurs mâts et hors d'état de manœuvrer, continuèrent à combattre avec la même chaleur. La frégate anglaise le Québec, ayant pris feu, l'incendie se communiqua rapidement au beaupré de la Surveillante. Du Couëdic parvint, à l'aide de quelques avirons, à s'éloigner du bâtiment, et réussit à éteindre le feu de son beaupré; dès lors il ne s'occupa plus qu à sauver quelques Anglais qui s'étaient jetésà la mer, et à quatre heures la frégate anglaise sauta en l'air.

\section{Combat naval en vue de la Dominique.- 17 avril 1780.}

Par Gilbert, d'après le marquis de Rossel. - H. 0,99. - L. 1,63.

Le 17 avril 1780, les armées navales de France et d'Angleterre étaient en présence, en vue de la Dominique, dans l'ordre suivant: Flotte anglaise : à l'avant-garde, sept vaisseaux de haut bord, le vice-amiral Hyde-Parker, commandant, sur la Princesse-Royale; au corps de bataille, sept vaisseaux, l'amiral Rodney, généralissime, sur le Sandwich; à l'arrière-garde, six vaisseaux. La flotte française était rangée dans l'ordre inverse : A l'arrière-garde, sept vaisseaux de haut bord, le comte de Grasse, commandant, sur le Robuste; au corps de bataille; sept vaisseaux de haut bord, le comte de Guichen, général en chef, sur la Couronne; et à l'avant-garde, huit vaisseaux de haut bord, le cho- 
SALLES DES MARINES, $N^{0} 65$.

valier de Sade, commandant, sur le Triomphant. L'action commença à onze heures du matin et ne se termina qu'à quatre heures du soir, sans qu'aucun des deux partis eût obtenu un avantage marqué.

Le tableau original est dans la galerie du Ministère de la Marine.

\section{Combat naval de la Praya. - 16 avril 1781.}

Par Gilbert, d'après le marquis de Rossel. - II. 0,30. - L. 1,63.

A la demande des Hollandais, le gouvernement français avait expédié sous les ordres de Suffren une petite flotte pour porter des troupes et des munitions de guerre au cap de Bonne-Espérance, qui était menacé par les Anglais. Suffren approchait de la baie de la Praya, dans l'île de San-Iago, lorsqu'il reconmut l'escadre anglaise : voyant qu'il avait été prévenu, il prit aussitôt le parti de l'attaquer. Après un engagement très-vif, l'escadre du commodore Johnstone, trop maltraitée pour pouvoir s'opposer au passage de Suffren, fut obligée de regagner la rade de Praya. Le parti courageux que prit le commandeur de Suffren dans cette circonstance, lui procura l'avantage inappréciable d'arriver dans l'Inde avant les Anglais, dont le départ avait précédé le sien, et c'est à juste titre qu'on doit lui attribuer tout l'honneur de cette journée.

Le tableau original est dans la galerie du Ministère de la Marine.

\section{Combat naval devant la Chesapeak. - 3 sep- tembre 1781.}

Par M. Th. Gudin. - I. 0,57. - L. 1,35.

Le comte de Grasse parut le 28 août devant le cap Henri, en dehors de la baie de Chesapeak, le même jour que le contre-amiral Samuel Hood arrivait des îles du Vent avec quatorze vaisseaux de ligne. Deux jours après il jeta l'ancre devant Linn-Haven, ayant pris position à l'entrée des rivières James et d'York pour en former le blocus. Pendant qu'il attendait à son mouillage, sa frégate de découverte lui signala vingt-sept voiles dirigeant leur route sur la baie. A l'instant l'amiral ordonna de se préparer au combat, en se tenant prêt à appareiller. Ces ordres furent exécutés avec tant de célérité, que l'armée navale francaise fut sous voile en moins de trois-quarts d"heure et sa ligne formée dans l'ordre suivant: Avant-garde, de Bougainville, commandant, sur l'Auguste; au corps de bataille, le comte de Grasse, sur la Ville-dle-Paris; et à l'arrière-garde, le chevalier de Monteil, sur le Languedoc. L'armée anglaise avait l'avantage du vent : elle marchait dans l'ordre de bataille inverse : le contre-amiral 
Drake, sur la Princesse, à l'arrière-garde; l'amiral Graves, au corps de bataille, sur le London; et à l'avant-garde, le rice-amiral Samuel Hood, sur le Barfleur. Laction s'engagea par un feu très-vif et dans l'ordre inverse entre les deux avant-gardes des deux armées, et à la portée de la mousqueterie entre leurs vaisseaux de tête. Quelques vaisseaux des deux corps de bataille prirent aussi part à ce combat, mais à une grande distance : l'arrière-garde anglaise, en tenant constamment le vent, évita l'attaque de celle des Français, qui faisait tous ses efforts pour l'approcher, ainsi que le corps de bataille anglais. Le combal dura jusqu'à six heures et demie du soir, et ce fut en vain que les Français cherchèrent, pendant quatre jours, à le rengager. Les vents variables et les temps orageux finirent par leur faire perdre de vue l'armée anglaise.

Ce tableau a èté exposé au Salon de 1848.

\section{Prise des îles Saint-Christophe et Névis. - 13 février 1782.}

Par le marquis de Rossel. - H. 0,98. - L. 1,63.

Le comte de Grasse était sorti de la Martinique le 17 décembre 1781 dans le dessin d'attaquer la Barbade. Le mauvais temps qu'il essuya dans le canal de Sainte-Lucie ne lui permit pas d'entreprendre cette expédition; il se dirigea alors sur l'île Saint-Christophe. Ayant rencontré l'armée navale de l'amiral Hood, il lui livra combat et poursuivit sa route vers les îles Saint-Christophe et Névis. Le 3 février, les armées de terre et de mer, aux ordres du marquis de Bouillé et du comte de Grasse, s'emparèrent de ces deux îles après trente-trois jours de siége.

Ce tableau, commandé par Louis XVI, lui fut présenté à Versailles le 6 septembre 1789.

1435. Combat des frégates françaises la Nymphe et l'Amphitrite contre le vaisseau anglais l'Argo. - 11 février 1783.

Par Gilbe:rt. - H. 0,90. - L. 1,63.

Les frégates françaises la Nymphe et $l$ Amphitrite, s'emparent, à la hauteur de Tortola, du vaisseau $l$ Argo, de cinquante-deux canons. Ce raisseau fut repris le mème jour par cinquante-deux vaisseaux ennemis; mais les deux frégates françaises, commandées par le ricomte de Mortemart, capitaine de vaisseau, et de Saint-Ours, lieutenant, partinlent à leur échapper.

Le tableau original est dans la galerie du Ministère de la Marine. 
QUATRIÈME SALLE.

1436. Combat de la frégate française l'Embuscade contre la frégate anglaise le Boston.-30 juillet 1793.

Par M. Th. Gudin. - H. 0,74. - L. 1,09.

La frégate l'Émbuscade, commandée par le capitaine Bompard, avait été expédiée de Rochefort pour transporter le premier ambassadeur chargé de représenter la république francaise auprès du gouvernement des Etats-Unis. Vers la fin de juillet 1793 le capitaine Bompard se trouvait dans le port de New-York, attendant les instructions et les dépêches de l'ambassadeur pour retourner en France. La frégate le Boston, commandée par le capitaine Courtenay, épiait la sortie de la frégate française; mais celle-ci ne paraissait pas faire de préparatifs pour mettre à la voile. Le capitaine de Courtenay adressa au capitaine Bompard un cartel dans lequel il proposail un combat singulier entre $l e$ Boston et l'Embuscude. Bompard accepta le défi du capitaine anglais. Il se hâta de sortir du port, se mit à la recherche du Boston, et le 30 juillet, à cinq heures du matin, il le rejoignit en arborant le signal convenu pour se faire reconnaître. En ce moment les hauteurs voisines de la côte étaient couvertes de spectateurs, et quantité de ciloyens de New-York, montés sur des bâtiments léger's et même sur de frêles embarcations, avaient suivi l' $\mathrm{Em}$ buscade pour observer de plus près ce duel étrange. L'action se prolongea pendant deux heures avec le plus grand acharnement; mais la victoire, si vivement disputée, demeura au pavillon français. Le Boston, en partie démâté et désemparé de presque toutes ses voiles, ayant eu son capitaine tué et tous ses officiers blessés, prit la fuite, et, escortée de la petite flottille de curieux qui était sortie sur ses traces, l'Embuscade rentra dans le port aux acclamations des habitants de la ville et de la campagne, accourus de toutes parts pour le féliciter de sa victoire.

\section{Combat de la frégate française la Bayonnaise contre la frégate anglaise l'Embuscade. - 14 décembre 1798.}

par Grepin. - H. 2,46. - L. 3,40.

La frégate la Bayonnaise, commandée par le lieutenant de vaisseau Richer, venait de Cayenne le 14 décembre 1798, et n'était plus qu'à trente-cinq ou quarante lieues de Rochefort, lor'squ'elle fut attaquée par la frégate anglaise l'Embuscade. On combattit 
quelque temps bord à bord, ensuite à douze toises de distance. Le feu devint terrible et dura cinq heures sans être décisif. La position de sa frégate au vent de l'ennemi décida le commandant français à tenter l'abordage. Dans le choc des deux bâtiments, le beaupré de la Bayonnaise se brise et tombe à la mer, ainsi que le mât d'artimon de l'Embuscade. Le contre-coup sépare les deux vaisseaux. Richer saisit l'occasion et lâche dans le travers de son adversaire quatre coups de canon qui balayent sa batterie et lui meitent trente ou quarante hommes hors de combat. Au même instant les marins français sautent à bord de l'ennemi, et les Anglais, débusqués de leurs gaillards d'arrière et d'avant, sont forcés de se rendre.

Ce tableau, exposé au Salon de 1801, était un prix d'encouragement accordé à l'artiste.

\section{Arrivée en France du général Bonaparte à son relour de la campagne d'Egypte. - 9 octo- bre ${ }_{1}^{\text {a }} 99$.}

Par M. Louis MeYer en 1843. - H. 2,70. - L. 3,80.

A la pointe du jour, les frégates le Muiiron et la Carrère, les chebecks la Revanche et la Fortune, sous les ordres du contreamiral Gantheaume, vinrent mouiller dans le golfe de Fréjus. En apprenant que le général Bonaparte était mouillé sur la côte, tous les habitants de Fréjus accoururent, et en un instant la mer fut couverte d'embarcations. « Une multitude, ivre d'enthousiasme et de curiosité, envahit les vaisseaux, et violant toutes les lois sanitaires, communiqua avec les nouveaux arrivés. Tous demandaient Bonaparte, tous voulaient le voir. Le général fut dispensé de la quarantaine, car il aurait fallu condamner à la même précaution toute la population qui avait déjà communiqué avec les équipages. Aussitôt Bonaparte descendit à terre, et le jour même il monta en voiture pour se rendre à Paris. "(Histoire de la Révolution française, par M. THIERs.)

Ce tableau a été exposé au Salon de 1843.

\section{Combat naval devant Cadix. - 13 juillet 1801.}

Par Gilbert. - H. 0,74. - L. 1,15.

Le vaisseau le Formidable, commandé par le capitaine Troude, se rendait à Cadix lorsqu'il se trouva, le 13 juillet, à la pointe du jour, en présence de trois vaisseaux anglais, le Césur, le Spencer, le Vénérable, et de la frégate anglaise la Tamise, faisant partie de l'escadre de l'amiral Saumarez. Par une habile ma- 
SALLES DES MARINES, No 65 .

nouvre et un feu soutenu, le Formidable réduisit l'un des vaisseaux ennemis et força les autres à le laisser entrer à Cadix.

Ce tableau a été exposé au Salon de 1833.

\section{Capitulation obtenue par l'adjudant-comman- dant Binot, à Pondichéry, - 11 sept. 1803.}

Par M. Hipp. BelLaNGé en 1854 - - H. 0,74 . - L. 1,15.

Le général Binot, alors adjudant-commandant, avait pris possession, au nom de la France, de la ville de Pondichéry, où il s'était établi avec deux cents hommes de la 102 demi-brigade, attendant l'escadre du contre-amiral Linois, qui devait l'appuyer, mais qui dans l'intervalle avait reçu contre ordre. Bientôt cerné dans l'hôtel de la Monnaie, où il s'était fortifié, par huit cents Anglais qui s'élevèrent successivement au nombre de quinze cents, il obtint, par une défense énergique et à la suite d'une seconde sommation, de retourner en Francesans conditions et avee les honneurs de la guerre.

Le tableau représente l'a(jjudant-commandant Binot quittant l'hôtelde la Monnaie à la tête de sa pelite garnison et défilant devant l'armée anglaise, qui lui rend les honneurs dus à son hérö̈que résistance.

\section{La frégate française la Poursuivante force l'en-} trée du pertuis d'Antioche. - 2 mai 1804.

Par M. Th. Gudin en 1842. - H. 0,74. - L. 0,64.

Le commandant Wuillaumez avait reçu du ministre Decrès l'ordre de faire sortir de la Gironde la frégate la Poursuivante, et de la conduire à Rochefort. Un vaisseau de ligne anglais était à l'ancre à une assez grande distance au large de la pointe nord-ouest de l'île d'oléron. Le vaisseau anglais, apercevant la Poursuivante qui franchit l'embouchure du fleuve, appareille mais trop tard. Par une habile manœuvre elle lui gagne le vent, essuie son feu à petite distance, et en ripostant lui fait dans son gréement des avaries qui l'empêchent de virer de bord en même temps que la frégate. Celle-ci, débarrassée de son formidable adversaire, donne dans le pertuis et se dirige à pleine voile vers la rade de Rochefort.

1442. Prise de la corvette anglaise le Vimiejo par une section de la flottille impériale. -8 mai 1804 .

Par M. Th. Gudin. - H. 0,70.-L. 0,61.

Une section de canonnières commandée par le lieutenant de vaisseau Tourneur, qui se rendait à Lorient, fut rencontrée en 
mer, le 8 mai 1804, par une forie corvette, le Vimiejo, el un lougre anglais. Le combat se soutint longtemps avec acharnement. Ecrasés par les boulets et la mitraille que vomissaient les canons de vingt-quatre des canonnières, la corvette et le lougre prirent le large en forçant de voiles. Le commandant des canonnières donna ordre de les poursuivre, et les ayant atteints il les contraignit à amener leur pavillon.

GINQUIĖME SALLE.

\title{
1443. Combat naval dans la baie d'Algésiras. - 5 juil- let 1801.
}

\author{
Par M. MOREL-Fatio. - H. 1,59. - L. 2,84.
}

Le contre-amiral Linois, à la tête d'une division navale, faisait voile vers Cadix où il devait faire sa jonction avec l'escadre espagnole. Arrivé dans le détroit de Gibraltar, il apprit que Cadix était étroitement bloqué, et que l'amiral Saumarez marchait à sa rencontre avec des forces supérieures. Il se retira à Algésiras où il se plaça sous la protection des batteries de terre pour se défendre en cas d'attaque.

Le vaisseau le Formidable, monté par le contre-amiral Linois, est sur la gauche, entre le Desaix et la frégate le Muiron. L'aniral Saumarez occupe le milieu du tableau; la bordée de l'Indomptable et l'artillerie du fort l'ont réduit ì donner le signal d'une retraite prématurée. Linois s'est particulièrement attaqué à l'Annibal, qui est resté au pouvoir de l'amiral français comme trophée de cette journée.

Ce tableau a été exposé au Salon de 1836.

\section{Combat naval devant Boulogne. - Nuit du 15 au 16 août 1801.}

Par Crépin. - H. 2,42. - L. 3,38.

Une flottille composée de bateaux plats et de canonnières, destinée à exécuter une descente en Angleterre, avait été organisée à Boulogne par les soins de l'amiral La Touche-Tréville. Nelson se présenta le 4 août devant Boulogne avec qquarante voiles composées de trois vaisseaux, quatre frégates, de brûlots, de bombardes et de canonnières, fut forcé de se retirer, puis revint au bout de quelques jours avec un renfort de trente bâtiments et de trois à quatre mille soldats de marine, destinés à enlever la flottille à l'abordage ou à l'incendier. L'attaque eut lieu de nuit. La division du capitaine Parker, engagée la première, fut vivement reçue par la canonnière l'Etna; la mitraille, et surtout le feu de l'infanterie placée à bord des bâtiments français, tua ou blessa en peu de minutes la moitié des soldats qui montaient les péniches anglaises, et le capitaine 
Parker lui-même fut blessé à mori. Le combat, devenu général, offrit partout le même résultat; la division de réserve tenta vainement de se glisser entre la ligne et la terre: elle fut accablée sous le feu des batteries de côte, et contrainte à s'éloigner promptement. A la pointe du jour, cest-à-dire vers quatre heures, le combat cessa, et Nelson donna le signal de la retraite, après avoir perdu deux cents hommes d'élite.

Ce tableau a été exposé au Salon de 1806.

\section{Combat de la frégate française la Canonnière contre le vaisseau anglais le Tremendous. - 21 avril 1806.}

Par Gilbert. - H. 0,93. - L. 1,71.

Ic 21 avril 1806, à six heures et demie du matin, la frégate de quarante canons la Canonnière, commandée par le capitaine de vaisseau César Bourayne, en croisière sur la côte sud-est de l'Afrique, aperçut treize voiles sur lesquelles elle se dirigea pour les reconnaître. Le capitaine Bourayne, après s'être assuré que deux de ces bâtiments appartenaient à la compagnie des Indes et formaient un convoi escorté par un vaisseau de ligne, le Tremendous, jugea prudent de se retirer devant des forces aussi supérieures. Mais le Tremendous prit chasse sur elle, la joignit vers quatre heures du soir et la força à accepter le combat. Malgre lénorme disproportion de forces entre les deux adversaires, l'action dura une heure et demie. L'équipage de la frégate y déploya une ardeur et un courage extraordinaires. Le vaisseau anglais fut tellement maltraité, qu'il lui fut impossible de poursuivre la frégate qui, heureuse de n'avoir pas succombé, s'éloigna du champ de bataille.

\section{Entrée de l'empereur Napoléon $I^{e r}$ à Venise 29 novembre 1807.}

École italienne modernc. - I. 0,64. - L. 0,88.

" Le 29, Sa Majesté a passé en revue les troupes qui étaient aux environs de Stra. Elle s'est ensuite mise en route pour Fusine. La princesse de Lucques y attendait son frère. Le patriarche de Venise, les ministres du royaume d'Italie y étaient réunis. Le port de Fusine etait couvert de barques ornées de riches étoffes, de plumes et de guirlandes. L'élégante et riche péote destinée par la ville à recevoir Sa Majesté, était conduite par des gondoliers en habit de satin blanc, bordés de galons d'or. La marine avait de son côté préparé un canot couvert de velours nacarat; il était monté par les marins de la garde. L'Empereur s'est em- 
barqué dans la péote de la ville. Le Roi, la Reine et la princesse Charlotte de Bavière étaient avec lui. Il était aussi accompagné de LL. AA. II. la princesse de Lueques, le prince vice-roi et le grand-duc de Berg, et de S. A. S. le prince de Neufchâtel. Le canot de la garde a suivi. Au signal du départ, la mer a élé couverte de barques; le trajet a duré une demi-heure. Un are de triomphe avait éte élevé a l'entrée du grand canal. La péote montée par Sa Majesté a seule passé sous cette porte triomphale, et la foule immense des gondoles s'est divisée pour défiler des deux côtés. Sa Majesté esi descendue à cinq heures au palais impérial, qui était ci-devant le palais des procureurs. ”) (Moniteur du 8 décembre 1807.)

\section{L'empereur Napoléon I ${ }^{e r}$ préside la régate à Venise. - 2 décembre 1807.}

École italienne moderne. - H. 0,64. - L. 0,88.

Le 2 décembre, l'empereur, après av'oir vu lancer une frégate à l'arsenal, présida, à deux heures, aux jeux de la régate. " La régate est une course de gondoles divisée en trois concours. La première a eu lieu entre des bateaux montés par un seul conducteur; la deuxième et la troisième entre des bateaux montés par deux conducteurs. La carrière était le grand canal qui traverse la ville dans toute la longueur. Les belles péotes qui avaient servi à l'entrée de l'empereur fendaient la foule et préparaient le passage aux gondoles de la course. Sa Majesté s'était placée, avec toute sa cour, sur le balcon d'un palais qui domine sur le canal et au pied duquel était le but. „ (Moniteur du 11 décembre 1807.)

\section{Combat de la frégate française la Sirène contre une division anglaise. - 22 mars 1808.}

Par Gilbert. - H. 0,93. - L. 1,71.

La frégate la Sirène, capitaine Duperré, après avoir rempli une mission aux Antilles, vint, de concert avec l' Italierne, atterrer sur les côtes de Bretagne. Elles faisaient route vers le port de Lorient, lorsque le 22 mars 1808 , elles se virent chassées par une division de deux vaisseaux et de trois frégates, qui leur coupaient le chemin. Obligées l'une et l'autre de chercher protection sous les forts de Groix, l'Italienne y parvint facilement; mais il n'en fut pas de même de la Sirère, qui ne put rallier la côte qu'en se battant des deux bords, pendant cinq quarts d'heure, contre un vaisseau et une frégate. Forcé enfin de s'échouer pour ne pas tomber au pouvoir de ses adversaires, Duperré mit tant d'habi- 
SALLES DES MARINES, $\mathrm{N}^{\circ} 65$.

leté dans sa manœuvre, que trois jours après il avait renfloué sa frégate et rentrait à Lorient.

\section{Napoléon et Marie-Louise visitent l'escadre mouillée dans l'Escaut devant Anvers. - $1^{\mathrm{er}}$ mai 1810.}

Par VAN BREE. - H. 0,70. - L. 1,10.

Le 27 avril, Napoléon et Marie-Louise étaient partis de Compiègne pour faire un voyage dans les provinces du Nord et en Belgique. Leur arrivée à Anvers fut annoncée par des décharges réitérées de l'artillerie de tous les bâtiments de la flotte et des fortifications de la ville. Ayant mis pied à terre à la cale de l'arsenal, le maire et le commandant de la place présentèrent les clefs à l'Empereur. La foule du peuple était immense, elle exprimait la reconnaissance des habitants de cette importante cité pour son second fondateur.

\section{Le Friedland lancé dans le port d'Anvers. - . 2 mai 1810.}

Par VAN BRÊE. - H. 0,70. - L. 1,20.

Pendant son séjour à Anvers, Napoléon visita les travaux du port et les fortifications. Le vaisseau de ligne le Friedland, de quatre-vingts canons, fut lancé le 2 mai, en présence de l'Empereur et de l'Impératrice. L'archevêque de Malines, à la tête de son clergé, fit la bénédiction du vaisseau, qui pendant cette cérémonie ayant été séparé de tous ses accorses, ne reposait plus que sur son berceau et n'était retenu que par les saisines placées en avant, le vaisseau devant entrer dans l'eau par l'arrière. Les saisines furent coupées en un instant à coups de hache, et à trois heures précises le vaisseau s'élança de sa cale et entra majestueusement dans le fleuve au bruit des acclamations de tous les spectateurs.

\section{Combat de l'île de la Passe ou du Grand-Port. - 24 août 1810.}

Par Gilbert en 1836. - H. 0,93. - L. 1,45.

Le capitaine Duperré commandait une division française composée des frégates la Bellone et la Minerve, et de la corvette le Victor, venant des mers de l'Inde. Il s'était embossé le 23 août dans le port Impérial (Grand-port, île de France) sous la protection des forts, lorsqu'il fut attaqué par une division anglaise de quatre frégates, la Néréide, le Sirius, l'Iphigénie et la Magi- 
cienne. Le combat commenca à cinq heures et demie du soir et continua presque toute la nuit sans interruption. Le 2'1, au point du jour, on vit la Néréide entièrement démâtée et daus l'état le plus affreux; sur un troncon die màt flottait encore le pavillon anglais, mais il fut bientờt remplacé par les couleurs françaises. La Magicienne, criblée de boulets, combattait encoro; mais bientòt les débris de son équipage se refugièrent vers l'îlo de la Passe et sur les deux autres frégates, et le soir le feu s? manifesta de toutes parts.

Ce tableau a été exposé au Salon de 1837.

\section{Combat de la frégate française la Pomone contre les frégates anglaises l'Alceste et l'Ac- tive. - 29 novembre 1811. \\ Par Gilbert. - Forme ronde; diam. 0,76.}

La frégate la Pomone, capitaine Ducampe de Rosamel, étant. séparée de la division française, dont elle faisait partie, et qui croisait dans la mer Adriatique, se troura seule engagée, le 29 novembre 1811 , à la hauteur de lìle Pelagosa, contre deux frégrates anglaises l'Alceste et l'Actice: La lutte fut longue ci acharnée : la Pomone fit des araries considérables ì ses deux adversaires. Après deux heures de combat, ne pouvant plus goulverner et ayant quatre pieds d'eau dans sa cale, le capitaine hos?mel réunit ses officiers et ses premiers maîtres, et sur l'aris unanime de ne pouvoir continuer une plus longue résistance. il fit cesser le feu.

Ce tableau a été exposé au salon de 1837.

\section{Combat naval en vue de l'âle d'Aix. - 27 dé- cembre 1811.}

Par Dusaulchox. - H. 1,62. - L. 2,60.

Un convoi français venant de la Rochelle, poursuivi le 27 décembre 1811 par cinq péniches de l'escadre anglaise mouillée c!1 rade des Basques, était venu se réfugier au fond de la baie entre La Rochelle et l'ile d'Aix. La division française, retenue à l'ancre par les vents contraires et par un violent orage qui se préparait, laissa s'avancer les péniches anglaises, et quand elles furent assez compromises, elle fit couper leur retraite par ses embareations qui les prirent toutes.

Ce tableau a été exposé au Saloa de 1835. 
1454. Combat naval en vue des îles de Loz.- 7 fév. 1813.

Par Crépin. - H. 1,62, - L. 2,58.

Le capitaine Bouvet, commandant la frégate l'A réthuse, rencontra, le 7 février 1813, la frégate anglaise l'Améliı, près des îles de Loz, sur la côte de Guinée. Après un combat assez vif, dans lequel le capitaine Bouvet conserva l'avantage, il força la frógate anglaise à se retirer devant lui.

1455. Combat du vaisseau français le Romulus contre trois vaisseaux anglais, à l'entrée de la rade de Toulon. - 13 février 1814.

Par M. Gilbert. - H. 0,93. - L. 1,45.

Le vaisseau le Romulus, commandé depuis 1812 par le capitaine Rolland, faisait partie, en 1814, de la division du contreamiral Cosmao. Cette division, composée de trois vaisseaux et de trois frégates, était chargée de protéger l'entrée à Toulon dı vaisseau le Scipion, venant de Giênes, où il avait été construit. Sortie le 12 février, elle eut, le lendemain, connaissance de la flotte anglaise, qui n'avait pas moins de quinze vaisseaux. Le contre-amiral manceuvra pour faire rentrer la division dans le port de Toulon, en passant par les îles d'Hières. J'armée angrlaise forca de voiles pour couper la route aux vaisseaux francais. Le Romulus se trourait en serre-file. Le capitaine Rolland, qui connaissait parfaitement la côte, la serra le plus près possible; mais bientôt la Boyne, que montait l'amiral Pellew, ainsi que le Caledonia, commencèrent à canonner le Romulus. Le feu le plus vif régnait de part et d'autre à portée de pistolet, lorsqu'un troisieme vaisseau à trois ponts vint se joindre aux deux premiers. Cependant le Romulus s'approchait de la rade de Toulon, et les vaisseaux qui le combattaient, craignant de s'engolfer dans la baie, l'abandonnèrent enfin, et il rentra dans la rade de Toulon. Ses bas mâts avaient reçı plusieurs boulets; celui de misaine était hors de service; ses mâts de hune et ceux de perroquet étaient coupés, ses voiles étaient criblées, et toutes ses manoeuvres courantes hachées. Plusieurs boulets avaient pénétré dans la flottaison, ct l'un d'eux avait traversé la soute aux poudres. Presque tous les officiers avaient été blessés, dont trois mortellement. Cent cinquante hommes de l'équipage avaient élé tuŕs ou blessés. Ie lendemain de ce combat le Scipion rentra en rade sans avoir été inquiété dans sa traversée.

Ce tableau a été exposé au Salon de 1837. 


\section{5̌6. Retour de l'âle d'Elbe. - 28 février 1815.}

Par Louis Garnerey. - H. 1,87. - L. $2,27$.

Le 27 février 1815, à cinq heures du soir, Napoléon I ${ }^{\text {er }}$ quitta l'île d'Elbe avec quatre cents hommes de sa garde embarqués sur le plus grand navire de la flottille le brick l'Inconstant, de 20 canons. Cinq cents militaires de différentes armes furent répartis sur trois autres navires stationnant à Porto-Ferrajo. L'escadrille ayant été desservie sur la tombée de la brise pendant la nuit, on ne put faire que six lieues avant le jour. On se trouvait alors entre l'île de Capraja et l'île d'Elbe, en vue de la croisière établie pour surveiller les mouvements de l'ille. Cette croisière se composait de deux frégates et d'un brick francais, le Zéphyr, secondé par un vaisseau anglais de 74. A ce möment on fit cacher la troupe sous le pont, et la floltille, guidée par l'Inconstant, vogua toute la journée toutes voiles dehors. A cinq heures du soir, la route que suivait l'Inconstant courant celle du Zéphyr, les deux navires passèrent si près l'un de l'autre que leurs capitaines parlementèrent ensemble. A ce moment on proposa de faire arborer à ce brick le pavillon tricolore ; mais l'Empereur s'y opposa, craignant une collision générale qui eût pu compromettre l'entreprise.

Le tableau représente le moment où, étant encore en vue du cap Corse, les deux bricks se croisent, et où l'Empereur, monté sur la caronade de l'avant et portant l'uniforme d'officier de marine, ordonne de continuer la route.

\section{Bombardement de Cadix par l'escadre fran- caise. - 23 septembre 1823.}

Par Crépin en 1824. - H. 1,62. - L. 2,58.

La prise du Trocadéro n'ayant pas amené la reddition de Cadix, le duc d'Angoulême se décida à faire bombarder la ville par l'escadre française, en même temps qu'on la resserrait par terre. Le contre-amiral Duperré, commandant une flottille composée de sept bombardes françaises, trois espagnoles et cinq obusiers, appuyés par une division de chaloupes canonnières, fit commencer le feu le 23 septembre. Cadix prolongea quelques

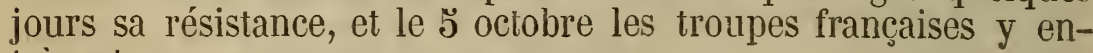
trèrent.

Ce tableau a été exposé au Salon de 1824.

1458. Prise du fort de Saint-Jean-d'Ulloa. - 23 novembre 1838.

Par M. Th. Gudin en 1839. - H. 1,51. - I. $2,27$.

Le feu de l'escadre française, commandée par le contre-amiral 
SALLES DES MARINES, $\mathrm{N}^{\circ} 65$.

Baudin, fait sauter la tour des Signaux, élevée sur le cavalier du bastion de Saint-Crispin.

Ce tableau a été exposé au Salon de 1839.

\section{Combat naval de Punto-Obligado. - 20 no- vembre 1845.}

Par M. BaRRY en 1845. - H. 0,78. - L. 1,71.

Le 22 septembre 1845 , les ports et les côtes de la province de Buenos-Ayres avaient été déclarés en état de blocus par la France et la Grande-Bretagne, et le gouverneur de la République Argentine, Rosas, avait de son côté interdit la navigation du Parana. Le 18 novembre l'escadre anglo-française se mit en devoir de forcer le passage; elle se composait : Pour les Anglais, des vapeurs Gorgon et Firebrand, capitaine Hope; de la corvette $\mathrm{Co}$ mus, capitaine Ingelfield; des bricks Philomèle, capitaine Sullivan ; Dolphin, capitaine Leving; du brick-goëlette Fanny, capitaine Key; le capitaine Hotham, commandant en chef des forces anglaises, montait le Gorgon. Pour les Francais, du vapeur Fulton, capitaine Nazères; de la corvette l'Expéditive, capitaine de Miniac; des bricks Pandour, capitaine Du Parc; San Martin, et du brick-goëlette Procida, capitaine de La Rivière; le capitaine Tréhouart, commandant en chef les forces françaises, montait le San Martin. Quatre batteries étaient établies sur la rive droite du fleuve, qui etait barré par une estacade formée avec vingtquatre bâtiments liés entre eux par trois fortes chaînes de fer. Le 20 au matin les forces combinées se formèrent en trois divisions pour l'attaque. Après un combat de sept heures, l'estacade ayant été forcée, les capitaines Hotham et Tréhouart opérèrent leur descente et s'emparèrent des batteries.

\section{Prise des batteries de Punto-Obligado. - 20 novembre 1845.}

Par M. BARRY. - H. 0,80.- L. 1,71.

Ces deux tableaux ont été exposés au Salon de 1847. La position des bâtiments des deux divisions combinées a été assignée à chacun d'eux d'après le plan dressé par le capitaine anglais Sullivan, de la Philomèle.

\section{Prise du fort de Fautahua, à Taïti. - 17 dé- cembre 1846.}

Par M. Charles Giraud. - H. 1,51. - L. 1,09.

Le capitaine de corvette Bonard, à la tête de la $3^{\mathrm{e}}$ compagnie de débarquement de l'Uranie, guidé par le chef indien Tariérii, prend à revers le fort de Fautahua, dernier retranchement des 
Indiens à Taïti. On parvint à escalader le roc à pic au moyen de cordes et en se hissant à force de bras, nayant pour appuyer les pieds et franchir une distance de cent cinquante mètres, que les roches nues et quelques touffes de verdure. L'occupation de ce fort mit fin à la guerre de Taïti et assura la pacification de lîle sous le gouvernement du contre-amiral Bruat. (Annules maritimes, mai 1847, pages 449 et suiv.).

Ce tableau et le suivant ont ėté exposés au Salon de $\mathbf{1 8 5 5 .}$

\section{Fausse attaque du fort de Fautahua à Taïti.-} 17 décembre 1816.

Par M. Charles Giraud. - H. 1,51. - L. 1,09.

Pour occuper l'ennemi pendant l'attaque dirigée par le capitaine Bonard, une fausse attaque est exécutée contre le fort de Fautahua par une compagnie de voltigeurs et la $3 I^{\mathrm{e}}$ du $1^{\mathrm{er}}$ régiment dinfanterie de marine, sous les ordres du commandant Masset.

\section{Bombardement de Salé. - 26 novembre 1851.}

Par M. Th, GudIx en 18,5. - H. 1,60. - L. 2,84.

Le contre-amiral Dubourdieu, commandant en chef la division navale expéditionnaire au Maroc, ourre à dix heures du matin le feu contre les forts nord-ouest et sud-ouest de Salé, avec le Henri $I V$, vaisseau de 100 canons, capitaine de Gueydon; le Gomer, frégate à vapeur de 450 chevaux, capitaine Allain; et le Sané, frégate à vapeur de 4000 chevaux, capitaine de Rosamel. "Le fort du N.-O. eut successivement toutes ses embrasures démolies et ses pièces démontées; le fort du S.-0. fut plus promptement entamé, quoique sa résistance se soit prolongée tard. Ce n'est qu à cinq heures du soir, après un engagement de sept heures, que nous arons fait taire tous les forts et les batteries qui les reliaient. „ (Moniteur du 8 décembre 18ว̈1.)

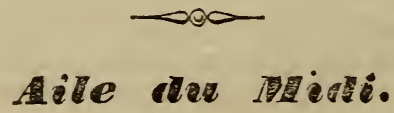

(REZ-DE-CHAUSSEE.)

\section{VESTIBULE DE L'AILE DU MIDI, No 66.}

Ce vestibule servait d'entrée aux appartements de l'aile du midi et à la petite salle de spectarle, iemplacée depuis par le passage yui conduit de l'ancienne our des Pritces dans le parc, $6 !$ par le restibule $\mathrm{n}^{\circ} 40$. 
VESTIBULE DE L'AILE DU MIDI, $\mathrm{N}^{\circ} 66$.

1464. Napoléon $\boldsymbol{I}^{\text {er }}$, empereur des Français. (Noir n ${ }^{\circ 20 .)}$

Par Rutcriel; statue en marbre.-H. 2,30.

\section{David (Jacques-Louis), peintre d'histoire.}

Par RUDE; buste en plâtre. - H. 0,80.

Né à Paris en 1748, il fut d'abord élève de Boucher, puis de Vien, obtint en 1774 le grand prix de peinture, et se rendit à Rome avec Vien, nommé directeur de l'Académie. De retour à Paris en 1780, il exposa au Salon de 1781 le Bélisaire secourı par un soldat, qui le fit agréer à l'Académie royale de peinture. Reçu de l'Académie en 1783, il obtint un logement au Louvre avec le titre de peintre du roi, fit un nouveau voyage à Rome en 1784, y composa le Serment des Horaces, et revint en France en 1787. En 1789 il prit une part active aux événements de la Révolution, fut chargé par l'Assemblée constituante de peindre le Serment du Jeu de Paume, et devint membre de la Convention en 1792. Il peignit pour la Convention les portraits de Lepelletier de SaintFargeau et de Marat, et fut détenu au Luxembourg après le 9 thermidor. Rendu à la liberté il se livra tout entier à son art, et fut nommé premier peintre de l'Empereur. Membre de l'Institut depuis la création, il fut chevalier, puis officier de la Légion d'honneur en 1808. Banni en 181 pour avoir voté la mort de Louis XVI, David se retira à Bruxelles et y mourut le 29 décembre 1825.

Le buste original est au Musée du Louvre.

\section{Gérard (François, baron), peintre d'histoire.}

Par Pradier; buste en plâtre. - H. 0,68.

Né à Rome en 1770; son père était Français et sa mère Italienne. Il étudia d'abord la sculpture chez Pajou, et fut ensuite élève de Brenet et de David. Sa première œuvre importante futle Bélisaire exposé au Salon de 1795, et dès cette époque il commença à peindre les portraits des plus célèbres personnages de l'époque. Chevalier de la Légion d'honneur en 1803, professeur à l'école des Beaux-Arts en 1811, membre de l'Institut en 1814, chevalier de l'ordre de Saint-Michel, baron et officier de la Légion d'honneur en 1828, il mourut à Paris le 11 janvier 1837. - Les Musées du Louvre et de Versailles renferment les principaux tableaux de Gérard. Il a peint aussi les quatre pendentifs de la coupole du Panthéon.

Le buste original est au Musée du Louvre. 


\section{Girodet-Trioson(Anne-Louis), peintre d'histoire.}

Par Rousix; buste en plâtre. - H. 0,70.

Né à Montargis en $\mathbf{1 7 6 7}$, il fut élève de David et remporta le grand prix en 1789. Après un séjour de cinq ans en Italie, pendant lequel il peignit le Sommeil $d^{*}$ Endlymion et Hippocrate recevant les présents d'Artaxerce, il revint à Paris où sa Scène du Déluge obtint le grand prix décennal. Membre de l'Institut en 1816, et chevalier de la Légion d'honneur en 1818, il mourut à Paris le 9 décembre 1821. - Les principaux tableaux de Girodet sont placés dans les Musées du Louvre et de Versailles. - Ses œuvres poétiques ont été publiées en 1829.

Le buste original est au Musée du Lourre.

\section{Gros (Antoine-Jean, baron), peintre d'histoire.}

Par M. DEBaY; buste en plàtre. - H. 0,74.

Né à Paris en 1771, il fut d'abord élève de David. Atteint par la réquisition, il fit partie de l'armée d'Italie, dans laquelle il fut attaché à l'état-major. De retour à Paris, le tableau des Pestiférés de Jaffa, exposé au Salon de 1804, le placa parmi les premiers artistes de cette époque. Chevalier de la Légion d'honneur en 1808, membre de l'Académie et professeur à l'école des Beaux-Arts en 1816, il fut en 1828 chevalier de l'ordre de Saint-Yichel, baron et officier de la Légion d'honneur. Il périt le 26 juin $183 \partial$ dans un étang près de Meudon. - Outre ses grands tableaux exposés dans les Musées du Louvre et de Versailles, Gros a peint une grande quantité de portraits et la coupole du Panthéon.

\section{Guérin (Pierre-Narcisse, baron), peintre d'his- toire.}

Par M. Aug. Dujort ; buste en plàtre. - H. 0,63.

Né à Paris en 1774, il fut élève de Regnault, et obtint le grand prix de peinture en 1797. L'année suirante il exposa le Harcus Sextus, tableau couronné par l'Institut, puis il se rendit en Italie. Chevalier de la Légion d'honneur en 1803, membre de l'Institut en 1816, il fut nommé directeur de l'école de Rome en 1823, et en 1829 baron et chevalier de l'ordre de Saint-Michel. Il se rendit de nouveau à Rome en 1833 , et mourut dans cette ville le 16 juillet 1833.

Le buste origina est au Nusée du Lourre. 


\section{Prud'hon (Pierre-Paul), peintre d'histoire.}

Buste en marbre. - H. 0,67 .

Né à Cluny (Saône-et-Loire) en 17ã8, il eut pour maitre Desvosges, peintre de Dijon, et remporta dans cette ville le grand prix de peinture proposé par les états de Bourgogne. Il continua ses études à Rome, revint en France en 1789, fut chargé de peindre pour le Musée des Antiques, au Louvre, un plafond représentant Diane aux pieds de Jupiter. Son tableau de la Justice divine poursuivant le Crime, exposé en 1808 , le fit nommer chevalier de la Légion d'honneur, et en $\mathbf{1 8 1 6}$ il fut membre de l'Institut. Il mourut à Paris le 16 février 1823.- Prud'hon a exécuté, outre ses tableaux, un grand nombre de compositions qui ont été reproduites par la gravure.

\section{Percier (Charles), architecte.}

Par Pradier; buste en plâtre. - H. 0,66.

Né à Paris en 1764, il obtint le grand prix d'architecture en 1786. Associé à tous les travaux exécutés par Fontaine, son ami d'enfance et son collègue, il fut avec lui architecte de l'empereur Napoléon Ier; ildonna les dessins de l'arc de triomphe qui décore la place du Carrousel, du grand escalier du Louvre, et contribua à l'achèvement et à la restauration du Louvre et des Tuileries. Architecte du Louvre en 180כ, membre de l'Institut en 1811, chevalier de l'ordre de la Légion d'honneur en 1819 et officier en 1828, il mourut à Paris le 5 décembre 1838.

Le buste original est au IIusée du Louvre.

\section{SALLE No 67.}

Cette salle formait, arec les suivantes jusqu'au n 73 , un appartement habité, sous Louis XIV, par le duc et la duchesse de Bourbon; sous Louis XV, par le comte de Charolais et sa sœur, mademoiselle de Charolais; sous Louis XVI, par les enfants de France.

Les panneaux sont décorẻs de trophées et de sujets peints par MII. ALAUX, Oscar Gué, Guiaud, Guyon, Lafaye, Hipp. Leconte et Parmentier, représentant divers faits de la campagne de 1796, en Italie ; ce sont : Bonaparte prend à Nice le commandement de l'armée d'Italie (27 mars). - Entrée de l'armée à Savone (9 avril). - Bataille de Montenotte (11 avril). - Blocus du chàteau de Cossaria (13 avril). - Attaque et prise des hauteurs de Saint-Michel (20 avril). - Bataille de Mondovi (22 avril). - Prise de Coni (29 avril). - Bataille de Lodi (10 mai). - Prise de Crémone (12 mai). - Entrée de l'armée à Milan (15 mai). - Bataille de Lonato (3 août).

\section{Mort de Viala. - Juillet 1793.}

Par M. Mathieu-Meusnier; statue en marbre. - H. 1,46.

L'ennemi s'était emparé des barques laissées sur la Durance, à 
Avignon, et se préparait à passer cette rivière pour se rendre à Lyon. Le seul moyen d'empêcher ce passage était de couper les câbles qui servaient au trajet des bacs, mais le feu le plus violent, dirigé sur ce point, rendait cette entreprise très-périlleuse. Joseph-Agricole Viala, d'Avignon, enfant de treize ans, se présente pour couper le câble; il se saisit d'une hache, se précipite vers la Durance, s'approche du poteau auquel la corde du bac est attachée, et pendant qu'il s'efforçait de couper le câble, une balle lui traverse la poitrine. Frappé à mort, la hache lui échappe, et il tombe en s'écriant: " Ils ne m'ont pas manqué, mais je suis content, je meurs pour mon pays? ”

Cette statue a été exposée au Salon de 1844.

\section{Le colonel Rampon, à la tête de la $32^{\mathrm{e}}$ demi- brigade, défend la redoute de Monte-Legino. - 10 avril 1796.}

Par M. Berthon. - H. 1,80. - L. 2,50.

Le 10 avril 1796, quinze mille Autrichiens attaquent la redoute de Monte-Legino, occupée par douze cents Français. Le colonel Rampon fait prêter, au milieu du feu, le serment de la défendre jusqu'à la mort.

Ce tableau a été exposé au Salon de 1812.

\section{Attaque du château de Cossaria.-13 avril1796.}

Par Taunay. - H. 2,36. - L. 1,86.

Le général autrichien Provera avait èté contraint de se réfugier sur le sommet de la montagne de Cossaria et s'était retranché dans les ruines d'un vieux château. Ce château est assis sur la montagne la plus élevée de l'Apennin, au nœud de trois contreforts qui, à la distance de trois ou quatre cents toises, forment un glacis gazonné, d'une pente régulière, quoique très-raide, dont le pied est tapissé d'épaisses broussailles. Augereau résolut d'emporter Cossaria; déjà ses colonnes d'attaque, aux ordres du général Banel et des adjudants généraux Joubert et Quesnel, étaient formées sur chacun des contre-forts. Elles en suivirent les crêtes et furent accueillies par un feu de mousqueterie très-vif; puis les ennemis firent rouler sur les trois colonnes des quartiers de rochers qui renversèrent et écrasèrent tout ce qu'ils rencontraient. En moins d'un quart d'heure près de mille hommes furent tués ou mis hors de combat. Banel et Quesnel étaient du nombre des premiers, et Joubert, renversé par deux coups de pierre, avait roulé au fond du glacis. La nuit suspendit le combat sur ce point, 
mais Provera fut bientôt au bout de sa résistance, et il fut forcé de se rendre le 15 avril.

\section{Le général Bonaparte reçoit à Millesimo les dra- peaux enlevés à l'ennemi. - Avril 1796.}

Par M. Adolphe RoenN. - H. 1,62. - L. 2,50.

Bonaparte était à Millesimo, où il avait établi son quartier général dans la ville de Caretti, lorsque ses aides de camp Marmont et Junot vinrent lui présenter les premiers drapeaux enlevés à l'armée des Austro-Sardes à la bataille de Montenotte et à la prise du château de Cossaria.

Le général, assis sur un lit, s'entretient avec l'archiprêtre de Millesimo et Monge. Berthier, chef de l'état-major d'Italie, expédie les ordres du général en cher.

Ce tableau a été exposé au Salon de 1812.

\section{Mort du général Causse à Dego.-16avril1796.} Par M. MulaRd. - H. 1,80. - L. 2,50.

Lors du combat de Dego, le général Causse, chargé d'attaquer' la grande redoute de Magliani, avait été blessé mortellement. Le général Bonaparte passant près de l'endroit où Causse avait été frappé, s'arrêta près de lui : " Dego est-il pris? » demanda le mourant, et sur la réponse affirmative du général en chef, il ajouta : "Vive la République! je meurs content."

Ce tableau a été exposé au Salon de 1812.

\section{Passage du Pô sous Plaisance. - 7 mai 1796.}

\section{Par BOGUET. - H. 1,63 - L. 2,50.}

Le 6 mai, le général Bonaparte s'était porté par une marche forcée à Castel-San-Giovanni avec trois mille grenadiers et quinze cents chevaux. Des officiers d'état-major côtoyèrent, avec un parti de cavalerie, toute la rive gauche du Pô, pour enlever les embar. cations jusqu'à Plaisance. Le 7 mai, le corps de grenadiers, conduit par le général Lannes, arriva vis-à-vis de Plaisance, et se précipita immédiatement dans les embarcations. Deux escadrons autrichiens étaient en bataille sur la rive opposée; le général Lannes débarqua avec audace et fit bientôt replier cette cavalerie. Aussitôt Plaisance démasqué, toutes les divisions forcèrent de marche pour arriver et commencèrent à passer dans la journée. Celles des généraux Laharpe et Masséna vers Plaisance, celle d'Augereau à Verato. Le général Bonaparte se rendit au bord du fleuve, où il demeura jusqu'à ce que le passage fût effectué. 


\section{Combat de Salo. - 31 juillet 1796.}

Par M. Hipp. Lecomтe. - H. 1,06. - L. 1,86.

Bonaparte avait placé à Salo, où aboutissait une des routes du Tyrol, le général Sauret avee trois mille hommes. Quasdanowitch, après avoir tourné le lac de Garda, arrive à Salo avec la droite de l'armée autrichienne qu'il commandait, surprend le général Sauret et le repousse du poste qu'il occupe. Le général Guyeux y reste seul avec six cents hommes de la 15 e demi-brigade d'infanterie légère, et s'enferme dans une grande maison de Salo (maison Martinenga), d'où il refuse de sortir, quoiqu'il n'ait ni pain, ni eau, et à peine quelques munitions. Bonaparte fit remarcher Sauret sur Salo pour dégager le général Guyeux, compromis dans le mauvais poste où ce général l'avait laissé; cependant. il s'y était battu quarante-huit heures contre toute une division ennemie, qui cinq fois lui avait livré l'assaut, et cinq fois avait été rerepoussée. Sauret arriva au moment même où l'ennemi tentait un dernier effort; il tomba sur ses flancs, le défit entièrement, lui prit des drapeaux, des canons et des prisonniers.

Ce tableau a été exposé au Salon de 1836.

\section{Vue du lac de Garda.-Aoút 1796.}

Par M. Hipp. LEconTE. - H. 1,06. - L. 1,85.

Joséphine, femme du général Bonaparte, allait à Dezenzano, lorsque sa voiture fut arrêtée par des officiers de l'armée française, qui l'avertirent que l'ennemi était sur la route, et lui offrirent des chevaux pour retourner plus promptement à Peschiera. Pendant ce temps des chaloupes canonnières, en croisière sur le lac de Garda, firent feu sur sa voiture.

Sur le devant on voit la grande route de Peschiera à Dezenzano.

Ce tableau a été exposé au Salon de 1806.

\section{Prise du château de la Pietra. - 4 sept. 1796.}

Par Madzaisse en 1836. - H. 2,36. - L. 1,85 .

La division Masséna venait de prendre position en avant de Roveredo, lorsque Bonaparte s'aperçut que l'ennemi établissait un point de défense à la position du château de la Pietra ou Coliano, appuyant sa gauche à une montagne inaccessible, et sa droite à l'Adige, par une forte muraille crénelée où il établit plusieurs pièces d'artillerie. La division Masséna arrive devant la position défendue par l'ennemi ; l'artillerie, placée avec avantage, et des colonnes disposées, l'une pour gravir quelques parties de rocher à peine accessibles, l'autre tournant par l'Adige, forcent 
l'ennemi à fuir de sa position. La porte du retranchement est enfoncée, la cavalerie s'élance à la poursuite de l'ennemi et l'infanterie la suit au pas de course. L'ennemi fuyant est atteint, culbuté, renversé et poursuivi jusqu'à trois milles de Trente.

\section{Mort de Marceau à Altenkirchen.-20 sept.1796.}

par M. Aug. Couder. - H. 1,15. - L. 1,67.

A la bataille d'Altenkirchen, le général Marceau, qui commandait l'arrière-garde de l'armée de Sambre-et-Mleuse, contint le prince Charles et sauva l'armée, en lui permettant d'opérer sa retraite. Les troupes légères du corps d'armée qu'il commandait étaient engagées dans la forêt d'Hochsteinhall. Marceau, voulant mieux reconnaître l'ennemi qui s'avançait, s'approche parmi les premiers éclaireurs, accompagné seulement du capitaine de génie Souhait et de deux ordonnances. Un hussard du régiment de Kayser, qui caracolait devant lui l'amuse et le distrait par les divers mouvements qu'il fait faire à son cheval, et pendant ce temps Marceau est ajusté par un chasseur tyrolien caché derrière une haie, qui lui tire un coup de carabine à peu de distance. L'intrépide général avance encore de quelques pas, mais bientôt il sent qu'il est blessé à mort, se fait descendre de cheval et tombe dans les bras de ceux qui sont accourus pour le recevoir.

\section{Le général Augereau au pont d'Arcole.-15 no- vembre 1796.}

Par Charles Théveniv en 1796. - H. 3,62. - L. 2,68.

Le village d'Arcole, extrêmement fort par sa position au milieu des marais et des canaux, arrêta l'avant-garde de l'armée française pendant toute la journée du 15 novembre. Ce fut en vain que tous les généraux, sentant l'importance du temps, se précipitèrent à la tête pour obliger nos colonnes à passer le petit pont d'Arcole : trop de courage nuisit; ils furent presque tous blessés. Augereau, saisissant un drapeau, le porta jusqu'à l'extrémité du pont; il resta là plusieurs minutes jusqu'à l'arrivée du général en chef.

\section{Bataille d'Arcole. - 17 novembre 1796.}

Par BACLER-D'Albe. - H. 1,91. - L, 3,57.

Cette bataille, qui décida du sort de l'Italie, fut gagnée par Bonaparte, après trois jours d'une lutte opiniâtre. Le peintre a choisi l'instant où, vers la fin de la journée du 17, la victoire se décide en faveur des Français.

Le premier plan du tableau est sur la rive droite de l'Adige, en avant de 
l'église de Rouco. A droite, le général en chef Bonaparte est entouré des officiers de son état-major; des officiers prisonniers sont conduits par un dragon français; le général Berthier, chef de l'état-major, donne des ordres aux chirurgiens; plus loin, le général Robert, blessé mortellement sur la digue du centre, est transporté par des grenadiers. A gauche, la cour de la maison où était placé le quartier gé-

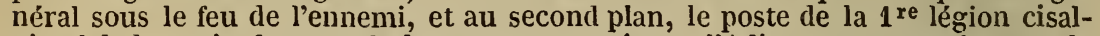
pine à la batterie du pont de bateaux construit sur l'Adige, en quatre heures de temps, par le commandant Andréossy. Au clelà du pont, à gauche, sur la jetée, le général Masséna, après avoir détruit l'ennemi qui lui était opposé, revient au secours du centre; il est précédé d'un drapeau et des prisonniers ennemis. La $75^{\mathrm{e}}$ demi-brigade ralliée, retourne à la charge et seconde l'effort de la $32^{\mathrm{e}}$, qu'on aperçoit plus loin sortant du bois et coupant l'avant-garde ennemie, qui jette ses armes et se rend prisonnière; le reste de la colonne autrichienne est en retraite sur Arcole. Près de ce village enveloppé le fumée, un coup de soleil éclaire le champ de bataille du 15 et le pont vers lequel Bonaparte s'était élancé un drapeau à la main. Dans la plaine, près du village, la division du général Augereau achève de se déployer et de repousser l'ennemi; plus loin, au centre du tableau, la garnison de Legnano arrive pour couper la retraite de l'ennemi. A gauclie, l'armée autrichienne en pleine retraite sur Vicence; à droite, à travers les grand's arbres, le petit pont jeté pendant la nuit du 16 au 17 sur l'Alpone, pour favoriser la marche du général Augereau.

$\therefore \ldots$

Ce tableau a été exposé au Salon de 1804.

\section{Le général Joubert reprend le plateau de Rivoli. - 15 janvier 1797.}

par M. Aug. Debay. - H. 1,15. - L. 1,67.

Alvinzi ayant attaqué le plateau de Rivoli, le général Joubert fit descendre des hauteurs de San-Marco, que sa division occupait, quelques bataillons, qui se portèrent vivement sur l'ennemi; Joubert prit un fusil, chargea lui-même à la tête d'un peloton, et obligea les Autrichiens, assaillis de toutes parts, à évacuer le plateau.

\section{Leclerc (Charles-Emmanuel), général en chef.} (Voir n⿳ 1228.)

Par Chivand; buste en marbre. - H. 0,68.

Ce buste a été exposé au Salon de 1808.

\section{Watrin (François), général de division.}

Par Вогснот; buste en marbre. - H. 0,61 .

Né à Beauvais le 29 janvier 1772, il entra en 1792 dans la légion belge, devenue le $17^{\mathrm{e}}$ régiment de chasseurs à cheval, et servit dans l'armée du Nord où il devint adjudant général chef de bataillon en 1794. Chef de brigade en 1790 , général de brigade en 1796, il fut employé aux armées des côtes de l'Océan et de Sambre-et-Meuse, passa à Saint-Domingue avec le général Hédouville, fit partie de l'armée de Rome en 1799 et fut nommé général de division par le général en chef de l'armée de Naples. Après s'être signalé à la bataille de Marengo où il reçut un sabre 
d'honneur', le général Watrin fit partie de l'armée d'observation du Midi, puis fut attaché en 1802 à l'armée de Saint-Domingue. Il mourut dans cette colonie le 22 décembre 1805 .

\section{SALLE No 68. (Voir Salle no 67 .)}

Antichambre de l'appartement du duc et de la duchesse de Bourbon en 1735, et de celui du comte de Charolais en 1741.

Les panneaux de cette salle sont décorés de trophées peints par MM. ALAUX, Oscar GUÉ et Hipp. LEComTE, et ornés de sujets de la campagne d'Italie: Combat d'Anghiari (14 janvier 1797). - Passage du Tagliamento (16 mars 1797). Entrée de l'armée française à Rome (15 février 1798).

\section{Bataille de Castiglione. - 5 août 1796.}

Par M. Victor ADAM. - H. 1,59. - L. 2,57.

Bonaparte avait arrêté une attaque générale contre Wurmser. Le כ̆ août, avant le jour, l'armée française, forte de vingt mille hommes, occupait les hauteurs de Castiglione. La division $\mathrm{Au}-$ gereau se forna sur deux lignes en avant de Castiglione. La réserve, aux ordres du général Kilmaine, était placeee à sa droite; la division Masséna tint la gauche. L'armée autrichienne se forma en bataille sur deux lignes, la gauche au mamelon de Medolano, la droite au delà de Salferino. La division Sérurier, forte de cinq mille hommes, avait reçu ordre de partir de Marcaria, de mar-cher toute la nuit, et de tomber au jour sur les derrières de la gauche de Wurmser; són feu devait être le signal de la bataille. Aussitôt qu'on entendit les premiers coups de canon du corps de Sérurier, qui, étant malade, était remplacé par le général Fiorella, l'armée française marcha vivement à l'ennemi. Le mamelon de Medolano, au milieu de la plaine, était l'appui de la gauche ennemie; l'adjudant général Verdier fut chargé de l'attaquer. L'aide de calp Marmont y dirigea plusieurs batteries d'artillerie. Le poste fut enlevé ; Masséna attaqua la droite, Augereau le centre; Fiorella prit la gauche à revers, la cavalerie légère sur-prit le quartier général et faillit de prendre Wurmser. Partout l'ennemi se mit en pleine retraite, repassa le Mincio et coupa ses ponts, vivement harcelé par la cavalerie de Beaumont et par les troupes de la division Sérurier. Il perdit vingt pièces de canon et environ mille prisonniers, outre deux mille hommes tués et blessés.

\section{Bataille de Rivoli. - 14 janvier 1797.}

Par M. Lépaulue, d'après Carle Vernet. - H. 1,59. - L. 2, 57.

A gauche, le général Bonaparte à cheval, suivi de son état-major; à droite, 
les Autrichiens essayant de pénétrer sur le plateau de Rivoli en gravissant le chemin escarpé d'Incarnale; au second plan, les hauteurs de San-Marco défendues par Joubert. Dans le fond, les hauteurs de Monte-Baldo.

\section{Le général Bonaparte recoit des prisonniers sur le champ de bataille. $\mathbf{- 1 7 9 7 .}$}

Par Taunay. - H. 1,61. - L. 2,57.

Après une de ses victoires d'Italie, le général Bonaparte visite le champ de bataille; il reçoit le sabre diun officier général autrichien. Sur le devant, des blessés et des morts; danıs le fond, une villa en flammes.

Ce tableau, exposé au Salon de 1801, était un prix d'encouragement accordé à l'artiste.

\section{Reddition de Mantoue. - 2 février 1797.}

Par M. Hipp. Leconte. - H. 1,61. - L. 2,57.

La victoire de Rivoli décida du sort de Mantoue; la famine était dans la place, et il était impossible qu'elle pût tenir plus longtemps. Le 2 février, c ce dernier boulevard de l'Italie tomba après six ans d'une résistance qui fit honneur aux troupes autrichiennes. La garnison avait alors la moitié de son monde dans les hôpitaux; elle avait mangé tous les chevaux de sa nombreuse cavalerie, et la misère et la mortalité exerçaient les plus grands ravages. La capitulation, en donnant un tẻmoignage d'estime à Wurmser, ajouta un nouveau lustre à la gloire de son vainqueur. Le maréchal sortit librement de la place avec tout son état-major et défila devant le général Sérurier, commandant les troupes françaises. On lui accorda une escorte de deux cents cavaliers, cinq cents hommes à son choix et six pièces de canon; mais la garnison déposa les armes et fut conduite à Trieste pour être échangée : on l'estimait encore à treize mille hommes. ") (Histoire des guerres de la Révolution, par Jomini.)

Ce tableau a été exposé au Salon de 1812.

\section{Prise d'Ancône. - 9 février 1797.}

par Boguet. - H. 1,61. - L. 2,57.

Le général Victor arriva le 9 février à Ancône. Un corps d'environ douze cents hommes avait pris position sur les hauteurs en avant de la place, s'y croyant sans doute à l'abri de toute attaque; Victor l'enveloppa et le forca à mettre bas les armes. Alors Ancône ouvrit ses portes. On y trouva plusieurs milliers de fusils envoyés par l'Autriche pour l'armement des milices pontificales, un arsenal bien approvisionné et cent vingt bouches à feu. 


\section{Combat dans les gorges du Tyrol.-Mars 1797.}

Par BOGUET. - H. 1,61. - L. 2,57.

L'archiduc Charles avait pris le commandement des troupes impériales le 2 février 1797, et avait établi son quartier général à Inspruck, capital du Tyrol autrichien. L'aile droite des Autrichiens, sous les ordres des généraux Kerpen et Laudon, avait pris position entre le Lavis et la Noss, dans le Tyrol italien. La brigade Lusignan était à Feltre, et le prince de Hohenzollern observait la Piave. Le 9 mars, le général Bonaparte avait transporté son quartier général à Bassano. Après avoir passé la Piave et forcé une partie de la brigade Lusignan de mettre bas les armes, il arriva le 16 à Valvasone, où il établit son quartier général.

\section{Préliminaires de la paix signés à Léoben.- 17 avril 1797.}

Par Guillon LeThière en 1805. - H. 3,32. - L. 5,90.

La signature des préliminaires de la paix eut lieu le 17 avril, au château d'Ekwald, près de Léoben, entre le marquis de Gallo et le général Merfeld, stipulant pour l'Autriche, et Bonaparte au nom de la République.

Ce tableau, exécuté pour la salle des Conférences du Corps Legislatif, a été exposé au Salon de 1806.

\section{Bataille de Neuwied. - 18 avril 1797.}

Par M. Victor ADAM en 1835. - H. 1,59. - L. 2,57.

L'armée de Sambre-el-Meuse, commandée par le général Hoche, était cantonnée depuis Dusseldorf jusqu'à Coblentz; Hoche gardait la première de ces places et le pont de Neuwied; en face de lui était l'armée autrichienne sous les ordres du général Latour. Le 18 avril 1797, le feu commença sur tout le front des ouvrages de l'ennemi. A ce signal l'armée de Sambre-et-Meuse se met en mouvement ; les redoutes ennemies sont attaquées par l'artillerie légère soutenue des hussards et des chasseurs; les Autrichiens abandonnent celle du centre. Hoche fait avancer sa droite pour tourner l'ennemi; il ordonne à l'infanterie légère de charger et d'enlever les redoutes à la baïonnette. Lui-même, à la tête de deux régiments de chasseurs, coupe la ligne des Autrichiens et culbute leur cavalerie. En un instant les redoutes sont emportées et la déroute est complète.

Ce tableau a été exposé au Salon de 1836. 


\section{Entrée de l'armée française à Naples. - 21 jan- vier 1799.}

Par Jacques TACREL. - H. 1,59. - L. 2,57.

Championnet se dirigeait sur Naples, lorsque le général Mack, qui commandait l'armée Napolitaine, fut forcé d'abandonner la ville à linsurrection des lazzaroni et de chercher un asile dans le camp français. Il fallut attaquer la ville de vive force, et après plusieurs jours de combat Championnet mit en fuite les lazzaroni et occupa la ville de Naples.

Ce tableau a été exposé au Salon de 1799.

\section{SALLE No 69. (Voir Salle no 67.)}

Les panneaux de cette salle sont décorés de trophées, peints par MIM. ALAux, Guiadd, Pingret et Vincext, et offrent divers sujets de la campagne d'Egypte : Prise de l'âle de Malte (13 juin 1798). - Débarquement de l'armée en Egypte (2 juillet 1798). - Prise d'Alexandrie (3 juillet 1793). - Bataille des Pyramides (21 juillet 1798). - L'armée traverse les ruines de Thèbes (janvier 1799). - Combat d'Aboumana (17 février 1799).

\section{Bonaparte haranguant l'armée avant la bataille des Pyramides. - 21 juillet 1798.}

Par Gros. - H. 3,89. - L. 5,11.

L'armée, arrivée aux villages d'Ebverach et de Boutis n'était plus qu'à trois quarts de lieue d'Embabé, lorsqu'elle aperçoit de loin le corps de Mamlouks qui se trouvait dans le village. Un spectacle aussi imposant n'avait point encore frappé les regards des Francais. La cavalerie des Mamlouks était couverte darmes étincelantes. On voyait en arrière de sa gauche ces fameuses pyramides dont la masse indestructible a survécu à tant dempires, et brave depuis trente siècles les outrages du temps. Derrière sa droite étaient le Nil, le Caire, le Mokattam et les champs de l'antique Memphis.

Les troupes, impatientes d'en renir aux mains, sont aussitôt rangées en bataille; Bonaparte appelle les principaux chefs de larmée, parcourt les rangs, dicte les ordres : Soldats, sécrie-t-il, souvenez-rous que du haut de ces monuments quarante siècles rous contemplent. „ On royait alors autour de liui Berthier, Desaix, Dugua, généraux de division; Murat, Belliard, généraux de brigade; Duroc, chef de bataillon d'artillerie; Eugène Beauharnais et Lavalette, tous destinés plus tard à des fortunes si imprévues et si diverses.

Ce tableau, exposé au Salon de 1810, le fut de nouveau au Salon de 1836, après 
la mort de l'auteur et avec les augmentations exécutées par M. Auguste Debay, ćlève de Gros, d'après la composition du maître.

\section{Révolte du Caire. - 21 octobre 1798.}

Par Girodet-Trioson. - H. 3,65. - L. 5,00.

Depuis deux mois que Bonaparte était au Caire, la plus grande tranquillité n'avait cessé d'y régner. " Les notables de toutes les provinces délibéraient avec calme, et d'après les propositions des commissaires français Monge et Berthollet, sur l'organisation définitive des divans, sur les lois civiles et criminelles, sur l'établissement et la répartition des impôts et sur divers objets d'admir.istration et de police générale. Tout à coup des indices d'une sédition prochaine se manifestent. Le 21 octobre, à la pointe du jour, des rassemblements se forment dans divers quartiers de la ville, et surtout à la grande mosquée. Le général Dupuy, commandant la place, s'avance à la tête d'une faible escorte pour les dissiper; il est assassiné avec plusieurs officiers et quelques dragons au milieu de l'un de ces attroupements. La sédition devient aussitôt générale : tous les Français que les révoltés rencontrent sont égorgés; les Arabes se montrent aux portes de la ville.

"La générale est battue; les Français s'arment et se forment en colonnes mobiles; ils marchent contre les rebelles avec plusieurs pièces de canon. Ceux-ci se retranchent dans leurs mosquées, d'où ils font un feu violent; les mosquées sont aussitôt enfoncées; un combat terrible s'engage entre les assiégants et les assiégés; l'indignation et la vengeance doublent la force et l'intrépidité des Francais. Des batteries, placées sur différentes hauteurs, et le canon de la citadelle tirent sur la ville; le quartier des rebelles et la grande mosquée sont incendiés. ") (Relation des campagnes du général Bonaparte en Egypte, par BERTHER.)

Le moment représenté est celui où les Français, ayant pénétrẻ dans la grande mosquée, combattent et mettent en fuite les rebelles qui s'y étaient retranchés.

Ce tableau a été exposé au Salon de 1810.

\section{Le général Bonaparte fait grâce aux révoltés du Caire. - 23 octobre 1798.}

Par Gutrin. - H. 3,65. - L. 5,00.

Après une action meurtrière, les Francais avaient contraint les révoltés du Caire à l'obéissance; les schérifs et les principaux du Caire vinrent implorer la générosité des vainqueurs et la clémence de Bonaparte. L'ordre fut donné d'amener les prisonniers sur la place d'El-Bekir, l'une des plus spacieuses de la 
ville. Le général en chef y vint accompagné de son état-major, et annonça aux révoltés qu'il leur faisait grâce de la vie.

A gauche, appuyé sur un canon, est Murat en uniforme de hussard. Au centre, près de Bonaparte, se tient l'interprète qui transmet aux habitants les paroles du général en chef. Au fond, parmi les personnages de sa suite, on reconnaît Denon, membre de l'Institut d'Égypte.

Ce tableau a été exposé au Salon de 1808.

\section{Mort de Kléber. - 14 juin 1800.}

Par M. L. V. Bougron; groupe en marbre.-H. 0,81 .

Kléber fut assassiné au Caire, dans le jardin de son palais, par un jeune fanatique ture nommé Soleïman, qui lui porta quatre coups de poignard.

\section{SALLE No 70 (Voir Salle no 67 ).}

Les panneaux de celte salle sont ornés de sujets peints au milieu de trophées, par MII. ALAUX et LESTANG-PARADE; ils représentent : Le dix-huit brumaire (9 novembre 1799). - Revue du premier consul dans la cour des Tuileries (1800). - Signature du concordat entre la France et le Saint-Siége (15 juillet 1801).

1500. La consulta de la République cisalpine, réunie en comices à Lyon, décerne la présidence au premier consul Bonaparte. - 26 janv. 1802.

Par Monsiad en 1808. - H. 3,19. - L. 4,83.

Le 14 novembre 1801, une proclamation de la commission extraordinaire du gouvernement annonça au peuple cisalpin la convocation d'une consulta extraordinaire à Lyon, pour fonder les bases de la République sous les auspices et en présence du premier consul de la République française. Tous les membres de la consulta, au nombre de quatre cent cinquante-deux, furent réunis le 31 décembre. Elle ouvrit ses séances le 4 janvier 1802, et le 26 du même mois le premier consul vint assister à la séance de clôture. On avait élevé, dans l'ancienne église des Jésuites de Lyon, une salle destinée à l'assemblée générale; en face du fauteuil du président se trouvait une tribune pour le premier consul; elle était ornée de trophées qui rappelaient ses victoires en Italie et en Egypte. Après le discours du général Bonaparte, Regnaud de Saint-Jean-d'Angely, conseiller d'Etat, donna lecture de la constitution de la République cisalpine. Les membres de la consulta demandèrent ensuite à l'unanimité qu'elle prît le nom de République italienne, et avant la clôture de la séance on proclama les listes des colléges et les noms des 
principaux membres du gouvernement : le général Bonaparte, président ; de Melzi, vice-président; Guicciardi, secrétaire d'État; et Spanocchi, grand juge.

Ce tableau a été exposé au Salon de 1808.

\section{Entrée de Bonaparte, premier consul, à An- vers. - 18 juillet 1803.}

Par VAN BRÉ. - H. 3,72. - L. 6,10.

Le premier consul, accompagné de madame Bonaparte, arriva à Anvers le 18 juillet, à cinq heures du soir ; il fut reçu dans le port, à son débarquement, par toutes les autorités : le général Paradis, commandant de la ville d'Anvers, M. d'Herbouville, préfet du département des Deux-Nèthes, les conseillers de préfecture, M. Werenbrouck, maire de la ville, les membres du corps municipal, les présidents et les juges des tribunaux. Le premier consul et madame Bonaparte, accompagnée de mesdames de Talhouet et de Rémusat, étaient dans un canot avec l'amiral Decrès, ministre de la marine, le général Duroc, M. Maret, secrétaire d'État, et M. Salmatoris, préfet du palais. Talleyrand, ministre des affaires étrangères, Chaptal, ministre de l'intérieur, les généraux Caulaincourt, Savary, Lauriston, et le colonel Lebrun, aide de camp du premier consul, le général Soult, colonel général de la garde, le conseiller d'État Forfait, les généraux Belliard et de Tilly, débarquèrent avant le premier consul. Les chasseurs à cheval, commandés alors par Eugène Beauharnais, formaient l'escorte; ils passèrent la rivière dans plusieurs canots.

\section{Napoléon, au camp de Boulogne, distribue les croix de la Légion d'honneur. - 16 août 1804.}

Par HeNnequiN. - H. 3,19. - L. 4,83.

Sur un vaste plateau qui couronne la falaise de Boulogne, on avait formé un cirque au centre duquel se trouvait le trône de l'Empereur. Napoléon avait à sa droite le prince Joseph, derrière lui les grands officiers de la couronne, et à ses côtés les ministres, les maréchaux de l'empire, les colonels généraux; en avant et sur les marches étaient les aides de camp de l'Empereur, et au,pied du trône, sur des banes, étaient à droite les conseillers d'État, les généraux venus de l'intérieur et les officiers étrangers; à gauche, les officiers civils et religieux. Le reste du diamètre était occupé par la garde impériale, par la musique d'un côté et par deux mille tambours de l'autre. A ses extrémités étaient le grand état-major de l'armée et les états- 
majors généraux des camps. L'Empereur découvrait à sa droite les deux camps et les batteries, l'entrée du port et une partie de la rade; il avait à sa gauche le port de Vimereux et les côtes d'Angleterre. Devant lui savançaient, en vingt colonnes, soixante bataillons, dont les têtes occupaient la demi-circonférence dı cirque. En avant et dans l'intérieur étaient plus près du tròne les pelotons de légionnaires de tous les grades et de toutes les armes. L'extrémité des colonnes allait s'élevant sur les hauteurs que couronnaient vingt escadrons en bataille et qu'achevaient de couvrir et d'orner une foule immense et les tentes réservées aux dames.

Après un discours du grand chancelier de la Légion d'honneur, l'Empereur remit lui-même les décorations à chacun des militaires qui les avaient obtenues et aux fonctionnaires civils et ecclésiastiques. Des officiers tenaient les décorations dans des casques et sur des boncliers des armures de Duguesclin et de Bayard. Le défilé qui termina la cérémonie dura plus de trois heures, et à ce moment l'avant-garde de la flottille du Havre, composée de cinquante voiles, entrait dans le port de Boulogne.

Ce tableau a été exposé au Salon de 1806.

\section{SALLE No 71.}

Cette salle et la suivante formaient en 1735 l'appartement de Mademoiselle (Louise-Anne de Bourbon), et en 1755 celui de Mille de Charolais.

Les panneaux de cette salle sont ornés de sujets peints au milieu de trophées par MII. Alaux et Gibert : Entrevue de Napoléon et de Pie VII dans la forêt de Fontainebleau (26 novembre 1804).- Sacre de l'Empereur i Notre-Dame ( 2 décembre 1804). - Napoléon donnant des àgles a l'armée (5 décembre 1804).

1503. Napoléon reçoit à Saint-Cloud le sénatusconsulte qui le proclame empereur des Français. - 18 mai 1804 .

Par M. ROdGeT. - H. 4,03. - L. 6,42.

Le 30 avril 1804 , le tribunat avait adopté à la presque unanimité la proposition de créer Napoléon Bonaparte empereur des Franęais, et le 18 mai suivant, le sénat, présidé par le consul Cambacérès, avait décrété le sénatus-consulte organique qui déférait le titre d'empereur au premier consul. Immédiatement après sa séance, le sénat se rendit à Saint-Cloud pour présenter le sénatus-consulte à l'Empereur.

Napoléon, en costume de premier consul, reçoit, dans la galerie du palais de Saint-Cloud, l'acte que lui présente Cambacérès, suivi de son collègue Lebrun. Madame Bonaparte, sa fille Hortense et madame Nurat sont près de l'Empe- 
reur, ainsi que ses aides de camp et les officiers gẻnéraux de service auprès de sa personne, Duroc, Soult, Junot, Murat, Kellermann, Masséna, Berthier, Eugène Beauharnais, Bernadotte et Bessières; on remarque, parmi les sénateurs, Talleyrand, Lacépède, Volney et Vien.

\section{Première distribution des croix de la Légion d'honneur, dans l'église des Invalides. - 14 juillet 1804.}

Par DEBRET en 1812. - H. 4,03. - L. 5,31.

Une loi, en date du 19 mai 1802, avait institué l'ordre de la Légion d'honneur. Les membres nommés n'étaient pas encore recus. La première cérémonie de réception eut lieu le dimanche 14 juillet 1804, dans l'église de l'Hôtel des Invalides. Le cardinal Fesch, archevếque de Paris, accompagné de son clergé, reçut l'Empereur à la porte de l'église et le conduisit processionnellement jusqu'au tròne impérial. Napoléon s'y plaça, ayant derrière lui les colonels généraux de la garde, le gouverneur des Invalides et les grands officiers de la couronne. Aux deux côtés et à la seconde marche du trône étaient les grands dignitaires; plus bas, à droite, les ministres; à gauche, les maréchaux de l'empire; au pied des marches du trône, le grand maitre et le maître des cérémonies ; en face du grand maître, le grand chancelier et le grand trésorier de la Légion d'honneur. Les aides de camp de l'Empereur étaient debout en haie sur les degrés du trône. Derrière l'autel, sur un immense amphithéâtre, étaient rangés sept cents Invalides et deux cents élèves de l'Ecole polytechnique. Toute la nef était occupéepar les grands officiers, commandeurs, officiers et membres de la Légion d'honneur. Après la messe, célébrée par le cardinal légat, les décorations furent déposées au pied du trône dans des bassins d'or. Le prince Louis, depuis roi de Hollande, reçut du grand chambellan les deux décorations de l'ordre et les attacha à l'habit de l'Empereur. Ensuite, les commandeurs, les officiers et les légionnaires vinrent au pied du trône recevoir individuellement la décoration des mains de l'Empereur.

Napoléon remet la croix de la Légion d'honneur à un jeune invalide man-, cloot. On remarque, parmi les personnages représentés, le cardinal Fesch, David, Muraire, Denon, Cambacérès, Berthier, Regnaud dc Saint-Jean-d'Angely' Lacépède et Lebrun.

Ce tableau a été exposẻ au Salon de 1812.

1505. Napoléon reçoit au Louvre les députés de l'armée après son couronnement. -8 décembre 1804.

Par Serangeli. - H. 4,03. - L. 5,31.

Les députations de tous les corps des armées de terre et de 
mer, celles des gardes d'honneur et celles des gardes nationales, au nombre de plus de sept mille hommes, étaient réunies dans le Musée Napoléon, sous les ordres de Murat, gouverneur de Paris. L'Empereur se rendit dans les galeries et passa la revue de toutes les députations.

La réception a lieu dans une des salles d'entrée du Musée des Antiques; on aperçoit, dans le fond, le groupe du Laocoon, qui y avait été transporté de Rome.

Ce tableau a été exposé au Salon de 1808.

\section{SALLE No 72 (Voir Salle No 71 ).}

Les panneaux de cette salle sont ornés de sujets de la campagne de $\mathbf{1 8 0 5}$, peints au milieu de trophées, par MM. ALAUx, MAY, LESTANG-PARADE, V. ADAM et O. GuÉ : Passage du Rhin à Strasbourg (25 septembre).-Combat et prise de Guntzbourg (9 octobre).-Combat d'Albeck (11 octobre).-Capitulation de Memmingen et entrée de l'armée à Memmingen (14 octobre).

1506. Napoléon recoit aux Tuileries la consulta de la République italienne qui le proclame roi d'Italie. - 19 mars 1805.

Par Godbaud en 1807. - H. 2,36. - L. 3,73.

La députation de la République italienne, qui avait été appelée à Paris pour assister à la cérémonie du sacre, fut reçue aux Tuileries le 19 mars $180 \preceq ٌ$ pour présenter à l'Empereur le statut constitutionnel arrêté par la consulta. L'Empereur était assis sur son trône et entouré des grands dignitaires, des grands officiers et des membres du conseil d'Etat. Melzi, vice-président de la République italienne, porta la parole; il exposa d'abord la situation de la République italienne, les dangers dont elle était environnée, et présenta l'établissement d'un gouvernement monarchique comme l'unique moyen de salut. Il fit ensuite lecture de l'acte fondamental qui conférait à l'empereur Napoléon le titre de roi d'Italie.

\section{Napoléon reçu à Ettlingen par le prince élec- teur de Bade. - $1^{\mathrm{er}}$ octobre 1805.}

Par J.-V. Bertin. - H. 2,58. - L. 1,55.

L'Empereur, parti de Strasbourg le $1^{\mathrm{er}}$ octobre, à trois heures après midi, arriva à huit heures du soir à Ettlingen. L'électeur de Bade, le prince Frédéric, son fils, et le prince électoral, son petit-fils, s'y étaient rendus et lui furent présentés.

Ce tableau a étẻ exposẻ au Salon de 1812. 
1508. Napoléon reçu au château de Louisbourg par le duc de Wurtemberg. - 2 octobre 1805.

Par M. Watelet. - H. 2,36. - L. 1,90.

L'Empereur, parti d'Ettlingen le 2 octobre, à midi, arriva à Louisbourg à neuf heures du soir. Sur les limites des états de Wurlemberg, il trouva des corps de troupe; les chevaux de ses voitures furent changés et remplacés par ceux de l'électeur. A son entrée à Louisbourg, la garde électorale à pied et à cheval était sous les armes, et la ville illuminée. La réception de l'Empereur dans le palais électoral, où toute la cour était réunie, fut de la plus grande magnificence.

Ce tableau a été exposé au Salon de 1812.

\section{Combat de Wertingen. - 8 octobre 1805.}

Par M. Eug. Lepoittevin en 1835.-H.1,03. - L. 1,77.

Murat, à la tête des divisions de dragons des généraux Beaumont et Klein, et de la division de carabiniers et de cuirassiers commandée par le général Nansouty, arrive à Wertingen, et aperçoit une division considérable d'infanterie ennemie, appuyée par quatre escadrons de cuirassiers d'Albert. Il enveloppe aussitôt tout ce corps. Le maréchal Lannes, qui marchait derrière ces divisions de cavalerie, survient avec la division Oudinot, et après un engagement de deux heures, drapeaux, canons, bagages, officiers et soldats, toute la division ennemie est prise.

Ce tableau a été exposé au Salon de 1836.

\section{Combat d'Aïcha. -8 octobre 1805.}

Par M. Jollivet. - H. 1,03. - L. 1,77.

Aïcha, petite ville dans la Haute-Bavière, est à huit lieues d'Augsbourg et sur la route de cette ville à Munich. Le maréchal Soult, après avoir manœuvré les 7 et 8 octobre avec la division Legrand, rejoignit celle de Vandamme pour se rendre avec elle à Augshourg par la rive droite du Lech, tandis que le général SaintHilaire s'y portait par la rive gauche. Le maréchal rencontra à Aïcha les débris de la colonne autrichienne battue à Wertingen; il les chassa de ce village, et entra le 9, à midi, à Augsbourg, avec les divisions Vandamme, Saint-Hilaire et Legrand.

Ce tableau a été exposé au. Salon de 1836.

\section{Combat de Landsberg. - 11 octobre 1805.}

Par M. Hip. BellaNGé en 1835. - H. 0,85. - L. 1,82.

Le maréchal Soult s'était porté avec son corps d'armée à Lands 
berg, pour couper une des principales communications de l'ennemi. Il y arriva le $\mathbf{1 1}$ octobre, à quatre heures après midi, et y rencontra un régiment de cuirassiers autrichiens, accompagné de six pièces de canon, qui se rendait à Ulm à marches forcées. L'ayant fait aussitôt attaquer par le $26^{\mathrm{e}}$ régiment de chasseurs, il resta maître dı champ de bataille, s'empara de deux pièces de canon et fit à l'ennemi cent-vingt soldats prisonniers, un lieutenant-colonel et deux capitaines.

Ce tableau a été exposé au Salon de 1836.

\section{Napoléon harangue le $2^{\mathrm{e}}$ corps de la grande armée sur le pont de Lech, à Augsbourg. - 12 octobre 1805.}

Par Gautherot en 1808. - H. 3,85, - L. 6,20.

Napoléon quittait Augsbourg pour se diriger sur Burgau, lorsqu'il rencontra sur le pont de Lech le $2^{\mathrm{e}}$ corps de la grande armée, commandé par le général Narmont, qui se mettait en marche forcée pour prendre position sur les hauteurs d'Iller'sheim. Le temps était affreux, la neige tombait à gros flocons, et les soldats surchargés, parce qu'ils portaient leurs vivres pour plusieurs jours, marchaient péniblement sur une route dégradée. L'Empereur ordonna de faire halte, fit serrer la colonne en masse et former le cercle autaut que fut possible à la portée de la voix : il félicita, remercia ses soldats de leur constance dans les marches pénibles qu'ils venaient de faire ; il leur dit quel en était le résultat, expliqua, comme il l'eût fait à ses généraux, la situation de l'ennemi; démontra l'imminence d'une grande bataille, et leur promit une victoire aussi certaine que la confiance qu'il avait en leur valeur et leur dérouement. Cette courte harangue électrisa tous ceux qui l'entendirent.

I'Empereur, monté sur un cheval blanc, indique aux soldats, par un mouvement de la main droite, le point vers lequel ils doivent marcher; près de l'Empereur, le maréchal Bessières, sur un cheval noir, tient le bâton de conmancement; plus loin est le maréchal Narmont, monté sur un cheval isabelle, qui s'élance en avant. Dans le fond, la ville d'Augsbourg.

Ce tableau a été exposé au Salon de 1898.

\section{Batcille d’Elchingen. - 15 octobre 1805.}

Par Camille Roqueplax. - H. 0,85. - I, 1,55.

Le 14 octobre, l'Empereur s'était porté au camp devant Ulm et avait ordonné l'investissement de l'armée ennemie. La première opération fut de s'emparer du pont et de la position d'Elchingen. Le 1ّ̋, à la pointe du jour, le maréchal Ney passa ce pont à la tête de la division Loison. L'ennemi lui disputait la po- 
sition d'Elchingen avec seize mille hommes; il fut culbuté partout, perdit huit mille hommes: faits prisonniers, un général major, et fut poursuivi dans ses retranchements. A la suite de cette bataille, le maréchal Ney reçut le titre de duc d'Elchingen.

Ce tableau a été exposé au Salon de 1837.

\section{Capitulation de Nordlingen.-18 octobre 1805.}

Par M. Victor ADAM en 1835. - H. 1,03. - L. 1,90.

Le prince Murat, arrivé de Nordlingen à cinq heures du matin, avait réussi à cerner la division Werneck, et ce général avait demandé à capituler. Les lieutenants généraux Werneck, Baillet, Hohenzollern, les généraux Vogel, Mackery, Hohenfeld et Dienesberg furent prisonniers sur parole, avec la réserve de se rendre chez eux. Les troupes prisonnières de guerre furent envoyées en France, et une brigade de dragons à pied fut montée avec les chevaux de plus de deux mille hommes de cavalerie qui avaient mis pied à terre.

Ce tableau a été exposẻ au Salon de 1836.

\section{Reddition d'Ulm - 20 octobre 1805.}

Par Charles Thévenis en 1815. - H. 2,48. - L. 3,82.

L'Empereur avait fait sommer le gẻnéral Mack de lui rendre la place et l'armée prisonnière. Il recut le prince de Lichtenstein et envoya ensuite à Ulm le maréchal Berthier, major général, pour arrêter la capitulation. Aucune des réserves proposées ne fut acceptée. Napoléon accorda seulement, sans difficulté, la clause que le feld-maréchal considérait comme le dégageant, aux yeux de son souverain, de toute responsabilité, et qu'il rédigea lui-même dans les termes suivants : "Si, jusqu'au 2 octobre, à minuit inclusivement, des troupes autrichiennes ou russes débloquaient la ville de quelque côté ou porte que ce soit, la garnison sortira librement avec ses armes, son artillerie et sa cavalerie pour joindre les troupes qui l'auront débloquée. "Le général Mack ayant eu connaissance de la capitulation du général Wernek à Nordlingen, ne tarda pas à être convaincu qu'il lui était impossible de recevoir aucun secours, et le 19 octobre il signa une nouvelle convention en vertu de lacpuelle les troupes renfermées dans Ulm, au nombre de trente mille hommes, dont deux mille de cavalerie, sortirent avec les honneurs de la guerre. Soixante pièces de canon attelées et quarante drapeaux, dix - huit généraux à la tête de leur's divisions et brigades, défilèrent devant l'armée francaise en bataille sur les hauteurs de Michelsberg et du Frauenberg. Napoléon, entouré de son état-major et de sa garde, placé devant un feu de bivouac, sur un rocher escarpé du côté de la 
ville, vit, pendant cinq heures, passer à ses pieds cette armée : il fit appeler près de lui tous les généraux autrichiens, et les y retint jusqu'à ce que la colonne eût achevé de défiler, leur témoignant beaucoup d'égards et conversant alternativement avec eux. Il accueillit particulièrement ceux qu'il avait connus dans les guerres d'Italie, les lieutenants généraux Klenau, Giulay, Gottesheim, l'ami et l'ancien compagnon d'armes du maréchal Ney, les princes de Lichtenstein et plusieurs autres. (Précis des événements militaires, par le comte Mathieu Dumas.)

\section{Combat de Diernstein. - 11 novembre 1805.}

Par M. Beaume. - H. 0,85. - L. 1,82 .

Le maréchal Mortier, après s'être emparé du village de Léoben, aperçut, avant d'atteindre Diernstein, plusieurs colonnes russes, fortes d'environ douze mille hommes, qui se dirigeaient vers ce village. L'une d'elles suivait un chemin resserré entre deux murs de pierre sèche, pouvant donner passage à huit hommes de front. Par la marche et la disposition des Russes, quatre mille Français se trouvaient avoir devant et derrière eux deux masses énormes d'ennemis, à gauche, un escarpement sans aucun débouché, et à droite, le Danube sans aucun moyen de passage. Dans cet instant critique, le colonel Henriod, à la tête du $100^{\circ}$ de ligne, ordonne la charge. Les Français s'avancent avec impétuosité sans répondre à une vive fusillade, marchent droit à l'ennemi, et après trois-quarts d'heure de combat, se font jour à travers les lignes. Bientôt le désordre devient général ; dans cette horrible confusion, quelques soldats, voulant éclairer leur retraite, mettent le feu au village de Léoben. Le maréchal Mortier avait pris place dans la colonne d'attaque, entre le $1^{\mathrm{er}}$ et le $2^{\mathrm{e}}$ ba-

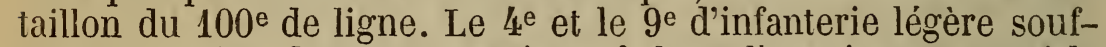
frirent le plus dans cette action, à laquelle prit part aussi le $103^{\mathrm{e}}$ et le $4^{\mathrm{e}}$ dragons, dont le colonel Wattier fut tué.

Ce tableau a été exposé au Salon de 1836.

\section{VESTIBULE NAPOLÉON, No 73.}

Ce vestibule, qui séparait les grands appartements du rez-de-chaussée de l'aile du midi, avait été divisé sous Louis XV et sous Louis XVI en plusieurs petites pièces avec entre-sol au-dessus, et où les colonnes existaient encore cachées dans des corps de menuiserie, mais mutilées. Il a été rétabli et restauré de 1810 aे 1814.

\section{Bonaparte (Charles-Marie).}

Par M. Élias RoBert en 1855 ; buste en marbre. - H. 0,78.

Né à Ajaccio, le 26 mars 1746, conseiller du roi et assesseur 
de la ville et province d'Ajaccio en 1774, il fut nommé en $\mathbf{1 7 7 7}$ député de la noblesse de l'île de Corse à la cour et membre du Conseil des douze en 1781. Il mourut à Montpellier le 24 février 178ว. - Il avait épousé en 1767 Marie-Lætitia Ramolino, dont il eut : $1^{\circ}$ Joseph, roi de Naples, puis dEspagne; 20 Napoléon, empereur des Français ; $3^{\circ}$ Lucien, prince de Canino; $4^{\circ}$ Elisa, grande duchesse de Toscane ; 50 Louis, roi de Hollande ; $6^{\circ}$ MariePauline, princesse Borghèse; $7^{\circ}$ Caroline, reine de Naples; $8^{0}$ Jérôme, roi de Westphalie.

\section{Napoléon Ier, empereur des Français. (Voir no ${ }^{\circ}{ }^{720 .}$ )}

Par Houdon; buste en marbre. - H. 0,59.

1519. Napoléon Ier, empereur des Français. (Voir n ${ }^{\circ} 720$.)

Par F. Bosio; buste en marbre. - H. 0, 55 .

1520. Napoléon Ier, empereur des Français. (Voir no 720.)

Par M. E. SEunRe; statue en bronze. - H. 1,80.

Cette figure, fondue par MM. Soyer et Ingé, est une réduction de celle placée sur la colonne de la place Vendôme. Elle est de grandeur naturelle, et l'épée a été moulée sur celle que portait habituellement l'Empereur.

\section{Joséphine, impératrice des Français.}

Par Houdon en 1808 ; buste en marbre. - H. 0,58.

Marie-Rose-Joséphine de Tascher de la Pagerie, née à SaintPierre de la Martinique le 24 juin 1763 , fut mariée le 13 décembre 1779 à Alexandre-François-Marie, vicomte de Beauharnais, qui fut plus tard général en chef de l'armée du Rhin. Restée reuve le 24 juillet 1794 avec deux enfants, Eugène et Hortense de Beauharnais, elle épousa, le 8 mars 1796, Napoléon Bonaparte, alors général en chef de l'armée d'Italie. Devenue impératrice des Français, elle fut sacrée et couronnée à Notre-Dame par le pape Pie VII, le 2 décembre 1804. Divorcée en 1809, elle se retira à la Malmaison et y mourut le 9 mai 1814.

\section{Joséphine, impératrice des Français. (Voir n ${ }^{1521 .)}$}

Par M. Vital DubraY en 1856; statue en plàtre. - H. 2,70.

Modèle de la statue en marbrè exposée au Salon de 1857, et exécutée pour la ville de Saint-Pierre (Martinique). 
1523. Marie-Louise, archiduchesse d'Autriche, impératrice des Français.

Par Spalla; buste en marbre. - H. 0,64.

Fille de Francois Ier, empereur d'Autriche, née le 12 décembre 1791. Mariée le 2 avril 1810 à l'empereur Napoléon Ier, elle fut pendant les campagnes de 1812 à 1814 proclamée régente, quitta la France en 1814, et reçut du congrès de Vienne le duché de Parme, de Plaisance et de Guastalla. Elle mourut le 17 décembre 1847.

On lit derrière ce buste : SPALLA SCVLPSIT TAVRINI ANNo 1810.

\section{Napoléon-Francois-Charles-Joseph, prince im- périal, roi de Rome.}

Statue couchée; marbre. - Long. 0,68 .

Fils de Napoléon Ier et de Marie-Louise, né au palais des Tuileries le 20 mars 1811. Après l'abdication de l'Empereur, il fut remis entre les mains de son grand-père, François Ier, empereur d'Autriche, qui lui donna, en 1818, le titre de duc de Reichstadt et un régiment de cavalerie. Il mourut au château de Schœenbrunn le 22 juillet 1832.

\section{Joseph Bonaparte, roi d'Espagne.}

Par F. Delaistre; statue en marbre. - H. 1,95.

Frère aîné de l'empereur Napoléon Ier, né à Corte le 7 janvier 1768. Elu en 1792 membre de l'adminisiration du département de la Corse, il fut en 1796 commissaire des guerres de l'armée d'Italie, dont son frère avait le commandement. Député de la Corse au conseil des Cinq-Cents, il fut en 1797 ambassadeur à Parme et à Rome. Membre du conseil d'Etat sous le Consulat, il se signala comme négociateur et signa un traité de paix et de commerce arec les Etais - Unis en 1800, le traité de Lunéville en 1801, le traité d'Amiens en 1802, et le concordat avec la cour de Rome en 1803. Grand officier de la Légion d'honneur et membre du sénat, il fut, à l'avénement de Napoléon I ${ }^{\text {er }}$, prince impérial, grand électeur de l'Empire, et pendant la campagne de $1800 ّ$, il eut la direction du gouvernement. Roi de Naples le 30 mars 1806 , ii fut appelé au trône d'Espagne le 7 juillet 1808, et ful obligé de rentrer en France en 1813. Lieutenant général de l'Empire en 1814 et pendant les Cent-Jours, il se retira en 1815 aux EtatsUnis et prit le nom de comte de Survilliers. De retour en Europe, il habita successivement l'Angleterre et l'Italie, et mourut à Flo- 
VESTIBULE NAPOLÉON, No 73.

rence le 28 juillet 1844. - Joseph Bonaparte avait épousé, en 1794, Marie-Julie Clary, dont la sœur fut plus tard femme du général Bernadotte et reine de Suède.

Cette statue a été exposée au Salon de 1808. Le prince est représenté en costume de grand électeur de l'Empire.

\section{Joseph Bonaparte, roi d'Espagne. (Voir n ${ }^{1525 .)}$}

Far BaRtoloni; buste en marbre. - I. 0,56.

\section{Joseph Bonaparte, roi d'Espagne. (Voir n 1525.)}

Buste en marbre. - H. 0,52.

\section{Lucien Bonaparte, prince de Canino.}

Buste en marbre. - H. 0,52.

Troisième fils de Charles-Marie Bonaparte. Né à Ajaccio le 21 mai 1755 ; président du conseil des Cinq-Cents en 1799 ; prince de Canino en 1804; mort à Viterbe le 30 juin 1840.

\section{Louis Bonaparte, roi de Hollande.}

Par P. GaRTellier en 1810 ; statue en marbre. - H. $1,87$.

Quatrième fils de Charles Bonaparte et frère puiné de l'empepereur Napoléon I ${ }^{\text {er }}$, né à Ajaccio le 2 septembre 1778. Il fut d'abord, en 1794, lieutenant de son frère, qui l'attacha à l'étatmajor de larmée des Alpes, et commanda en second une compagnie de canonniers. A l'armée d'Italie, dont son frère était général en chef, il devint son aide de camp, et reçut le brevet de capitaine après la bataille de Castiglione. Il accompagna son frère en Egypte, revint à Paris en 1799, et fut appelé au commandement du Je régiment de dragons. Marié le 3 janvier 1802 à HortenseEugénie de Beaukarnais, fille du général Alexandre de Beauharnais et de Joséphine, il devint en 1804 général de division et recut, à l'avénement de l'Empire, les titres de connétable et de colonel général des carabiniers. En 1805, il accompagna l'Empereur en Italie, fut nommé gouverneur dı Piémont, et fut chargé à la fin de la même année d'organiser l'armée du Nord. Proclamé roi de Hollande le 24 mai 1806, il gouverna ce pays avec sagesse et modération, et abdiqua le 1 er juillet 1810 . Retiré d'abord à Groetz, il se rendit ensuite en Italie et y vécut dans la retraite sous le nom de comte de Saint-Leu. Il mourut à Florence le 25 juillet 1846.

Cette statue a été exposéc au Salon de 1810. Le prince est représenté en costume de grand connétable. 


\section{Louis Bonaparte, roi de Hollande. (Voir n 1529.)}

Par P. Cartellier en 1808; buste en marbre. - H. 0,61.

\section{Hortense-Eugénie, reine de Hollande.}

Par M. Émile Chatrousse en 1852 ; groupe en marbre. - H. $0,89$.

Née à Paris le 10 avril 1783, Hortense-Eugénie de Beauharnais ètait fille d'Alexandre, vicomte de Beauharnais, et de Marie-RoseJoséphine de Tascher de la Pagerie. Elle fut mariée le 3 janvier 1802 à Louis Bonaparte, depuis roi de Hollande, et mourut le 3 octobre 1837.

La reine de Hollande est représentée assise, ayant près d'elle son troisième fils Charles-Louis-Napoléon Bonaparte, aujourd'hui Napoléon III, empereur des Français.

\section{Jérôme Bonaparte, roi de Westphalie.}

Par BArtoloxi; buste en marbre. - H. 0,58.

Dernier frère de l'empereur Napoléon I Ier, né à Ajaccio le 15 décembre 1784. Aspirant provisoire, puis aspirant de 2 e classe à Brest en 1800 , il fut embarqué sur le vaisseau l'Indivisible, fut aspirant de $1^{\text {re }}$ classe en 1801, passa sur le vaisseau le Foudroyant, et fut enseigne de vaisseau en 1802 . Il fit partie en 1802 de l'expédition de Saint-Domingue, servit sur la corvette l'Epervier, fut lieutenant de vaisseau, puis capitaine de frégate en $\mathbf{1 8 0 3 ,}$ et partit pour la Nouvelle-Angleterre en 1804. Il commanda la frégate la Pomone en 180 ă, fut nommé capitaine de vaisseau de 2 e classe et commanda le Vétéran. Contre-amiral en 1806, il commanda les forces navales à Gênes et fut grand-croix de la Légion d'honneur. Commandant en chef des contingents bavarois, badois et westphaliens en 1806, il passa au commandement en chef du 9 e corps de la grande armée, et fut général de division en 1807. Marié le 22 août 1807 à Frédérique-Catherine-Sophie-Dorothée, princesse de Wurtemberg, il fut roi de Westphalie le $\mathbf{1}^{\mathrm{er}}$ décembre 1807 . Commandant en chef le $10^{\mathrm{e}}$ corps de l'armée d'Allemagne en 1809, et investi du commandement supérieur des $5^{\mathrm{e}}, 7^{\mathrm{C}}$ et $8^{\mathrm{e}}$ corps, comiposés de Polonais, de Saxons et de Westphaliens, il fit les campagnes de Prusse, de Pologne, d'Allemagne et de Russie. Commandant la $6^{\mathrm{e}}$ division d'infanterie du $10^{\mathrm{e}}$ corps en 1815 , il prit le commandement de l'armée à Waterloo le 18 juin, à dix heures du soir, et le conserva jusqu'au $1^{\text {er }}$ juillet suivant. Gouverneur de l'hôtel des Invalides en 1848, maréchal de France le

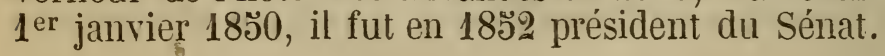

1533. Jérôme Bonaparte, roi de Westphalie. (Voir nº 1532.)

Buste en marbre. - H. 0,53. 
1534. Frédérique - Catherine - Sophie - Dorothée de Wurtemberg, reine de Westphalie.

Buste en marbre. - H. 0,54.

Fille de Frédéric, roi de Wurtemberg, et de AugustineCaroline - Frédérique - Louise de Brunswick - Wolfenbuttel, sa première femme. Née le 2 février 1783 ; mariée le 22 août 1807 à Jérôme Bonaparte, roi de Westphalie; morte le 28 novembre 1835 .

1535. Eugène de Beauharnais, vice-roi d'Italie. (Voir $\mathrm{n}^{\circ}$ 1222.)

Par J.-B. Comolli en 1809; buste en marbre. - H. 0,65.

Il est représenté en costume de prince de l'Empire. On lit derrière ce buste I. B. COMOLLI SCU ET FECIT 1809.

1536. Eugène de Beauharnais, vice-roi d'Italie. (Voir $\mathrm{n}^{\circ}$ 1222.)

Par C. RaMeY; statue en marbre. - H. 1,88.

Cette figure a étẻ exposée au Salon de 1810.

1537. Félix Bacchiochi, grand-duc de Toscane.

Buste en marbre. - H. 0,57.

Marié le 5 mai 1797 à Marie-Anne-Élisa Bonaparte, prince de Lucques et de Piombino en 180今̆, grand-duc de Toscane en 1809 ; mort à Rome le 27 avril 1841.

1538. Marie-Anne-Élisa Bonaparte, princesse de Lucques et de Piombino.

Par Bartolini; buste en marbre. - H. 0,57.

Fille aînée de Charles-Marie Bonaparte. Née à Ajaccio le 3 janvier 1777; mariée le 5 mai 1797 à Félix Bacchiochi, depuis prince de Lucques et de Piombino et grand-duc de Toscane; morte à Trieste en août 1820.

1539. Marie-Anne-Elisa Bonaparté, grande-duchesse de Toscane. (voir $\mathrm{n}^{\circ}$ 1539.)

Groupe en marbre. - H. 1,80.

Elle est représentée avec sa fille Napoléone-Élisa Bacchiochi, depuis comtesse Camerata. 
1540. Marie-Anne-Élisa Bonaparle, grande-duchesse de Toscane. (Voir no 1538.)

Buste en marbre. - H. 0,43.

1541. Camille, prince Borghèse, duc de Guastalla.

Buste en marbre. - H. 0,56 .

Né à Rome le 8 aoùt $1770 ั$; marié le 28 aoùt 1803 à MariePauline Bonaparte, veuve du genéral Leclerc; prince et duc de Guastalla en 1806; mort à Florence en 1832.

1542. Marie-Pauline Bonaparte, princesse Borghèse.

Buste en marbre. - H. 0,46 .

Seconde fille de Charles-Marie Bonaparte. Née le 20 octobre 1780 ; mariée : $1^{\circ}$ en 1801 au général Charles-Emmanuel Leclere; $2^{\circ}$ le 28 aoùt 1803 à Camille, prince Borghèse, duc de Guastalla; morte à Florence le 9 juin 1820̈.

1543. Joachim Murat, roi de Naples. (Voir no 936.)

Par LEMOT; statue en marbre. - H. 2,15.

Cette statue a été exposée au Salon de 1810.

1514. Marie-Annunciade-Caroline Bonaparte, reine de Naples.

Buste en marbre. - H. 0,50.

Troisième fille de Charles-IIarie Bonaparte, Née le 25 mars 1782; mariée le 30 janvier 1800 à Joachim Murat, depuis roi de Naples. Restée veuve en 1810 , elle prit le nom de contesse de Lipona et mourut le 18 mai 1839.

1545. Napoléone-Élisa Bacchiochi, comtesse Camcrata.

Buste en marbre. - H. 0,46.

Fille de Félix Bacchiochi et de Marie-Anne-Elisa Bonaparte. Née le 3 juin 1806 ; mariée au comte Camerata.

$$
\text { SALLE No } 74 .
$$

Cette salle formait, avec les suivantes jusqu'au $n^{\circ} 79$, un appartement dont la disposition et la division furent souvent cbangées. Cette partie fut habitée sous 
Louis XIV par le prince et la princesse de Condé; sous Louis XV par la duchesse de Bourbon, douairière, puis par les petits-fils du roi, le duc de Bourgogne, le duc de Berry (Louis XVI), le comite de Provence (Louis XVIII), et les persomnes qui en prenaient soin. Sous Louis XVI, l'aile tout entière fut destinćc aux appartements des enfants de France.

Les panneaux de cette salle sont ornés de trophées et de sujets de la campagne de 1804, peints par MM. Alaux, Lafaye, Guiaud, Guyon et PhilippoTEAUX, savoir : Prise du pont du vieux chateau de Vérone (18 octobre). Prise de Lintz et Entrée de l'armée a Lintz (13 novembre). - Combat d'Amstetlen (6 novembre). - Passage du Tagliamento (13 novembre). Entrée de l'armée à Vienne (13 novembre).

\section{Napoléon rend honneur au courage malheu- reux. - Octobre 1805.}

Par Debret. - H. 3,90. - L. 6,21.

Après la prise d'Ulm, lorsque plus de trente mille hommes sortirent de cette ville pour déposer les armes, des militaires allemands racontèrent que, dans une circonstance semblable, en Italie, Napoléon, voyant passer des Autrichiens blessés et faits prisonniers, ôta son chapeau en disant: Honneur au courage malheureux! Aussi les prisonniers autrichiens, en défilant devant l'Empereur, témoignaient-ils un extrême empressement de le voir.

Napoléon, suivi de son état-major, arrête son cheval et se découvre à la vuc d'un convoi d'Autrichiens blessés, les uns placés sur des chariots, les autres portés par des Allemands et des Français qui leur ont fait un brancard avec des fusils. Près de l'empereur se troúvent le maréchal Bessières et le général Lemarrois, et tout à fait à droite le maréchal Augereau.

Ce tableau, exposé au Salon de 1806, avait été exécuté pour le palais du Corps Législatif.

\section{Le maréchal Ney remet aux soldats $d u 7^{\mathrm{e}}$ régiment de ligne leurs drapeaux retrouvés dans l'arsenal d'Inspruck. - 7 nov. 1805.}

Par Meynier en 1805. - H. 3,60. - I. 5,24.

Le maréchal Ney ayant reçu mission de s'emparer du Tyrol, s'en était acquitté avec son intelligence et son intrépidité accoutumées, et avait fait son entrée à Inspruck le 7 novembre. Il y trouva un arsenal rempli d'une artillerie considérable, seize mille fusils et une immense quantité de poudre. Un officier du $76^{\mathrm{e}}$ de ligne ayant reconnu trois drapeaux que ce régiment avait perdus autrefois dans le pays des Grisons, el qui avaient été déposés à l'arsenal d'Inspruck, le maréchal Ney les remit aux soldats avec pornpe. Des larmes coulaient des yeux de tous les vieux soldats, et les jeunes conscrits étaient fiers d'avoir servi à reprendre ces 
enseignes enlevées à leurs aînés par les vicissitudes de la guerre. L'Empereur ordonna que cette scène touchante fùt consacrée par un tableau.

Ce tableau a été exposé au Salon de 1808.

\section{Combat de Guntersdorf.-16 novembre 1805.}

Par MI. FÉRox en 1837. - H. 3,60. - L. 5,24.

« Le prince Murat a marché à l'ennemi et l'a attaqué le 16 novembre, à quatre heures après midi, ce qui a donné lieu au combat de Guntersdorf, dans lequel la parlie de l'armée russe qui formait l'arrière-garde a été mise en déroute, a perdu douze pièces de canon, cent voitures de bagages, deux mille prisonniers et deux mille hommes restés sur le champ de bataille. Le maréchal Lannes a fait attaquer l'ennemi de front; et tandis qu'il le faisait tourner par la gauche par la brigade de grenadiers du général Dupas, le maréchal Soult le faisait tourner par la droite par la brigade du général Levasseur de la division Legrand, composée du $3^{\text {e }}$ et du $18^{\mathrm{e}}$ régiment de ligne. Le général de division Walther a chargé les Russes avec une brigade de dragons et a fait trois cents prisonniers.'La brigade de grenadiers du général Laplanche-Mortier s'est distinguée. Sans la nuit rien n'eût échappé. On s'est battu à l'arme blanche plusieurs fois. Des bataillons de grenadiers russes ont montré de lintrépidité. Le général Oudinot a été blessé; ses deux aides de camp, chefs d'escadron Demengeot et Lamotte, l'ont été à ses côtés.» - (Vingtsixième bulletin de la grande armée.)

Ce tableau a été exposé au Salon de 1837.

\section{SALLE No 70 .}

Chambre à coucher de la duchesse du Maine en 1735 et des enfants de France en $173 ั 5$.

Les panneaux de cette salle sont ornés de trophées et de sujets de la campagne de 1805, peints par MII. ROEHN, AlaUx, Brocas et BRISSET. lls représentent : Uccupation de l'abbaye de Molk (10 novembre). - Bivouac de l'armée française la veille de la bataille d'A usterlitz (1 ${ }^{\mathrm{er}}$ (lécembre). - Mort du général Valhubert (2 décembre).

1549. Napoléon reçoit les clefs de la ville de Vienne. -13 novembre 1805 .

Par Girodet-Triosor en 1808. - H. 3,80. - L. 5,32.

Napoléon était à peu de distance de Vienne, lorsqu'il reçut à son quartier général une députation des magistrats de la ville, conduite par le prince de Sinzendorf, Napoléon leur donna l'as- 
surance que les proprietés seraient respectées, et il fut convenu que la garde bourgeoise, qui formait seule la garnison de Vienne, conserverait ses armes et son arsenal particulier, qu'elle continuerait son service et partagerait les postes intérieurs avec les troupes françaises. L'Empereur fut recu à la porte du Danube par la députation de la ville, composée du prince de Sinzendorf, du prélat de Seidenstetten, du comte de Veterani, du baron de Kees, du bourgmestre de la ville, M. de Wohleben, et du général Bourgeois, du corps du génie.

L'Empereur, accompagné de ses officiers généraux Murat, Berthier et Bessières, reçoit les clefs de la ville qui lui sont présentées par les officiers municipaux, le clergé et les officiers commandant la place. Dans le fond se trouve l'entrée de Schoenbrunn, et sur le haut de la montagne on aperçoit une construction qui se nomme la Gloriette.

Ce tableau a été exposé au Salon de 1808. - Gravé par Pigeot,

\section{Napoléon donnant l'ordre avant la bataille d'Austerlitz. - 2 décembre 1805.}

Par Carle Vernet en 1808. - H. 3,80. - L. 6,44.

Le jour de la bataille d'Austerlitz, Napoléon, à cheval avant le jour, entouré de tous ses généraux, attendait, pour donner ses derniers ordres, que l'horizon fùt bien éclairci. Aux premiers rayons du jour; s'apercevant que l'armée combinée quittait les hauteurs de Pratzen, il donna ordre au maréchal Soult de s'en emparer.

L'Empereur, accompagnẻ du prince Murat, des maréchaux Berthier, Bessières, Bernadotte, et de plusieurs autres généraux, tous à cheval, donne ses ordres pour la bataille. Le maréchal Bernadotte les a déjà reçus, et partant au galop, va rejoindre son corps d'armée. Un autre, vu de dos, attend, pour s'éloigner, les dernières instructions de l'Empereur.

Ce tableau a été exposé au Salon de 1808.

\section{Entrevue de Napoléon et de François II après la bataille d'Austerlitz. - 4 décembre 1805.}

\section{Par Gros. - H. 3,80. - L. 5,32.}

Le lendemain de la bataille d'Austerlitz, l'empereur d'Autriche envoya le prince Jean de Lichtenstein au quartier général francais pour demander un armistice et proposer à l'empereur Napoléon une entrevue où les conditions seraient réglées. Napoléon accueillit gracieusement le prince de Lichtenstein, et accepta l'entrevue pour le lendemain 4 décembre avec l'empereur Francois II. Il fut convenu qu'il se rendrait sur la route d'Austerlitz à Goeden, au point où se trouvaient les avant-postes de l'armée française. L'empereur Napoléon s'était rendu à ses avantpostes près de Sarutschitz, et avait fait établir son bivouac 
auprès d'un moulin, à còté de la grande route. Il y attendit l'em. pereur d'Autriche, alla au-devant de lui dès qu'il eut mis pied à terre, et l'invitant à s'approcher du feu de son bivouac: "Je vous recois, lui dit-il, dans le seul palais que jhabite depuis deux mois. - Vous tirez si bon parti de cette habitation qu'elle doit vous plaire , répondit en souriant François II.

Le foncl représente le quartier de l'Empereur; un feu est allumé devant sí tente. A droite sont quelques officiers français et un page qui tient le cheval de l'Empereur.

Ce tableau a été exposé au Salon de 1812.

\section{SALLE No 76.} 1755.

Chambre à coucher de $\mathrm{A}^{11 \mathrm{e}}$ du Maine en 1735 et des enfants de France en

Les panneaux de cette salle sont ornés de trophées et de sujets peints par MM. ALAUx, BaILlif et Hipp. LEConte; ils représentent : la colonne de Rosbach renversée par l'armée francaise (18 octobre 1806). - Napoléon au tombeau du grand Frédéric (25 octobre 1806). - Bivouac d'Osterode (mars 1807).

\section{Entrée de Napoléon à Berlin. - 27 oct. 1806.}

Par Charles Meyvier en 1810. - H. 3,63. - L. 4,93.

Le 27 octobre, Napoléon fit une entrée solennelle à Berlin. Il étail accompagné du prince de Westphalie, du prince de Neufchâtel, des maréchaux Daroust et Augereau, du grand maréchal du palais Duroc, du grand écuyer Caulaincourt et de ses aides de camp. Le maréchal Lefebrre ourrait la marche à la tète de la garde impériale à pied; les cuirassiers de la division Nansouty étaient en bataille sur le chemin. L'Empereur marchait entre les grenadiers et les chasseurs à cheval de sa garde. Il descendit au palais à trois heures après midi et fut recu par le grand maréchal du palais Duroc. Une foule immense était accourue sur son passage. L'avenue de Charlottembourg à Berlin est très-belle; l'entrée par cette porte est magnifique. La journée était superbe. Tout le corps de la ville, présenté par le général Hulin, commandant de ha place, vint à la porte offrir les clefs de la ville à l'Empereur. Ce corps se rendit ensuite chez l'Empereur, le général prince d'Hatzfeld à la tète.

Ce tableau a été exposé au Salon de $\mathbf{1 8 1 0 .}$

1553. Napoléon recoit au palais royal de Berlin les députés du Sénat. - 19 novembre 1806.

par Berthor en 1808. - H. 3,63. - L. 4,03.

Le sénat conservateur ayant délibéré, le 14 octobre 1806, 
qu'une députation de trois de ses membres se rendrait auprès de l'Empereur à Berlin, pour lui offrir l'hommage du dévoutement du sénat et du peuple français, le 18 novembre, les sénateurs d'Aremberg, François de Neufchâteau et Colchen arrivèrent à Berlin pour remplir cette mission. Le 19, l'Empereur les reçut au retour de la parade; François de Neufchâteau porta la parole au nom du sénat. L'Empereur, en répondant qu'il remerçiait le sénat de sa démarche, chargea la députation de rapporter à Paris les trois cent quarante drapeaux et étendards pris dans cette campagne sur l'armée prussienne. L'Empereur fit aussi remettre à la députation l'épée, l'écharpe, le hausse-col et le cordon du grand Frédéric, pour être transportés aux Invalides, remis au gouverneur et gardés à l'Hôtel. (Moniteur du 30 novembre 1806.)

L'Empereur est accompagné des maréchaux de l'Empire, Murat, Berthier, Davout, Soult, Ney, Lefebvre, du général Caulincourt et de divers personnages parmi lesquels on reconnaît Maret, ministre d'Etat, et Denon, directeur général des Musées. Deux chambellans tiennent, sur un coussin, les objets ayant appartenu au grand Frédéric. Derrière les trois sénateurs d'Aremberg, François de Neufchâteau et Colchen, se trouve l'écrivain Etienne, alors secrétaire du ministre Naret et depuis membre de l'Académie française.

Ce tableau a été exposé au salon de 1808.

\section{Napoléon sur le champ de bataille d'Eylau. - 9 février 1807.}

Par MaUzaisse, d'après Gros. - H. 3,81 - - L. 6,12.

Le lendemain de la bataille d'Eylau, l'Empereur passa en revue plusieurs divisions, et parcourut toutes les positions que les deux armées avaient occupées la veille. Napoléon était accompagné du grand-duc de Berg, du prince de Neufchâtel, des maréchaux Davout, Soult, Bessières, et du chirurgien en chef Percy. La campagne était couverte d'une neige épaisse. L'Empereur fit donner des secours aux Russes blessés.

I'Empereur s'arrête devant un jeune chasseur lithuanien blessé qui lui témoigne sa reconnaissance. On aperçoit dans le fond l'armée française dont l'Empereur va passer la revue.

Le tableau original, dont le sujet avait été donné au concours par l'Institut en 1807, fut exposé au Salon de 1808. Il est au Musée du Louvre. - Gravé par Oortman.

\section{SALLE No 77.}

Partie de l'appartement de $\mathrm{M}^{\mathrm{me}}$ et de Mlle du Maine en 1735 et des enfants de France en 1755.

Les panneaux de cette salle sont décorés de trophées et de sujets de la campagne de 1807, peints par MM. ALAUX, GUiAud, RubIO et Hipp. LEComte. IIs représentent : Entrée de l'armée à Dantzick (27 mai). -Napoléon ì Finkenstein (27 avril). - Prise de Stralsund (20 aont). 


\section{Napoléon reçoit la reine de Prusse à Tilsitt. - 6 juillet 1807.}

Par M. Gosse. - H. 3,51. - L. 4,92.

Lors de l'arrivée de la reine de Prusse à Tilsitt, l'empereur Napoléon fut au-devant de la reine jusque dans la rue, et la reçut au bas des degrés de l'escalier. La garde impériale était sous les armes; le grand-duc de Berg, les maréchaux Berthier et Ney, le général Duroc et le ministre des relations extérieures Talleyrand accompagnaient l'Empereur.

\section{Napoléon à Tilsitt décore un soldat de l'armée russe. - 9 juillet 1807.}

Par Debret en 1808. - H. 3,51.- L. 4,92.

L'Empereur, désirant accorder une marque d'estime particulière à la bravoure de la garde impériale russe, demanda à l'empereur de Russie de décorer de la croix de la Légion d'honneur le plus brave cavalier de sa garde. Aussitôt l'empereur Alexandre ordonna au colonel de sa garde de faire sortir des rangs le soldat qu'on pouvait présenter comme tel. Napoléon détacha sa croix et la donna à ce brave, qui, pénétré de reconnaissance, se précipita sur la main de Napoléon pour la baiser.

Ce tableau a été exposé au Salon de 1808.

\section{Adieux des empereurs Napoléon et Alexandre à Tilsitt. - 9 juillet 1807.}

Par Serangeli. - H. 3,51.-L. 5,10.

La paix avait été conclue entre l'empereur des Français et l'empereur de Russie le 8 juillet et signée par Talleyrand, ninisistre des relations extérieures de France, et par les princes Kourakin et Labanoff de Rostoff pour l'empereur de Russie. Les ratifications furent échangées le 9 juillet, les deux souverains se trouvant encore à Tilsitt. Ils restèrent ensemble pendant trois heures et se rendirent au bord du Niémen, où l'empereur Alexandre devait s'embarquer; Napoléon demeura sur le rivage jusqu'à ce qu'Alexandre fùt arrivé sur l'autre bord.

Ce tableau a été exposé au Salon de 1810.

\section{SALLE No 78 (Voir Salle no 74 ).}

Partie de l'appartement de la duchesse douairière de Bourbon en 1735 et des enfants de France en 1755.

Les panneaux de cette salle sont ornés de trophées et de sujets peints par 
MM. Alaux, Lestang-Parade, H. Lecomte, lafaye et Baillif. Ce sont : Entrée de Ferdinand VII en France (20 avril 1808). - Combat de SomoSierra (30 nor.. 1808). - Passage des défilés du Guadarrama (24 déc. 1808). Mademoiselle de Saint-Simon obtenant la grace de son père (déc. 1808).Napoléon à Astorga (janvier 1809).

\section{Mariage du prince Jérôme Bonaparte et de la} princesse Frédérique-Catherine de Wurtemberg. - 22 aout 1807.

Par Regnault en 1810. - H. 4,02. - L. 6,46.

Le mariage du prince Jérôme Bonaparte et de la princesse Frédérique-Catherine-Sophie-Dorothée de Wurtemberg fut célébré à Paris dans le mois d'août 1807, six semaines après la paix de Tilsitt. La cérémonie de la signature du contrat se fit, le 22 à huit heures du soir, dans la galerie de Diane, aux Tuileries, où l'Empereur et l'Impératrice se rendirent, suiviš des princes et princesses, des grands de l'Empire. Leurs Majestés se placèrent sur leur trône ayant devant elles les deux époux. Regnaud de SaintJean-d'Angely, secrétaire d'Etat de la famille impériale, fit lecture du contrat de mariage, qui fut signé par Leurs Majestés, par les haules parties contractantes, par Joseph Napoléon, roi de Naples; la reine de Naples; Louis Napoléon, roi de Hollande; la reine de Hollande; Madame Mère; le prince primat; les princes, les princesses, les grands dignitaires et les témoins. Les témoins de la cour de France furent : le prince Borghèse, le grand-duc de Berg et le prince de Neufchâtel, vice-connétable. Ceux de la cour de Wurtemberg: le prince de Bade, le prince de Nassau et le comte de Vinzingerode, ministre d'état du roi de Wurtemberg. La cérémonie religieuse fut ensuite célébrée dans la chapelle du palais des Tuileries par le prince primat, le 23 août.

\section{Napoléon devant Madrid.-3 décembre 1808.}

Par Carle Vernet en 1810. - H. 3,61. - L. 5,00.

L'Empereur sort de sa tente pour recevoir une députation de la ville de Madrid, et dit à ceux qui la composent : "Si dans une heure, à cette montre (le duc de Frioul tenait la sienne à la main), vous ne m'apportez pas la soumission du peuple, vous serez tous passés par les armes. »

Ce tableau a été exposé au Salon de 1810.

\section{Capitulation de Madrid. - 4 décembre 1808.}

Par Gros en 1810. - H. 3,61. - L. 5,00.

Le 4, à six heures du matin, le général Morla et le général don Fernando de la Vera, gouverneur de la ville, se présentèrent à 
la tente du prince major général. Les discours de l'Empereur, répétés au milieu des notables, la certitude qu'il commandait en personne, les pertes éprouvées pendant la journée précédente avaient porté le repentir et la terreur dans tous les esprits. Pendant la nuit, les plus mutins s'étaient soustraits au danger par la fuite, et une partie des troupes s'était débandée. A dix heures, le général Belliard prit le commandement de Madrid; tous les postes furent remis aux Français, et un pardon général fut proclamé.

Ce tableau a été exposé au Salon de 1810.

\section{SALLE No 79 (Voir Salle $n^{0} 74$ ).}

Les panneaux de cette salle sont ornés de trophées et de sujets de la campagne de 1809, peints par MM. Aladx, Gibert, Jules Rigo, LAFaYe et PHiLIPPOTEAUX. Ils représentent : Bataille d'Eckmuhl (22 avril). - Attaque de Ratisbonne (23 avril). - Passage du Tagliamento (11 mai). - Bataille d'Essling (22 mai). - Prise de Raab (22 juin). - Passage du Danube (4 juillet).

\section{Napoléon harangue les troupes bavaroises et wurtembergeoises à Abensberg. — 20 avril 1809.}

Par Debret en 1810. - H. 3,68. - L. 4,94.

Le 20 avril, l'Empereur se porta à Abensberg, où il se trouva bientôt en présence des troupes autrichiennes. Il y rencontra le corps des Bavarois et des Wurtembergeois, et voulut combattre à leur tête. Il fit réunir en cercle les officiers de ces deux armées Ton distinguait au milieu d'eux le général de Wrede, le comte Deroy, etc.), et leur parla longtemps. Le prince royal de Bavière traduisait en allemand le discours de l'Empereur, qui fut ensuite répété aux compagnies par les capitaines.

Ce tableau a été exposé au Salon de $\mathbf{1 8 1 0 .}$

\section{Combat d'Ebersberg. - 3 mai 1809.}

Par TAUNAY. - H. 2,20. - L. 2,03.

Un corps de troupes autrichien fort de trois mille cinq cents hommes était en avant de la Traun; menacé d'être tourné par le duc de Montebello, il se porta sur Ebersberg pour y passer la rivière. Alors l'avant-garde du général Claparède, composée des bataillons des tireurs corses et des tirailleurs du Pô, attaque l'ennemi au passage du pont, culbute dans la rivière les chariots, les canons et huit à neuf cents hommes, s'empare de la ville et de trois à quatre mille hommes qui, ne pouvant la défendre, l'incendient.

Ce tableau a été exposé au Salon de 1810. 
1563. Bivouac de Napoléon près du château d'Ebersberg. - 4 mai 1809.

Par Mongin. - H. 1,35. - L. 2,03.

Après la prise de Ratisbonne, le quartier général de l'Empereur fut transféré à Burghausen, et de là à Ens, où il était le 4 . Napoléon coucha dans le château du prince d'Auersberg. Les députés des Etats de la Haute-Autriche lui furent présentés à son bivouac d'Ebersberg.

Ce tableau a été exposé au Salon de 1810.

\section{Derniers moments du maréchal Lannes à Essling. - 22 mai 1809.}

Par A.-P. Bourgeors. - H. 3,67. - L. 3,96.

A la bataille d'Essling, le duc de Montebello eut la cuisse emportée par un boulet, sur les six heures du soir. L'amputation fut faite, et au premier moment on le crut mort : transporté sur un brancard auprès de l'Empereur, ses adieux furent touchants. Au milieu des sollicitudes de cette journée, l'Empereur se livra à la tendre amitié qu'il portait depuis tant d'années à ce brave compagnon d'armes, Quelques larmes coulèrent de ses yeux, et se tournant vers ceux qui l'environnaient : " Il fallait, dit-il, que dans cette journée mon cœur fut frappé par un coup aussi sensible, pour que je pusse m'abandonner à d'autres soins qu'à ceux de mon armée. » Le duc de Montebello avait perdu connaissance: la présence de l'Empereur le fit revenir; il se jeta à son cou en luidisant : " Dans une heure vous aurez perdu celui qui meurt avec la gloire et la conviction d'avoir été et d'être votre meilleur ami.» (Campagne d'Autriche, $10^{\mathrm{e}}$ bulletin.)

Ce tableau a été exposé au Salon de 1810.

1565. Mariage de l'empereur Napoléon et de MarieLouise, archiduchesse d'Autriche, au palais du Louvre. - 2 avril 1810.

Par M. Rouget en 1836. - H. 3,67. - L. 4,94.

Une chapelle avait été élevée dans le grand salon, à l'extrémité de la grande galerie du Musée. Deux rangs de tribunes avaient été construits au pourtour de ce vaste vaisseau d'une dimension parfaitement carrée. L'autel était placé en face de la galerie; il était magnifiquement revêtu d'un grand bas-relief et de différents ornements très-riches. L'estrade sur laquelle étaient placés les fauteuils, le prie-Dieu et les coussins de Leurs Majestés, était recouverte d'un tapis en velours de soie cramoisi, brodé et galonné en 
or. La chapelle rassemblait dans le sanctuaire, dans la nef et dans les tribunes, les princes, les grands dignitaires, les ministres, les grands officiers de l'empire, les cardinaux et les évêques, des députations du sénat, du conseil d'Etat et du corps législatif, le corps diplomatique, les étrangers de distinction et un grand nombre d'officiers et de dames de la cour. L'Empereur et l'Impératrice, précédés par le grand maître des cérémonies, le grand chambellan, le grand écuyer, et suivis du grand maréchal du palais, du colonel général de la garde de service, prirent place sur le trône, l'Impératrice à la gauche de l'Empereur. A droite de l'Empereur et au bas de l'estrade : le prince Louis Napoléon, roi de Hollande; le prince Jérôme Napoléon, roi de Westphalie; le prince Borghèse, duc de Guastalla; le prince Joachim Napoléon, roi de Naples; le prince Eugène Napoléon, vice-roi d'Italie; le grand-duc héréditaire de Bade; le prince archi-chancelier; le prince archi-trésorier; le prince vice-connétable; le prince vice-grand électeur. A gauche de l'Impératrice, au bas de l'estrade, étaient : Madame Mère; la princesse Julie, reine d'Espagne; la princesse Hortense, reine de Hollande; la princesse Catherine, reine de Westphalie; la princesse Elisa, grande-duchesse de Toscane; la princesse Pauline ; la princesse Caroline, reine de Naples ; le grand-duc de Wurtzbourg ; la princesse Auguste, vice-reine d'Italie; la princesse Stéphanie, grande-duchesse héréditaire de Bade. La bénédiction nuptiale fut donnée aux augustes époux par son éminence le cardinal Fesch, grand aumônier.

Ce tableau a été exposé au Salon de 1837.

\section{SALLE DE MARENGO, No 80.}

Cette salle occupe l'emplacement d'un appartement qui dépendait, sous Louis XV, de celui de la duchesse de Bourbon. Cet appartement fut ensuite destiné aux gouvernantes des enfants de France et habité à ce titre, sous Louis XV, par madame de Marsan, et sous Louis XVI, par madame de Polignac.

Les panneaux de cette salle sont ornés de trophées peints par MM. ALADX, H. LECOMTE et V. ADAM. Les sujets, représentant des faits de la campagne de 1800 , sont : Passage du Saint-Bernard (20 mai). - Prise du défilé de la C'luse (21 mai). - Passage de l'artillerie sous le fort de Bard (21 mai). - Entrée dans Ivrée (21 mai). - Passage de la Chiusella (26 mai). - Passage de la Sesia (27 mai). - Attaque du fort d'Arona (1 ${ }^{\mathrm{er}}$ juin). - Prise du fort de Plaisance (6 juin). - Bataille de Montebello, première et deuxième attaque (8 juin).

\section{Passage du grand Saint-Bernard par l'armée française. -20 mai 1800.}

Par Charles Théverin. - H. 4,65. - L. 7,9'4.

L'armée est en marche et monte à l'hospice du Saint-Bernard; au milieu du tableau, le premier consul à pied, entouré de l'état- 
major, des généraux Duroc, Bessières, etc., montre aux soldats le haut du passage comme le but de leurs travaux; à sa gauche, Murat à cheval, donne des ordres à un grenadier dont le détachement est en marche. Sur le devant, à droite, le gériéral Marmont, commandant en chef l'artillerie, dirige des canonniers qui, avec des leviers, font mouvoir une pièce de canon encaissée dans un tronc d'arbre et traînée par des soldats. Eugène Beauharnais est à la tête d'un détachement des guides, et des officiers du $12^{\mathrm{e}}$ régiment de hussards sont près de lui. A gauche, sur le devant, une forge de campagne, en partie démontée, est portée par deux mulets; plus loin des paysans soutiennent l'affüt d'une pièce de quatre; un caisson, une boîte à gargousses, une roue de rechange et différentes parties d'affût sont également portées sur les épaules. Au-dessus, un mulet chargé d'une paire de roue d'artillerie; des soldats, des mulets portant des bagages arrivent sur un pont près duquel est arrêté le général Berthier. Dans le fond, à droite, on aperçoit le haut de deux petites cabanes dont l'une sert d'abri aux voyageurs surpris par la tourmente et l'autre sert de sépulture à ceux qui périssent sur la montagne. L'armée, marchant sur une seule ligne ou se divisant lorsque le sol le permet, occupe le haut du tableau, et après différentes sinuosités arrive enfin à l'hospice.

Ce tableau a été exposé au Salon de 1806. L'auteur avait dessiné d'après nature les différents points de vue qui en forment l'ensemble; il a représenté le tiers supérieur de la vallée qui conduit à l'hospice du mont Saint-Bernard, du côté du Valais.

\section{Le premier consul franchissant le mont Saint- Bernard. - 20 mai 1800.}

Par David en 1805. - H. 2,71. - L. 2,32.

Toute l'armée passa le Saint-Bernard du 17 au 20 mai; le premier consul le passa lui-même le 20.

On rapporte que Bonaparte, au retour de sa première campagne d'Italie, s'étant rencontré avec David chez Lagarde, secrétaire dı Directoire, la conversation s'établit entre le général et le peintre dès qu'ils se virent. "Je vous peindrai, dit David, l'épée à la main sur le champ de bataille. - Non, reprit Bonaparte, ce n'est plus avec l'épée qu'on gagne les batailles; je veux être peint calme sur un cheval fougueux. " Cette idée fut exécutée plus tard lorsque David fut chargé de peindre le premier consul pour la bibliothèque de l'Hôtel des Invalides.

\section{Bataille de Marengo. - 14 juin 1800.}

\section{Par Carle Vernet. - H. 4,65. - L. 9,55.}

La division Boudet, commandée par le général Desaix, attaque en tête une cọlonne de huit mille grenadiers hongrois, pendant que la cavalerie, commandée par le général Kellermann, la prend par le flanc et la traverse.

L'esquisse de ce tableau a été exposée au Salon de 1804. 


\section{Mort de Desaix à Marengo. - 14 juin 1800.}

Par Regnault. - H. 3,22. - L. 2,60.

Frappé par une balle au milieu de la poitrine, Desaix tombe dans les bras du fils du consul Lebrun en s'écriant : "Allez dire au premier consul que je meurs avec le regret de n'avoir pas assez fait pour vivre dans la postérité. »

\section{Convention d'Alexandrie. - 15 juin 1800.}

Par Drolling en 1837. - H. 3,22. - L. $2,60$.

Le lendemain de la bataille de Marengo, la fusillade était déjà engagée aux avant-postes, lorsqu' un parlementaire annonça que le général Mélas demandait à faire passer un officier de son étatmajor chargé de propositions. Celui-ci fut introduit au quartier général français. Après une première conférence, le général en chef Berthier, muni de pleins pouvoirs pour traiter avec Mélas, se rendit à Alexandrie, et revint quelques heures après présenter à l'acceptation du premier consul la capitulation connue sous le titre de Convention entre les généraux en chef des armées francaises et impériales en Italie. Les chàteaux de Tortone, d'Alexandrie, de Milan, de Turin, de Pizzighettone, d'Arona, de Plaisance, la place de Coni, les châteaux de Ceva, Savone, la ville de Gênes et le fort Urbain furent remis à l'armée française. Enfin, l'armée autrichienne dut se retirer sur Mantoue.

\section{GALERIE No 81.}

Cette galerie servait autrefois de dégagement et de couloir de service pour les appartements du rez-de-chaussée de l’aile du Midi ou aile des Princes; àla place des niches pratiquées vis-à-vis des fenêtres se trouvaient les baies de portes communiquant aux salles n $n^{\circ 8} 67$ à 79 .

\section{Malesherbes (Chrétien-Guillaume de Lamoignon de), ministre.}

Par J.-E. Duxont ; statue en plâtre. - H. 2,10.

Né à Paris en 1721, fils du chancelier Guillaume de Lamoignon, il fut successivement substitut du procureur général en 1741, conseiller au parlement en $\mathbf{1 7 4 4}$, premier président à la cour des aides en 1750 , membre de l'Académie des sciences, de celle des inscriptions et belles-lettres, et enfin de l'Académie française. La cour des aides ayant été supprimée en 1771, Nalesherbes fut exile et ne reprit ses fonctions qu à l'avénement de Louis XVI. Appelé en 1775 au ministère avec Turgot, son ami, il donna sa démission l'année suivante, lors du renvoi de Turgot, et ne rentra que peu 
de temps aux affaires en 1787. Lors du procès de Louis XVI, Malesherbes, alors âgé de soixante-douze ans, se dévoua à sa défense et l'assista jusqu'au dernier moment. Arrêté ensuite et traduit devant le tribunal révolutionnaire, il fut condamné à mort et exécuté le 22 avril 1794.

La statue en marbre, exposée au Salon de 1819, fait partie du monument érigé à Malesherbes dans la salle des Pas-Perdus, au Palais de Justice de Paris.

\section{Turgot (Anne-Robert-Jacques), baron del'Aulne, ministre d'Etat.}

Par Legendre-Héral; statue en plâtre. - H. 2,20.

Né à Paris en 1727, fils de Michel-Étienne Turgot, prévot des marchands, il fut d'abord substitut du procureur général du parlement et fut recu conseiller au parlement et maitre des requêtes en 1753. Nommé intendant de Limoges en 1761, il fut appelé au ministère par Louis XVI en 1774 et devint contrôleur général des finances. Eloigné du ministère en 1776, il mourut dans la retraite le 20 mars 1781.

La statue en marbre, exposée au Salon de 1843, a été exécutée pour la chambre des Pairs.

1573. La Fayette (Marie-Joseph-Paul-Yves-RochGilbert Mottier, marquis de). (Voir $\left.\mathrm{n}^{\circ} 650.\right)$

Par Houdon; buste en marbre. - H. 0,67.

Ce buste est signé : Houdon fecit an 1790.

1574. Dumouriez (Charles-François), général en chef. (Voir no 1204.)

Par M. LAITIE; statue en plâtre. - H. 2,08.

1575. Gouvion (Jean-Baptiste), maréchal de camp. (Voir n०533.)

Par M. Dantan aîné en 1837; buste en marbre. - H. 0,67.

1576. Richer-Drouet (François), maréchal de camp. (Voir $\mathrm{n}^{\circ}$ 534.)

Par M. VaLOIS; buste en marbre. - H. 0,68.

1577. Guiscar de Bar (Georges), général de brigade.

(Voir n 535.)

Par II. Dantan jeune en 1837; buste en marbre. - II. 0,69. 
1578. Custine (Adam-Philippe, comte de), général en chef. (Voir n⿳2 1206.)

Par MoItTe; statue en marbre. - H. 2,08.

1579. Dampierre (Auguste-Marie-Henri Picot, comte de), général en chef. (Voir n 1207.)

Par Foucov ; buste en plâtre. - H. 0,65.

1580. Dugommier (Jacques-Christophe-Coquille), général en chef. (Voir no 1209.)

Par Chaddet; statue en marbre. - H. 2,15.

1581. Stengel (Henri-Christian-Michaël, baron de), général de division. (Voir $\mathrm{n}^{\circ}$ 536.)

Par M. Thérasse; buste en plâtre. - H. 0,74.

1582. Marceau (François-Severin), général en chef. (Voir $n^{\circ}$ 526.)

Par J.-E. DUMont; buste en plâtre. - H. 0,68.

1583. Joubert (Barthélemy-Catherine), général en chef. (Voir no 1213.)

Par STouf; statue en marbre. - H. 2,13.

Cette statue, exposée au Salon de 1804, était destinée au palais du Sénat.

1584. Hoche (Louis-Lazare), général en chef. (Voir $n^{\circ}$ 1214.)

Par Milнoмme; statue en marbre. - H. 1,90.

Le général est représentẻ assis, vêtu à l'antique, tenant un rouleau de la main droite et appuyant la gauche sur son sabre.

Cette statue, exécutée à Rome en 1808, a étẻ exposée aux Salons de 1812 et de 1814. Elle faisait partie, avec les deux bas-reliefs représentant le passage du Rhin et la bataille de Neuwied, d'un monument élevé sur la place Hoche, à Versailles.

1585. Passage du Rhin. - 17 avril 1797. (Voir no 1584.)

Par MiLномав; bas-relief en marbre。 - H. 1,18. - L. 2,47.

1586. Bataille de Neuwied. - 18 avril 1797. (Voir $\mathrm{n}^{\text {os }} 1493$ et 1584.)

Dar MiLHodne; bas-relief en marbre. - H. 1,18, - L. 2,47. 
1587. Kléber (Jean-Baptiste), général en chef. (Voir $\mathrm{n}^{\circ}$ 532.)

Par LemaIRe en 1835 ; statue en marbre. - H. 2,17.

\section{Caffarelli Du Falga (Louis-Marie-Joseph- Maximilien), général de division.}

Par Masson en 1807; statue en marbre. - H. 2,00.

Né au château du Falga, en Languedoc, le 13 février 1756, il fut nommé en 1792 officier d'artillerie à l'armée du Rhin, et fut destitué pour avoir refusé de reconnaître l'autorité de l'assemblée nationale après la journée du 10 août. Rentré au service en 179̋̈, il fut employé à l'armée de Sambre-et-Meuse comme chef de bataillon du génie et se distingua au passage du Rhin, où il perdit une jambe. Il commanda l'arme du génie à l'expédition d'Egypte en qualité de général de brigade et contribua à la prise d'Alexandrie. Blessé devant Saint-Jean-d'Acre le 9 avril 1799, il mourut des suites de cette blessure le 27 du même mois.

Cette statue a été exposée au Salon de 1808.

1589. Passage dugrand Saint-Bernard.-20 mai 1800. (Voir n० 1566.)

Par M. LaITIÉ ; bas-relief en plâtre. - H. 1,20. - L. $2,55$.

1590. Desaix (Louis-Charles-Antoine), général de division. (Voir $\mathrm{n}^{\circ}$ 1216.)

Par ChInARD; buste en marbre. - H. 0,80.

Ce buste a été exposé au Salon de 1808.

\section{Desaix (Louis-Charles-Antoine), général de di- vision. (Voir $\mathrm{n}^{\circ} 1227$.)}

Par M. Dantan aîné; buste en plâtre. - H. 0,76.

1592. Mort de Desaix à Marengo. - 14 juin 1800. (Voir n० 1569.)

Par M. LaituE; bas-relief en plâtre. - H. 1,20. - L. 2,55.

1593. Leclerc (Charles-Emmanuel), général en chef. (Voir no 1217.)

Par DuPatY; statue en marbre. - H. 2,12.

Le général est représenté presque entièrement nix, debout, et la jambe droite croisée sur la gauche; d'une main il tient une épée renfermée dans le fourreau, et de l'autre un papier roulé. Un manteau qui couvre une partie du bras droit et 
tombe au-dessous du genoux, cache le sommet du cippe sur lequel le bras gauche est appuyé.

Cette statue a eté exposée au Salon de 1812.

1594. Hatry (Jacques-Maurice), général en chef. (Voir $\mathrm{n}^{\circ}$ 1218.)

Buste en plâtre. - H. 0,65.

1595. Pichegru (Jean-Charles), général en chef. (Voir no 1219.)

Par Cartellier; statue en inarbre. - H. 2,15.

Cette statue a été exposée au Salon de 1819.

1596. Moreau (Jean-Victor), général en chef. (loir $n^{\circ}$ 1220.)

Statue en plâtre. - H. 2,16.

1597. Daubenton (Louis-Jean-Marie), naturaliste.

Par Borzot; buste en plâtre. - H. 0,63. ,

Né à Montbar en 1716, il exerça d'abord la médecine, devint ensuite professeur de minéralogie au Muséum d'histoire naturelle et fut le collaborateur de Buffon. Garde du cabinet en 1745, professeur d'histoire naturelle, de minéralogie et d'économie rurale au collége de France, à l'école d'Alfort et à la première Ecole normale, Daubenton fut membre de l'Académie des sciences. Il fit partie de l'Institut en $\mathbf{1 7 9 5}$, fut nommé membre du sénat conservateur en 1799, et mourut à Paris le $\mathbf{1}^{\text {er }}$ janvier 1800.

\section{Darcet (Jean), médecin et chimisle.}

Buste en plâtre. - H. 0,66.

Né à Douazit (Landes) en 1725, il fut l'ami de Montesquieu, chez lequel il était entré comme précepteur de ses fils. Reçu médecin en 1762, il s'occupa de chimie avec Rouelle; il fut en 1774 professeur au collége de France, puis directeur de la manufacture de Sèvres, inspecteur des essais des monnaies et membre de l'Académie des sciences. Membre de l'Institut en 17950 , il entra au sénat conservateur et mourut à Paris le 13 février 1801 .

1599. Napoléon $I^{e r}$, empereur des Français. (Voir n ${ }^{\circ 20 .)}$

Par Bartolini; buste en marbre. - H. 0,75. 
1600. Entrée de l'armée française à Vienne. -13 novembre 1805.

Par Deseine; bas-relief en plâtre. - H. 1,75. - L. 3,50.

Le bas-relief original a été exécuté pour l'arc de triomphe de la place du Carrousel.

\section{Paix de Presbourg. - 26 décembre 1805.}

Par Lesueur; bas-relief en plâtre. - H. 1,75. - L. 3,30.

Le bas-relief original, exposé au Salon de 1810, a été exécuté pour l'arc de triomphe de la place du Carrousel.

1602. Murat (Joachim), roi de Naples. (Voir no $\left.{ }^{0} 36.\right)$

Par M. H.-F. IsELiN en 1853; buste en marbre. - H. 0,90.

Ce buste, exposé au Salon de 1853, a été exécuté d'après un portrait appartenant à M. le luc de Baufremont.

1603. Berthier (Louis-Alexandre), prince de Neufchâtel et de Wagram. (Voir n 1113.$)$

Buste en plâtre. - H. 0,61 .

Le buste original est dans la salle des Maréchaux, au palais des Tuileries.

1604. Masséna (André), duc de Rivoli, princed'Essling. (Voir $\mathrm{n}^{\circ}$ 1128.)

Par F. MASson; buste en plâtre. - H. 0,62.

Le buste original est dans la salle des Maréchaux, au palais des Tuileries.

1605. Augereau (Charles-Pierre-François), duc de Castiglione. (Voir n ${ }^{\circ} 1129$.)

Buste en plâtre. - H. 0,61 .

Le buste original est dans la salle des Maréclıaux, au palais des Tuileries.

1606. Lannes (Jean), duc de Montebello. (Voir n $\left.^{\circ} 1133.\right)$

Par Cortot; statue en plâtre. - H. 2,22.

1607. Ney (Michel), duc d’Elchingen, prince de la Moskowa. (Voir n⿳⺈ 1135.)

Par Houdon; buste en plâtre. - II. 0,60.

Le buste original, exposé au Salon de 1804, est dans la salle des Maréchaux, au palais des Tuileries. 
1608. Davout (Louis-Nicolas), duc d'Auerstaëdt, prince d'Eckmühl. (Yoir no $\mathbf{0} 36$.)

Par Bosio; buste en plâtre. - H. 0,62.

Le buste original est dans la salle des Maréchaux, au palais des Tuileries.

1609. Kellermann (François-Christophe), duc deValmy.

(Voir no 1138.)

Bustc en plâtre. - H. 0,60.

Le buste original est dans la salle des Maréchaux, au palais des Tuileries.

1610. Lefebvre (François-Joseph), duc de Dantzick. (Voir n⿳1139.)

Buste en plâtre. - H. 0,62.

Le buste original est dans la salle des Maréchaux, au palais des Tuileries.

1611. Pérignon (Dominique-Catherine, marquis). (Voir no 1140.)

Par MatTE; buste en plâtre. - H. 0,59.

Le buste original, exposé au Salon de 1819, est dans la salle des Maréchaux, au palais des Tuileries.

1612. Sérurier (Jean-Mathieu-Philibert, comte). (Voir $n^{\circ}$ 1141.)

Buste en plâtre. - H. 0,61 .

Le buste original est dans la salle des Maréchaux, au palais des Tuileries.

1613. Suchet (Louis-Gabriel), duc d'Albuféra. (Voir no 1159.)

Par M. Hosson en 1838 ; buste en marbre. - H. 0,63.

1614. Gouvion-Saint-Cyr (Laurent, marquis de). (Voir no 1160.)

Par David; buste en plâtre. - H. 0,65 .

Le buste original est dans la salle des Marécliaux, au palais des Tuileries.

1615. La Touche Tréville (Louis-Réné-Madeleine Le Vassor de), vice-amiral. (Voir no 651.)

Par A. Revaud; buste en marbre. - H. 0,58.

1616. Valhubert (Jean-Marie-M Llon Roger), général de brigade. (Voir $\mathrm{n}^{\circ}$ 537.)

par M. DebaY père; buste en marbre. - H. 0,70. 
1617. Roussel (François-Xavier), général de division. (Voir $\left.\mathrm{n}^{\circ} 510.\right)$

Par ESPERCIEUX en 1837; buste en marbre. - H. 0,70.

1618. D'Hautpoul (Jean-Joseph, comte), général de division. (Voir $\left.\mathrm{n}^{\circ} 538.\right)$

Par M. JALEY ; buste en marbre. - H. 0,74.

1619. Lasalle (Antoine-Charles-Louis, comte de), général de division. (Voir $\mathrm{n}^{\circ}$ 1223.)

Par Taunay; statue en plâtre. - H. 2,19.

Le général est debout, en uniforme de hussard, la main gauche posée sur la poignée de son sabre, et tenant de la droite un rouleau.

Ce modèle, exposé au Salon de 1812, devait être exécuté en marbre de double proportion pour le pont de la Concorde.

1620. Colbert (Auguste-François-Marie), général de brigade. (Voir $\mathrm{n}^{\circ}$ 511.)

Par Renaud; buste en plâtre. - H. 0,65.

1621. Espagne (Jean-Louis-Brigitte, comte), général de division. (Voir $\left.\mathrm{n}^{\circ} 521.\right)$

Par Gallamard; buste en plàtre. - H. 0,70.

1622. Saint-Hilaire (Louis-Joseph Leblond, comte de), général de division. (Voir ${ }^{\circ}{ }^{522 .)}$

Par Bridan fils, buste en plâtre. - H. 0,65.

1623. Boudet (Jean, comte), général de division.

Par J.-E. Dumont; buste en plâtre. - H. 0,62.

Né à Bordeaux le 19 février 1769, il fut nommé en 1792 lieutenant dans le $7^{\mathrm{e}}$ bataillon de la Gironde, se rendit avec ce corps à l'armée des Pyrénées-Orientales, et devint en 1793 chef d'un des bataillons que l'on avait formés avec les différentes compagnies franches qui se trouvaient à l'armée des Pyrénées-0rientales. En 1794 il se rendit à la Guadeloupe, envahie par les Anglais, et fut nomme chef puis général de brigade. Général de division en $\mathbf{1 7 9 6}$ il revint en France en 1798, fut envoyé à l'armée de Hollande, sous les ordres du général Brune, en 1799, fit la campagne de Marengo en 1800, et fut désigné en 1801, par le premier consul, pour faire partie de l'expédition de Saint-Domingue sous le gé- 
néral Leclerc. Membre de la Légion d'honneur en 1803, il fut employé à l'armée de Hollande puis à celle d'Allemagne, et fut nommé en 1807 comte de l'Empire. Il fit- la campagne de 1809, fut promu au grade de grand officier de la Légion d'honneur, et mourut à Znaïm en Moravie, le 14 septembre 1809.

\section{Caulaincourt (Auguste-Jean-Gabriel, comte de), général de division.}

Par M. VaLors; buste en marbre. - H. 0,63.

Né le 16 septembre 1777 à Caulaincourt (Aisne), il entra dans le régiment des cuirassiers du roi en 1792 et fut nommé souslieutenant en 179 s̆ pour servir d'aide de camp au général Aubertdu-Bayet. Capitaine au $21^{\mathrm{e}}$ de dragons en 1797, il fit les campagnes du Tyrol et des Grisons, servit ensuite dans l'armée d'Italie et se distingua à Marengo. Chef de brigade au $19^{\mathrm{e}}$ dragons en 1801, membre de la Légion d'honneur en 1803 et officier de l'ordre en 1804, il fit en 180 วั et 1806 les campagnes d'Autriche et de Prusse et fut nommé général de brigade. Après avoir été attaché pendant deux ans au roi de Hollande comme aide de camp, il fit la campagne d'Espagne en 1808, fut nommé général de division en 1809, et devint en 1810 gouverneur des pages, grand cordon de l'ordre de la Réunion et comte de l'Empire. Appelé à faire partie de l'expédition de Russie, il fut nommé commandant du grand quartier général impérial, et fut tué le 7 septembre 1812, à la bataille de la Moskowa, où il commandait le $2^{\mathrm{e}}$ corps de cavalerie.

\section{Duroc (Géraud-Christophe-Michel), duc de Frioul, général de division. (Voir n 541.)}

Par M. JACQUoT en 1838; buste en marbre. - H. 0,71.

\section{Baraguey d'Hilliers (Louis), général de divi- sion.}

Par ChINARD; buste en plåtre. - H. 0,60.

Né à Paris en 1764, il entra à lâge de vingt ans comme cadet dans le régiment d'Alsace, et y obtint bientôt les grades de souslieutenant et de lieutenant. Capitaine au $10^{\mathrm{e}}$ bataillon de chasseurs en 1790, il fut aide de camp des généraux Crillon et Labourdomnaye, et fut chargé par le général Montesquiou d'organiser la légion des Alpes. Il passa en 1792 , avec ce corps, à l'armée du Rhin, et fut nommé en $\mathbf{1 7 9 4}$ chef d'état-major de l'armée du Rhin. Membre du comité militaire, puis chef d'état-major de l'armée de 'intérieur en 1795, il servit successivement dans les armées des 
côtes de Cherbourg, de l'Ouest et d'Italie, et fut nomme genéral de division. Chef d'état-major de l'armée du Bas-Rhin en 1799, il commanda en 1800 une division de l'armée de Moreau, et fut l'année suivante élu candidat au sénat conservateur. Membre, puis grand officier de la Légion d'honneur en 1805, il obtint le titre de colonel général des dragons et fit la campagne d'Allemagne. Gouverneur de Venise en 1808, il fit la campagne d'Autriche en 1809, passa en 1811 à l'armée d'Espagne, et eut le commandement d'une division à l'armée de Russie en 1812. Il mourut à Berlin en 1813.

\section{Letort (Louis-Michel, baron), général de division.} (Voir $\mathrm{n}^{\circ}$ 542.)

Par M. Debay fils; buste en marbre. - H. 0,71.

\section{Duhesme (Guillaume-Philibert, comte), général de division.}

I'ar PRAD́IER; buste en plâtre. - H. 0,66.

Né à Bourgneuf (Saône-et-Loire), le 7 janvier 1766, il commandait la garde nationale de son canton en $\mathbf{1 7 9 1}$, entra comme capitaine dans le $2^{\mathrm{e}}$ bataillon de Saône-et-Loire et fit la campagne du Nord. Général de brigade en 1793 et général de division en 1794, il passa à l'armée des côtes de Brest sous les ordres du général Hoche, fit avec lui la guerre de la Vendée, et servit ensuite à l'armée du Rhin sous Pichegru, à l'armée de Rhin-et-Moselle sous Moreau et à celle de Rome sous Championnet. Appelé en 1799 à l'armée de réserve, puis à l'armée gallo-batave, Duhesme eut en 1800 le commandement de la $19 \mathrm{e}$ division militaire à Lyon, fut en 1803 membre de la Légion d'honneur, grand officier de l'ordre, président du collége électoral de Saône-et-Loire et servit à l'armée d'Italie. En 1806, il fit partie de l'armée chargée de la conquête du royaume de Naples et commanda en Catalogne de 1808 à 1810. Comte de l'Empire en 1814, il fit la campagne de France, eut ensuite les fonctions d'inspecteur général de l'infanterie, et reçut la croix de Saint-Louis. Pair de France en 1815, il commanda la jeune garde à la bataille de Waterloo et y fut tué le 18 juin 1815 .

\section{Savary (Anne-Jean-Marie-René), duc de Rovigo, ministre de la police générale.}

Par M. Camille Demesmay en 1856; buste en marbre. - H. 0,92.

Né à Marq (Ardennes), le 26 avril 1774, il entra en 1790 dans le régiment de cavalerie Royal-Normandie, devint sous-lieutenant 
en 1791, lieutenant en 1793 et fit toutes les campagnes de l'armée du Rhin de 1791 à 1797. Aide de camp de Desaix, il le suivit en Egypte et à Marengo, puis devint aide de camp du général Bonaparte et l'accompagna dans toutes ses campagnes jusquen 1810 . Général de brigade en 1804, général de division en 180ă, grand aigle de la Légion d'honneur en 1807, duc de Rovigo en 1808, il reçut en 1810 le portefeuille de la police générale. En 1814 il fit partie du conseil de régence, fut pendant les Cent-Jours premier inspecteur général de gendarmerie et pair de France, accompagna l'Empereur sur le Bellérophon et fut conduit à Malte par les Anglais. De retour en France en 1819, il vécut dans la retraite pendant le gouvernement de la Restauration, recut en 1831 le commandement en chef de l'armée d'Afrique, et revint à Paris où il mourut le 2 juin 1833 .

\section{Cambacérès (Jean-Jacques-Régis de), duc de Parme, archichancelier de l'Empire.}

Par Rolard en 1810 ; statue en marbre. - H. 2,12.

Né à Montpellier le 18 octobre 17 อั3, il succéda en 1771 à son frère comme conseiller à la cour des comptes de Montpellier. President du tribunal criminel de l'Hérault en 1791, député de ce département à la Convention nationale en 1792, il contesta à cette assemblée le droit de juger Louis XVI, et son vote fut compris parmi les rotes dabsolution. Chargé conjointement arec Merlin (de Douai) de la classification des lois et de la rédaction du Code, il fut après le 9 thermidor, président de la Convention et du Comité de Salut public. Membre de l'Institut (de l'Académie des sciences morales et politiques, puis de l'Académie française), il fut ministre de la justice sous le Directoire et second consul après le 18 brumaire. Lors de l'organisation de la Légion d'honneur, il fut un des sept grands officiers composant le grand conseil de l'ordre. Il derint en 180' archichancelier de l'Empire, président perpétuel du Sénat, prince de l'Empire et duc de Parme. Président du conseil de régence en 1814, il fut exilé en 1810ั, rentra en France en 1818, et mourut à Paris le 8 mars 1824.

Cette statue, exposée au Salon de 1810, avait été exécutée par ordre de l'Empereur pour être placée au conseil d'Etat.

\section{Lebrun (Charles-François), duc de Plaisance, architrésorier de l'Empire.}

Par F. Massox en 1807; statue en marbre. - H. 2,15.

Né à Saint-Sauveur-Landelain (Manche) le 19 mars 1739, il fut secrétaire du chancelier Maupeou, partagea sa disgrâce en 1774 et traduisit dans sa retraite la Jérusalem déliorée, l'Iliade, et plus 
tard l'Odyssée. Député par le baillage de Dourdan aux états généraux en 1789, il se fit remarquer dans les questions de finances et d'administration, et présida en $\mathbf{1 7 9 2}$ le directoire de Seine-et-Oise. Détenu en 1793 et 1794, il fut membre du conseil des anciens en 1795 et devint troisième consul en 1799. Membre du grand conseil de la Légion d'honneur en 1803, il fut en 1804 architrésorier de l'Empire et duc de Plaisance, puis gouverneur général de la Ligurie et administrateur général de la Hollande. Nommé pendant les Cent-Jours membre de la chambre des pairs et grand maître de l'Université, il fut rayé de la liste des pairs à la seconde rentrée de Louis XVIII et réintégré en 1819. Il mourut au château de Saint-Mesme, près Dourdan, le 16 juin 1824.

Cette statue a été exposée au Salon de 1810, après la mort de l'artiste.

\section{Portalis (Jean-Étienne-Marie, comte), ministre des cultes.}

Par DESEINE; statue en marbre. - H. 2,10.

Né au Beausset, près de Toulon (Var), le $\mathbf{1}^{\mathrm{er}}$ avril $\mathbf{1 7 4 5}$, il fut reçu avocat à l'âge de dix-neuf ans, et fit ses premiers débuts au parlement d'Aix.En 1794 il entra au conseil des anciens, et se réfugia en Allemagne en 1797, après le 18 fructidor. Membre cu conseil d'Etat en 1800, il prit part à la rédaction du Code civil et fut reçu de l'Académie française. Membre de la Légion d'honneur en 1803, ministre des cultes en 1804 et grand aigle de la Légion d'honneur en 1805, il mourutle 25 août 1807.

Cette statue, exposée au Salon de 1812, avait été exécutée pour le conseil d'Etat.

\section{Tronchet (François-Denis), jurisconsulte.}

Par Roland en 1812; statue en marbre. - H. 2,03.

Né à Paris le 23 mars 1706, il fut connu de bonne heure comme avocat consultant, et résista en 1753 à l'installation du parlement Maupeou en fermant son cabinet. Il était en 1789 chef de l'ordre des avocats de Paris, lorsqu'il fut nommé député de cette ville aux états généraux. Choisi par Louis XVI pour être un de ses défenseurs, il partagea ce dangereux honneur avec Malesherbes et Desèze, et fut nommé député au conseil des anciens par le département de Seine-et-Oise en 1795. Premier président de la cour de cassation en 1799 et sénateur en 1801, Tronchet prit, comme conseiller d'Etat, une grande part à la rédaction du Code civil. Il fut membre de la Légion d'honneur en 1803, commandeur de l'ordre en 1804, et mourut le 10 mars 1806.

Cette statue, exposée au Salon de 1812, avait été exécutée par ordre de l'impereur pour étre placée dans la salle des séances du conseil d'Etat. 


\section{Fontenay (Pierre-Nicolas de), sénateur.}

Par DESEINE en 1807; buste en marbre. - H. 0,69.

Né à Rouen le 27 septembre 1743, il fut élu député de cette ville aux états généraux en 1789. Maire de Rouen en 1791, président de l'administration du département de la Seine-Inférieure en 1792, il fut détenu en 1793 et redevint maire de Rouen en 1799. Membre du conseil général des manufactures et du commerce en 1802, membre de la Légion d'honneur en 1803, il fut commandant de l'ordre et sénateur en 1804, et mourut à Paris le 18 février 1806.

\section{Petiet (Claude), sénateur.}

Buste en plâtre. - H. 0,70.

Né à Châtillon-sur-Seine le 10 février 1749, il entra d'abord dans les gendarmes de la maison militaire du roi, eut ensuite l'emploi de commissaire des guerres et celui de secrétaire subdélégué de l'intendant de Bretagne. Procureur syndic du dépar-

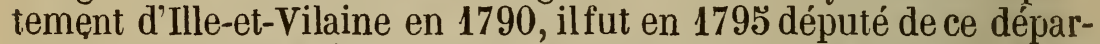
tement au conseil des anciens et ministre de la guerre en 1796 et 1797. Membre du conseil des Cinq-Cents en 1798, il entra au conseil d'Etat en 1799, et après la bataille de Marengo se rendit en Lombardie avec le titre de ministre extraordinaire près la République cisalpine. Membre de la Légion d'honneur en 1803, commandant de l'ordre en 1804, Petiet avait été intendant de l'armée rassemblée au camp de Boulogne et avait accompagné l'empereur Napoléon en Autriche. Il revint à Paris après la bataille d'Austerlitz, fut en 1806 grand officier de la Légion d'honneur, membre du Sénat, et mourut le 20 mai 1806.

\section{Resnier (Louis-Pierre-Pantaléon), sénateur.}

Buste en marbre. - H. 0,68.

Né à Paris le 23 novembre 1759 , il fut d'abord auteur dramatique, puis sous-bibliothécaire à la bibliothèque Mazarine, et contribua à la rédaction du Moniteur. Envoyé de la République francaise à Genève, Resnier fut ensuite membre du Tribunat et devint sénateur en 1799. Membre de la Légion d'honneur en 1803, commandant de l'ordre en 1804, il mourut à Paris le 8 octobre 1807.

\section{Luynes (Louis-Joseph-Charles-Amable d'Al- bert, duc de), sénateur.}

Par Deseine; buste en plâtre. - H. 0,61.

Né le 4 novembre 1748 , il fut connu d'abord sous le nom de 
comte d'Albert, puis sous celui de duc de Luynes. Sous-lieutenant du régiment Colonel-Général des dragons en 1764, il fut capitaine en 1766 et mestre de camp lieutenant en 1769. Elu aux états généraux par la noblesse de Touraine, il devint en 1799 maire du 9e arrondissement de Paris, et fut candidat du corps électoral de la Seine pour le sénat conservateur, où il entra en 1802. Membre de la Légion d'honneur en 1803, commandant de l'ordre en 1804, il mourut en 1808.

\section{Bougainville (Louis-Antoine, comte de), séna- teur.}

Buste en plâtre. - H. 0,67 .

Né à Paris le 11 novembre 1729, il fut d'abord destiné au barreau et entra ensuite dans la carrière militaire. Aide-major dans le bataillon provincial de Picardie en 1753, il devint en 1754 aide de camp de Chevert, partit en $\mathbf{1 7 5 6}$ pour le Canada comme capitaine de dragons et aide de camp de Montcalm, et obtint le grade de colonel en 1759 . En 1766 il entreprit un voyage autour du monde, fut nommé chef d'escadre en 1779 et servit dans la guerre en Amérique. Il se signala en $\mathbf{1 7 8 1}$ dans un combat contre l'amiral Hood, vis-à-vis du fort royal de la Martinique, et à la prise des îles de Tabago et de Saint-Christophe. Chargé en 1790 de commander l'armée navale de Brest, il se retira du service la même année et se consacra à l'étude des sciences. Membre de l'Institut et du bureau des Longitudes en 1796, il entra au sénat conservateur en 1799, fut grand officier de la Légion d'honneur en 1804 et eut le titre de comte en 1808. Il mourut le 31 août 1811.

\section{Lagrange (Joseph-Louis, comte), sénateur.}

Par Deseine; buste en plâtre. - H. 0,67.

Né à Turin le 25 janvier 1736 , de parents d'origine française, il fut en $\mathbf{1 7 5 5}$ professeur de mathématiques aux écoles d'artillerie de Turin, fut admis à l'école de Berlin en 1759 et concourut à l'établissement de la Société de Turin. Après avoir remporté cinq fois le prix de mathématiques proposé par l'Académie des sciences de Paris, il fut en 1766 directeur de l'Ácadémie de Berlin, et vint se fixer à Paris en 1787. Professeur à l'École normale, puis à l'École polytechnique, membre de l'Institut et du bureau des Longitudes en 1796, Lagrange entra au sénat conservateur en 1799, fut grand officier de la Légion d'honneur en 1804 et comte de l'Empire en 1808. Il mourut à Paris le 10 avril 1813.

Le buste original en marbre, exposé au Salon de 1817, fait partie de la galerie du Sénat au palais du Luxembourg. 
1640. Sabatier (Raphael-Bienvenu), chirurgien.

Par M. Mathied-Medsier en 1853 ; buste en marbre. - H. 0,65.

Né à Paris le 11 octobre 1732 , il étudia la chirurgie sous Petit et Verdier, et fut nommé en 1732 membre de l'Académie de chirurgie. Membre de l'Académie des sciences et chirurgien en chef de l'Hôtel des Invalides en 1773, il fut ensuite secrétaire perpétuel de l'Académie de chirurgie. Lors de la création de l'Institut, Sabatier y entra un des premiers et fut professeur de médecine opératoire à l'Ecole de Santé. Membre de la Légion d'honneur en 1803, il fut l'un des médecins consultants de l'empereur Napoléon Ier, et mourut le 19 juillet 1811. - Il a laissé, entre autres écrits, un Traité complet de l'Anatomie, un Cours de médecine opératoire, et un Traité complet de chirurgie.

\section{Lauriston (Jacques-Alexandre-Bernard Law marquis de), maréchal de France. (Voir n 1166.)}

Par Bosio; buste en plâtre. - H. 0,62.

1642. Maison (Nicolas-Joseph, marquis), marécha. de France. (Voir n 1168.)

Par M. Dantar aîné; buste en plâtre. - H. 0,63.

Ce buste a été exposé au Salon de $18 \not 2$.

1643. Sébastiani (Francois-Horace, comte), maréchal de France. (Voir n⿳ ${ }^{1177 .)}$

Par M. Clésinger; buste en marbre. - H. 0,67.

1644. Foy (Maximilien-Sébastien, comte), lieutenant général.

Par M. BRA; buste en plâtre. - H. 0,61.

Né à Ham le 3 février 177 , il entra en 1790 à l'école de La Fère comme aspirant au corps d'artillerie. Nommé sous-lieutenant en 1792, lieutenant, puis capitaine l'année suivante, il fit les campagnes de l'armée du Nord sous les généraux Dumouriez, Dampierre, Custine, Houchard, Jourdan et Pichegru. Chef d'escadron en 1797, il fit les campagnes de 179 à à 1797 à l'armée de Rhin-etMoselle, passa en 1798 à l'armée d'Angleterre et revint à la fin de cette année servir en Suisse. Adjudant général chef de brigade en 1799, il servit à l'armée du Danube, fut nommé colonel du ge régiment d'artillerie à cheval, se rendit à l'armée du Rhin, puis passa en Italie avec le corps d'armée commandé par Moncey. Chargé du commandement des batteries flottantes destinées à la défense 
des côtes de la $16^{\mathrm{e}}$ division militaire en 1803 , il fut en 1804 membre, puis officier de la Légion d'honneur, et fut employé comme chef d'état-major d'artillerie au camp d'Utrecht. En 180š et en 1806 , il fit la campagne d'Autriche à la grande armée, et se rendit à Constantinople en 1807 pour y commander un corps de canonniers auxiliaires envoyé au sultan Sélim. Commandant de l'artillerie de la division de réserve de l'armée de Portugal en 1808, il fut nommé général de brigade et prit part aux affaires d'oporto et du passage du Duero. Général de division en 1810, comte de l'Empire, il commanda en 1812 l'aile droite à la bataille de Salamanque et continua de servir sous le maréchal Soult jusqu'en 1814. Chevalier de Saint-Louis et inspecteur général d'infanterie en 1814, il commanda une division à la bataille de Waterloo et remplit de nouveau, en 1819 , les fonctions d'inspecteur général. Elu membre de la chambre des députés en 1819, il déploya un grand talent d'orateur en luttant contre le gouvernement de la Restauration, et mourut à Paris le 28 novembre 1820 .

\section{Chasseloup-Laubat (François, marquis), lieute- nant général.}

Buste en plâtre. - H. 0,62.

Né à Saint-Sornin (Charente-Inférieure) le 18 août 175̆4, il entra en 1770 à l'école de Mézières, et en sortit en 1774 avec le grade de lieutenant d'artillerie. Lieutenant-colonel en 1792, il contribua à la défense de Montmédy, passa en 1793 à l'armée de Sambre-et-Meuse, et obtint le grade de colonel du génie. Après avoir servi au siége de Mayence en 1794, il passa à l'armée d'Italie et fut nommé général de brigade de génie en 1796 . Général de division en 1798, il eut le commandement de l'arme du génie à la campagne de Marengo, devint membre de la Légion d'honneur en 1803, et fut appelé à la grande armée en 1806. Grand officier de la Légion d'honneur et conseiller d'Etat en 1811, il commanda en chef le génie lors de la campagne de Russie et fut nommé sénateur en 1813. Pair de France, chevalier de Szint-Louis et grandcroix de la Légion d'honneur en 1815 , il obtint en 1818 le titre de marquis, et devint en 1820 président du conseil de perfectionnement de l'Ecole polytechnique. Il mourut à Parisle 9 octobre 1833.

\section{Sanson (Nicolas-Antoine, comte), général de division.}

Par M. Dantan aîné; buste en plâtre. - H. 0,63.

Né à Paris le 5 décembre $17.0 \% 6$, il entra en 1792 comme volontaire dans le $1^{\text {er }}$ bataillon du Tarn, et servit dans l'armée de l'in- 
térieur. Capitaine provisoire du génie en 1793, il fit les campagnes de 1793 à 179 à à l'armée des Pyrénées-Orientales, et devint chef de bataillon. Employé dans la place de Bellegarde comme ingénieur en chef, il passa ensuite à l'armée d'Italie, et fut nomme chef de brigade du génie en 1797. Il fit partie de l'expédition d'Egypte, fut nommé général de brigade en 1799, et eut le commandement en chef du génie à l'armée d'Orient. A son relour en France en 1801, il fut nommé directeur du dépôt général de la guerre. Membre de la Légion d'honneur en $18 \cdot 3$, commandant de lordre en 1804, il fut employé comme aide-major général chargé de la direction du service topographique pendantles guerres d'Autriche, de Prusse et de Pologne, de 180ă à 1807. Général de division en 1807, comte de $1^{\circ}$ Empire en 1808, il fut envové à l'armée de Catalogne comme commandant en chef du génie, et fut nommé en 1809 inspecteur général des fortifications. Employé à l'état-major de la grande armée en 1812, il fit la campagne de Russie, fut fait prisonnier de guerre pendant la retraite de Moscou, et de retour en France en 1814, fut nommé chevalier de SaintLouis. Il mourut le 29 octobre 1824.

\section{Cambronne (Pierre-Jacques-Étienne, comte), général de brigade.}

Par M. Debay père, bustc en marbre.-H. 0,68.

Né à Nantes le 26 décembre 1770. Grenadier dans le $1^{\text {er }}$ bataillon de Mayenne-et-Loire en 1792, il servit à l'armée du Nord. Sergent dans la $2^{e}$ légion nantaise, puis lieutenant en 1793 , capitaine de carabiniers dans la $2^{\mathrm{e}}$ légion des Francs en 1794, il servit aux armées des côtes de Brest, de Cherbourg et de l'Ouest jusqu'en 1796, puis à celles de Rhin et Moselle, d'Angleterre, et fit la campagne du Danube en 1799. Employé à l'armée du Rhin il se signala en 1800 au combat d'Ober-Hausen, où périt La Tour d'Auvergne, et fut désigné pour succéder au titre de premier grenadier de France. Membre de la Légion d'honneur en 1804, chef de bataillon au $88^{\mathrm{e}}$ régiment d'infanterie de ligne en 1805 , il fit les campagnes de Prusse et de Pologne. Employé à l'armée d'Espagne en 1808 il passa en 1809 dans le $1^{\text {er }}$ régiment de voltigeurs de la garde impériale et fit la campagne d'Allemagne. Baron de l'Empire en 1810, colonel major du $3^{\mathrm{e}}$ régiment de voltigeurs de la garde en 1811, général de brigade major du $1^{\text {er }}$ régiment de chasseurs à pied de la vieille garde en 1813, il servit en Espagne de 1810 à 1812, fit la campagne de Saxe en 1813 et celle de France en 1814. Il accompagna l'empereur Napoléon à lî̀le d'Elbe, fut nommé grand officier de la Légion d'honneur, comte de l'Empire et pair de France en 1815้. Le 18 
juin 1815, à la bataille du Mont-Saint-Jean, son régiment fut presque entièrement détruit et Cambronne, blessé à la tête, fut fait prisonnier par les Anglais. Chevalier de Saint-Louis en 1819, il recut en 1820 le commandement de la $1^{\text {re }}$ subdivision de la 16 e division militaire. Il mourut le 29 janvier 1842.

\section{Daumesnil (Pierre, baron), lieutenant général.}

Par M. J. DEBAY; buste en plâtre. - H. 0,68.

Né à Périgueux le 14 juillet 1777 , il entra comme soldat dans le $22 \mathrm{e}$ régiment de chasseurs à cheval en 1794 et fit sa première campagne à l'armée des Pyrénées-Orientales. Il servit en Italie en 1795, et fut incorporé en 1797 dans les guides du général Bonaparte, où il eut les grades de brigadier et de maréchaldes-logis. Lors de la campagne d'Égypte, il se signala au siége de Saint-Jean-d'Acre et à la bataille d'Aboukir, et entra en $\mathbf{1 7 9 9}$ dans les chasseurs à cheval de la garde des Consuls, où il fut lieutenant, puis capitaine. Membre de la Légion d'honneur en 1804 , chef d'escadron en 1805 , et officier de la Légion d'honneur en 1806, il fit les guerres d'Autriche, de Prusse et de Pologne de 180 ă à 1807 , et suivit l'Empereur en Espagne en 1808. Il fit partie de l'armée d'Allemagne en 1809, fut promu au grade de major de la garde, et eut la jambe emportée par un boulet de canon à la bataille de Wagram. Général de brigade en 1812, il eut le gouvernement de Vincennes, et défendit ce poste contre les alliês en $\mathbf{1 8 1 4}$ et $\mathbf{1 8 1 5}$. Nommé chevalier de Saint-

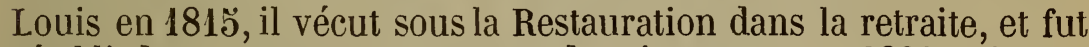
rétabli dans son gouvernement de Vincennes en 1830. Lieutenant général en 1831, il mourut à Vincennes le 17 août 1832.

\section{Petit (Jean-Martin, baron), lieutenant général.}

Par M. BoITEL en 1853; buste en marbre. - H. 0,68.

Né à Paris le 22 juillet 1772. Colonel en 1806, il fit les campagnes d'Allemagne et de Prusse, fut membre, puis officier de la Légion d'honneur, général de brigade et baron de l'Empire en 1813. Il fit la campagne de France, reçut le baiser d'adieu de l'Empereur (1) à Fontainebleau et se trouva à la bataille de Waterloo en qualité de major du $1^{\mathrm{er}}$ régiment des grenadiers à pied de la garde. Bien que nommé lieutenant général par l'Empereur, ce titre ne lui fut restitué qu'en $\mathbf{1 8 3 1}$; il devint grand officier de la Légion d'honneur en 1835, pair de France en 1837, et fut

(1) On lit sur le piédouche de ce buste ces paroles de l'Empereur : a Je ne puis vous embrasser tous, mais j'embrasse votre général : Venez, général Petit, que je vous presse sur mon cœur. - Fontainebleau, 1814. 
nommé commandant de l'Hôtel des Invalides. Senateur et grand officier de la Légion d'honneur en 18522, il mourut à Paris le 8 juin 1856.

Ce buste a été exposé au Salon de 1853.

\section{Partouneaux (Louis, comte), lieutenant gé- néral,}

Par M. JANSON en 1853; buste en marbre. - H. 0,83.

Né à Romilly-sur-Seine (Aube) le 26 septembre 1770, il entra au service comme grenadier volontaire au $1^{\mathrm{er}}$ bataillon de Paris en 1791, passa en 1792 au 50 $0^{e}$ régiment d'infanterie, où il fut d'abord sous-lieutenant, et fit aux armées du Nord et d'Italie les campagnes de 1792. Capitaine en 1793, il fut nommé adjudant-général chef de bataillon après la prise de Toulon, adjudantgénéral chef de brigade en $\mathbf{1 7 9 5}$, el servit à l'armée d'Italie jusqu'en 1798. Général de brigade en 1799, général de division en 1803, commandant de la Légion d'honneur en 1804, il servit de nouveau en Italie de 180כ à 1811. Lors de l'expédition de Russie, il eut le commandement de la $12^{\mathrm{e}}$ division du $9^{\mathrm{e}}$ corps de la grande armée, et fut fait prisonnier de guerre. Chevalier de SaintLouis et grand officier de la Légion d'honneur en 1814, il eut en 1815 le commandement de la $8^{\mathrm{e}}$ puis de la $10^{\mathrm{e}}$ division militaire. Appelé en 1820 au commandement de la $1^{\text {re }}$ division d'infanterie de la garde royale, président du collége départemental du Var en 1821, grand-croix de la Légion d'honneur en 1823, grand-croix de l'ordre de Saint-Louis, il commanda de nouveau la $8^{\mathrm{e}}$ division militaire en 1829. Il mourut à Menton (principauté de Monaco) le 14 janvier 1835.

Ce buste a été exposé au Salon de 1853 .

\section{Pajol (Claude-Pierre, comte), lieutenant gé- néral.}

Par M. Élias ᄃовеRT en 1852; buste en marbre.-H. 0,87.

Né à Besancon le 3 février 1772, il entra en 1791 dans le 1 er bataillon des volontaires du Doubs, et passa en 1792 au $82 \mathrm{e}$ régiment d'infanterie, où il fut d'abord sous-lieutenant, puis lieutenant. Employé à l'armée de Mayence, puis à celle de Sambre-et-Meuse, capitaine au $6^{\mathrm{e}}$ bataillon d'infanterie légère en 1795 , chef de bataillon en 1796, il entra en 1797 dans le 4e régiment de hussards, et passa à l'armée du Danube. Chef de brigade en 1799, il servit à l'armée d'Helvétie et à l'armée du Rhin, fut nommé officier de la Légion d'honneur en 1804 et fit les campagnes d'Allemagne et de Prusse. Général de brigade en 1807, baron de l'Em- 
pire en 1808, général de division en 1812, il commanda l'avantgarde du $1^{\text {er }}$ corps de la grande armée lors de l'expédition de

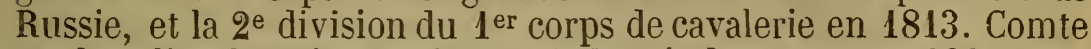
et chevalier de Saint-Louis en 1814, pair de France en $1815{ }^{\circ}$ pendant les Cent-Jours, il fut admis à la retraite en 1816. Grandcroix de la Légion d'honneur, et appelé au commandement de la $1^{\text {re }}$ division militaire en 1830 , le général Pajol rentra à la chambre des pairs en 1831, et mourut à Paris le 20 mars 1844 .

Ce buste a été cxposé au Salon de 1853.

\section{Bailly de Monthion (François-Gédéon, comte), lieutenant général.}

Par M. Élias Robert en 1853; buste en marbre.-H. 0,86.

Né à l'île Bourbon le 27 janvier 1776, il fit, comme souslieutenant dans le $74^{\mathrm{e}}$ régiment d'infanterie, les campagnes de 1793 aux armées de la Moselle et du Nord. Lieutenant en 1795̆, capitaine-adjoint en 1796, il servit comme aide de camp du général Turreau aux armées de Sambre-et-Meuse, de Mayence, et fit les campagnes de 1797 à 1799 sur le Rhin, en Helvétie, sur le Danube et en Italie. Chef d'escadron au ge de chasseurs à cheval en 1800, il servit jusqu'en 1802 dans le Simplon et dans le Valais, fut membre de la Légion d'honneur en 1804, et fit la campagne d'Autriche. Adjudant commandant et officier de la Légion d'honneur en 1806, il suivit la grande armée en Prusse et en Pologne, fut commandant de la Légion d honneur en $\mathbf{1 8 0 7}$, baron de l'Empire et général de brigade en 1808. Comte de l'Empire en 1809, général de division en 1812, il fit les campagnes d'Autriche et de Russie, et remplit en 1813 les fonctions de major général de la grande armée. Chevalier de Saint-Louis en 1814, il remplit les fonctions de chef d'état-major général en 181วั et fut mis en non activité après les Cent-Jours. Inspecteur général de l'infanterie en 1830, pair de France en 1837, grand-croix de la Légion d'honneur en 1843, il mourut à Paris le 7 septembre 18 ä0.

Ce buste a été exposé au Salon de 1853.

\section{Corbineau (Jean-Baptiste-Juvénal, comte), lieutenant général.}

Par M. LoIson en 1851; buste en marbre. - H. 0,76.

Né à Marchiennes (Nord) le $1^{\mathrm{er}}$ aoùt 1776, il entra au service comme sous-lieutenant dans le $18^{\mathrm{e}}$ régiment de cavalerie en 1792, passa en 1793 dans le כ̌e régiment de hussards, où il fut nommé lieutenant, et servit successivement aux armées du Nord, de Sambre-et-Meuse, du Danube et du Rhin. Lieutenant 
adjudant-major en 1801, capitaine en 1802 , membre de la Légion d'honneur en 1803 , major du $10^{\circ}$ régiment de hussards en 1806 , il devint colonel du 20 e régiment de dragons en 1807, et fit la campagne de Pologne. Créé baron de l'Empire et commandant de la Légion d'honneur en 1808, il servit en Espagne jusquen 1810, fut nommé général de brigade en 1811, et fit la campagne de Russie. Aide de camp de l'Empereur, général de division et comte de l'Empire en 1813, grand officier de la Légion d'honneur en 1814, il fut mis à la retraite pendant la Restauration. Chargé du commandement de la $16^{\mathrm{e}}$ division militaire en $\mathbf{1 8 3 0}$, pair de France en 183วั, grand-croix de la Légion d'honneur en 1838, il mourut à Paris en 1848.

Ce buste a été exposé au Salon de 1852.

\section{Des Michels (Louis-Alexis, baron), lieutenant général.}

Par II. FERRAT en 185'4; buste en marbre. - H. 0,71.

Né à Dignne (Basses-Alpes) le 1 ŏ mars 1779 , il entra en 1794 comme volontaire dans le $13^{\mathrm{e}}$ régiment de hussards, passa en 1796 dans la compagnie des guides à cheral et fit les campagnes d'Italie et d'Égypte. Brigadier, puis maréchal-des-logis en 1799 , il entra en 1801 comme sous-lieutenant dans les chasseurs à cheral de la garde des Consuls, depuis garde impériale, fut lieutenant en second en 1802, et servit à l'armée de l'Océan. Membre de la Légion d'honneur et lieutenant en premier en 180\%, il se signala à la bataille d'Ulm, fut nommé capitaine et officier de la Légion d honneur en 1806, combattit à Austerlitz et à Iéna et recut le grade de chef descadron après la bataille d'Evlau en 1807. Passé à l'armée d'Espagne en 1808 et rappelé à celle d'Allemagne en 1809, il fut nommé en 1811 colonel du $31^{\text {e }}$ régiment de chasseurs à cheval, servit en Espagne jusqu'en 1813, à l'armée d'Italie en 1814, et commanda le $4^{\mathrm{e}}$ régiment de chasseurs à Waterloo. En 1821, le baron Des Michels reçut le commandement du régiment des chasseurs des Ardennes, fut nommé maréchal de camp en 1823, commandant dans les Hautes-Alpes en 1824. chevalier de l'ordre de Saint-Louis, puis commandeur de la Légion d'honneur en 1826. Placé en 1832 à la tête d'une brigade de cavalerie, il commanda en 1833 la place doran et se rendit maitre de Mostaganem, puis d'Arzew. Nommé lieutenant général en 1830 et commandant de la $1 \overline{7}^{\mathrm{e}}$ division militaire en 1837, il résida en Corse pendant sept années. Membre du comité de cavalerie en 1844, le général Des Michels mourut à Paris le 7 juin $184 ว ั$. 


\section{Blanquet du Chayla (Armand-Simon-Marie), vice-amiral.}

Par M. Élias RoberT en 1858; buste en marbre. - H. 0,83.

Né le 9 mai 17 à9 à Marjevols (Lozère). Aspirant garde de la marine en 1775, garde de la marine en 1777, enseigne de vaisseau en 1778, il fit la campagne d'Amérique sous le comte d'Estaing et assista aux combats livrés à l'entrée et à la sortie de Newport (Rhode-Island). En 1780 il fit partie de l'escadre de la Manche, ensuite de l'escadre d'Amérique aux ordres du comte de Grasse et prit part en 1781 et $\mathbf{1 7 8 2}$ aux combats livrés devant la baie du fort royal de la Martinique, à l'entrée de la baie de Chasapeak, devant l'île Saint-Christophe et entre les îles de la Dominique et de la Guadeloupe; il fut nommé lieutenant de vaisseau en 1786. Capitaine de vaisseau de 2 e classe en 1792 et de $1^{\text {re }}$ classe en 1793 , contre-amiral en 1796, il commanda la $2^{\mathrm{e}}$ escadre de la flotte d'Egypte en 1798 et se couvrit de gloire au combat naval d'Aboukir. (Moniteur universel des 11 frimaire an VII et 15 mai 185̋.). Membre de la Légion d'honneur en 1804, chevalier de Saint-Louis et officier de la Légion d'honneur en 1814, officier supérieur de la compagnie de marine de la garde royale en 1815 , il recut en 1816 le brevet de vice-amiral et mourut à Versailles le 29 avril 1826.

\section{Talleyrand-Périgord (Charles-Maurice-Élie, duc de), prince de Bénévent.}

Par M. Desprez en 1837; buste en narbre.-H. 0,58.

Né à Paris le 7 mars $175 \%$, il fut destiné de bonne heure à l'état ecclésiastique, et devint évêque d'Autun en 1788. Député du clergé aux états généraux en 1789 , il célébra la messe au Champ de Mars sur l'autel de la patrie le jour de la Fédération de 1790. Chargé par Louis XVI d'une mission à Londres en 1792, il se rendit en 1794 aux États-Unis, revint en France en 1796 et entra à l'Institut (section des Sciences morales et politiques). Appelé en 1797 par le Directoire au ministère des relations extérieures, il conserva ce poste sous le Consulat et dans les premières années de l'Empire, et signa les traités de Lunéville, d'Amiens, de Presbourg et de Tilsitt. Grand-aigle de la Légion d'honneur, puis membre du grand conseil de l'ordre, grand chambellan en 1804, prince de Bénévent en 1806, et vice-grand électeur en 1807, Talleyrand fut, en 1814, membre du gouvernement provisoire. puis ministre des aflaires étrangères et pair de France, et assista au congrès de Vienne. Ministre plénipotentiaire à Londres en 1830, il signa en 1834 le traité de la Quadruple-Alliance, et moulut à Paris le 17 mai 1838. 


\section{Cuvier (Georges-Léopold-Chrétien-Frédéric- Dagobert, baron), naturaliste.}

Par Pradier; buste en plâtre. - H. 0,70.

Né à Montbéliard (Doubs) le 23 août 1769, il fit ses études au collége de Montbéliard, et entra ensuite à l'Académie Caroline de Stuttgard. Ses premiers travaux d'histoire naturelle datent de 1792. En 1795 il fut appelé comme suppléant à la chaire d'anatomie comparée, et fut nommé membre de l'Institut. Professeur aux écoles normales, il remplaça Daubenton au collége de France en 1799, fut nommé membre de la Société de médecine en 1801, commissaire pour la formation des Lycées en 1802, secrétaire perpétuel de la première classe de l'Institut en 1803, et membre de la Légion d'honneur. Conseiller de l'Université en 1808, vicerecteur de l'Académie de Paris en 1809, maitre des requêtes au conseil d'État en 1813, il fut conseiller d'État en 1814. Membre de l'Académie française en 1818, président du Comité de l'intérieur au conseil d'Etat en 1819, il reçut en 1820 le titre de baron, et fut successivement commandeur et grand officier de la Légion d'honneur. Recu de l'Académie des inscriptions et belles-lettres en 1830, il devint pair de France en 1831, et mourut à Paris, le 13 mai 1832.

1658. Laplace (Pierre-Simon, marquis de), géomètre.

Par M. A. BARre en 1846; statue en plâtre. - H. 2,15.

Né à Beaumont-en-Auge (Calvados), le 23 mars 1745, il fut d'abord professeur de mathématiques à l'École militaire de Beaumont, puis à l'École militaire de Paris, et remplaça Bezout en 1784 comme examinateur du corps de l'artillerie. Membre de l'Institut en 1795 (classe des Sciences physiques et mathématıques), il présida en 1796 la députation qui fut chargée de présenter au conseil des Cinq-Cents l'exposition des travaux de l'Institut. depuis sa création. Ministre de lintérieur et sénateur en 1799, il fut nommé président du sénat en 1803, grand officier de la Légion d'honneur en 180', et comte de l'Empire en 1808. Pair de France en 1814, il reçut le titre de marquis et entra à l'Academie française en 1816 . Il mourut le 5 mai 1827.

Gette figure est le modèle d'une statue en bronze, commandée par la ville de Caen, et exposée au Salon de 1847.

\section{Boulay de la Meurthe (Antoine-Jacques-Claude. Joseph, comte), ministre d'État.}

Par Carle Elschoect en 1850; buste en marbre. - H. 0,71.

Né à Chaumouzey (Vosges) le 19 février 1761, il exerça d'a- 
bord la profession d'avocat, fit comme volontaire dans un bataillon de la Meurthe la campagne de 1792, fut promu au grade de capitaine en 1793, puis rentra dans ses foyers. Député de la Meurthe au conseil des Cinq-Cents en 1796, il fut en 1790 président de la section de législation au conseil d'État et contribua à la rédaction du Code civil. Membre de la Légion d'honneur en 1803, comte de l'Empire en 1808, grand-croix de la Légion d'honneur en 1813, il fit partie du conseil privé et du conseil de régence, et fut ministre d'Etat en 1815 . Proscrit en 1815 , il revint en France en 1819, et mourut à Paris le 2 février 1840 .

Ce buste a été exposé au Salon de 1850.

1660. Mollien (Francois-Nicolas, comte), ministre du Trésor public.

Par M. Daniel en 1853; buste en marbre. - H. 0,67.

Né à Rouen le 23 février 1758 , il entra de bonne heure dans les bureaux du contrôle général et fut chargé en 1784 du renouvellement du bail de la ferme générale. Détenu en 1793, il devint en 1800 directeur général de la caisse d'amortissement et entra ensuite au Conseil d'Etat; nommé ministre du Trésor public en 1806 , il devint comte de l'Empire et grand cordon de la Légion d'honneur. Pair de France en 1819, il mourut à Paris le 20 avril 18 อ.

Ce buste a étẻ exposé au Salon de 1853.

1661. La Rochefoucauld-Liancourt (Francois-Alexandre-Frédéric, duc de).

Par M. Bougron en 1835; buste en marbre. - H. 0,61.

Né le 11 janvier 1747, il fut grand maître de la garde-robe sous Louis XV et sous Louis XVI, chevalier des ordres du roi en 1784, maréchal de camp, puis lieutenant général. Député aux états généraux en 1789, il se rendit aux Etats-Unis en 1792, revint en France en 1800, s'occupa d'entreprises philanthropiques, fonda beaucoup de manufactures, créa l'Ecole des arts-et-métiers, et fut un des protecteurs de l'enseignement mutuel. Pair de France en 1815 , il mourut en 1827.

Ce buste a été exposé au Salon de 1835.

\section{Champollion (Jean-François), orientaliste.}

Par M. E. Tномаs; buste en marbre. - H. 0,74.

Né à Figeac (Lot) le 23 décembre 1790, il fut nommé en 1800, professeur d'histoire à Grenoble, et publia en 1814 son ouvrage 
intitulé l Egypte sous les Pharaons. Il communiqua à l'Institut en 1821 et 1822 ses découvertes sur les hiéroglyphes, visita les musées égyptiens de Turin et de Rome, et fut chargé de décrire celui de Paris dont il fut nommé conservateur. Il se rendit en Egypte en 1828, fut reçı de l'Académie des inscriptions et belleslettres en 1830, et mourut le 4 mars $\mathbf{1 8 3 2}$.

Ce buste a été exposé au Salon de 1850.

\section{Azaïs (Pierre-Hyacinthe), philosophe.}

Par M. Mathied-Mecsier en 1842; buste en marbre. - H. $0,80$.

Né à Sorrèze en 1766, il cultiva d'abord la musique, fut ensuite jrofesseur d'histoire au Prytanée de Saint-Cyr, et remplit les fonctions d'inspecteur de la librairie jusqu'en 181̄o. Il publia dès 1808 son lirre Des compensations dans les destinées humaines, et de 1823 à 1828 un Cours de Philosophie générale. Il mourut à Paris en 18łวั.

Ce buste a été exposé au Salon de 18‘3.

\section{Pelletier (Joseph), chimiste.}

Par M. Deuesua ; buste en marbre. - H, $0,72$.

Né à Paris le 22 mars 1788, il suivit la carrière où son père, Bertrand Pelletier, pharmacien et chimiste, membre de l'Académie des sciences, s'était illustré. A làge de vingt ans il reçut à l'École de pharmacie les premiers prix de chimie, de botanique et d'histoire naturelle, et à vingt-quatre ans il fut nommé professeur à la même école, où il fonda l'enseignement de la minéralogie. Il découvrit la strychnine, la brucine, la rératrine, et enfin la quinine; cette dernière découverte que Pelletier laissa par désintéressement dans le domaine public, lui valut en 1820 le prix Ionthyon et la croix de la Légion d'honneur. Membre de l'Académie de médecine et membre de l'Institut (section de Chimie), Pelletier mourut le 19 juillet 18 ' 2 .

166.5. Aubé (Ambroise-Guillaume), président du tribunal de commerce.

Par M. E. Thomas; buste en marbre. - H. 0,80 .

Né le 1 J̆ janvier 1773 , il fut juge suppléant au tribunal de commerce en 1822, et juge titulaire en 1824 et 1827 . Membre du Conseil général de la Seine en 1830 , président du tribunal de commerce et membre de la Légion d'honneur en 1831, président du Conseil général de la Seine en 183əั, officier de la Légion d'honneur en 1836, conseiller d'État en 1838, il fut président de 
VESTIBULE DE L'ESGALIER DES PRINCES, N 82.

la Chambre de commerce de 1840 à 1844 . Il mourut à Paris le 21 mai 1849.

Ce buste, exposé au Salon de 1852, a été donné au Musée de Versailles par les membres du Tribunal de Commerce.

\section{Legentil (Charles), président de la Chambre de Commerce de Paris.}

Par M. J. Gavelier en 1856 ; buste en marbre. - H. 0,65.

Né en 1788, il fut successivement membre dı Conseil général de la Seine, député, pair de France, président de la Chambre de commerce de Paris, régent de la Banque de France, membre du Conseil supérieur du commerce, du Comité consultatif des arts et manufactures, du Comité consultatif des chemins de fer, du jury international de l'Exposition universelle, commandeur de la Légion d'honneur, etc. Il mourut à son château de Saint-Ouen le 10 octobre $185 \%$.

1667. Affre (Denis-Auguste), archevêque de Paris.

Par R. GAYRARD; buste en marbre. - H. 0,66.

Né en 1793 à Saint-Rome-de-Tarn (Aveyron). Grand vicaire à Luçon, à Amiens, puis à Paris en 1834, il fut sacré archevêque de Paris en 1840. Blessé mortellement le 25̃ juin 1848 à l'entrée du faubourg Saint-Antoine, il mourut deux jours après.

\section{VESTIBULE DE L'ESCALIER DES PRINCES, № 82.}

L'aile du Midi ayant été consacrée au logement des enfants de France, la cour qui sépare cette aile du corps central du palais fut nommée Cour des Princes et le grand escalier de cette aile : Escalier des Princes.

\section{Gaston-Jean-Baptiste de France (Monsieur), duc d'Orléans.}

Par Pradier en 1841 ; statue en marbre. - H. 2,15.

Fils puîné de Henri IV et de Marie de Médicis, né à Fontainebleau le 25 avril 1608. Il porta d'abord le titre de duc d'Anjou jusqu'en juillet 1616, et prit alors celui de due d'Orléans, après avoir reçu du roi Louis XIII le duché d'Orléans en apanage, par lettres patentes enregistrées au Parlement. Il fut en 1627 chef des armées de Poitou, de Saintonge, d'Angoumois et d'Aunis. Lieutenant général du royaume en 1643 , après la mort de Louis XIII, et chef des conseils de régence pendant la minorité 
de Louis XIV, le duc d'Orléans fit en Flandre les campagnes de 1643,1645 et 1646 , où il commanda en chef; il se retira en 1632 à Blois, où il mourut le 2 février 1660. Il avait épousé en 1626 Marie de Bourbon-Montpensier, et en 1632 Marguerite de Lorraine, fille de François II, duc de Lorraine.

\section{Vouet (Simon), premier peintre du roi.}

Par M. FesSARD; buste en plâtre. - H. 0,68.

Né à Paris en 1590, il fut élève de son père Laurent Vouet et suivit dans sa jeunesse le baron Harlay de Sancy dans son ambassade à Constantinople en 1611; il parcourut ensuite une partie de l'Italie, et sur la demande du pape Urbain VIII, il peignit plusieurs ouvrages pour les églises de Saint-Pierre et de San-Lorenzo, et fut élu prince de l'Académie de Saint-Luc. Vouet fit aussi plusieurs tableaux à Gênes. Nommé premier peintre du roi, il fonda à Paris une école de peinture d'où sont sortis la plupart des artistes célèbres du règne de Louis XIV, Lesueur, Lebrun, Mignard, Dufresnoy, etc. Louis XIII voulut recevoir de cet artiste des leçons de peinture. Il mourut à Paris le 30 juin 1649.

Le buste original est au Musée du Louvre.

1670. Philippe de France (Monsieur) duc d'Orléans. (Voir no 817.)

Par M. DURET; statue en marbre. - H. 2,15.

\section{Lesueur (Eustache), peintre d'histoire.}

Par Roland; buste en plàtre. - H. 0,70.

Né à Paris en 1617, il fut élève de Simon Vouet, entra d'abord dans la communauté des maîtres-peintres, puis fut au nombre des fondateurs de l'Académie royale de peinture et de sculpture en 1648. Ses principaux ouvrages, exécutés pour l'hôtel Lambert et le cloître des Chartreux de Paris, se trouvent au Musée du Louvre. Il mourut à Paris le 30 avril 16505 sur la paroisse de Saint-Louisen-l'Ile, et fut enterré à Saint-Etienne-du-Mont.

Le buste original est au Musée du Louvre.

1672. Lebrun (Charles), premier peintre du roi.

(Voir $\mathrm{n}^{\circ}$ 795.)

Par Coyzevox; buste en plâtre. - H. 0,68.

On lit sur les côtés de ce buste : C. Le Brun, premier peintre du Roy, et chancelier de l'Académie. - A. Coyzevox, fecit 1679 par ordre de l'Académie.

Le buste original est au Musée du Louvre. 
Vestibule de L'ESCALIER DES PRINCES, N 82.

1673. Mignard (Pierre), premier peintre du roi. (Voir $\mathrm{n}^{\circ}$ 819.)

Par Coyzevox; buste en plâtre. - H. 0,64.

1674. Mansart (Jules-Hardouin), architecte.

(Voir n⿳227.)

Par Coyzevox; buste en plâtre. - H. 0,73.

On lit derrière ce buste : Coyzevox FEcrT 1670, et sur le piédouche :

JULIVS HARDOVIN MANSART

COM. SAGON. EQ. S. M. REG. AR. IN

CONS. SVPREM. REG. EDI. PR $£ F$. OB, XI

MAII. 1708. ET. 62. D. DEDIT CATHARINA

MANSART DE MONTARGIS FILIA.

1675. Lenôtre (André), architecte. (Voir n 793.)

Par Coyzevox; buste en plâtre. - H. 0,65.

1676. Louis de France, dauphin, surnommé le GrandDauphin. (Voir no ${ }^{133 .)}$

Par M. Desprez en 1836; buste en marbre. - H. 0,84 .

1677. Louis de France, duc de Bourgogne.

(Voir $n^{\circ}$ 167.)

Par M. BRion en 1835; buste en marbre. - H. 0,84 .

\section{Philippe $V$ (Philippe de France, duc d'Anjou), roi d'Espagne.}

Par M. Lescorvé en 1836; buste en marbre.- H. 0,79.

Second fils de Louis de France, dauphin (le Grand-Dauphin). Né à Versailles le 19 décembre 1683, il porta d'abord le titre de duc d'Anjou. Appelé à la couronne d'Espagne par le testament de Charles II, il fut déclaré par Louis XIV, roi d'Espagne, le 16 novembre 1700 à Versailles, et le 24 du même mois à Madrid, où il fit son entrée solennelle le 14 avril 1701. L'avénement de Philippe $V$ à la couronne d'Espagne devint le signal de la longue guerre dite guerre de la succession, où ce prince passa, par une perpétuelle alternative de succès et de revers, jusqu'à la bataille de Villaviciosa qui l'affermit définitivement sur le trône. A la paix de Rastadt en 1714, Philippe V, qui avait été 
reconnu roi d'Espagne par quelques - unes des puissances de l'Europe dès l'année 1700 , le fut alors solennellement par les Etats-Généraux, le roi d'Angleterre et l'empereur Charles VI. Par décret du 1วّ janvier 1724, Philippe V abdiqua en faveur de son fils don Louis, et à la mort de ce prince le 31 aoùt suivant, il remonta sur le trône par décret du 6 septembre, et mourut à Madrid le 9 juillet 1746. Il arait épousé en 1701 Louise-Gabrielle de Savoie, fille de Victor-Amédée $H$, roi de Sardaigne, et en 1714 Elisabeth Farnèse, fille d'Edouard II, duc de Parme.

\section{Charles de France, duc de Berry.}

Par Carle Elshoect en 1836; buste en marbre. - H. 0,78.

Troisième fils du Grand-Dauphin, né à Versailles le 31 aoùt 1686. Reçu chevalier du Saint-Esprit en 1699, il fut la même année capitaine de deux compagnies de gendarmes, et fit en 1708 , comme volontaire, la campagne de Flandre sous les ordres du duc de Bourgogne son frère. Il épousa en 1710 Marie-LouiseElisabeth d'Orléans, fille de Philippe, duc d'Orléans, depuis régent, et mourut à Marly le 4 mai 1714 .

FIN DE LA PREMIÈRE PARTIE. 


\section{ADDITIONS ET CORREGTIONS.}

Page 57, ligne 44. - A u lieu de le 10 août, lisez le 10 juin.

Page 84 , ligne $15,2^{\mathrm{e}}$ colonne. - Après le nom de Géraud de Boysseulh, ajoutez celui de Jean de Lur.

Page $90,2^{\mathrm{e}}$ colonne. - Après le nom de Guillaume de Sareuse, ajoutez celui de Colard de Sainte-Marie.

Page 129, no 508. - Ajoutez:

Par M. MERGier.

Page 149. - Après le no 575, ajoutez:

575 bis. Mansart (Jules-Hardouin), architecte. (Voir $\mathrm{n}^{\circ}$ 227.)

Par M. Aug. Preault en 1854; statue en marbre. - H. 2,32.

575 ter. Lenôtre (André), architecte.

(Voir $n^{\circ}$ 793.)

Par M. Aug. Préault en 1858; statue en marbre. - H. 2,40.

Page 231. - Après le no 840 , ajoutez:

840 bis. Pascal (Blaise), géomètre et philosophe.

Par M. J. Cavelier en 1857; statue en plâtre. - H. 2,54.

Mod? le de la statue en marbre exécutée pour la tour de Saint-Jacques-la-Boucherie, à Paris.

Page $302, n^{\circ} 1067$. - Au lieu de 26 mai 1653, lisez 26 juin $16 \div 8$. 




\section{DIRECTION DES MUSÉES NATIONAUX.}

\section{LISTE DES CATALOGUES PUBLIÉS ET EN COURS DE VENTE}

Edites par CIIARLES DE MOLRGLES frères, §̋, rue J.-J.-Rousseau.

Conservation des peintures, des dessins tt de la chalcogräphie.

\section{Frédéric villot.}

Peintures. École italienne, 1 v. in $-8 \ldots \ldots \ldots \ldots \ldots \ldots \ldots, 5$, 5 ,

Écoles flamande, allemande et hollandaise, 1 v. in-12.......

Les trois écoles réunies, cart. $1 \mathrm{v}$. in $-12 \ldots \ldots \ldots \ldots \ldots \ldots$.

\section{Reiset.}

Dessins, 1 re partie, 1 v. in-12.. 2 》 Dessins, 2 partie, 1 v. in-12.. 2 , Idem. 1 v. in-8... 5 n

Musée Napoléon III, 1 v. in-12. Collection La Caze, 1 v. in-12. 50 Idem. 1 v. in-8.. 5 ,

\section{E. Soulle.}

Musée de Versailles, $1^{\text {re }}$ partie, 1 v. in $-12 \ldots \ldots \ldots \ldots \ldots \ldots$ Alusée de Versailles, 2 e partie, 1 v. in $-12 \ldots \ldots \ldots \ldots \ldots \ldots$ Musée de Versailles, $3 \theta$ partie, 1 v. in-12 ............ 3 , Palais de Trianon, 1 v. in-12... 0 . 50

\section{Ie vte de Tauzla.}

Peintures. École italienne, 1 v. in $-12 . \ldots \ldots \ldots \ldots \ldots \ldots \ldots$. Tableaux du Palais $\mathrm{d} \theta \mathrm{Com}$ piègne, 1 v. in-12..........

\section{P. Dubois.}

Musée du Luxembourg, 1 v. in $-12 \ldots \ldots \ldots \ldots \ldots \ldots \ldots, \quad 75$

Conservation des antiquites assyriennes, grecques et romaines. objets américains.

\section{M. de Longpérier.}

Bronzes antiques, $1^{\text {re }}$ partie, $1 \mathrm{\nabla}$. in $-12 \ldots \ldots \ldots \ldots \ldots \ldots \ldots \ldots$.

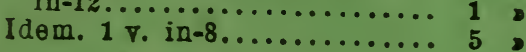

\section{W. Frohner.}

Colonne trajane, 1 v. in-8.... 5 , Inscriptions grecques, 1 v. in-12 125 Idem. 1 v. in-8 Sculpture antique, 1re partie, 1 v.in-12................
M. Ant. Hẻron de villefosse. Monuments de la Palestine, $1 \mathrm{v}$. in -12 Idem. (Grand papier), 1 r.iu. 12 . " Conservation de lasculptureet do objets d'art du Moyen age, de l. Renaissance et des temps $m$ dernes.

\section{Barbet de Jouy.}

Sculpture Moyen Age et Renaissance, 1 v. in-12........... Sculpture Moderre, 1 v. in-12.. Musèe des Souveraiıs, 1 $\nabla$.

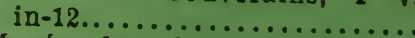

Musée des Sourerains, 1 v. in $-8 \ldots \ldots \ldots \ldots \ldots \ldots \ldots$. Gemmes et joyaux, 1 v. $\ldots$ in-12. Idem. 1 v. in-8. Don Philippe Lenoir, 1 v. in-12 Idem. Grand papier in-12 ....

\section{A. Sauzay.}

Iroires, 1 v. in-12.......... Idem. 1 v. in-8........... Bois sculptés, 1 v. in-8...... 5

Verreries, 1 v. in-12......... Idem. 1 v. in- $8 \ldots \ldots \ldots \ldots .5$

\section{M. le cte clénient de mis.}

Faïences françaises, 1 v. in-12 7

Fers, cuivres, étains, 1 v. in-12 Idem. $\quad 1$ v. in-8.

\section{Alfred Darcel.}

Émaux et orférrerie,1 r. in-12. 2 Conservation des antiquites égyptiennes.

\section{M. le vte Emmanuel de rougé}

Notice sommaire, 1 v. in-12... 1

Monuments du Rez-de-chaussée.

1 v. in -12

\section{Th. Devéria.}

Manuscrits, 1 v. in-12....... 1

\section{P. Pierret.}

Salle historique, 1 . in-12.... 1 Conservation du Musée de Marine et $d^{\cdot}$ Ethnographie.

M. I'amiral Paris.

Le Canal de Suez, 1 v. in-12 .. „75 


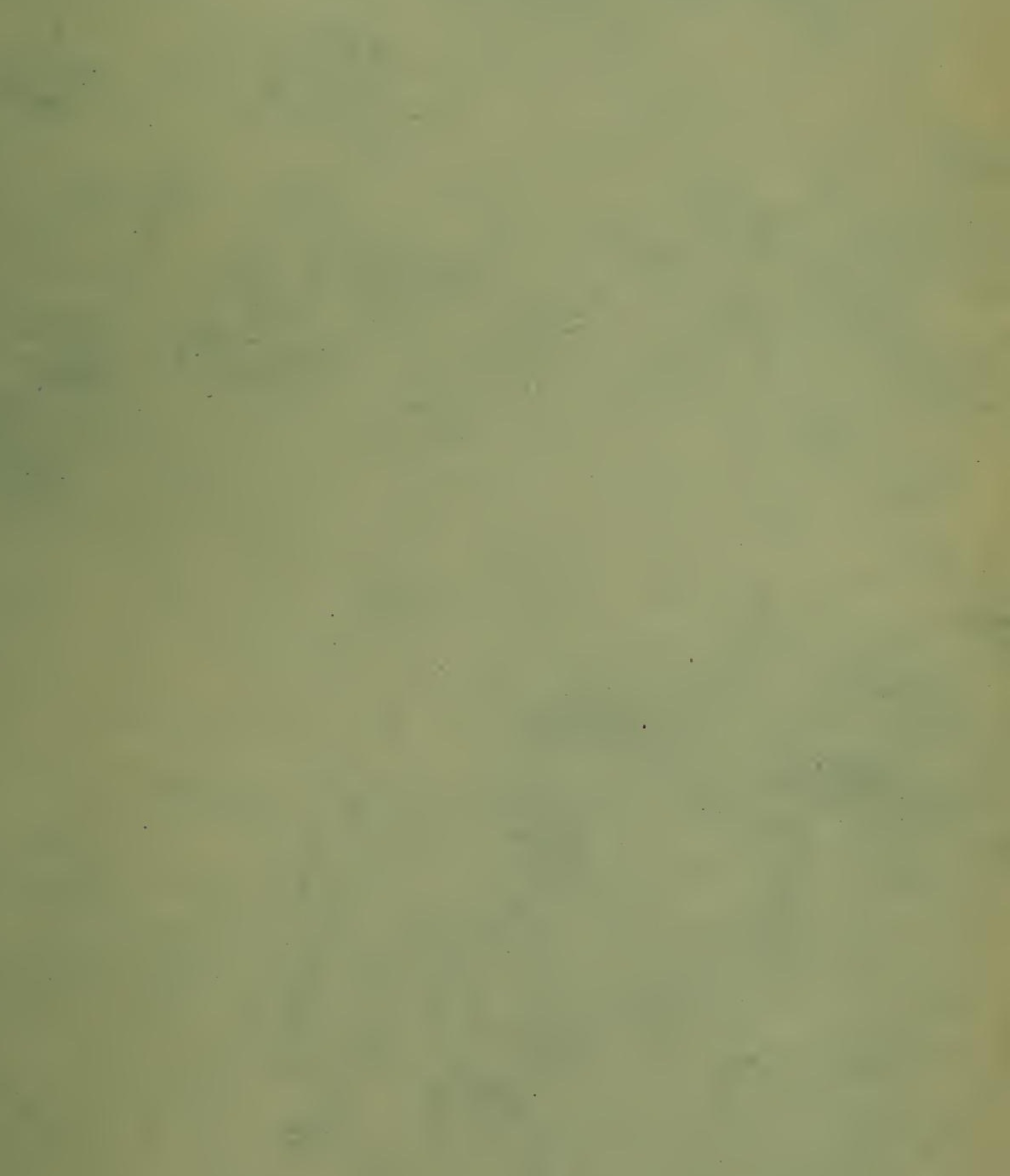



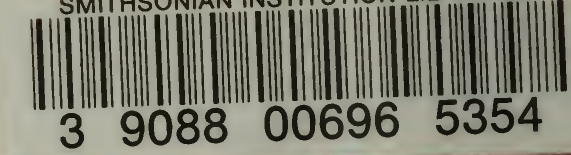

